Marc Hieronimus (Hg.)

\author{
Visuelle Medien \\ im DaF-Unterricht
}

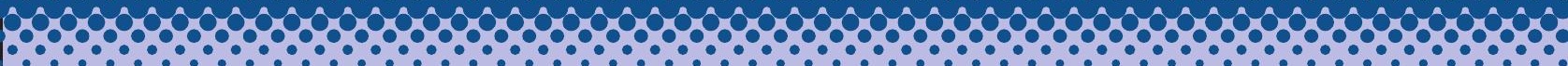

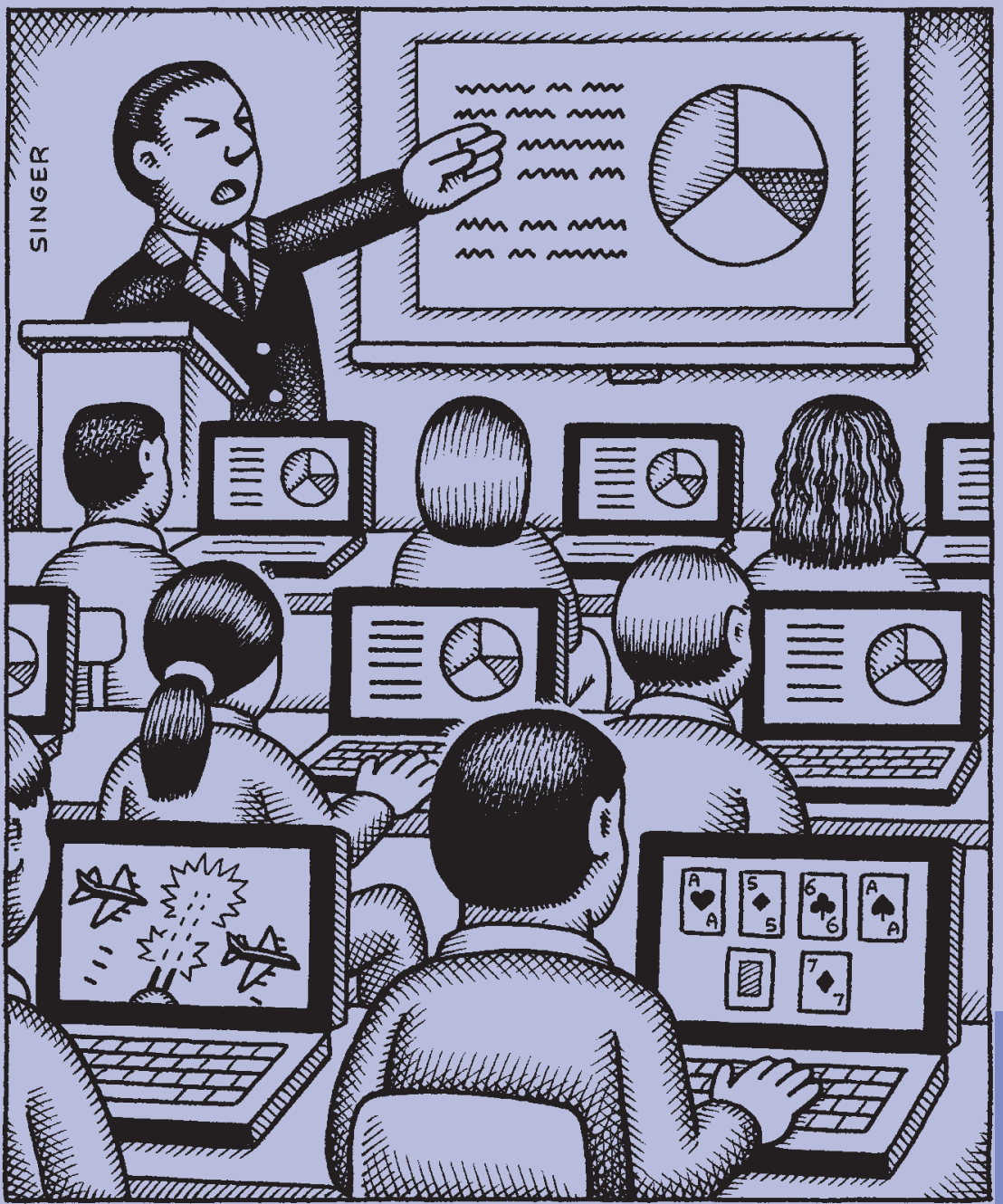

Universitätsdrucke Göttingen

\section{Band 90}

Materialien

Deutsch als Fremdsprache

fadaf 

Marc Hieronimus (Hg.)

Visuelle Medien im DaF-Unterricht

Dieses Werk ist lizenziert unter einer

Creative Commons

Namensnennung - Weitergabe unter gleichen Bedingungen

4.0 International Lizenz.

(9) (1) (2) 
erschienen als Band 90 in der Reihe „Materialien Deutsch als Fremdsprache“ in den Universitätsdrucken im Universitätsverlag Göttingen 2014 
Marc Hieronimus (Hg.)

Visuelle Medien im DaF-Unterricht

Materialien

Deutsch als Fremdsprache Band 90

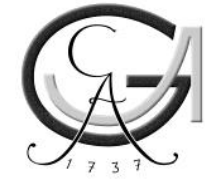

Universitätsverlag Göttingen 2014 


\section{Bibliographische Information der Deutschen Nationalbibliothek}

Die Deutsche Nationalbibliothek verzeichnet diese Publikation in der Deutschen Nationalbibliographie; detaillierte bibliographische Daten sind im Internet über $<$ http://dnb.ddb.de $>$ abrufbar.

Die „Materialien Deutsch als Fremdsprache“ sind eine Reihe des Fachverbands Deutsch als Fremdsprache e.V. $(\mathrm{FaDaF})$, in der Tagungsergebnisse, Dissertationen und andere wichtige Einzeldarstellungen aus dem Bereich Deutsch als Fremdsprache veröffentlicht werden.

http://www.fadaf.de/de/Publikationen/mat_daf/

\section{fadaf}

Schriftleitung: Annett Eichstaedt; Annegret Middeke

Dieses Buch ist nach einer Schutzfrist auch als freie Onlineversion über die Homepage des Verlags sowie über den OPAC der Niedersächsischen Staats- und Universitätsbibliothek (http://www.sub.uni-goettingen.de) erreichbar. Es gelten die Lizenzbestimmungen der Onlineversion.

Satz und Layout: Marc Hieronimus Umschlaggestaltung: Jutta Pabst Titelabbildung: Andy Singer

(C) 2014 Universitätsverlag Göttingen http:/ / univerlag.uni-goettingen.de ISBN: 978-3-86395-174-0

ISSN: $1866-8283$ 


\section{Inhalt}

\section{Einleitung}

Ein Bild sagt mehr als tausend Worte....................................................... III

\section{Grundlagen}

\section{Tobias Schöttler}

Was ist Bildwissenschaft? Ihre Gegenstände, Fragen und Methoden......... 3

\section{Markus Raith}

Multimodales Verstehen und kulturelles Lernen.

$\mathrm{Zu}$ einer Didaktik des Logovisuellen.

\section{Dorothea Spaniel-Weise}

Evaluationskriterien audio-visueller Verbundmedien

für den DaF-/DaZ-Unterricht.

\section{Ralf Palandt}

Comics - Geschichte, Struktur, Interpretation

\section{Starre Bilder}

\section{Chiara Cerri}

Comics zu aktuellen zeitgeschichtlichen Sujets. Eine visuell-sprachliche

Herausforderung für den landeskundlichen DaF-Unterricht

\section{Miriam Bertocchi}

Graffiti und Street Art im DaF-Unterricht

\section{Michael Reichelt}

Der Einsatz von Printwerbung im DaF-Unterricht.

Grenzen und Möglichkeiten von Bild-Text-Relationen

im Sprach- und Landeskundeunterricht

\section{Dorit Kluge}

Kunst und Kunstgeschichte im Deutschunterricht.

Ein Unterrichtsbeispiel zu Porträts der Renaissance-Zeit. 


\section{Franziska Flucke}

Bilderbuch einer Freundschaft? Die deutsch-französische Geschichte in Bild- und Tondokumenten des 19. und 20. Jahrhunderts

\section{Bewegte Bilder}

\section{Renate Bürner-Kotzam}

Ansätze einer medienintegrativen Narratologie im Unterricht.

\section{Anastasia Novikova}

Lyrikverfilmungen im DaF-Unterricht.

Neue Möglichkeiten der Text- und Filmarbeit

\section{Luise Holke}

Dokumentarfilme und Künstlerportraits! Gerhard Richter,

Pina Bausch und Sasha Waltz im DaF-Unterricht.

\section{Benjamin Schmäling}

Aktuelle Kurzfilme im DaF-Unterricht: „Feierlich reist““ und „Fraktur“.... 319

\section{Anna Svet}

Fernseh-Werbespots

im handlungsorientierten Fremdsprachenunterricht.

\section{Monika Wolf}

Der Einsatz der Videokamera im Sprechtraining DaF.

Ein Werkstattbericht...

\section{Neue Medien}

\section{Christina Margrit Siever}

Multimodale Kompetenz und multimodale Kommunikation im DaF-Unterricht

\section{Danielle Verena Kollig und Japhet Johnstone}

„Queer Media“: (Audio-)Visuelle Medien und Gender-Vielfalt im DaF-Unterricht.

\section{Christian Müller und Ralph Olsen}

Deutsch lernen mit DaF-Apps 


\title{
Einleitung: Ein Bild sagt mehr als tausend Worte
}

\author{
Marc Hieronimus
}

Gerald E. Stearn: Is there a real danger in the new media?

Marshall McLuhan: It seems to me that the great advantage in understanding the operational dynamics of various media is to quiet them down, not exploit them. If you understand these dynamics, you can control media, eliminate their effects from the environment. And this is most desirable. I think we would do ourselves a considerable kindness if we closed down TV operations for a few years. If TV was simply eliminated from the United States scene, it would be a very good thing. [...] It is destroying our entire political, educational, social, institutional life. TV will dissolve the entire fabric of society in a short time. If you understood its dynamics, you would choose to eliminate it as soon as possible. TV changes the sensory and psychic life.

(McLuban; Stearn 1967: 291)

Video killed the radio star

(The Buggles 1979)

Medienoptimismus, Medienpessimismus, Medienpragmatismus, Medienzynismus. Pendel des Zeitgeists.

(Kinter 1994: 205)

„Medien“ sind ein vieldeutiger Begriff. Wenn junge Menschen ,irgendwas mit Medien" machen wollen, haben sie weder die immer abstrakter werdenden Kom- 
munikations- und Gesellschaftstheorien im Sinn, noch meinen sie Mode, Sprache oder gar die Menschen, die in Trance mit den Toten reden. Die traditionellen Medien in diesem Sinne sind Presse, Fernsehen, Radio und neuerdings ihre Ableger im Metamedium Internet. Nach diesem Verständnis haben auch viele - wenn nicht alle - computer- bzw. mobiltelefonbasierten Anwendungen Mediencharakter, nämlich mindestens all jene, die über den individuellen (Spiele) und Paargebrauch (Telefon, Mails) hinausgehen; hier ist besonders an Datenbanken, Suchmaschinen und soziale Netzwerke zu denken.

Die Medienrevolution, der wir seit einigen Jahrzehnten und beschleunigt in etwa seit der Jahrtausendwende beiwohnen, ist noch lange nicht abgeschlossen, und bis auf weiteres gehen die Begriffe noch durcheinander. Im hiesigen Kontext (vor allem DaF-, in zweiter Linie DaZ- und DaM-Unterricht) seien visuelle Medien zunächst ganz banal als bildliche Darstellungen verstanden. Man verliert sich schnell in den Ordnungen, wenn man in Begriffen von Material, Original/Kopie, Trägermedium etc. denkt, also versucht, irgendwo handfest existierende Aufnahmen, Plakatentwürfe, Gemälde, Comiczeichnungen, Filmrollen etc. von den Reproduktionen, Inhalten, Elementen der Veranschaulichung (Foto, Plakat, Darstellung des Gemäldes, Comicheft, gezeigter Film etc.) zu trennen. Zweitens seien visuelle Medien, wiederum dem Alltagsverständnis folgend, nicht die einzelnen Gerätschaften, aber all jene optischen Verbreitungsmittel höherer und eigener Ordnung, die, und das ist das Neue an den neueren und „Neuen“ Medien, nicht ohne elektrische und elektronische Unterstützung funktionieren, egal wieweit sie vorher produziertes Bildliches nur wiedergeben oder selbst generieren. Der Fernsehapparat, der spür- und sichtbar vorhandene Rechner verlieren spätestens beim Stromausfall ihren Mediencharakter, wenn ihnen je einer zukam; der abgestürzte oder unterbrochene Film oder „das Fernsehen“ dagegen nicht.

Visuelle Medien sind also nicht die Medien, aber auch nicht mit Bildern gleichzusetzen, die einerseits eine Teilmenge darstellen (nicht alle visuellen Medien sind Bilder), andererseits über den Bereich der visuellen Medien hinausreichen. Annähernd dreißig Einzelwissenschaften widmen sich heute innerhalb der noch jungen Bildwissenschaft dem Bild im weiteren Sinne (vgl. Sachs-Hombach 2005), und das hat seinen Grund. Der Mensch ist ein animal symbolicum (Ernst Cassirer), homo pictor (Hans Jonas), nicht weil er sich mit Gerätschaften oder Anwendungen, sondern weil er sich mit Bildern umgibt. Neben den perzeptuellen, d.h. graphischen oder optischen Bildern (eben bildlichen Darstellungen) mit all ihren Unterarten, Verwendungs- und Betrachtungsweisen gibt es schließlich auch sprachliche und mentale Bilder, und diese drei sind wahrscheinlich sogar ,unauflösbar miteinander verknüpft" (Klemm; Stöckl 2011: 9). Tobias Schöttlers Beitrag zu den Gegenständen, Fragen und Methoden der Bildwissenschaft eröffnet den vorliegenden Band und vertieft diese Fragen.

Die Beschäftigung mit visuellen Medien hat in der Lehrausbildung schon vor einiger Zeit begonnen. Unter den zahlreichen Bildungsreformvorhaben der frühen Siebziger Jahre gab es ein Projekt, den vermeintlich überholten schulischen Kunst- 
unterricht durch ein Fach „Visuelle Kommunikation“ zu ersetzen, in dem es weniger um Kunstgeschichte und künstlerische Fertigkeiten als um Bildanalysen in einem weiter gesteckten Rahmen gegangen wäre. Nicht die museale Kunst, so die Überlegung, unterhalte, bewege, präge eine Gesellschaft, sondern das immerzu wachsende Angebot von Werbeplakaten, Fernsehsendungen, Markenzeichen und anderen visuellen Medien. ${ }^{1}$ In einem Lehrerhandbuch zu den ,audio-visuellen Mittlern im Deutschunterricht“ konnte man damals lesen: „Zwar bemüht sich die Didaktik, der natürlicherweise immer vorauseilenden Technik möglichst schnell hinterherzulaufen, doch scheint deren Vorsprung immer größer zu werden“ - so weit, so immer noch richtig. Der zweite Teil des Satzes stimmt nicht mehr: „,[D]ies nicht zuletzt deshalb, weil gerade auf vielen Gebieten des Unterrichts die Diskrepanz zwischen theoretischen Erkenntnissen wie deren punktueller Erprobung und Realisierung in einigen Versuchen und den Möglichkeiten der schulischen Alltagswirklichkeit zumindest derzeit fast unüberbrückbar groß ist." (Lutz; Sauter; Wächtershäuser 1971: 13)

In vielerlei Hinsicht ist es heute eher umgekehrt. Die Schülerinnen und Schüler der spät- oder postindustriellen Länder sind als digital natives ihren (älteren) Lehrkräften in puncto Mediennutzung quantitativ in der Regel weit voraus und auch besser ausgerüstet. Zwar setzen (DaF-)Lehrerinnen und Lehrer neue oder zumindest neuere Medien auch im Unterricht ein, sei es, um mit der Zeit zu gehen, um das Interesse der LernerInnen zu erwecken oder, im besten Falle, aus Überlegung und Überzeugung heraus; nach dem Siegeszug der immer auch visuellen und längst nicht mehr neuen elektronischen Medien und der Preis- und technischen Entwicklung des Papierdrucks hat sich die Präsenz der Bildmedien auch im Klassenraum vervielfacht. Die Fragen nach Möglichkeiten, Wirkungen und Gefahren des Visuellen aber werden von der Sprachdidaktik trotz einschlägiger turns in den anderen Geisteswissenschaften immer noch sehr verhalten gestellt.

Das soll nicht heißen, es habe sich in den letzten fünfzig Jahren nichts getan. Der Umgang mit Medien soll heute Teil des Unterrichts sein, und zwar vor allem des (muttersprachlichen) Deutschunterrichts:

Das Fach Deutsch gehört zu den Kernfächern, in denen Medien eingesetzt, vor allem aber thematisiert und reflektiert werden. Die Medienentwicklung und der Stand der Diskussion um Medien haben folgerichtig Eingang in die Rahmenpläne „Deutsch“ aller Schulformen und Jahrgangsstufen gefunden. Parallel hat sich die Deutschdidaktik den Medien hin geöffnet und Modelle entwickelt, um mediendidaktische Fragestellungen in den Deutschunterricht sinnvoll zu integrieren. Mit dieser Medienorientierung zeichnet sich ein Deutschunterricht ab, der stärker als bisher an den Wissensbeständen, Erfahrungen und der Lebenswelt von Schülerinnen und Schülern anknüpft. (Barsch 2006: 162).

\footnotetext{
1 Vgl. die Beiträge von Helmut Hartwig, Heino R. Möller und der Adhoc-Gruppe Visuelle Kommunikation in Ehmer 1971.
} 
Ziel der Öffnung ist das Erreichen von Medienkompetenz auf Seiten der Schülerinnen und Schüler. Doch das Aber bleibt: Wie kompetent sind denn die Lehrkräfte? Wie weit und wie tief reicht ihr kritischer Blick? Und wie steht es mit dem sprach- und kulturübergreifenden Medienunterricht, der doch eigentlich besonders spannend und wichtig sein sollte? Die DaF- oder DaZ-Lehrkraft tritt im In- und Ausland als Bildvermittlerin auf. Sie nutzt im Idealfall nicht nur die (zumeist heiterseichten) Lehrwerksillustrationen, also Abbilder einer vorgestellten deutschen „Realität", die bildlich allenfalls bruchstückhaft darzustellen ist, sondern versucht, Bildwelten zu verbinden. Die Deutsch-Studentin im Ausland, der Nachgezogene, der „Wirtschaftsflüchtling“, die politische Asylantin hierzulande haben ganz andere Bilder und Assoziationen im Kopf als ihre DozentInnen, ein Umstand, der sich in der Fachdidaktik nur langsam herumspricht (vgl. Scherling; Schuckall 1992; Macaire; Hosch 1999 sowie Reinfried 2008 zur Geschichte der DaF-BuchIllustration). Vor allem

gibt [es] bisher keine systematische oder konsensuelle Beschreibung der Funktionen von Bildern im Fremdsprachenunterricht. [...] Bei der Untersuchung der Funktionen von Bildern stellt sich heraus, dass deren allgemeinkulturelle Bedeutung sich zwar quantitativ, nicht aber qualitativ im Fremdsprachenunterricht niederschlägt. Damit ist gemeint, dass der Anteil der Bilder für die Generierung kultureller Bedeutungen und ihre Rolle in kulturellen Diskursen und Prozessen dem Individuum erhebliche Kompetenzen abverlangt, die sich in einem bildungstheoretisch fundierten Konzept des Fremdsprachenlernens (wie im Übrigen allen schulischen Lernens) niederschlagen müssen. Dieses stellt jedoch nach wie vor ein Desiderat dar [...]. Ein fremdsprachendidaktisches Konzept, das die Fähigkeit der Lernenden konzeptualisiert, Bilder zu verstehen und mittels Bildern zu kommunizieren (visual literacy) steckt noch in den Anfängen. (Hallet 2008: 213).

Ganz ähnlich sieht es Michael Staiger mit Blick auf den schulischen Deutschunterricht:

Offenbar herrscht heute das Missverständnis vor, dass [...] das Bildlesen im Unterschied zum Schriftlesen nicht gelehrt oder gelernt werden müsse. Jedenfalls steckt die Theoriebildung im Bereich Bildkompetenz und Bilddidaktik in der Erziehungswissenschaft und den Fachdidaktiken derzeit immer noch in den Anfängen. (Staiger 2012: 42f.).

Markus Raiths hier vorliegender Beitrag zu einer Didaktik des Logovisuellen und Dorothea Spaniel-Weises Evaluationskriterien audio-visueller Verbundmedien leisten also wichtige Arbeit. Ansonsten? In den Lehrbibliotheken der erziehungswissenschaftlichen Fakultäten stehen durchaus einige medienpädagogische und mediendidaktische Handbücher, in denen über die bloße Gebrauchslehre hinaus zuweilen auch einmal kritisch-tastend nach den Gefahren oder unerwünschten 
Nebenwirkungen von Medien (d.h. auch Bildmedien) gefragt wird. ${ }^{2}$ Für den Geschichtsunterricht hat Hans-Jürgen Pandel an einige bildinterpretatorische Selbstverständlichkeiten erinnert, die doch den meisten Lernern (und vielen Lehrern) erst (wieder) zu Bewusstsein gebracht werden müssen, etwa dass Bilder weder Negationen ausdrücken noch Häufigkeitsaussagen machen können (Pandel 2008: 16f., vgl. a. Pandel; Schneider 2011). Das ist nicht wenig. Doch nur wenige Werke beschäftigen sich mit neuen Medien im Unterricht, darunter einige wenige gute Handbücher (Roche 2008; Issing; Klimsa 2009), aber auch zahlreiche bei darauf spezialisierten Verlagen veröffentlichte und online gut platzierte „Studienarbeiten“ von weniger als 20 Buchseiten (etwa Valentin 2013; Lenczowski 2013; Herzlinger 2013).

Und vor allem: Wie weit ist derlei Medienpädagogik vom aufklärerisch-emanzipatorischen Impetus der 1960er und Folgejahre entfernt, als die uns heute unverzichtbaren Online-Medien noch gänzlich unbekannt waren, man noch Bücher las und doch die gerade erst in den Alltag hineinreichenden Massen(bild)medien als Herrschaftsinstrumente oder Werkzeuge einer kapitalistischen Bewusstseinsindustrie sah?! Es ist, als hätte die Allgegenwart des Visuellen jede grundsätzliche Kritik verdrängt. Dabei ist es keineswegs so, als seien wir heute einfach schlauer als damals, im Gegenteil. Wir sind heute potentiell besser als früher über die humanitären und Umweltkatastrophen informiert, die unser unverhandelbarer Lebensstil hervorruft, und sitzen als DaF- und DaZ-Lehrkräfte nicht selten den (übrigens medial nicht nur anders, sondern oft auch weniger erfahrenen) Betroffenen direkt gegenüber, aber irgendetwas am „Spektakel“ der Medien macht, dass wir uns zu Gegenmaßnahmen oder zumindest -überlegungen weder befugt noch befähigt oder gar genötigt sehen. Das haben Guy Debord oder der eingangs zitierte Marshall McLuhan schon vor fast einem halben Jahrhundert vorhergesehen. ${ }^{3}$

Der Band 90 der Reihe „Materialien Deutsch als Fremdsprache“ ist keine politische Streitschrift. Aber Medien gehen uns an und bergen selbst im Kleinen gewisse Gefahren. Ein aufmerksamer Blick auf die Titelseite des vorliegenden Werks mag einige Aspekte der hier zwangsläufig nur angeschnittenen Problematik verdeutlichen.

Wir sehen eine Unterrichtssituation, wie sie vielen DaF- und DaZ-Lehrkräften an gut ausgerüsteten Instituten vertraut sein dürfte: Die eingesetzten Computer sind bisweilen kontraproduktiv, denn in den hinteren Reihen werden die modernen Geräte zum Spielen zweckentfremdet. Bild- und Medieneinsatz will also durch-

\footnotetext{
2 Vgl. etwa Hiegemann; Swoboda 1994; Barsch; Erlinger 2002, Tolodziecki; Herzig 2004; Moser 2006; Barsch 2006; Niegemann et all. 2008; Lieber 2008; Frederking; Krommer; Maiwald 2012.

3 Vgl. Debord 1994 (frz. Original 1967). Marshall McLuhan wird heute so gut wie gar nicht mehr gelesen. In der Internet-Euphorie um die Jahrtausendwende wurde seine Horrorvorstellung des „globalen Dorfs“ zum Begriff einer unvermeidlichen, aber begrüßenswerten, wenn nicht alle Welt beglückenden Entwicklung verkehrt; viel mehr bleibt von seinem Werk im Medienspektakel nicht übrig.
} 
dacht und wohldosiert sein. Wer glaubt, damit das Bild „verstanden“ zu haben, sei zum Innehalten ermahnt.

Zunächst einmal handelt es sich um eine gezeichnete Umschlagillustration. Graphisch/stilistisch ist Andy Singers Kunst mit Comics verwandt, die allerdings, wie wir spätestens im Beitrag von Ralf Palandt lernen, erst bei zwei Bildern beginnen, lässt aber auch an Street-Art-Künstler wie Banksy denken. Comics und StreetArt lassen sich - wie wahrscheinlich alle visuellen Medien - sehr gewinnbringend im DaF-Unterricht einsetzen, wie Miriam Bertocchi und Chiara Cerri in ihren Beiträgen aufzeigen. Die Illustration der Titelseite steht in einem spezifischen Kontext, hier einer an Lehrkräfte gerichteten Fachpublikation, und erfüllt dort zweifellos einen anderen Zweck und hat wahrscheinlich auch eine andere Bedeutung als zum Beispiel als Karikatur in einer technik- und wachstumskritischen Monatszeitschrift. ${ }^{4}$ Titelbilder wollen eyecatcher sein, also das Auge ergreifen. Bilder werden schneller als Texte oder Zahlen erfasst, ein gut illustriertes Buch liest sich angenehmer als eine „Bleiwüste“, ja: Bilder schlagen Texte und Argumente - daher der Erfolg der ursprünglich für Werbezwecke entworfenen „Powerpoint-Präsentation“ (vgl. Frommer 2012). Die Zeichnung auf Seite 1 hat demnach ihren Zweck erfüllt, wenn sie den/die LeserIn wie im vorliegenden Fall zum Lesen des Buches verleitet hat. Ganz ähnlich verhält es sich mit dem Großteil der Lehrbuchillustrationen und all dem Visuellen, das man als Lehrkraft in bester Absicht in den Unterricht einbringt, nämlich „damit die Leute bei der Stange bleiben“. Das ist kein Missbrauch, weder der Bilder, noch der BetrachterInnen.

Aber Bilder leisten selbstverständlich mehr. So zeigt die Zeichnung eine Unterrichtssituation, sie ist es aber nicht, und das liegt nicht nur an der Verfremdung (Zeichnung) oder an ihrem Ort (Titelbild): „Das ist keine Pfeife“ schrieb Magritte unter sein Bild einer Pfeife. Wir sagen: „Das ist Bismarck“, „das ist Lady Gaga“, dabei sind es nur Aufnahmen von ihnen, und nicht einmal treffende, falls es das überhaupt gibt. Wir sehen, sofern wir die Gesichter überhaupt zuordnen können, Inszenierungen des Reichskanzlers und der schrillen Künstlerin. Selbstinszenierungen sind kein Phänomen des 19. oder 20. Jahrhunderts, wie Dorit Kluge weiter unten in ihrem Beitrag zu Porträts der Renaissance aufzeigt, aber unser Geschichts- und Realitätsbewusstsein wird doch immer stärker von uns umgebenden Bildern geprägt. Nicht nur war schon das Zwanzigste ein „Jahrhundert der Bilder“, wie Franziska Flucke weiter unten in ihrem Beitrag über das deutsch-französische „Bilderbuch einer Freundschaft" aufzeigt; Geschichte findet/fand überhaupt nur noch statt, wenn sie bildlich dokumentiert, und das heißt fast immer auch inszeniert ist. ${ }^{5}$

\footnotetext{
${ }^{4}$ Der Erstabdruck erfolgte in der Nr. 106 der einschlägigen französischen Zeitschrift La Décroissance vom Februar 2014; der Illustrator Andy Singer ist dort ein regelmäßiger Beiträger, vgl. www.ladecroissance.net und www.andysinger.com.

5 Geschichtliche Ereignisse ohne beeindruckende Bilder geraten gegenüber den zeigbaren in Vergessenheit, vgl. Sontag 2004. Ansehnliche Bildbände gibt es zuhauf. Zur visuellen Geschichte im Allgemeinen vgl. einführend Paul 2006. Sehr tiefsinnige Analysen emblematischer Bilder des Zwanzigsten Jahrhunderts bieten Paul 2008; 2009. Im deutschen und DaF-Kontext sind die (meist auch an Bil-
} 
In der Sprache schlägt sich der trügerische Charakter der Bilder durchaus nieder. „Bildhübsch“ ist eine Frau, die auch ,in echt“ gut aussieht; schöner als schön ist ein Mann, wenn er „ein Bild von einem Mann“ ist; im Französischen kann man sogar „,sage comme une image“, brav wie ein Bild sein - wir dürfen den Bildern also nicht trauen. Nun sind wir aber unaufhörlich mit Bildern in Form von oder als Beiwerk zu Nachrichten, Werbebotschaften, Graphiken usw. konfrontiert, und das hinterlässt nicht bloß Spuren, es prägt. Michael Reichelt streicht in seinem Beitrag zur Printwerbung im DaF-Unterricht zurecht den möglichen Nutzen von Printwerbung für den Sprach- und Landeskundeunterricht heraus, aber auch ihre Grenzen. „Außenwerbung trifft jeden“ wirbt die Werbeindustrie unverblümt für sich selbst und äußert damit zugleich eine Banalität und das Ungeheuerliche schlechthin: Nicht nur unsere Kaufentscheidungen, auch unsere Geschmäcker, Werturteile, Vorlieben und Ängste, unsere gesamte Wahrnehmung ist nicht etwa vom Verstand geprägt, sondern wird tagtäglich von Tausenden an unsere verborgenen Gefühle und Triebe, unser „Es“ appellierenden Bildbotschaften bestimmt. ${ }^{6}$

Eine wichtige Folge der Bilderflut ist der flüchtige Blick, die Blindheit fürs Detail. Bei allen philosophischen Erwägungen sollte die Titelillustration also noch einmal zum genauen Hinsehen, Nach-Denken, close reading ermahnen. Was ist uns so vertraut an der Situation? Die LernerInnen der ersten Reihen sehen an den Bildschirmen, was die Lehrkraft gleichzeitig an die Tafel wirft, hier eines dieser für wissenschaftliche Exaktheit stehenden Kuchendiagramme, wie man sie heute auf Knopfdruck erstellen kann. Das wirft zum einen die spannende Frage nach Zweck von und Manipulation durch (verbildlichte) Statistik auf: Was ist überhaupt darstellbar, was nicht? Wenn Bilder anders (stärker?) als Texte wirken, Messbares stärker (anders?) als nicht Messbares überzeugt, was ist der Wert/Sinn/Nutzen, die Gefahr der Graphik? Und wenn es es um Umfragewerte geht: Wer hat überhaupt wen wonach gefragt, was wurde untersucht, und was nicht? Was sind die Leitunterscheidungen? Warum diese und keine anderen?

Aber angenommen, diese Fragen seien geklärt oder gar Gegenstand der Unterrichtseinheit - wäre es nicht besser, die Computer auszuschalten, oder angesichts des offensichtlichen Verführungspotentials gleich in einem herkömmlichen Klassenraum zu unterrichten? Dort könnte man anders als in den üblichen Medienräumen auch die Sitzordnung ändern - besonders kommunikativ und/oder handlungsorientiert scheint der gezeigte Unterricht ja nicht zu sein.

Es gibt offenbar viel zu bedenken. Sollten wir im Zweifelsfall also lieber ganz auf visuelle Medien verzichten? Nein, natürlich nicht! Und zwar aus zwei Gründen:

\footnotetext{
dikonen gebundenen) „Deutschen Erinnerungsorte“ zu erwähnen (François; Schulte 2005; DaF-Didaktisierung: Schmidt; Schmidt 2007; Clemens 2009).

${ }^{6}$ Vgl. die Selbstdarstellung unter www.trifft-jeden.de. Die dort aufgelisteten (niedrigen) Zugriffszahlen weisen auf einen weiteren wichtigen Umstand hin: Werbung interessiert nicht als solche und wird auch kaum als solche wahrgenommen. Ähnlich interessiert am Bild des Popsternchens nicht das Medium (Zeitung, Plakat, CD-Cover) mit seinem Herstellungs- und Verwertungskontext, sondern die Marke „Lady Gaga“ und das Image, d.h. die Gefühle, Werturteile usw., für die sie steht.
} 
Erstens fangen visuelle Medien beim Tafelbild an. Ein gutes Tafelbild sagt manchmal buchstäblich mehr als tausend Worte, und das gilt im Fremdsprachenunterricht noch mehr als anderswo. In Integrations- und berufsvorbereitenden Kursen ${ }^{7}$ beherrscht die Lehrkraft meist nicht alle vertretenen Muttersprachen, und was die Klasse auf Deutsch nicht versteht, begreift sie in der Regel auch nicht auf Englisch. Fast alles Gegenständliche lässt sich aber mit ein wenig Übung zeichnen, genau wie die Bedeutung der meisten Verben und vieler Adjektive. Auch Grammatik lässt sich visualisieren, und zwar nicht nur die Bedeutung der Wechselpräpositionen (man zeichne eine große 9 und positioniere die neun Präpositionen entsprechend) und ihre Verwendung (ein Pfeil für Akkusativ, ein örtlich und zeitlich zu verstehender Punkt für Dativ), sondern auch Dativ und Akkusativ selbst. Folgende leicht an der Tafel reproduzierbare Zeichnung möge das verdeutlichen.

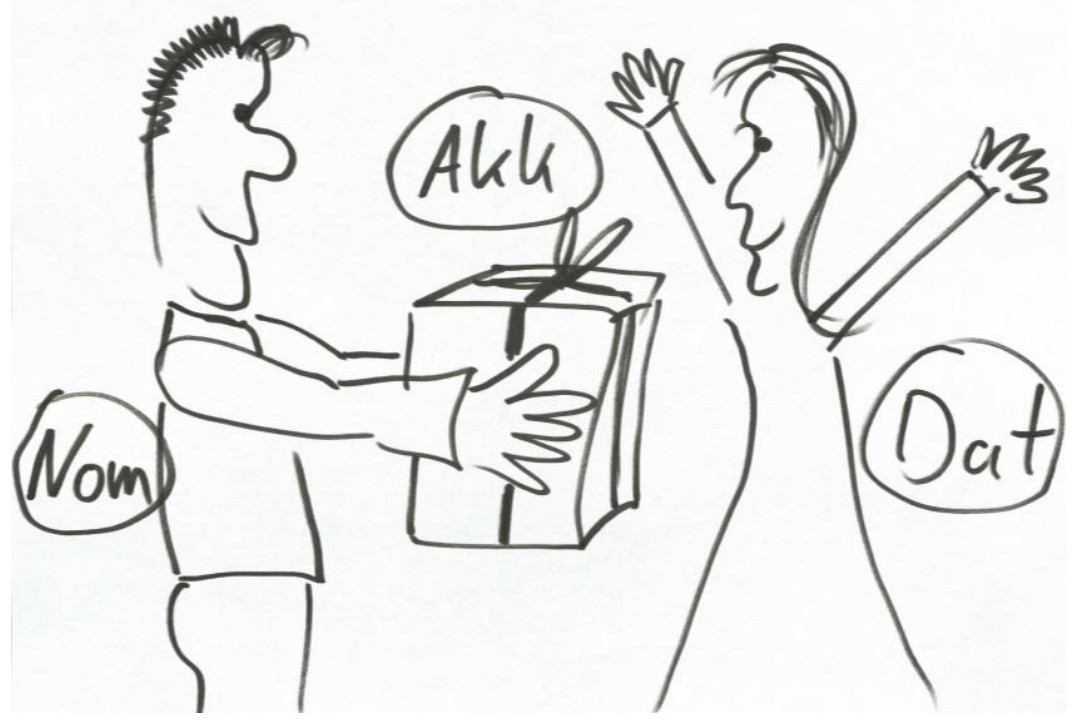

\section{Nicht schön, aber nützlich: Tafelbild zu ditransitiven Verben}

Die Zeichnung zeigt ein Verb mit zwei Objekten: „schenken“, „,zeigen“, „anbieten“, „leihen“ - egal, welches. Vielleicht stiehlt der Herr der Dame das Geschenk oder spielt ihr das Schenken vor. Versteht man die Zeichnung symbolisch, kann sie auch „erzählen“, „,erklären“, ,,vorlesen“ usw. bedeuten. Immer gilt: Der Gegenstand

\footnotetext{
7 Integrationskurse bringen Ausländer auf das für einen dauerhaften Aufenthalt in Deutschland vorgeschriebene Niveau B1. Die sogenannten ESF/BAMF-Kurse werden vom Europäischen Sozialfonds und dem Bundesamt für Migration und Flüchtlinge bezahlt und sollen der Integration in den Arbeitsmarkt dienen. Das dort angestrebte Sprachniveau ist B1+ bzw. B2+, wobei das Plus für die Ausrichtung auf Berufsvokabular steht.
} 
steht im Akkusativ (oder ist wie bei „sagen“ ein pronominalisierbarer Satz), die Person im Dativ. ${ }^{8}$

Diese Regel lässt sich noch ausweiten. Die Verben mit zwei Objekten sind sehr gängig, aber nicht sehr zahlreich. Die meisten Verben haben nur ein Objekt und/ oder ein Präpositionalobjekt bzw. eine (meist verzichtbare) präpositionale Ergänzung. ${ }^{9}$ Verben mit Präposition verlangen ein Objekt im Kasus der Präposition, und die sind auf klassische Art zu büffeln, da gibt es (wahrscheinlich) noch keine überzeugende Visualisierung;10 Verben mit Wechselpräpositionen wie „denken an“, „sich verlassen auf“ etc. fordern meist den Akkusativ.

Nun brauchen aber Verben mit einem Objekt wie „,verschenken“ und hunderte andere mehr auch fast immer den Akkusativ, selbst wenn es kein (indirektes) Dativobjekt gibt, also niemand beschenkt, bestohlen usw. wird. Somit gilt in den meisten Fällen: Objekt $=$ Akkusativ. $\mathrm{Na}$, wenn das keine Faustregel ist! Und bei allen Feminina, Neutra und im Plural gibt es nicht einmal einen Unterschied zwischen Nominativ und Akkusativ, d.h. das zunächst verwirrende System der deutschen Deklination reduziert sich bei genauerer Betrachtung ganz erheblich. Die ebenfalls häufigen, aber an (sagen wir: wenig mehr als) zwei Händen abzählbaren Verben mit einem Dativobjekt sind auswendig zu lernen; als Gedankenstütze kann der Umstand dienen, dass die Objekte dieser Verben wie in der Zeichnung meist Personen sind, als hätte der Dativ etwas mit Menschen zu tun. Die Assoziation bzw. Illustration Gegenstand = Akkusativ, Person $=$ Dativ kann also durchaus dienlich sein, und zu Fertigung und Gebrauch von Tafelbildern sei dringend geraten. ${ }^{11}$

\footnotetext{
${ }^{8}$ Linguistische Genauigkeit würde natürlich an dieser Stelle die Aufzählung sämtlicher Ausnahmen à la ,jemanden eines Besseren belehren“, „,jemanden des Betrugs verdächtigen“ usw. verlangen, aber wie häufig sind diese hier gar nicht zur Debatte stehenden Genitiv-Beispiele, zumal in der gesprochenen Sprache? Was gibt es noch? „Nennen“ ist auf den zweiten Blick kein Gegenbeispiel, denn man kann jemanden und jemandem einen Blödmann nennen. Der erste, scheinbar regelwidrige Fall stellt über die Kasusentsprechung die behauptete Identität her, ganz wie „sein“ und „scheinen“, die die Regel brechen, nach der ein Satz nur einen Nominativ haben darf. Weitere bzw. echte Gegenbeispiele sind ausgesprochen selten, sperrig, ungewöhnlich, etwa ,jemanden einen Lügner schelten“: Das wiederum dem Nennen verwandte ,schelten“ wird in der Regel nicht einmal in die Ablauttabelle der unregelmäßigen Verben aufgenommen. Ein echtes Beispiel ist „jemanden einer Gefahr aussetzen“: hier ist die Person das direkte Objekt.

9 „Wohnen“ z.B. hat keine feste Präposition, braucht aber eine lokale Ergänzung, weil das Verb sonst keine über „nicht im Freien leben“ hinausgehende Bedeutung hat, was sich ein allseits bekannter schwedischer Möbelfabrikant vor ein paar Jahren für eine großangelegte Werbekampagne zu Nutze gemacht hat. Das Deutsche hat viele Ausnahmen und Eigenheiten. Meist ist die Überlegung dienlich, was am vermeintlich Komplizierten idiosynkratisch (also deutsch-spezifisch) und was allgemeinsprachlich ist. /Schenken/ z.B. kann wohl in jeder Sprache zwei Objekte haben, für das Schenken mit einem Objekt haben wir im Deutschen allerdings eigene Wörter (,beschenken“" und „verschenken“).

${ }^{10}$ Sehr wohl gib es Eselsbrücken. Der Dativ ist z.B. eine Dame namens „Aubemina von Seizu“ (aus, bei, mit, nach, von, seit, zu), die gängigsten Akkusativ-Präpositionen lassen sich mit dem Merkwort FUDOGE behalten (für, um, durch, ohne, gegen, entlang, wobei es sich bei letzterer um eine Postposition handelt). Der Autor ist dankbar für Visualierungvorschläge.

${ }^{11}$ Wieder geht es nur ums grobe Bild. Die wichtigsten Verben mit Dativobjekt sind „helfen“, „folgen“, ,gehören“, „gefallen“, „passen“, ,gratulieren“, „,begegnen“, „danken“, ,,vertrauen“. Bei einigen weiteren Verben - „nachlaufen“, „,beiwohnen“, „zuprosten“ und anderen mit denselben Vorsilben dürfte historisch eine Dativpräposition zum Präfix geworden sein. In dieser Zeichnung steckt noch mehr: Wenn der Gegenstand „verpackt“, d.h. ein Pronomen ist, kommt er im Satz zuerst, während
} 
Zweitens und vor allem sollte spätestens der vorliegende Band die Vielfalt und Wichtigkeit der visuellen Medien für den DaF-Unterricht unterstreichen. Die bereits angerissenen ,grundlegenden“ Beiträge mögen der Einleitung dienen. Auch die Artikel des zweiten Teils der „starren“ Bilder wurden (zu) kurz erwähnt - das Weiterlesen ist so informativ wie vergnüglich. Im dritten Teil geht es um Filme: Renate Bürner-Kotzams „Ansätze einer medienintegrativen Narratologie im Unterricht" gehören mit ihrem Fokus auf Filmnarratologie an den Anfang des dritten Teils der „bewegten Bilder“, gerade weil sie die Gemeinsamkeiten und Unterschiede der starren bzw. bewegten Medien Comic und Film erläutert und beide mit dem viel älteren Medium Literatur in Verbindung bringt. Benjamin Schmäling stellt mit „Feierlich reist“ und „Fraktur“ zwei neue Werke innerhalb des gewissermaßen „klassischen“ DaF-Mediums Kurzfilm vor. Anastasia Novikova, Luise Holke und Anna Svet zeigen in ihren Beiträgen, wie auch Lyrikverfilmungen, Künstlerporträts und Werbespots sinnvoll eingesetzt werden können. Monika Wolfs Werkstattbericht über ihren Kameraeinsatz im Sprechtraining, also die praktische und produktive Seite des (Film-)Bildeinsatzes, schließt den dritten Teil ab.

Wie allgemein in der Fachliteratur kommen leider auch hier die neuen Medien zu kurz. Christina Margrit Siever macht sich anhand zahlreicher Social-Web-Beispiele grundlegende Gedanken zu multimodaler Kompetenz und Kommunikation. Christian Müller und Ralph Olsen haben sich nützlicherweise die den meisten DaF-Lehrkräften unbekannten Deutschlern-Apps der großen Verlage angeschaut. Und Danielle Verena Kollig und Japhet Johnstone erinnern in ihrem abschließenden Beitrag zu „Queer Media“ daran, dass wir trotz gelegentlicher Schwulen- oder Lesbenpärchen im Vorabendprogramm noch weit von einer generellen Akzeptanz neuer Lebensentwürfe und Inszenierungen sind und häufig noch ganz der alten Sichtweisen und Zuschreibungen verhaftet sind. In ihrem Sinne könnte man anhand obiger Zeichnung auch trefflich Geschlechterrollen und die einschlägigen Klischees und Erwartungen hinterfragen.

Der Band 90 der Reihe „Materialien Deutsch als Fremdsprache“ konnte nur durch die Mitarbeit und Unterstützung zahlreicher Personen und Institutionen zustande kommen. Der Dank des Herausgebers gilt in chronologischer Reihenfolge Tobias Beilicke und Sandra Schmidt für die Organisation des Fachseminars, das am Anfang des Buchprojektes stand; dem DAAD und der Universität Clermont-Ferrand für die finanzielle und logistische Unterstützung; den Autorinnen und Autoren für ihre spannenden Vor- und Beiträge; den BAMF-Deutschkursteilnehmern der Tertia Köln, Brühl und Frechen für die Erdung aller Theorie; den dortigen Kolleginnen (kein Binnen-I) für das Klima; Annegret Middeke und Annett Eichstaedt für die geduldige Betreuung des Buchprojekts für den Fachverband; Jutta Pabst und Petra Lepschy, die sich die gleiche Arbeit für den Göttinger Universitätsverlag

sonst Dativ vor Akkusativ kommt. Weiterführende Ideen zu Tafelbildern im Deutschunterricht bei Berger 1996. 
gemacht haben - und ganz unabhängig von aller Chronologie und Theorie Louise und Mathilde, Miriam, „smart-r.at“ Ingo, Timo und seinem Lichtwolf (.de), Olaf, Valerie und allen anderen in den vergangenen Monaten präsenten Bekannten und Verwandten für jede willkommene Ablenkung davon.

\section{Literatur}

Adhoc-Gruppe Visuelle Kommunikation (1971): Visuelle Kommunikation Zur gesellschaftlichen Begründung eines neuen Unterrichtsfaches. In: Ehmer, Hermann K. (Hrsg.) (1971), 367-373.

Barsch, Achim (2006): Mediendidaktik Deutsch. Paderborn: Schöningh.

Barsch, Achim; Erlinger, Hans Dieter (2002): Medienpädagogik. Eine Einführung. Stuttgart: Klett-Cotta.

Berger, Norbert: Deutsch unterrichten. Tafelbilder zu Grammatik-, Sprach- und Aufsatzunterricht. Donauwörth: Auer.

Clemens, Catharina (2009): Deutsch-französische Erinnerungsorte im Landeskundeunterricht am Beispiel von Versailles. In: Nieradka, Magali Laure; Specht, Denise (Hrsg.): Fremdkörper? Aspekte der Geisteswissenschaften in der Auslandsgermanistik und im DaF-Unterricht. Berlin: LIT-Verlag, 63-78.

Debord, Guy (1994): Die Gesellschaft des Spektakels. Hamburg: Edition Nautilus.

Ehmer, Hermann K. (Hrsg.) (1971): Visuelle Kommunikation. Beiträge zur Kritik der Bewußtseinsindustrie. Köln: DuMont Schauberg.

François, Etienne; Schulze, Hagen (Hrsg.) (2005): Deutsche Erinnerungsorte. München: C.H. Beck.

Frederking, Volker; Krommer, Axel; Maiwald, Klaus (2012): Mediendidaktik Deutsch. Eine Einführung. Berlin: Erich Schmidt.

Frommer, Franck (2012): La pensée PowerPoint. Enquête sur ce logiciel qui rend stupide. Paris: Pocket.

Hallet, Wolfgang (2008): Die Visualisierung des Fremdsprachenlernens. Funktionen von Bildern und visual literacy im Fremdsprachenunterricht. In: Lieber, Gabriele (Hrsg.): Lehren und Lernen mit Bildern. Ein Handbuch zur Bilddidaktik. Baltmannsweiler: Schneider Verlag Hohengehren, 212-222.

Hartwig, Helmut (1971): Visuelle Kommunikation. Methodologische Bemerkungen zur Ableitung von Lernzielen aus dem sozialen Bereich „Freie Zeit“. In: Ehmer, Hermann K. (Hrsg.) (1971), 334-339. 
Herzlinger, Sara (2013): Der Einsatz von Neuen Medien in der Schule am Beispiels des WebQuest-Modells. München: Grin Verlag.

Hiegemann, Susanne; Swoboda, Wolfgang H. (Hrsg.) (1994): Handbuch der Medienpädagogik. Opladen: Leske + Budrich.

Issing, Ludwig; Klimsa, Paul (Hrsg.) (2009): Online-Lernen. Handbuch für Wissenschaft und Praxis. München: Oldenbourg.

Kinter, Jürgen (1994): Gegenöffentlichkeit und Selbsttätigkeit: Ende einer medienpolitischen Utopie? Zur Geschichte und Theorie alternativer Öffentlichkeit. In: Hiegemann, Susanne; Swoboda, Wolfgang H. (Hrsg.) (1994), 205-222.

Klemm, Michael; Stöckl, Hartmut (2011): Bildlinguistik - Standortbestimmung, Überblick, Forschungsdesiderate. In: Diekmannshenke, Hajo; Klemm, Michael; Stöckl, Hartmut (Hrsg.): Bildlinguistik. Theorien - Methoden - Fallbeispiele. Berlin: Schmidt, 7-18.

Lenczowski, Katarina (2013): Lernen mit WEQuests: Zum didaktischen und methodischen Einsatzvvon WebQuests in computergestützten Lernungebungen/E-Learning-Szenerien. München: Grin Verlag.

Lieber, Gabriele (Hrsg.) (2008): Lebren und Lernen mit Bildern. Ein Handbuch zur Bilddidaktik. Baltmannsweiler: Schneider Verlag Hohengehren.

Lutz, Eugen; Sauter, Rudolf; Wächtershäuser, Gabriele (1971): Die audio-visuellen Mittler im Deutschunterricht. Ein Handbuch für Lehrer und Erzieher. München: Keimer Verlag.

Macaire, Dominique; Hosch, Wolfram (1999): Bilder in der Landeskunde. Berlin u.a.: Langenscheidt.

McLuhan, Marshall; Stearn, Gerald Emanuel (1967): A dialogue. In: Stearn, Gerald Emanuel (Hrsg.): McLuban: Hot \& Cool. A primer for the understanding of \& a critical symposium with a rebuttal by McLuhan. New York: Signet, 260-292.

Möller, Heino R. (1971): Kunstunterricht und Visuelle Kommunikation. Sieben Arbeitsthesen zur Konzeption eines neuen Unterrichtsfaches. In: Ehmer, Hermann K. (Hrsg.) (1971), 363-366.

Moser, Heinz (2006): Einführung in die Medienpädagogik. Aufwachsen im Medienzeitalter. Wiesbaden: Verlag für Sozialwissenschaften.

Niegemann, Helmut M; Domagk, Steffi; Hessel, Silvia; Hein, Alexandra; Hupfer, Matthias; Zobel, Annett (2008): Kompendium multimediales Lernen. Berlin: Springer.

Pandel, Hans-Jürgen (2008): Bildinterpretation. Die Bildquelle im Geschichtsunterricht. Schwalbach/Taunus: Wochenschau. 
Pandel, Hans-Jürgen; Schneider, Gerhard (Hrsg.) (2011): Handbuch Medien im Geschichtsunterricht. Schwalbach/Taunus: Wochenschau.

Paul, Gerhard (Hrsg.) (2006): Visual History. Ein Studienbuch. Göttingen: Vandenhoeck \& Ruprecht.

Paul, Gerhard (Hrsg.) (2008): Das Jahrbundert der Bilder. 1949 bis heute. Göttingen: Vandenhoeck \& Ruprecht.

Paul, Gerhard (Hrsg.) (2009): Das Jahrbundert der Bilder. 1900 bis 1949. Göttingen: Vandenhoeck \& Ruprecht.

Reinfried, Marcus (2008): Vom „Stellvertreter“ zum „Türöffner“. Bilder in Fremdsprachen-Lehrwerken. In: Lieber, Gabriele (Hrsg.) (2008), 198-211.

Roche, Jörg (2008): Handbuch Mediendidaktik Fremdsprachen. Ismaning: Hueber.

Sachs-Hombach, Klaus (Hrsg.) (2005): Bildwissenschaft. Disziplinen, Themen, Methoden. Frankfurt/Main: Suhrkamp.

Scherling, Theo; Schuckall, Hans-Friedrich (1992): Mit Bildern lernen. Handbuch für den Fremdsprachenunterricht. Berlin u.a.: Langenscheidt.

Schmidt, Katrin; Schmidt, Sabine (2007): Erinnerungsorte. Deutsche Geschichte im DaFUnterricht. Berlin: Cornelsen.

Sontag, Susan (2004): Regarding the pain of others. London: Penguin.

Staiger, Michael (2012): Bilder erzählen. Zum Umgang mit visueller Narrativität im Deutschunterricht. In: Oomen-Welke, Ingelore; Staiger, Michael (Hrsg.): Bilder in Medien, Kunst, Literatur, Sprache, Didaktik. Festschrift für Adalbert Wichert. Freiburg/Br.: Fillibach, 41-52.

Tulodziecki, Gerhard; Herzig, Bardo (2004): Handbuch Medienpädagogik Band 2: Medien in Lehr-und Lernprozessen. Stuttgart: Klett-Cotta.

Valentin, Mark (2013): Einsatz der didaktischen Methode „Webquest“ im Unterricht: Chancen und Herausforderungen im Umgang mit der Methode. München: Grin Verlag. 



\section{Grundlagen}





\title{
Was ist Bildwissenschaft? Ihre Gegenstände, Fragen und Methoden
}

\author{
Tobias Schöttler
}

\section{Einleitung: Von der Werbung zum Produkt selbst}

In einigen Fällen ist die Werbung bekannter als das Produkt. In den 80er Jahren bemühten sich einige Werbetreibende darum, die Werbung als eigene Kunstform zu etablieren oder sie für Zwecke fruchtbar zu machen, die weit über die Bewerbung des jeweiligen Produktes hinausging. ${ }^{1}$ Ein hervorragendes Beispiel dafür ist die Benetton-Werbung Toscanis, die er zusammenfassend in seinem Buch „Die Werbung ist ein lächelndes Aas“ (Toscani 1997) thematisiert. Der damalige Diskurs konzentrierte sich auf die provokanten und aufmerksamkeitserheischenden Werbeplakate. Sicherlich wurden dadurch auch Themen wie der Umgang mit HIV, der Krieg in Bosnien usw. ins Gespräch gebracht und der Markenname Benetton tauchte in den entsprechenden Diskussionen immer wieder auf. Das eigentlich zu bewerbende Produkt trat jedoch weitgehend in den Hintergrund, auch weil auf Toscanis Benetton-Plakaten nichts aus der Produktlinie abgebildet ist.

Ein ähnliches Schicksal teilt die Bildwissenschaft. Sie wurde vor allem durch die Schlagworte „pictorial turn“ (Mitchell 1992) und „iconic turn“ (Boehm 1994)

\footnotetext{
${ }^{1}$ Der Wandel in der Bewertung von Werbung lässt sich hervorragend anhand zweier Arbeiten über Fernsehwerbung ersehen: Während Kloepfer; Landbeck 1991 die Entwicklung der Werbung zur Kunst begrüßt, diagnostizieren Schmidt; Spieß 1997 wenige Jahre später die Probleme, die sich aus dieser Entwicklung ergeben haben.
} 
beworben. Diese Schlagworte sind im akademischen Diskurs allseits bekannt. Was es damit aber auf sich hat und um was es sich bei dem „beworbenen Produkt“ der Bildwissenschaft - eigentlich handelt, ist dagegen außerhalb des damit befassten Spezialdiskurses kaum bekannt. Weiter noch: Selbst die „Werbung“ selbst Mitchells Aufsatz zum „pictorial turn“ und Boehms Aufsatz zur ,ikonischen Wende" - sind den meisten wohl nur vom Hörensagen bekannt. Dadurch beruhen die verbreiteten Vorstellungen von der Bildwissenschaft vielfach bloß auf Hörensagen und Assoziationen. Deshalb gilt es zunächst einmal zu fragen, was es mit dem „pictorial“ bzw. ,iconic turn“ überhaupt auf sich hat.

Beide bemühen sich, mit der von ihnen ausgerufenen Wende zum Bild den sogenannten „linguistic turn“ zu beerben. Eben diese Wende zur Sprache hatte Richard Rorty in der Einleitung zum gleichnamigen Sammelband - „The Linguistic Turn: Recent Essays in Philosophcial Method“ (Rorty 1967) - proklamiert. Dabei teilt er die Geschichte der Philosophie in drei Phasen oder Paradigmen ein, welche sich hinsichtlich ihres (primären) Gegenstandsbereichs und ihrer Ausgangsfrage unterscheiden. ${ }^{2}$ Demzufolge ist die Philosophie der Antike und des Mittelalters dem ontologischen Paradigma verpflichtet. Ihr Gegenstand ist das Seiende und ihre Ausgangsfrage lautet: „Was ist?“. Die Philosophie der Neuzeit löst sich vom ontologischen Paradigma und wendet sich dem Bewusstsein und den Vorstellungen als Gegenstand zu. Die Ausgangsfrage des mentalistischen Paradigmas lautet: „Was kann ich wissen?"“. Im 20. Jahrhundert wendet sich die Philosophie der Sprache als ihrem primärem Gegenstandsbereich zu. Die Ausgangsfrage des linguistischen Paradigmas lautet: „Was kann ich verstehen?“

Damit beansprucht die Rede vom „linguistic turn“ nicht, dass es vorher keine Beschäftigung mit der Sprache gegeben habe. Vielmehr begreift Rorty den linguistic turn - im Anschluss an Moritz Schlick (1930/1931) und Gustav Bergmann (1953/1967) - als methodische Neuorientierung der Philosophie, wie er in der Einleitung deutlich macht:

The purpose of the present volume is to provide materials for reflection on the most recent philosophical revolution, that of linguistic philosophy. I shall mean by "linguistic philosophy" the view that philosophical problems are problems which may be solved (or dissolved) either by reforming language, or by understanding more about the language we presently use. (Rorty 1967b: 3).

Die philosophische Revolution besteht also vorrangig darin, dass die alten philosophischen Probleme gelöst oder aufgelöst werden sollen - und zwar durch eine Analyse oder eine Reform der Sprache, in der sie formuliert werden.

\footnotetext{
${ }^{2}$ Vgl. Rorty 1967b und Schnädelbach 1985. Das es sich bei der Einteilung der Philosophiegeschichte in die drei Paradigmen um eine „starke Typisierung und Vereinfachung“ (ebd.: 39) handelt, gesteht Schnädelbach offen ein.
} 
Ob die Wende zum Bild nun wirklich die Nachfolge der Wende zur Sprache für sich beanspruchen kann, ist mehr als fraglich. Radikaler formuliert: Es ist zweifelhaft, ob die Wende zum Bild in der von Mitchell und Boehm proklamierten Weise jemals stattgefunden hat. Diese Frage zielt auf die historische Verortung wie auch auf die methodischen Ansprüche. ${ }^{3}$

Sowohl Mitchell als auch Boehm verorten die Wende zum Bild in der Mitte des 20. Jahrhunderts und setzen sie von einer logoszentrierten Vorzeit ab. Diese historische Verortung unterlaufen sie allerdings beide, indem sie auf zahlreiche Untersuchungen zu Bildern vor der Wende verweisen. Insbesondere aber kann die Bildwissenschaft keinen methodischen Anspruch erheben, der dem des „linguistic turn" vergleichbar wäre, alleine schon weil philosophische Probleme üblicherweise nicht mittels Bildern formuliert werden. Den Anspruch der methodischen Neuorientierung übergehen Mitchell und Boehm. An ihre Stelle treten Beteuerungen, dass Bilder eine wesentliche Rolle in unserer Gesellschaft spielen und unser Weltverhältnis prägen, was sicherlich zutreffend ist. ${ }^{4}$ Insofern jedoch unser Weltverhältnis ebenso von der Sprache abhängt, könnte die Bildwissenschaft bestenfalls den Anspruch erheben, eine Ergänzung zum linguistischen Ansatz zu liefern, aber nicht ihn zu ersetzen. Die Bildwissenschaft sollte daher in ihrem Anspruch bescheidender auftreten.

Das Ergebnis ist somit ernüchternd, eine Wende zum Bild, welche die Nachfolge des linguistic turn antritt, hat nie stattgefunden. Die zweite ernüchternde Einsicht lautet: Es gibt keine allgemeine Bildwissenschaft! Jedenfalls nicht, wenn man eine institutionalisierte Disziplin mit einem fixierten Gegenstandsbereich und einem verbindlichen Kanon von Fragestellungen und Methoden zur ihrer Beantwortung erwartet. Vielmehr handelt es sich bei der „Bildwissenschaft" um eine Sammelbezeichnung für bildbezogene Forschung in verschiedenen Disziplinen, die von je eigenen Voraussetzungen und Fragestellungen ausgehen. Der interdisziplinäre Charakter der Bildwissenschaft äußert sich vor allem in drei Punkten, nämlich erstens in den heterogenen und zum Teil disparaten Bestimmungen des Gegenstandsbereichs, zweitens in der Fülle verschiedener Fragestellungen und Erkenntnisinteressen und drittens in dem reichhaltigen Angebot an methodischen Ansätzen. Diesen drei Aspekten möchte ich in diesem Aufsatz nachgehen, wobei ich gerade angesichts der unübersichtlichen Verflechtung der verschiedenen Ansätze eine stark vereinfachte Karte der Bildwissenschaft zeichnen werde und zum Abschluss nicht etwa alle bildwissenschaftlichen Methoden im Detail vorstellen werde, sondern eher einige Probleme einer genuin bildwissenschaftlichen Methode kenntlich machen werde.

\footnotetext{
3 Zur Kritik an den Ansprüchen des pictorial und des iconic turn vgl. Lüdeking 2005 und Liebsch 2012: 58-60 und 75-77.

${ }^{4}$ Damit sind ihre Perspektiven anschlussfähig an die Untersuchungen der sogenannten Visual Studies - vgl. dazu zusammenfassend Rimmele; Stiegler 2012.
} 


\section{Bildbegriffe und Gegenstände der Bildwissenschaft}

Die Frage nach dem Gegenstandsbereich der Bildwissenschaft scheint leicht beantwortet: Bilder bzw. das Bild! Die Frage, was aber ein Bild ist, stellt uns bereits vor größere Schwierigkeiten. Bereits ein flüchtiger Blick auf die Phänomene, die gemeinhin als „Bild“ bezeichnet werden, führt uns die Heterogenität der Extension des Bildbegriffs vor Augen. Neben materiellen Bildern wie dem klassischen Tafelbild, aber auch Schaubildern, reden wir von mentalen Bildern, sprachlichen Bildern und ethisch-normativen Vorbildern. ${ }^{5}$ Es dürfte schwierig, wenn nicht unmöglich sein, ein Merkmal ausfindig zu machen, das allen diesen Phänomenen und nur diesen Phänomenen gemeinsam ist, es sei denn, man zieht sich auf die Annahme einer ominösen Bildlichkeit zurück, die man dann aber ihrerseits bestimmen müsste.

Im Hinblick auf seine synchrone Mehrdeutigkeit lässt sich der Bildbegriff als Familienähnlichkeitsbegriff im Sinne Wittgensteins bezeichnen (vgl. Wittgenstein 1953: \65ff.). Die verschiedenen Phänomene werden nicht als „Bild“ bezeichnet, weil sie alle das ihnen eigentümliche Merkmal der Bildlichkeit aufweisen; vielmehr besteht zwischen den als Bild bezeichneten Phänomenen wie zwischen den Mitgliedern einer Familie „ein kompliziertes Netz von Ähnlichkeiten, die einander

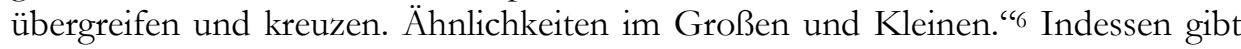
es keine Eigenschaft, die allen Mitgliedern einer Familie und nur ihnen gemeinsam wäre.

Auffälligerweise berücksichtigt Wittgenstein die genetische Perspektive überhaupt nicht, obwohl sie sich doch durch seine Metapher der Familienähnlichkeit geradezu aufdrängt (vgl. die Kritik von Mandelbaum 1965 und Danto 1999: 98). Sicherlich können die Beziehungen zwischen den verschiedenen Arten von Bildern durch die historische Semantik aufgehellt werden (zur Begriffsgeschichte des Bildbegriffs vgl. Liebsch 2012). Aber die wort- oder begriffsgeschichtliche Perspektive führt uns vor allem die diachrone Offenheit des Bildbegriffs vor Augen. Denn offensichtlich sind der Ausdruck „Bild“ und seine fremdsprachlichen Entsprechungen nach und nach auf immer unterschiedlichere Phänomene angewandt worden. Dazu kommt noch, dass die Entwicklung späterer Bildmedien wie Fotografie und Röntgenaufnahmen wiederum zu einer Erweiterung der Extension des Bildbegriffs geführt hat.

Angesichts seiner synchronen Mehrdeutigkeit und diachronen Offenheit ist jede Definition des Bildbegriffs eine künstliche Einschränkung. Dennoch setzen die verschiedenen Bildtheorien jeweils - explizit oder implizit - einen spezifischen

\footnotetext{
${ }^{5}$ Zur Vieldeutigkeit des Bildbegriffs vgl. Mitchell 1986: 7-46 und Sachs-Hombach; Schürmann 2005: bes. 110 .

${ }^{6}$ Wittgenstein 1953: \66. Holenstein 1985: 169ff. unterscheidet eine enge und eine weitere Interpretation von Familienähnlichkeit. Ich schließe im folgenden an die weitere Interpretation an, wonach es möglich ist, dass die extremen Mitglieder nur noch über Zwischenglieder (durch ihre Familienähnlichkeit zu anderen Mitgliedern) verbunden sind, aber selber kein gemeinsames Merkmal mehr aufweisen.
} 
Bildbegriff voraus. Gewisse Einschränkungen sind freilich unproblematisch; denn sicherlich will kaum jemand sprachliche Bilder wie Metaphern oder natürliche Bilder wie Spiegelungen als Gegenstand einer Bildwissenschaft zählen. Der Ausgrenzung dieser Phänomene dienen Sachs-Hombachs Kriterien der Materialität, der Artifizialität und der Persistenz (Sachs-Hombach 2005a: 13). Mittels des Kriteriums der Materialität werden sprachliche Bilder, Vorbilder und mentale Bilder ausgeschlossen; das Kriterium der Artifizialität grenzt natürliche Bilder wie etwa Spiegelbilder aus, während das Kriterium der Persistenz sicherstellt, dass es sich um einen wiederholt wahrnehmbaren Gegenstand handelt und eben nicht um Wolkenbilder oder dergleichen.

Auf eine solche Bestimmung der Grenzen des Gegenstandsbereichs der Bildwissenschaft können sich die Bildwissenschaftler noch ohne weiteres einigen. ${ }^{7}$ Deutlich umstrittener sind die spezifischeren Bildbegriffe, die von den verschiedenen Ansätzen vorausgesetzt werden. ${ }^{8}$ Für eine erste Orientierung im Labyrinth der verschiedenen Bildbegriffe können die jeweiligen Positionen danach befragt werden, welchen Oberbegriff sie voraussetzen, also in welche Klasse von Dingen sie Bilder einteilen. Das entspricht in etwa der klassischen, Aristoteles zugeschriebenen Auffassung von Definitionen als Angabe der nächsthöheren Gattung und des spezifizierenden Merkmals (genus proximum et differentia specifica). ${ }^{9}$ Vor dem Hintergrund der Frage nach der nächsthöheren Gattung lassen sich (mindestens) vier Bildbegriffe unterscheiden, nämlich das Bild als Artefakt oder Werk (2.1), das Bild als Werkzeug (2.2), das Bild als Wahrnehmungsobjekt (2.3) und das Bild als Zeichen (2.4). Nach der Charakterisierung der vier Bildbegriffe werde ich kurz ihr Verhältnis zueinander beleuchten (2.5).

\subsection{Das Bild als Artefakt oder Werk}

Entsprechend dem Kriterium der Artifizialität handelt es sich bei Bildern um Artefakte. Daraus lassen sich ein anthropologischer und ein werkorientierter Bildbegriff ableiten. Aus einer anthropologischen Perspektive hebt Hans Jonas (1961) die Fähigkeit zur Bildherstellung - das „Bilden“ - wie auch zur Bildrezeption als spezifisch menschliche Fähigkeit hervor und prägte dafür den Terminus vom „homo pictor“.

\footnotetext{
${ }^{7}$ Mitchell 1986: bes. 9-14 und Boehm 1978 vertreten dagegen eine deutlich weitere Fassung des Gegenstandsbereichs, die z.B. auch Metaphern als Formen der Bildlichkeit einschließt.

${ }^{8}$ In der Bildwissenschaft wurden verschiedene Einteilungen von Bildbegriffen vorgeschlagen: Beispielsweise unterschiedet Scholz 2004 eine Ähnlichkeitstheorie, eine Kausaltheorie, eine Symboltheorie und eine Gebrauchstheorie des Bildes. Dagegen unterscheidet Wiesing 2005: Kap. 2 einen anthropologischen, einen zeichentheoretischen und einen wahrnehmungstheoretischen Bildbegriff. Eher an speziellen Richtungen der Bildwissenschaft orientiert sind die Überblicksdarstellungen von Sonesson 1993 und Nöth 2009 (Semiotik), Steinbrenner 2009 (analytische Philosophie) und Kapust 2009 (Phänomenologie). Eine eher kulturwissenschaftliche Einführung in die Bildwissenschaft liefert der Band von Frank; Lange 2010.

${ }^{9}$ Die gleiche Strategie verfolgt Lambert Wiesing 2005: Kap. 2 bei seiner Typologie von Bildbegriffen, kommt jedoch zu einer etwas anderen Einteilung der Bildbegriffe.
} 
Mehr am „Gehalt“ der bildlichen Darstellung interessiert sind dagegen Ansätze aus der ikonologisch-hermeneutischen Tradition, wie sie vor allem von Erwin Panofsky (1939), Max Imdahl (1979) und Gottfried Boehm (1978) vertreten wird. Gemeinsam ist diesen Ansätzen, dass sie das Bild als Werk und Sinngefüge betrachten. Während Panofskys Ansatz noch stark an traditionellen Konzeptionen der Textinterpretation und Hermeneutik orientiert ist und damit Gefahr läuft, dem Bild eine Textförmigkeit zu unterstellen (vgl. Boehm 1978: bes. 452), bemühen sich Imdahl und Boehm um eine Bestimmung der medialen Eigenqualität des Bildes. Boehm (1978: 461 und 1994: 29-36) sieht dieses Bemühen mit seiner Idee der „ikonischen Differenz" eingelöst. Er nimmt an, dass die bildliche Darstellung durch spezifische Kontraste konstituiert werde.

\subsection{Das Bild als Werkzeug}

Die Auffassung des Bildes als Artefakt betont sein Hergestelltsein und analysiert daraufhin das Bild als Sinngefüge und im Hinblick auf seine Strukturen. Dagegen betont die Auffassung des Bildes als Werkzeug seine Zweckgerichtetheit. Ein solcher funktionsorientierter Bildbegriff bietet sich vor allem für kommunikationsorientierte Ansätze an und kann Ansätze aus der Rhetorik und der Sprechakttheorie auf Bilder übertragen. In dieser Perspektive erweisen sich Bilder jedoch als multifunktionale Werkzeuge, weshalb Christian Doelker (2001) in seinem Funktionenmodell gleich zehn verschiedene Funktionen ausmacht, nämlich die simulative, die registrative, die mimetische, die explikative, die diegetische, die dekorative, die phatische, die ontische, die appelative und die energetische Funktion.

Doelker leitet von seiner Unterscheidung der Bildfunktionen eine Bildtypologie ab. Dabei korreliert er die simulative Funktion mit Surrogatbildern, die als Ersatz für das Abgebildete behandelt werden, und die registrative Funktion mit Bildern, die aufgrund ihrer kausalen Beziehung zum Bezugsobjekt als Spur gedeutet werden können. Mimetisch sind für ihn Abbildungen, explikative Funktionen erfüllen Schaubilder, wohingegen Phantasiebilder (mit fiktiven Sujets) eine diegetische Funktion ausüben. Die Zierbilder erfüllen eine dekorative Funktion. Füllbilder erfüllen eine phatische Funktion, indem sie nicht primär Inhalte kommunizieren, sondern lediglich die Kommunikation aufrechterhalten. Doelker zählt dazu u.a. die Logos von Fernsehsendern. Die von ihm so genannten „Clipbilder“ mit ihrer ontischen Funktion übernehmen letztlich keine kommunikative Funktion; im Mittelpunkt stehen vielmehr ihre ästhetischen Qualitäten. Die von ihm als „Pushbilder“ bezeichneten Bilder üben eine phatische Funktion aus, indem sie hauptsächlich emotional wirken. Von den „Wirkbildern“ und deren energetischer Funktion unterscheiden sich die Pushbilder nur durch die zeitliche Länge ihrer Wirkung. Die Pushbilder wirken kurzfristig und die Wirkbilder längerfristig. Die von Doelker vorgenommene Korrelation einzelner Bildfunktionen mit bestimmten Bildtypen darf nicht zu der Annahme verleiten, dass ein bestimmtes Bild nur jeweils eine dieser Funktionen ausüben kann. Vielmehr kann ein und dasselbe Bild 
zu verschiedenen Zwecken verwendet bzw. auf verschiedene Funktionen hin gelesen werden.

Mit ihrer Betonung der verschiedenen (kommunikativen) Zwecke von Bildern bietet sich ein funktionsorientierter Bildbegriff auch als Erweiterung semiotischer Ansätze an. Dabei geht die Bestimmung von Bildern als Werkzeugen häufig mit einem intentionalistischen Verständnis des Bildes einher, insofern die bildliche Darstellung und die weiteren Funktionen des Bildes als abhängig von den Absichten des Bildproduzenten oder -verwenders gedacht werden. ${ }^{10}$

\subsection{Das Bild als Wahrnehmungsobjekt}

Als Minimalbedingung einer jeden Bildrezeption kann gelten, dass das Bild allererst wahrgenommen werden muss. Dies wird von keiner Bildtheorie bestritten. Einige Bildtheorien setzen jedoch beim Bild als Wahrnehmungsobjekt an. Dabei lassen sich grob zwei Varianten perzeptualistischer Ansätze unterscheiden. Die erste Variante betont die Rolle der aktiven Rezeptionsleistungen für die Konstitution der bildlichen Darstellung (1). Die zweite Variante vertritt im Grunde die gegensätzliche These, nämlich dass unsere visuelle Wahrnehmung nichts Naturgegebenes ist, sondern vielmehr durch die Wahrnehmung bestimmter Bildarten strukturiert und organisiert wird (2). Die erste Variante lässt sich als subjektorientierter Perzeptualismus bezeichnen und die zweite Variante als medien- oder technologieorientierter Perzeptualismus.

1) Erste Ansätze eines subjektorientierten Perzeptualismus finden sich in Fiedlers Bestimmung von Bildern als reine Sichtbarkeit (vgl. Fiedler 1887: bes. 192 und dazu Wiesing 2005: 30ff.). Ausgearbeitet wurden wahrnehmungstheoretische Bildbegriffe in der Phänomenologie (Husserl 1904/1905; Wiesing 2005), in der Gestalttheorie (Arnheim 1978) und in einigen Spielarten der analytischen Bildphilosophie (Gombrich 1960; Wollheim 1980; Peacocke 1987, Hopkins 1995, Lopes 1996 und Sachs-Hombach 2006). Gemeinsam ist jenen Ansätzen, dass sie Wahrnehmung nicht als passives Registrieren des Gegebenen auffassen, sondern als aktive Rezeptionsleistung, womit die Bildwahrnehmung und die entsprechenden Wahrnehmungskompetenzen maßgeblich an der Konstitution der bildlichen Darstellung beteiligt sind. So betont Rudolf Arnheim im Anschluss an die Gestaltpsychologie, dass wir immer erst Ganzheiten wahrnehmen und diese erst nachträglich in ihre Teile „zerlegen“. 11 Durch eine solche Zergliederung kann die Komposition oder Struktur des Bildes ermittelt werden; diese Struktur ergibt sich jedoch durch ein Zusammenspiel zwischen den Punkten, Linien und dergleichen auf der Bildfläche

\footnotetext{
${ }^{10}$ Dies wird besonders deutlich bei Novitz 1977 und Kjørup 1978, die beide an Searles Sprechakttheorie anschließen, vgl. Searle 1969. Einen Überblick über verschiedene handlungstheoretische Bildtheorien liefern Seja 2009 und Schöttler 2013.

11 Vgl. Arnheim 1978: 9f. und 56. Zum Primat der Gestalten vor ihren Teilen vgl. Ehrenfels 1890: $251 \mathrm{ff}$.
} 
und ihrer Wahrnehmung vermittels der Gestaltgesetze, insofern die Gestaltgesetze allererst unsere Wahrnehmung organisieren (vgl. Arnheim 1978: 49 und 57ff.).

2) Der medienorientierte Perzeptualismus wird vor allem im Bereich der Visual Studies vertreten. So heben Jonathan Crary und Jean-Louis Baudry die Strukturierung oder Organisation der visuellen Wahrnehmung durch bestimmte Bildmedien und die damit verbundenen Technologien hervor (vgl. Crary 1990 und Baudry 1994). Als Vorläufer dieser Forschungsperspektive kann Panofsky mit seinem Aufsatz „Die Perspektive als symbolische Form“ (1924/1925) gelten. Die damit unterstellte Historizität und Kulturalität der visuellen Wahrnehmung wird vor allem in den Visual Studies untersucht (vgl. Rimmele; Stiegler 2012: Kap. 1 und 2).

\subsection{Das Bild als Zeichen}

Die Auffassung, dass es sich beim Bild um ein Zeichen oder einen Komplex von Zeichen handelt, kann wohl als der dominante Bildbegriff innerhalb der bildwissenschaftlichen Diskussion gelten. Sicherlich kann hier nicht der Anspruch erhoben werden, alle Spielarten eines semiotischen Bildbegriffs nachzuzeichnen. Grob können eine strukturalistische und eine analytische Semiotik unterschieden werden. Während die strukturalistische Semiotik des Bildes sich auf die Unterscheidung verschiedener Ebenen oder Arten der bildlichen Bedeutung konzentriert, steht in der analytischen Semiotik des Bildes die Frage nach der Art der bildlichen Bezugnahme im Mittelpunkt der Diskussion. Den Hintergrund beider Diskussionsfelder bildet Peirces Trichotomie dreier Zeichenarten: das ikonische, das indexikalische und das symbolische Zeichen (vgl. Peirce: 1958, bes. 2.247-2.249). Unterschieden werden diese Zeichenarten nach ihrer Objektrelation. Das ikonische Zeichen steht in einer Ähnlichkeitsrelation zu seinem Bezugsobjekt, das indexikalische Zeichen in einer Kausalrelation und die Bezugnahme des symbolischen Zeichens auf sein Objekt beruht auf einer Konvention oder Gewohnheit.

Frühe Bildanalysen der strukturalistischen Semiotik - wie sie Roland Barthes (1990a und 1990b) sowie Umberto Eco (1994: 271ff.) vorgelegt haben - bestimmen bildliche Zeichen auf der Ebene der Denotation als ikonische Zeichen und interessieren sich dann vorrangig für die Konnotation und die Möglichkeit visueller Tropen. Für Barthes (1990a: bes. 13) ist die Fotografie als ikonisches Zeichen eine Botschaft ohne Code - zumindest auf der Ebene der Denotation, auf der Ebene der Konnotation begreift er die fotografische Botschaft als codeabhängig. Ecos Auffassung geht in eine ähnliche Richtung. Im Vergleich zu Barthes erweitert er lediglich die Anzahl der Bedeutungsebenen, stimmt aber zugleich auch mit Barthes darin überein, dass Bilder aufgrund ihrer Polysemie der sprachlichen Verankerung bedürfen.

Seit Nelson Goodmans „Languages of Art“ (1968) wird in der analytischen Semiotik gerade das in Frage gestellt, was in den Analysen von Barthes und Eco als 
selbstverständlich vorausgesetzt wird, nämlich die Annahme, dass es sich bei Bildern um ikonische Zeichen handelt. ${ }^{12}$ Verstanden als ikonische Zeichen beziehen sich Bilder auf ihren Bezugsgegenstand, weil sie dem Abgebildeten ähnlich sind. ${ }^{13}$ Goodman entwickelt seine Symboltheorie ausgehend von einer Kritik der Ähnlichkeitstheorie des Bildes, indem er nachweist, dass Ähnlichkeit weder notwendig noch hinreichend für die Festlegung der bildlichen Bezugnahme ist. Ähnlichkeit ist keine notwendige Bedingung für bildliche Darstellung, weil es offensichtlich Bilder gibt, die in keiner Ähnlichkeitsbeziehung zum Abgebildeten stehen: Entweder weil das Abgebildete nicht existiert, wie im Falle fiktionaler Sujets, oder weil es das Abgebildete noch nicht gibt, wie im Falle entwerfender Bilder (z.B. Konstruktionszeichnungen). Ähnlichkeit ist aber auch keine hinreichende Bedingung für bildliche Darstellung. Denn zum einen unterscheiden sich die Ähnlichkeitsrelation und die Darstellungsbeziehung hinsichtlich ihrer logischen Eigenschaften: Ähnlichkeit ist reflexiv und symmetrisch; Darstellung zeichnet sich dagegen durch Irreflexivität und Direktionaliät aus. Anders als eine Ähnlichkeitsbeziehung ist eine Darstellungsbeziehung irreflexiv, weil ein Gegenstand sich zwar selbst im höchsten Maße ähnelt, doch keine Darstellung von sich selbst ist. Ferner ist die Darstellungsbeziehung direktional: Die Ähnlichkeit zwischen Bild und Abgebildetem besteht in beide Richtungen; das Bild ähnelt dem Abgebildetem ebenso wie das Abgebildete dem Bild ähnelt; dennoch würden wir nicht sagen, dass jemand ein Bild seines Passfotos sei. Zum anderen gibt es Fälle von Ähnlichkeit, die keine Bildbeziehung konstituieren.

An object resembles itself to the maximum degree but rarely represents itself; resemblance, unlike representation, is reflexive. Again, unlike representation, resemblance is symmetric: B is as much like A as A is like B, but while a painting may represent the Duke of Wellington, the Duke doesn't represent the painting. Furthermore, in many cases neither one of a pair of very like objects represents the other: none of the automobiles off an assembly line is a picture of any of the rest; and a man is not normally a representation of another man, even his twin brother. Plainly, resemblance in any degree is no sufficient condition for representation. (Goodman 1968: 4).

Erschwerend kommt hierbei die Vagheit des Ähnlichkeitsbegriffs hinzu. Denn ohne weitere Einschränkungen der Ähnlichkeitshinsicht oder des Grades der Ähnlichkeit werden wir zwischen zwei beliebigen Gegenständen immer irgendeine Ähnlichkeit feststellen können, und wenn es nur eine Übereinstimmung in der Farbe oder dem Material ist. Wenn man Ähnlichkeit als hinreichende Bedingung für

\footnotetext{
${ }^{12}$ Für eine Kritik der Ähnlichkeitstheorie der bildlichen Darstellung wie auch anderer Begründungsansätze vgl. Black 1972.

${ }^{13}$ Gleichsam klassische Ähnlichkeitstheorien vertreten Hospers 1946: 40f. und Beardsley 1958: 270ff.
} 
eine Abbildung auffassen wollte, müsste man demzufolge einen Stuhl als Bild eines Holzbretts begreifen.

Der Ähnlichkeitstheorie des Bildes stellt Goodman seine Symboltheorie gegenüber. Gemäß seiner konventionalistischen Bildtheorie beziehen sich Bilder eben nicht wegen irgendeiner Ähnlichkeit auf das Abgebildete, sondern wegen ihrer Zugehörigkeit zu bestimmten bildhaften Symbolsystemen. Indem Goodman ein konventionalistisches Sprachverständnis auf bildliche Zeichensysteme überträgt, ist sein Ansatz vor allem mit zwei Problemen konfrontiert. Zum einen muss er erklären, woher diese Konventionen kommen, welche die Semantik und die Syntax des jeweiligen Zeichensystems regeln. ${ }^{14}$ Zum anderen kann seine Theorie die Phänomenologiebedingung nicht erfüllen, d.h. seine Theorie kann unsere Intuition einer Wahrnehmungsnähe realistischer Bilder nicht erklären (Lopes 1996: 36).

Sowohl die Deutung von Bildern als ikonische als auch die Deutung als symbolische Zeichen (im Sinne Peirces) gerät also in Schwierigkeiten. Abgesehen davon blenden beide Ansätze die pragmatische Dimension völlig aus, also die Bildfunktionen jenseits der reinen Darstellungsfunktion. Um ihre Schwächen zu kompensieren, integrieren die Ähnlichkeitstheorie wie auch die Konventionstheorie des Bildes andere Bildbegriffe, d.h. sie kombinieren eine Ähnlichkeitstheorie oder eine Konventionstheorie des Bildes mit einem funktionalistischen oder einem perzeptualistischen Bildbegriff.

\subsection{Zum Verhältnis der Bildbegriffe}

Durch die idealtypische Charakterisierung der verschiedenen Bildbegriffe sollte lediglich eine übersichtliche Darstellung über die Bestimmungen des Gegenstandsbereichs ermöglicht werden. Tatsächlich werden die verschiedenen Bildbegriffe in der Praxis häufig miteinander kombiniert, wodurch sich eine Vielzahl weiterer Spielarten ergibt.

So verspricht der funktionalistische Bildbegriff eine Ergänzung anderer Bildbegriffe um die pragmatische Dimension. Im Falle der Kombination einer Ähnlichkeitstheorie des Bildes mit einem funktionalistischen Bildbegriff besteht zudem die Möglichkeit, dass die trivialen Fälle von Ähnlichkeit ausgeschlossen werden, indem die Intentionen des Bildbenutzers die relevanten Ähnlichkeitshinsichten festlegen (so z.B. bei Novitz 1977: 13-16).

Der perzeptualistische Bildbegriff verspricht, als Ergänzung eines konventionalistischen Ansatzes die Phänomenologiebedingung zu erfüllen (Lopes 1996: 35f.). Gerade Vertreter einer Ähnlichkeitstheorie des Bildes kombinieren ihren Ansatz häufig mit einem perzeptualistischen Bildbegriff in der Hoffnung, damit die Beliebigkeit des Ähnlichkeitsbegriffs in den Griff zu bekommen. Wabrnehmungstheoretische Ähnlichkeitstheorien ersetzen die Annahme einer externen Ähnlichkeit zwischen Bild

\footnotetext{
14 Vgl. die Kritik an Goodmans Konventionstheorie in Schöttler 2012: 267-270.
} 
und Abgebildetem durch die Annahme einer internen Ähnlichkeit zwischen wahrgenommener Abbildung und wahrgenommenem Abgebildetem. Ähnlichkeit gilt ihnen demnach als subjektabhängige Beziehung: „ähnlich ist, was wir als ähnlich wahrnehmen." (Sachs-Hombach 2006: 141; vgl. auch Hopkins 1995: 440; Hopkins 1998: 50 und Sachs-Hombach 2006: 134). Zur Explikation dieser internen Ähnlichkeit führt Peacocke (1987: bes. 385-388) die Annahme eines „visuellen Feldes“ ein. Die Ähnlichkeit besteht danach zwischen der wahrgenommenen Form der Abbildung und der Form, die der wahrgenommene Gegenstand mit allen perspektivischen Verzerrungen im visuellen Feld des Betrachters hätte (vgl. dazu die Kritik von McIntosh 2003). Sachs-Hombach (2006: 10, 23 et passim) bestimmt Bilder als wabrnehmungsnahe Zeichen. Die wahgenommene oder interne Ähnlichkeit dient ihm dabei lediglich zur Unterscheidung bildhafter und nicht-bildhafter Zeichen (vgl. Sachs-Hombach 2006: 139).

Der Umstand, dass die verschiedenen Bildbegriffe miteinander kombiniert werden und kombiniert werden können, zeigt, dass es sich bei den skizzierten Ansätzen um Idealtypen handelt. Dennoch beanspruchen einige Bildwissenschaftler mit dem von ihnen vorausgesetzten Bildbegriff eine Definition des Bildes zu liefern. Damit das gelingt, müssten sie ein geeignetes spezifizierendes Merkmal benennen. Sie müssten also ein Merkmal finden, was Bilder von allen anderen Artefakten, allen anderen Werkzeugen, allen anderen Wahrnehmungsobjekten oder allen anderen Zeichen abgrenzt. Bislang konnte in dieser Hinsicht keiner der Definitionsversuche überzeugen.

Allerdings sollte bei der Beurteilung solcher Definitionen der Zweck der Definitionen nicht aus den Augen verloren werden. Sicherlich besteht der Zweck einer Definition des Bildbegriffs nicht darin, dass wir dadurch in die Lage versetzt werden, Bilder als Bilder identifizieren zu können. Wenn man von Grenzfällen absieht, bei denen ihr Bildstatus strittig ist, würde unser umgangssprachlicher und zugegebenermaßen vager Bildbegriff für die Identifizierung von Gegenständen als Bildern völlig ausreichen. Dementsprechend erscheint es deutlich fruchtbarer, die skizzierten Bildbegriffe nicht als Definitionen zu verstehen, sondern als Forschungsperspektiven, die bestimmte Aspekte des Phänomens Bild hervorheben und damit Fragestellungen und Untersuchungsperspektiven eröffnen. ${ }^{15}$ Die Karte der Bildbegriffe liefert uns einige Orientierungspunkte oder Wegmarken für die folgende Wanderung durch die Bildwissenschaft, wenngleich diese Wanderung sich aus Gründen des Umfangs und zugunsten der Übersichtlichkeit im Wesentlichen auf einige kleinere Tagesausflüge beschränken muss.

\footnotetext{
15 Diese Perspektive ist inspiriert von Morris Weitz' Vorstellung von der Rolle der Definitionen des Kunstbegriffs in der Ästhetik - vgl. Weitz 1956: bes. 35.
} 


\section{Fragestellungen und Themen der Bildwissenschaft}

Einige Fragen und Themen der Bildwissenschaft wurden bereits angesprochen, so vor allem das Bemühen um einen konsensfäbigen Bildbegriff. Damit verbunden ist der Aufbau von Bildtypologien, um zum einen die je eigenen Darstellungspotentiale der unterschiedlichen Bildtypen wie Tafelbild, Zeichnung, Schaubild, Diagramm usw. herauszuarbeiten und zum anderen um eine begriffliche Präzision in der Beschreibung der verschiedenen Bilder zu ermöglichen. ${ }^{16}$ Allgemein gesprochen sind eigentlich alle bildbezogenen Ansätze damit befasst, die bildliche Darstellung zu beschreiben und ggf. ihre Voraussetzungen zu klären. Über diese Fragestellungen hinaus erlauben die verschiedenen Bildbegriffe noch speziellere Fragestellungen, insofern die skizzierten Bildbegriffe in unterschiedlichem Maße als Ausgangspunkte für die Beantwortung jener Fragen geeignet sind.

Abgesehen davon, dass der semiotische Bildbegriff eine deutliche präzisere Fassung der bildlichen Bezugnahme ermöglicht und fordert, schafft die semiotische Beschreibung des Bildes auch die Voraussetzungen für die Analyse des Zusammenwirkens von Bildern mit anderen Zeichensystemen, so etwa die Frage nach dem Zusammenwirken von Bild und Sprache (Intermedialität). Gerade in ihren Anfängen hat die Bildwissenschaft häufig nahezu gänzlich von dem sprachlichen (und situativen) Kontext der Bildrezeption abgesehen. Wenn Bilder in sprachlichen Kontexten in den Blick genommen wurden (wie etwa bei Presse- oder Werbebildern), wurde das Bild entweder auf seine illustrative Funktion reduziert oder die Festlegung der bildlichen Bedeutung durch den sprachlichen Kontext hervorgehoben (so etwa mit Roland Barthes' Konzept der sprachlichen Verankerung des Bildes; vgl. Barthes 1990b: 34ff. und im Anschluss daran Kjørup 1989). In kritischer Abgrenzung zu einer solchen einseitigen Betrachtung etabliert sich neuerdings die sogenannte Bildlinguistik (Diekmannshenke; Klemm; Stöckl 2011), die beansprucht, die wechselseitige Deutung von Bild und Text sowie das Zusammenspiel der verschiedenen semiotischen und kommunikativen Möglichkeiten und Funktionen der beiden Medien in den Blick zu nehmen. ${ }^{17}$

Der semiotische und der werkorientierte Bildbegriff ähneln sich darin, dass sie das Bild als Komplex oder Gefüge von Zeichen oder Sinnelementen begreifen. Dadurch kann vor dem Hintergrund dieser Bildbegriffe nach Bedeutungsdimensionen und nach der Komposition und dem Stil eines Bildes gefragt werden. Die Frage nach der Komposition und dem Stil kann auch im Rahmen einiger perzeptualistischer Ansätze gestellt werden, insbesondere auf der Basis der Gestalttheorie (z.B. Arnheim 1978).

Die perzeptualistischen Ansätze sind natürlich prädestiniert für die Untersuchung der Bildwahrnehmung. Entsprechend der beiden Arten perzeptualistischer

\footnotetext{
16 Zum Vergleich verschiedener Bildmedien und ihrer je eigenen Ausdrucksmöglichkeiten (auch in Abgrenzung zu anderen Medien) vgl. etwa Goodman 1968, Heßler; Mersch 2009 und Krämer 2009.

${ }^{17}$ Vorläufer dieses Forschungsprogramms sind vor allem Muckenhaupt 1986 und Leeuwen 2005.
} 
Ansätze kann dabei entweder die schöpferische Rolle der Bildwahrnehmung für die Konstitution der bildlichen Darstellung untersucht werden oder die Organisation bzw. Strukturierung unserer Wahrnehmung durch bestimmte Bildmedien (siehe Kap. 2.3).

Sofern die perzeptualistischen Ansätze auch an der kognitiven Verarbeitung von Bildern interessiert sind, ermöglichen sie auch eine Behandlung des sogenannten visuellen Denkens, wie es beispielsweise Arnheim (1972) vor dem Hintergrund der Gestalttheorie in den Blick nimmt. Insofern das visuelle und das sprachliche Denken an verschiedene Medientypen gekoppelt werden, erweist sich die medienund zeichentheoretische Charakterisierung dieser Medien hilfreich. Neuere Ansätze greifen in diesem Zusammenhang Lessings Gegenüberstellung von Bild und Sprache wieder auf, die er in seinem Laokoon (1766: bes. 116) vornimmt. Kern dieser Gegenüberstellung ist die Charakterisierung der gesprochenen Sprache als sequentielles, zeitlich organisiertes Medium und des Bildes als räumlich strukturiertes Medium (vgl. Heßler; Mersch 2009, Krämer 2009 und Kulvicki 2010).

Der funktionalistische Bildbegriff bzw. die um das funktionalistischen Moment erweiterten Bildbegriffe eröffnen die Frage nach dem weiten Feld der Bildverwendungen (vgl. Doelker 2001 und Sachs-Hombach 2001). Wenngleich man bei Bildern meist zuerst an die bildliche Darstellung und die Illustration denkt, sind damit die möglichen Funktionen von Bildern keinesfalls erschöpft. Gerade in der Werbung und in der politischen Ikonographie werden Bilder zur Persuasion verwendet - mit welchem Erfolg, sei an dieser Stelle dahingestellt. Bilder werden in Anleitungen verwendet. Eine übliche IKEA-Anleitung enthält kaum Text; und durch Gombrichs Aufsatz über „Bildliche Anleitungen“ (1989) habe ich erfahren, dass ich auch mittels Bildern das Binden einer Krawatte hätte lernen können, wenn mein Vater mir dies nicht bereits beigebracht hätte. Neben solchen Formen einer anschaulichen Wissensvermittlung spielen Bilder auch eine tragende Rolle in verschiedenen empirischen Wissenschaften. Insbesondere fungieren Bilder in der Physik, der Biologie und der Medizin häufig als Wahmehmungsersatz und empirische Basis von Untersuchungen. ${ }^{18}$ Gerade in ihrer evidenzstiftenden Funktion in den Wissenschaften, aber auch in Berichterstattungen, sind jedoch die Wege der technischen Vermittlung und die je eigenen Voraussetzungen der verschiedenen Bildmedien stets zu berücksichtigen. Damit soll aber nicht das postmoderne Horrorszenario einer durchgängigen Täuschung beschworen werden. ${ }^{19}$ Vielmehr soll damit die Relevanz einer Bildkompetenz hervorgehoben werden und die Notwendigkeit geeigneter Analysekategorien für den Umgang mit Bildern in ihren verschiedenen Verwendungen und Kontexten.

18 Zur wissenschaftstheoretischen Diskussion dieser Bildfunktion vgl. Mößner 2012 und SachsHombach 2012, zur Rolle von Bildern in den Wissenschaften vgl. Mersch 2006, Liebsch; Mößner 2012.

19 Zur Problematisierung der dokumentarischen Funktion von Bildern vgl. Mitchell 1994, bes. 42 und Savedoff 2008. 


\section{Methoden der Bildwissenschaft}

Bezüglich ihrer Methoden und Analysekategorien bedient sich die Bildwissenschaft bei verschiedenen Disziplinen und bemüht sich dabei um Anpassung an ihren Gegenstandsbereich. Abgesehen von Verfahren der Bildanalyse selber sind in diesem Zusammenhang empirische Untersuchung zur Bildrezeption mittels psychologischer und neurowissenschaftlicher Tests $\mathrm{zu}$ nennen, aber auch Analyseverfahren für spezifische Medien wie etwa dem Film. Aber selbst wenn man sich auf die spezifisch bildanalytischen Verfahren beschränkt, bleibt immer noch eine Fülle von Methoden, die im Rahmen eines Aufsatzes nicht alle eingehend dargestellt, geschweige denn angemessen gewürdigt werden können. Stattdessen möchte ich anhand zweier Beispiele die Probleme skizzieren, die sich bei der Entwicklung genuin bildwissenschaftlicher Analyseverfahren stellen - und zwar anhand zweier gleichsam „klassischer“ Beispiele, nämlich Panofskys ikonografisch-ikonologische Methode einerseits und Barthes' strukturalistisch geprägter Bildanalyse andererseits. Die Wahl dieser beiden Verfahren legitimiert sich nicht zuletzt dadurch, dass ihre Verfahren immer wieder modifizierend adaptiert wurden.

Mit seiner ikonografisch-ikonologischen Methode schließt Panofsky einerseits an die Motivgeschichte und die Emblematik an und andererseits an die hermeneutische Tradition. Panofskys Bildanalyse zielt dementsprechend auf die Bestimmung von Bedeutungsdimensionen eines bildlichen Kunstwerks ab, wobei er Fragen nach dem Stil und der Komposition weitgehend außer Acht lässt (Panofsky 1939: 36). Ausgangspunkt ist die Unterscheidung dreier Bedeutungsebenen von Bildern, denen je eine Stufe der Analyse entspricht (vgl. hierzu und zum Folgenden Panofsky 1939: bes. 36-43). Die erste Stufe bezeichnet Panofsky als vorikonographische Beschreibung. Auf dieser Ebene soll das „,primäre oder natürliche Sujet“ des Bildes bestimmt werden, d.h. die Farben und Formen werden als Darstellungen von Gegenständen und Personen identifiziert. Auf der Ebene der ikonographischen Analyse wird das „sekundäre oder konventionale Sujet“" erfasst, d.h. die dargestellten Motive werden als Allegorien, Personifikationen usw. gedeutet. Mittels der ikonologischen Interpretation als dritter Ebene wird die ,eigentliche Bedeutung oder der Gehalt" des Bildes bestimmt: Bestimmte Darstellungsweisen und Techniken werden als symptomatisch für den Künstler oder seine Epoche gedeutet.

Offensichtlich ist Panofskys Methode auf eine bestimmte Art von Kunstwerken ausgerichtet, nämlich darstellende Bilder, die Allegorien verwenden. Ob bei anderen Arten von Bildern tatsächlich alle drei Stufen angewendet werden können, darf durchaus bezweifelt werden. Gerade vor dem Hintergrund der analytischen Diskussion über die Ähnlichkeitstheorie des Bildes scheint es sich Panofsky zudem mit der Identifizierung der dargestellten Motive auf der Ebene der vorikonographischen Beschreibung doch sehr einfach zu machen.

Im Fall einer vorikonographischen Beschreibung, die sich im Rahmen der Motivwelt hält, scheint die Angelegenheit recht einfach zu sein. Die Objekte und Ereignisse, deren Darstellung durch Linien, Farben und Volumen die 
Motivwelt bildet, lassen sich, wie wir gesehen haben, auf der Grundlage unserer praktischen Erfahrung identifizieren. (Panofsky 1939: 43).

Ja, die Angelegenheit scheint recht einfach zu sein. Aber zum einen übergeht $\mathrm{Pa}-$ nofsky die Historizität der bildlichen Darstellung auf der Ebene der ikonographischen Beschreibung (vgl. Bätschmann 1979: bes. 466), und zum anderen setzt er die Angemessenheit einer sprachlichen Beschreibung von Bildern voraus, was ihm den Vorwurf eingebracht hat, er unterstelle den Bildern eine Textförmigkeit (vgl. Boehm 1978: 452). Panofskys Modell der Bilddeutung ist aus diesen und anderen Gründen stark kritisiert worden, wurde aber auch immer wieder aufgegriffen und weiterentwickelt, so z.B. von Max Imdahl, Gottfried Boehm, Oskar Bätschmann und William Mitchell.

Auch Roland Barthes' strukturalistische Bildanalyse wurde immer wieder modifizierend aufgegriffen, ist jedoch ähnlich wie Panofskys Modell mit schwerwiegenden Problemen konfrontiert. In Barthes’ Überlegungen zum Bild in „Die Fotografie als Botschaft“ und „Die Rhetorik des Bildes“ erhält das fotografische Bild einen irritierenden Charakter zugesprochen. In „Die Rhetorik des Bildes“ (1990b, Original 1964) analysiert Barthes eine Werbung für Panzani und unterscheidet dabei drei Botschaften. Die eine Botschaft besteht aus dem sprachlichen Paratext der Werbung. Die zweite Botschaft besteht in den Konnotationen, die mit den abgebildeten Objekten verbunden sind, und die dritte Botschaft besteht aus den dargestellten Objekten.

In seinem Essay „Die Fotografie als Botschaft“ (1990a, Original 1961) unterscheidet Barthes zwei Botschaften der Fotografie. Auf der Ebene der Denotation, also der Bezugnahme auf die dargestellten Gegenstände, handelt es sich um eine „Botschaft ohne Code“, insofern diese Bezugnahme nicht konventional vermittelt ist, sondern für ihn letztlich auf Wahrnehmungskompetenzen beruht. Auf der Ebene der Konnotation handelt es sich um eine „Botschaft mit Code“, insofern für ihn die konnotativen Bedeutungsaspekte einer Historizität unterliegen und kulturabhängig sind.

Ähnlich wie Panofsky scheint die Identifizierung der dargestellten Gegenständlichkeit für Barthes kein Problem zu sein. Schlimmer noch: Während er einerseits die Fotografie im Hinblick auf ihre Bezugnahme für ein transparentes Medium hält, betont er andererseits ihren sprachlichen Charakter:

Falls es, gewissen Hypothesen von Bruner und Piaget zufolge, keine Wahrnehmung ohne unmittelbare Kategorisierung gibt, so wird die Fotografie im Moment der Wahrnehmung verbalisiert; oder besser noch: Sie wird nur verbalisiert wahrgenommen [...]. (Barthes 1990a: 24).

Wenngleich sich Spuren der bildanalytischen Ansätze von Panofsky und Barthes in einigen neueren Ansätzen wiederfinden, habe ich Panofsky und Barthes an dieser Stelle nicht ausgewählt, um den endgültigen Status quo der Bildanalyse darzustellen, sondern um einige Fallstricke und Beschränkungen der Bildanalyse deutlich zu 
machen. Sicherlich ist die Unterscheidung verschiedener Bedeutungs- oder Sinndimensionen für die Analyse einiger Bildtypen von Wert. Aber im Gegenzug übergehen beide maßgebliche Fragen wie die nach der Konstitution der bildlichen Bezugnahme bzw. der Denotation. Gerade Barthes’ Annahme der Verbalisierung der Bildwahrnehmung lässt zudem an der Angemessenheit seiner Analysekategorien zweifeln. Gerade auf diese Angemessenheit muss jedoch bei der Adaption der Verfahren geachtet werden. Abgesehen von den skizzierten Schwächen oder Problemen der beiden Ansätze zeigen sie auch, dass sie nicht alle Fragestellungen der Bildwissenschaft beantworten können, aber diese Hoffnung auf eine Universalmethode wird zumindest bislang von keinem bildwissenschaftlichen Ansatz erfüllt.

\section{Abschlussbetrachtung: Bildwissenschaft zwischen Reflexion und Anwendung}

Auf der Wanderung durch die Bildwissenschaft wurden manche Sehenswürdigkeiten näher betrachtet und einige nur aus der Ferne. Dennoch sollte deutlich geworden sein, dass die Landschaft durchaus abwechslungsreich ist - um die Metapher von der Wanderung nun ein letztes Mal zu bemühen. Anders formuliert, die Bildwissenschaft präsentiert sich als plurales, wenn nicht heterogenes, Unternehmen. Angesichts dieser Pluralität handelt es sich bei der Bildwissenschaft um keine Normalwissenschaft im Kuhnschen Sinne, insofern diese durch eine verbindliche Bestimmung des Gegenstandsbereichs und durch einen Kanon von Fragestellungen und Methoden charakterisiert ist (vgl. Kuhn 1970, bes. 10).

Vielmehr handelt es sich bei der Bildwissenschaft um eine vorparadigmatische Wissenschaft im Sinne Kuhns. Als solche pendelt die Bildwissenschaft zwischen Reflexion und Anwendung. ${ }^{20}$ Einerseits wird die Bildwissenschaft angewendet, insofern sie Bilder, ihre Verwendungen usw. analysiert. Während im Rahmen dieser konkreten Analysen bestimmte Bildbegriffe, Fragestellungen und Methoden vorausgesetzt werden, reflektiert die Bildwissenschaft aber andererseits eben jene $\mathrm{V}_{\mathrm{O}-}$ raussetzungen und stellt sie immer wieder in Frage.

$\mathrm{Ob}$ die Bildwissenschaft jemals den Status einer Normalwissenschaft erlangen wird, ist zweifelhaft - Kuhn bezweifelt dies übrigens für alle Geisteswissenschaften. Fraglich ist allerdings auch, ob dies überhaupt erstrebenswert ist. Denn das Pendeln zwischen Anwendung und Reflexion zusammen mit der Pluralität der bildwissenschaftlichen Ansätze birgt auch spezifische Potentiale. Angesichts der Vielfältigkeit dessen, was unter das Phänomen Bild und Visualisierung subsumiert

\footnotetext{
20 So auch der Titel eines Sammelbandes zur Bildwissenschaft: „Bildwissenschaft zwischen Reflexion und Anwendung“ (Sachs-Hombach 2005b). Nach Kuhn kommt es im Rahmen einer Normalwissenschaft nur zur Reflexion der eigenen Voraussetzungen, wenn sich Anomalien ergeben, deren Lösung oder Erklärung immer dringlicher wird und die mit den kanonisierten Methoden nicht in den Griff zu bekommen sind (vgl. Kuhn 1970).
} 
wird, ist diese Pluralität durchaus begrüßenswert, insofern die unterschiedliche Bildbegriffe und die damit verbundenen Fragestellungen und Methoden für die Analyse verschiedener Verwendungsweisen von Bildmedien geeignet sind.

Die Bildwissenschaft wäre dagegen als Normalwissenschaft nur denkbar, wenn sich ein Bildbegriff als der einzig verbindliche durchsetzen würde. Dann ergäbe sich eine Fixierung (und auch Normierung) des Gegenstandsbereichs, und es ließe sich ein fester Kanon bildwissenschaftlicher Methoden bestimmen. Der Preis für diese Vereinheitlichungsstrategie wäre jedoch sehr hoch, würden doch einige Aspekte des Gegenstandsbereichs und einige Fragestellungen verloren gehen. Denn eine Kombination aller Bildbegriffe zu einer Art Super-Bildbegriff scheint ausgeschlossen, insofern diese zum Teil auf Voraussetzungen beruhen, die sich gegenseitig ausschließen.

Die Alternative zu einer vereinheitlichten Bildwissenschaft besteht darin, die Pluralität der bildwissenschaftlichen Ansätze als Chance zu begreifen. Damit soll jedoch nicht einem postmodernen „anything goes“ das Wort geredet werden. Vielmehr bietet die Pluralität nicht nur die Möglichkeit, dem heterogenen Gegenstandsbereich gerecht zu werden, sondern auch die Möglichkeit, durch den Kontrast zu konkurrierenden Ansätzen die Potentiale, Grenzen und Probleme der einzelnen Ansätze kritisch zu hinterfragen und diese dadurch weiterzuentwickeln.

\section{Literatur}

Arnheim, Rudolf (1978): Kunst und Sehen. Eine Psychologie des schöpferischen Auges . Berlin/New York: de Gruyter.

Arnheim, Rudolf (1972): Anschauliches Denken. Köln: Dumont 1972.

Barthes, Roland (1990a): Die Fotografie als Botschaft. In: Ders.: Der entgegenkommende und der stumpfe Sinn. Kritische Essays III. Frankfurt/Main: Suhrkamp, 11-27.

Barthes, Roland (1990b): Die Rhetorik des Bildes. In: Ders.: Der entgegenkommende und der stumpfe Sinn. Kritische Essays III. Frankfurt/Main: Suhrkamp, 28-46.

Baudry, Jean-Louis (1994): Das Dispositiv: Metapsychologische Betrachtungen des Realitätseindrucks. In: Psyche. Zeitschrift für Psychoanalyse und ibre Anwendung 48 (11), 1047-1074.

Bätschmann, Oskar (1979): Beiträge zu einem Übergang von der Ikonologie zu kunstgeschichtlicher Hermeneutik. In: Kaemmerling, Ekkehard (Hrsg.): Ikonographie und Ikonologie. Theorien - Entwicklung - Probleme. Bildende Kunst als Zeichensystem Band 1. Köln: DuMont, 460-484.

Beardsley, Monroe C. (1958): Aesthetics: Problems in the Philosophy of Criticism. New York: Harcourt, Brace \& World. 
Bergmann, Gustav (1953): Logical Positivism, Language, and the Reconstruction of Metaphysics. In: Rorty, Richard (Hrsg.): The Linguistic Turn. Recent Essays in Philosophical Method. Chicago/London: The University of Chicago Press 1967, 63-71.

Black, Max (1972): How do Pictures represent? In: Gombrich, Ernst H.; Hochberg, Julian; Black, Max: Art, Perception, and Reality. Baltimore/London: Johns Hopkins University Press, 95-130.

Boehm, Gottfried (1978): Zu einer Hermeneutik des Bildes. In: Gadamer, HansGeorg; Boehm, Gottfried (Hrsg.): Die Hermeneutik und die Wissenschaften. Frankfurt/Main: Suhrkamp, 444-471.

Boehm, Gottfried (1994): Die Wiederkehr der Bilder. In: Ders. (Hrsg.): Was ist ein Bild? München: Fink, 11-38.

Crary, Jonathan (1990): Techniken des Betrachters. Seben und Moderne im 19. Jabrbundert. Dresden/Basel: Verlag der Kunst 1996.

Danto, Arthur C. (1999): Die Verklärung des Gewöhnlichen. Eine Philosophie der Kunst. Frankfurt/Main: Suhrkamp.

Diekmannshenke, Hajo; Klemm, Michael; Stöckl, Hartmut (Hrsg.) (2011): Bildlinguistik. Theorien - Methoden - Fallbeispiele. Berlin: Schmidt.

Doelker, Christian (2001): Ein Funktionenmodell für Bildtexte. In: Sachs-Hombach, Klaus (Hrsg.): Bildhandeln. Magdeburg: Scriptum, 29-39.

Eco, Umberto (1994): Einführung in die Semiotik [La struttura assente]. München: Fink.

Ehrenfels, Christian Von (1890): Über Gestaltqualitäten. In: Vierteljahrsschrift für wissenschaftliche Philosophie 14, 249-292.

Fiedler, Konrad (1887): Vom Ursprung der künstlerischen Tätigkeit. In: Ders.: Schriften zur Kunst. München: Fink 21991, 111-220.

Frank, Gustav; Lange, Barbara (2010): Einführung in die Bildwissenschaft. Darmstadt: Wissenschaftliche Buchgesellschaft.

Gombrich, Ernst H. (1960): Art and Illusion. A Study in the Psychology of Pictorial Representation. The A.W. Mellon Lectures in the Fine Arts 1956. Princeton: Princeton University Press ${ }^{31969 .}$

Gombrich, Ernst (1989): Bildliche Anleitungen. In: Schuster, Martin; Woschek Bernard (Hrsg.): Nonverbale Kommunikation durch Bilder. Stuttgart: Verlag für angewandte Psychologie, 123-142.

Goodman, Nelson (1968): Languages of Art. An Approach to a Theory of Symbols. Indianapolis/Cambridge: Hackett 21976. 
Heßler, Martina; Mersch, Dieter (2009): Bildlogik oder Was heißt visuelles Denken. In: Dies. (Hrsg.): Logik des Bildlichen. Zur Kritik der ikonischen Vernunft. Bielefeld: transcript, 8-62.

Holenstein, Elmar (1985): Sprachliche Universalien. Eine Untersuchung zur Natur des menscblichen Geistes. Bochum: Brockmeyer.

Hopkins, Robert (1995): Explaining Depiction. In: The Philosophical Review 104(3), 425-455.

Hospers, John (1946): Meaning and Truth in the Arts. Chapell Hill, N.C.: University of North Carolina Press.

Husserl, Edmund (1904/1905): Phantasie und Bildbewusstsein. In: Ders: Husserliana. Bd. XXIII: Phantasie, Bildbewnsstsein, Erinnerung. Zur Phänomenologie der anschaulichen Vergegenwärtigung. Texte aus dem Nachlaß (1898-1925). Den Haag u.a.: Nijhoff 1980, 1-169.

Imdahl, Max (1979): Giotto. Zur Frage der ikonischen Sinnstruktur. In: Ders.: Gesammelte Schriften. Bd. 3: Reflexion - Theorie - Methode. Frankfurt/Main: Suhrkamp 1996, 424-463.

Jonas, Hans (1961): Die Freiheit des Bildens - Homo pictor und die differentia des Menschen. In: Zeitschrift für Philosophische Forschung 15, 161-176.

Kapust, Antje (2009): Phänomenologische Bildpositionen. In: Sachs-Hombach, Klaus (Hrsg.): Bildtheorien. Anthropologische und kulturelle Grundlagen des Visualistic Turn. Frankfurt/Main: Suhrkamp, 255-283.

Kjørup, Søren (1978): Pictorial Speech Acts. In: Erkenntnis 12, 55-71.

Kjørup, Søren (1989): Die sprachliche Verankerung des Bildes. In: Zeitschrift für Semiotik 11(4), 305-317.

Kloepfer, Rolf; Landbeck, Hanne (1991): Ästhetik der Werbung. Der Fernsebspot in Europa als Symptom neuer Macht. Frankfurt/Main: Fischer.

Krämer, Sybille (2009): Operative Bildlichkeit. Von der „Grammatologie“ zu einer „Diagrammatologie“? Reflexionen über erkennendes „Sehen“. In: Heßler, Martina; Mersch, Dieter (Hrsg.): Logik des Bildlichen. Zur Kritik der ikonischen Vernunft. Bielefeld: transcript, 94-122.

Kuhn, Thomas S. (1970): The Structure of Scientific Revolutions. Chicago: University of Chicago Press.

Kulvicki, John (2010): Knowing with Images: Medium and Message. In: Philosophy of Science 77, 295-313. 
Lessing, Gotthold Ephraim (1766): Laokoon oder über die Grenzen der Malerei und Poesie. In: Ders.: Werke und Briefe in zwölf Bänden. Bd. 5/2: Werke 17661769. Frankfurt/Main: Deutscher Klassiker Verlag 1990, 11-206.

Leeuwen, Theo van (2005): Introducing Social Semiotics. London/New York: Routledge.

Liebsch, Dimitri (2012): „Uneigentliche Bilder“. Zur (historischen) Bildsemantik und -metaphorik. In: Liebsch, Dimitri; Mößner, Nicola (Hrsg.): Visualisierung und Erkenntnis. Bildverstehen und Bildverwenden in Natur- und Geisteswissenschaften. Köln: Halem, 58-80.

Lopes, Dominic McIver (1996): Understanding pictures. New York: Oxford University Press.

Lüdeking, Karlheinz (2005): Was unterscheidet den pictorial turn vom linguistic turn?. In: Sachs-Hombach, Klaus (Hrsg.): Bildwissenschaft zwischen Reflexion und Anwendung. Köln: Halem, 122-131.

Mandelbaum, Maurice (1965): Family Resemblances and Generalization Concerning the Arts. In: American Philosophical Quarterly 2, 219-228.

McIntosh, Gavin (2003): Depiction unexplained: Peacocke and Hopkins on Pictorial Representation. In: British Journal of Aesthetics 43(3), 279-288.

Mersch, Dieter (2006): Visuelle Argumente. Zur Rolle der Bilder in den Naturwissenschaften. In: Maasen, Sabine; Mayerhauser, Torsten; Renggli, Cornelia (Hrsg.): Bilder als Diskurse. Bilddiskurse. Weilerswist: Velbrück, 95-116.

Mitchell, W.J. Thomas (1986): Iconology. Image, Text, Ideology. Chicago/London: University of Chicago Press.

Mitchell, William John Thomas (1992): The Pictorial Turn. In: Ders.: Picture Theory. Essays on Verbal and Visual Information. Chicago/London: The University of Chicago Press 1994, 11-34.

Mitchell, William J. (1994): The Reconfigured Eye. Visual Truth in Post-Photographic Era. Cambridge/London: MIT Press.

Mößner, Nicola (2012): Die Realität wissenschaftlicher Bilder. In: Liebsch, Dimitri; Mößner, Nicola (Hrsg.): Visualisierung und Erkenntnis. Bildverstehen und Bildverwenden in Natur- und Geisteswissenschaften. Köln: Halem, 96-112.

Muckenhaupt, Manfred (1986): Text und Bild. Grundfragen der Beschreibung von TextBild-Kommunikationen aus sprachwissenschaftlicher Sicht. Tübingen: Narr.

Nöth, Winfried (2009): Bildsemiotik. In: Sachs-Hombach, Klaus (Hrsg.): Bildtheorien. Anthropologische und kulturelle Grundlagen des Visualistic Turn. Frankfurt/Main: Suhrkamp, 235-254. 
Novitz, David (1977): Pictures and their Use in Communication. A philosophical Essay. Den Haag: Nijhoff.

Panofsky, Erwin (1924/1925): Die Perspektive als „symbolische Form“. In: Ders.: Aufsätze zu Grundfragen der Kunstwissenschaft. Berlin: Hessling 21974, 99-167.

Panofsky, Erwin (1939): Ikonographie und Ikonologie. Eine Einführung in die Kunst der Renaissance. In: Ders.: Sinn und Deutung in der bildenden Kunst. Köln: Du Mont 1975, 36-67.

Peacocke, Christopher (1987): Depiction. In: The Philosophical Review 96(3), 383-410.

Peirce, Charles Sanders (1958): Collected Papers. 8 Bände. Cambridge (MA): Harvard University Press.

Rimmele, Marius; Stiegler, Bernd (2012): Visuelle Kulturen/Visual Culture zur Einführung. Hamburg: Junius.

Rorty, Richard (Hrsg.) (1967a): The Linguistic Turn. Recent Essays in Philosophical Method. Chicago/London: The University of Chicago Press.

Rorty, Richard (1967b): Introduction: Metaphilosophical Difficulties of Linguistic Philosophy. In: Ders. (Hrsg.) (1967a), 1-39.

Sachs-Hombach, Klaus (Hrsg.) (2001): Bildhandeln. Magdeburg: Scriptum.

Sachs-Hombach, Klaus (2005a): Konzeptionelle Rahmenüberlegungen zur interdisziplinären Bildwissenschaft. In: Sachs-Hombach, Klaus (Hrsg.) (2005b), 11-20.

Sachs-Hombach, Klaus (Hrsg.) (2005b): Bildwissenschaft zwischen Reflexion und Anwendung. Köln: Halem.

Sachs-Hombach, Klaus; Schürmann, Eva (2005). Philosophie. In: Sachs-Hombach, Klaus (Hrsg.): Bildwissenschaft. Disziplinen, Themen, Methoden. Frankfurt/ Main: Suhrkamp, 109-123.

Sachs-Hombach, Klaus (2006): Das Bild als kommunikatives Medium. Köln: Halem.

Sachs-Hombach, Klaus (2012) Bilder in der Wissenschaft. In: Liebsch, Dimitri; Mößner, Nicola (Hrsg.): Visualisierung und Erkenntnis. Bildverstehen und Bildverwenden in Natur- und Geisteswissenschaften. Köln: Halem, 31-42.

Savedoff, Barbara (2008): Documentary Authority and the Art of Photography. In: Walden, Scott (Hrsg.): Photography and Philosophy. Essays on the Pencil of Nature. Malden, MA, 111-137.

Schlick, Moritz (1930/31): Die Wende der Philosophie. In: Erkenntnis 1, 4-11.

Schmidt, Siegfried J.; Spieß, Brigitte (1997): Die Kommerzialisierung der Kommunikation. Fernsehwerbung und sozialer $W$ andel 1956-1989. Frankfurt/Main: Suhrkamp. 
Schnädelbach, Herbert (1985): Philosophie. In: Martens, Ekkehard; Schnädelbach, Herbert (Hrsg.): Philosophie. Ein Grundkurs. Reinbeck bei Hamburg: Rowohlt, $37-76$.

Scholz, Oliver Robert (2004): Bild, Darstellung, Zeichen. Philosophische Theorien bildlicher Darstellung. Frankfurt/Main: Klostermann.

Schöttler, Tobias (2012): Von der Darstellungsmetaphysik zur Darstellungspragmatik. Eine historisch-systematische Untersuchung von Platon bis Davidson. Münster: Mentis.

Schöttler, Tobias (2013): Bildhandeln. In: Glossar der Bildphilosophie: DFG-Netzuverk Bildphilosophie (http://www.gib.uni-tuebingen.de/netzwerk/glossar/index.php? title $=$ Bildhandeln).

Searle, John R. (1969): Speech Acts. An Essay in the Philosophy of Language. Cambridge: Cambridge University Press.

Seja, Silvia (2009): Handlungstheorien des Bildes. Köln: Halem.

Sonesson, Göran (1993): Die Semiotik des Bildes. Zum Forschungsstand Anfang der 90er Jahre. In: Zeitschrift für Semiotik 15, 127-160.

Steinbrenner, Jakob (2009): Bildtheorien der analytischen Tradition. In: SachsHombach, Klaus (Hrsg.): Bildtheorien. Anthropologische und kulturelle Grundlagen des Visualistic Turn. Frankfurt/Main: Suhrkamp, 284-315.

Stöckl, Hartmut (2011): Sprache-Bild-Texte lesen. Bausteine zur Methodik einer Grundkompetenz. In: Diekmannshenke, Hajo; Klemm, Michael; Stöckl, Hartmut (Hrsg.): Bildlinguistik. Theorien - Methoden - Fallbeispiele. Berlin: Schmidt, 45-70.

Toscani, Oliviero (1997): Die Werbung ist ein lächelndes Aas. Frankfurt/Main: Fischer.

Weitz, Morris (1956): The Role of Theory in Aesthetics. In: The Journal of Aesthetics and Art Criticism 15(1), 27-35.

Wiesing, Lambert (2005): Artifizielle Präsenz. Studien zur Philosophie des Bildes. Frankfurt/Main: Suhrkamp.

Wittgenstein, Ludwig (1953): Philosophische Untersuchungen. In: Ders.: Werkausgabe. Bd. 1. Frankfurt/Main: Suhrkamp 121999, 225-580.

Wollheim, Richard (1980): Art and its objects. Cambridge: Cambridge University Press. 


\title{
Multimodales Verstehen und kulturelles Lernen. Zu einer Didaktik des Logovisuellen
}

\author{
Markus Raith
}

\section{Text und Bild - Bild und Text}

Die Wiederentdeckung der Bilder und allgemeiner des Visuellen schreitet spätestens seit der Ausrufung des visual oder pictorial turn rasch voran. Verschiedene Disziplinen bemühen sich neben der ohnehin zuständigen Kulturwissenschaft darum, mit ihren jeweils eigenen Perspektiven und Methoden Bildern theoretisch beizukommen. Mittlerweile hat sich der Begriff „Bildwissenschaft(en)“ etabliert, der auf die Theorie und Praxis des Visuellen insgesamt abzielt, also viel mehr umfasst als den Umgang mit kunstgeschichtlichen Bildern.

Damit einher geht eine zweite Wiederentdeckung: die der Texte im Kontext von Bildern, weswegen Bucher (2012: 54) vorschlägt, eher von einer multimodalen Wende als von einem pictorial turn zu sprechen. In den neuen Medien und insbesondere im Internet sind Texte und Bilder mehrheitlich in Kombinationen zu finden: „Unter Hypertextbedingungen werden Schreiben und Lesen zu bildhaften Vollzügen.“ (Sandbothe1997: 73). Es gibt vergleichsweise wenige Webseiten, die nur aus Bild oder nur aus Text bestehen. Dabei sind mit Bildern nicht nur Fotografien oder Abbildungen gemeint, sondern auch Logos, Grafiken und andere Elemente des visuellen Layouts. Wie sich Sprache in dieser neuen medialen Umgebung verändert, welche Funktionen sie einnimmt und in welchem Verhältnis sie zu Bildern steht, untersucht die sich derzeit formierende Bildlinguistik. 
In diesem Zusammenhang hat Ulrich Schmitz für Text-Bild-Gefüge ${ }^{1}$ in neuen (aber nicht nur neuen) Medien den Begriff „Sehfläche“ vorgeschlagen. Er trägt dem Umstand Rechnung, dass diese diskontinuierlichen und fragmentarischen Formate anders produziert und vor allem anders rezipiert werden als lineare Texte. Sie sind als semiotische Arrangements aufzufassen, in denen Bild und Text in einem komplexen, spannungsreichen Verhältnis stehen. Das Bild gibt den situativen Rahmen für die Textelemente ab, der Text fungiert als Interpretationsvorschlag für die Rezeption des Bildes. Dabei rekurrieren diese Formate häufig auf wechselseitige Bedeutungsübertragungen zwischen Text und Bild durch die Technik der Metapher (Schmitz 2004a: 227). Hinzu kommen großflächige Referenz- oder Analogiezusammenhänge (Schmitz 2004a: 230) - auch durch die visuelle Gestaltung und topographische Position der Textfelder -, welche der Sehfläche insgesamt eine ganz spezifische Art der Kohärenz und Kohäsion verleihen: „Ästhetisch erzeugte Präsentation, nicht gedanklich durchdachte Entwicklung bilden kohäsive Ganzheit und kohärenten Sinn.“ (Schmitz 2004b: 121).

Dass diese Formate anders rezipiert werden als lineare Texte liegt auf der Hand (Schmitz 2004a: 223). Text-Bild-Kombinationen werden, ähnlich wie Bilder, vor allem in den neuen Medien einer selektiven Schnell-Lektüre unterzogen: vom Ganzen zum Detail und von außen nach innen (top down). Der Blickweg der Rezipienten wird dabei vom optischen Design der Fläche geführt, sie gibt Wahrnehmungsrichtung und Leseweg vor. Insgesamt kann man von einer gemischten Lektüre - also holistisch, linear und punktuell - ausgehen, bei der Bildfläche und Leselinie gleichermaßen wirksam werden (Schmitz 2004b: 125). Insofern ist die häufig gebrauchte Metapher vom Bilder lesen irreführend, weil sie suggeriert, dass Bilder wie Texte funktionieren und entsprechend rezipiert werden können. Auch Versuche, eine systematische Bildgrammatik oder Bildsyntax zu erstellen, überstrapazieren entsprechende Analogien.

Text-Bild-Kombinationen sind selbstredend keine Erfindung des ausgehenden 20. und beginnenden 21. Jahrhunderts. Sie haben eine lange Tradition, die von mittelalterlichen Dokumenten über die barocke Emblematik bis zur später aufkommenden, bebilderten Presse reicht. ${ }^{2}$ Neu ist allerdings ihre Ubiquität, Simultanität und Instanteinität, bedingt durch hochmoderne Produktions- bzw. Distributionsmöglichkeiten, was zu globaler Zirkulation und massenhafter Rezeption führt.

Dies macht sie auch als Gegenstand von Lehr- und Lernprozessen interessant. Text-Bild-Kombinationen spielen mittlerweile nicht nur eine wesentliche Rolle in der Mediensozialisation Jugendlicher, sondern sind zu einem dominierenden Format in medienkommunikativen Zusammenhängen geworden. Vielleicht ist es nicht

\footnotetext{
${ }^{1} \mathrm{Da}$ es sich um ein noch junges Forschungsgebiet handelt, ist die Terminologie nicht einheitlich, bisweilen auch verwirrend. Neben Text-Bild-Gefüge finden sich (unter anderen) die Begriffe TextBild-Kombinationen, Text-Bild-Kommunikate und Sehflächen. Zur Problematik dieser Terminologie, insbesondere im Hinblick auf einen erweiterten Textbegriff, vgl. Müller 2012.

${ }^{2}$ Vgl. zum Comic und seinen Vorläufern den Beitrag von Ralf Palandt im vorliegenden Band.
} 
übertrieben zu sagen, dass man sich ihnen kaum entziehen kann, denn sie bestimmen via Werbeplakat, Info-Screen usw. zunehmend den öffentlichen Raum.

Der unterrichtliche Umgang mit diesen Formaten sollte aber nicht nur ihrer Omnipräsenz geschuldet sein, er bietet auch enormes didaktisches Potential. TextBild-Kombinationen - und ich beschränke mich hier auf Gefüge aus Schrifttext und statischen Bildern - können als kleine Formen aufgefasst werden, die in ihrer Knappheit und Verdichtung bereits eine didaktische Reduktion per se mit sich bringen. Sie bieten sich an für genaues, sozusagen text-bild-nahes Arbeiten und für die Integration von sprachlichem, medialem und kulturellem, im Fremdsprachenunterricht also auch landeskundlichem Lernen. Sie funktionieren in hohem Maß über Kollektivsymbolik, die visuell und sprachlich aufgerufen wird und ihre Wirkung erst im Zusammenspiel beider Zeichensysteme voll entfaltet.

Dazu zwei Beispiele zum Thema Papstwahl, jeweils eines aus dem Print- und eines aus dem online-Bereich, welche unter die Textsorte journalistische Texte fallen. Die Titelseite der „Bild“-Zeitung zur Wahl Benedikts ist mittlerweile fester Bestandteil des kollektiven Gedächtnisses, auf die immer wieder Bezug genommen wird. Das Photo des neuen Papstes, der die Hände zum Gruß erhebt, wird durch die Schlagzeile „Wir sind Papst“ kontextualisiert. Durch die spezifische sprachliche Form der Überschrift wird das eigentlich religiöse Ereignis, auf dem Foto durch den neuen Papst in vollem Ornat visualisiert, zu einem gesamtgesellschaftlichen, das in die Nähe großer Sport-Events gerückt wird, etwa der Fußballweltmeisterschaft, welche zumindest potentiell Schlagzeilen wie „Wir sind Weltmeister“ zu generieren vermag. Zudem vollzieht sich die Nationalisierung eines eigentlich globalen Ereignisses, wenn die Kollektivpronomen „wir“ und „unser“ („Unser Joseph Ratzinger ist Benedikt XVI") auf Deutschland bezogen werden. Dieser Vorgang wird visuell durch ein Foto verstärkt, welches am unteren Seitenrand die deutsche Flagge zeigt, die von begeisterten Landsleuten geschwenkt wird. Es findet also via sprachlicher und bildlicher Kontextualisierung eine Neuinterpretation des durch das Hauptfoto visualisierten Ereignisses statt. ${ }^{3}$

Das zweite Beispiel bezieht sich auf die Wahl eines neuen Papstes nach dem Rücktritt Benedikts. Es findet sich im headline-Bereich der Startseite des Internetdienstes „web.de“ (Zugriff am 12.3.2013), der in Deutschland überaus populär ist, vor allem für die Nutzung von e-mail. Auf einem Foto sind zwei Kardinäle zu sehen, die sich offenbar vertraut und ungestört unterhalten, im Hintergrund erkennt man - allerdings durch den Zoom-Effekt nur verschwommen - weitere Kardinäle. Das Foto bietet also eine durchaus ernsthafte Inszenierung des anste-

\footnotetext{
${ }^{3}$ Ein ähnlicher Mechanismus war auch bei der Wahl des neuen Papstes Franziskus wirksam. Die „Bild“-Zeitung titelte: „Die neue Hand Gottes“. Hier handelt es sich gewissermaßen um das „,reentry“ einer Suggestion in ihren ursprünglichen Bereich. Nachdem im Falle des umstrittenen WMTores des argentinischen Fußballstars Diego Maradona der Sport an Religiöses gekoppelt worden ist - eben jene ominöse „Hand Gottes“, die beim Tor im Spiel gewesen sein soll -, wird das Bild vom Sport wieder auf den religiösen Bereich rückübertragen, mit allen Bedeutungsverschiebungen und neuen Konnotationen, die sich im Verlaufe dieses Prozesses angesammelt haben. Verbindendes Element ist dabei die (argentinische) Nationalität von Fußballstar und neuem Papst.
} 
henden Konklave, indem zwei exemplarische Vertreter einer Gruppe den jahrhundertealten Wahlvorgang gewissermaßen personifizieren. Diese Seriosität wird durch die - typographisch relativ kleine - Bildunterschrift aufgenommen, wo es heißt: „Reformer oder Traditionalist: Kardinäle treffen sich zum ersten Wahlgang“. Der zweite Teil der Unterschrift verbalisiert mithin die visuelle Botschaft, der erste bietet eine Erklärung für das, was visuell nicht vermittelt, allenfalls erahnt werden kann: den Inhalt des vertraulichen Gesprächs zwischen den beiden Kardinälen auf dem Bild.

Konterkariert wird dieses Zusammenspiel von Wort und Bild allerdings durch die fett erscheinende Überschrift, die lautet: „Kirche sucht den Super-Papst“. Auf diese Weise wird das Text-Bild-Ensemble in ein anderes Licht gerückt. Die Wahl des Papstes erscheint als religiöse Casting-Show, welche den dramaturgischen Gesetzen beliebter Fernsehformate folgt. Nichts Anderes suggeriert der sprachliche Verweis auf das TV-Format „Deutschland sucht den Super-Star“.

Geht man, allgemeiner formuliert, davon aus, dass jede mediale Darstellung sei sie verbaler oder visueller Art - bereits eine Deutung, eine bestimmte Perspektive und also einen Rezeptionsrahmen durch die Art ihrer Konstruktion vorgibt, zeigt sich die wahrnehmungsformende Wirkung der Massenmedien:

Sie erzeugen eine „Hintergrundrealität“, von der man ausgehen kann [...]. Auf diese Weise freilich werden genau die (nur scheinbar selbstverständlichen) Perspektiven formiert, in denen Menschen ihre Wirklichkeit wahrnehmen. Und es werden [...] Normen verbreitet, die Menschen sich bewusst oder unbewusst zu Eigen machen. In diesem Sinne wirken Massenmedien auch als normative Leitmedien und erzeugen Konformität gerade durch Einübung in routinierten Umgang mit Irritation. (Schmitz 2004c: 18).

Zieht man die für gewöhnlich flüchtige und oft nebenbei sich vollziehende Rezeption dieser Formate in Betracht, leuchtet diese Diagnose umso mehr ein. Während Bilder - insbesondere Fotos - vermeintlich Realität abbilden, da die Betrachter bei ihrer semantischen Verarbeitung ,auf kognitive Schemata der alltäglichen Wahrnehmung zurückgreifen“ (Schnotz; Dutke 2004: 75) können, nehmen (Schrift-) Texte oft explikative Funktionen ein. Kurz gesagt: Bilder zeigen und Texte erklären; auf diese Weise formieren sie in ihrem massenmedialen Zusammenspiel häufig en passant - unsere Perspektive(n) auf die Welt.

Ein zentrales Verfahren dabei ist das Operieren mit Analogien, die ,auf Ähnlichkeiten und Gemeinsamkeiten von zwei verschiedenen Ideen oder Gegenständen“ verweisen, „sie reduzieren das Unbekannte durch Bekanntes und sie bewirken damit vor allem eines: Sie erleichtern den Umgang mit Komplexität." (Reinmann-Rothmeier; Vohle 2002: 347). Im Falle unseres Beispiels funktioniert dies über den Kontrast von Bild und Text. Das Foto steht für einen komplexen und für heutige Menschen durchaus befremdlichen, wenn nicht fremden uralten Wahlvorgang. Der Text hingegen nimmt diesem Vorgang seine Fremdheit, indem 
er - für eine bestimmte Zielgruppe mit einer bestimmten Kommunikationsabsicht - eine Analogie zu vertrauten TV-Castingshows eröffnet und so Komplexität nicht nur reduziert, sondern auch Fremdes in Vertrautes überführt. ${ }^{4}$ Dies wird auch über einen gewissen Überraschungseffekt bewirkt und durch die Kürze und Simplizität der Aussage verstärkt. Allerdings besteht dabei die Gefahr, dass womöglich unstimmige Vergleiche oder unpassende, zumindest fragwürdige Analogien als selbstverständlich daherkommen und nicht mehr hinterfragt werden (vgl. ReinmannRothmeier; Vohle 2002: 352).

Genau deswegen sollten massenmediale Text-Bild-Formate verstärkt zum Gegenstand von Lehr- und Lernprozessen gemacht werden, mit dem Ziel, entsprechende Analogiekonstruktionen sichtbar und unbewusst ablaufende Verstehensprozesse bewusst zu machen, oder metaphorisch gesprochen: das Hintergrundrauschen vordergründig hörbar werden zu lassen. Und im Fremdsprachenunterricht: die kulturellen Deutungsmuster und das präsupponierte Wissen (vgl. Altmayer 2004), welches die Basis dieser Verstehensprozesse bildet, für Lerner anderer Herkunftskulturen sichtbar zu machen. Gerade die Konfrontation zweier Zeichensysteme bietet das didaktische Potential, durch Vergleich ihre jeweiligen Möglichkeiten zu konturieren. Anders gesagt: (Schrift-)Sprache kann dazu beitragen, die Spezifika von Bildern zu erhellen, genauso wie Bilder dazu beitragen können, die genuinen Leistungen von Sprache zu verdeutlichen.

Dazu eignen sich Text-Bild-Gefüge im online- wie im Printbereich. Denn sie wollen informieren und unterhalten (infotainment). Beim Wettbewerb um das knappe Gut Aufmerksamkeit setzen Produzenten auf komplexe und subtile Inszenierungsstrategien, welche vom rhetorischen Potential von Sprache und Bild reichlich Gebrauch machen. Visuell wird etwa mit räumlichen Relationen, mit Farbsymbolik, mit Personifizierungen und Allegorien gearbeitet, sprachlich mit Zuspitzungen, Verknappungen, Konnotationenvielfalt, poetisch-lyrischer Sprache und natürlich mit Metaphorik.

Dass diesen Formaten didaktisch nur mit einer Erweiterung der Lesedidaktik beizukommen ist, betont Ulrich Schmitz (2004: 230). Es gehe um konzentrierten Nachvollzug, Verstehen der Bauweise, kritische Reflexion und gegebenenfalls bewusste Eigenproduktion, um eine Didaktik symbolischer Kommunikation also, welche ihren Platz in einem ganzheitlich angelegten Unterricht habe. Allerdings, konzediert Schmitz, gibt es noch keine entsprechenden logovisuellen Didaktiken, allenfalls verstreute Versuche in verschiedenen Disziplinen.

\footnotetext{
${ }^{4}$ Natürlich wäre auch der gegenteilige Effekt denkbar: dass (Alt-)Vertrautes in einem neuen, überraschenden Licht gezeigt wird, dass also die Papstwahl als Casting-Show erscheint und so auf (verblüffende) Ähnlichkeiten verwiesen wird, die man ansonsten übersehen hätte. Dies hängt sicherlich auch von der Rezipientengruppe ab.
} 


\section{Text-Bild-Gefüge in der (Fach-)Didaktik}

Um die nachfolgenden Überlegungen zu einer solch logovisuellen Didaktik in den aktuellen Forschungskontext einzuordnen, sei an dieser Stelle kurz auf verschiedene Ansätze verwiesen, die sich in jüngster Zeit abzeichnen.

In kognitionspsychologischer Hinsicht sind vor allem die Arbeiten von Schnotz und Weidenmann zu nennen. Vor dem Hintergrund der wachsenden Bedeutung von Bildern und Text-Bild-Kombinationen, auch für das Lernen in Multimedia-Umgebungen, entstanden grundlegende Untersuchungen zum Text-BildVerstehen, welche auf entsprechende Arbeiten der Multimodalitätsforschung Bezug nehmen. Vor allem die unterschiedliche Wahrnehmung bzw. kognitive Verarbeitung der beiden Zeichensysteme und ihre Konsequenzen für Lehr-/Lernprozesse stehen im Fokus des Interesses. Weidenmann stellt in diesem Zusammenhang fest:

Die Symbolsysteme als kulturell konventionalisierte Zeichensysteme werden umso effektiver verarbeitet, je mehr Erfahrung die Nutzer mit ihnen [...] haben. Während die sprachlichen Kulturtechniken Lesen und Schreiben im Bildungssystem systematisch trainiert werden, ist die Entwicklung der Kompetenz im Umgang mit Bildern in unseren Schulen ausbaufähig. (Weidenmann 2009: 80).

Hinzu kommen komplexere multimodale Gebilde, die Sprache, Bild und Ton vereinen und von ihren Rezipienten entsprechend hohe Verstehensleistungen erfordern.

Neben diesen allgemein psychologisch-pädagogischen Forschungsansätzen beschäftigen sich verschiedene Fachdidaktiken mit der Rolle von Text-Bild-Kombinationen. Die Fächer Geschichte und Politik arbeiten mit Bildern aller Art, aber auch mit Karikaturen, Cartoons und anderen nicht-linearen Textdokumenten, die analysiert und interpretiert werden. Insbesondere in Geschichte spielen die visual bistory und entsprechende didaktische Vorschläge (vgl. Sauer 2000, Paul 2006 und Lange 2011) eine bedeutende Rolle. Allerdings stehen dabei zumeist Bilder - oder Bilder mit erläuternden Texten -, aber nicht dezidiert Text-Bild-Kombinationen im Vordergrund des Interesses. Die größten Überschneidungen gibt es daher bei den Formaten „Plakat“ und „Karikatur“. Insgesamt geht es in der Geschichtsdidaktik freilich um historisches Lernen, und nicht in erster Linie um sprachlichästhetisch-mediales Lernen, was sie von den Fremdsprachendidaktiken erheblich unterscheidet, selbst wenn im Bereich der Landeskunde enge Wechselwirkungen zu verzeichnen sind.

Ähnlich verhält es sich mit der Kunstdidaktik, zu deren Kernbereichen die grundlegende Schulung visueller Wahrnehmung gehört. In diesem Fach spielt Sprache eine eher marginale Rolle. Zwar experimentieren vor allem neuere künstlerische Arbeiten mit der Materialität und Medialität von Schrift, mit der Verbindung von Bild, Ton und Sprache - etwa in der Medienkunst oder in der performance -, 
diese Formate finden aber erst allmählich Eingang in die Kunstdidaktik und den Kunstunterricht. Breiten Raum nehmen nach wie vor Gemälde, mithin Bilder ohne Textelemente, ein. Dass sich die Kunstdidaktik aber in Richtung allgemeine visuelle Kompetenz unter Einschluss der neuen Medien bewegt, zeichnet sich mittlerweile ab (vgl. Huber 2002). Daraus resultieren Annäherungen an andere Fachdidaktiken, die vielversprechend scheinen. So wurde jüngst eine Ausgabe der Zeitschrift „Praxis Deutsch“ zum Thema Texte und Bilder von Deutschdidaktikern in Kooperation mit Kunstdidaktikern erstellt.

Und schließlich ist die Medienpädagogik für Texte und Bilder im Rahmen einer allgemeinen Beschäftigung mit Medien zuständig. Hier spielen vor allem Fotografien, Fernsehen und Videos eine wichtige Rolle, was ebenfalls zu disziplinenübergreifenden Überlegungen geführt hat. Der Band „Bildinterpretation und Bildverstehen“ (Marotzki; Niesyto 2006) etwa vereint methodische Ansätze aus sozialwissenschaftlicher, kunst- und medienpädagogischer Perspektive, so sein Untertitel. Dabei stehen in der Medienpädagogik neben dem Erwerb von Medienkompetenz(en) immer auch handlungs- und produktionsorientierte Zugänge im Vordergrund. Dem liegt die Idee zugrunde, dass Kinder und Jugendliche vor allem durch Eigenaktivität die (nicht nur technische) Funktionsweise von Medien in all ihren Dimensionen kennenlernen.

Kommen wir zuletzt zum Fremdsprachenunterricht, der seit geraumer Zeit mit Bildern und Text-Bild-Kombinationen operiert. Dabei können Bilder, grob vereinfacht, verschiedene didaktische Funktionen einnehmen. Im Aufgabenbereich Sprechen und Schreiben dienen sie etwa als Redeanlass oder als Schreibimpuls, ähnlich wie in der muttersprachlichen Deutschdidaktik, und können interkulturelle Lernprozesse in Gang setzen. Daneben gibt es die klassische Bildbeschreibung, die häufig als Ausgangspunkt für weitergehende Bildanalysen und -interpretationen dient. Dabei können unterschiedliche Akzente gesetzt werden. Mit Kunstwerken im Fremdsprachenunterricht etwa lässt sich auch landeskundliches und historisches Wissen vermitteln.

Ein weiterer Bereich wäre das literarische Lernen, in dem Bilder als Illustrationen, in paratextueller Funktion (Buchcover, Autorenfoto etc.) oder als Textverstehenshilfen eingesetzt werden. Hierzu zählt sicherlich auch die Arbeit mit bewegten Bildern, vor allem mit Filmen, Filmausschnitten und Videoclips.

Schließlich ist der Bereich der Landeskunde zu nennen und die damit verbunden Prozesse interkulturellen Lernens. Neben Fotos, Filmen und Gemälden fungieren Karikaturen, Cartoons, Diagramme, Presseausschnitte u.v.m. als Text-BildDokumente der Zielkultur, die erschlossen werden soll. Auch Werbung als spezifisches Format von Text-Bild-Gefügen erfreut sich zunehmender Beliebtheit, um sprachliches, mediales und kulturelles Lernen zu integrieren. ${ }^{5}$ Dazu kommen neue Erscheinungsformen alter Formate im Internet, das in der Fremdsprachendidaktik als authentischer, leicht zugänglicher Raum für Lernprozesse geschätzt wird.

${ }^{5}$ Vgl. den Beitrag von Michael Reichelt im vorliegenden Band. 
Dieser skizzenhafte Überblick zeigt, dass Text-Bild-Kombinationen als Unterrichtsgegenstand in vielgestaltiger Form genutzt werden. Allerdings zeigt er auch, wie heterogen die Zugänge zu diesen Formaten sind. Vonnöten wäre eine systematische, fachwissenschaftlich und fachdidaktisch begründete Erschließungskompetenz, die methodisch-unterrichtspraktisch operationalisierbar ist. Dazu gibt es in der Deutschdidaktik bereits grundsätzliche wie auch medienspezifische Überlegungen. Prinzipiell lassen sich zwei Richtungen unterscheiden

Einerseits der Bereich der Literatur- und Mediendidaktik, wo man tendenziell literarisch-ästhetisches Lernen anvisiert. Auf semiotischer Grundlage wurden didaktische Modelle hauptsächlich zu narrativen Formaten entwickelt: zu bewegten Bildern in Kombination mit Sprache und Ton, also zu Filmen, Video-Clips, Werbeclips (vgl. Maiwald 2005); aber auch zu statischen Bildern in Kombination mit Schriftsprache, etwa zu Comics und Bilderbüchern. Auf diesem Feld bieten vor allem die Bilderbuchforschung und die Grundschuldidaktik avancierte Reflexionen. Hinzu kommt die intensive Diskussion über paratextuelle Elemente und Illustrationen als Ausgangspunkt für literarisches Lernen (vgl. Baum; Laudenberg 2012).

Andererseits kommt dem Bereich der allgemeinen Lesedidaktik eine Schlüsselrolle zu. Dort wird nicht nur dem Lesen in der Mediengesellschaft Rechnung getragen, es wird auch die Rezeption neuer Medienformate reflektiert:

Gerade am Beispiel des Internets wird aber zugleich auch deutlich, dass das Lesen speziell im Kontext der digitalen Medien über die Dekodierung geschriebener Sprache weit hinausgeht: Das Internet als multimediale Umgebung, die Schrift, Ton, Bild und Animation integriert, erfordert vielmehr die Fähigkeit, diese Informationen nicht nur zu dekodieren, sondern auch untereinander in Beziehung zu setzen. (Schreier; Rupp 2002: 252).

Spätestens seit der PISA-Studie stellt man sich in der Lesedidaktik verstärkt die Frage nach der Lektüre sogenannter diskontinuierlicher Texte, zu denen Text-BildKombinationen aller Art gehören. Im Vordergrund stehen dabei Gebrauchstexte und Diagramm, also Text-Bild-Grafik-Gefüge, zu denen es eine eigene Forschungstradition gibt (vgl. Lischeid 2012). In diesem Bereich wurde auch das Verstehensmodell entwickelt, das im Folgenden vorgestellt und für die DaFDidaktik adaptiert werden soll. Es trägt der eingangs erwähnten Forderung von Schmitz Rechnung, die Lesedidaktik auf eine Symboldidaktik hin zu erweitern.

An diesem Punkt treffen sich denn auch Überlegungen aus Deutschdidaktik, interkultureller Germanistik und Deutsch als Fremdsprache. Insbesondere die Vorschläge Bernd Müller-Jacquiers scheinen mir in eine ähnliche Richtung zu weisen. Er definiert interkulturelle Kompetenz primär als Kompetenz zur Entschlüsselung von Zeichenbedeutungen (vgl. Müller-Jacquier 2008). Dieser rezipientenbezogene, kultursemiotische Ansatz visiert verschiedene Zeichensysteme in ihrem Zusammenspiel an, darunter an prominenter Stelle Texte und Bilder. Die rezipientenbezogene Perspektive teilt Müller-Jacquier mit Altmayer, der auf 
kulturwissenschaftlicher Basis Vorschläge zum kulturellen Lernen in der Fremdsprachendidaktik macht. Ausdrücklich bezieht er sich auf verschiedene Medienformate und Zeichensysteme, welche auf je eigene Weise bei den Rezipienten die Aktivierung von kulturellen Deutungsmustern aufrufen oder eben nicht aufrufen, weil sie aufgrund eines anderen kulturellen Hintergrundes unbekannt sind. Rezeption heißt mithin immer Rekonstruktion, die durch (fremdsprachliche) Lehr/Lernprozesse angeregt und unterstützt werden kann. Altmayer (2004) belegt seinen theoretischen Entwurf am Beispiel von Plakaten einer Kampagne der Bundesregierung, bezieht sich also ausdrücklich auf das Zusammenspiel der beiden Zeichensysteme Bild und Schrift. Allerdings ist es nicht Ziel seiner Arbeit, ein entsprechendes didaktisches Modell zu entwerfen.

Dies soll im Folgenden auf der Grundlage von Modellen des Leseverstehens symbolischer Darstellungen unternommen werden, wie sie vor allem in der Leseund Mediendidaktik zu finden sind. ${ }^{6}$ Sie könnten dazu beitragen, die theoretischen Überlegungen zu Rezeptionskompetenz und Dekodierfähigkeit auf eine solide didaktische Basis mit logovisueller Ausrichtung zu stellen. Diese Didaktik sollte auch dem weitverbreiteten Missverständnis entgegenwirken, dass Text-Bild-Kombinationen leicht zu verstehen und also mühelos für weitergehende Lernprozesse eingesetzt werden können; dass Bilder ohnehin keine Verstehensschwierigkeiten aufwerfen, was sich in der Redewendung „Ein Bild sagt mehr als tausend Worte“ niederschlägt (vgl. Spinner 2002: 192); und dass sie keine ausgiebige Lektüre lohnen, weil es sich häufig um Sachtexte mit vermeintlich klaren Botschaften handelt.

\section{Prozessmodelle multimodalen Verstehens}

Zugrunde liegt unserem Vorschlag ein Prozessmodell des Leseverstehens symbolischer Darstellungen, ${ }^{8}$ welches seinerseits im Kontext integrativer Modelle des Text-Bild-Verstehens, namentlich dem Modell von Schnotz; Dutke (2004) entwickelt worden ist. Sie alle basieren, wie auch das dreistufige PISA-Modell, ${ }^{9}$ auf der Annahme, dass Lesen ein interaktiver Konstruktionsprozess ist. Externe Informationen aus dem Text werden mit internen Wissensbeständen der Leser zu einem kohärenten mentalen Gebilde verknüpft. Dies gilt nicht nur für schriftsprachliche

\footnotetext{
${ }^{6}$ Wir folgen also einem anderen Ansatz als Ranjakasoa 2012, der sich - neben Baackes Dimensionen der Medienkompetenz - auch auf die muttersprachliche Deutschdidaktik und namentlich auf Frederkings Vorschläge zum symmedialen Deutschunterricht bezieht

${ }^{7}$ „Es sieht so aus, als ob Bilder von allen auf Anhieb verstanden würden, ohne dass es dazu besonderer Fähigkeiten und Anstrengungen bedürfte. Aber Bilder sind nicht so einfach, wie sie aussehen. Alle denkbaren Zugänge zu dem, was ein Bild zeigt, sagt, lehrt, bewirkt, scheinen offen zu stehen aber durch welche Tür sollen wir gehen?" (Spinner 2002: 192).

8 Vgl. zum Symbolbegriff, insbesondere in Bezug auf den Zeichenbegriff, Lischeid 2012: $78 \mathrm{ff}$.

9 Vgl. auch die Interaktionale Blickforschung, welche vier Phasen vorschlägt: Orientierungsphase, selektive Informationsphase, intensive Informationsphase und Ausstiegsphase (vgl. Lengelsen 2012).
} 
Texte, sondern modifiziert auch für multimodale Dokumente, die Bild und Sprache kombinieren. ${ }^{10}$ Grundsätzlich ist dabei zu berücksichtigen:

Ein multimodales Angebot zu verstehen heißt [...] immer auch zu erkennen, wie ein simultan präsentiertes Kommunikationsangebot aus mehreren kommunikativen Elementen räumlich strukturiert ist: Welche Elemente gehören enger zusammen? Welche Zusammenhänge bestehen zwischen ihnen? Wie sind sie hierarchisiert? (Bucher 2012: 68).

In dieser Hinsicht lassen sich zwei Strukturebenen des multimodalen Verstehens erkennen: die Identifizierung und Gruppierung bedeutungstragender Elemente (Selektionsproblem) und die Ebene der Kohärenz bzw. der Erschließungspfade im Kommunikationsraum (Bucher 2012: 69). Das bedeutet, dass multimodale Kommunikate in einem fortlaufenden Deutungsprozess erschlossen werden, der reziprok und rekursiv verläuft (vgl. ebd.: 70f).

Um diesen Spezifika des multimodalen Verstehens gerecht zu werden, unterscheiden die gängigen psychologisch-didaktischen Modelle fünf Phasen, die in heuristischer Sicht einen klareren Blick auf das (idealtypische) Leseverstehen symbolischer Darstellungen erlauben. Einem ersten Allgemeinverständnis (Verstehen des nicht-symbolischen Para- bzw. Kontextes bei mentaler Modellbildung) folgt eine Phase des Fokussierens und Inferierens jeweils auf Text- und auf Bildebene. Dabei werden einzelne denotierte Elemente identifiziert und ein Verstehen des „literalen Sinns" anvisiert. Daran schließt sich eine zweite Phase an, in der Vor- bzw. Kontextwissen zum Fokussieren und Inferieren herangezogen wird. Semantisch motivierte Äquivalenzen zwischen Elementebene und Sinnebene werden erkannt, ein Verständnis des „,nicht-literalen Sinns“ hergestellt. Es folgt eine Phase des Analysierens und Interpretierens des Gesamtgefüges (Verständnis der Einheit von , ,literalem“ und „nicht-literalem“ Sinn) und als letzter Schritt das Reflektieren, welches die Aktivierung von systematischem, historischem und sozialem Wissen voraussetzt. Hier wird die Geltungskraft der vorgenommenen symbolbildenden Operationen in einer abschließenden metakognitiven Operation abgeschätzt.

Insgesamt kommt in diesem Modell also Inferenzen eine zentrale Bedeutung zu, was sowohl an der extrem reduzierten Textmenge als auch am Symbolsystem Bild liegt, das zeigt und darstellt, aber keine diskursiv verknüpften Erklärungen liefert. Auf drei Ebenen muss in hohem Maße inferiert werden: auf der Ebene des Textes, auf der Ebene des Bildes und auf der Gesamtebene der Text-Bild-Kombination. Dabei ist zu beachten, dass beide Symbolsysteme wechselseitig Inferenzprozesse unterstützen können. Was die Rezipienten an Vorwissen aktivieren müs-

\footnotetext{
${ }^{10}$ Vgl. dazu Bucher 2012: 59, der betont, dass man dem Verstehensprozess nur mit einer doppelten Perspektive beikommt: „Die Frage, wie Rezipienten die non-linearen und fragmentierten multimodalen Kommunikationsangebote zu einem kohärenten Verständnis integrieren, kann nicht unabhängig von einer Theorie des entsprechenden Gegegstandsbereichs geklärt werden." Bucher legt der Multimodalitätsforschung eine Theorie des kommunikativen Handelns zugrunde, welche auch für das multimodale Verstehen gilt.
} 
sen, um den Text zu verstehen, kann vom Bild unterstützt werden und umgekehrt. Im Falle des bereits erwähnten Beispiels zur Papstwahl würde das bedeuten: Der Satz „Die Kirche sucht den Superpapst“, welcher zu seinem Verständnis eine Vielzahl von Inferenzen erfordert, wird im Rezeptionsprozess durch das Bild der beiden Kardinäle verständlicher gemacht. Das Foto unterstützt die Aktivierung des Vorwissens „(Katholische) Kardinäle kommen zum Konklave zusammen um einen neuen Papst zu wählen“, was den weiten und allgemeinen Begriff , die Kirche“ näher spezifiziert. Umgekehrt stützt der Text das Verständnis des Bildes, das ohne sprachliche Verweise von den Rezipienten nur schwer einzuordnen wäre und keinesfalls auf ein spezifisches Ereignis hin verstanden werden könnte.

Betrachten wir im Folgenden die verschiedenen Phasen des Modells genauer und sehen uns zugleich an, welche spezifischen Fragen sich bei Rezeptionsprozessen im Bereich Deutsch als Fremdsprache stellen. Dabei bietet es sich analytisch wie unterrichtspraktisch an, Text und Bild zunächst getrennt zu behandeln. Welche Verstehensleistungen sind also auf der Textebene zu leisten? ${ }^{11}$ Anders als bei längeren journalistischen Texten besteht die Schwierigkeit für Fremdsprachenlerner hier nicht in der Textmenge und folglich nicht in den syntaktischen und semantischen Verknüpfungen zwischen einzelnen Abschnitten, Teilen oder Argumentationslinien. Auch unbekannte Wörter können angesichts der extremen Reduktion verbaler Elemente relativ zügig im Lexikon nachgeschlagen werden. Denn zumeist bestehen Text-Bild-Kombinationen in journalistischen Kontexten aus einer zweigliedrigen (Bild und Titel) oder einer dreigliedrigen Struktur (Bild, Titel und eine kleine Legende/Unterschrift). Gerade diese verdichtende Reduktion stellt aber eine große Herausforderung im Hinblick auf die Aktivierung von kulturellen Deutungsmustern und präsupponiertem Wissen (Altmayer) dar, über das Fremdsprachenlerner oft nicht oder nur bedingt verfügen. Hinzu kommen die sprachlichen Verfahren, mit denen diese Deutungsmuster aufgerufen werden: Innerhalb einer Vielzahl von rhetorisch-literarischen Verfahren (u.a. Klang und Reim, Wiederholungen etc.) spielen vor allem Vergleiche, Sprachbilder und Analogien eine zentrale Rolle. Im Falle der Papstwahl wären dies die Analogien von Fußballstar und Papst bzw. von Papstwahl und Casting-Show. Manche dieser Analogien sind offensichtlich, andere nur schwer auszumachen.

Didaktisch-methodisch müsste man auf Analogieverstehen daher größten Wert legen. Lernstrategisch bieten sich dazu Visualisierungen in Tabellen- oder Matrixform an, in denen entsprechende Ähnlichkeitsverhältnisse und Übertragungen aufgelistet und analysiert werden. Sowohl zum Analogietraining (vgl. ReinmannRothmeier; Vohle 2002) wie auch zu Visualisierungstechniken gibt es methodische Vorschläge aus Pädagogik und Didaktik. So betonen Renkl und Nückles (2006: 138) in ihren Ausführungen zu Lernstrategien der externen Visualisierung die Nützlichkeit von Concept Maps: „, Das Anfertigen einer Concept Map verlangt Ex-

\footnotetext{
${ }^{11} \mathrm{Da}$ Sprache das Kerngeschäft des Fremdsprachenunterrichtes ist, werden hierzu nur einige Anmerkungen gemacht, um dann den Ausführungen zum Bildverstehen breiteren Raum zu geben.
} 
plikation der logisch-semantischen Beziehungen zwischen den zu verbindenden Begriffen." Darüber hinaus werde der Umgang mit graphischen Darstellungen gefördert - eine zunehmend wichtige Kompetenz, auch in der PISA-Studie - und die Fähigkeit verschiedenartige Repräsentationen aufeinander zu beziehen, denn: „Diese oft fehlende Kompetenz ist aufgrund der wachsenden Anzahl multimedialer Lernangebote von besonderer Bedeutung.“ (Renkl; Nückles 2006: 143).

Neben allgemeinen Fähigkeiten des Symbolverstehens würden aber auch landeskundliche Kenntnisse erworben. Denn welche Analogien im Rezeptionsprozess wie und warum aktiviert werden, ist in gewissem Maße kulturabhängig. Dabei gilt es „die in Texten angelegte Struktur kultureller Deutungsmuster, die vom Text als selbstverständlich und allgemein bekannt vorausgesetzt werden [...] in der Analyse explizit zu machen" (Altmayer 2004: 189).

Hinzu kommt die Arbeit mit hotwords, mit kulturellen Schlüsselwörtern. Ähnlich wie Gedichte zeichnen sich Bildtitel und Legenden in Text-Bild-Gefügen durch hohe symbolische Aufladung und Konnotationenvielfalt aus. Diesen Bedeutungsreichtum in möglichst vielen Facetten zu erfassen ist eine zentrale Anforderung im Verstehensprozess. Neben der Arbeit mit Lexika und Symbolwörterbüchern könnte hier im Sinne des forschend-entdeckenden Lernens sicherlich auch mit Interviews gearbeitet werden. DaF-Lerner würden dabei herauszufinden versuchen, welche Vorstellungen und Assoziationen Muttersprachler mit bestimmten Begriffen verbinden und wie diese sich womöglich von den eigenen unterscheiden. Dabei würde auch deutlich, dass innerhalb einer Kultur eine große Bandbreite an Variationen auftritt, zugleich aber rekurrierende Muster anzutreffen sind. Entsprechende Arbeitsschritte könnten so das Bewusstsein für die Komplexität und Heterogenität von Kultur schärfen.

Kommen wir, zweitens, zu den Verstehensleistungen, die auf Bildebene erforderlich sind. Bildebene meint im Hinblick auf journalistische Texte vor allem Fotos, in geringerem Maße auch Zeichnungen, Grafiken und Comics. Obwohl Fotos mittlerweile massenhaft und weltweit zirkulieren, ist zunächst zu beachten, dass die Rezeption von Bildern kulturabhängig ist. Das betrifft sowohl den Status, den man Bildern generell zuweist - dies kann bis zum religiös motivierten Bilderverbot reichen -, als auch Inhalte und Form der Darstellung. Am offensichtlichsten wird dies an den Themen Sexualität und Religion, es existieren aber auch subtile, nur schwer wahrnehmbare kulturabhängige Unterschiede, etwa im Bereich von Darstellungskonventionen. Dieser Umstand ist sicherlich generell im Hinblick auf $\mathrm{DaF}-$ Lerner zu berücksichtigen. In heterogenen Lerngruppen bietet er aber auch das Potential, diese Vielfalt erst zu entdecken und zu thematisieren.

Eine zweite Voraussetzung, der für Lehr- und Lernprozesse mit Bildern große Bedeutung zukommt, ist der erkenntnistheoretische Status von Fotografien. Sie verfügen gewissermaßen über einen ontologischen Vertrauensvorschuss, weil sie suggerieren, Realität abzubilden und nicht zu konstruieren. Der Inszenierungscharakter von Bildern wird häufig unterschätzt, wenn nicht vollständig verkannt. Weidenmann bezeichnet dieses Phänomen auch als Scheinduplizierung, da das 
„Konzept der Ikonizität [...] Bilder als Medien der Mimesis“ bestimmt (Weidenmann 1988: 58). Andererseits können Bilder auch als Informationsträger aufgefasst werden und zeichnen sich - ähnlich wie Sprache - durch einen spezifischen Code, den ikonischen, aus. Diese Perspektive betrifft die kommunikative Funktionsfähigkeit von Bildern und ist insofern gerade in bildanalytischer und didaktischer Hinsicht von Bedeutung (vgl. Weidenmann 1988: 63f). Im Hinblick auf Bildverstehensprozesse spricht man daher in diesem Fall von indikatorischem Bildverstehen, im oben genannten Fall von ökologischem Bildverstehen: „Der zentrale Unterschied zwischen ökologischem und indiaktorischem Modus läßt sich auf die Formel bringen: Für ökologisches Bildverstehen ist jede perzipierte Ähnlichkeit mit Realität informativ, für indikatorisches Bildverstehen jede Besonderheit der Bildgestaltung." (Weidenmann 1988: 79).12

Weidenmann (1988: 97) entwirft vor diesem Hintergrund ein idealtypisches 5Phasen-Modell des Bildverstehens, das sich aus Vorphase, Initialphase, Progressionsphase, Stabilisierungsphase und Speicherphase zusammensetzt. Für unsere Belange wichtig sind vor allem die zweite und dritte Phase. In der Initialphase ist der Kontakt mit dem Bild „durch automatische Normalisierungsversuche geprägt", sodass „bevorzugt globale Schemata im Rahmen des ökologischen Verstehensmodus aktiviert werden." Dies hat dem Prinzip der minimalen Verarbeitung zufolge den Effekt, dass häufig ein Abbruch des Bildkontaktes erfolgt. Anders gesagt: die vermeintlich eindeutige Abbildung von Realität veranlasst die Rezipienten, keine weiteren Verstehensanstrengungen zu unternehmen. Gelingt es durch intensitätsfördernde Bedingungen, einen Abbruch nach der Initialphase zu verhindern, können in der Progressionsphase weitere Bildelemente perzipiert werden. Günstigenfalls kommt es dann zu einem „Verstehen zweiter Ordnung“ (Weidenmann 1988: 98).

Dass die genannten intensitätsfördernden Bedingungen in Lehr-/Lernkontexten hergestellt werden können, hat die Didaktik bereits seit einiger Zeit erkannt; und dass der geschulte Umgang mit ikonischer Codierung und der Erwerb von Fähigkeiten des indikatorischen Bildverstehens gerade heute eine wichtige pädagogische Aufgabe ist, wird aus verschiedener Richtung betont: visual literacy oder visuelle Kompetenz müssten Schüler und Studierende erwerben. In der Kunstdidaktik existieren neben der klassischen, an Panofsky geschulten Ikonographie auch andere, subjektivere Verfahren der Bilderschließung. Dazu gehört etwa das „Bildmapping". Zu einzelnen Elementen des Bildes, die besonders auffallen, irritieren oder auch faszinieren, werden kleine Kommentare verfasst und an die jeweilige Stelle des Bildes geheftet. Dieses Verfahren lässt sich natürlich systematisieren und auf alle Bildelemente ausdehnen. In diesem Fall würde es die Ikonographie um eine besonders subjektive, aber durchaus auch reflexive Komponente ergänzen.

\footnotetext{
12 Zur Problematik der Ähnlichkeit in der Bildwissenschaft vgl. den Beitrag von Tobias Schöttler im vorliegenden Band.
} 
Ganz gleich, welchem Verfahren man nun in konkreten Unterrichtssituationen den Vorzug gibt, immer handelt es sich um eine doppelte Transkription. Einerseits wird Visuelles sprachlich transkribiert und andererseits ist diese Sprache nicht die eigene, sondern eine zu erlernende Fremdsprache. Daran koppeln lässt sich eine Fülle sprachfördernder Aufgaben, sowohl schriftlicher als auch mündlicher Art. In der Ikonographie dringt man von der klassischen Bildbeschreibung in tiefere Bedeutungsschichten vor, schreitet vom „was“ zum „wie“ voran und benötigt auf diese Weise andere, komplexere Ausdrucksmittel. Beim Bild-mapping wiederum geht es um den sprachlichen Ausdruck von Eindrücken, Emotionen, vielleicht auch Befindlichkeiten, über die in der Gruppe diskutiert werden kann. Die einzelnen Bild-mappings können verglichen und besonders auffällige, von allen markierte Elemente vertiefend besprochen werden. Schreibaufgaben müssten gestellt werden, mit denen die ausgelösten Eindrücke ergründet werden.

Man könnte sich auch den frozen moment didaktisch zu eigen machen, der allen statischen Bildern zugrunde liegt. Das Foto als Inszenierung zeigt immer einen stillgestellten Augenblick, dem ein potentielles Vorher und Nachher anhaftet. Jedes Bild erzählt eine (oder mehrere) Geschichte(n), die es freizulegen und zu verschriftlichen bzw. zu verbalisieren gilt. ${ }^{13}$ All diesen Arbeitsschritten liegt das doppelte Ziel zugrunde, sowohl die sprachlichen Ausdrucksmöglichkeiten und -fähigkeiten in der Fremdsprache zu trainieren als auch beim Bildverstehen von der Initialphase in die Progressionsphase und so zu einem vertieften Verständnis des Visuellen zu gelangen.

Schließlich existieren Verfahren, die ganz bewusst auf eine sprachliche Transkription von Bildern verzichten und Visuelles durch Visuelles erschließen. Dazu zählt das Kommentieren von Fotos durch andere Bilder oder - in handlungs- und produktionsorientierter Hinsicht - die Eigenproduktion von Bildern, die eine visuelle Interpretation von Visuellem vornimmt. Lässt man Lerner eigene Fotos desselben Objektes oder Ereignisses machen, wird überdies die Gemachtheit von Bildern deutlich und so indikatorisches Bildverstehen gefördert.

Diese Vorschläge sind im einzelnen nicht unbedingt neu. Bezieht man sie allerdings konsequent auf Text-Bild-Gefüge vor dem Hintergrund einer Didaktik des Symbolverstehens, ergeben sich interessante und durchaus neue Perspektiven. $\mathrm{Zu}$ fragen ist, welche Rolle Text und Bild für den Verstehensprozess des jeweils anderen Symbolsystems im Gesamtgefüge spielen und wie ihr Zusammenwirken Kohärenz und Kohäsion erzeugt. Da das „besondere Risiko eines Bild-Sprache-Vergleichs [...] in der Einebnung wesentlicher Unterschiede“ (Weidenmann 1988: 67)

\footnotetext{
${ }_{13}$ Bildern wohnt „eine narrative Kraft inne“ (Fuhs 2006: 216), nicht nur, wenn sie in Serie rezipiert werden, auch Einzelbilder weisen eine bestimmte Narrativität auf. Ihre visuelle Botschaft kann einerseits im Rezeptionsprozess in Sprache transformiert und so zu einer Erzählung gemacht werden. Andererseits erzählen Bilder auch, wenn sie ,in eine bestehende Erzählkultur gehören. So wie sich das Heidi-Bild der Werbung auf eine lange Heidi-Bild-Kultur bezieht, die im konkreten Bild weitererzählt wird. [...] Die narrativen Bildwelten sind nicht nur im öffentlichen Raum präsent, sie sind es auch in den Köpfen.“ Dabei hat sich, folgt man der Argumentation von Fuhs, eine „emotional erzählende Fotokultur als Teil einer „weltweite[n] narrative[n] Bildkultur“" herausgebildet (Fuhs 2006: 218).
} 
liegt, ist es didaktisch unerlässlich, die funktionalen Unterschiede zwischen Bild und Sprache zu erarbeiten, um dann ihre Äquivalenzen zu konturieren.

Zunächst zu den Unterschieden: Dabei ist immer zu bedenken, inwiefern die Funktionalität des einen Symbolsystems die des anderen im Gesamtgefüge beeinflusst. Folgen wir dem Überblick von Weidenmann (1988: 68f), so gibt es in Bildern keine Entsprechung für das sprachliche Verb, was mit der „eingefrorenen Zeit“ zusammenhängt. In Text-Bild-Gefügen wäre also zu überprüfen, ob der Textteil Verben enthält und wie sie die eingefrorene Zeit im Bild kontextualisieren, vielleicht sogar verflüssigen. Zumindest legen Verben eine Lesart für das potentielle Vorher und Nachher des frozen moment nahe.

Dann gibt es in Bildern kein Äquivalent für das „Ich“ bzw. „Wir“ eines Textes. $\mathrm{Zu}$ fragen wäre, ob die Textelemente darauf einen Hinweis geben. Im Falle der „Bild“-Zeitungsmeldung zur Papstwahl wird dieses „Wir“ in der Aussage „Wir sind Papst" benannt und den Betrachtern so eine andere, ungewöhnliche Lesart angeraten. Betrachtete man nur das Foto, müsste die Bildaussage lauten: „Er/der dargestellte Mann ist Papst", denn Bilder sind prinzipiell Impersonalien (Weidenmann 1988: 69).

Drittens: Bilder können aufgrund ihrer Abbildungsfunktion keine Äquivalenzkategorien, also abstrakte Gattungsbegriffe, darstellen. Rezipienten verarbeiten abgebildete Personen qua Identitäskategorie so, als seien bestimmte Menschen gemeint. In diesem Fall können Textelemente sprachliche Hinweise auf Konzepte oder Gattungsbegriffe geben, also innerhalb des Text-Bild-Gefüges Abstraktionsleistungen erbringen. Ein bekanntes Beispiel für dieses Phänomen ist die Werbung eines Baufinanzierers, welche konkrete Menschen in konkreten (exotischen) Situationen zeigt: einen Buschmann beim Errichten einer Hütte, einen Eskimo beim Bau eines Iglu usw. Erst die sprachliche Ergänzung: „Ein Haus zu bauen liegt in der Natur des Menschen, Miete zahlen nicht" gibt den abstrahierenden Hinweis auf die Gattung und erlaubt so Rückschlüsse auf die Lebenswelt der (deutschen) Rezipienten und mithin potentiellen Kunden.

Viertens: Bilder können nicht verneinen, sie zeigen was ist (oder im Sinne Roland Barthes: was gewesen ist). Textelemente können in diesem Fall eingesetzt werden, um das Gezeigte infrage zu stellen oder kritisch zu beleuchten. Insbesondere die Werbung, aber auch politische Reportagen spielen mit diesem „Wir können unseren Augen nicht trauen"-Effekt. Das Gezeigte scheint nur, was es ist, erst der Text erläutert, was sich hinter dem Sichtbaren verbirgt. So kann die Darstellung einer idyllisch anmutenden Landschaft durch den sprachlichen Verweis, dass hier Radioaktivität gemessen worden ist, gleichsam verneint werden.

Und schließlich können Bildproduzenten keine expliziten Hinweise geben, wie und in welcher Reihenfolge die Informationen zu verarbeiten sind, wohingegen Autoren über effektive Mittel der Leserlenkung verfügen. In diesem Sinne können die Textelemente in Text-Bild-Kombinationen auch die Rezeption des Bildes oder der Bildelemente lenken - sie müssen aber nicht. 
Neben diesen Unterschieden gibt es eine Reihe von funktionalen Äquivalenzen zwischen Text und Bild, die hier nur angedeutet seien. Sowohl Bilder als auch Texte haben auf je spezifische Art und Weise eine Binnengliederung: hier die Syntax und sequentielle Anordnung, dort Gliederungselemente wie Umrisse, Farbe oder Helligkeit. Beide können betonen, hier etwa durch die Stellung eines Wortes am Satzanfang, dort durch die Platzierung eines Elementes in die Bildmitte. Und schließlich generieren beide Konnotationen und können somit symbolisch oder metaphorisch eingesetzt werden, also für etwas Anderes stehen. In Text-BildGefügen ist mithin zu berücksichtigen, wie diese funktionalen Äquivalenzen in ihrem Zusammenspiel wirken. Werden Analogien erst durch die Kombination von Wort und Bild deutlich? Wird sprachliche Metaphorik im Bild visualisiert oder nicht? Werden Konnotationen eines bestimmten Begriffes abgebildet: wenn ja, welche und warum? Entsprechen sich die Binnengliederungen und Betonungsstrategien der beiden Symbolsysteme oder konterkarieren sie sich? In welchem generellen Zusammenhang stehen Bild und Text? Wiederholen sie sich bloß oder erzeugt ihr Zusammenspiel Spannung, weil etwa der Text das visuell Gezeigte ironisch bricht oder das Bild allzu hehre Textbotschaften durch die Abbildung realistischer Zustände entlarvt?

\section{4 „Allah im Abendland“ - ein Beispiel}

Wie dieses bislang allgemein vorgestellte didaktische Modell in konkreten Unterrichtszusammenhängen funktionieren kann, sei nun ausführlicher an einem Beispiel gezeigt: an der Titelseite des Nachrichtenmagazins „Der Spiegel“ zum Thema „der Islam und Deutschland“. Diese Thematik ist sowohl für interkulturelles Lernen bedeutsam als auch von landeskundlichem Interesse - nicht nur für den DaFUnterricht, sondern entsprechend auch für den Französisch- und Englisch-alsFremdsprache-Unterricht. Denn es geht im weiten Sinne um Kulturkontakte im Kontext von Migrationsphänomenen. Schließlich ist die Rolle des Islam für Gesellschaft und Politik ein weltweit diskutiertes Thema und besonders interessant aber auch brisant - in religiös gemischten Lerngruppen.

Um sprachliches, mediales und kulturelles Lernen zu verknüpfen, können für den Unterricht sowohl das Titelcover der Printausgabe als auch die entsprechende Internet-Seite herangezogen werden. Beginnen wir mit der Printausgabe, deren Titel aus einer dreigliedrigen Struktur besteht: erstens aus einer fett gedruckten Überschrift (,Allah im Abendland“), die von einer kleineren, farblich abgesetzten, aber räumlich nahen zweiten Überschrift ergänzt wird, zweitens aus einer Fotomontage und drittens aus kleinen Textblöcken unterhalb des Fotos, die auf inhaltliche Aspekte im Innenteil der Zeitschrift verweisen. Bevor wir die einzelnen Elemente näher betrachten, sollte das Layout des Gesamtgefüges in seiner Gestaltung deutlich werden. Aus dem Kunstunterricht könnte etwa die Idee übernommen werden, auf einem darüberliegenden Cellophan-Papier die Umrisse des Titelcovers 
festzuhalten und in einzelne Segmente aufzuteilen, um einen ersten Überblick über die räumliche Anordnung von Text- und Bildteilen zu bekommen.

Hernach bietet es sich an, die eingangs vorgeschlagene Trennung von Text und Bild vorzunehmen und zunächst den doppelten Titel anzuvisieren. Das fett gedruckte, schwarze „Allah im Abendland“ fällt sofort auf, nicht nur, weil es in größerem Abstand noch gelesen werden kann, sondern auch, weil es sich von dem hellen Hintergrund abhebt. Diesen Titel werden Rezipienten normalerweise zuerst lesen. Wie ist er sprachlich gestaltet? Zunächst fällt auf, dass er mit Alliterationen und Assonanzen arbeitet und so eine lyrisch-poetische Qualität erhält, was sich durch mehrmaliges, expressives Lesen sicherlich erarbeiten lässt. Dann wird mit einer Personifikation, mit dem Namen Allah, gearbeitet. Didaktisch interessant wäre herauszufinden, wer sich Allah als Person wie vorstellt, zumal es im Islam ein Darstellungsverbot gibt. Vermutlich würden westliche Rezipienten eher an Darstellungen Mohammeds, zumindest aber an bärtige, Turban tragende Männer denken - genauso wie wir auch ein bestimmtes, kulturell konventionalisiertes Bild des christlichen Gottes als gütiger, weißbärtiger Mann haben. In einem weiteren Schritt wäre dann das zweite hotword des Titels, das „Abendland“, über Begriffsarbeit zu klären. In welchen Kontexten wird der Begriff gebraucht, welche Konnotationen ruft er hervor, wie hat er sich geschichtlich entwickelt, und wie lässt sich das Verhältnis zu seinem Pendant, dem „Morgenland“, bestimmen?

Betrachtet man den Titel als Ganzes, wird man feststellen, dass hier inhaltlich von einer bestimmten Person (,Allah") an einem bestimmten Ort (,im Abendland") die Rede ist. Falls notwendig könnte diese grammatikalische Struktur auch mit einer Übung zu Orts- und Richtungsbestimmungen mit Dativ bzw. Akkusativ einhergehen. Denn dies scheint eine wichtige Botschaft zu sein: Allah befindet sich bereits im Abendland, er ist nicht auf dem Weg dorthin (also ins Abendland).

Zweitens fällt auf, dass es sich, wie so oft bei Titeln, um einen unvollständigen Satz handelt, es fehlt das Verb. Dies ist einerseits nicht ungewöhnlich, andererseits aber auffällig, wenn man die funktionalen Unterschiede zwischen Sprache und Bild in Betracht zieht. Das spezifisch Sprachliche, das Verb, zu dem es keine Analogie im Bild gibt, fehlt hier. Es wird gerade nicht gesagt, was Allah im Abendland macht. Das heißt, Sprache erklärt hier nicht, sondern stellt eher dar, zeigt etwas, aber in ihrem spezifischen Code, nämlich durch Nomen und Präposition. In ihrer Funktionalität scheint sie sich dem Bild anzunähern, ein Umstand, der beim Betrachten des Gesamtgefüges geklärt werden müsste.

Die Frage, welche der Titel herausfordert und auf die in einer Schreibaufgabe möglicherweise geantwortet werden kann, lautet also: Was macht Allah im Abendland? Und warum? Schließlich wäre zu klären, dass die Nomen „Allah“ und „Abendland“ aufgrund des fehlenden Verbs eher vage verknüpft sind, über die Ortspräposition und über den Wortklang. Es fehlen kausale, argumentative Bezüge.

Ein weiterer Arbeitsschritt in Bezug auf den Titel wäre der Umgang mit Textsorten. „Allah im Abendland“ erinnert sowohl in seiner syntaktischen wie auch 
semantischen Struktur an Märchentitel, beispielsweise „Aladin und die Wunderlampe“ oder „Hans im Glück“. Diese sprachliche Besonderheit ließe sich über ein Verzeichnis von Märchentiteln konturieren und würde die Frage nach sich ziehen, welche mögliche Geschichte denn der Titel „Allah im Abendland“ nahelegt, vor allem dann, wenn man den typischen Verlauf von Märchen berücksichtigt.

Betrachten wir in einem zweiten Schritt den Untertitel „Der Islam und die Deutschen“ näher. Dieser Untertitel ist analog zum Haupttitel aufgebaut. Den Nomen „Allah“ und „Abendland“ entsprechen „der Islam“ und „,die Deutschen“, die Ortspräposition „im“ wird durch das verbindende „und“ ersetzt. Auch hier fehlt das Verb, die beiden Nomen werden nur vage verknüpft. Auf lexikalischer Ebene sind die Unterschiede allerdings enorm und bieten auf diese Weise didaktisches Potential für Wortschatzarbeit. Der märchenhaft abstrakt-distanzierte Titel wird konkretisiert, aktualisiert und politisiert, indem zwei Kollektive in Relation zueinander gesetzt werden, allerdings über unterschiedliche Kategorien: „Islam“ ist eine religiöse Kategorie, „die Deutschen“ hingegen eine nationalstaatliche Kategorie. Der Untertitel beruht also gleichsam auf einer schiefen Äquivalenz. Hinzu kommt, dass das „Abendland“ nun im Hinblick auf die Nationalität der Leser des Magazins spezifiziert wird. Auch hier sind die Textelemente durch das Fehlen des Verbs unterdeterminiert. Wie ist das „und“ zu verstehen? In welchem Verhältnis steht der Islam zu den Deutschen? Wie im Haupttitel werden durch die sprachliche Struktur eher Fragen aufgeworfen und Unklarheiten geschaffen.

An dieser Stelle kommt das Bild ins Spiel. Und hier zeigt sich auch, dass TextBild-Gefüge nur dann adäquat verstanden werden können, wenn die spezifische Funktionalität von Text und Bild geklärt ist. Denn eine Antwort auf die vom Text aufgeworfenen Fragen liefert das Bild mit seinen spezifischen Darstellungsmitteln. Drei distinkte Bildelemente dominieren das Foto: in der Mitte eine deutsche Flagge, in deren Mitte sich wiederum - also im roten Farbteil - ein gelber Halbmond mit Stern befindet. Rechts neben der Flagge sehen wir eine lichtbeglänzte Moschee, links davon einen Teil eines Minaretts, das die Flagge augenscheinlich überragt.

Die Fotomontage ist in ihrer Gesamtheit daraufhin ausgelegt, visuell Größe und Macht des Islam zu demonstrieren. Wie gelingt ihr das? Zunächst durch die Perspektive: die Betrachter blicken gleichsam aus einer extremen Untersicht zu den Gebäuden hinauf. Diese Perspektive lässt sich didaktisch überzeugend erarbeiten, wenn man analog zum impliziten Leser den impliziten Betrachter ins Spiel bringt. Wo in einem angenommenen urbanen Raum stehen wir, wenn wir den auf dem Bild gezeigten Blick einnehmen? Dann durch die Darstellung und Anordnung der Gebäude: Das Dach der Moschee ist lichtbeglänzt und erinnert so an historische Visualisierungen von Macht durch Gloriolen, Heiligenscheine oder Sonnenstrahlen. Beide Gebäude, das riesig wirkende Minarett und die golden-gleißende Kuppel der Moschee, rahmen die deutsche Flagge und scheinen sie gleichsam zwischen sich einzuzwängen. Dieser Inszenierung islamischer Macht auf räumlich-architektonischer Ebene entspricht die Anordnung des Halbmondes auf der deutschen 
Flagge. Er befindet sich geometrisch genau in ihrer Mitte und suggeriert so, dass sich der Islam mitten in Deutschland, oder metaphorisch gesprochen: im Herzen der Republik befindet. Dass diese Lokalisierung von latenter Aggressivität begleitet wird, erweist sich daran, dass das Errichten von Nationalsymbolen und namentlich von Flaggen immer auch mit Souveränitäts- und Herrschaftsansprüchen verbunden wird. Das Flaggehissen ist ein extrem konventionalisierter symbolischer Akt, der weltweit verstanden wird.

Die Fotomontage gibt also eine visuelle Antwort auf die offenen Fragen, welche die Unterdeterminiertheit des schriftsprachlichen Titels erzeugt. Hier wird gewissermaßen bildlich erläutert, was Allah im Abendland macht und wie das Verhältnis von Islam und Deutschen zu verstehen ist. Dass Bild und Sprache hier als Frage-Antwort-Relation funktionieren, zeigt auch die Parallelisierung durch Betonung. Das erste Wort des Titels („Allah“) und des Untertitels („Islam“) werden syntaktisch hervorgehoben, ihre visuelle Entsprechung, der Halbmond in der Flagge, wird durch die Platzierung in der Bildmitte akzentuiert. Anders gesagt: Wie das märchenhaft-geheimnisvolle „Allah im Abendland“ konkret zu verstehen ist, wird auf dem Bild in architektonisch-städtebaulicher Weise anschaulich gezeigt. Das Bild erscheint dabei umso suggestiver, als es ausschließlich Moschee und Minarett zeigt, also keine vertrauten Gebäude, welche die Betrachter mit Deutschland in Verbindung bringen würden. Über die didaktisch ergiebige Frage, was denn auf Bildern nicht zu sehen ist, aber eigentlich zur Thematik gehören würde, lässt sich erarbeiten, dass hier zwei funktionale Stärken von Bildern (vgl. Weidenmann 1988: 70) ausgespielt werden: Sichtbares mitzuteilen und in höherem Maße als Sprache Emotionen bei den Betrachtern auszulösen. Indem mit starker politisch-sozialer Kollektivsymbolik gearbeitet wird, die an anschaulich-räumliche Verhältnisse gekoppelt ist, sollen durch das Text-Bild-Gefüge Emotionen ausgelöst werden, vor allem wohl diffuse Ängste vor Identitätsverlust und dem Fremdem schlechthin. Zugespitzt formuliert: Das „Spiegel“-Cover steht in seiner Inszenierung Sarrazins „Deutschland schafft sich ab“ wesentlich näher als Christian Wulffs „der Islam gehört zu Deutschland““.

Dabei macht man sich die Eigenschaft von Bildern zunutze, dass sie etwas zeigen, dass sie - im Vergleich zur Sprache - „quasi im Präsens Indikativ des ,so ist es"“ (Weidenmann 1988: 69) stehen. Genau genommen greift das Bild eine aktuelle gesellschaftliche Debatte auf, den Bau von Moscheen in Deutschland, und gibt vor, ein konjunktivisches Futur zu zeigen, nämlich einen öffentlichen Raum, in dem nur (noch) muslimische Gotteshäuser zu sehen sind. Da Bildern aber sowohl die konjunktivische als auch die futurische Dimension weitgehend fehlt, erscheint dieser fiktive Zustand im Präsens als hier und jetzt beschaubarer (und so Emotionen auslösender) Zustand. Dies gelingt nur durch die Fotomontage, und genau hier hat die Didaktik anzusetzen. Das Bild stellt seine Gemachtheit aus und lädt somit auch zur Reflexion über die Inszenierung von kollektiven Identitäten ein. Aber auch um die Intention der Bildproduzenten müsste es gehen, die mit dem Titelcover um die knappe Ressource Aufmerksamkeit buhlen. Das Cover ist des- 
wegen so interessant, weil es eine Schnittstelle von ästhetischen, sozialen und ökonomischen Belangen darstellt.

Einer solchen Reflexion muss freilich die Analyse der Bildelemente vorausgehen. Dabei wäre zunächst mit Verfahren des Bild-mappings zu arbeiten, um zu sehen, welche Stellen auffallen oder irritieren. Dass dazu höchstwahrscheinlich die deutsche Flagge mit Halbmond gehören wird, kann die Wirkung von Kollektivsymbolik verdeutlichen, auch und gerade im vermeintlichen Zeitalter der postnationalen Identitäten. Weiter wäre zu fragen, was auf dem Bild nicht zu sehen ist: keine „deutschen“, sprich den Lesern vertrauten Gebäude; keine Menschen, was umso interessanter ist, als gerade in journalistischen Medieninhalten bevorzugt Personen und Personifikationen gezeigt werden. Die Bezüge von Architektur und Kollektivsymbolik wären zu thematisieren und in zeitgenössische Diskurse einzuordnen. Dazu könnten beispielsweise Plakatdokumente aus der Kampagne gegen Moscheebau in der Schweiz ergänzend herangezogen werden, wo visuelle Analogien zwischen Minarett und Raketen suggeriert werden.

Und schließlich müssten im Sinne des vorgeschlagenen Trainings zum Metaphern- und Analogieverstehen die Bezüge von Sprache und Bild herausgearbeitet werden. Dazu gehören auch die bisher noch nicht erwähnten Textelemente unterhalb des Bildes, über die viel zu sagen wäre, die hier aber nicht ausführlich besprochen werden können und daher zur eigenen Analyse einladen sollen. Sie lauten: „Die neuen Moscheen. Propagandazentren der Parallelgesellschaft?" und „Schäubles Islamkonferenz. Warum konservative Muslime den Ton angeben“. Für diese Phase des Text-Bild-Verstehens bietet sich eine Symbolmatrix als Visualisierungshilfe an, die etwa so aussehen könnte:

\begin{tabular}{|l|l|l|l|l|l|}
\hline & Titel 1 & Tite1 2 & Textblock 1 & Textblock 2 & \multicolumn{1}{|c|}{ Bild } \\
\hline $\begin{array}{l}\text { Ele- } \\
\text { ment 1 }\end{array}$ & Allah & Islam & $\begin{array}{l}\text { Die neuen } \\
\text { Moscheen } \\
\text { Parallel- } \\
\text { gesellschaft }\end{array}$ & $\begin{array}{l}\text { Konservative } \\
\text { Muslime }\end{array}$ & $\begin{array}{l}\text { Moschee } \\
\text { Minarett } \\
\text { Halbmond } \\
\text { in der Flagge } \\
\text { (gelb) }\end{array}$ \\
\hline $\begin{array}{l}\text { Ele- } \\
\text { ment 2 }\end{array}$ & $\begin{array}{l}\text { Abend- } \\
\text { land }\end{array}$ & $\begin{array}{l}\text { Die } \\
\text { Deut- } \\
\text { schen }\end{array}$ & & Schäuble & $\begin{array}{l}\text { National- } \\
\text { flagge } \\
\text { schwarz / } \\
\text { rot /gold }\end{array}$ \\
\hline
\end{tabular}




\begin{tabular}{|l|l|l|l|l|}
\hline $\begin{array}{l}\text { Ele- } \\
\text { ment 3 }\end{array}$ & & $\begin{array}{l}\text { Propaganda- } \\
\text { zentrum }\end{array}$ & $\begin{array}{l}\text { Den Ton } \\
\text { angeben }\end{array}$ & $\begin{array}{l}\text { Halbmond } \\
\text { in der Flagge } \\
\text { Moschee } \\
\text { und Mina- } \\
\text { rett aus } \\
\text { Frosch- } \\
\text { perspektive }\end{array}$ \\
& & & & \\
& & & & \\
\end{tabular}

Tab. 1: Visualisierung von Bezügen innerhalb des Text-Bild-Gefüges

Wichtig ist, dass nicht zwanghaft eindeutige Zuweisungen stattfinden, sondern dass gerade Mehrdeutigkeiten, Doppelcodierungen und komplexe Bezüge zum Gegenstand der Reflexion gemacht werden. Die Visualisierung kann helfen, die Bedeutungsschichten zu erschließen, die sich hinter der konkreten Textaussage bzw. Bilddarstellung befinden, ähnlich wie im barocken Emblem, wo sich stets eine Pictura-Seite auf eine Subscriptio-Seite beziehen lässt. Eine andere Visualisierungsstrategie wäre, in eine Arbeitskopie des Covers entsprechende Analogierelationen über Pfeile und Verbindungslinien einzuzeichnen, zu benennen und eventuell mit offenen Fragen zu versehen. Dabei würde deutlich, dass bei diesem Beispiel das Bild gerade nicht normalisiert, also das Neue zu Bekannten macht (vgl. ReinmannRothmeier; Vohle 2002: 349), sondern durch seinen Montagecharakter einen gegenteiligen Effekt erzielt. Das eigentlich Bekannte - die Nationalflagge - wird verfremdet, während die sprachlichen Elemente das im Bild Fremd-Bedrohliche zunächst verharmlosen und in den eigenen Deutungshorizont hereinholen: „Allah im Abendland“ evoziert ein bekanntes Märchenschema.

Schließlich könnten in der online-Ausgabe von Nachrichtenmagazinen zusätzlich die mit dem Titel verlinkten Fließtexte bearbeitet werden. Im Prinzip wird hier eine Grundstruktur der Printausgabe aufgegriffen: dass Text- und Bildelemente des Titels auf Artikel und Reportagen im Inneren verweisen. Im Internet bekommt dieser Bezug durch die Hypertextstruktur eine neue Qualität und natürlich Quantität, die genutzt werden können. Zu erarbeiten wäre, welche Text- und Bildelemente des Covers in den verlinkten Texten wieder auftauchen und wie sie diskursiv verknüpft sind. Denn zwischen Cover und Innenteil bzw. zwischen online-Aufmacher und verlinktem Text besteht die didaktisch reizvolle Relation, dass das, was im Text-Bild-Gefüge nur angedeutet wird und sowohl Kohärenz als auch Kohäsion eher assoziativ und über das Layout erhält, im Textteil argumentativ entfaltet wird. Das Leseverstehen diskontinuierlicher Texte ließe sich so an das Leseverstehen kontinuierlicher Texte koppeln. Dadurch würden auch die Unterschiede in der Rezeption hervortreten. 


\section{Zusammenfassung und Ausblick}

Fassen wir an dieser Stelle zusammen, welche Arbeitsschritte des Phasenmodells zum Symbolverstehen wir bislang am Beispiel des „Spiegel“-Themas „Allah im Abendland“ skizziert haben. Im Vordergrund der Betrachtung standen die wichtigen Phasen zwei und drei: Fokussieren und Inferieren auf Textebene bzw. Bildebene, und Fokussieren/Inferieren auf der Ebene des Text-Bild-Gefüges unter Zuhilfenahme von Kontextwissen. Diese Phasen sind deswegen so wichtig, weil hier nach der ersten spontanen Rezeption die Weichen für eine umfassendere, tiefgreifendere Beschäftigung mit dem Format gestellt werden, sodass - in der Terminologie von Weidenmann - der Initialphase die didaktisch so bedeutsame Progressionsphase folgt. Sie ist gekennzeichnet durch „mehr perzipierte Bildaspekte“, eine „exhaustive Aktivierung von Wissensbeständen“ und eine „Vielfalt der involvierten psychischen Prozesse“ (Weidenmann 1988: 97). Ihr folgen, wenn eine gewisse Sättigung des Normalisierungsbedarfes erreicht ist, die Stabilisierungsphase und die Phase der Speicherung eines mentalen Modells. Im Gegensatz zum „bloBen“ Bildverstehen erfordert die Rezeption multimodaler Kommunikate dabei die Integration der verschiedenen Modi, wie sie oben skizziert worden sind.

Einige Hinweise zur Interpretation des Gesamtgefüges, welche auf der Basis der Fokussierungs- und Inferenzaktivitäten der vorangehenden Phasen erfolgt, haben wir bereits gegeben. Es geht um kollektive Identitäten vor der Folie von Alteritätskonstruktionen, die am Thema „Der Islam und die Deutschen“ illustriert werden. Dieses Thema wäre dann in einen größeren Rahmen zu stellen, um eine letzte Phase der Reflexion zu initiieren, welche das Titelcover mit anderen, thematisch verwandten Dokumenten in Beziehung setzt. Das könnten beispielsweise weitere „Spiegel“-Cover in Print- oder Onlineformat sein, die sich des Themas annehmen. Der Fundus dafür ist enorm. Nur einige wenige Beispiele für die Textelemente: „Saudi-Arabien. Alptraum aus 2001 Nacht“; „Das Übermorgenland. Goldrausch am Golf“; „Allahs rechtlose Töchter“; „Rätsel Islam. Weltmacht hinterm Schleier“. Vor allem der letzte Titel, welcher auf einer raffinierten Fotomontage beruht, die den Ausschnitt eines verschleierten Frauengesichtes zeigt, dessen Augenbraue die Form eines Krummsäbels hat, wäre unterrichtspraktisch sehr ergiebig. Er würde zeigen, dass journalistische Texte häufig mit Personifikationen, in diesem Falle Allegorien arbeiten. Er würde auch zeigen, dass dabei den Geschlechtern jeweils spezifische Funktionen zugeschrieben werden.

Die verschleierte Muslima scheint insbesondere „Spiegel“-Redakteure zu faszinieren. Dabei hat man in der kollektiven Wahrnehmung der „orientalischen“ Frau von der verführerischen Haremsdame, wie sie vor allem durch das 19. Jahrhundert spukt, auf die muslimische Frau in ihrer Opferrolle als Unterdrückte umgestellt. Fungiert der Schleier im 19. Jahrhundert als erotisches Versprechen, symbolisiert er heute fehlende Liberalität, ein archaisches Verhülltsein-Müssen. Interessant wäre auch, entsprechende Nachrichtenformate mit fiktionalen Genres zu vergleichen, etwa mit Romanen und (pseudo)biographischen Berichten, die Titel tragen wie 
„Gefangen in Deutschland“, „Die fremde Braut“, „Mein Leben zwischen Moschee und Minirock“, und in Kombination mit entsprechenden Bildelementen ganz ähnliche Inszenierungsstrategien aufweisen wie die Cover der Nachrichtenmagazine oder die Aufmacher der Internetdienste. Ergänzt werden könnten sie schließlich durch Werbung, Infografiken oder Cartoons zum Thema Islam, die ebenfalls zu den medial omnipräsenten Text-Bild-Gefügen zu zählen sind. In komparatistischer Hinsicht ließen sich weltweit zirkulierende Fotos als Ausgangspunkt für intra- und interkulturellen Vergleich nutzen. Welche unterschiedlichen Titel und Textergänzungen erhalten diese Bilder, und wie beeinflussen sie die Rezeption des Gesamtgefüges? Man könnte sich dabei auf deutschsprachige Medien beschränken, aber auch Webseiten aus den Herkunftsländern und -sprachen der DaF-Lerner einbeziehen. Dazu gehören alle Bilder von Ereignissen mit Weltrang, seien es politische Ereignisse, Sportveranstaltungen oder Gesellschaftliches wie eben die Wahl des neuen Papstes.

Diese letzte Phase multimodalen Verstehens legt eine Ausweitung des didaktisch-methodischen Horizontes nahe. Hier hätten nicht nur neuere Lernformen wie Portfolio-und Projektarbeit oder Medienlogbücher ihren Platz, hier wäre auch auf handlungs- und produktionsorientierte Aufgaben zurückzugreifen. Mittlerweile ist es unterrichtlich ohne Aufwand möglich, selbst Text-Bild-Kombinationen herzustellen und auszuprobieren, wie die beiden Symbolsysteme zusammenwirken. was also passiert, wenn man - wie in unserem Beispiel - den Begleittext zu den Moschee-Fotos ändert. In diesem Zusammenhang könnten Lerngruppen selbst auf fotografische Spurensuche gehen, mit dem Arbeitsauftrag, „den Islam“ in Deutschland räumlich-architektonisch festzuhalten, um Alternativen zum „Spiegel"'-Titel aufzuzeigen und somit andere Perspektiven anzubieten.

In unterrichtspraktischer Hinsicht könnten die skizzierten Phasen des Symbolverstehens in ein Aufgabenset eingebettet werden, wie es etwa Wolfgang Hallet (2012) im Bereich der Englisch-Didaktik für die komplexe Kompetenzaufgabe vorschlägt. Ziel aller unterrichtlichen Bemühungen muss dabei die Diskursfähigkeit der Lerner sein. In unserem Beispiel wäre dies eine bestimmte Form des Alteritätsdiskurses, welche die öffentlichen Debatten im deutschsprachigen Raum nicht erst seit den Mohammed-Karikaturen und Sarrazins Buch prägt.

Dazu bieten sich Text-Bild-Kombinationen, wie sie sich allerorts in neuen Medien finden, in besonderer Weise an. Sie ermöglichen, ja erfordern geradezu einen integrativen Zugang. Sprachliches, mediales und landeskundlich-kulturelles Lernen kommen hier zusammen. An den Textelementen kann detailliert mit Sprache gearbeitet werden: mit Begriffen, mit Satzstrukturen (vgl. die oft fehlenden Verben), mit Rhetorik, insbesondere mit Metaphern. Folgt man der Argumentation von Lakoff; Johnson (1997), so interessieren hier vor allem Metaphern als konzeptuelle Filter (Pielenz 1993: 100f.), welche unsere Blicke codieren. Konzeptuelle Metaphern, also Metaphern, die unser Sprechen, Denken und Handeln leiten, sind bekanntlich kulturgebunden, da die involvierten Konzepte ,in verschiedenen Kulturen höchst unterschiedliche Deutungen erfahren“ (ebd.: 107) können. Die Kom- 
bination von Text und Bild enthält in dieser Hinsicht großes (medien-)didaktisches Potential, insbesondere wenn man komplexere Formen miteinbezieht, die Ton und bewegte Bilder integrieren. So wäre zu untersuchen, ob und wie sprachlich-konzeptuelle Metaphern visuell aufgegriffen werden.

Schließlich eignen sich Text-Bild-Kombinationen für landeskundlich-kulturelles Lernen, weil an ihnen eine Fülle von Deutungsmustern, präsupponiertem und implizitem Wissen erarbeitet werden kann. Letztlich geht es um eine Didaktik der Bewusst- und Sichtbarmachung latenter, (bei Muttersprachlern) oft automatisierter Rezeptionsanforderungen, welche sich verstehenspsychologisch im Akt des Inferierens manifestieren. Man kann deshalb auch - ähnlich wie in der Geschichtsdidaktik - von inferenziellem Lernen (Lange 2011) sprechen. Diese Form der Rezeption lässt sich im Bild des archäologischen Arbeitens fassen. Es geht gleichsam darum, durch Tiefenbohrungen verschiedene Sinnschichten zu erschließen und freizulegen, die sich im Zusammenspiel von Bild und Text ablagern. Dass diese räumliche Metapher gerade im Internet ihre Berechtigung hat, betont Schmitz, wenn er auf die „Architektur semiotischer Angebote“ (Schmitz 2004b: 122) in neuen Medien hinweist. Die Text-Bild-Aufmacher dienen in ihrer Funktion als „Aufmerksamkeitsheischer“ (Schmitz 2004b: 123) gewissermaßen als Eingang zu einem komplexen Höhlensystem weiterer Informationen. Mit Genette könnte man auch von einer paratextuellen Schwelle sprechen, die überschritten wird und so Zugang zum eigentlichen Textraum ermöglicht.

In der pädagogischen Psychologie wird eben diese, eigentlich fachwissenschaftliche Überlegung aufgenommen und dezidiert didaktisch genutzt. Es geht dann darum, wie Schatzsucher Geschichten zu entdecken, die sich hinter der Oberfläche befinden und „heimliche Regeln oder implizite Wertvorstellungen“ (ReinmannRothmeier; Vohle 2002: 355) transportieren. In der sogenannten Historiker-Variante besteht die Herausforderung darin, Geschichten, die sich in der Tiefe befinden, ,anhand verschiedener Hinweise [zu] rekonstruieren“ (ebd.: 354).

Ganz ähnlich lässt sich mit visuellen Medien im fremd- und muttersprachlichen Unterricht arbeiten. Dabei bieten vor allem die neuen Medien erhebliches didaktisches Potential. Hinter den Text-Bild-Aufmachern befinden sich hypertextuell zumeist lineare Schriftdokumente, welche auf die ersteren bezogen werden können. Zu fragen wäre, wie das multimodale Kommunikationsangebot im linearen Text aufgenommen wird, welche Bezüge sich erkennen lassen und wie die logovisuelle Botschaft - in unserem Beispiel „Allah im Abendland“ - diskursivargumentativ enfaltet wird. Auf diese Weise käme es zu zwei verschiedenen, miteinander verschränkten Formen des deep reading. Seiner klassischen Form - das konzentrierte Lesen eines linearen Textes - würde eine zweite, neuere Form vorangehen, bei der deep eine bestimmte Weise des Verstehens multimodaler, diskontinuierlicher Kommunikate bedeutet, die im archäologischen Sinn in ihrer symbolischen Tiefe erschlossen werden. Dies betrifft vor allem die Tiefenstruktur von Analogien, die über das Zusammenspiel von Text und Bild erzeugt werden. Dergestalt könnten auch jene Formate einem deep reading unterzogen werden, die man 
gemeinhin flüchtig rezipiert und denen genau dies von kulturkritischen Stimmen vorgeworfen wird.

Dass eine Didaktik des Logovisuellen auch eine logovisuelle Didaktik sein kann (oder sollte?), legt gerade die Erschließung von Sprach- und Bildsymbolik nahe. Das komplexe Verweissystem innerhalb des Text-Bild-Gefüges lässt sich gewinnbringend mit Visualisierungen erarbeiten - was selbstredend auch den Lehrkräften bei der Vorbereitung dienlich sein kann. Ob dies nun in Form von Tabellen, Bild-mappings, Concept Maps, Symbolmatrices oder eher spielerisch in Form verschiedener „Grabungsschichten“ geschieht, muss im jeweiligen Lehr-/Lernkontext entschieden werden. Auf alle Fälle sind Visualisierungen ein wichtiger Schritt auf dem Weg zur Versprachlichung und überhaupt für das Verstehen multimodaler Kommunikate, insbesondere bei heterogenen Gruppen, die Differenzierung im Unterricht benötigen.

Ziel all dieser Arbeitsschritte ist die Ausbildung multimodaler Kompetenz, die auch für den muttersprachlichen Deutschunterricht postuliert wird. Als Teilbereich der Medienkompetenz, wie sie prominent von Baacke formuliert worden ist, umfasst sie visuelle, verbale und in manchen Fällen auch auditive Kompetenzen, welche sowohl die Produktion als auch die Rezeption entsprechender Kommunikate betreffen. Stöckl führt dafür fünf Komponenten an:

1. Sorten bzw. Typen von Bildern kategorisierend zu erkennen

2. dem Bild eine im Verwendungskontext relevante Bedeutung zuzuweisen

3. den Sprachtext im Abgleich mit der visuellen Botschaft zu verstehen

4. semantisierte Sprache und kontextualisiertes Bild zu integrieren

5. die Bildlichkeit der Sprache und der Textfläche bzw. des Schriftkörpers in den Prozess des Gesamtverstehens einzubeziehen (zitiert nach Müller 2012: 29)

Multimodale Kompetenzentwicklung ist mithin eine zentrale Voraussetzung für Symbolverstehen in Bezug auf bilddominierte Medien. Dieses Verstehen wiederum kann als Teil eines (inter-)kulturellen Lernprozesses aufgefasst werden, der zentral für den Fremdsprachenunterricht ist. Es gilt, so Altmayer in einem Aufsatz zur Didaktik kulturellen Lernens, „durch die Sichtbarmachung kultureller Deutungsmuster Deutsch als Fremdsprache-Lernern ein Potenzial an kulturellen Bezügen bereit zu stellen, das diese für ihren individuellen Verstehens- und Sinnbildungsprozess nutzen [...] können“" (Altmayer 2006: 57). Diese kulturellen Deutungsmuster aber manifestieren sich vor allem in neueren Medien in multimodaler, zumeist audiovisueller Form.

Auf dem Weg zu einer Didaktik multimodalen Lernens und Verstehens stehen wir erst am Anfang, dies darf als Konsens in der Forschung gelten. Nichtsdestotrotz gibt es vielversprechende Überlegungen, die bereits in didaktische Modelle und konkrete Vorschläge für die Unterrichtspraxis münden. Allerdings ist noch zu wenig bekannt, wie multimodale Rezeptionsprozesse tatsächlich ablaufen. Es bedarf erheblicher empirischer Anstrengungen, um dies herauszufinden, die aufge- 
stellten didaktischen Modelle zu überprüfen und gegebenenfalls zu modifizieren. In diese Richtung weist die interaktionale Rezeptionsforschung, welche bewährte qualitative und quantitative Verfahren um die Methode der Blickaufzeichnung ergänzt (vgl. Bucher; Schumacher 2012).

Sie betrifft Lernprozesse sowohl im Fremdsprachenunterricht als auch im Deutschunterricht, weil sie die Medienwelten, in denen sich insbesondere jüngere Lerner bewegen, ernst nimmt und zum Gegenstand der Rezeptionsforschung macht. Denn Text-Bild-Kombinationen sind in modernen Medien omnipräsent. So basieren etwa Formate des sogenannten social web fast ausschließlich auf TextBild-Kombinationen: Auf „Facebook“ werden Texte und Bilder zu einer oft kunstvollen Selbstinszenierung zusammengefügt, in Blogs ergänzen sich Texte und Bilder zu Essays, Berichten und Reflexionen, auf „Youtube“ werden bewegte, mit Ton unterlegte Bilder sprachlich kommentiert. Mit diesen Formaten sind viele Menschen mittlerweile weltweit vertraut. Sie betreffen fast alle Wissensgebiete, auch die der traditionellen Schul- und Hochschulfächer. Und so kommen die meisten Fachdidaktiken nicht umhin, sich visuellen Medien zuzuwenden. Wenn sie dabei gegenseitig ihre Forschungs- und Arbeitsergebnisse wahrnehmen und konstruktiv aufgreifen, dürfen wir mit lohnenden Ergebnissen rechnen.

\section{Literatur}

Altmayer, Claus (2006): „Kulturelle Deutungsmuster“ als Lerngegenstand. Zur kulturwissenschaftlichen Transformation der Landeskunde. In: FluL 35, 44-59.

Altmayer, Claus (2004): Kultur als Hypertext. München: Iudicium.

Bucher, Hans-Jürgen (2012): Multimodalität - ein universelles Merkmal der Medienkommuniaktion. Zum Verhältnis von Medienangebot und Medienrezeption. In: Bucher, Hans-Jürgen; Schumacher, Peter (Hrsg.): Interaktionale Rezeptionsforschung. Theorie und Methode der Blickaufzeichnung in der Medienforschung. Wiesbaden: Springer VS, 51-82.

Fuhs, Burkhard (2006): Narratives Bildverstehen. Plädoyer für die erzählende Dimension der Fotografie. In: Marotzki, Winfried; Niesyto, Horst (Hrsg.): Bildinterpretation und Bildverstehen. Methodische Ansätže aus sozialwissenschaftlicher, kunstund medienpädagogischer Perspektive. Wiesbaden: VS Verlag für Sozialwissenschaften, 207-226.

Hallet, Wolfgang (2012): Die komplexe Kompetenzaufgabe. Fremdsprachige Diskursfähigkeit als kulturelle Teilhabe und Unterrichtspraxis. In: Hallet, Wolfgang; Krämer,Ulrich (Hrsg.): Kompetenzaufgaben im Englischunterricht. Grundlagen und Unterrichtsbeispiele. Seelze: Klett Kallmeyer, 8-19.

Lakoff, George; Johnson, Mark (1997): Leben in Metaphern. Konstruktion und Gebrauch von Spracbbildern. Heidelberg: Carl-Auer-Verlag. 
Lange, Kristina (2011): Historisches Bildverstehen oder Wie lernen Schüler mit Bildquellen? Münster: LIT Verlag.

Lengelsen, Nils (2012): Text-Bild-Kommunikation in Zeitschriften. In: Bucher, Hans-Jürgen; Schumacher, Peter (Hrsg.): Interaktionale Rezeptionsforschung. Theorie und Methode der Blickaufzeichnung in der Medienforschung. Wiesbaden: Springer VS, 159-176.

Lischeid, Thomas (2012): Mediensymbolik und Diagrammatik. Multimodale Darstellungsformen am Beispiel der Infografik. Duisburg: Universitätsverlag Rhein-Ruhr.

Maiwald, Klaus (2005): Wahrnehmung-Sprache-Beobachtung. Eine Deutschdidaktik bilddominierter Medienangebote. München: Kopaed.

Müller, Christina Margrit (2012): Multimodalität und multimodale Kompetenz. Text-Bild-Kommunikate im Social Web. In: Der Deutschunterricht 64, 22-33.

Müller-Jacquier, Bernd (2008): Interkulturelle Kompetenz als Entschlüsselung von Zeichenbedeutungen. In: Der Deutschunterricht 60, 21-36.

Nückles, Matthias; Renkl, Alexander (2006): Lernstrategien der externen Visualisierung. In: Mandl, Heinz; Friedrich, Helmut Felix (Hrsg.): Handbuch Lernstrategien. Göttingen: Hogrefe.

Paul, Gerhard (2006): Visual history. Göttingen: Vandenhoek \& Ruprecht.

Pielenz, Michael (1993): Argumentation und Metapher. Tübingen: Gunter Narr.

Raith, Markus (2006): Bilder der Ferne - Europa und der Orient. In: Deutschunterricht 59, 10-14.

Raith, Markus (2007): „Sozusagen in der Fremde“ - Deutschdidaktik, Mediendidaktik und Deutsch als Fremdsprache. In: Jonas, Hartmut; Josting, Petra (Hrsg.): Jabrbuch Medien im Deutschunterricht 2006. München: Kopaed, 153-171.

Ranjakasoa, Andriatiana (2012): Theorie und Praxis symmedialen DaF-Literaturunterrichts am Beispiel der Auslandsgermanistik Madagaskars. In: Baum, Michael; Laudenberg, Beate (Hrsg.): Illustration und Paratext. Jahrbuch Medien im Deutschunterricht 2011. München: kopaed.

Reinmann-Rothmeier, Gabi; Vohle, Frank (2002): Pädagogisch-psychologische Ideen für die Repräsentation und Kommunikation von Wissen im Netz - ein narrativer Ansatz. In: Huber, Hans-Dieter; Lockemann, Bettina; Scheibel, Michael (Hrsg.): Bild-Wissen-Medien. Visuelle Kompetenz im Medienzeitalter. München: Kopaed, 337-362.

Rupp, Gerhard; Schreier, Margrit (2002): Ziele/Funktionen der Lesekompetenz im medialen Umbruch. In: Groeben, Norbert; Hurrelmann, Bettina (Hrsg.): Lesekompetenz: Bedingungen, Dimensionen, Funktionen. Weinheim: Juventa-Verlag, 251274. 
Sandbothe, Mike (1997): Interaktivität - Hypertextualität -Transversalität. Eine medienphilosophische Analyse des Internet. In: Münker, Stefan; Roesler, Alexander (Hrsg.), Mythos Internet. Frankfurt/Main: Suhrkamp, 56-82.

Sauer, Michael (2000): Bilder im Geschichtsunterricht. Seelze: Friedrich-Verlag.

Schmitz, Ulrich (2004a): Bildung für Bilder. Text-Bild-Lektüre im Deutschunterricht. In: Jonas, Hartmut; Josting, Petra (Hrsg.): Medien-Deutschunterricht-Ästhetik. Festschrift für Jutta Wermke). München: Kopaed, 219-232.

Schmitz, Ulrich (2004b): Das blaue Wunder. Text-Bild-Bezüge in alten und neuen Medien. In: Jonas, Hartmut; Josting, Petra (Hrsg.): Medien: Kritik und Sprache. Jabrbuch Medien im Deutschunterricht 2004. München: Kopaed, 117-126.

Schmitz, Ulrich (2004c): Sprache in modernen Medien. Berlin: E. Schmidt-Verlag.

Spinner, Helmut (2002): Ein Wort sagt mehr als tausend Bilder? Entwurf einer Wissenstheorie des Bildes. In: Huber, Hans-Dieter; Lockemann, Bettina; Scheibel, Michael (Hrsg.): Bild - Wissen - Medien. Visuelle Kompetenz im Medienzeitalter. München: Kopaed, 175-208.

Schnotz, Wolfgang; Stephan Dutke (2004): Kognitionspsychologische Grundlagen der Lesekompetenz: Mehrebenenverarbeitung anhand multipler Informationsquellen. In: Artelt, Cordula; Schiefele, Ulrich; Schneider, Wolfgang; Stanat, Petra (Hrsg): Struktur, Entwicklung und Förderung von Lesekompeten₹. Vertiefende Analysen im Rahmen von PISA 2000. Wiesbaden: VS Verlag für Sozialwissenschaften, 61-99.

Schnotz, Wolfgang (2009): Online-Lernen mit Texten und Bildern. In: Issing, Ludwig; Klimsa, Paul (Hrsg.): Online-Lernen. Stuttgart: Metzler, 88-103.

Weidenmann, Bernd (2009): Multimedia, Multicodierung und Multimodalität beim Online-Lernen. In: Issing, Ludwig; Klimsa, Paul (Hrsg.), Online-Lemen. Stuttgart: Metzler, 73-86.

Weidenmann, Bernd (1988): Psychische Prozesse beim Verstehen von Bildern. Bern: Verlag Hans Huber. 


\title{
Evaluationskriterien audio-visueller Verbundmedien für den DaF-/DaZ-Unterricht
}

\author{
Dorothea Spaniel-Weise
}

\section{Einleitung}

Lehrwerke haben in den letzten Jahren eine Expansion ihrer Komponenten erfahren. Neben klassischen Printtiteln wie Lehrbuch, Arbeitsbuch, Lehrerhandbuch und Glossar gehören heute auch multimediale Angebote wie online-Übungen, Lernsoftware, Lernplattformen, Whiteboardmaterialien, Apps und weitere webbasierte Tools dazu. Man spricht daher vom Lehrwerk im Medienverbund, wozu beispielweise beim Anfängerlehrwerk „studio d“ A1 insgesamt 14 Titel zählen. ${ }^{1}$ Eine Reihe der lehrwerkbegleitenden Zusatzmaterialien trainieren die Hörfertigkeit und das Hör-Sehverstehen. Während das Sehverstehen die „übersehene fünfte Fertigkeit“" (vgl. Schwerdtfeger 1989: 24) darstellt, erweitert das Hör-Seh-Verstehen das „klassische“ Konzept der Fertigkeiten Lesen, Hören, Sprechen, Schreiben um bildliche und audio-visuelle Zeichen (vgl. Biechele 2010a). Seine Schulung zielt im Fremdsprachenunterricht auf das mehrkanalige Erfassen von Kommunikationssituationen in ihrer Gesamtheit, d.h. das Verstehen verbaler, non-verbaler und extraverbaler Informationen und ihrer situations- und intentionsgerechten Interpretation (vgl. Biechele 2006: 109) ab. Die gestiegene Bedeutung der Hör-Seh-Fertigkeit zeigt sich in den Deskriptoren zur mündlichen Rezeption im Gemeinsamen Europäischen Referenzrahmen (vgl. Europarat 2001: 26).

\footnotetext{
1 Vgl. http://www.cornelsen.de/studio_d/1.c.2598975.de. Zur Unterscheidung Lehrwerk/Lehrbuch
} vgl. Neuner (2003). 
Lehrenden und Lernern stehen nun lehrwerkbegleitende ${ }^{2}$ Filmmaterialien zur Auswahl, die unterschiedliche filmische Textsorten bzw. Genres (z.B. Nachrichten, Werbefilme, Dokumentationen, Fernsehserien) beinhalten. Lehrwerkunabhängig finden sich zudem bei allen großen Verlagen für Deutsch als Fremdsprache ${ }^{3}$ „Leichte Lektüren“, d.h. an das Sprachniveau der Lerner angepasste Erzählungen, deren illustrierter Printausgabe eine Hör-CD beigefügt ist. Für diese Lesereihen stellt sich nun ebenso wie für Filme die Frage, wie die verschiedenen Präsentationsebenen, Lesetext, Hörfassung, (bewegte) Bilder miteinander verknüpft sind, um den Verstehensprozess der Rezipienten zu fördern.

Auf technischer Seite sind sowohl die Qualität des Ton-Bildmaterials gestiegen, als auch die Kosten für die Herstellung und Vervielfältigung von Datenträgern gesunken. So werden CDs bzw. DVDs für Lerner in vielen Fällen den Lehr- oder Arbeitsbüchern direkt beigelegt, und die mehrfarbige, visuelle Gestaltung von Printmaterialien hat zugenommen (vgl. Hallet 2008). Auf den Internetseiten der Verlage finden sich im Lehrwerkservice kostenlos didaktische Hinweise und Kommentare für Lehrende zur Arbeit mit den verschiedenen Medien. Das Vorhandensein dieser Zusatzmaterialien kann per se jedoch noch nicht als Qualitätskriterium für ein Lehrwerk gelten, wie Funk bereits 2005 (Funk 2005: 15) schreibt:

Die meisten Lehrwerke der deutschen Verlage haben sich auf den ersten Blick auf eine nie gekannte Weise angeglichen. [...] Fast alle kleben inzwischen CDs ins Buch und bieten Internetseiten an. Alle beziehen sich explizit auf die Niveaustufen des Europarats. Fast alle [...] bestellen ihre Bilder bei den gleichen Agenturen [...]

Trotz dieser Konvergenz unterscheiden sich einzelne Lehrwerktitel in Konzeption, technischer Umsetzung und didaktischen Hilfestellungen durchaus, sodass es für Lehrende nicht immer leicht ist, zu beurteilen, welche der zur Verfügung stehenden Komponenten eines Lehrwerkes für ihre Lerner und entsprechenden Lernziele des Kurses geeignet sind. Einige Kollegen kritisieren die unübersichtliche „Materialschwemme“ (Doff; Klippel 2007: 143) und befürchten sogar einen „Abarbeitungsdruck“ auf Seiten der Lehrkräfte (Thaler 2011: 22). Der Beitrag stellt daher einen praxisorientierten Kriterienkatalog vor, der die Wahl auditiver lehrwerksunabhängiger und audio-visueller lehrwerksbegleitender Materialien begründet ausfallen lässt. Dazu werden ausgewählte Verlagstitel einer kriteriengeleiteten Analyse unterzogen und bezüglich ihrer Einsatzmöglichkeiten im Fremdsprachenunterricht bewertet.

\footnotetext{
${ }^{2}$ Auch wenn die DVDs im Titel den Bezug zu einem bestimmten Lehrwerk herstellen, können sie in der Regel lehrwerksunabhängig eingesetzt werden.

${ }^{3}$ Die Langenscheidt KG verkaufte zum 1.1.2013 den Bereich „Erwachsenenbildung und Schule“ und damit auch die Lehrbuchproduktion an den Klett-Verlag (http://www.boersenblatt.net/556099/).
} 


\section{Zum Nutzen kriteriengeleiteter Lehrwerkanalyse}

Dem Lehrbuch als „Ankermedium“ (Funk 1999: 12) kommt im Medienverbund zur Strukturierung des Fremdsprachenunterrichts weiterhin eine wichtige Funktion zu (vgl. Schlegel 2003). Ohne eine „Lehrwerkskompetenz“ (vgl. Thaler 2011: 25) ist es jedoch oft schwierig, die Konzeption eines Lehrwerkes zu erkennen und hinsichtlich seiner Eignung für einen bestimmten Lernkontext zu bewerten. Dazu wäre eine zeitaufwändige Analyse des Materials anhand von Kriterien notwendig (vgl. Schmidt 1994: 400), die realistisch nur in Ausbildungs- oder Fortbildungskontexten erfolgen kann. Die Arbeit mit Kriterienkatalogen (vgl. Engel 1977; Barkowski 1980) erwies sich für viele Unterrichtende hingegen als wenig praktikabel, da die zu untersuchenden Merkmale sehr komplex waren. So umfasst z.B. das Mannheimer Gutachten (Engel et al. 1977) 14 Kriterien, die in bis zu 16 Unterkriterien aufgeteilt werden und Fragen enthalten wie: „Wird ausdrücklich auf bestimmte grammatische Theorien und Schulen Bezug genommen?" (6.4.3.) oder „Wird das hermeneutische Problem verdeutlicht?" (14.6.2.). Ergebnisse systematischer Lehrwerkanalysen finden wiederum nur selten ihren Niederschlag in Publikationen für eine breite Lehrerschaft, sieht man von Lehrwerksrezensionen in regelmäßig erscheinenden Organen, z.B. „Info DaF - Für Sie gelesen“ oder Unterrichtsportalen ab. ${ }^{4}$ Arbeiten zur Lehrwerksverwendung oder dem Einsatz von Verbundmaterialien sind kaum zu finden. Es verwundert daher nicht, dass Entscheidungsprozesse für die Lehrwerkauswahl häufig in Lehrerkollegien durch die „Daumenprobe“, d.h. einem kurzen Durchblättern „aus dem Bauch heraus“ (vgl. Funk 2005: 14) oder aufgrund von marktökonomischen und strategischen Gründen wie Preis, Bezugsbedingungen und Nutzerfreundlichkeit erfolgen.

Neben der schwierigen Entscheidung für oder gegen ein Lehrwerk liegt es oft in der Verantwortung der einzelnen Lehrperson festzulegen, inwieweit sie die zu einem Lehrwerk angebotenen Zusatzmaterialien in den Unterricht einbezieht. Audiovisuelle Lehrwerkkomponenten können häufig nicht vorab geprüft werden ${ }^{5}$ und stellen so eine Unsicherheit für die Kursplanung dar. Obgleich der regelmäßige Einsatz von Audio- und Videomaterial im Unterricht gewünscht wird, wie Umfragen unter Lehrenden und Lernern zeigen (vgl. Bohnensteffen 2011: 124, 126), ist ihre Verwendung nicht selbstverständlich. Eine hohe Nachfrage an aktuellen Hörund Filmmaterialien zeigen indes Nutzerzahlen für Audio- und Videodateien im Internet, wie es beispielsweise die Deutsche Welle für Deutschlehrende und -lernende zur Verfügung stellt. ${ }^{6}$ Aus spracherwerbstheoretischer Sicht sind audio-visuelle Verbundmaterialien nicht nur ein attraktives und effizientes Lernmedium (vgl. Biechele 2010b: 71), sondern bieten facettenreiche Einblicke in die Zielsprachen-

\footnotetext{
${ }^{4}$ Z.B. Deutschportal unter: https://www.deutsch-portal.com.

${ }^{5}$ Einige Verlage bieten auf ihren Internetseiten Demoversionen des Filmmaterials an, z.B. „studio d“ B2 unter: http://www.cornelsen.de/erw/reihe/1.c.3230034.de/titel/9783060201099.

${ }^{6} \mathrm{Vgl}$. http://www.dw.de/deutsch-lernen/deutsch-unterrichten/s-2233.
} 
kultur, die der Motivation der Lerner ebenso wie der Schulung kulturellen Bewusstseins dient.

Für eine begründete Wahl fehlt es Lehrenden jedoch an Bewertungskriterien für auditive bzw. audio-visuelle Materialien sowie Unterrichtsvorschlägen. ${ }^{7}$ Wichtige Fragen lauten daher aus Lehrerperspektive (vgl. Börner et al. 2011: 41):

- Wie didaktisch sinnvoll sind die unterschiedlichen medialen Angebote miteinander verknüpft und ergänzen sich gegenseitig?

- Wie leicht lassen sie sich in den Unterricht integrieren?

- Welche Lernaufgaben begleiten den Medieneinsatz?

Um diese Fragen beantworten zu können, erscheint die Arbeit mit einem praxisnahen Kriterienkatalog als Bewertungsgrundlage sinnvoll. Eine letzte umfassende Dokumentation zur Lehrwerkanalyse erfolgte 1994 in der Herausgeberschaft von Bernd Kast und Gerhard Neuner. Die Beurteilung der Hörseh-Materialien blieb zu diesem Zeitpunkt jedoch größtenteils ausgespart bzw. auf die Frage, wie gut Visualisierung generell gelungen sei, beschränkt (vgl. Neuner 1994: 118). Fast 10 Jahre später entstand als Ergebnis des EU-Projektes zur Qualitätssicherung von Unterricht ein Qualitätsleitfaden zur Bewertung und Entwicklung von Programmen und Materialien zum Sprachenlernen und -lehren (vgl. Lasnier et al. 2003). Lehrende und Lehrwerkautoren können damit die Qualität eines Titels mit Hilfe von Indikatoren bewerten. Erstmalig wurden Indikatoren für die technische Qualität audiovisuellen Materials, z.B. Studioqualität der Audio- bzw. Videoaufnahme oder schauspielerische Darstellung, detailliert in die Raster aufgenommen. Die einzelnen Items sind jedoch noch immer sehr umfangreich beschrieben. Der langsame Bearbeitungsmodus der CD-ROM führt zudem dazu, dass Lehrende aus Zeitgründen nicht vollständig damit arbeiten werden. Einen praxisorientierten Kriterienkatalog für Kursleitende entwickelte Hermann Funk, indem er 12 Qualitätsbereiche beschreibt, zu denen u.a. die mediale Ausstattung und mediendidaktische Konzeption (Funk 2004: 44 bzw. 2005: 21) des Lehrwerkverbundes gehört. Fragen in diesem Qualitätsbereich (Q1) sind:

- Gibt es mehrere CDs pro Lehrbuchband?

- Sind die CDs für Lerner verfügbar?

- Gibt es eine Internetseite zum Lehrwerk mit online-Übungen, didaktischen Tipps und integrierte Verweise im Kurs- und Lehrerhandbuch?

- Gibt es eine CD-ROM?

- Wird die mediendidaktische Konzeption im Lehrerhandbuch beschrieben?

\footnotetext{
7 Mitarbeiter der Arbeitsstelle für Lehrwerkforschung und Materialentwicklung an der FSU Jena (http://www.alm.uni-jena.de/) entwickeln in Zusammenarbeit mit dem Fraunhofer-Institut Erfurt zur Zeit einen Kriterienkatalog zur Bewertung von E-Books und Whiteboardmaterialien.
} 
Entscheidendes Merkmal des Katalogs ist seine explizite Offenheit als „zu ergänzendes Arbeitsinstrument, als Strukturierungshilfe kollegialer Diskussion [...], nicht als Normvorgabe“ durch die Gewichtung der einzelnen Merkmale (,wie wichtig für mich“) (Funk 2004: 44). Schließlich erschien 2012 eine Publikation des GoetheInstitutes (vgl. Buhlmann 2012), in der Kriterienraster zu Fortbildungszwecken vorgestellt werden. Trotz der fundierten Zusammenstellung bleiben die Items zur Beurteilung auditiver bzw. audio-visueller Zusatzmaterialien auf deren Vorhandensein reduziert. Daher stellt sich die Frage, wie die Bewertung audio-visueller Verbundmaterialien erfolgen kann.

\section{Zur Analyse auditiver und audio-visueller Zusatzmaterialien}

Zur Beantwortung obiger Frage wurde im Rahmen eines Seminars im Masterstudiengang Deutsch als Fremd- und Zweitsprache an der Friedrich-Schiller-Universität Jena ein Kriterienkatalog entwickelt. Dieser beinhaltete zum einen allgemeine Kriterien zur medialen Ausstattung von Lehrwerken und zum anderen konkrete Kriterien zur Analyse von Hör- bzw. Hörsehverstehensmaterialien. Hierfür konnte sich an Kriterien zur Bewertung von Hörmaterialien von Solmecke orientiert werden (Solmecke 2000, vgl. Tab. 1).

Untersucht wurden Lesereihen mit Hör-CD, die Lernern als Selbstlernmaterial dienen und zum anderen lehrwerksbegleitende Filmmaterialien, die als DVD Lehrwerken beigelegt oder einzeln erworben werden können. Nicht in die Analyse gehen Tipps zur Arbeit mit Spielfilmen ein, wie man sie beispielsweise für die Lehrwerkreihe em oder studio $d$ schon länger finden kann (siehe dazu den Beitrag von Hahn in diesem Band). Stattdessen stehen speziell zu Lehrwerken entwickelte Filme, die in den 2000er Jahren eine neue Tendenz in der Lehrwerkproduktion darstellten (vgl. Sass 2007: 7), im Zentrum der Überlegungen. Im Folgenden sollen ausgewählte Ergebnisse zur Diskussion gestellt werden.

\begin{tabular}{|l|l|l|l|l|l|l|}
\hline \multicolumn{7}{|c|}{ Textschwierigkeit } \\
\hline & $\leftarrow$ eher leicht & \multicolumn{3}{|l|}{ eher schwierig $\rightarrow$} \\
\hline Akustische Komponente & & 1 & 2 & 3 & 4 & \\
\hline Störgeräusche & leise & & & & & laut \\
\hline Raumakustik & gut & & & & & schlecht \\
\hline Aufnahmequalität & gut & & & & & schlecht \\
\hline Sprechgeschwindigkeit & langsam & & & & & schnell \\
\hline
\end{tabular}




\begin{tabular}{|l|l|l|l|l|l|l|}
\hline Artikulaion & deutlich & & & & & undeutlich \\
\hline Intonation & gliedernd & & & & & monoton \\
\hline Pausen zwischen Sätzen und Satzteilen & eher länger & & & & & eher kürzer \\
\hline Dialekt-, Regiolekt-, Soziolektfärbung & keine & & & & & stark \\
\hline Sonstige Abweichungen vom Standard & keine & & & & & starke \\
\hline Zahl der Sprecher/innen & eine/r & & & & & mehrere \\
\hline Unterscheidbarkeit der Dialogstimmen & problemlos & & & & & schlecht \\
\hline Sprecherwechsel überlappend & nie & & & & & häufig \\
\hline Zwischenrufe/sonst. Unterbrechungen & nie & & & & & häufig \\
\hline Präsentationshäufigkeit & mehrmals & & & & & einmal \\
\hline
\end{tabular}

Tab. 1 Kriterien zur Beurteilung der Schwierigkeit von Hörtexten (Solmecke 2000).

\subsection{Zur Analyse lehrwerksunabhängiger Materialien: Lernkrimis}

Kriminalliteratur gehört zu den populärsten Literaturformen, die eine breite gesellschaftliche Leserschaft bindet und in medial unterschiedlichen Umsetzungen als Buchtitel, Hörspiel und Film präsentiert werden. Ihr Aufbau folgt meist einem festen Schema aus dem Mord als zentralem Ereignis, der Fahndung und schließlich der Aufklärung und Überführung des Täters. Falsche Spuren verhindern das frühzeitige Lösen des Falls und regen zu ständiger Hypothesenbildung über Motiv und Täter an. Dieser hypothesengeleitete Rezeptionsprozess eignet sich besonders für den Fremdsprachenunterricht, da „Spannung ein tragendes Element“ für die Aufmerksamkeit des Lerners ist (vgl. Schmidt 1993: 665) und einen hohen Motivationsfaktor darstellt. Unter dem Begriff „Lern-Krimi“ sind kriminalistische Lesereihen fester Bestandteil aller DaF-Verlagsprogramme. Durch das Beilegen einer Hör-CD soll neben Lesen auch die Fertigkeit Hören trainiert werden. Auf niedrigen Sprachniveaus wird zur Unterstützung des Verstehensprozesses mit Bildelementen (Illustrationen, Fotos) gearbeitet. Nachfolgend werden ausgewählte Reihen der Verlage in Bezug auf die Integration von textuellen, visuellen und auditiven Informationen sowie Aufgaben und Übungen analysiert. Damit können Lehrende ihre Eignung für den Unterricht bzw. als Selbstlernmaterial beurteilen. 
Die im Klett-Verlag erscheinende Hörkrimi-Reihe „Tatort DaF“ spricht erwachsene Lerner an. ${ }^{8}$ Sie fokussiert neben der kriminalistischen Handlung landeskundliche Themen, da jeder Krimi in einer anderen deutschen oder österreichischen Stadt spielt und diese mit ihren Sehenswürdigkeiten, „Spezialitäten und Dialekten“ vorgestellt wird (vgl. Verlagskatalog 2013: 46). Das Sprachniveau A2/B19 könnte aufgrund der dialektalen Äußerungen der Personen eher B1 sein. Einfacher Wortschatz, kurze Sätze und die Verwendung der Zeitformen Präsens und Perfekt sichern das Verständnis auf A2-Niveau. Aufgaben und Übungen werden vor und nach der Präsentation des eigentlichen Lesetextes angeboten und der Lesetext selbst mit textuellen und graphischen Verstehenshilfen versehen:

- vor der Präsentation des Lesetextes:

- geographische Einordung der Handlungsortes (Landkarte, Stadtplan)

- Vorstellung der handelnden Personen als Kurzporträt auf der Einstiegsseite

- Lesetext:

○ bildunterstützte Texte (Zeichnungen und landeskundliche Fotos)

$\circ \quad$ einsprachige Worterklärungen am jeweiligen Seitenende

- bei dialektalen Äußerungen hochdeutsches Äquivalent am Seitenende, z.B. „Guggesegleischmol. Fehld was?“ (Wülfing 2011: 17)

- tabellarische Zusammenstellung von Regionalismen „So sagt man in..." am Textende

- nach dem Lesetext:

○ Übungen zum Lesetext kapitelweise bzw. zum Gesamttext

○ Übungen zur Verstehenskontrolle am Ende des Buches mit Lösungsschlüssel

○ überwiegend geschlossene Aufgaben wie Multiple Choice, richtig/falsch, Zuordnungs- und Ergänzungsübungen

○ Übungen zur Sprachproduktion, z.B. „Beschreiben Sie und zeichnen Sie seinen Weg.“ (Baier 2007: 44)

○ offene Schreibaufgaben mit vorgegebenen Leerzeilen, z.B. „Was denken Sie?“ (Wülfing 2011: 44); „Gibt es bei Festen in Ihrer Heimat auch ein besonderes Essen? Welches?" (Dittrich 2007b: 42)

- Verweis auf Internetrecherchen „Suchen Sie im Internet etwas über die Loreley! Können Sie sich das Lied auch anhören?“ (Dittrich 2007: 44)

Die beigelegte Hör-CD enthält den kompletten Text, der von einem Sprecher bzw. einer Sprecherin gelesen wird, auch wenn die handelnden Personen unterschiedlichen Geschlechts sind. Durch den Lösungsschlüssel sind die Titel als Selbstlern-

8 Alle Lektüren im Überblick unter: http://www.lektueren.com/deutsch-als-fremdsprache/reihen.html.

${ }^{9}$ Die problematische Doppelkennzeichnung der Sprachniveaus findet sich häufig. 
material für Lerner geeignet, die offenen Übungen zur Sprachproduktion (mündlich und schriftlich) erfordern in der Regel jedoch die Auswertung im Unterricht. Aufgaben, die Lernende in kooperativen Sozialformen (vgl. Brüning; Saum 2006) lösen können, fehlen.

Im Mittelpunkt der Krimi-Reihe „lex:tra“ des Cornelsen-Verlages steht der Privatdetektiv Patrick Reich, der seine Fälle in Kassel löst. Das ausgewiesene Sprachniveau ist A2/B1. Die Lernkrimis stehen als mobiles App ${ }^{10}$ mit Übungen, Hyperlinks zu Vokabelerklärungen oder landeskundlichen Inhalten zur Verfügung. Die zweite Krimi-Reihe „SIRIUS ermittelt“ ist laut Verlag bereits auf Niveau A1/A2 einsetzbar. Die Niveauunterscheidung wird über verstärkte Visualisierungen, die die Kernaussagen der Handlung zusammenfassen, erzielt. Die beiden Detektive Elisabeth Aumann und Markus Berg von der Detektei SIRIUS lösen ihre Fälle in unterschiedlichen Städten Deutschlands, Österreichs und der Schweiz. Die Lernkrimis enthalten neben den Illustrationen, Worterklärungen, Fragen und Aufgaben mit Lösungen eine Doppelseite mit landeskundlichen Informationen und Bildern. Die beigelegte Hör-CD enthält bei beiden Reihen den kompletten von einem Sprecher bzw. einer Sprecherin gelesenen Text. Die Sprechgeschwindigkeit ist bei den Krimis auf A2/B1-Niveau erhöht. Eine weitere Differenzierung des Schwierigkeitsgrades (z.B. durch dialektale Äußerungen oder Hintergrundgeräusche) erfolgt nicht. Verstehenshilfen sind hier:

- vor der Präsentation des Lesetextes:

- geographische Einordung der Handlungsortes (Landkarte, Stadtplan)

- Vorstellung der handelnden Personen als Kurzporträt auf der Einstiegsseite

- Lesetext:

○ bildunterstützte Texte (in den Fließtext integrierte farbige Illustrationen)

$\circ$ einsprachige Worterklärungen am jeweiligen Seitenende

○ zahlreiche idiomatische Wendungen, z.B. ,gute Miene zum bösen Spiel machen“, „ein Licht aufgehen“ (Borbein; Lohéac-Wieders 2008: 20f.)

○ Verweise auf weiterführende Internetseiten zu landeskundlichen Informationen (in der Regel Wikipedia), z.B. zum Badeort Binz auf der Insel Rügen; dem Maler Caspar David Friedrich (Borbein; Lohéac-Wieders 2008: 26)

- nach dem Lesetext:

- kapitelweise Übungen zum Lesetext

- Übungen zur Lenkung des Rezeptionsprozesses (die Reihe auf Sprachniveau A1/A2)

10 Http://www.cornelsen.de/mobil/1.c.2266116.de; zu Deutschlern-Apps vgl. den Beitrag von Christian Müller und Ralph Olsen im vorliegenden Band. 
○ Übungen zur Verstehenskontrolle am Ende des Buches mit Lösungsschlüssel

○ überwiegend geschlossene Aufgaben, z.T. in Rätselform (z.B. in Borbein; Lohéac-Wieders 2008: 46)

- Übungen zur Sprachproduktion (Beantwortung von Fragen)

O offene Aufgabenstellung: Planung einer Stadtrundfahrt durch Berlin (z.B. in Dittrich 2011)

Der Langenscheidt-Verlag bietet Kriminalliteratur für Jugendliche und erwachsene Lerner getrennt an. Die Krimi-Reihen für Jugendliche heißen „Klara \& Theo“ bzw. „Leo \& Co.“ (Jugendliche und Erwachsene) sowie „Felix \& Theo“ für alle Altersstufen, wobei letztere um die zentrale Figur des Privatdetektivs Helmut Müller aufgebaut ist. ${ }^{11}$ Im Anhang des Leseheftes befinden sich wenige Übungen und landeskundliche Anmerkungen. Die Ausgaben mit beigelegter Mini-CD enthalten eine leicht gekürzte Hörfassung des Lesetexts. Zu den Lektüre-Reihen „Leo \& Co.“ sowie „Felix \& Theo“ werden Lösungsvorschläge im Unterrichtsportal des Verlags online angeboten. ${ }^{12}$ Verstehenshilfen sind:

- vor der Präsentation des Lesetextes:

○ Vorstellung der Hauptpersonen ohne Fotos

- Lesetext:

○ bildunterstützte Texte (Zeichnungen und Illustrationen) ohne Worterklärungen

- $\quad$ nach dem Lesetext:

○ unter der Überschrift „landeskundliche Anmerkungen“ sprachliche Hinweise, jedoch eher als Glossar, z.B. „Kap Arkona, klauen = stehlen“ („Ein Fall auf Rügen“ 2003: 39)

○ geschlossene Aufgaben im Testformat

- produktive Aufgaben, z.B. einen Antwortbrief schreiben („Ebbe \& Flut“ 2005: 37); Telefongespräch („Berliner Pokalfieber“ 2005: 38)

- Sprechgeschwindigkeit auf der Hör-CD hoch

Der Hueber-Verlag bietet als Lektürereihen ${ }^{13}$ für Jugendliche vereinfachte Belletristik, sogenannte ,leichte Literatur“ und „Lese-Novelas“ an. ${ }^{14}$ Letztere orientieren sich an Tele-Novelas, d.h. TV-Serien, und zeichnen sich durch die Verwen-

\footnotetext{
${ }^{11} \mathrm{Http}: / /$ www.klett-langenscheidt.de/Lesen_und_Schreiben/Deutsch_als_Fremdsprache/9359.

12 Http://www.klett-langenscheidt.de/Zusatzmaterialien/Arbeitsmaterialien_zu_den_Lektueren/Lek tueren_Leo_und_Co/9985.

13 Alle Reihen sind als kostenpflichtiger Download im PDF oder MP3-Format erhältlich, zudem gibt es ein online-Rätsel „,5x5 Die Deutschdetektive“ unter: http://www.hueber.de/deutsch-als-fremdsprache/detektive

14 „Lesespaß, der nicht durch Didaktisierung gedämpft wird“ (vgl. http://shop-hu.hueber.de/hu/ reihen-und-lehrwerke/hueber-lese-novelas.html). Didaktisierungsvorschläge finden sich bspw. auf den Seiten des Goethe-Institutes, z.B. unter: http://www.goethe.de/ins/kz/alm/bib/lew/tit/abf/ de9114620.htm.
} 
dung von Jugendsprache und Anglizismen aus. Für erwachsene Lerner gibt es die Reihe „Krimis mit Carsten Tsara“, einem Privatdetektiv aus München. Jedes Krimiheft enthält im Anhang einsprachige Worterklärungen und Übungen zum Leseverstehen. Die Lesehefte mit beigelegter Audio-CD enthalten die komplette, von einem Sprecher gelesene Hörfassung. Vor der Präsentation des Lesetextes werden keine vorentlastenden Übungen angeboten. Hilfestellungen zum Text sind:

- Lesetext:

$\circ$ kapitelweise Worterklärungen im Anhang mit Kennzeichnung von umgangssprachlichen Varianten und idiomatischen Redewendungen, z.B. „die Ziege = hier: dumme Frau“, „Sie kann mich mal!“ (Specht 2002: 36)

○ Dialoge in mündlicher Form bzw. Umgangssprache transkribiert (,hab"“; ,nee du“; ,',ne Antwort")

○ Zeilennummerierung des Lesetextes

$\circ$ nur wenige Illustrationen

- Nach dem Lesetext:

- kapitelweise Aufgaben zum Lesetext überwiegend als geschlossene Übungen

○ offene Aufgabenstellung: „Was wäre passiert, wenn...“ (In: Specht 2002: 51)

Zusammenfassend sind folgende Fragen zur Materialanalyse zu beantworten:

1. Für welche Zielgruppe ist der Titel ausgewiesen? Ist die Zielgruppe (jugendliche/erwachsene Lerner) angemessen in der Thematik/den handelnden Personen/im Register vertreten?

2. Für welches Sprachniveau ist der Titel ausgewiesen? Ist das Niveau angemessen?

3. Enthält das Hörmaterial den gesamten Text oder Auszüge? Ist der Schwierigkeitsgrad des Hörmaterials angemessen (vgl. Tab. 1)?

4. Gibt es im Buch Lesehilfen zum Textverständnis und sprachliche Hilfestellungen (Visualisierungshilfen, Glossar, Vokabellisten) für die Lernenden?

5. Wie werden landeskundliche Erläuterungen für die Lernenden gegeben (Visualisierungshilfen, weiterführende Links im Internet)?

6. Eignet sich das Buch als Selbstlernmaterial (Lösungsschlüssel)?

7. Gibt es im Buch Didaktisierungshinweise für die Lehrenden (Aufgaben/Übungen vor, während und nach dem Lesen des Textes, landeskundliche Hinweise, weiterführende Links)?

8. Gibt es Zusatzmaterial zum Einsatz der Lektüre im Unterricht (z.B. Arbeitsblätter, Rätsel- bzw. Quizfragen, Testaufgaben zum Leseverstehen)? 
9. Gibt es Aufgaben zur Sicherung des Leseverständnisses nach jedem Kapitel und zum gesamten Lesetext? Gibt es Hörverstehensaufgaben zur Audio-CD?

10. Sind die Aufgaben und Übungen eher rezeptiv oder dienen sie auch als Anregung für Sprachproduktion (offene Aufgabenstellungen als Sprechund Schreibanlass)? Sind die Aufgaben auch für die Arbeit in kooperativen Sozialformen (Partner- und Gruppenarbeit) für den Unterricht geeignet?

Für die Mehrheit der Materialien sind weitere Aufgaben und Übungen notwendig. Das bezieht sich vor allem auf die Erweiterung um offene Aufgaben und Übungen, sowie Aufgaben, die die Interaktion zwischen den Lernern im Fremdsprachenunterricht fördern. Außerdem müssen in der Regel Aufgaben und Übungen zur Arbeit mit dem Hörtext ergänzt werden. Es ist offensichtlich, dass die Hörfassung erst später der Textfassung beigelegt wurde.

Wie verschieden kodierte Texte sinnvoll in den Unterricht integriert werden können und sich als Selbstlernmaterial eignen, zeigt das Material „Das Glückskind und andere Geschichten - Deutsch lernen mit der Geschichtenerzählerin“" (Gerndt 2007). Dieses enthält märchenhafte Geschichten, die auf der beigelegten CD gehört werden können. Nach jeder Kurzgeschichte gibt es im Buch Aufgaben zum detaillierten Hörverstehen, Grammatikübungen, Aufgaben für die Lösung in Partner- und Gruppenarbeit (z.B. freie Diskussion) sowie landeskundliche Informationen zur Vertiefung, z.B. Märchenwissen. Der Lesetext ist durch Zeilennummerierung strukturiert, Worterklärungen in einem Wörterkasten am Ende des Textes und Bildleisten erleichtern das Textverständnis. Im Anhang befindet sich ein Lösungsschlüssel mit Vorschlägen für die offenen Fragen, sodass das Material auch im Selbststudium bearbeitet werden kann. Die Hörgeschichten werden mit unterschiedlichen Sprechern gelesen. Damit erfüllt das Buch die oben aufgeführten Kriterien und macht deutlich, dass die Arbeit mit Lese-Hör-Geschichten nicht nur die Wiedergabe eines Lesetextes auf CD sein kann, sondern dem didaktischen Mehrwert der Mehrkanaligkeit für den Lernprozess Rechnung getragen werden muss. Ein Bewertungsbogen für eigene Analysen könnte wie folgt aussehen:

\begin{tabular}{|l|l|l|l|}
\hline A. Qualitätsmerkmal & $\begin{array}{c}\text { ja/vor- } \\
\text { handen }\end{array}$ & $\begin{array}{c}\text { nein/nicht } \\
\text { vorhanden }\end{array}$ & $\begin{array}{c}\text { wichtig für } \\
\text { mich } \\
\text { (Skala 1-5) }\end{array}$ \\
\hline beigelegte CD für Lerner & & & \\
\hline $\begin{array}{l}\text { Internetseite zum Material oder } \\
\text { Vorwort mit: } \\
\text { transparenter Darstellung der } \\
\text { Konzeption } \\
\text { Orientierung am GER }\end{array}$ & & & \\
\hline
\end{tabular}




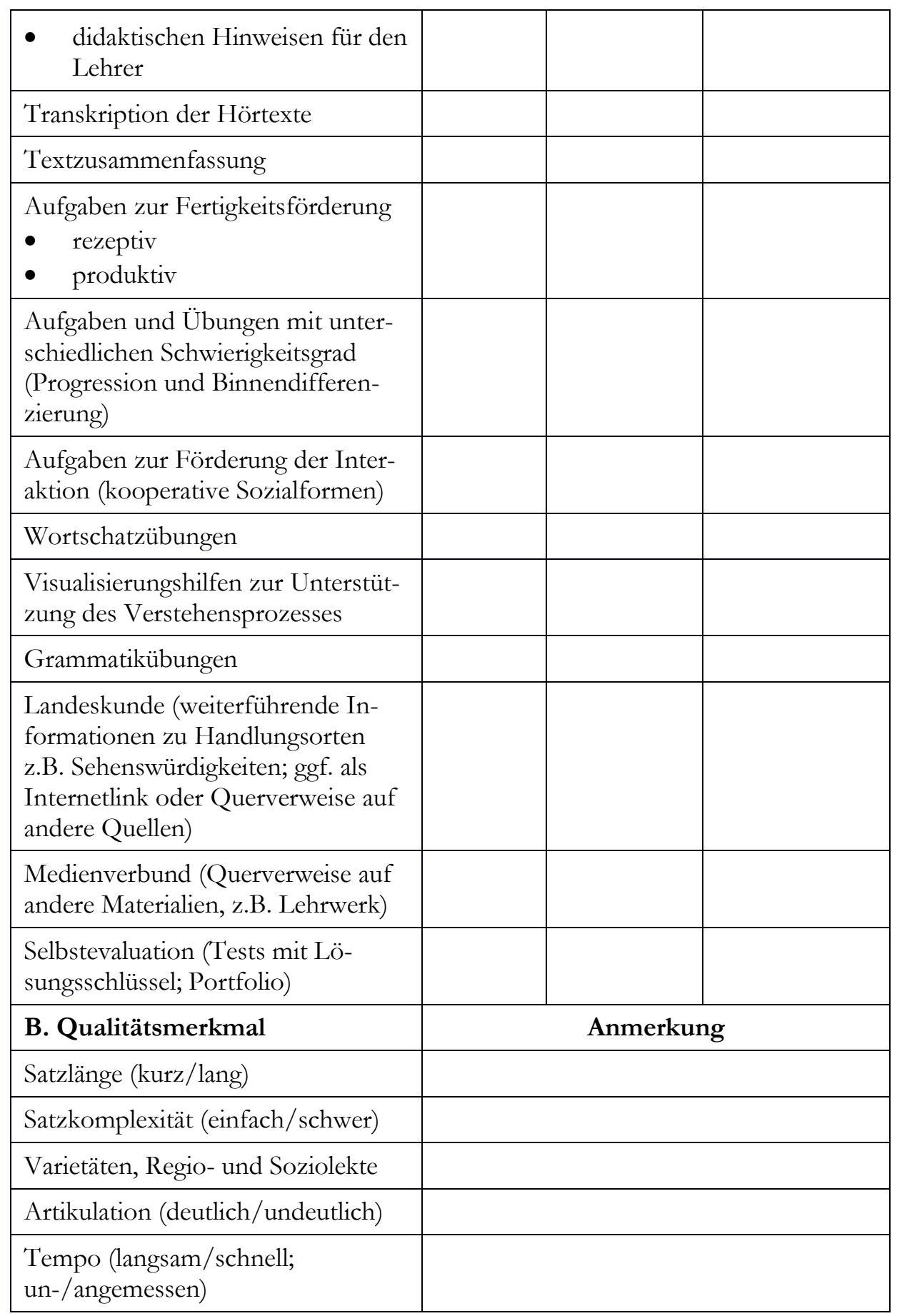




\begin{tabular}{|l|l|}
\hline Pausen & \\
\hline Zahl der Sprecher & \\
\hline Unterscheidbarkeit der Sprecher & \\
\hline Hintergrundgeräusche & \\
\hline C. Zusätzliche Anmerkungen & \\
\hline
\end{tabular}

\section{Zur Analyse lehrwerksbegleitender Materialien: audio-visuelle Komponenten}

Nach Vorstellung von Kriterienkatalogen zu auditiven Materialien soll im folgenden Lehrmaterial aus dem audio-visuellen Bereich analysiert werden. Der Gemeinsame Europäische Referenzrahmen weist unter audio-visueller Rezeption explizit den Punkt „Fernsehsendungen und Filme verstehen“ aus, bei denen auf den einzelnen Sprachniveaus folgende Verstehensleistung gefordert wird (Europarat 2001: 77):

A2+: Kann Hauptinformationen von Fernsehmeldungen über Ereignisse, Unglücksfälle usw. erfassen, wenn der Kommentar durch das Bild gestützt wird.

B1: Kann vielen Filmen folgen, deren Handlung im Wesentlichen durch Bildung und Aktion getragen wird und deren Sprache klar und unkompliziert ist.

B2: $\quad$ Kann Fernsehreportagen, Live-Interviews, Talk-Shows, Fernsehspiele sowie die meisten Filme verstehen, sofern Standardsprache gesprochen wird.

B2+: Kann im Fernsehen die meisten Nachrichtensendungen und Reportagen verstehen.

C1: Kann Spielfilme verstehen, auch wenn viel saloppe Umgangssprache und Gruppensprache und viel idiomatischer Sprachgebrauch darin vorkommen.

Die Kann-Beschreibungen machen deutlich, welche Kriterien in Hinblick auf die Eignung für ein bestimmtes Sprachniveau von Bedeutung sind: einfache Sätze, Standardsprache, Bild-Text-Korrespondenz, thematische Anknüpfung an das Weltwissen der Lerner. Für Lehrende stellt sich bei der Auswahl eines Lehrwerkes die Frage, inwieweit Filme das Hör-Seh-Verstehen entsprechend obigen Zielstellungen trainieren. Der Vorteil lehrwerksbegleitender Materialien liegt dabei trotz der großen Auswahl an Sendungen, die als Podcast von deutschen Rundfunksendern und Fernsehanstalten online zur Verfügung stehen, auf der Hand: 
- die Inbalte sind in der Regel auf die im Lehrbuch behandelten Themen abgestimmt und können somit ohne Schwierigkeiten in den Kursablauf integriert werden

- das Sprachniveau, das zur Bewältigung der Aufgaben notwendig ist, ist auf das Sprachniveau der Lerner abgestimmt, auch wenn authentisches Material verwendet wird

- unbekannter Wortschatz wird vorentlastet, bekannte Lexik wiederholt

- grammatische Strukturen werden erarbeitet, wiederholt und vertieft

- für Lehrende stehen didaktische Hinweise und Kommentare (z.B. zur Landeskunde) zur Verfügung

Bei näherer Untersuchung auf dem Markt befindlicher Lehrwerke fällt das unterschiedliche Vorgehen bei der Integration der audio-visuellen Begleitmaterialien, der technischen Umsetzung und den angebotenen Didaktisierungshinweisen auf. Im Folgenden soll ein vergleichender Überblick gegeben werden, wobei sich wiederum an einem Kriterienkatalog orientiert wird. Dieser enthält die Bewertung anhand von Leitfragen in drei Analyseschritten. In einem ersten Scbritt erfolgt die Beurteilung des Materials in Bezug auf die Ton- und Bildspur (Qualität des Materials). In einem zweiten Analyseschritt wird untersucht, welche Hilfestellungen zur Integration des Materials in den Unterricht für Lehrende (Didaktisierungen) angeboten werden. Im letzten Analyseschritt erfolgt die Bewertung aus Lernerperspektive in Bezug auf die Polysensorik, d.h. die multikodale, graphisch-akustische Präsentation des Lerngegenstands.

\section{Fragen an das lehrwerksbegleitende audio-visuelle Material}

1. Qualität des Filmmaterials

a. Ist die Installation des Datenträgers und die Navigation benutzerfreundlich?

b. Entspricht die ikonische und technische Präsentation der Inhalte den Vorkenntnissen und dem Anspruchsniveau des Benutzers (Studioqualität der Ton- und Videoaufnahmen, schauspielerische Darstellung der Handlungsträger)?

c. Wie ist die Tonspur des Materials in Bezug auf den Schwierigkeitsgrad zu bewerten (vgl. Schwierigkeiten beim Hörverstehen im vorangegangenen Kapitel)?

d. Entspricht das Sprachniveau zur Bewältigung der Aufgabenstellungen dem Niveau der Lerner, für das es ausgewiesen wird (Sprechgeschwindigkeit, Soziolekte)?

e. Welchen didaktischen Mehrwert hat das Bildmaterial gegenüber einer Hörfassung (z.B. Authentizität der dargestellten Kultur, Zusatzinformationen, z.B. Handlungsort)? 
2. Didaktisierungshilfen für den Lehrenden

a. Wo befinden sich Informationen zur Konzeption des audio-visuellen Begleitmaterials (direkt auf der DVD, im Lehrwerkservice im Internet, Lehrerhandreichung)?

b. Gibt es Didaktisierungshinweise (Aufgaben/Übungen mit Lösungen)? Gibt es Querverweise im Lehrbuch zur obligatorischen oder fakultativen Bearbeitung der Filmmaterialien? Gibt es Transkripte zu den Filmtexten?

c. Wie erfolgt die Integration des Medienangebotes in das Unterrichtskonzept (Inhalte der Filmmaterialien zu den einzelnen Lehrwerkslektionen oder isoliert; Handlungsträger aus Lehrwerkslektionen bekannt oder eigene Geschichten)?

d. Können Unterrichtsmaterialien, z.B. Arbeitsblätter selbst generiert (interaktive Lehrerhandbücher) oder vorhandene Materialien bearbeitet werden (PDF-Modus)?

e. Gibt es die Möglichkeit, sich mit anderen Lehrenden in Foren auszutauschen, Arbeitsblätter über eine Plattform (z.B. Moodle) zu teilen?

3. Rezeptionshilfen für den Lernenden

a. Ist das Material für die Zielgruppe ansprechend (Identifikation mit den handelnden Personen; angesprochene Thematik relevant für die Lerner)?

b. Gibt es motivierende Aufgaben und Übungen vor - während - nach dem Sehen?15

c. Können die Aufgaben und Übungen in Bezug auf das Sprachniveau und andere soziokulturelle Faktoren innerhalb der Lernergruppe modifiziert werden (Binnendifferenzierung)?

d. Gibt es Übungen, in denen nur visuelle oder nur auditive Aspekte im Fokus stehen?

e. Sind die Aufgaben und Übungen eher rezeptiv (Überprüfung des Hör-Seh-Verstehens) oder geben sie auch Anregungen zur Sprachproduktion (mündlich/schriftlich) bzw. Interaktion im Fremdsprachenunterricht?

Nachfolgend werden exemplarisch zwei Materialien für jugendliche Lerner gegenübergestellt sowie der Vergleich von drei Lehrwerken für erwachsene Lerner auf dem Sprachniveau A1 durchgeführt. Die Auswahl der Lehrwerke erfolgte dabei nicht unter der Maßgabe der Vollständigkeit, sondern zur Demonstration verschiedener Herangehensweisen bei der Integration der lehrwerksbegleitenden Filmmaterialien im Anfangsunterricht Deutsch. Hingegen enthalten Filmmaterialien zu Lehrwerken für fortgeschrittene Lerner ab Niveau B1+ wie „Aspekte“, „Ziel“,

\footnotetext{
15 Wie in der Filmdidaktik mehrfach betont, ist es Lehrenden unabdingbar, die Filmmaterialien trotz der Übungsangebote vor ihrem Einsatz im Unterricht mehrfach anzusehen.
} 
„studio d Mittelstufe“ authentische Filmtextsorten wie Reportagen, Nachrichten, Interviews. So umfassen die didaktisierten Beiträge zu „studio d“ B2 Reportagen aus dem ZDF-Archiv, einen Filmtrailer und eine Folge der ARD-Fernsehserie Lindenstraße. ${ }^{16}$

Die 30minütige DVD zum Lehrwerk „geni@1 klick“ für jugendliche Lerner zeigt Szenen aus dem Alltag von Schülern, die an einer Schule in einer Medien-AG zusammenarbeiten. Die handelnden Figuren bieten gute Identifikationsmöglichkeiten für Lerner zwischen 12 und 16 Jahren. ${ }^{17}$ Die einzelnen Filme repräsentieren verschiedene Textsorten (z.B. Schulwegbeschreibung, Lehrerinterview, Einladung zu einer Geburtstagsfeier). Die Sprechgeschwindigkeit ist für das Sprachniveau A1 angemessen und wird durch die visuellen Komponenten unterstützt (keine TonBild-Scheren). Die Arbeit mit der DVD kann in das Kurskonzept integriert werden, da sich Aufgaben und Übungen zum Video sowohl in den Plateaukapiteln des Kursbuches als auch dem 6 seitigen Videotrainer am Ende des Arbeitsbuches befinden. Die Aufgaben im Kursbuch sind in der Regel Verstehenstests (richtig/falsch; Zuordnung Text-Bild; Reihenfolgen herstellen). Im Videotrainer sind die Aufgaben nach dem didaktischen 3er-Schritt (vgl. Übungstypologie bei Brandi 1996: 18) gegliedert. Diese schließen reine Sehaufgaben ohne Ton oder Höraufgaben ohne Bild ein. Im Arbeitsbuch gibt es die Lösungen für die Filmaufgaben, aber keine Transkripte. Diese können im Lehrerhandbuch nachgelesen werden.

Das Filmmaterial zum Lehrwerk „Planet“ fasst Filme der Bände A1 und A2 zusammen. Dabei können die 6 Filmkapitel mit den Themen Hobbies, Schule, Sport, Tagesablauf, Einkaufen, Familie/Wohnen den Lektionsthemen beider Lehrwerke zugeordnet werden. Im Filmclip „Begrüßung“ stellen sich die beiden Moderatoren Alex und Katarina vor, denn jedes Filmkapitel beginnt mit ihrer Anmoderation. Beide sind witzig, sprechen authentische Jugendsprache und kommen in den einzelnen Filmbeiträgen immer wieder vor. Allerdings ist die Sprech-geschwindigkeit für Anfänger teilweise sehr hoch, sodass die Transkriptionen im Lehrwerkservice $^{18}$ für die Unterrichtsplanung eine wichtige Rolle spielen. Außerdem sind die Moderatoren deutlich „erwachsener“ als die vom Lehrwerk angesprochene Zielgruppe (10-16 Jahre). Auf den Verlagsseiten wird im Bereich Lehren das Konzept in den „Allgemeinen Überlegungen zum Arbeiten mit Videomaterial“" erläutert. ${ }^{19}$ Die Didaktisierungsvorschläge für die einzelnen Filmkapitel beinhalten Aufgaben nach dem didaktischen 3er-Schritt sowie Arbeitsblätter im PDF-Format, jedoch ohne Lösungen. Die Aufgaben nach dem Sehen regen zur Produktion verschiedener Textsorten wie Argumentation, Interview, Beschreibung, Referate in kooperativen Sozialformen an. Der Einsatz von Musik z.B. im „Wohnungs-Rap“ ist motivierend. Außerdem findet man im Lehrwerkservice ein Spielposter zur DVD.

\footnotetext{
16 Vgl. http://www.cornelsen.de/home/reihe/r-4530/ra-4343/titel/9783060201099.

17 Auch wenn die Altersangabe der Zielgruppe problematisch ist, ist sie gerade bei jugendlichen Lernern ein wichtiges Element für die Identifikation mit dem Material und somit auch dem Inhalt.

${ }^{18} \mathrm{Http} / /$ /www.hueber.de/seite/pg_lehren_dvd_didakt_pla?menu=80391.

${ }^{19} \mathrm{Vgl}$. http://www.hueber.de/sixcms/media.php/36/planet-dvd-allg-didakt.pdf.
} 
Für das Lehrwerk „Schritte“ für erwachsene Lerner wurde zur Ausgabe für das Ausland „Schritte international“ eine DVD für die Niveaustufen 1 und 2 herausgegeben. Die Filmbeiträge sind an die Progression des Lehrwerks angepasst und orientieren sich inhaltlich an dessen Themenbereichen: „sich vorstellen“, „Essen und Wohnen“, „Arbeit“, „Wegbeschreibung“" sowie „Kleidung und Feste“. Neben den humorvollen Filmgeschichten um die Hauptfiguren Emma und Walter gibt es jeweils einen Bonusfilm mit landeskundlichen Informationen, z.B. zu nonverbaler Kommunikation beim Begrüßen oder zu Biergärten in Deutschland. Der Filmclip zum Thema „Feste“ wird durch eine Liedkomposition „Wie lange noch?“ begleitet. Dieser Film macht deutlich, wie mit visuellen Mitteln Einblicke in landeskundliche Themen gegeben werden können. Allerdings werden Kenntnisse deutscher Feste vorausgesetzt, da die gezeigten Abläufe bei einer Hochzeit nicht in jedem Kulturkreis bekannt sein dürften. Die DVD enthält neben den Clips allgemeine Hinweise für den Kursleiter für die Arbeit mit der DVD und zusätzlich zu jedem Kapitel Arbeitsblätter im PDF-Format sowie didaktische Hinweise mit Lösungsvorschlägen, aber keine Transkripte. Die Aufgaben sind nach dem didaktischen 3er-Schritt gegliedert und regen zur Arbeit in unterschiedlichen Sozialformen an.

Im Lehrwerk „Aussichten“ für Lerner ohne Vorkenntnisse und Sprachlernerfahrung stehen die Porträts von neun Personen im Mittelpunkt der Filme auf der DVD. Dabei wird bei der Vorstellung jeweils ein Aspekt stärker fokussiert, der zu dem Thema der jeweiligen Lektion passt (z.B. Restaurantbesitzer zum Thema „Essen und Trinken“; Tangotänzerin zum Thema „Kleidung"). Die Personen bilden Menschen aus unterschiedlichen Regionen Deutschlands und verschiedener Altersgruppen sowie sozialer und ethnischer Herkunft ab (z.B. Nezam Al Jaru aus Berlin). Auf der „Film-ab-Doppelseite“ im Arbeitsbuch am Ende jeder Lektion befinden sich Aufgaben und Übungen. Das Konzept kann im Leitfaden zur Arbeit mit der DVD auf den Internetseiten des Verlages nachgelesen werden. ${ }^{20}$ Hier finden sich auch die Transkriptionen der Filmtexte. Zur Schulung des Sehverstehens enthält die DVD zusätzlich ein Quiz. Objekte aus den Filmen sollen der jeweiligen Person zugeordnet werden. Die Lösungen zeigen dann jeweils Gegenstand und Filmausschnitt, in dem dieser zu sehen ist. Hier handelt es sich um eine Übung für Lerner ohne Vorkenntnisse, die gut zur Arbeit mit einem Lehrwerk mit relativ flacher Progression passt. Anspruchsvoll hingegen ist das Motto der Filmauswahl „Reinschauen ins echte Leben“, das sich in dialektalen Äußerungen der Hauptfiguren zeigt und zum Teil zu Abweichungen zwischen der gesprochenen und verschriftlichten Sprache in der Transkription führt. Zum leichteren Verständnis werden Ton-Bild-Schere vermieden, d.h. es wird gezeigt, worüber gesprochen wird. Allerdings entspricht das Einsprechen der Fragen der Interviewerin aus dem Off nur bedingt dieser Korrespondenz. Alle Filme können in Sequenzen oder vollständig gesehen werden. Die Didaktisierungsvorschläge beinhalten zudem Projektideen

${ }^{20} \mathrm{Http}: / /$ www2.klett.de/sixcms/list.php?page=lehrwerk_extra\&titelfamilie=Aussichten\&extra=Aus sichtenOnlne\&inhalt=klett71prod_1.c.724423.de\&modul=inhaltsammlung\&kapitel=1290849\#Mate rialien $\% 20$ zur $\% 20 \mathrm{DVD}$. 
zur Vertiefung landeskundlicher Themen mit Verweisen auf entsprechende Internetseiten, z.B. zur Namensrecherche, Karneval in Köln sowie Anregungen für weitere Übungen, z.B. Multiple Choice-Fragen.

Das Lehrwerk „Netzwerk“ richtet sich an erwachsene Lerner, die bereits über Sprachlernerfahrungen verfügen und in ihrem Alltag mit neuen Medien vertraut sind, da Layout, Textsorten, Themen und Aufgaben ,eine Verbindung zur digitalen Welt herstellen“ (vgl. Internetseite des Verlages). Die Filmkapitel auf der DVD erzählen die Geschichte von Bea, einer jungen Frau aus Berlin, die in München ein Praktikum macht. Die Filmsequenzen sind thematisch mit dem jeweiligen Kapitel verknüpft (z.B. Wegbeschreibung, Einkaufen), und zu jeder Filmszene gibt es im Lehrbuchkapitel eine gekennzeichnete Filmaufgabe. Am Ende jedes Kapitels gibt es zudem eine DVD-Seite mit Aufgaben und Übungen, allerdings befinden sich die Lösungen dazu nur im Lehrerhandbuch. Die Transkripte der Filmtexte stehen als Download im Unterrichtsportal zum Lehrwerk zur Verfügung. ${ }^{21}$ Zusätzlich gibt es eine Facebook-Seite der Protagonistin Bea, mit der die Lerner online kommunizieren und aktuelle Informationen über die deutschsprachigen Länder (z.B. auch gepostete Filme) erhalten können. Die Identifikation mit der Protagonistin ist für junge erwachsene Lerner gut möglich, auch Sprechtempo und Aussprache sind dem Sprachniveau angemessen. Für die Lehrenden gibt es ebenfalls eine Facebookseite mit Kontaktmöglichkeiten zum Autorenteam und weiterführenden Links (z.B. Fortbildungsveranstaltungen), aber keine weiteren Hör-Seh-Aufgaben zum Film.22

Die nachfolgende Übersicht verdeutlicht, dass die Transparenz des Medienverbundes bei den untersuchten Materialien nicht in jedem Fall gegeben ist. Lehrende sollten daher für ihre Kursplanung das Verweissystem der Zusatzmaterialien gut kennen.

\footnotetext{
${ }^{21} \mathrm{Http}$ // /www.klett-langenscheidt.de/_downloads/lupo/Netzwerk-A1.1-DVD-Transkripte.pdf.

22 Beispielsweise bietet der Film in Lektion 3 Redeanlässe zum Thema „Stadtrundfahrt durch München", die in den Aufgaben nicht thematisiert werden und daher durch die Lehrerperson ergänzt werden sollten.
} 


\begin{tabular}{|l|c|c|c|c|c|}
\hline & $\begin{array}{c}\text { geni@1 } \\
\text { klick }\end{array}$ & Planet & $\begin{array}{c}\text { Schritte } \\
\text { inter- } \\
\text { national }\end{array}$ & $\begin{array}{c}\text { Aussich- } \\
\text { ten }\end{array}$ & $\begin{array}{r}\text { Netz- } \\
\text { werk }\end{array}$ \\
\hline $\begin{array}{l}\text { Konzept des } \\
\text { Medien- } \\
\text { verbundes }\end{array}$ & im LHB & im LWS & $\begin{array}{c}\text { auf der } \\
\text { DVD }\end{array}$ & im LWS & im LHB \\
\hline $\begin{array}{l}\text { Aufgaben zum } \\
\text { Film nach 3er- }\end{array}$ & $\mathrm{xx}$ & xxx & xxx & xxx & xx \\
\hline $\begin{array}{l}\text { Filmkapitel } \\
\text { teau-Seiten } \\
\text { des KB })\end{array}$ & $\begin{array}{c}\text { kapitel } \\
\text { kilm- }\end{array}$ & $\begin{array}{c}5 \text { Film- } \\
\text { geschich- } \\
\text { ten }\end{array}$ & $\begin{array}{c}\text { zu jeder } \\
\text { Lektion }\end{array}$ & $\begin{array}{c}\text { zu jeder } \\
\text { Lektion }\end{array}$ \\
\hline $\begin{array}{l}\text { Filmaufgaben } \\
\text { im KB; AB }\end{array}$ & im LWS & $\begin{array}{c}\text { auf der } \\
\text { DVD }\end{array}$ & im AB & im KB \\
\hline $\begin{array}{l}\text { Lösungen zu } \\
\text { Filmaufgaben }\end{array}$ & im AB & keine & $\begin{array}{c}\text { auf der } \\
\text { DVD }\end{array}$ & im KB & im LHB \\
\hline $\begin{array}{l}\text { Transkription } \\
\text { der Filmtext }\end{array}$ & im LHB & im LWS & keine & im LWS & im LWS \\
\hline
\end{tabular}

Legende: $\mathrm{KB}=$ Kursbuch; $\mathrm{AB}=$ Arbeitsbuch; LHB = Lehrerhandbuch; LWS = kostenloser Download im Lehrwerkservice auf den Internetseiten des Verlages/Unterrichtsportal; ++ angemessen

\section{Zusammenfassung und Ausblick}

Wie in der Analyse der lehrwerksbegleitenden Filmmaterialien gezeigt werden konnte, verfügen alle zu Lehrwerken entwickelten Filme über ansprechendes visuelles Material, das Einblicke in die Zielsprachenkultur bietet. Die Didaktisierungshilfen machen deutlich, dass die Arbeit mit audio-visuellen Medien bereits auf Niveau A1 fester Bestandteil des Unterrichts sein kann, vor allem wenn nach dem didaktischen 3er-Schritt gearbeitet wird. Die untersuchten Filme unterscheiden sich in dieser Hinsicht ebenso wie in Art und Umfang der Aufgabenstellungen. Letztere umfassen mehrheitlich Hörverstehensaufgaben, sodass eine Erweiterung des Aufgabenspektrums um filmspezifische Aufgaben zur Schulung des Seh- bzw. Hörsehverstehens (z.B. Sehen ohne Tonspur) ebenso wünschenswert wie die Interpretation und Diskussion der kulturgebundenen Bildimpulse ist. Die qualitativ hochwertigen Filmproduktionen bieten in vielen Fällen also mehr Übungsimpulse als bisher in den Aufgabenstellungen genutzt werden, um den Spracherwerb und das kulturelle Verstehen der Lerner zu unterstützen. Ähnlich wie bei der Analyse 
der Lektürereihen muss der Mehrwert der Filmfassung gegenüber einer Textfassung für die Lernenden erkennbar sein.

Es bedarf daher in einem weiteren Schritt der Analyse neuer Lehrwerke, um zu prüfen, ob einerseits mit E-Books (z.B. „studio 21“) die transparente und einfache Vernetzung aller Medienangebote sichergestellt und andererseits der didaktischmethodische Mehrwert bildunterstützten Lernens (z.B. „Menschen") herausgearbeitet werden konnte. Die umfangreiche Bebilderung von Lehrwerken oder das Beilegen von Hör-CDs bzw. Film-DVDs allein wird für die Sicherstellung effektiven Sprachunterrichts nicht ausreichend sein. Dazu sind nicht zuletzt empirische Studien zum Einsatz von Lehrwerken und ihrer Verwendung durch die Lernenden notwendig. ${ }^{23}$

\section{Literatur}

Barkowski, Hans et al. (Hrsg.) (1980): Deutsch für ausländische Arbeiter: Gutachten ₹u ausgewählten Lebrwerken. Königstein/Ts: Scriptor.

Biechele, Barbara (2006): Film/Video/DVD in Deutsch als Fremdsprache - Bestandsaufnahme und Perspektiven. In: Barkowski, Hans; Wolff, Armin (Hrsg.): Umbrüche. Göttingen: Universitätsverlag Göttingen, 309-328.

Biechele, Barbara (2010a): Hör-Seh-Verstehen. In: Barkowski, Hans; Krumm, Hans-Jürgen (Hrsg.): Facblexikon Deutsch als Fremd- und Zweitsprache. Tübingen: Francke, 118.

Biechele, Barbara (2010b): Film im Unterricht Deutsch als Fremdsprache: Lernpotenzen und didaktisch-methodische Implikationen. In: Deutschunterricht in Japan $15,71-89$.

Bohnensteffen, Markus (2011): Englischlehrwerke und ihre unterrichtliche Verwendung. Ergebnisse einer Befragung. In: Kurtz, Jürgen (Koord.): Fremdsprachen Lebren und Lernen (FLuL) 2, Themenschwerpunkt: Lebrwerkkeritik, Lehrwerkverwendung, Lehrwerkentwicklung, 120-133.

Börner, Otfried; Edelhoff, Christoph; Rebel, Karlheiz; Schmidt, Torben; Schröder, Konrad (2011): Funktion und Profil von Lehrwerken in der Epoche von Standards und Kompetenzen. In: Kurtz, J. (Koord.): Fremdsprachen Lebren und Lernen (FLuL) 2, 31-48.

Brandi, Marie-Luise (1996): Video im Fremdsprachenunterricht. München: Langenscheidt.

\footnotetext{
23 Beispielsweise kann mit Hilfe des Eye-Tracking-Verfahrens gemessen werden, in welcher Reihenfolge und wie lange Lerner einen bestimmten Bereich einer Lehrwerkseite betrachten (vgl. Funk; Niemann 2013).
} 
Brüning, Ludger; Saum, Tobias (2006): Erfolgreich unterrichten durch Kooperatives Lernen. Strategien zur Schüleraktivierung. Essen: Neue deutsche Verlagsgesellschaft.

Buhlmann, Rosemarie (2012): Lebrwerkanalyse und Lebrwerksbeurteilung. Hinweise für die Beratung bei der Lehrwerksauswabl. München: Goethe-Institut.

Doff, Sabine; Klippel, Friederike (2007): Englischdidaktik. Praxishandbuch für die Sekundarstufe I und II. Berlin: Cornelsen.

Dunker, Michael (1991): Beeinflussung und Steuerung des Lesers in der englischsprachigen Detektiv- und Kriminalliteratur. Frankfurt/Main: Lang.

Engel, Ulrich et al. (1977): Mannheimer Gutachten zu Lebrwerken Deutsch als Fremdsprache. Heidelberg: Groos.

Europarat (2001): Gemeinsamer europäischer Referen₹rabmen für Sprachen. München: Langenscheidt.

Funk, Hermann (1999): Lehrwerke und andere neue Medien. Zur Integration rechnergestützter Verfahren in den Unterrichtsalltag. In: Fremdsprache Deutsch 21, 5-12.

Funk, Hermann (2004): Qualitätsmerkmale von Lehrwerken prüfen - ein Verfahrensvorschlag. In: Babylonia 3, 41-47.

Funk, Hermann. (2005): Ist die Qualität von Lehrwerken messbar? Ja und Nein. Ein Verfahrensvorschlag. In: Neue Beiträge zur Germanistik 4, 14-28.

Funk, Hermann; Niemann, Rita (2013): Lehrwerkverbundkomponenten zur Gestaltung interaktiver Lehr-Lernszenarien - Qualitätsanforderungen, Trends und Integrationsmodelle. Vortrag auf dem DGFF-Kongress 2013, Augsburg, Sektion 7: Lehrwerke und Unterrichtsinteraktion, unveröffentlicht.

Hallet, Wolfgang (2008): Die Visualisierung des Fremdsprachenlernen - Funktionen von Bildern und visual literacy im Fremdsprachenunterricht. In: Lieber, Gabriele (Hrsg.): Lehren und Lernen mit Bildern. Baltmannsweiler: Schneider, 212-222.

Kast, Bernd; Neuner, Gerd (Hrsg.) (1994): Zur Analyse, Begutachtung und Entwicklung von Lehrwerken für den fremdsprachlichen Unterricht. Berlin: Langenscheidt.

Kurtz, Jürgen (Koord.): Fremdsprachen Lehren und Lernen (FLuL) 2, Themenschwerpunkt: Lehrwerkekitik, Lehrwerkverwendung, Lehrwerkentwicklung.

Lasnier, Jean-Claude; Morfeld, Petra; North, Brian, Serra Borneto, Carlo; Späth, Preben (2003): Qualitätsleiffaden zur Bewertung und Entwicklung von Programmen und Materialien zum Sprachenlernen und -lehren. Brüssel: Eurydice.

Neuner, Gerd (1994): Lehrwerkbegutachtung für die Praxis: die Lehrstoff-, Lehrerund Lernerperspektive. In: Kast, B.; Neuner, G. (Hrsg.) (1994), 111-118. 
Neuner, Gerd (2003): Lehrwerke. In: Bausch, Karl-Richard; Christ, Herbert;

Krumm, Hans-Jürgen (Hrsg.): Handbuch Fremdsprachenunterricht. Tübingen: UTB, 399-402.

Schlegel, Clemens M. (2003): Schulbuch und Software als Medienpaket. Beurteilungskriterien und didaktische Einsatzmöglichkeiten für integrierte Lernsoftware. In: Wiater, Werner (Hrsg.): Schulbuchforschung in Europa. Bestandsaufnabme und Zukunftsperspektive. Bad Heilbrunn: Klinkhardt, 175-190.

Sass, Anne (2007): Filme im Unterricht - Sehen(d) lernen. In: Fremdsprache Deutsch 26, 5-13.

Schmidt, Reiner (1994): Lehr- und Lernmittel. In: Henrici, Gert; Riemer, Claudia (Hrsg.): Einführung in die Didaktik des Unterrichts Deutsch als Fremdsprache mit Videobeispielen, Bd. 2. Hohengehren: Schneider, 397-418.

Schmidt, Carla (1993): Hören Sie mal, Sie werden schon sehen. Zum Einsatz von Hörspielen im Fremdsprachenunterricht. In: Info DaF 20, 6, 659-673.

Schwerdtfeger, Inge (1989): Sehen und Verstehen. Zur Arbeit mit Film und Video im Fremdsprachenunterricht. München: Langenscheidt.

Solmecke, Gert (2000): Faktoren der Schwierigkeit von Hörtests. In: Bolton, S. (Hrsg.): TestDaF: Grundlagen für die Entwicklung eines neuen Sprachtests. Beiträge aus einem Expertenseminar. Köln: VUB Gilde, 57-76.

Thaler, Engelbert (2011): Die Zukunft des Lehrwerks - Das Lehrwerk der Zukunft. In: Kurtz, J. (Koord.): Fremdsprachen Lebren und Lernen (FLuL) 2, 1530 .

Weber, Till (2003): Deutscher Film und DaF-Unterricht in Japan. Wie lassen sich deutsche Sprache und Landeskunde durch Spielfilme vermitteln? In: DuppelTakaymana, Mechthild et al. (Hrsg.): Deutschunterricht an japanischen Universitäten. München: iudicium, 200-215.

\section{Lehrwerke}

\section{Lese-Hör-Geschichten}

o.A. (2003): Ein Fall auf Rügen. Berlin: Langenscheidt.

o.A. (2005): Berliner Pokalfieber. Berlin: Langenscheidt.

o.A. (2005): Ebbe\& Flut. Berlin: Langenscheidt.

Baier, Gabi (2007): Verschollen in Berlin. Stuttgart: Klett.

Borbein, Volker/Lohéac-Wieders, Marie-Claire (2009): Tod in der Oper. Berlin: Cornelsen. 
Dittrich, Roland (2007a): Der Schützenkönig vom Chiemsee. Stuttgart: Klett.

Dittrich, Roland (2007b): Die Loreley lebt! Stuttgart: Klett.

Dittrich, Roland (2011): Haifische in der Spree. Berlin: Cornelsen.

Gerndt, Cordula (2007). Das Glückskind und andere Geschichten. München: Verlag für Deutsch Renate Luscher.

Specht, Franz (2002): Schöne Augen. Carsten Tsara ist verliebt. Ismaning: Hueber.

Wülfing, Stefanie (2011): Böses Erwachen in Heidelberg. Stuttgart: Klett.

2. Lehrwerke und lehrwerksbegleitende Filmmaterialien

Dallapiazza, Rosa-Maria; Evans, Sandra; Fischer, Roland; Kiliman, Angela, Schümann, Anja; Winkler, Maresa (2008): Ziel B2. Ismaning: Hueber.

Dengler, Stefanie; Rusch, Paul; Schmitz, Helen; Sieber, Tanja (2011): Netzwerk A1. Berlin: Langenscheidt.

Evans, Sandra; Pude, Angela; Specht, Franz (2012): Menschen A1. Ismaning: Hueber.

Funk, Hermann; Kuhn, Christina; Demme, Silke (2005): Studio d A1. Berlin: Cornelsen.

Funk, Hermann; Kuhn, Christina (2013): Studio 21 A1. Berlin: Cornelsen.

Koithan, Ute; Schmitz, Helen; Sieber, Tanja; Sonntag, Ralf (2007): Aspekte B1+. München: Langenscheidt.

König, Michael; Koithan, Ute; Scherling, Theo (2011): geni@l klick A1. München: Langenscheidt.

Kopp, Gabriele; Büttner, Siegfried (2004): Planet A1. Ismaning: Hueber.

Kuhn, Christina; Niemann, Rita; Winzer-Kiontke, Britta (2010): Studio d B2 - Die Mittelstufe. Berlin: Cornelsen.

Niebisch, Daniela; Penning.Hiemstra, Sylvette; Specht, Franz; Bovermann, Monika; Reimann, Monika (2006): Schritte International A1/1. Ismaning: Hueber.

Perlmann-Balme, Michaela; Schwalb, Susanne; Weers, Dörte (2000): Em - Brückenkurs. 2. Auflage. Ismaning: Hueber.

Ros, Lourdes; Swerlowa, Olga; Klötzer, Sylvia; Reinke, Kerstin; Raths, Angelika; Lundquist-Mog, Angelika; Jentges, Sabine; Jenkins-Krumm, Eva-Maria (2009): Aussichten. Stuttgart: Klett. 



\title{
Comics - Geschichte, Struktur, Interpretation
}

\author{
Ralf Palandt
}

Franz Christian Kinzel veröffentlichte 1995 seine „Metaanalyse von Comics aus psychoanalytischer Sicht“ im "Jahrbuch der Forschung zu populär-visuellen Medien“. Er schrieb: „Der deutsche Beitrag zum Thema Comic-Analyse beschränkte sich vor dem II. Weltkrieg noch auf die Bemerkung Goebbels, wonach Superman Jude und antidiktatorischer Propagandist sei (Bender \& Lurie [sic], 1941)." (Kinzel 1995: 141). Für diese Aussage bezog er sich auf Bender und Louries Aufsatz „Effect of Comic Books on the Ideology of Children“ von 1941. Darin kommt der Name Goebbels kein einziges Mal vor. Lauretta Bender und Reginald S. Lourie erwähnten lediglich hinsichtlich von Comic-Plots: „So true are they sometimes to fact that a short while ago a Nazi newspaper was reported to have protested against the anti-dictator policies of Superman." (Bender; Lourie 1964: 541). Sie spielten damit auf eine Ausgabe der SS-Wochenzeitschrift „Das schwarze Korps“ vom April 1940 an, in der Superman als „Bizepsheini“ und sein jüdischer ComicAutor Jerry Siegel als ,geistig und körperlich Beschnittener“ und „Israelit“ verunglimpft worden waren. Der Artikel war die Reaktion auf einen Superman-Comic in der US-Illustrierten „Look“ vom Februar 1940, in welchem Superman Hitler und Stalin als Kriegstreiber nach Genf vor den Völkerbund brachte (vgl. Palandt 2005: 83-86).

Die Gleichsetzung des Presseorgans der SS mit dem Reichsminister für Volksaufklärung und Propaganda weist als ein Beispiel auf einen fragwürdigen Zustand der Literatur über Comics hin. Wie ernsthaft und gewissenhaft erfolgt hier die Beschäftigung mit dem Gegenstand? Doch auch laxe Quellenarbeit einiger AutorInnen kann die vielen unterschiedlichen und zum Teil widersprüchlichen Aussagen 
über Comics, Mangas und Graphic Novels nicht erklären, die die (Fach-)Literatur beherrschen. Augenscheinlich kann hier jede/r alles Mögliche und Unmögliche schreiben, ohne Widerspruch befürchten zu müssen. Was ist davon zu halten und wie findet man sich in diesem Durcheinander zurecht? Der folgende Aufsatz richtet den Blick auf die Bereiche Comic-Definition, Comic-Entstehung, ComicGeschichte, Manga und Graphic Novel. Die Betrachtungen sind ein Angebot zur Orientierung, im Einklang mit und im Unterschied zu Ausführungen anderer FachautorInnen.

\section{Was ist ein Comic?}

Es gibt bis dato keine allgemeingültige Comic-Definition. Das hat mehrere Gründe. Es gibt einzelne ComicforscherInnen und Zusammenschlüsse, wie die Arbeitsstelle für Graphische Literatur (ArGL) und die Gesellschaft für Comicforschung (ComFor), die neben ihren Projekten Tagungen und Ringvorlesungen organisieren sowie über Comics referieren und publizieren. Es gibt jedoch (noch) keine allgemein anerkannte Comicwissenschaft (Comicologie). Dieser institutionelle Rahmen wäre aber nötig, um die Forschungsergebnisse zu sammeln, in Beziehung zueinander zu setzen und das gewonnene Wissen durch Lehre weiterzugeben. Bislang kommen ComicforscherInnen aus verschiedenen Fachbereichen, u.a. aus der Anglistik, Germanistik, Japanologie, Komparatistik, Romanistik, Geschichts-, Kommunikations-, Kultur-, Kunst-, Literatur- und Medienwissenschaft. Entsprechend vielfältig und unterschiedlich fallen die Forschungsinteressen, -perspektiven, -methoden, -fragen, -ergebnisse und wissenschaftlichen Standards aus, wie auch die Vorstellungen darüber, was ein Comic ist und was nicht. ${ }^{1}$

In seinem Aufsatz „Comics sind nicht nur komisch. Zur Benennung und Definition" betrachtete Eckart Sackmann internationale Comic-Definitionen und Eigenbenennungen aus den Jahren 1924 bis 2000. ${ }^{2}$ Sein Ergebnis:

Die Geschichte der Comicliteratur und auch die der Auseinandersetzung mit der Form belegen, dass die Gründe, aus denen Begriffe geprägt und Definitionen abgegeben wurden, stets vom Zeitgeist des Urteilenden geprägt wurden. [...] Die Geschichte der Definitionen des Comics zeigt, dass ein und dieselbe Sache zu verschiedenen Zeiten verschieden beurteilt worden ist. So wird es voraussichtlich auch in Zukunft sein. (Sackmann 2007a: 16).

Nichtsdestotrotz ist zumindest im wissenschaftlichen Bereich eine Comic-Definition nötig. Denn gemäß wissenschaftlicher Standards und Prinzipien muss das

\footnotetext{
${ }^{1}$ Vgl. Lino Wirag 2012: 6: „Comicwissenschaften, so behaupte ich, sind heute nur noch denkbar als comicforscherische Kulturwissenschaften (auch diese im Plural).“

2 Sackmann 2007a. Sein Ausgangspunkt war Scott McClouds Äußerung: „Unsere Anstrengungen, den Comic zu definieren, bilden einen fortlaufenden Prozess, der so schnell nicht abzuschließen ist". (McCloud 1994: 31).
} 
Untersuchungsmaterial auch für Dritte unzweideutig erkennbar und müssen Aussagen über das Untersuchungsmaterial dadurch vergleichbar und nachprüfbar sein. Daher müssten StudentInnen ihren akademischen Arbeiten über Comics in der Regel stets eine Comic-Definition und bei Bedarf auch ihrer Untergruppen, wie z.B. Genres, voranstellen. Angesichts vieler und sich zum Teil widersprechender Comic-Definitionen keine leichte Sache. Schließlich ist eine Comic-Definition eine Festlegung, die auf weiterführende Betrachtungen Auswirkungen hat, wie z.B. auf die Geschichte der Comics. Darauf werde ich später noch eingehen.

Viele AutorInnen berufen sich auf die deutsche Übersetzung der Comic-Definition von Scott McCloud: „Zu räumlichen Sequenzen angeordnete, bildliche oder andere Zeichen, die Informationen vermitteln und/oder eine ästhetische Wirkung beim Betrachter erzeugen sollen.“ (McCloud 1994b: 17). Hier fehlt jedoch das im Originaltext angeführte Merkmal „deliberate sequence“ (intendierte Sequenz). ${ }^{3}$

Enger gefasst definiert Eckart Sackmann Comics als „eine Erzählung in wenigstens zwei stehenden Bildern“. Damit ist „Comic“ Oberbegriff auch für ComicStrip, Bildgeschichte, Bildergeschichte, Manga. „Der Terminus steht in Abgrenzung zu illustriertem Text (bei dem die Erzählung durch den Text getragen wird), zum (Trick-)Film (fließende Bilder, Ton) und zur Einzelbild-Erzählung (Cartoon, Einzelbildwitz). [...] Comic ist nicht nur Bezeichnung der Erzählform, sondern auch der medialen Form (abgekürzt für Comic-Heft, Comicalbum, Graphic Novel etc.).“(Sackmann 2009: 6).

Mit Analogien zum Film möchte ich alternativ eine Definition anbieten, die versucht, das Wesen des Phänomens Comic einzufangen. ${ }^{4}$ Dafür möchte ich die „enge Bildfolge“ ins Spiel bringen, wie sie Dietrich Grünewald beschreibt. Im Film „verschmilzt das Einzelbild mit den anderen zu einem bewegt erlebten Bild [...].“ (Grünewald 2000: 13). Ähnlich die „enge Bildfolge“: „Die Bildgeschichte bleibt statisch, aber ihre Panel [-Inhalte] folgen zeitlich so dicht aufeinander, dass der Betrachter keine Mühe hat, sie zu verknüpfen und imaginativ zu verlebendigen.“ (Grünewald 2000: 13). Im Gegensatz dazu die „weite Bildfolge“:

Hier liegen die Einzelbilder zeitlich recht weit auseinander. Die Bildabfolge reiht Höhepunkte, Stationen eines umfangreichen Geschehens aneinander. Das fordert vom Rezipienten aufmerksames Betrachten und assoziatives, kombinierendes Geschick, um den Zusammenhang der Bilder zu erfassen. Oft gelingt das nur, weil der erzählte Stoff schon vertraut ist oder, wie in vielen Bilderbogen- oder Bilderbuchgeschichten dieser Erzählweise, ein erzählender Untertext Verbindungen herstellt. (Grünewald 2000: 13).

Bei einem einzelnen projizierten Dia sprechen wir nicht von „Film“ im Sinne eines „bewegten Bildes“. Auch nicht bei einer Dia-Show, die zeitlich nacheinander lie-

\footnotetext{
3 "Juxtaposed pictorial and other images in deliberate sequence, intended to convey information and/or to produce an aesthetic response in the viewer." (McCloud 1994a: 9).

4 Auch andere FachautorInnen verwenden Comic-Film-Vergleiche, u.a. Grünewald 1982 und McCloud 1994a, 1994b.
} 
gende Momentaufnahmen eines Ereignisses (z.B. einer Reise) zeigt. Wenn nun die zeitlichen Abstände, die zwischen diesen Momentaufnahmen liegen, immer kürzer werden, und die Dias immer schneller und kürzer projiziert werden, überschreitet die Dia-Show einen Punkt, ab dem sie ein einziges Bild mit Bewegung vortäuscht. ${ }^{5}$ Dank einer entsprechenden Projektionstechnik und der Trägheit des Auges verschmelzen die vielen hintereinander gezeigten Bilder zu einem Bild, verschmelzen die auf den einzelnen Dias festgehalten Ausschnitte einer Bewegung zu einer flieBenden Bewegung. Die so zusammengehörenden Bilder bilden eine Film-Sequenz.

Ähnliches geschieht beim Comic, mit dem Unterschied, dass beim Film die Bilder zeitlich nacheinander, im Comic jedoch räumlich hintereinander dargeboten werden. In der „engen Bildfolge“ sind die Bilder keine autonomen, für sich stehenden Einzelbilder mehr, sondern funktionale Momentaufnahmen einer Sequenz. Intuitiv ergänzt der/die RezipientIn die fehlenden Bilder zwischen den Momentaufnahmen quasi zu einem Film, der mitunter unbewusst vor dem ,inneren Auge“ abläuft (Abb. 1-4). Um dieses Phänomen hervorzurufen, braucht es mindestens zwei Bilder.

Was ist ein Comic? Visuelle Darlegung anhand eines Ausschnitts aus einer „Zepis Zaubergarten“-Folge (Nemeth 2010).

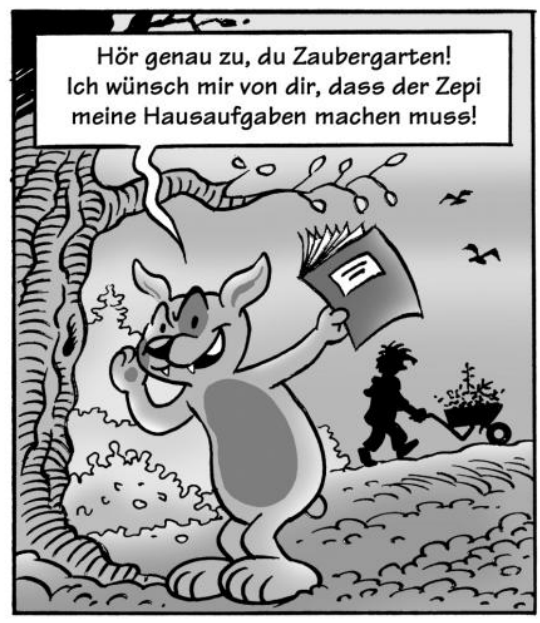

Abb. 1: Ein einzelnes Bild ist noch kein Comic.

${ }^{5}$ Folgende Standards sind üblich: Schmalfilmbereich: 18 Bilder/Sek.; Kino: 24 oder 48 Bilder/Sek.; Video und Fernsehen: 25 Bilder/Sek. 

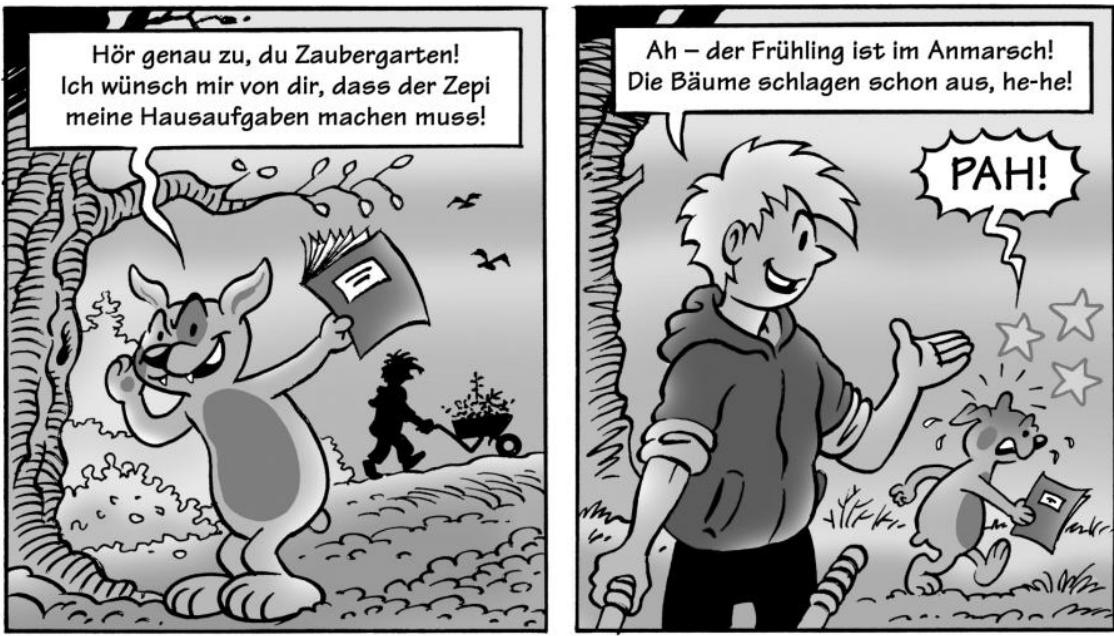

Abb. 2: Die inhaltliche Lücke zwischen beiden Bildern ist noch zu groß (weite Bildfolge), so dass keine Sequenz entsteht.
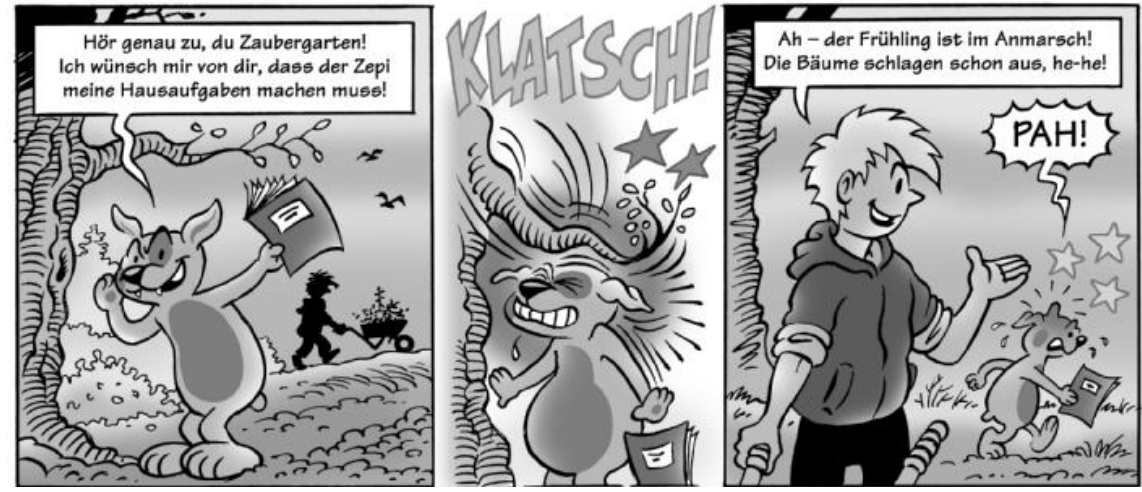

Abb. 3: Das Bild in der Mitte verbindet das erste und das letzte Bild zu einer engen Bildfolge. 


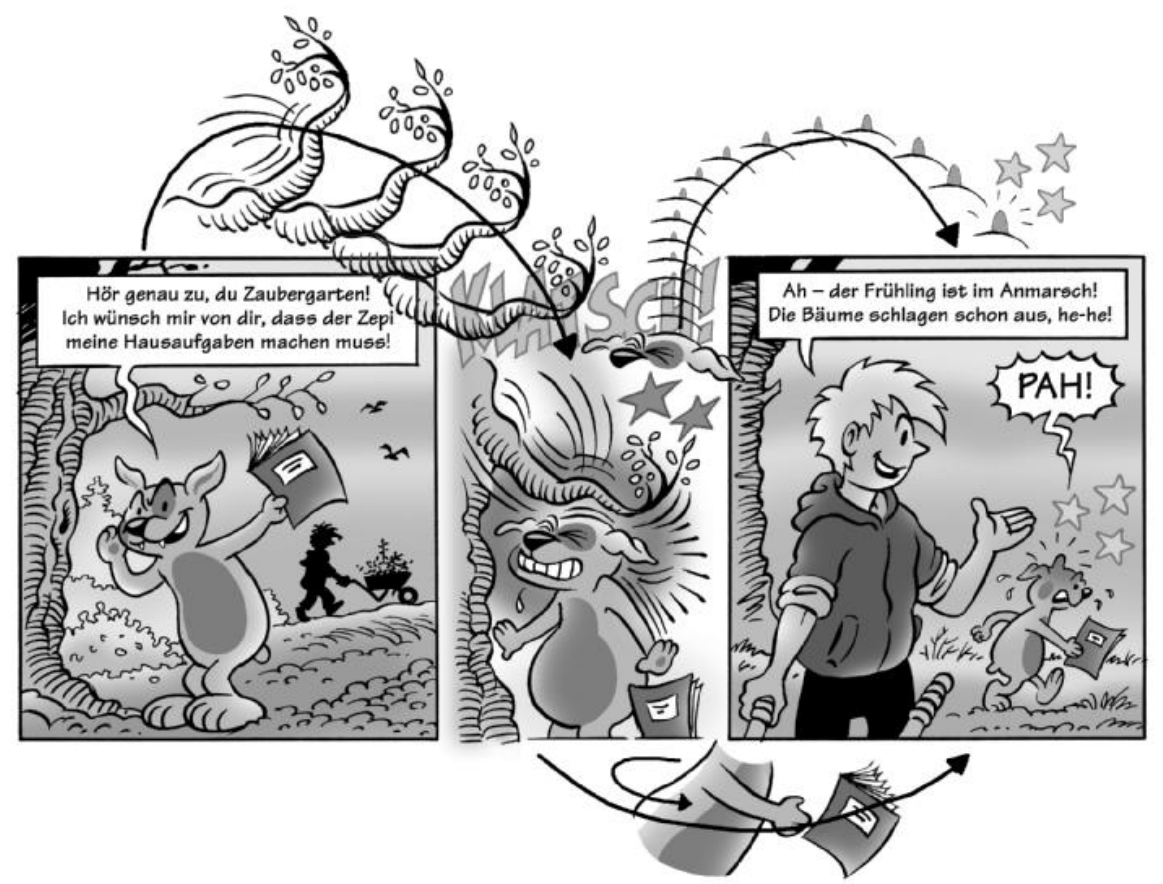

Abb. 4: Der/die RezipientIn ergänzt die Bilder, so dass quasi vor dem „inneren Auge“ ein Film abläuft.

Aus Sicht der Semiotik entspricht eine Comic-Sequenz einer Verweiskette gesetzter Zeichen. So kann eine Sequenz z.B. mit dem Auftritt einer Comic-Figur beginnen und mit ihrem Abgang enden. Die Comic-Figur kommt in den einzelnen Panels nicht immer wieder vor, sondern immer noch. Dabei muss die Figur nicht ständig als Ganzes zu sehen sein. Ist ein Teil der Figur verdeckt oder außerhalb des Bildrandes, so stehen die sichtbaren Elemente als Statthalter für die ganze Figur. So gesehen ist ein Comic ein Geflecht von Verweisketten (Abb. 5, vgl. Krafft 1978: 15-28).

Scott McCloud verwendet hier den Begriff „closure“6 und betont deren Bedeutung: „If visual iconography is the vocabulary of comics, closure is its grammar. And since our definition of comics hinges on the arrangement of elements... then, in a very real sense, comic is closure!" (McCloud 1994-1: 67).

6 "This phenomenon of observing the parts but perceiving the whole has a name. It's called closure." (McCloud 1994a: 63). 

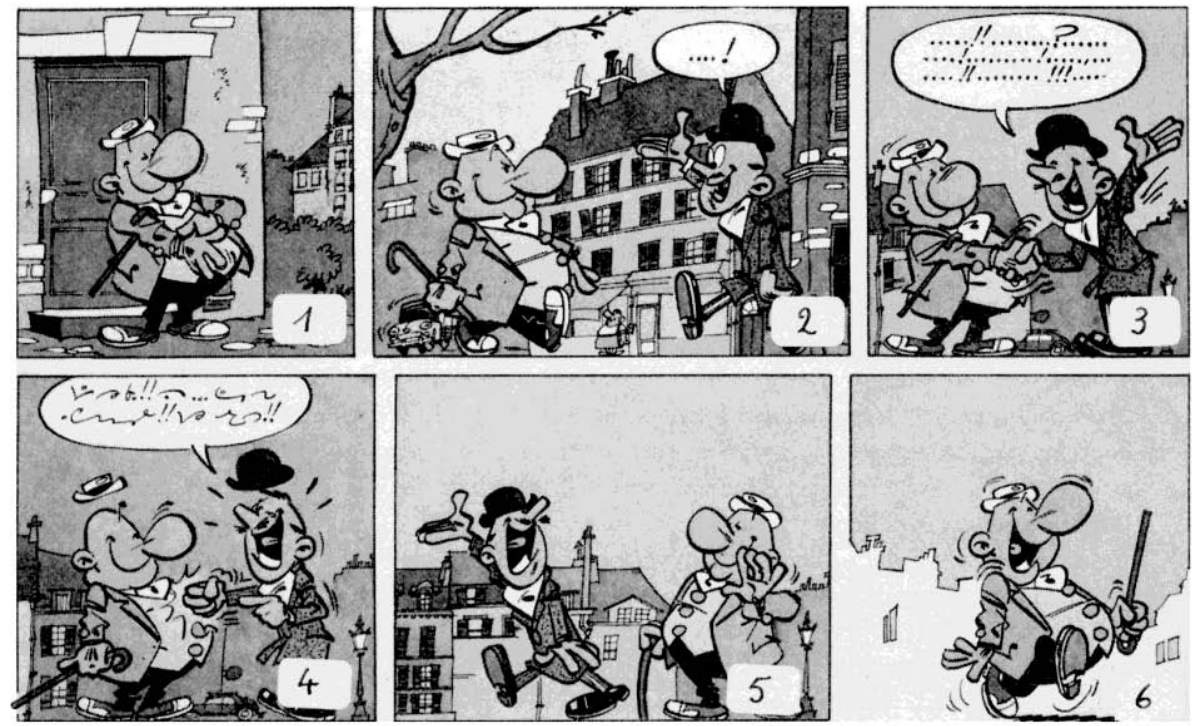

\begin{tabular}{|c|c|c|c|c|}
\hline \multirow[b]{2}{*}{$\mathbf{P}$} & \multicolumn{2}{|c|}{ Vordergrund } & \multicolumn{2}{|c|}{ Hintergrund } \\
\hline & Personen & Gegenstände & Personen & Gegenstände \\
\hline 1 & Achille, Talon & Wand, Tür, Hecke & & Häuser \\
\hline 2 & 0 Bekannter & Baum & Hausfrau & Häuser, Auto \\
\hline 3 & $\begin{array}{ll}0 & \uparrow \\
\uparrow & \uparrow\end{array}$ & & & $\begin{array}{c}\text { Häuser, Auto } \\
\uparrow \quad \text { Laterne } \uparrow\end{array}$ \\
\hline 4 & 00 & & & 0 \\
\hline 5 & $\begin{array}{ll}1 \\
0 & 0\end{array}$ & & & 0 0 Häuser \\
\hline 6 & 0 & & & Häuser \\
\hline
\end{tabular}

Abb. 5: Ausschnitt aus Ulrich Kraffts Beispiel für Verweisketten in einem Achille Talon-Comic. (Krafft 1978: 16 und 20).

$\mathrm{Ob}$ ein Comic funktioniert, hängt also nicht nur von der vorliegenden Arbeit der Comic-AutorInnen und ZeichnerInnen ab, sondern entscheidend auch von den RezipientInnen. In seinem Artikel über das Lesen von Comics geht Klaus Podak auf die visuelle pars-pro-toto-Leistung des Gehirns ein, wie sie der Neurophysiologe Otto-Joachim Grüsser auf einem Medienökologie-Kongress 1992 vorstellte. Die visuelle pars-pro-toto-Leistung des Gehirns ermöglicht es dem Menschen, Zeichen zu deuten und dadurch auch Comics zu lesen, d.h. 
das Ergänzen - möglichst zur Vollständigkeit; das Erinnern - was die Zeichen schon einmal sagen wollten; das Einordnen in einen (dabei erst entstehenden) Zusammenhang, der Sinn ergibt; das Bewerten (das heißt: emotionale Stellung beziehen), ob man dem Zusammenhang zustimmen kann oder ihn ablehnen will; das blitzschnelle Durchspielen von Handlungsmöglichkeiten - soll ich flüchten oder standhalten oder mich der Sache sogar freundlich zuwenden? (Podak 1998).

Mit anderen Worten: „O ja, das Comic-Lesen, richtig betrieben als Zeichendeutung mit allen Sinnen, fordert die Konzentration sehr vieler Wahrnehmungsmöglichkeiten, ist, wahrnehmungspsychologisch betrachtet, eine hochkomplexe Syntheseleistung." (Ebd.)

Dabei ist das „Lesen“ eines Comics eher ein „Betrachten“. Dietrich Grünewald schreibt:

Die meisten formalistischen Beschreibungen des Comics setzen ihren Schwerpunkt auf das Zeichenrepertoire, wobei sich diese Elemente nur zu leicht verselbstständigen und ihr Stellenwert im Erzählkontext der Bildfolge vernachlässigt wird. Das Spezifische der Bildergeschichte ist ihre Erzählweise, die narrative Bildfolge und ihr mehr oder weniger ausgeprägter WortBild-Bezug, nicht die visuellen Zeichen der Comics, die ebenso im autonomen Einzelbild ihren Platz haben. Eine Auflistung der Einzelelemente kann nur aus arbeitstechnischen Gründen erfolgen, in der Rezeption sind sie nicht isoliert, sondern stets funktional zum Kontext zu sehen. Der Leser „buchstabiert" nicht, sondern zieht zusammen, sieht ganzheitlich. (Grünewald 1982: 38).

Wie kann eine Bildsequenz aussehen? Eckart Sackmann unterscheidet zwischen „drei Prinzipien des Comics“:

Beim kontinuierenden Prinzip werden zeitlich aufeinanderfolgende Szenen ohne Trennung aneinandergereiht. [...] Das integrierende Prinzip entspricht dem Simultanbild, das zeitlich versetzte Szenen in einem Bild vereint, wo sie vom Betrachter simultan wahrgenommen werden. [...] Künstlerisch durchgesetzt hat sich das separierende Prinzip, die Aufteilung einer Fläche in Bildräume (Panels), die durch trennende Elemente voneinander isoliert sind. Heute üblich sind durch Linien eingeschlossene Panels, zwischen denen sich eine Lücke ergibt. Dieser Graben, der auch ein zeitlicher zwischen den dargestellten Szenen ist, wird vom Betrachter beim Lesen überbrückt. Hierin liegt das Besondere des Comic. (Sackmann 2009: 8).

Viele Comic-Definitionen stellen auf die Verbindung von Bild und Text ab. Was sagt der Vergleich mit Film dazu? Man unterscheidet Ton- und Stummfilme. Manche Stummfilme beinhalten Texttafeln mit Zwischentiteln (Orts- und Zeitangaben, Dialoge etc.). Das Phänomen des bewegten Bildes jedoch basiert rein auf Bildern. 
Auch im Erzählen ihrer Geschichte kommen etliche Filme ohne Ton und Texte aus. Diese Beobachtung lässt sich auf Comics übertragen. Auch die enge Bildfolge braucht für die Illusion der verlebendigten Bildsequenz keinen Text, und auch etliche Comic-Geschichten kommen ohne ihn aus. Manche FachautorInnen sprechen dann von Pantomime-Comics. Aber natürlich sind Texte als Ergänzung zum Bild sehr hilfreich, um Erklärungen und Dialoge wiederzugeben. ${ }^{7}$ Manche FachautorInnen schließen in ihren Comic-Definition Text unter den Bildern aus. Doch egal ob ein Text in und/oder unter den Bildern steht, wesentlich ist, das die Bildsequenz als bestimmendes Element der Erzählung erhalten bleibt. Schlimmstenfalls gerät die Rezeption der Bildsequenz ins Stottern und Ruckeln, wie bei der Projektion eines kaputten Filmstreifens. Kein Comic liegt vor, wenn der Text für sich alleine stehen könnte, d.h. das beherrschende Element ist und die Bilder lediglich Ergänzung. Da der Übergang fließend ist, kommt es bei einer Beurteilung auf den jeweiligen Einzelfall an. So bestimmt in der Praxis z.B. bei „Prinz Eisenherz“ die jeweilige Text-Bearbeitung und -Präsentation, angesichts der verschiedenen Versionen, ob es im speziellen Fall (noch) gerechtfertigt ist, von einem Comic zu sprechen, oder nicht (mehr).

Natürlich hat die Aufnahme- und Abspieltechnik Einfluss auf die Entstehung und das Ergebnis, aber um „bewegte Bilder“ zu sehen, ist es einerlei, ob der Film als Zelluloidstreifen, Video-Kassette, DVD-Scheibe oder Filmdatei abgespielt wird. Gleiches gilt für Comics und ihr Trägermedium. Sie können in Heften, Alben und Büchern, auf Verpackungen und T-Shirts abgedruckt sowie auf (Kirchen-)Fenster gemalt oder als Reliefs in Stein gemeißelt sein, um nur einige Erscheinungsformen zu nennen.

„Film ist ein Hybrid-, ein Misch-, ein Zwittermedium, aus Fotographie (BildPerspektive, -Ausschnitt, etc.), Literatur (Zwischen- und Untertext, Erzähltheorie, etc.), Theater (Inszenierung, Schauspiel, etc.), ... - kaum jemand würde heute eine solche Behauptung unterschreiben, denn Film ist als eigenständige Kunstform anerkannt und wird darin durch eine eigene Fachwissenschaft, die Filmwissenschaft, bestätigt. Auch Comic ist eine eigenständige Kunstform, die sich durch ganz eigene, immanente, spezifische Merkmale auszeichnet. Diese Erkenntnis muss sich allerdings erst noch durchsetzen. Angesichts des Mangels einer Comicwissenschaft haben, wie oben schon erwähnt, andere Wissenschaften Comic für sich entdeckt. Ihr Blick auf das Forschungsobjekt ist durch ihre jeweilige Disziplin geprägt. LiteraturwissenschaftlerInnen sehen im Comic Literatur, KunstwissenschaftlerInnen Kunst, MedienwissenschaftlerInnen ein (Massen-)Medium usw. Damit rechtfertigen sie aus ihrem Fach heraus ihre Beschäftigung mit Comic mit zum Teil gegensätzlichen $\mathrm{Zu}$ - und Einordnungen (z.B. anspruchsvolle „Neunte Kunst“ versus triviales Populärmedium). Doch Comic ist nicht halb Literatur, halb bildende Kunst, halb Film, halb dieses und halb jenes. Zwar kann man z.B. Comic-

\footnotetext{
7 Üblich sind Onomatopöien (Soundwords, Pengwörter) für Geräusche, Blocktexte für Erklärungen in Kästchen (z.B. Zeit- und Ortsangaben, Rückblicke, etc.) und gesprochene Texte in Sprechblasen.
} 
Zeichnungen aus der Perspektive der Kunstwissenschaft heraus betrachten, aber diese Zeichnungen sind nicht Selbstzweck, sondern Mittel zum Zweck. Comic ist mehr als die Summe seiner Teile.

Eine Definition sollte so viele Merkmale wie nötig, aber so wenige wie möglich aufzählen. Mein Vorschlag: Comic ist eine narrative Sequenz aus wenigstens zwei räumlich angeordneten Bildern.

\section{Wie entsteht ein Comic?}

Spielfilm-Komödien über Comic-Zeichner, wie „Der Agentenschreck“8 mit Jerry Lewis und Dean Martin, „Ich heirate meine Frau“9 mit Bob Hope und „Wie bringt man seine Frau um"10 mit Jack Lemmon präsentieren den Schaffensprozess als eine sehr unterhaltsame, lustige Angelegenheit. In Wirklichkeit ist die Comic-Produktion ein langer, kreativer Arbeitsablauf in mehreren Schritten, der neben handwerklichem Können und Talent auch viel Geduld und Disziplin verlangt. Da es viele, bis ins Detail gehende Anleitungsbücher zum Comic-Zeichnen gibt, ${ }^{11}$ wird das Thema hier nur soweit behandelt, wie es zum besseren Verständnis des Phänomens Comic dienlich erscheint.

Wie bei anderen Berufen auch, haben sich mit der Zeit Fachbegriffe eingebürgert. Gute Anleitungsbücher verfügen zusätzlich zu den Erklärungen im Text über ein Glossar. Zwei „Wörterbuch“-Listen der wichtigsten Ausdrücke und ihrer internationalen Übersetzungen, zusammengestellt von Pascal Lefèvre, hat Eckart Sackmann online gestellt (Lefèvre 2009).

In der Regel steht die Idee einer Geschichte am Anfang. Der/die Comic-AutorIn (SzenaristIn) schreibt sie einem Drehbuch gleich mit möglichst vielen Angaben auf (Ort, Zeit, Personen, Handlung, Dialoge, etc.). Sofern reale Ereignisse, Personen, etc. vorkommen sollen, müssen die diesbezüglichen Informationen recherchiert werden.

Dieses Skript (Exposé) dient dem/r Comic-ZeichnerIn als Vorlage. Aus der Geschichte heraus entwickelt sich das Ensemble der benötigten Figuren. Hilfreich für die Entwicklung eines widerspruchsfreien Handlungsablaufs sind von Anfang an „Steckbriefe“ zu den Figuren, die auch Charaktereigenschaften festlegen.

Auf das Zielpublikum ${ }^{12}$ und das Genre ${ }^{13}$ hin werden das Aussehen der Figuren und der Zeichenstil bestimmt (Modell-Skizzen, Abb. 6). Aussehen und Zeichenstil sollen Atmosphäre schaffen und die Geschichte unterstützen. Manche Kreative

\footnotetext{
8 „Artists and Models“, USA 1955, Regie: Frank Tashlin.

9 „That Certain Feeling“, USA 1956, Regie: Melvin Frank, Norman Panama.

10 „How to Murder Your Wife“, USA 1965, Regie: Richard Quine.

11 Siehe z.B. die Online-Liste „Sekundärliteratur": http://www.comicforum.de/comicforum/show thread php?s $=\&$ threadid $=49125$.

12 Grobe Einteilung: Kinder, Jugendliche, Erwachsene.

${ }^{13}$ Funny, Krimi, Horror, etc.
} 
entwerfen zuerst die Figuren, die dann die Geschichte auf den Leib geschrieben bekommen. Wenn AutorIn und ZeichnerIn eine Person sind, zeichnet er/sie die Handlung möglicherweise aus der Routine heraus gleich in Skizzen auf das Papier (Seitenentwurf, siehe nachfolgender Text). So oder so wird die Geschichte in Bildsequenzen umgesetzt.

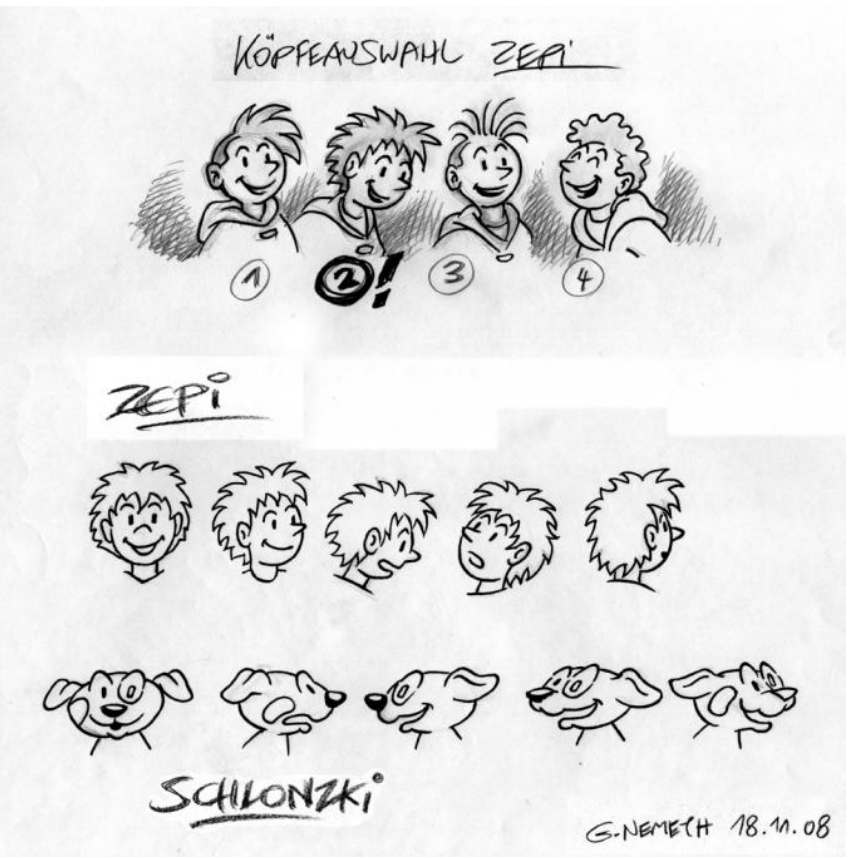

Abb. 6: Entwürfe für die Titelfigur der Comic-Reihe „Zepis Zaubergarten“ sowie
Zepis und Schlonzkis Kopf aus verschiedenen Perspektiven.

Dabei kann die Kunstform auch gezielt eingesetzt werden, um abstrakte und komplizierte Sachverhalte zu veranschaulichen. Dazu ein persönliches Erlebnis: ${ }^{14}$ Während des Psychologiestudiums erzählte ein Dozent folgende Geschichte: „Ein Zweibein sitzt auf einem Dreibein und isst ein Einbein. Da kommt ein Vierbein und nimmt dem Zweibein das Einbein weg. Da nimmt das Zweibein das Dreibein und schlägt das Vierbein.“ Wir StudentInnen sollten diese Geschichte nacherzählen, kamen aber angesichts der vielen Zahlen stets durcheinander. Dann erzählte uns der Dozent die Geschichte nochmal: „Ein Mensch sitzt auf einem Hocker und isst ein Hühnerbein. Da kommt ein Hund und nimmt dem Mensch das Hühner-

\footnotetext{
14 Das folgende Experiment ist im Kontext Informationsverarbeitung im Gehirn und Gedächtnistraining sehr beliebt.
} 
bein weg. Da nimmt der Mensch den Hocker und schlägt den Hund.“ Durch die Verbildlichung spielte sich das Geschehen vor unserem inneren Auge ab. Jetzt konnte jede/ $r$ die Geschichte von dem Menschen (Zweibein), dem Hocker (Dreibein), dem Hühnerbein (Einbein) und dem Hund (Vierbein) nacherzählen, sich merken, und auch Rückübersetzen in den Zweibein-Dreibein-Einbein-VierbeinAblauf. Dieses Experiment kann auf Comics übertragen werden. Wenn die Möglichkeiten der Kunstform adäquat genutzt werden, lassen sich nicht nur unterhaltsame Geschichten erzählen, sondern u.a. auch Vorgänge aus der Chemie, Physik, Mathematik usw. zum besseren Verständnis veranschaulichen.

Dem/r ZeichnerIn stehen zahlreiche textliche und graphische Mittel und Gestaltungsmöglichkeiten zur Verfügung: Zeichen wie Bewegungslinien (= Geschwindigkeit), Sterne (= Schmerz), Spiralen (= Benommenheit), Noten (= Musik), Glühbirne (= Geistesblitz), Herz (= Liebe), Eiszapfen (= Gemütskälte), Zeichen wie Sprech- und Gedankenblase, Panel- und Blockrand, Sehlinien und Hinweispfeile, Frage- und Ausrufezeichen (= sich fragen/sich wundern und etwas erkennen/verstehen), Onomatopöien (lautmalende Pengwörter), und vieles mehr. Die jeweiligen Bildmotive können durch Bildaufbau, Perspektive, Ausschnitt, Größe, Nah-/Fern-Einstellung etc. gestaltet werden. ${ }^{15}$ Das Anleitungsbuch „How to draw Comics the Marvel way" zeigt im Kapitel Komposition anhand von Gegenüberstellungen, wie durch den gezielten Einsatz dieser Mittel und Gestaltungsmöglichkeiten die Dramatik der Handlung durch die Bilder gesteigert werden kann (vgl. Buscema; Lee 1986: 109-123).

Alle diese Mittel und Gestaltungsmöglichkeiten können, aber sie müssen nicht verwendet werden. So gibt es Comics, die auch ohne Panelränder um die Bilder herum funktionieren. Der/die AutorIn und ZeichnerIn kann Text einsetzen oder auch darauf verzichten. ${ }^{16}$ Gesprochener Text kann in einer Sprechblase eingefangen sein, aber auch ohne diese frei im Bild oder an/unter den Bildrand plaziert sein, solange gewährleistet ist, dass er der sprechenden Figur zugeordnet werden kann.

Nicht nur die Bildsequenzen an sich, auch ihre organische Verteilung auf dem Papier $^{17}$ sind für das Funktionieren des Comics wichtig. Der Seitenentwurf (Seitenaufriss) soll sich an der Handlung orientieren und die Vermittlung unterstützen. Z.B. kann der Fluss der Bilder dynamischer oder ruhiger verlaufen, je nachdem welcher Rhythmus gebraucht wird. Es können auch Layouts entstehen, die sich weit vom üblichen Neben- und Untereinander der Panels entfernen.

\footnotetext{
${ }_{15}$ Dass diese Gestaltungsmöglichkeiten auch aus anderen Kunstformen (Malerei, Fotographie, Film, etc.) bekannt sind, nimmt dem Comic nicht seine Eigenständigkeit, denn diese Gestaltungsmöglichkeiten stehen diesen anderen Kunstformen ebenfalls lediglich nur zur Verfügung.

${ }^{16}$ Gerade hierin liegt ein Vorteil des Comics gegenüber anderen Kunstformen. Ein Beispiel: Die Bildsequenzen auf den Flugzeug-Sicherheitsanweisungen zeigen bzw. erklären ohne Text und dadurch international verständlich, wie man sich bei Notsituation verhalten soll.

17 Oder was immer als Trägermedium dienen soll.
} 
Dazu Beispiele des integrierenden Prinzips: ${ }^{18}$ In „Elektra Lives Again“ zeigt ein die ganze Seite füllendes Panel eine über mehrere Stockwerke gehende Treppe (Miller; Lynn 1991: 15; Online-Abb. s. Gravett 2009). Ein Mann steigt diese Treppe hinunter und zieht sich dabei einen Bademantel über. Der Mann ist in seiner Bewegung gleichzeitig an neun Stellen in diesem einen Panel zu sehen. Auch so kann eine Sequenz zustande kommen. In „Amazing Spider-Man Spidey Sunday Spectacular“ Nr. 1 zeigt eine Doppelseite die gesamte Wohnung Spider-Mans (Lee; Marcos 2011: 8-9). Dieser ist in diesem einen Grundriss-Panel sieben Mal zu sehen: Als eine Sequenz gezeichnet kommt er durchs Fenster ins Wohnzimmer, wechselt im Schlafzimmer seine Kleidung, wäscht sich im Bad die Hände und geht in die Küche.

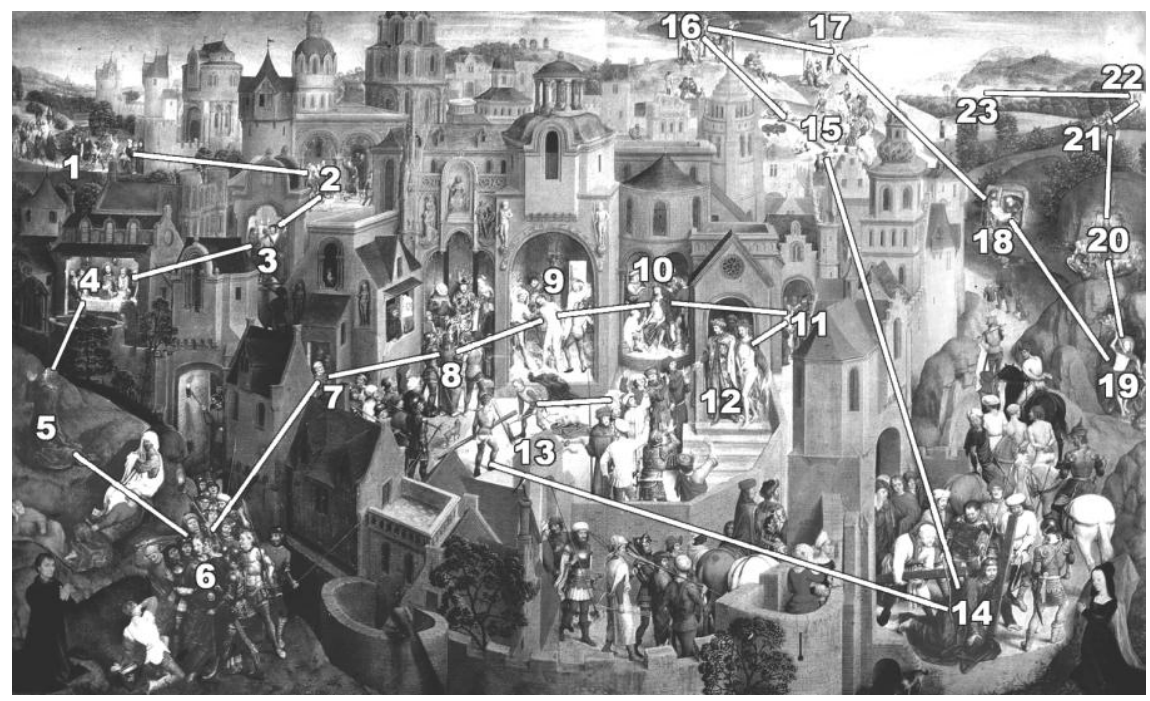

\begin{abstract}
Abb. 7: Eckart Sackmann hat den Ablauf des Leidensweges Jesu Christi im Simultanbild „Turiner Passion“ gekennzeichnet (Sackmann 2006/2009 und Sackmann 2006: 9-10; für die s/w-Abb. modifiziert)
\end{abstract}

In „Basel Beach“ ist auf einer ganzen Seite ein Flussufer zu sehen, während die Figuren bis zu fünf mal in diesem einen Panel vorkommen (Mawil 2004: k.S.a.). Die Comic-Sonntagsbeilagen mehrerer US-amerikanischer Zeitungen präsentierten am 25. März 1934 diese Folge von Frank Kings Comic-Serie „Gasoline Alley“: Auf der ganzen Zeitungsseite entfaltete sich eine große Baugrube, wobei die Gesamtansicht wie bei einem Puzzle aus zwölf Panels zusammengesetzt war (Online-Abb. King 1934.) In jedem Panel waren Frank Kings Figuren zu sehen und trugen die Handlung voran. Diese Seitengestaltung wurde wiederholt: Am 15. April 1934 war

${ }^{18}$ Es gibt natürlich noch viel mehr als die hier genannten Beispiele. 
der Hausbau schon so weit gediehen, dass der erste Teil eines Holzgerüstes zu sehen war. Am 22. April 1934 wurde schließlich ein zweistöckiges Holzhaus gezeigt, auf dem und um das herum die Kinder spielten, in jedem der zwölf Panels (Gravett 2009).

Gleich, ob sich die enge Bildfolge auf einer Treppe, in den Zimmern einer Wohnung, an einem Ufer, oder in und um ein Haus herum abspielt; ob sie in einem Comic-Album, einem Comic-Heft oder einer Zeitungsbeilage abgebildet wird: man hat es mit einem Comic zu tun. Auch das Gemälde „Turiner Passion“ geht in diese Richtung: Das Motiv zeigt die Leidensgeschichte Jesu Christi in dreiundzwanzig Szenen, die vor und in eine Stadt als Hintergrund plaziert wurden. ${ }^{19}$ Einige Stationen sind vom Ablauf her sehr eng miteinander verbunden (Abb. 7).

Dem Seitenentwurf folgt die Roh- bzw. Vorzeichnung, traditionell mit Buntoder Bleistift und moderner via Zeichenprogramm am Computer. Der/die ZeichnerIn legt sich in Bezug auf die Bildelemente fest und Panel für Panel nehmen die Details Gestalt an. Sofern die Comic-Geschichte in keiner reinen Phantasie-Welt spielen soll, dienen Bilder von Schauplätzen, Kleidung, Möbeln, Maschinen, usw. bis hin zu zeit- und ortsbedingten Verhaltensweisen, Gesten, Mimik, usw. als Vorlagen für die eigene Darstellung (Abb. 8). Bei Bedarf werden die Stellen für den Text eingezeichnet ${ }^{20} \mathrm{bzw}$. freigehalten, der im nächsten Schritt eingefügt wird.

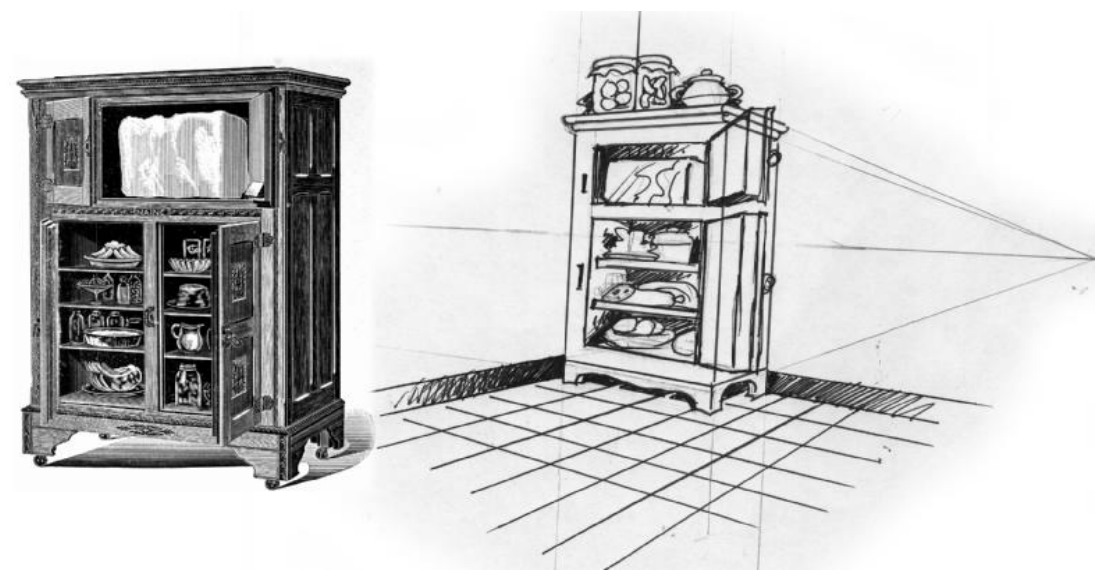

Abb. 8: Eisschrank-Detail-Skizze für die Comic-Folge „Zepis Zaubergarten“ für „Weite Welt - Magazin für Aufgeweckte“ Sept. 2009 (Nemeth 2009), mit Bleistift.

\footnotetext{
19 „Turiner Passion“ (um 1470) von Hans Memling. Siehe Sackmann 2006.

${ }^{20}$ Sprech- und Gedankenblasen usw.
} 
Bei der anschließenden Reinzeichnung werden die vorgezeichneten Konturen und entsprechenden Flächen schwarz nachgezeichnet (Abb. 9), mit Tuschefeder, Filzstift oder am Computer. Dabei sind noch Korrekturen möglich, etwa wenn ein eingefügter Text über die vorgezeichneten Ränder einer Sprechblase hinausgeht, wird diese jetzt entsprechend größer gemacht. Um eine schwarz/weiß-Version des Comics als Ergebnis zu erhalten, werden danach die Buntstiftstriche herausgefiltert oder wie die Bleistiftstriche wegradiert.

Manche Comics bleiben schwarz/weiß, weil die Kontraste zur Geschichte passen. Oder Zeichnungen bekommen durch graue Flächen Plastizität verliehen. Eine oder mehrere Schmuckfarben können Akzente setzen. Meistens sollen Comics bunt sein und werden entsprechend mit Pinsel, Farbstiften oder am Computer eingefärbt.

Im Rahmen einer Arbeitsteilung bzw. Team-Arbeit werden die einzelnen Arbeitsschritte von verschiedenen bzw. mehreren KollegInnen geleistet. Soweit der kreative Teil. Danach fängt der technische Teil der Produktion an, an dessen Ende dann in der Regel der gedruckte Comic steht.

Wer sich auf Comics einlässt kann auf mehreren Ebenen ein sinnliches Erlebnis haben. Formen und Flächen in Farben oder auch nur schwarz/weiß, Bilder voller Dynamik, und dazu die eigentliche Comic-Geschichte. Und unter bestimmten Bedingungen kann die Kunstform den RezipientInnen auch multi-sensorische Eindrücke vermitteln. Indirekt sieht, hört, riecht, schmeckt und fühlt der/die RezipientIn dann mit den Figuren mit. Das Phänomen heißt Synästhesie. 

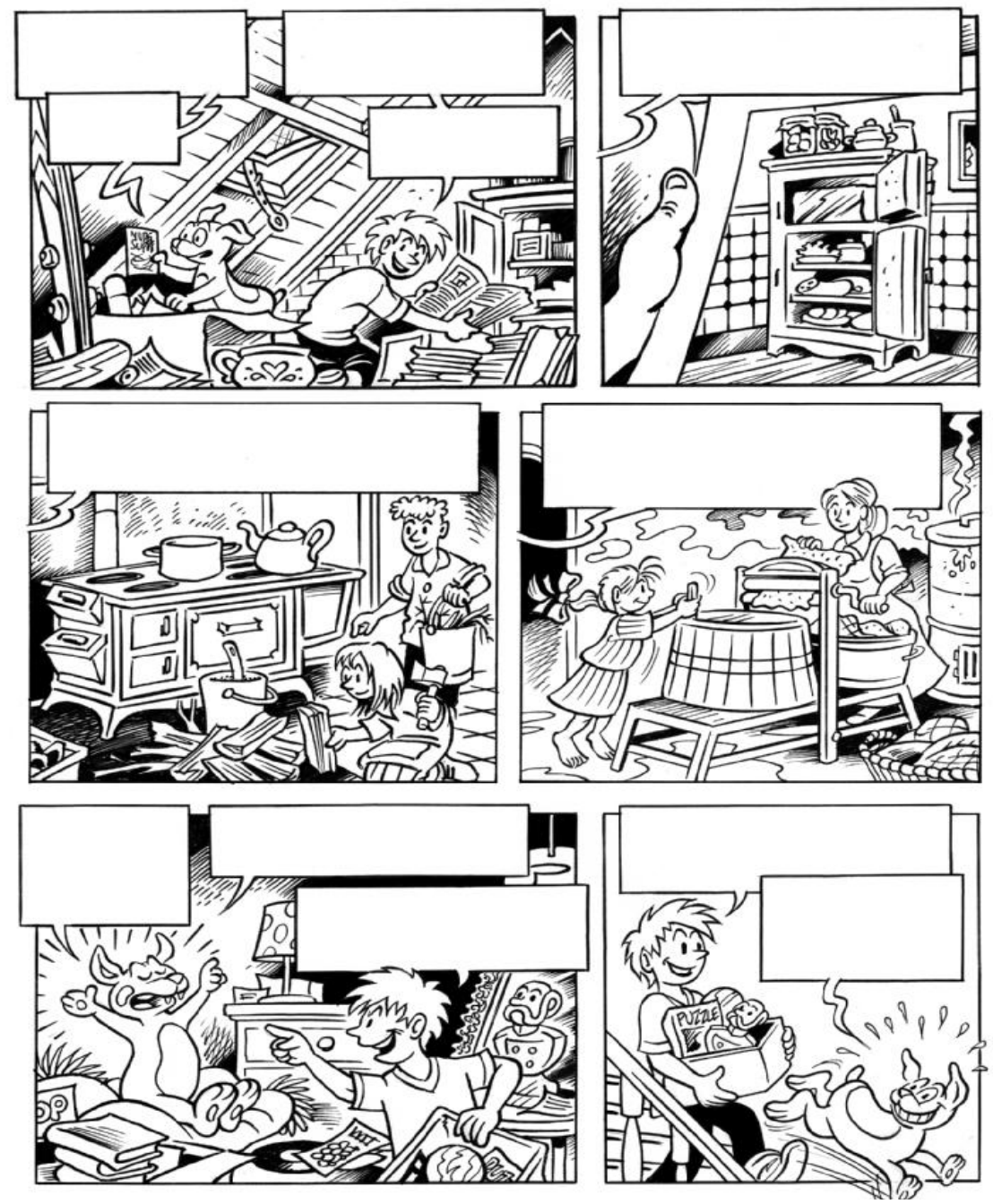

Abb. 9: Reinzeichnung der Comic-Folge „Zepis Zaubergarten“ für „Weite Welt Magazin für Aufgeweckte“ Ausgabe September 2009 (Nemeth 2009), mit Tusche.

\section{Geschichte der Comics}

Wenn es um die Geschichte der Comics geht, bemühen viele FachautorInnen den Zeitungskrieg in New York Ende des 19. Jahrhunderts, um zu beweisen, dass „die Comics tatsächlich in Amerika entstanden“ wären: „Die Väter waren Europäer, die 
Mutter war das westliche Kulturgut, die Wiege aber stand in Nordamerika." (Fuchs; Reitberger 1978: 22).

Im 19. Jahrhundert erfreuten sich Bilderbogen und Bildergeschichten der humoristisch-satirischen Presse („La Caricature“, „Charivari“, „Fliegende Blätter“, „Meggendorfer Blätter“, „Kladderadatsch“, „Ulk“, „Der wahre Jacob“, usw.) in ganz Europa größter Beliebtheit - auch in Amerika. EinwanderInnen brachten die Bildergeschichten mit in ihre Neue Welt, und so wurden sie rasch verbreitet. Sie lagen an öffentlichen Plätzen aus, wie in Kaffeehäusern, Bibliotheken und Geschäften, in denen die ImmigrantInnen verkehrten. Dem Trend der steigenden Popularität folgend wurden nach europäischem Vorbild eigene satirische Zeitschriften gegründet, wie zum Beispiel „Puck“ und ,Judge“.

Ab 1830 setzten die amerikanischen Zeitungsverlage die Dampfpresse ein, die eine größere Druckkapazität ermöglichte. Für eine optimale Auslastung der Maschinen ließen die Zeitungsverleger höhere Auflagen drucken. Jedoch musste für einen gleichfalls steigenden Absatz eine breite LeserInnenschaft gewonnen werden. Es entwickelte sich ein harter Konkurrenzkampf zwischen den Verlagshäusern. Um die Gunst der LeserInnen bemüht sorgten die Verleger nicht nur für neuen Lese-, sondern auch für neuen Bilderstoff und druckten humoristische Bildergeschichten ab (vgl. Fuchs; Reitberger 1978: 13).

Das „New York Journal“ wurde von William Randolph Hearst herausgegeben. Durch den Erfolg der Bildergeschichten im Konkurrenzblatt „New Yorker World“ in Zugzwang geraten engagierte er den Zeichner Rudolph Dirks, ${ }^{21}$ eine Serie zu entwickeln, mit dem ausdrücklichen Hinweis: „something like Max und Moritz“ (Knigge 2004: 23). William Randolph Hearst hatte als Kind die englische Übersetzung von Wilhelm Buschs Bildergeschichte gelesen und sie auf einer Europareise wiederentdeckt (ebd.). Am 12. Dezember 1897 erschien die erste Folge der „Katzenjammer Kids“ in der Sonntagsbeilage „American Humorist“. Ein Kauderwelsch aus Deutsch und Amerikanisch sprechend treiben die Brüder Hans und Fritz diabolische Streiche gegen die Mutter, den Stiefvater (der Seemann „Captain“), den Schulinspektor und schließlich gegen alles und jeden. Einige Fachautoren sprechen hier vom ersten Comic Strip bzw. Comic: „Dank der Aufteilung in Felder, dem Blasendialog, dem Wirbel der Ereignisse um ein feststehendes Personal sind ,The Katzenjammer Kids' der erste richtige Comic Strip [...].“ (Metken 1970: 26).22 Sein Verdienst laut Andreas C. Knigge:

Dirks war der erste Zeichner, der in den Sonntagsbeilagen nicht nur Gags vorführte, sondern aus dem Alltag gegriffene Geschichten erzählte, die sich aus einer festen Figurenkonstellation ergaben und sich später oft über mehrere Monate erstreckten. Und er erfand ein Repertoire bildsprachlicher Mit-

\footnotetext{
${ }^{21}$ Rudolph Dirks, geboren am 26. Februar 1877 in Heide/Deutschland, gestorben am 20. April 1968 in New York.

22 Vgl. auch Zimmermann 1970: 11, Schröder 1982: 21, Habarta; Havas 1992: 10 („Die ZeitungsStrips").
} 
tel, die der Comic bis heute benutzt: Wenn eine Figur rennt, zeigt Dirks das durch Speedlines, erhält jemand einen Schlag, signalisieren kleine Sternchen Schmerz, und wer einen Tritt in den Hintern bekommt, dessen Allerwertester weist anschließend einen markanten Fußabdruck auf. (Knigge 2004: 24.).

Die „New Yorker World“ wurde von Joseph Pulitzer herausgegeben. Er hatte das Blatt zum Prototyp der modernen Massenpresse gemacht, mit Balkentiteln, Sensationsartikeln, breitem Sportteil und vielen Illustrationen. Für die farbige Sonntagsbeilage „Sunday World“ engagierte er den Zeichner Richard Felton Outcault, ${ }^{23}$ bekannt durch humoristische Arbeiten in der Zeitschrift „Truth“. Die Witzzeichnungen zeigten wechselnde Schauplätze aus dem New Yorker Slummilieu, doch am häufigsten wurde „Hoogan’s Alley“ gezeigt. Das Treiben der Straßenkinder in den Hinterhöfen der billigen Mietskasernen wurde dabei eher unverbindlich lustig als sozialkritisch dargestellt. Es waren ganz- oder halbseitige Illustrationen im Stil der humoristischen Presse, bei denen Outcault teilweise schon mit Sprechblasen experimentierte. Da Richard Felton Outcaults Zeichnungen ab dem 5. Mai 1895 in der Beilage erschienen, wurde 1995 international der 100. Geburtstag der Comics gefeiert. ${ }^{24}$ Die Serie wurde später „Yellow Kid“ genannt, auf Grund der gelben Hemdfarbe der beliebten Hauptfigur, eines kahlköpfigen, mongolisch aussehenden Jungen mit Segelohren. 1896 wechselte Richard Felton Outcault zum „New York Journal“. Dass ab dem 25. Oktober 1896 die „Yellow Kid“-Geschichten dort nicht mehr als Wimmelbilder, sondern mit Sprechblasen in Sequenzen erschienen, macht diese Serie in den Augen einiger FachautorInnen zum ersten Comic (u.a. Habarta; Havas 1993: 28, Knigge 2004: 21, Platthaus 2008: 19-21).

Der erste Comic? Ulrich Pohl (Rolf Kauka Verlag) ging dafür in der Zeit weiter zurück: „1865 schlägt die Geburtsstunde der deutschen Bildgeschichten, der Comic-Strips überhaupt: Wilhelm Buschs Böse-Buben-Posse ,Max und Moritz erscheint." (Pohl 1970: 16). Andere FachautorInnen bezeichnen Wilhelm Busch25 als den „Vater der Comics“ und seine Bildergeschichten lediglich als „Vorformen“ und „Wurzeln“ der Comics. In ihrem „Comics Handbuch" konstatierten Wolfgang J. Fuchs und Reinhold Reitberger zwar, auf „Max und Moritz“ träfen „die meisten Definitionen für Comics zu“, relativierten aber die Bedeutung des Künstlers:

Erscheinungsweise in Fortsetzungen, regelmäßig wiederkehrende Figuren, Zeichnungen und Texte, die sich ergänzten; diese Bedingungen der Definition von Comics erfüllte Busch. Aber er beherrschte auch Onomatopöien, lautmalende Worte, wenngleich er sie nicht groß ins Bild schrieb: „Rickeracke! Rickeracke! / Geht die Mühle mit Geknacke." Selbst action lines zur Andeutung von Bewegung findet man bei Busch, etwa im [Bilder-]Bogen

\footnotetext{
${ }^{23}$ Richard Felton Outcault, geboren am 14. Januar 1863 in Lancaster/Ohio, gestorben am 25. September 1928 in Flushing/New York.

24 Siehe als Beispiele der Presseberichterstattung Panskus 1995 und Althen 1995.

25 Wilhelm Busch, geboren am 15. April 1832 in Wiedensahl, gestorben am 9. Januar 1908 in Mechtshausen.
} 
„Der Klaviervirtuose“. Es wäre allerdings zu hoch gegriffen, Busch nun gleich zum Vater der Comics schlechthin zu erklären. (Fuchs; Reitberger 1978: 12.; ebd.: 16-18).

Wilhelm Busch war sich bewusst, dass er mit Zeichen arbeitete, als er seine Figuren in den Geschichten auf groteske Art und Weise quälte und sie dabei unmenschliche Formen ${ }^{26}$ annehmen ließ. Er schrieb:

Lachen ist ein Ausdruck relativer Behaglichkeit. Der Franzel hinterm Ofen freut sich der Wärme um so mehr, wenn er sieht, wie sich draußen der Hansel in die rötlichen Hände pustet. Zum Gebrauch in der Öffentlichkeit habe ich jedoch nur Phantasiehanseln genommen. Man kann sie auch besser herrichten nach Bedarf und sie eher tun und sagen lassen, was man will. Gut schien mir oft der Trochäus für biederes Reden; stets praktisch der Holzschnittstrich für stilvoll heitre Gestalten. So ein Konturwesen macht sich leicht frei von dem Gesetze der Schwere und kann, besonders wenn es nicht schön ist, viel aushalten, eh' es uns weh tut. Man sieht die Sach an und schwebt derweil in behaglichem Selbstgefühl über den Leiden der Welt, ja über dem Künstler, der gar so naiv ist. (Busch 1959: 20f.).

Der erste Comic? Thierry Groensteen ging in der Zeit noch weiter zurück: „Wenn ein Datum angeführt werden soll, das den Beginn der Ausdrucksform markiert, die später Comic genannt wird, so ist es das Jahr 1835, das man sich merken muß, das heißt das Jahr, in dem das Buch ,Die Geschichte des Monsieur Jabot' in Umlauf gebracht wurde." (Groensteen 2000: 15). Zwar, so Thierry Groensteen, war Rodolphe Töpffer ${ }^{27}$ nicht der erste, der mit dieser neuen Ausdrucksform experimentiert hat, doch wäre „die Verbreitung des ersten Buches von Töpffer (das in ganz Europa verkauft und bald auch übersetzt wurde) ein entscheidendes Kriterium.“ (Groensteen 2000: 15). Und David Kunzle schreibt in seinem Buch „Father of the Comic Strip: Rodolphe Töpffer“: „A word on terminology: Töpffer called his invention by all kinds of disparaging terms, and more formally, as ,histoire en estampes $^{6}$ (story in prints, picture story). I use the terms picture story and comic strip indifferently; [...].” (Kunzel 2007: XI).

\footnotetext{
${ }^{26}$ Oft werden die Körper auf unnatürliche Weise verdreht oder gekrümmt. Eispeter zerfließt.

${ }^{27}$ Rodolphe Töpffer, geboren am 31. Januar 1799 in Genf, gestorben am 8. Juni 1846 in Genf.
} 

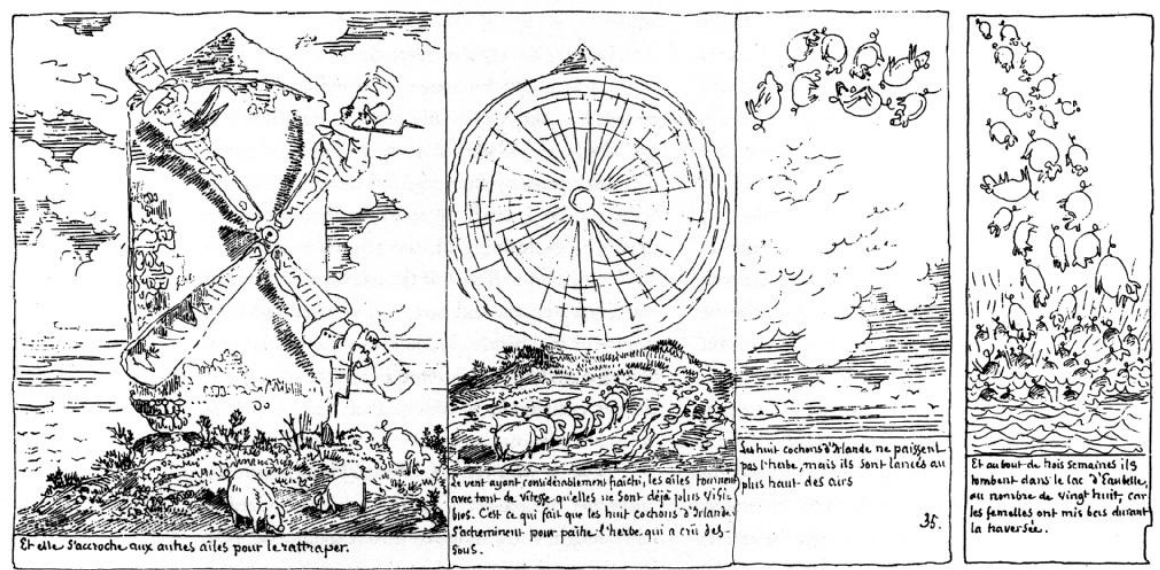

Abb. 10: Bildsequenz aus Rodolphe Töpffers „Voyages et Aventures du Docteur Festus“, veröffentlicht 1840 (Kunzle 2007: 80).

Zwischen 1827 und 1844 vollendete Rodolphe Töpffer sieben Bildromane, die nach und nach veröffentlicht wurden. Zu seinen Texten, die stets unter den Bildmotiven standen (Abb. 10), erklärte er in der Einleitung seiner „Geschichte des Monsieur Jabot“: „Jede dieser Zeichnungen wird von einer oder zwei Zeilen Text begleitet. Ohne diesen Text hätten die Zeichnungen nur eine verschwommene Bedeutung; der Text würde ohne die Zeichnung nichts bedeuten.“ (Zitiert von Groensteen 2000: 16). 1845 schrieb er über seine „Literatur in Bildern“ den „essai de physiognomonie":

Man kann Geschichten schreiben mit Kapiteln, Zeilen, Wörtern: das ist wirkliche Literatur. Man kann Geschichten schreiben in Bildern und fortgesetzten Szenen: das ist Literatur in Bildern. [...] Die Literatur in Bildern hat Vorteile eigener Art: durch den Reichtum an Details erlaubt sie eine recht konzise Ausdrucksweise. [...] Sie hat auch den Vorteil eigener Art, sich irgendwie intuitiv erfassen zu lassen und demgemäß von recht großer Klarheit zu sein. (Toepffer 1980: 1).

Das Wesen und die Sprache von Comics (Induktion, Abstraktion, Ausdruckszeichen, etc.) wurden hier weitgehend bereits von ihm dargelegt. Hinsichtlich seiner Striche, die nur Mittel zum Zweck sein sollten, und seiner engen Bildfolgen schrieb er:

Schließlich und endlich ist die Strichzeichnung unvergleichlich vorteilhaft wenn sie, wie in einer Bildgeschichte, dazu dient, schnelle und fortlaufende Skizzen zu machen, die nur lebhaft und amüsant sein müssen und die, als Glieder einer Serie oft nur an Ideen erinnern, wie Symbole oder in einer Re- 
de verstreute rhetorische Figuren und nicht integrierende Kapitel des Hauptthemas darstellen. (Toepffer 1980: 9).

Wer von den genannten Zeichnern hat denn nun den oder die ersten Comics geschaffen? Das hängt von der Comic-Definition ab: Muss Text vorkommen? Muss der Text in Sprechblasen stehen? Muss eine Massenproduktion vorliegen? Usw. Etliche Definitionen machen Comics an Inhalten (Funny, Abenteuer, etc.), dem äußeren Erscheinungsbild (Sprechblasen, Panelkästchen, etc.), dem Umfeld (Zeitungsbeilage, hohe Auflagen, etc.) und/oder dem Einfluss auf andere KünstlerInnen fest. Indem FachautorInnen diese oder jene Merkmale weglassen oder hinzufügen, kann beinah alles ein Comic und damit auch der ,erste“ Comic sein, oder auch nicht. Wer sich hier erstmal auf (s)eine Definition festgelegt hat, hält oft daran fest, selbst wenn neue Entdeckungen und Erkenntnisse sie widerlegen. Was in der Vergangenheit geschrieben wurde, wird selten hinterfragt oder aktualisiert, sondern oft einfach nur reproduziert. Daher existieren nicht nur verschiedene ComicDefinitionen nebeneinander, sondern auch verschiedene Comic-Geschichtsschreibungen.

Für andere FachautorInnen sind diese Definitionen und Geschichtsschreibungen keine endgültigen Dogmen. Stattdessen sehen sie das Wissen über Comics einem fortlaufenden Erkenntnisprozess unterworfen. Diese Einstellung öffnet den Weg zur einer Comic-Geschichte, in der einerseits Rudolph Dirks, Richard Felton Outcault, Wilhelm Busch und Rodolphe Töpffer Namen und Stationen sind, die aber andererseits weiter zurückreicht.

Eckart Sackmann veröffentlicht auf seiner Internetplattform patrimonium.de nicht nur seine Aufsätze zur Comic-Definition, sondern auch eine daraus resultierende Übersicht von „Comics im Mittelalter“ (Sackmann 2006/2009) mit Bildern von Handschriften, Bilderbögen und -rollen, Wand- und Tafelmalereien, Steinund Bronzeplastiken, Mosaiken, Glasfenstern und Teppichen. In seiner Reihe "Jahrbuch der deutschen Comicforschung" liefern AutorInnen detailierte Betrachtungen, so zu einer/m „Sigenot“-Handschrift/Druck (15. Jh., Grünewald 2005), zu Hans Memlings Gemälde „Turiner Passion“ (um 1470, Sackmann 2006), zur Freiburger Bilderbibel (um 1410, Neuner-Warthorst 2009), zum Evangeliar Heinrichs des Löwen (12. Jh., Sackmann 2007b) und zur Berliner „Eneide“-Handschrift (12. Jhr., Grünewald 2012). Eckart Sackmann verfolgt die Spur der Comics zurück bis zum „Papyrus des Hunefer“ (1300 v. Chr. Ägypten), der von der Reise des Verstorbenen ins Land der Toten und seiner Prüfung erzählt: „Die älteste bekannte sequentielle Bild-Erzählung, eine Szene in drei Bildern vom Wägen des Herzens, arbeitete bereits mit Dialogtext. Die Leserichtung des Textes verlief jeweils auf den Mund des Sprechers zu [...].“ (Sackmann 2007a: 7, Abb. 11). 


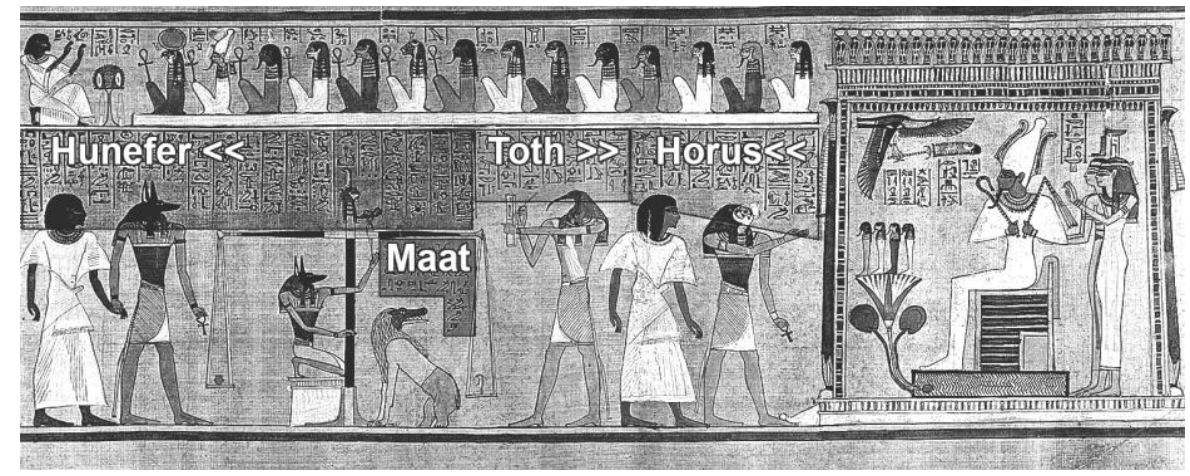

Abb. 11: Drei der vier Bilder des Papyrus des Hunefer (1300 v. Chr.) zeigen seinen Weg ins Jenseits. Die Texte über den Köpfen müssen in Richtung zum Mund des jeweils Sprechenden hin gelesen werden und erinnern an Sprechblasen. (Sackmann 2006/ 2009 und Sackmann 2009: 7; für die s/w-Abb. modifiziert)

\section{Comics versus Mangas}

„Japanische Comics heißen Manga, aber nicht alle Manga sind Comics.“ (Berndt 1998: 1). Die Bezeichnung Manga setzt sich aus zwei japanischen Schriftzeichen zusammen: „Das erste ,man' gelesene steht für ,spontan, impulsiv, ziellos' und damit auch für die Rhetorik der Übertreibung, für humoristische Traditionen und eine Abkehr von bestehender Ordnung. Das zweite, ga' gelesene heißt ,Bild', früher im Sinne der Verwendung von Pinsel und Tusche bzw. Kalligraphie und monochrome Tuschmalerei, seit dem 20. Jahrhundert unter dem Einfluß US-amerikanischer Comics im Sinne von ,Zeichnung “". (Ebd.: 4f.). Von daher umfasst die Bezeichnung nicht nur Comics unterschiedlicher Länge, sondern auch Einzelbilder, wie z.B. Karikaturen.

So groß die Vielfalt von Manga ist, so weit gehen die Meinungen über ihre Geschichte auseinander: Die einen FachautorInnen sehen den Ursprung in den „emakimono“, illustrierten Erzählungen auf Handrollen aus dem 11./12. Jahrhundert. Andere berufen sich auf satirische Skizzenbücher der Edo-Zeit (17. bis Mitte 19. Jahrhundert). Und wieder andere machen die Bezeichnung an den längeren und komplexeren Geschichten des Comic-Autors und -Zeichners Osamu Tezuka fest, die dieser nach dem Zweiten Weltkrieg zeichnete. Letztere werden auch StoryManga genannt (Brunner 2010: 15-16).

Während sich die Story-Manga („sutôrî manga“) an ein jüngeres Publikum wandten, entwickelten sich in der zweiten Hälfte der 1950er Jahre die „Dramatischen Bilder“ („gekiga“) für ein älteres Publikum (Köhn 2005: 233f.). Charakteristisch waren u.a. ein hoher Grad an Realismus in der Darstellung, eine betont filmische Erzählweise, die Hervorhebung des psychologischen Profils der Protagonis- 
ten und die Thematisierung gesellschaftlicher Antihelden (ebd. 236). Neben die vermehrte Verwendung von Energielinien zur Steigerung der Dynamik der Geschichten trat „eine weitere Darstellungsform, die sich zu einem entscheidenden Markenzeichen des modernen Manga entwickeln sollte: die subjektive Energielinie, die anstelle der eigentlichen Hintergrunddarstellung tritt und Bewegung somit nicht mehr objektiv in Relation zu einem statischen Hintergrund setzt, sondern aus der Sicht des dargestellten Handlungsträgers subjektiv erfahrbar macht [...]. “ Lautmalereien wurden „,nun in erster Linie als Bestandteile der bildlichen Ebene wahrgenommen“. [...]

Lange (filmische) Sequenzen von Rahmen, die in vielen Fällen gänzlich ohne einen Mitteilungstext auskommen, dienen zur Beschreibung komplexer Vorgänge und fangen durch die Konzentration auf einzelne Handlungsaugenblicke [...] oder durch die Verwendung einer fließenden Kameraführung [...] verschiedene Aspekte einer einzelnen Szene ein, wodurch erstmalig der Eindruck einer überwiegend bilddominanten epischen Erzählweise vermittelt wird. (Ebd. 239f.).

Ab den 1960er Jahren entstanden Geschichten für Jungen, Jugendliche und Erwachsene, die die „,beiden etablierten Erzählformen sutôrî manga und gekiga“ miteinander verbanden (Köhn 2005: 244).

Die Dominanz überwiegend aktionsbetonter Geschichten führte zur Ausbildung einer Vielzahl unterschiedlicher Genres. Neben zahlreichen Historiendramen [...] oder Mysterygeschichten [...] bestimmten bald schon temporeiche SF- und Horrorgeschichten [...] das Geschehen. (Ebd.: 245). Auffällig bei all diesen Geschichten ist die Verwendung einer weitgehend klassischen Rahmengestaltung unter Einsatz der aus dem gekiga entlehnten Elemente zur Dramaturgiesteigerung [...]. (Ebd.: 246). Selbst in reinen Gag- und Nonsensgeschichten [...], die durch groteske Übertreibung und Verzerrung gerade die vertraute Wirklichkeitserfahrung und Wertvorstellung der Leser ad absurdum führen wollten, hatten sich die Darstellungskonventionen der fusionierten Erzählformen sutôrî manga und gekiga soweit durchsetzen können, daß nicht mehr der Inhalt die Form bestimmte, sondern das Medium [...] für die Gestaltung der Geschichte allein verantwortlich war [...]. (Ebd.: 246f.).

Den Comics für Jungen (shōnen manga) und für junge Männer folgten gegen Ende der 1960er Jahre die sogenannten Mädchencomics (shöjo manga, ebd.: 247).

Im Gegensatz zu ihren männlichen „Vorgängern“ thematisierte die junge Zeichnerinnengeneration zum ersten Mal das psychische Innenleben der Trägerinnen der shöjo-Kultur. Im Mittelpunkt stand hierbei meist die Adoleszenzphase der Protagonistinnen, die als seelisches Moratorium empfunden wird, eine Zeit also, in der das völlige Verschließen vor der Außenwelt einen 
wesentlichen Teil des unausweichlichen Reifungs- und Selbstfindungsprozesses darstellt. [...] Im Gegensatz zu einer aktionsbetonten, von einem Höhepunkt zum anderen unaufhaltsam weitereilenden Handlung, die im Falle der Geschichten für Jungen und Jugendliche gerade auf den Einsatz dynamiksteigernder narrativer Elemente setzte, mußten nun für die Innenschau der Protagonistinnen, die häufig zu einem völligen Stillstand des Handlungsverlaufs in einer Szene führte, neue konventionalisierte Gestaltungsmittel gefunden werden, um das Dynamikdefizit während des Leseprozesses durch psychologische Tiefe zu kompensieren. (Ebd.: 251).

Stilbildend wurden

die sehr feminin wirkenden, großgewachsenen schlanken und wohlproportionierten Figuren mit ihren langen Beinen, wallenden, sich ornamentartig verschlingenden Haaren und den übergroßen runden Augen mit ihren langen Wimpern, in denen Sternchen oder weiße Punkte als Ausdruck der psychischen Befindlichkeit glitzern. [...] Unterstrichen wird die jeweilige Gemütsverfassung zudem noch durch teilweise unmotiviert wirkende Hintergrundornamentik im Blumendekor, die im Wechselspiel mit den Augen als Spiegelbild des Charakters bzw. der Seele ikonographisch kodiert sind [...]. (Ebd.: 252).

Das Motiv der Homoerotik bildete in den Mädchencomics ein eigenes Subgenre (shōnen-al):

Aber es geht dabei nicht in erster Linie um eine Enttabuisierung von Sexualität und schon gar nicht Homosexualität, sondern um eine Auflösung der Geschlechterdifferenz in eine Androgynität, die den Figuren wie der Leserin erlaubt, sich im anderen narzißstisch [sic!] zu spiegeln. Der Körper dient vor allem als Metapher der Innerlichkeit, und über die erotische Begegnung der Knaben wird im Medium des Manga mit neuen Modellen für zwischenmenschliche Beziehungen experimentiert. [...] Die unterschwellige Erotik, die sich hinter der Fassade des Bildungsromans verbirgt, sollte in den achtziger Jahren dann Ansatzpunkte für die pornographischen Parodien der Fanzine-Szene und für den weiblichen Soft-Porno à la Ladies' Comic [erotische Comics für Frauen] bieten. (Berndt 1998: 40). 


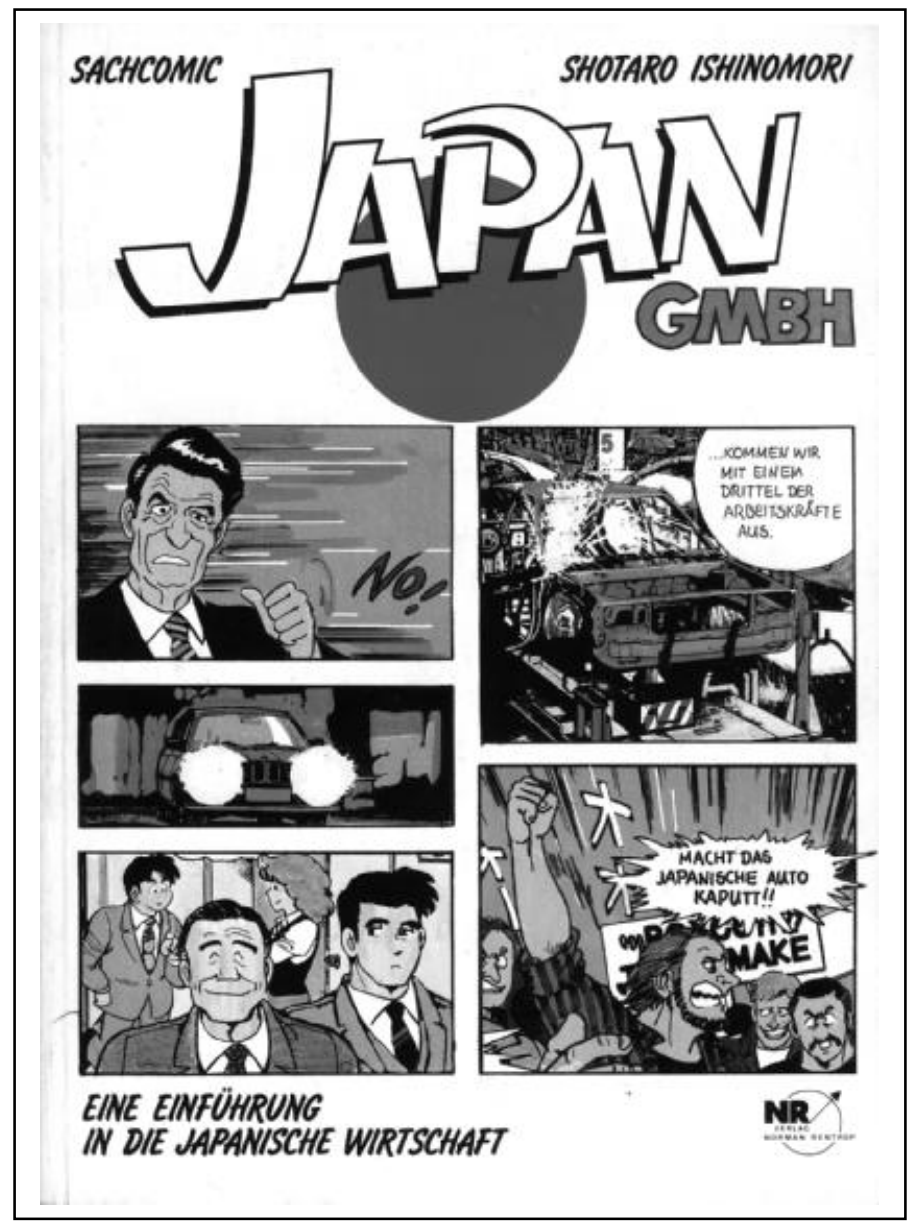

Abb. 12: Der japanische Comic „Nihon keizai nyūmon“ wurde 1989 unter dem Titel „Japan GmbH. Eine Einführung in die japanische Wirtschaft" vom Bonner Rentrop Verlag herausgegeben und gilt als eine der ersten Manga-Übersetzungen in Deutschland.

In den 1980er und 1990er kam es zu einer weiteren Modifikation, „die bis in die heutige Zeit weitgehend ihre Gültigkeit bewahrt hat,“ denn eine „,neue Generation von Zeichnern entzog sich mit ihren Werken bewußt der gängigen Darstellungspraxis,“ beeinflusst u.a. durch „die zunehmende Vernetzung weiter Bereiche der visuellen Kultur" (Animationsfilme, Computerspiele, interaktive Manga im Internet, Köhn 2005: 256f.). Mit dem Erfolg des Comics „Nihon keizai nyūmon“ von Shōtarō Ishinomori, der 1986 im Verlag einer Wirtschaftszeitung erschien, „entwickelte sich der fiktionale Sach- bzw. Bildungs-Comic zu einem neuen 
Subgenre“ (Abb. 12; Berndt 1998: 57). Zusätzlich bereichert eine aktive FanzineSzene den Manga-Markt:

In kleinen Zirkeln werden auf nichtkommerzielle Weise Manga gezeichnet, gedruckt und ausgetauscht. [...] Die „Dōjinshi“-Manga unterteilen sich in zwei Gruppen: Originalschöpfungen einerseits und Parodien anderseits. [...] Der „Lolikon“, der Kinder- wie Mädchenmanga parodierte, entstand in dieser Szene, und in seinem Gefolge stabilisierte sich dort um 1991 der „Schöne-Mädchen-Comic" [Bishōjo Comic] [...]. (Ebd.: 56).

„Ero manga/ero gekiga“:

Der erotisch-pornographische Comic - welcher Spielart auch immer - übernimmt seit den siebziger Jahren das Image des Unkonventionellen, das zuvor dem Manga insgesamt, besonders aber dem „Gekiga“ eignete. Mit seiner Betonung des Schmutzigen konterkariert er die Sauberkeit der soziokulturellen Ordnung und schafft eine unsinnige Gegenwelt zum Leistungsdruck in Firma, Schule und Familie. Folglich waren derartige Manga seit den späten sechziger Jahren immer wieder Eingriffen durch die Zensur ausgesetzt. (Berndt 1998: 54-56).

„Da nach dem Wortlaut des betreffenden Gesetzes keine Geschlechtsteile von erwachsenen Menschen gezeigt werden durften, war es kein Problem, wenn sich ein junges Schulmädchen, das vor der Pubertät steht und noch keine Schambehaarung hat, mit einem Tentakel von einem Roboter/Außerirdischen/Dämon vergnügt (,tentacle porn).“ (Weiß; Wüllner 2011: 118). „Schulmädchen in Matrosenuniform“ sind das „Aushängeschild für ein weit verbreitetes Phänomen: Lolicon. Dieser ist wiederum die Kurzform für ,Lolitakomplex ${ }^{6}$ (nach Vladimir Nabokovs Roman ,Lolita) und einer der Hauptgründe, warum Manga und Anime beim westlichen Publikum unter Generalverdacht des pornografischen Materials stehen.“ (Ebd., vgl. Berndt 1998: 52). „Besonders einfallsreich ist allerdings das Auslassen von grafischen Details an bestimmten Körperstellen oder das symbolische Verdecken selbiger [z.B. mit Gemüse, Obst oder Blumen].“ (Weiß; Wüllner 2011: 117, vgl. Berndt 1998: 54).

Ein weiterer Trick, ,um der gesetzlichen Einschränkung aus dem Weg zu gehen“, ist die hochgerutschte oder quasi durchsichtige Unterwäsche,

die ohnehin schon einen sexuellen Reiz auf männliche Japaner ausübt und in manchen Fällen so gut wie gar nichts mehr verdeckt. Unterwäsche wird erst seit der Öffnung des Landes zur westlichen Welt (USA) getragen, da es meist unüblich war, außer einem Fundoshi (Lendenschurz) unter Kimonos Unterwäsche zu tragen. [...] Der sinnliche Reiz von Unterwäsche steht in einer sich fortführenden Linie von Motiven in Manga. Stichwort Panty Shots: In Manga wird häufig ganz nebenbei bei einem kurzen Lüftchen oder in 
ähnlichen Situationen der Slip eines Mädchen unter seinem hochfliegenden Rock gezeigt. (Weiß, Wüllner 2011: 117).

Manche männlichen Figuren bekommen dabei Nasenbluten, in japanischen Manga und Anime (Zeichentrickfilme) das Zeichen für sexuelle Erregung, das sich bis zur Blutfontäne steigern kann (Abb. 13). ${ }^{28}$

Um das Befinden von Figuren und ihre Gefühle sichtbar zu machen, verwenden Mangazeichner eine eigene Symbolsprache, die sich vom westlichen Zeichencode unterscheidet und mit einem besonderen Zeichenmodus „Super-Deformed“ (SD) hervorgehoben wird. Die stilisierte Mimik der Figuren erinnert dabei an die asiatische Form der Emoticons. (Brunner 2010: 107).

Wenn japanische Manga und Anime vom Ausland übernommen werden, kann es ebenfalls zur Zensur kommen. Ein Beispiel aus den USA vom Ende der 1990er Jahre: Die Serie Pokémon sollte in Japan auch für ein älteres Publikum attraktiv sein. Und so zeigten die weiblichen Figuren mitunter viel Haut und Oberweite. In den USA wurden für die Manga-Veröffentlichung „kurze Röcke verlängert, große Brüste verkleinert und Dialogpassagen verändert, um die Serie einer jüngeren Zielgruppe anzupassen“ (Brunner 2010: 86, vgl. a. Schmidt 2006). Für die US-AnimeVersion wurden u.a. Bikini-Szenen herausgeschnitten (Kurisuteian 2009). Von Fall zu Fall greifen deutsche Verlage und Sender nicht auf das japanische Originalmaterial, sondern auf US-Vorlagen zurück. Daher können auch die deutschen Übersetzungen jene Zensuren enthalten. Zudem retuschier(t)en deutsche Verlage in einigen Fällen Hakenkreuze aus Angst vor strafrechtlicher Verfolgung und um Missverständnissen vorzubeugen, auch solche ohne NS-Bezug (Palandt 2010: 244-248; vgl. Schmidt 2006, Brunner 2010: 89).

\footnotetext{
${ }_{28}$ Weitere typische japanische Zustandszeichen sind z.B. ein großer Tropfen auf der Stirn für Verlegenheit, ein Kreuz auf der Stirn für Wut, Spiralaugen für Erschöpfung.
} 

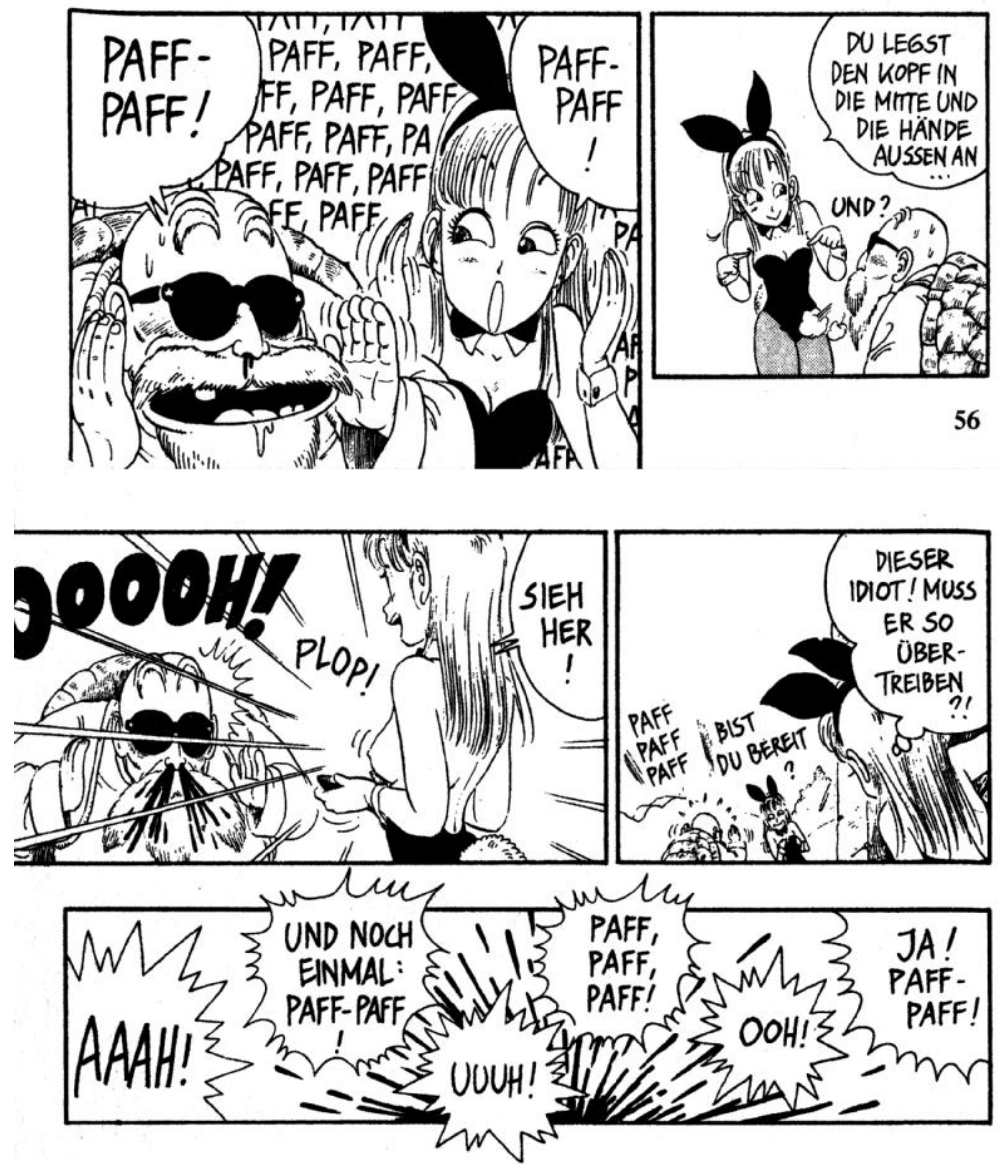

Abb. 13: Nasenbluten als Zeichen sexueller Erregung, hier zum Beispiel in der Übersetzung der japanischen Comic-Serie „Dragon Ball“ (japanische Leserichtung: von rechts nach links, Toriyama 1997: 56-57).

Japanische Comics werden entgegen der westlichen Seitenreihenfolge quasi von „hinten“ nach „vorne“ und von rechts oben nach links unten gelesen. Um den westlichen Lesegewohnheiten $\mathrm{zu}$ entsprechen wurden und werden bei machen Manga-Übersetzungen die Seiten gespiegelt. Sofern die Bilder nicht korrigiert werden, kann das entsprechende Konsequenzen nach sich ziehen. Ein Beispiel: Titelgebend für Osamu Tezukas mehrbändige Manga-Reihe „Adolf“29 sind drei Figuren mit diesem Vornamen: zwei japanische Jungen, der eine Sohn jüdischer Eltern, der andere der eines Nazi-Karrierediplomaten, sowie Adolf Hitler. In der gespiegelten US-Version (Tezuka 1995-1996) werden die linken statt die rechten Arme zum

${ }^{29}$ Erstveröffentlichung 1983. Sammelbände: Tezuka 1985. 
Hitlergruß gehoben und die Hakenkreuzarmbinden am rechten statt am linken Arm getragen (von wenigen Bildausnahmen abgesehen). Auch die deutsche Fassung (Tezuka 2005-2007) wird von vorne nach hinten, von links oben nach rechts unten gelesen, aber durch entsprechende Bearbeitung konnten Fehler dieser Art vermieden werden.

Angesichts all dieser Umstände wird deutlich: Wer sich näher mit japanischen Comics beschäftigen will, kann sich nicht auf die Übersetzungen verlassen, sondern muss sie mit den Originalveröffentlichungen vergleichen. Wobei die Printveröffentlichungen nicht immer für sich alleine stehen: „Realistisch betrachtet, ist der Manga als ganzes in erster Linie eine Industrie.“ (Berndt 1998: 5). Die Produktion in Japan geht Jahr für Jahr in die Milliarden, von Magazinen bis hin zu Publikationen vom Umfang eines Telefonbuchs. Doch „Manga und Anime bilden einen Medienverbund, der wiederum Teil einer Vermarktungskette ist. Ein Großteil der Gewinne wird nicht mit gedruckten Mangageschichten oder Anime-Produktionen, sondern durch Merchandise-Artikel und Lizenzprodukte erwirtschaftet." (Brunner 2010: 77-78). Hierzulande hatte diese „Industrie“ kulturelle Auswirkungen:

In Deutschland interessieren sich viele Manga-Fans nicht nur für Anime und Manga. Viele setzen sich ebenfalls intensiv mit der japanischen Kultur auseinander. [...] Im Jugendkulturellen Bereich lässt sich derzeit eine regelrechte Japan-Mode ausmachen. Japanische Musik (J-Pop und Visual Kei), japanisches Essen (z.B. Sushi), Cosplay [costume play], Karaoke [...], japanische Computerspiele [...], japanische Mode [...], etc. [...]. (Brunner 2010: 95).

Zurück zum Ausgangspunkt. Im Gegensatz zum japanischen Manga-Begriff übersetzen viele FachautorInnen, auf den westlichen Kulturraum Bezug nehmend, Manga schlicht als japanische Comics, und machen es sich dabei zu einfach:

Da sich inzwischen aber auch in anderen Ländern Zeichner am japanischen Manga-Vorbild orientieren, ist das Kriterium der Herkunft nicht mehr aussagekräftig genug. In der Folge werden auch jene Werke als „Manga“ bezeichnet, die der japanischen Zeichentradition stilistisch zugeordnet werden können - unabhängig von Produktionsort oder Herkunft des Zeichners. Die Bezeichnung als „Manga“ hängt also im westlichen Raum derzeit mit der Zuordnung eines Werkes zur japanischen Zeichentradition zusammen, wobei diese Zuordnung eine subjektive ist, denn die Stilistik von Manga ist breit gefächert und überschneidet sich mit der Stilistik anderer ComicTraditionen. (Brunner 2010: 12).

So oder so sind Comics gemeint. Daher täuschen die Buch- und Veranstaltungstitel „Comics und Mangas“ eine Abgrenzung zwischen zwei Kunstformen vor, die in Wirklichkeit eine sind: Comic. „Für Comics, zu denen auch Manga aller Art zählen, hat sich inzwischen auch in Japan der Anglizismus eingebürgert. Paradoxerweise halten die Europäer an dem Wort Manga fest.“ (Koyama-Richard 2008: 7). 


\section{Comics versus Graphic Novels}

Im August 2013 ging ich in eine große Buchhandlung und fragte eine der Verkäuferinnen nach Comics. Sie antwortete, es gäbe zwar keine Comic-Abteilung, aber eine für Graphic Novels. Ich äußerte mich erfreut, dass die Buchhandlung also Comics hätte, und wurde energisch von der Dame korrigiert, Graphic Novels wären keine Comics. Ähnliche Erlebnisse hatten Bekannte schon anderen Orts gemacht. ${ }^{30}$

Was soll man auch anderes denken, wenn Bücher und Aufsätze, Veranstaltungen und Vorträge im Titel Comics und Graphic Novels scheinbar als eigenständige, von einander zu trennende Phänomene aufzählen, ab und an ergänzt durch Mangas als drittes Phänomen in dieser Runde. ${ }^{31}$

Die Comic-Szene in der sechste Ausgabe des „Was sind Graphic Novels?“Folders spielt auch in einer Buchhandlung (Abb. 14). Doch hier klärt eine Verkäuferin eine andere darüber auf, dass Graphic Novels eigentlich nichts anderes als Comics seien, „nur eben... keine Serien, eher Romane, Erzählungen in Bildern... die sich vor allem inhaltlich von dem absetzen, was die Leute üblicherweise mit Comics verbinden... und deshalb eben auch nicht unbedingt komisch sein müssen oder nur etwas für Kinder... oder den typischen, meist männlichen Sammler mittleren Alters, Du weißt schon..."32

\footnotetext{
${ }^{30}$ Vgl. Comic-Verleger Dirk Rehm (Reprodukt) auf die Frage, ob er vom Graphic Novel-Label profitiert: „Klar. Das lässt sich ja allein daran feststellen, dass Leute sagen: ,Ich lese keine Comics, ich lese Graphic Novels."“ (Rehm 2012: 200f.)

31 Beispiele für Veranstaltungen: Fachkonferenz: Holocaust und Nationalsozialismus in Comic und Graphic Novel. Neue Wege für Unterricht und außerschulische politische Bildung? Veranstalter: Bundeszentrale für politische Bildung und Anne Frank Zentrum. Im Caritas-Pirckheimer-Haus in Nürnberg vom 9. Bis 12. Mai 2010. Seminar: Comic - Manga - Graphic Novel. Aktuelle Tendenzen in der grafischen Literatur für Kinder und Jugendliche. Veranstalter: Arbeitskreis für Jugendliteratur. Im Haus Hainstein in Eisenach vom 25. bis 27. November 2011. Veranstaltungsreihe: Erzählen in Bild und Text. Bilderbuch, Comic, Graphic Novel. Veranstalter: Zentrum für Kinder-und Jugendliteratur. In der Pädagogischen Hochschule Heidelberg im Wintersemester 2013/2014. Beispiele für Bücher und Aufsätze: McCloud 2007; Arnold 2009; Mounajed; Semel 2010; Cooney 2013; Mounajed 2011; Giesa 2012. Beispiele für Vorträge: Giesa, Felix, Leowald, Leo, Schikowski, Klaus: Comics, Manga, Graphic Novels: Bildgeschichten verstehen und machen. Im Rahmen der KölnerKinderUni, in der Universität zu Köln, am 22. März 2012. Frenzel, Martin: Wie politisch sind Comic und Graphic Novel? Von Walt Kellys ,Pogo' bis Art Spiegelmans ,Maus'. Ein internationaler Parforceritt durch ein Genre. In der Universität Siegen am 14. Dezember 2012. Dolle-Weinkauff, Bernd: Zwischen Abenteuergeschichte und Sachliteratur. Historisches Erzählen in Comic, Manga und Graphic Novel. Im Rahmen des Workshops Verflochtene Vergangenheit. Geschichtscomics in Deutschland seit den 1950er Jahren, im Alexander-von-Humboldt-Gästehaus der Justus-Liebig-Universität Gießen am 11. April 2013. Ders.: Comic - Graphic Novel - Manga. Eine Einführung, im Rahmen der Veranstaltungsreihe Erzählen in Bild und Text. Bilderbuch, Comic, Graphic Novel. In der Pädagogischen Hochschule Heidelberg am 18. November 2013.
}

32 „Was sind Graphic Novels-Folder“ Ausgabe 6 (2011), 3. 

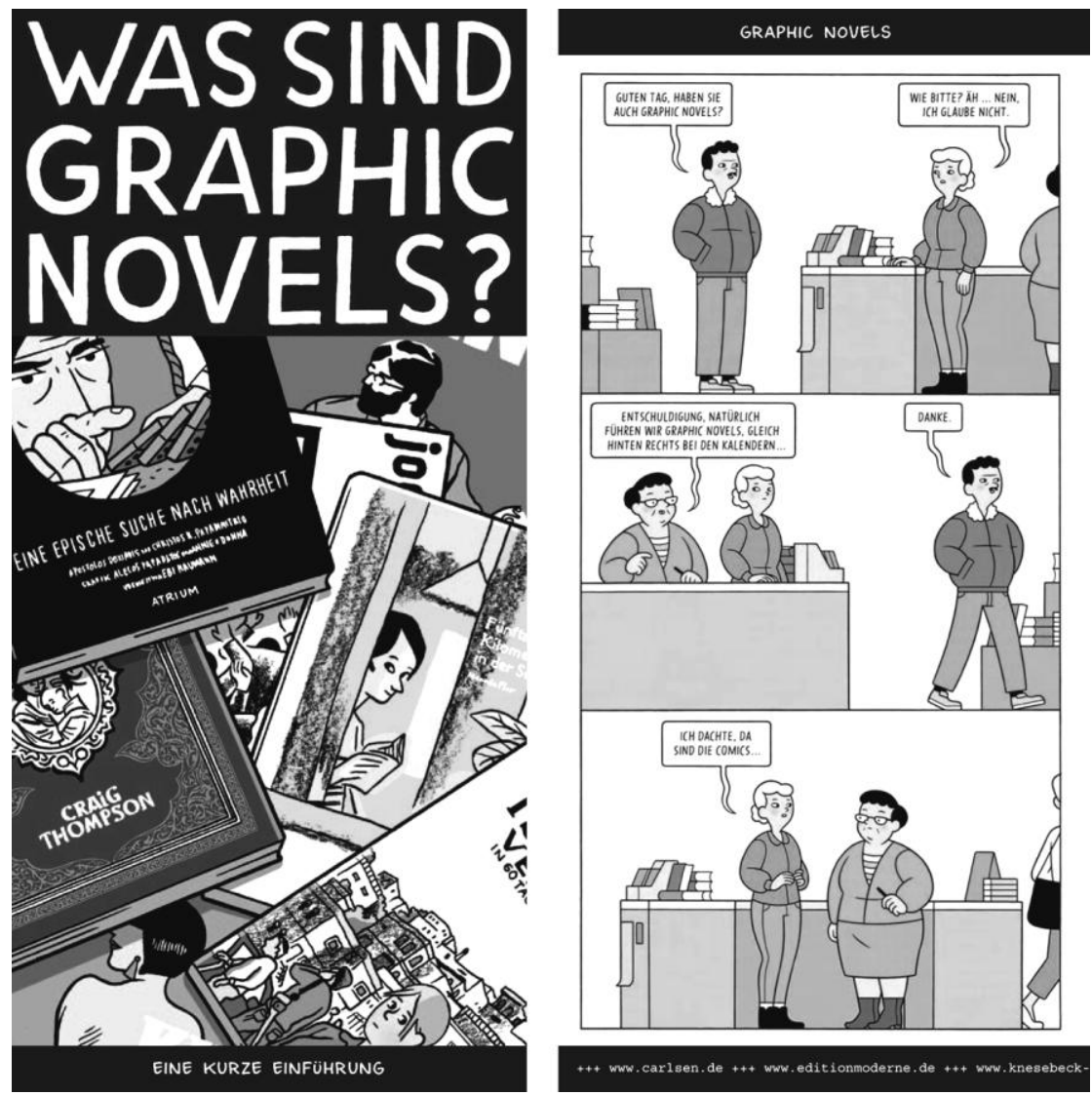

Abb. 14: Titelblatt des sechsten „Was sind Graphic Novels?“-Folders (2011) von Sascha Hommer und die erste Seite des Comics von Arne Bellstorf. (graphicnovel.info 24.10.2011, zit. 20.12.2013).

Die erste Ausgabe dieser Folder-Reihe entstand 2008 als Ergebnis der Zusammenarbeit der Verlage Avant, Carlsen, Edition 52, Fischer und Reprodukt (Giesa 2008). Seitdem werden sie als „Orientierungshilfe“ mit Titel-Empfehlungen der beteiligten Verlage in Comic- und Buchhandlungen ausgelegt. Zusammen mit dem Folder soll auch ihre Website www.graphic-novel.info „Graphic Novels/Comics einem uninformierten aber interessierten Lese- u. Buchhändlerpublikum näher bringen." (Ebd.). Neben Hinweisen auf Neuerscheinungen, Veranstaltungen und Medienberichten werden dem „Buchhandel/Vertrieb“ dort verkaufsfördernde Maßnahmen vorgeschlagen, z.B. diese: 
Es gibt mehrere Möglichkeiten, Graphic Novels in der Buchhandlung zu präsentieren. Am Besten ist es, ein eigenes Regal für Graphic Novels und verwandte andere Comics zu installieren. [...] Graphic Novels lassen sich vor allem auch an Nicht-ComicleserInnen verkaufen, ein einfaches Einsortieren in die Comicabteilung kann deshalb kontraproduktiv sein. (,Warum soll ich in der Comicabteilung schauen, ich lese keine Comics!' ${ }^{\circ 33}$

Entsprechend kennzeichneten die Verlage ihre zuvor als „Comics“ angebotenen Bildgeschichten durch „Graphic Novel“-Aufkleber, dann Aufdrucke, und verkauften diese laut VerlagssprecherInnen durch die neue Bezeichnung viel besser. ${ }^{34}$ Die Marketing-Aktion ${ }^{35}$ führte zu Trittbrettfahrern, d.h. auch andere Verlage bieten seit dem Comics als „Graphic Novel“ an.

Auf der Graphic Novel-Website wird der Begriff auf die Comic-ZeichnerLegende Will Eisner zurückgeführt, der, so die AutorInnen, „damit herausstellen [wollte], dass sein Comic als Literatur verstanden werden soll und die Geschichten sich explizit an ein erwachsenes Lesepublikum richten. "36 Entsprechend steht in den Foldern, Graphic Novels wären Comics, die sich „eher an Erwachsene richten “. ${ }^{37}$ Doch im Oktober 2008 verkündete ein Text auf der Graphic NovelWebsite: „Vermehrt erscheinen Graphic Novels, die sich nicht primär an ein erwachsenes Lesepublikum richten ", 38 gefolgt von einigen Titeln. ${ }^{39}$ Ein Widerspruch, der die Verlage nicht zu kümmern braucht, denn ihre Werbung soll und muss keine konkreten Bedeutungsinhalte liefern, sondern verkaufsfördernde Vorstellungen: „Eine eindeutige comicwissenschaftliche Definition der Graphic Novel gibt es bis heute nicht. Die Meinungen in der Fachpresse gehen auseinander. Schon der unglückliche Oberbegriff ,Comic (denn ,komisch' sind nun wahrlich nicht alle Comics) ist nicht einheitlich definiert und trotzdem hat ein jeder eine Vorstellung davon, was ein Comic ist." 40

Eine Vorstellung davon? Graphic Novel ist keine urheberrechtlich geschützte Bezeichnung. Jeder Verlag kann seine Comics als Graphic Novels anbieten. Und

\footnotetext{
33 Vgl. www.graphic-novel.info/ ?page_id=3414.

${ }^{34}$ U.a. auf Podiumsgesprächen verschiedener Comic-Tagungen und -Festivals.

35 Verlagsvertreter zur Graphic Novel 2008: „Für Carlsen stand laut Ralf Keiser eindeutig eine ,Marketingüberlegung 'im Vordergrund, als man sich dort für den Begriff der Graphic Novel entschied.“ „Auch der Verlagsleiter von Reprodukt, Dirk Rehm, sieht in der Graphic Novel hauptsächlich ein ,Marketingtool, um eine neue Leserschaft zu finden'.“

${ }^{36}$ Erste Schritte. Was sind Graphic Novels? http://www.graphic-novel.info/?page_id=3032.

${ }^{37}$ Folder Ausgabe 3 (2009) bis 5 (2010), jeweils Seite 4. Im Folder Ausgabe 1 (2008) und 2 (2009) steht jeweils auf Seite 2: „Graphic Novels sind Comics mit Themen, die sich nicht mehr nur an Kinder und Jugendliche, sondern an erwachsene Leser richten."

38 „Der Krieg der Knöpfe” als Comicadaption 2008.

39 Auch im Bereich der Kinder- und Jugendliteratur spricht man von Graphic Novels für Kinder. Beispiel Felix Giesa: „Die kinderliterarische Graphic Novel und der kinderliterarische Comic profilieren sich ästhetisch anspruchsvoll und inhaltlich wie thematisch am Kind ausgerichtet erfolgreich neben dem erzählenden Kinderbuch." Giesa 2012: 15.
}

${ }^{40}$ Erste Schritte. Was sind Graphic Novels? http://www.graphic-novel.info/?page_id=3032. 
das ist der Fall bei Comics, die sich an Erwachsene und/oder Kinder und Jugendliche richten, eine durchgehende Geschichte oder eine Sammlung von Kurz- oder Fortsetzungsgeschichten beinhalten, aus allen Genres kommen (von utopischen Fantasy-Comics mit SuperheldInnen bis hin zu geschichtsorientierten Auto-/Biographien und faktenorientierten Sachcomics), weniger oder gleichviel oder mehr Seiten als die klassischen Comic-Alben á la „Tim und Struppi“ umfassen, mit Softoder Hardcover ausgestattet sind. Offensichtlich gibt es kein substanzielles verbindendes „Sein“, keinen gemeinsamen Nenner aller dieser selbsternannten Graphic Novels. Einzig Hefte, Comics mit Klammerbindung, sind meines Wissens wohl noch nicht als Graphic Novels angepriesen worden. ${ }^{41}$

Sprachliche Bezeichnungen und Beschreibungen gehören zu den üblichen werblichen Gestaltungsmaßahmen der Produkt-Positionierung. In den 1980er Jahren verkündete die Firma Marlboro, ihre Zigarette habe den „Geschmack von Freiheit und Abenteuer“. Wie oder nach was „schmeckt" Freiheit und Abenteuer konkret? Natürlich haben Freiheit und Abenteuer keinen Geschmack. Die Aufgabe der Werbung war es lediglich, positive Assoziationen zu wecken, die zum Kauf der Marlboro-Zigaretten führen sollten. Dirk Rehm: „Der Begriff hat sich erstaunlich schnell durchgesetzt - innerhalb von wenigen Jahren. Das Label ,Graphic Novel ist für Verlage das unverbrauchte Etikett, das ihnen die Chance bietet, den Comic zurück in den Buchhandel zu bringen." (Rehm 2012: 201).

Die Marketing-Aktion war so erfolgreich, dass schließlich auch die (Fach-) Presse über bzw. von Graphic Novels schrieb. Doch Werbung und Journalismus haben unterschiedliche Aufgaben und Regeln. Was in der Werbung legitim ist, kann im Journalismus illegitim sein. In den Landespressegesetzen „wird der Presse eine, öffentliche Aufgabe' zugesprochen, wenn sie in Angelegenheiten von öffentlichem Interesse Nachrichten beschafft und verbreitet, Stellung nimmt, Kritik übt oder auf andere Weise an der Meinungsbildung mitwirkt'." (Noelle-Neumann, Schulz, Wilke 1994: 67). Zur Erfüllung dieser Aufgabe hat die Presse Sonderrechte. Diese sind an besondere Pflichten gebunden, wie die Sorgfaltspflicht, „die Journalisten anhält, alle Nachrichten vor ihrer Verbreitung mit der nach den Umständen gebotenen Sorgfalt auf Wahrheit, Inhalt und Herkunft zu überprüfen." (Ebd.). In der Praxis müssten Werbetexte kritisch hinterfragt und Marketing-Labels als das vorgestellt werden, was sie sind. Ein Blick in die (Fach-)Presse zeigt, das im Gegenteil die Bezeichnung Graphic Novel auch dort ein buntes Eigenleben führt.

Im gleichen Jahr, als die „Was sind Graphic Novels?"-Folder zum ersten Mal verteilt wurden, nahm sich Klaus Schikowski im Comic-Fachmagazin „Comixene“ der Graphic Novel an. Er schrieb: „Die Graphic Novel ist auch kein (sic!) neue Kunstform, die gleichberechtigt neben dem Alten steht - sie ist und bleibt ein Genre." (Schikowski 2008: 20). Er diskutierte die verschiedenen Graphic NovelAuffassungen und kam zum Ergebnis, ,was heute in Deutschland gemeinhin unter einer Graphic Novel verstanden wird, ist im Grunde genommen unter dem Titel

${ }^{41}$ Wie gesagt, Sammelausgaben allerdings schon. 
Comic-Roman schon seit vielen Jahren bekannt.“ (Ebd.: 22). Angesichts der Vielfalt an Themen und Erscheinungsformen ,wird es allerdings auch ein wenig problematisch mit dem Begriff der Graphic Novel und für Außenstehende beinah undurchschaubar.“ (Ebd.: 23). Bis zum Schluss blieb die Frage offen: „Doch wie lässt sich die Spreu vom Weizen trennen? Wie ist zu erkennen, ob es sich denn tatsächlich um eine Graphic Novel handelt? Muss man es überhaupt? Vielleicht liegt es auch einfach im Auge des Betrachters, ob der jeweilige Band dem Anspruch einer Graphic Novel genügt.“ (Ebd.).

Vier Jahre darauf thematisierte die „Comixene“ das Für und Wider des Gattungsbegriffs „Graphic Novel“. Martin Jurgeit vertrat die Pro-Seite:

Der Begriff konnte sich lange nicht durchsetzen, ist schwammig, wird hierzulande oft falsch verstanden - aber geschenkt. In einer konzertierten Aktion gelang es den Verlagen, die Graphic Novel als etwas völlig Neues bei Zielgruppen zu etablieren, die zuvor nie in einen Comic geschaut hätten. (Jurgeit 2012: 40).

Während für Martin Jurgeit im Ergebnis „der Zweck - gerade im vorliegenden Fall - ausdrücklich die Mittel heiligt“ (ebd.), argumentierte Thomas Hausmanninger als Vertreter der Kontra-Seite:

Das Etikett „Graphic Novel“ ist lediglich ein Marketing-Instrument. Hinter dem Begriff hat sich nie ein klar zu umschreibendes Phänomen verborgen. Schon Will Eisners Bemerkungen in Comics and Sequential Art sind diffus und machen lediglich deutlich, dass er mit dem Begriff „Graphic Novel“ ein erwachsenes Publikum gewinnen möchte. Auch dort dient er so letztlich dem Marketing. Das Marketing bedingt jedoch eine problematische Spaltung zwischen Comics und Graphic Novels. Es zielt auf den Zugewinn von Publikum, das keine oder kaum Comics liest, und will neben dem Buchhandel dazu auch das Feuilleton erobern. Dazu bedient es sich einer weitgehend überholten beziehungsweise nur noch wenig in gesellschaftlichen Großgruppen (Milieus) greifbaren Zweiteilung der Kultur: der Differenzierung zwischen „Hochkultur“ und „Trivialität“ oder „Massenkultur“. (Hausmanninger 2012: 40, Abb. 15).

Die Bezeichnung eignet sich auch nicht als Synonym für Comic-Roman oder Comic-Buch, weil sie dann falsche Voraussetzungen vortäuschen würde. Wie gesagt werden als Graphic Novels auch Sammelbände von Fortsetzungsgeschichten angeboten, die vorab einzeln in Heften veröffentlicht wurden. Diese sogenannten Graphic Novels weisen aber eine ganz andere inhaltliche Struktur auf als bei einer Geschichte, die frei von den Bedingungen einer Fortsetzungsveröffentlichung (Seiten-Begrenzungen, Cliffhanger als Kaufanreiz für das Folgeheft, etc.) von Anfang an für die Veröffentlichung im Ganzen als Roman oder Buch geschaffen wurde. 

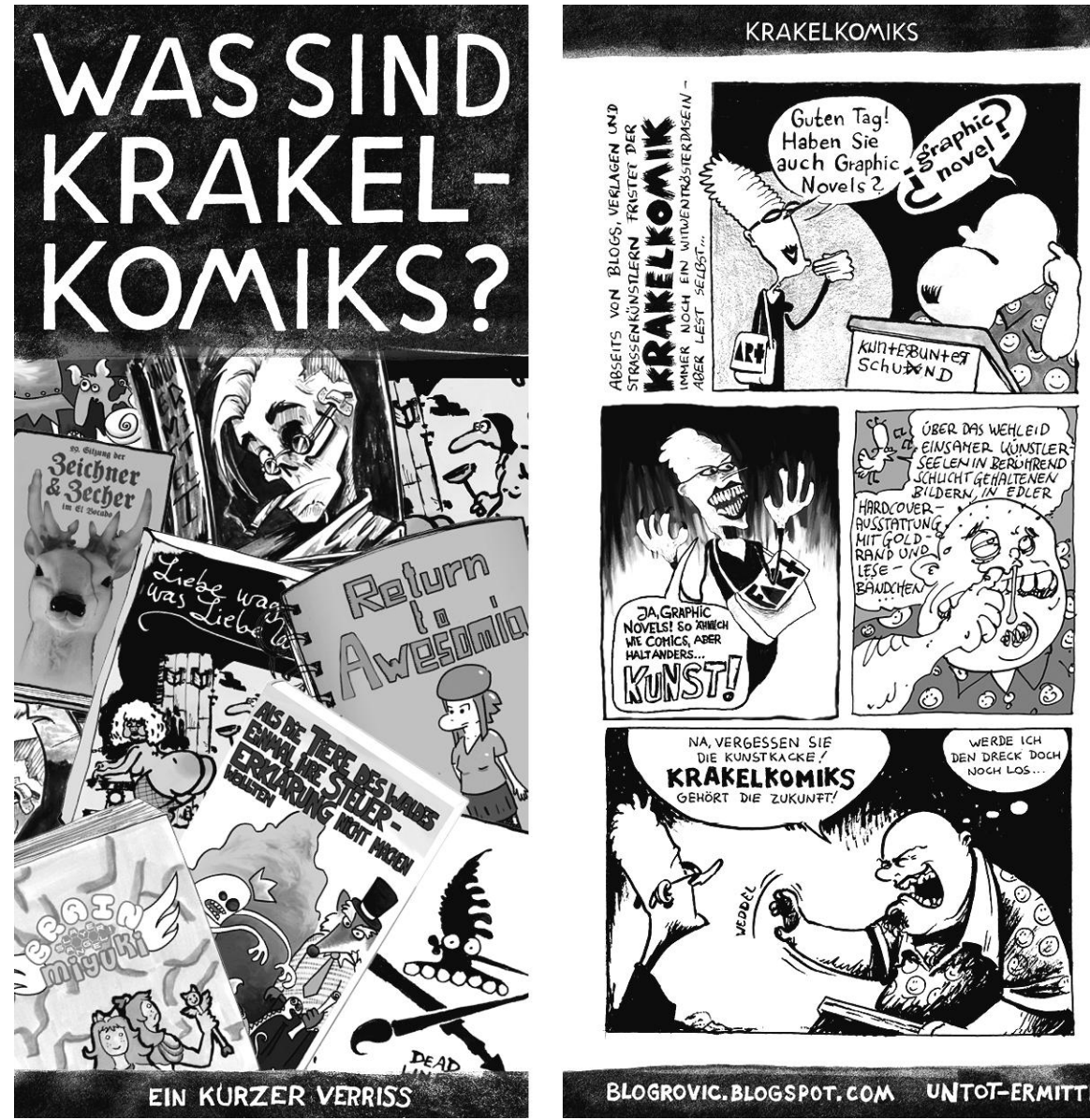

BLOGROVIC.BLOGSPOT. COM UNTOT-ERMITTE

Abb. 15: Parodie auf den „Was sind Graphic Novels?“-Folder: „Was sind Krakelkomiks?"-Folder von Armin Parr, Bob Hack, Bobrovic, Doomfried, Neffs und Zapf, der zum Comic-Salon Erlangen 2012 erschien (Parr 2012).

Tatsächlich scheinen Comics durch das Graphic Novel-Label eine höhere Wertigkeit zu bekommen und damit einen höheren Kaufanreiz und einen höheren Nachrichtenwert. ${ }^{42}$ Die Folge der inflationären, überwiegend unreflektierten Verwendung der Label-Bezeichnung in den Medien führte zu einem Chaos an Vorstellungen über Comics und Graphic Novels (siehe Kapitelanfang), und so zum Ge-

\footnotetext{
42 Einige sogenannte Graphic Novels wurden vor Einführung des Labels ja noch mit der Bezeichnung Comic beworben und besprochen. Einige AutorInnen sind auf den kommerziell-erfolgreichen Zug aufgesprungen und veröffentlichten Sach- und Zeichen-Bücher über Comics als Bücher über Graphic Novels, mit dem Hinweis, dass man nicht genau sagen könne, was genau eine Graphic Novel wäre.
} 
genteil von Aufklärung und Klarheit. Für Wissenschaft und Forschung, und damit auch für akademische Arbeiten gilt: „Begriffe sind Mittel, mit deren Hilfe wir das Chaos von Eindrücken sprachlich ordnen.“ (Friedrichs 1985: 73). Doch mittlerweile taucht die Label-Bezeichnung auch in akademischen Arbeiten als Synonym für Comics in allen möglichen Bezügen auf - offensichtlich von den KorrektorInnen und der wissenschaftlichen Öffentlichkeit unbeanstandet. Das Marketing-Label im Rang wissenschaftlicher Begrifflichkeiten? Ein Umstand, der die Notwendigkeit einer eigenständigen Comicwissenschaft um so eindringlicher deutlich macht.

Was ist also davon zu halten, wenn von „Comics und Graphic Novels“ die Rede ist? Seit ein paar Jahren kündigt der Fernsehsender Sat.1 im Fernsehprogramm und auf seiner Homepage ${ }^{43}$ seine Dienstagabend-Film-Highlights als „FilmFilme“ an. Trotzdem gibt es im Filmhandel- und -verleih deswegen weder ein eigenes FilmFilm-Fach, noch ein neues FilmFilm-Genre und daher auch keine Abhandlung über dieses oder jenes im FilmFilm. Was in Bezug auf Filme undenkbar ist, nämlich von „Filme und FilmFilme“ zu sprechen und zu schreiben, wenn es um Comics geht, ist es gang und gäbe. Im Bereich der Werbung mag die Verwendung des Marketing-Labels, wie andere verkaufsfördernde Maßnahmen auch, legitim sein. Kritik an der darüberhinausgehenden Verwendung gibt es, auch wenn sie sich bisher kaum Gehör schaffen konnte.

\section{Comic-Manifest}

Was der Comic zu seiner Anerkennung als eigenständige Kunstform bräuchte, wäre das geforderte Handeln der (Kultur-)PolitikerInnen. Auf dem Internationalen Literaturfestival Berlin 2013 veröffentlichte eine Gruppe von KünstlerInnen, VerlegerInnen und KulturveranstalterInnen ein „Comic-Manifest“. ${ }^{44}$ Darin steht: „Niemand bezweifelt heute, dass der Comic eine eigenständige Kunstform ist, der ein gleichberechtigter Platz neben Literatur, Theater, Film oder Oper zusteht. Es ist ein Skandal, dass dies noch immer nicht allgemeiner Konsens ist. Wir fordern daher, dass der Comic dieselbe Anerkennung erfährt wie die Literatur und bildende Kunst und entsprechend gefördert wird. Der Comic ist - wie alle anderen Künste - auf staatliche und private Unterstützung angewiesen. “45 In der anschließenden Diskussion (vgl. u.a. Kesler 2013, Wenk 2013) über eine finanzielle Förderung von Comic-ZeichnerInnen und -Projekten ging die weitere, wichtige Forderung des Manifests nach der Institutionalisierung leider unter:

Noch immer fehlt eine eigene Comicprofessur in Deutschland, noch immer fehlt eine Institution, die als zentrale Anlaufstelle und kommunikative Begegnungsstätte mit europäischer Ausstrahlung für alle Protagonisten des

\footnotetext{
${ }^{43}$ http://www.sat1.de/film/der-sat-1-filmfilm.

44 „Es ist ein Skandal, ...“ 2013.

${ }^{45}$ Das Comic Manifest 2013.
} 
Mediums dienen kann. Wir fordern daher die Schaffung eines deutschen Comicinstitutes, das Künstler zusammenführt, ihre Arbeit wissenschaftlich reflektiert und der kulturellen Bildung dient. (Das Comic Manifest 2013).

\section{Literatur}

Althen, Michael (1995): Sprungbrett ins Glück. In: Der Spiegel 18, 96-99. Online: spiegel.de, http:/ / www.spiegel.de/spiegel/print/d-9182978.html (publ. 1.5.1995, zit. 17.0.2013).

Arnold, Heinz Ludwig (Hrsg.) (2009): Comics, Mangas, Graphic Novels. München: Edition Text + Kritik.

Bender, Lauretta; Lourie, Reginald S. (1964): The effect of comic books on the ideology of children. In: American Journal of Orthopsychiatry Vol. XI 1941. New York: AMS Reprint, 540-550.

Berndt, Jaqueline (1998): Comics in Japan. In: Czerwionka, Marcus (Hrsg.): Lexikon der Comics Teil 3: Themen und Aspekte. Meitingen: Corian Verlag, 26. Erg.-Lfg. Juni 1998.

Brunner, Miriam (2010): Manga. Paderborn: Wilhelm Fink Verlag.

Buscema, John; Lee, Stan (1986): How to draw Comics the Marvel Way. London: Titan Books Ltd.

Busch, Wilhelm (1959): Von mir über mich (1886). In: Hochhuth, Rolf (Hrsg.): Wilhelm Busch. Sämtliche Werke und eine Auswabl der Skizzen und Gemälde in zwei Bänden. Zweiter Band: Was beliebt ist auch erlaubt. Gütersloh: Bertelsmann Lesering, 8-31.

Cooney, Daniel (2013): Comics und Graphic Novels zeichnen. Das ultimative Grundlagenwerk. Wie man Charaktere kreiert, zeichnet und zum Leben erweck.t. Stuttgart: Frech.

Friedrichs, Jürgen (1985): Methoden empirischer Sozialforschung. Opladen: Westdeutscher Verlag.

Fuchs, Wolfgang J., Reitberger, Reinhold (1978): Comics Handbuch. Reinbek bei Hamburg: Rowohlt Verlag.

Giesa, Felix (2008): Interview mit Sebastian Oehler zum Flyer „Was sind Graphic Novels?“. In: statt.org, http://www.satt.org/comic/08_09_gn.html (publ. 12.09.2008; zit. 23.08.2013).

Giesa, Felix (2012): Große Bandbreite. Die Spielarten von Comic und Graphic Novel für Kinder und Jugendliche sind vielfältig und nicht immer eindeutig voneinander abzugrenzen. Zu den Schwierigkeiten einer Begriffsbestimmung. In: JuLit Heft 1, München: Arbeitskreis für Jugendliteratur e.V., 15-22. 
Gravett, Paul (2009): Gianni De Luca \& Hamlet: Thinking Outside The Box. In: paulgravett.com, http:/ /www.paulgravett.com/index.php/articles/article/ gianni_de_luca_hamlet (publ. 12.04.2009; zit. 17.11.2013).

Groensteen, Thierry (2000): Asterix, Barbarella \& Co. Meisterwerke aus dem ComicMuseum Angoulême. Paris: Somogy éditions d'art.

Grünewald, Dietrich (1982): Comics - Kitsch oder Kunst? Die Bildgeschichte in Analyse und Unterricht. Ein Handbuch zur Comic-Didaktik. Weinheim: Beltz Verlag.

Grünewald, Dietrich (2000): Comics. Tübingen: Niemeyer.

Grünewald, Dietrich (2005): Sigenot - ein Daumenkino des Mittelalters? In: Sackmann, Eckart (Hrsg): Deutsche Comicforschung 2006. Hildesheim: Verlag comicplus+ Sackmann und Hörndl, 7-16.

Grünewald, Dietrich (2012): Die Berliner Eneide - ein Bildroman des Mittelalters. In: Sackmann, Eckart (Hrsg): Deutsche Comicforschung 2013. Hildesheim: Verlag comicplus + Sackmann und Hörndl, 6-21.

Habarta, Gerhard; Havas, Harald (Hrsg.) (1992): Comic Welten. Das Album. Wien: Edition Comic Forum.

Habarta, Gerhard,; Havas, Harald (1993): Comic Welten. Geschichte und Struktur der Neunten Kunst. Wien: Edition Comic Forum.

Hausmanninger, Thomas (2012): Graphic Novel - Ein umstrittener Gattungsbegriff - Kontra. In: Comixene Nr. 113. Berlin: Verlag Jurgeit, Krismann \& Nobst, 40-41.

Ishinomori, Shōtarō (1989): Japan GmbH. Eine Einführung in die japanische Wirtschaft. Bonn: Rentrop Verlag.

Jurgeit, Martin (2012): Graphic Novel - Ein umstrittener Gattungsbegriff - Pro. In: Comixene Nr. 113/2012. Berlin: Verlag Jurgeit, Krismann \& Nobst, 40.

Kesler, Waldemar: Comic-Künstler streiten um Staatsgelder. In: welt.de, http:/ / www.welt.de/kultur/literarischewelt/article119711007/Comic-Kuenstlerstreiten-um-Staatsgelder.html (publ. 05.09.2013, zit. 22.12.2013).

King, Frank (1934): Gasoline Alley-Folge vom 25.03.1934. In: sundaypressbooks.com, http://www.sundaypressbooks.com/WSSamples/GA19340325House12Ljpg. html (letztes update 15.08.2013; zit. 17.11.2013).

Kinzel, Franz Christian (1995): Mickey Mouse auf der Couch. Eine Metaanalyse von Comics aus psychoanalytischer Sicht. In: Kagelmann, H. Jürgen (Hrsg.): Comics Anno. Jahrbuch der Forschung zu populär-visuellen Medien 3. München: Profil Verlag, 140-167. 
Knigge, Andreas C. (2004): 50 Klassiker Comics. Von Lyonel Feininger bis Art Spiegelman. Hildesheim: Gerstenberg Verlag.

Köhn, Stephan (2005): Traditionen visuellen Erzählens in Japan. Eine paradigmatische Untersuchung der Entwicklungslinien vom Faltschirmbild zum narrativen Manga. Wiesbaden: Harrassowitz Verlag.

Koyama-Richard, Brigitte (2008): 1000 Jahre Manga. Das Kultmedium und seine Geschichte. Paris: Flammarion.

Krafft, Ulrich (1978): Comics lesen. Untersuchungen zur Textualität von Comics. Stuttgart: Klett-Cotta.

Kunzle, David (2007): Father of the Comic Strip: Rodolphe Töpffer (Great Comics Artists). Mississippi: University Press of Mississippi.

Kurisuteian (2009): Schnittbericht Pokémon Episode 1.18 Beauty and the Beach! Vergleich TV-Ausstrahlung Japan und USA. In: schnittberichte.com, http://www. schnittberichte.com/schnittbericht.php?ID=3727666 (publ. 26.06.2009, zit. 27.11.2013).

Lee, Stan (Text); Martin, Marcos (Zeichnung) (2011): Amazing Spider-Man Spidey Sunday Spectacular Nr. 1. New York: Marvel Comics.

Lefèvre, Pascal (2009): Wörterbuch. In: comicforschung.de. Teil 1: Die literaturwissenschaftlichen Fachbegriffe. http://www.comicforschung.de/woerterbuch.html (publ. 2009; zit. 02.12.2013). Teil 2: Die wichtigsten Fachbegriffe aus Verlagsproduktion und Szene. http://www. comicforschung.de/woerterbuch2.html (publ. 2009; zit. 02.12.2013).

Mawil (Markus Witzel) (2004): Basel Beach. In: Operation Läckerli. Comicreportagen aus Basel. Berlin: Monogatari, ohne Seitenzahlen.

McCloud, Scott (1994a): Understanding Comics. The invisible Art. New York: HarperCollins.

McCloud, Scott (1994b): Comics richtig lesen. Hamburg: Carlsen Comics.

McCloud, Scott (2007): Comics machen: Alles über Comics, Manga und Graphic Novels. Hamburg: Carlsen.

Metken, Günter (1970): Comics. Frankfurt/Main: Fischer Bücherei.

Miller, Frank (Text, Zeichnung), Varley, Lynn (Zeichnung) (1991): Elektra Lives Again. New York: Marvel Comics.

Mounajed, René (2011): Der Nationalsozialismus in aktuellen Comics und Graphic Novels. In: k.jl\&m Heft 3. München: kopaed, 21-30. 
Mounajed, René; Semel, Stefan (2010): Begleitmaterial Geschicbte. Comics er₹äblen Geschichte. Sequenzen aus Comics, Mangas und Graphic Novels für den Geschichtsunterricht. Bamberg: C.C. Buchner.

Nemeth, Gabriel (2009): „Zepis Zaubergarten“. In: Weite Welt-Magazin für Aufgeweckte Ausgabe September 2009. Maria Enzersdorf (Österreich): Gesellschaft des Göttlichen Wortes - Steyler Missionare, 32.

Nemeth, Gabriel (2010): „Zepis Zaubergarten“. In: Weite Welt-Magąin für Aufgeweckte Ausgabe März 2010. Maria Enzersdorf (Österreich): Gesellschaft des Göttlichen Wortes - Steyler Missionare, 32.

Neuner-Warthorst, Antje (2009): Zur Anschauung für Laien. Die sogenannte Freiburger Bilderbibel. In: Sackmann, Eckart (Hrsg): Deutsche Comicforschung 2010. Hildesheim: Verlag comicplus+ Sackmann und Hörndl, 10-21.

Noelle-Neumann, Elisabeth, Schulz, Winfried, Wilke, Jürgen (Hrsg.) (1994): Publizistik Massenkommunikation. Das Fischer Lexikon. Frankfurt/Main: Fischer.

Palandt, Ralf (2005): „Blühender Blödsinn“ an der Propagandafront. In: Sackmann, Eckart (Hrsg): Deutsche Comicforschung 2006. Hildesheim: Verlag comicplus+ Sackmann und Hörndl, 83-91.

Palandt, Ralf (2010): (Ohn-)Macht und Hakenkreuz - Comics im Schatten der Zensur. In: Grünewald, Dietrich (Hrsg.): Struktur und Geschicbte der Comics. Beiträge zur Comicforschung. Bochum: Christian A. Bachmann Verlag, 219-255.

Panskus, Hartmut (1995): 100 Jahre Comic. Die Erfindung der Sprechblase. In: Focus Magazin 18, 132-135. Online: focus.de, http://www.focus.de/kultur/ medien/100-jahre-comic-die-erfindung-der-sprechblase_aid_153252.html (publ. 29.4.1995; zit. 23.08.2013).

Parr, Armin (2012): Was sind Krakelkomiks? In: armerarmin.wordpress.com, http:// armerarmin.wordpress.com/2012/06/09/erlangen-2012, publ. 09.06.2012, zit. 20.12.2013.

Platthaus, Andreas (2008): Die 101 wichtigsten Fragen. Comics und Manga. München: C.H. Beck Verlag.

Podak, Klaus (1998): Spurensucher im Reich der Zeichen. In: SZ am Wochenende, Feuilleton-Beilage der Süddeutschen Zeitung, 14./15.11.1998, 1.

Pohl, Ulrich (1970): Von Max und Moritz, bis Fix und Foxi. Wiesbaden: VerlagsUnion.

Rehm, Dirk (2012): „Welcher Boom?““ Interview mit Dirk Rehm über den Comicmarkt. In: Neue Rundschau 3, 200-204. 
Sackmann, Eckart (2006/2009): Comics im Mittelalter. Online: Patrimonium. Deutsche Comicforschung, http://www.comicforschung.de/tagungen/06nov/sack mann/06nov_sackmann1.html bis ...4.html (publ. 2006/2009, zit. 24.10.2013).

Sackmann, Eckart (2006): Memlings „Turiner Passion“. In: Sackmann, Eckart (Hrsg): Deutsche Comicforschung 2007. Hildesheim: Verlag comicplus+ Sackmann und Hörndl, 7-15.

Sackmann, Eckart (2007a): Comics sind nicht nur komisch. Zur Benennung und Definition. In: Sackmann, Eckart (Hrsg): Deutsche Comicforschung 2008. Hildesheim: Verlag comicplus + Sackmann und Hörndl, 7-16. Online: Patrimonium. Deutsche Comicforschung, http://www.comicforschung.de/dtcom/ dtcom08/716.pdf (zit. 24.10.2013).

Sackmann, Eckart (2007b): Das Evangeliar Heinrich des Löwen. In: Sackmann, Eckart (Hrsg): Deutsche Comicforschung 2008. Hildesheim: Verlag comicplus+ Sackmann und Hörndl, 17-21.

Sackmann, Eckart (2009): Comic. Kommentierte Definition. In: Sackmann, Eckart (Hrsg): Deutsche Comicforschung 2010, Hildesheim: Verlag comicplus + Sackmann und Hörndl, 6-9. Online: Patrimonium. Deutsche Comicforschung, http://www. comicforschung.de/pdf/dc10_6-9.pdf (zit. 24.10.2013).

Schikowski, Klaus (2008): Die Graphic Novel - Das unbekannte Wesen! In: Comixene 102, 19-23.

Schmidt, Christian: Zensur in deutschen Mangas. In: animestreet.de, http://www. animestreet.de/artikel.php?aid=26 (publ. 01.09.2006, zit. 27.11.2013).

Schröder, Horst (1982): Die ersten Comics. Zeitungs-Comics in den USA von der Jahrhundertwende bis zu den dreißiger Jahren. Reinbek bei Hamburg: Carlsen Verlag.

Tezuka, Osamu (1985): Adolf ni tsugo Band 1-4. Tokio: Bungeishunjū Ltd.

Tezuka, Osamu (1995-1996): Adolf Band 1-5. San Francisco (CA): Cadence Books Inc.

Tezuka, Osamu (2005-2007): Adolf Band 1-5. Hamburg: Carlsen Verlag.

Toepffer, Rodolphe (1980). Essai de physiognomonie. Essay zur Physiognomonie. Siegen: Machwerk-Verlag.

Weiß, Katrin; Wüllner, Daniel (2011): Unzüchtige Schulmädchen und Tentacle Porn. Die Aufklärung des erotischen Manga. In: Comicgate Magaz̧in 6, 113-120.

Wenk, Erik: Förderprojekte statt Herzensprojekte? In: tagesspiegel.de, http://www. tagesspiegel.de/kultur/comics/kontroverse-ums-comic-manifest-foerderpro jekte-statt-herzensprojekte/8763884.html (publ. 09.09.2013, zit. 22.12.2013). 
Wirag, Lino (2012): Von Comicwissenschaft zu Comicwissenschaften. Comiqheft Nr. 3. Essen: A. Bachmann Verlag.

Zimmermann, Hans Dieter (1970): Vom Geist der Superhelden. Comic Strips.

Schriftenreihe der Akademie der Künste Band 8. Berlin: Gebr. Mann Verlag.

\section{Artikel ohne Autorangabe}

Das Comic Manifest (2013). In: literaturfestival.com, http://www.literaturfestival. com/comic/manifest (publ. 02.09.2013, zit. 22.12.2013).

„Der Krieg der Knöpfe” als Comicadaption. In: graphic-novel.info, http:/ / www. graphic-novel.info/?tag=krieg-der-knopfe (publ. 30.10..2008; zit. 23.08.2013).

Erste Schritte. Was sind Graphic Novels? In: graphic-novel.info, http://www.graphicnovel.info/?page_id=3032 (publ. ab 01.2008; zit. 23.08.2013).

„Es ist ein Skandal, dass dies noch nicht Konsens ist“. In: tagesspiegel.de, http:// www. tagesspiegel.de/kultur/comics/das-comic-manifest-es-ist-ein-skandaldass-dies-noch-nicht-konsens-ist/8723426.html (publ. 02.09.2013, zit. 22.12.2013).

graphic-novel.info, http://www.graphic-novel.info (publ. ab 01.2008; zit. 23.08.2013). Verantwortlich: Reprodukt. Redaktion: Groenewald, Michael; Harms, Jutta; Maiwald, Christian; Oehler, Sebastian; Rehm, Dirk.

Verlagsvertreter zur Graphic Novel (2008). In: Comixene 102, 23.

„W as sind Graphic Novels“-Folder Ausgabe 1 (2008) Comic: Hommer, Sascha; Redaktion: Oehler, Sebastian.

„W as sind Graphic Novels“-Folder Ausg. 2 u. 3 (2009) (Comic u. Red. unverändert). „W as sind Graphic Novels“-Folder Ausg. 4 u. 5 (2010) (Comic u. Red. unverändert). „W as sind Graphic Novels"-Folder Ausgabe 6 (2011) Comic: Bellstorf, Arne; Redaktion: Clausen, Andrea; Oehler, Sebastian.

„W as sind Krakelkomiks?"-Folder (2012). In: armerarmin.wordpress.com, http:/ / armerarmin.wordpress.com/2012/06/09/erlangen-2012/krakelflyer1 und http:/ / armerarmin.wordpress.com/2012/06/09/erlangen-2012/krakelflyer2-2 (publ. 10.06.2012, zit. 20.12.2013). 
2. Starre Bilder 



\title{
Comics zu aktuellen zeitgeschichtlichen Sujets. Eine visuell-sprachliche Herausforderung für den landeskundlichen DaF-Unterricht ${ }^{1}$
}

\author{
Chiara Cerri
}

\section{Vorneweg: Warum sich dieser Aufsatz einem Medium mit legendärem Ruf und nahezu keiner empirischen Überprüfung widmet}

Comics als visuell-sprachlichen Medien wird für den Fremdsprachenunterricht generell ein magisches, legendäres Potenzial zugewiesen. Am häufigsten werden erwähnt: die kreativitätsfördernde und affektive Wirkung, ein „hoher Motivationsfaktor" (auch deswegen, weil Comics „nicht allein verbal kommunizieren“ und „die Sinne auf mehrfache Weise an[sprechen]“, Schüwer 2005: 5); die „erhöhte Rezeptionsfähigkeit der Lernenden" dank des grafischen Kontexts, welches die Erschließung der Figurenhandlung und -äußerungen erleichtere und ermögliche, dass diese auch mit sehr geringen Sprachkenntnissen verstanden werden (Schüwer 2005: 5, vgl. auch Hieronimus 2009: 104); der Vorteil, dass unbekannte Wörter durch den (visuellen) Kontext erschlossen werden können und wichtige Infos

\footnotetext{
${ }^{1}$ Dieser Aufsatz stellt die Ergebnisse von zwei Workshops, die im März 2013 an der Radboud Universiteit (NL) mit Deutschstudierenden durchgeführt wurden, und einem Seminar über „Geschichte mit Comics im DaF-Unterricht" vor, welches ich im Wintersemester 2012/2013 in Marburg mit Masterstudierenden des Deutschen als Fremdsprache gehalten habe. Den Studierenden meines Seminars möchte ich für die tolle Mitarbeit und die spannenden Konzepte, aus denen einige der hier vorgestellten Aufgaben stammen, ganz herzlich danken.
} 
häufig ohne Worte ausgedruckt werden, z.B. über Bildmetapher, Lettering, Sprechblasenform (Doff; Wanders 2005: 10). Hieronimus (2009: 102) weist darauf hin, dass illustrierte Bildinhalte sich besser einprägen. Auch wird die Authentizität von Comics hervorgehoben, die zum „Erfolgserlebnis“ der Lernenden führt, wenn „Kulturprodukte in ihrer Originalform“ gelesen werden (Schüwer 2005: 4f.). AuBerdem ermöglichten Comics einen willkommenen „Medienwechsel im Unterricht“ (ebd.). Schließlich veranlassten manche anspruchsvolle Comics zur „Reflexion gesellschaftlicher Phänomene", denn sie stellen Kulturspezifisches dar (ebd., vgl. auch Vignaud 2009: 5). Arnold betont auch den Spaß- und Unterhaltungsfaktor sowie den Einsatz umgangssprachlicher, im situativen Rahmen eingebetteter Redemittel (vgl. Arnold 1998: 100).

Nun: Sind Comics wirklich ein solches Wundermittel für den Fremdsprachenunterricht?

Diese Frage kann nach dem jetzigen Forschungsstand leider weder bejaht noch verneint werden. Von Mempel (2010) stammt die einzige (!) vorhandene empirische Untersuchung zur Frage, ob die Kombination von textlichen und visuellen Informationen im Comic das Leseverstehen in der Fremdsprache wirklich begünstigt. Das Ergebnis zeigt, dass „die unreflektierte Aussage, dass Comics durch die Kombination von Text und Bild das Leseverstehen in der Fremdsprache erleichtern, problematisch erscheint" (Mempel 2010: 203) - Verständnisschwierigkeiten bezüglich Interjektionen, Jugendsprache, Soziolekte, Wortschatz seien aufgetreten, das Bildverstehen habe - besonders bei einem „eigenwillige[n] Zeichenstil““ des Zeichners - nicht reibungslos funktioniert, insbesondere wurden Schwierigkeiten in der Ausgleichung von Leerstellen durch die Verbindung von visuellen und sprachlichen Informationen festgestellt (Mempel 2010: 202). Mempels Untersuchung fand zwar in sehr kleinem Rahmen statt (5 Probanden insgesamt), trotzdem scheinen die Ergebnisse die Vermutung zu bestätigen: Comics sind doch kein Wundermittel für den Fremdsprachenunterricht, und ihr Einsatz führt zumindest nicht automatisch zu Erleichterungen des Spracherwerbs durch Begünstigung des Leseverstehens.

Und trotzdem: Selbst wenn eine empirische Untersuchung des didaktischen Mehrwerts von Comics noch ein Forschungsdesiderat darstellt, widmet sich dieser Aufsatz bewusst der Frage, wie Comics zu zeitgeschichtlichen Themen im DaFUnterricht gewinnbringend eingesetzt werden können. Dafür sprechen folgende zwei Gründe:

1. Comics sind ein ungewöhnliches Medium, das auch aufgrund seiner seltenen Verwendung im Unterricht bei Lernenden eine gewisse Neugier weckt und auf sie eine starke Faszination ausübt, v.a. dann, wenn es sich nicht um bekannte Walt-Disney-Funnies, Plauens „Vater und Sohn“ oder „Asterix" handelt (diese Beobachtung geht auf Erfahrungen der Verfasserin zurück). 
2. (Zeit)Geschichtliche Themen spielen bis heute im (landeskundlichen) DaF-Unterricht grundsätzlich eine ungeordnete Rolle, trotz der Forderung der ABCD-Thesen (vgl. ABCD-Thesen 1990; Cerri 2011: 337); sie erscheinen in Lehrwerken in sehr eingeschränkter thematischer Auswahl und mit Übungs- und Aufgabenmöglichkeiten (wie Text-Bild-Zuordnungen, Zeitleisten, Fragen), die primär auf Leseverstehen und Faktenvermittlung abzielen.

Warum also nicht historische Themen für den DaF-Unterricht mit einem ungewöhnlichen Medium als authentischem Text und mit handlungs- und produktionsorientierten Aufgaben aufbereiten? Dieser Aufsatz verfolgt das Ziel, diese Frage mit Hilfe von vielfältigen Aufgabenideen zu beantworten.

\subsection{Comics lesen $\rightarrow$ Analphabetismus?}

Der deutsche Comiczeichner Flix zeichnet in schematisch-karikaturistischem Stil nicht nur unterhaltsame Cartoons, sondern wagt sich auch an literarische Klassiker wie den ersten Teil von „Faust“ oder den spanischen Klassiker „Don Quijote“ heran. Die erste Episode von Flix' Comicadaption von „Don Quijote“ erschien 2012 in der F.A.Z. und löste einen polemischen Brief eines (fiktiven) Lesers „Alonso Quijano“" aus. In dem Brief ermahnt Quijano die Zeitung, die Veröffentlichung eines ,solchen intellektuellen Schmutzfleck[s]“ zu beenden; „schließlich ist allgemein bekannt, dass ,Comics' den Analphabetismus fördern und grade junge Menschen, die noch geistiger und moralischer Festigung bedürfen, zu Gewalt und Rache erziehen." "In einem Interview gefragt, was er von dieser abwertenden Haltung Comics gegenüber halte, erklärte der Zeichner Flix: ${ }^{3}$ „Eine Menge Leser haben die Ironie nicht erkannt, sondern diesem Brief beigepflichtet und sich bedankt, dass es endlich mal einer sagt. Und gefordert, dass die F.A.Z. jetzt wirklich mit dem Comic-Quatsch aufhören möge.“

Zum Glück ist, zumindest aus wissenschaftlicher Sicht, mehr als ein Jahrzehnt vergangen, seitdem Comics in Deutschland von der Bundesprüfstelle für jugendgefährdendes Schrifttum indiziert wurden und solche Urteile kursierten wie dies von 1956: „Was die Atombombe der Welt antun kann, nämlich ihr Ende herbeiführen, das kann das Comic Book der Welt antun - nämlich das Lesen ausrotten“" (zit. nach Gundermann 2007: 28, vgl. auch Munier 2000: 30). Die Leserreaktionen auf Quijanos Brief bezeichnete Flix im selben Interview zu Recht als eine „veraltete Haltung“", sie verraten jedoch, dass die Comicadaptionen von literarischen Klassikern oder Comics zu ernsten (gar historischen!) Themen immer noch fragende, verständnislose Reaktionen hervorrufen können (vgl. Gundermann 2007: 49). So

\footnotetext{
2 http://cult-mag.de/wp-content/uploads/2012/05/DonQuijote_Folge001.jpg (21.6.13).

${ }^{3}$ Interview: http://culturmag.de/litmag/comiczeichner-flix-im-interview/51053 (21.6.13).
} 
eröffnet Hieronimus (2009: 101) noch seinen Aufsatz mit der bitteren Feststellung: „Wer etwas mit Comics macht, muss sich dafür rechtfertigen.“

\subsection{Ernstzunehmende Comics}

Comics können historische Themen inhaltlich angemessen und ästhetisch anspruchsvoll umsetzen, genauso wie andere Medien und Erzählgattungen wie Romane, Filme, Hörspiele es auch vermögen. Zu dieser Annahme, die für diesen Aufsatz grundlegend ist, hat Munier (2000) mit der Gattungsbezeichnung und einer systematischen Kategorisierung historischer Comics beigetragen. Seit Munier und nach ihm Gundermann (2007) und Mounajed (2008, 2009 und 2010) haben historische Comics als neuer Weg der Geschichtsvermittlung sogar in das Fach Geschichte in den Schulunterricht Eingang gefunden, es liegen auch Materialien für die Behandlung des Holocaust mit dem extra für didaktische Zwecke gezeichneten Comic „Die Suche“ vor (vgl. Holocaust im Comic 2008). All diesen Veröffentlichungen ist zunächst die zwangsläufige Beschäftigung mit der Rechtfertigung für die Wahl des Mediums gemeinsam - sind denn Comics ein „würdiges“ Medium für die Behandlung und sogar Vermittlung historischer Themen solcher Ernsthaftigkeit wie der Holocaust? Zu dieser leider immer noch häufig gestellten Frage hat Art Spiegelmanns schon lange wie folgt gekontert: „But I spell it c-o-m-i-x, so you are not confused by the fact that comics have to be funny, as in comic. You think it is a co-mix of words and pictures" (Spiegelmann, zit. nach Gundermann 2007: 8). In Zustimmung zu Spiegelmann werden Comics im Rahmen dieses Aufsatzes neutral als narrative Medien verstanden, die materielle, anschauliche bildliche Zeichen mit abstrakten verbalen Zeichen verbinden (vgl. Mahne 2007: 45). ${ }^{4}$ Gerade in dem Wechselverhältnis zwischen Bild und Text steckt die narrative Chance von Comics (ebd.). Das Unterhaltsame und Lustige als historische Ursprungsmerkmale des Mediums müssen zwar keineswegs verleugnet werden; allerdings zeigt die aktuelle Comicproduktion eine so beeindruckende Breite an gesellschaftskritischen, zeitgeschichtlichen, politischen und historischen Themen, dass das „Funny“ automatisch in den Hintergrund rückt. Hoffentlich stellt dieser Aufsatz die letzte Veröffentlichung über Comics dar, in der eine solche - wenn auch kurz gehaltene - Rechtfertigung notwendig ist.

\section{Historische Comics (im DaF-Unterricht)}

\subsection{Historische Comics müssen viel leisten! Typologie und Authentizität}

Historische Comics als „visuelle Geschichtserzählungen“, die „von den Geschichts-Imaginationen ihrer Künstler leben“ (Mounajed 2008: 203), können in un-

${ }^{4}$ Vgl. zur Definition den Beitrag von Ralf Palandt in diesem Band. 
terschiedliche Kategorien aufgeteilt werden. Bevor auf einige dieser Kategorien eingegangen wird, möchte ich ein grundlegendes Merkmal von historischen Comics herausarbeiten: Die Geschichtserzählung in Comics, die primär durch visuelle Mittel erfolgt, führt zwangsläufig zu einer „Fiktionalisierung des historischen Ereignisses", so Dolle-Weinkauff (2000: 302). Dem Erzählen als medienunabhängig gesehene, narrative Grundkategorie unterliegt nämlich immer ein Konstruktionsprozess, der umso subjektiver ausfallen kann, je stärker die persönlichen Erinnerungsanteile sind, und der andererseits empirisch nachprüfbar sein muss, wenn es sich um ein historiografisches Werk handelt (vgl. Nünning 2005). Es gibt historische Comics (auch einige der hier verwendeten gehören dazu, z.B. „Grenzfall“, Henseler; Buddenberg 2012, oder „Grenzgebiete“, Lenkova 2009), die einen historiografischen Anspruch erheben und sich also der faktischen Nachprüfbarkeit verschreiben.

Visuelle Mittel mit solchem Anspruch müssen hier im Vergleich zu schriftlichen Mitteln zweierlei leisten: Sie müssen nämlich nicht nur faktentreu, sondern auch detailtreu erzählen, denn sie können sich von der Darstellung von Materialität nicht lösen. Während ein schreibender Chronist solche historisch nicht immer gesicherten Details wie Kleidung, Orte, Handlungen usw. auslassen kann, muss sie ein Comiczeichner stattdessen zeichnen und gegebenenfalls erfinden, wenn dazu keine Überlieferungen existieren (vgl. Dolle-Weinkauff 2000: 302f.). Schon die Darstellungsmittel, auf die der Comiczeichner zurückgreift - sein Zeichenstil, das Layout und die Panelgestaltung, die Farbwahl - haben auf Leser eine andere, viel anschaulichere Wirkungskraft als der Argumentationsstil eines Historikers es vermag, und überziehen die dargestellten und erzählten Ereignisse mit zusätzlichen Bedeutungsschichten. Dieser Aspekt spielt beim Authentizitätsgrad des Comics eine wichtige Rolle, denn Authentizität bezieht sich nicht nur auf Fakten- oder Erlebnistreue, sondern kommt auch durch die Darstellung zum Ausdruck.

Einige der hier verwendeten Comics gehören zur Kategorie der real-geschichtlichen Comic-Nacherzählungen. Als solche wird ein Comic verstanden, ,in dem zentrale Personen und Ereignisse dargestellt werden, die real verbürgt sind" (Munier 2000: 104). Dieser Comic als „gezeichnetes Geschichtsbuch“ existiert in drei Varianten: als Nacherzählung realer Geschehnisse, als Biografie oder als auf Vermittlungszwecke abzielender Sachcomic (vgl. Munier 2000: 109). „Grenzfall“ (Henseler; Buddenberg 2012) ist als Nacherzählung realer Geschehnisse einzustufen; ${ }^{5}$ der Comic erzählt die wahre Geschichte vom Schüler Peter Grimm, dessen Ideale in der DDR als nicht willkommen und nicht konform mit der Diktatur angesehen wurden, denen er aber treu blieb und für die er kämpfte. Die realgeschichtliche Comic-Nacherzählung verfügt immer über Faktenauthentizität, die gegeben ist, ,wenn zumindest exemplarisch nachgewiesen werden kann, dass die

\footnotetext{
${ }^{5}$ Von den gleichen Autoren ist auch „Berlin Geteilte Stadt. Zeitgeschichten“ (Buddenberg; Henseler 2012) erschienen, eine Nacherzählung realer Geschehnisse. Der Comic vereint fünf real verbürgte Zeitzeugengeschichten von jungen Menschen aus Ost-Berlin.
} 
geschilderten Personen tatsächlich gelebt haben und die Ereignisse tatsächlich vorgefallen sind. Fiktive Personen und Handlungen dürfen verwendet werden, wenn diese die historische Situation und die Großchronologie nicht verändern" (Gundermann 2007: 82). „Grenzfall“ (Henseler; Buddenberg 2012), sowie „Berlin Geteilte Stadt" (Buddenberg; Henseler 2012) wurden durch Mittel der Bundesstiftung zur Aufarbeitung der SED-Diktatur gefördert und gehören z.T. auch zu Sachcomics, weil sie mit einem Glossar und Quellenverzeichnis („Grenzfall“) bzw. mit zusätzlichen Texten zum historischen Hintergrund („Berlin Geteilte Stadt") versehen sind - Sachcomics kennzeichnen sich nämlich durch ,gesonderte Informationsteile, in denen durch Schrift und Bilder ohne comicale Elemente noch einmal wichtige Informationen dargeboten werden“ (Gundermann 2007: 93). "Grenzgebiete" von Claire Lenkova (2009) trägt die Merkmale eines autobiografischen Sachcomics. So erzählt die Zeichnerin Lenkova ihre Kindheit, die sie zunächst in Thüringen, dann bis zur Auswanderung der Familie in den Westen im Auffanglager Gießen verbrachte, und ergänzt ihre Erinnerungen mit zusätzlichen Informationen über historische Fakten, Institutionen und Personen, die unter wissenschaftlicher Betreuung der Stiftung Haus der Geschichte der Bundesrepublik Deutschland und des Zeitgeschichtlichen Forums Leipzig verfasst wurden.

Schwartz” „drüben“ (2009) kann, wie Flix” „da war mal was...“ (2009), an der Schnittstelle zwischen Comic-Autobiografie und biografischer Comic-Nacherzählung angesiedelt werden. In Comic-Autobiografien berichtet der Comiczeichner, der auch Texter und Protagonist ist, über das eigene Leben, einen Lebensabschnitt oder Episoden daraus, die sich auf dem Hintergrund historisch relevanter Ereignisse abgespielt haben. Die Einheit von Comiczeichner, Texter und Protagonist schafft „eine besondere Form der Authentizität, die in einer Biografie nicht zu finden ist“ (Gundermann 2007: 93) und als „Erlebnisauthentizität“ (ebd.: 82) bezeichnet werden kann. Schwartz erzählt von der schwierigen Entscheidung seiner Eltern, Anfang der 1980er Jahre die DDR und deren allgegenwärtige Diktatur für immer zu verlassen. In „da war mal was...“ zeichnet Flix zunächst die eigenen Erinnerungen, dann die Erinnerungen von Menschen an die Zeit vor, um und nach dem Mauerfall, Menschen, die zur Zeit des Mauerfalls zwischen 10 und 15 waren. Das Album vereint Fantasie-Geschichten von Westkindern über die DDR, tragische Fluchtversuche, Pionierträume, Liebesgeschichten über die Grenzen hinweg,

\footnotetext{
${ }^{6}$ Folgende Arten von historischen Comics werden hier nicht angesprochen, weil keiner der didaktisierten Comics zu diesen Kategorien gehört: historisierende Comic-Abenteuerimaginationen, die als fantastische Unterhaltungscomics entstehen und keinen historischen Anspruch erheben; ComicEpochalepos, die historisch verbürgte mit erfundenen Ereignissen verbinden (vgl. Munier 2000: 102, 105); Comic-Geschichtsgroteske und -parodien, bei denen der historische Rahmen nur „Vorlage zur Ironisierung der aktuellen Lebensumstände" ist (Gundermann 2007: 90) und Comic-Journalismus (vgl. Gundermann 2007: 95f.). Aus dem gleichen Grund soll hier auch auf Quellencomics nicht eingegangen werden (nach Munier 2000: 107 ein kategorieübergreifendes Merkmal, nach Gundermann 2007: 88ff. eine Comickategorie).
} 
Alltag im Osten und im Westen und bietet stark subjektiv und altersgeprägte Einblicke in dieses Kapitel deutsch-deutscher Geschichte.

Zur Kategorie von biografischen Sachcomics gehört „Das Leben von Anne Frank. Eine grafische-Biografie“ (Jacobson; Colón 2010). Thematisch fällt diese Comic-Sachbiografie, die in Zusammenarbeit mit dem Anne Frank-Haus Amsterdam entstand, aus dem Rahmen der anderen, sonst DDR/BRD-Geschichte fokussierenden Comics, zeichnet sich durch faktentreue Erzählung des Lebens der Anne Frank aus und verfügt über eine angehängte Zeittafel mit historischen Fotos sowie weiterführender Literatur.

Historische Comics können nicht nur Fakten- und Erlebnisauthentizität, sondern auch andere Arten von Authentizität aufweisen, wie z.B. Typenauthentizität, wenn fiktive Figuren auftreten, die einem „historischen Typus“ entsprechen oder fiktive Ereignisse, die treu zu historischen Ereignisabläufen gestaltet sind (Gundermann 2007: 83). Über eine solche Authentizität verfügt (hier nur als Beispiel erwähnt) der Comic „Die Entdeckung“/„Die Suche“ (Heuvel 2007), welcher das Schicksal einer fiktiven holländischen jüdischen Familie erzählt, die Auschwitz überlebt und nach Amerika auswandert. Trotz der Fiktionalität der Geschichte sind die Figuren historisch gesehen absolut plausibel konstruiert, und ihr Schicksal entspricht dem Schicksal vieler holländischer Juden, die in Konzentrationslager deportiert wurden. Insofern weist der Comic ebenfalls Repräsentationsauthentizität auf, weil die Ereignisse „exemplarisch für den Themenkomplex“ sind und sich in einen „historischen Gesamtzusammenhang einordnen“ lassen (Gundermann 2007: 83).

\subsection{Historische Comics im Unterricht: Überlegungen zu Auswahlkriterien und zur Einsetzbarkeit}

Will man einen Comic als Lehrmittel im Unterricht einsetzen, spielt zunächst die Art der Authentizität eine wichtige Rolle. Faktenauthentizität müsste vorhanden sein (vgl. Gundermann 2007: 100). Dieses Merkmal erfüllen, wenn auch in unterschiedlichem Maße, alle hier didaktisierten Comics; nur „da war mal was..." und „drüben!“, die am stärksten erlebnisauthentisch sind, erzählen zwar von stattgefundenen Ereignissen und realen Personen, die aber durch subjektive Wahrnehmung und Erinnerung gefiltert werden. Auch die Frage, was bei der Erzählung den größten Raum einnimmt, soll mit bedacht werden: ob Personen-Charakterisierungen, historische Ereignisse, Konflikte oder soziale Wirklichkeit im Mittelpunkt stehen bzw. eine geistige Auseinandersetzung mit Geschichte stattfindet und wie die Perspektive gestaltet ist (vgl. Munier 2000: 101). Ebenfalls spielt die Sichtweise eine Rolle: Eine synthetische breitet gesichertes geschichtliches Wissen aus, eine analytische geht fragend/forschend an den Handlungsinhalt heran (vgl. Munier 2000: 101). Herrscht die erste Sichtweise vor, eignet sich der Comic als Grundlagentext zur Faktenvermittlung, spielt die zweite Sichtweise eine größere Rolle, trägt er eher zu einer problemorientierten Auseinandersetzung bei. Die Fragen nach der Au- 
thentizität, der Perspektive und der Sichtweise entscheiden also z.B. darüber, ob in der Didaktisierung zusätzliche Materialien zum historischen Hintergrund oder Materialien, die verschiedene Sichten auf das gleiche Ereignis anbieten, herangezogen werden sollten.

Die Vielzahl von subjektiven Episoden im Comic „da war mal was...“ verursacht eine starke mehrperspektivische und zugleich analytische Brechung der Geschichte, was zur „Auflösung historischen Geschehens in eine Vielfalt heterogener Versionen [führt], die sich nicht mehr als synthetisierbar erweisen“ (Nünning 2005: 51). Flix' Episoden bieten sich also nicht für die Vermittlung von historisch gesichertem Wissen an und müssten bei einer Didaktisierung mit entsprechenden $\mathrm{Zu}$ satzmaterialien erweitert werden, die die Erinnerungen der Figuren mit Fakten ergänzen. Je mehr die historischen Fakten durch subjektive Bewertungen und Erinnerungen überlagert sind, desto notwendiger erweist sich also die Begleitung der Comicepisoden durch historisches Material und desto interessanter die Besprechung der Frage, durch welche visuellen Mittel diese Subjektivität zum Ausdruck kommt (was hervorragend als Narrative-Discourse-Aufgabe taugt, die die comicspezifische Gestaltung in den Mittelpunkt rückt - vgl. Kap. 3.1). Die Ergänzung des Comics mit historischem Material oder Zusatzinformationen ist auch beim stark erlebnisauthentischen „drüben!“ erforderlich. Bei Sachcomics wie „Grenzgebiete“ oder „Grenzfall“" sichern die Faktentreue sowie zusätzliche, als Texte angebotene und wissenschaftlich gesichtete Informationen Faktenauthentizität, so dass hier die Heranziehung weiterer Quellen und Materialien nicht zwingend erfolgen muss, sondern eher eine Möglichkeit darstellt, erwähnte, wenig bekannte Personen oder Ereignisse zu erklären. Dies gilt auch für die wissenschaftlich gesicherte Biografie von Anne Frank.

Bei der Didaktisierung sollten - zusätzlich zu den üblichen Kriterien für die Unterrichtsplanung wie Orientierung am Niveau der Zielgruppe, den Lernzielen und Rahmenbedingungen, methodische Vielfalt - schließlich folgende Aspekte mit bedacht werden: Handlung, Figuren und Konflikte der Episoden müssen erfasst werden, was Aufgaben zum Leseverstehen erfordert; der historische Hintergrund muss eingeführt, begleitet, vertieft werden; und - last but not least - die „piktorale Lesefähigkeit“ des Lesers muss geschult werden, denn nur ein breites ,visuelle[s] Vokabular“ erlaube „ein erfolgreiches Lesen des Comics“ (Gundermann 2007: 72). Alle AutorInnen, die sich mit dem Einsatz von Comics im Unterricht und auch Fremdsprachenunterricht beschäftigen, sind sich einig, dass diese piktorale Lesefähigkeit unverzichtbar ist (siehe auch Vignaud 2009; Hochbruck 2005). Dies verlangt, dass auch im DaF-Unterricht eine kurze Einführung in die comicspezifischen Grundlagen (Grundbegriffe, Funktionsmechanismen, Stil etc.) erfolgen muss. 


\section{Theorie ohne Praxis ist wie ein Fahrrad ohne Kette. Aufgabentypen, Aufgabenbeispiele und Unterrichtsideen}

In Veröffentlichungen aus der Französisch- und der neuesten Englischdidaktik nimmt der Einsatz von Comics im Fremdsprachenunterricht einen großen Raum ein (vgl. z.B. Vignaud 2009; Hallet 2012a, 2012b; Hochbruck 2005; Schüwer 2005; Stenz 2006). Nur ein kleiner Teil dieser Veröffentlichungen ist Comics zu landeskundlichen oder zeitgeschichtlichen Themen gewidmet (vgl. Hochbruck 2005; Vignaud 2009). Ein einziger mir bekannter Aufsatz (vgl. Hieronimus 2009) thematisiert schließlich historische Comics als gewinnbringende Materialien für den DaFUnterricht und geht auf vorhandene geschichtliche Comicveröffentlichungen und ihre Anwendungsmöglichkeiten ein (die allerdings den Schwerpunkt auf die didaktische Verwendbarkeit für Sprechanlässe setzen). ${ }^{7}$ Im Folgenden möchte ich zunächst eine mögliche Typologisierung von Aufgaben und anschließend Vorschläge zur Didaktisierung von historischen Comics im DaF-Unterricht vorstellen.

\subsection{Aufgabentypologie nach Hallet 2012}

Hallet (2012a), auf dessen Aufgabentypologie ich mich beziehe, verortet Comics im Literaturunterricht und schreibt ihnen als „grafische Literatur" (ebd., 2) das Potenzial zu, u.a. narrative Kompetenz und „literarästhetisches Denken“ (ebd., 8) zu schulen. Ihm zufolge richten sich, gute Aufgaben [...] zunächst auf das Geschehen und die Figuren des Romans [sic!], auf Konflikte und den Fortgang der Handlung sowie auf deren Ursachen und Auslöser" (Hallet 2012a: 7). Dieses Zitat macht seine Auffassung von Comics als zwar multimediale, aber primär literarische Erzählgattung deutlich. Das Verständnis von Comics, welches diesem Aufsatz zugrunde liegt, divergiert von Hallets Verständnis stark. Hallets Auffassung - hier etwas verkürzt zusammengefasst: Comics seien Erzählmedien, die mit Bildern Geschichten erzählen, wie Romane es mit Wörtern tun - sehe ich in Anlehnung an Hein (2002: 52, 54) als problematisch an, weil sie die medien-, also comicspezifische Form übersieht, die das Narrative erst durch das fruchtbare Wechselverhältnis zwischen Bild und Text schafft (vgl. Cerri, i.Vorb.). Diese Unstimmigkeit bei der Gegenstandsdefinition soll hier jedoch nicht daran hindern, Hallets Aufgabentypologie vorzustellen, die meines Wissens die einzige systematische ist, die sich für den Einsatz von narrativ und inhaltlich komplexen Comics im Fremdsprachenunterricht als Orientierungsgerüst gut eignet. Ein weiterer Vorteil besteht darin, dass diese Typologie, obwohl sie deutlich der Aufgabentypologie von epischen Texten entnommen ist und sich durch einen starken Fokus auf Leseverstehen

\footnotetext{
${ }^{7}$ Das Goethe Institut hat zwei CD-ROMs zum Einsatz von „drüben!“ und „Berlin - Steinerne Stadt" (Lutes 2003) veröffentlicht, in denen sich Aufgabenvorschläge für den Einsatz der Comics im DaF-Unterricht finden (vgl. Schott 2010).
} 
auszeichnet, außerdem genug Raum auch für Aufgaben zur comicspezifischen Gestaltung und Narration anbietet, was bei der Arbeit mit Comics unerlässlich ist.

Hallet zufolge (2012a: 7f.) können Aufgaben in folgenden Kategorien eingeteilt werden:

- begleitende, leseunterstützende Aufgaben, wie z.B. das Lesetagebuch, das sich vor allem für die Begleitung, Dokumentation und Reflexion des Leseprozesses anbietet (zum Lesetagebuch, das primär für die begleitete Lektüre von Ganzschriften eingesetzt wird, vgl. Hintz 2002);

- Plot-Rekonstruktionsaufgaben, die auf das „Erfassen des Geschehens- und Handlungsverläufe sowie der Kausalitäten“ abzielen (Hallet 2012a: 7), z.B. die Wiedergabe von Inhalt und Handlung in knappen Sätzen oder mit inhaltsbezogenen und anwendungsbezogenen Leseaufgaben; 8

- Story-orientierte Aufgaben für die die nähere Beschäftigung „mit einzelnen Figuren, ihren Merkmalen, Denken, Fühlen und Sprechen“ oder die Untersuchung der „Schauplätze, Räume und Bewegungen darin“ bzw. vom „Inventar der storyworld der graphic novel" (ebd.). Dazu gehören beispielweise die Charakterisierung von Figuren in Steckbriefen oder Pro-Contra-Diskussionen zu Entscheidungsfragen derselben;

- thematische Aufgaben, die „der Erschließung der jeweils im Vordergrund stehenden thematischen Aspekte" dienen (ebd.), z.B. die Herausarbeitung der Informationen zum landeskundlichen Hintergrund aus dem Comic und der anschließende Vergleich und die Ergänzung mit Zusatzmaterialien (z.B. aktuellen Statistiken);

- Narrative-Discourse-Aufgaben, die das Ausdrucksinventar von Comics fokussieren (Farben, Sprechblasen, Linien, Layout etc.) - Hallet betont diesbezüglich, dass diese Aufgaben „eine dienende Funktion“ haben, denn „sie sollen genaueres Lesen und tieferes Verstehen ermöglichen“ (Hallet 2012a: 8);

- aufmerksamkeitslenkende Aufgaben, die „weniger explizit gemachte Sachverhalte [...] wie z.B. das Handlungsmotiv einer Figur, die Bedeutung eines besonderen Gegenstandes oder die Beschaffenheit eines Schauplatzes“

\footnotetext{
8 Westhoff (1997: 19-23) unterscheidet zwischen inhaltsbezogenen und anwendungsorientierten Leseaufgaben. Inhaltsbezogene Aufgaben fragen den Inhalt des Textes ab (z.B. Richtig-Falsch-Fragen, Multiple-Choice, Zuordnung von Text und Bildern, Fragen zu Handlung und Figuren) und dienen in einer Unterrichtssituation als Verstehenshilfe für die Lernenden und zur Sicherung/Überprüfung des Textverständnisses (Lindauer; Schneider 2010: 114 bezeichnen diese Art von Aufgaben deswegen als „Prüfaufgaben“). Anwendungsbezogene Aufgaben dienen stattdessen zur Übung von Lesestrategien, die auf jeden Text angewendet werden können und deswegen die selbständige Erschließung von jedem Text fördern (z.B. W-Fragen, Teilung des Textes in Abschnitte und Finden passender Überschriften; nach Lindauer; Schneider 2010: 109 „Lernaufgaben“). Beide Arten von Leseaufgaben können in Verbindung miteinander sinnvoll sein. In diesem Aufsatz wird die Art der vorgeschlagenen Leseaufgaben zur Veranschaulichung immer spezifiziert.
} 
sowie „die Symbolsprache der graphic novel" (ebd.) in den Mittepunkt rücken sollen;

- und schließlich produktionsorientierte Aufgaben, die wie im produktionsorientierten Literaturunterricht das Ziel verfolgen, die Lernenden zum Verfassen eigener Texte anzuregen: Sie erzählen einen Comic weiter, setzen Comics in eine andere Textsorte um oder füllen leere Text- und Gedankenblasen aus, und natürlich erweitern sich produktionsorientierte Aufgaben mit Comics um die Möglichkeit der bildnerischen Gestaltung, so dass Lernende selbstgeschriebene Geschichten in Comics umsetzen.?

\subsection{Aufgabenbeispiele}

Die folgenden an Hallets Aufgabentypologie angelehnten Beispiele sind für Lernende ab B1+-Niveau geeignet, die über allgemeines Weltwissen über die angesprochenen Themen (DDR/BRD, Anne Frank) verfügen. D.h., die meisten Aufgaben müssen nicht zwingend landeskundlich vorentlastet werden (wenn notwendig, wird dies spezifiziert). Sollte die zur Verfügung stehende Zeit begrenzt sein, können einzelne Aufgaben mit der ganzen Lernergruppe an eine Lehrwerklektion als Erweiterung oder Vertiefung angeschlossen werden, wie z.B. bei „studio d B2/2“ (Kuhn; Winzer-Kiontke; Würz 2013: 88-89, 179) zum Thema geteiltes Deutschland. Sie können aber auch in einen größeren Unterrichtszusammenhang eingebettet werden, beispielsweise in einer mehrteiligen Stationenarbeit zu unterschiedlichen thematischen Schwerpunkten. Um die vielseitige Einsetzbarkeit der Beispiele in verschiedenen Unterrichtskontexten zu gewähren, werden die Aufgaben zwar in einem möglichen Lernkontext, aber noch nicht in vollständig ausgearbeiteten, fertigen Unterrichtskonzepten vorgestellt. Wo sich Möglichkeiten für Ergänzungen anbieten, wird darauf hingewiesen. Die Anpassung und der letzte Schliff - je nach Kontext und konkreter Lernergruppe - seien also den Lehrpersonen überlassen.

Es werden sechs Beispiele zu folgenden Themen vorgestellt: Opfer der Berliner Mauer, Schmuggeln über die Grenze, Ausreise aus der DDR, Grenzübergang, Meinungsfreiheit in der DDR sowie Anne Frank und ihr Tagebuch.

9 Comics selber erstellen kann man z.B. bei http://www.bitstrips.com/create/comic/ (29.6.13). 
3.2.1 Opfer der Berliner Mauer

\begin{tabular}{|c|c|c|c|}
\hline Thema & Comic & Aufgabentypen & Bemerkungen \\
\hline \multirow[t]{3}{*}{$\begin{array}{l}\text { Opfer der } \\
\text { Berliner } \\
\text { Mauer }\end{array}$} & \multirow[t]{3}{*}{$\begin{array}{l}\text { „da war mal } \\
\text { was..." } \\
\text { Episode von } \\
\text { Frank }\end{array}$} & $\begin{array}{l}\text { Plot-Rekonstruktions- } \\
\text { aufgabe: Erfassung der } \\
\text { Handlung mit anwen- } \\
\text { dungsbezogenen Lese- } \\
\text { aufgaben }\end{array}$ & \multirow[t]{3}{*}{$\begin{array}{l}\text { Vertiefung möglich } \\
\text { mit weiterer pro- } \\
\text { duktionsorientierten } \\
\text { Aufgaben (Rollen- } \\
\text { spiel) }\end{array}$} \\
\hline & & $\begin{array}{l}\text { Narrative-Discourse-Auf- } \\
\text { gabe: Analyse der visuellen } \\
\text { Gestaltung der Episode }\end{array}$ & \\
\hline & & $\begin{array}{l}\text { Produktionsorientierte } \\
\text { Aufgabe: Tagebuch der } \\
\text { Figur }\end{array}$ & \\
\hline
\end{tabular}

Im ersten Beispiel mit einer Geschichte aus Flix’ „da war mal was...“ erfolgt der Einstieg zunächst über eine thematische Vorentlastung mit Bildern zum geteilten Berlin, zu Fluchtversuchen und zu Maueropfern und setzt dann fort mit einer Erarbeitungsphase, in der drei kurze, mit Wortschatzerklärungen versehene Texte gelesen werden - der Ausschnitt aus der berühmten Rede von Walter Ulbricht am 15. Juni 1961, eine Übersicht der an der Mauer zu Tode gekommenen Menschen und kurze Infos zum ersten Maueropfer Ida Siekmann. ${ }^{10}$ Hier sehen die Lernenden einen Film über die Entstehung der Mauer und die ersten Fluchtversuche. ${ }^{11}$ Erst nach dieser thematischen Vorbereitung lesen die Lernenden die Episode von Frank aus Flix' Comic. Die Episode stellt den Tod eines Freunds von Franks Vater bei einem gemeinsamen Fluchtversuch in den Westen dar und ist eine der tragischsten im ganzen Comicalbum. Sie wird hauptsächlich visuell erzählt und bereitet also sprachlich keine Hindernisse. Das Ziel der ersten Plot-Rekonstruktionsaufgabe (siehe Arbeitsblatt 1) besteht deswegen nicht in einem klassischen Leseverstehen, sondern eher in der Förderung des Sehverstehens und will die Lernenden dazu bringen, in erster Linie den plot zu versprachlichen und sich genau mit der visuellen Gestaltung der Episode auseinanderzusetzen, die durch die trüben Farben und die Mimik der Figuren die Tragik des Ereignisses verstärkt. Das ein-

\footnotetext{
${ }^{10}$ Die Veröffentlichung aller Texte und Arbeitsblätter würde den Rahmen dieses Aufsatzes sprengen. Die Verfasserin stellt sie aber bei Nachfragen gerne via E-Mail zur Verfügung (cerri@staff.unimarburg.de ).

${ }^{11}$ Der Film ist abrufbar unter: http://www.youtube.com/watch?v=ddgqmhRN7GA (20.6.13). Der Film mischt Histotainment-Sequenzen, die manche Fluchtversuche nachstellen, und historische Aufnahmen und Fotos.
} 
zige Panel ohne Habitus ${ }^{12}$ (Umrandung) stellt den Tod des Freundes von Franks Vater dar. Wenn Panels nicht mehr über einen Habitus verfügen, löst sich der Zeitrahmen auf, was die Wirkung von Unendlichkeit oder eine starke emotionale Betroffenheit auslösen kann, so Gundermann (2007: 67). In der Episode von Franks Vater drückt das die emotionale Heftigkeit des Augenblicks aus, in dem der Freund erschossen wird, und verwandelt diesen zeitlos gewordenen Augenblick in einen immerwährenden Schmerz, der Franks Vater nicht mehr verlassen wird. Auch das Weglassen der Sprache gewinnt eine zusätzliche Bedeutung, denn das Ereignis hat Franks Vater nie erzählt - dieses unerzählbare Ereignis kann nur in einer sprachlosen Darstellung Ausdruck finden. In dieser Hinsicht beinhaltet die Aufgabe auch Aspekte des Narrative-Discourse. Durch die Tragik übt die Episode eine starke emotionale Involvierung der Lernenden aus. Diese emotionale Involvierung spielt bei der darauf folgenden produktionsorientierten Aufgabe, in der die Lernenden eine Tagebuchseite von Franks Vater schreiben, eine wichtige Rolle: „Stellen Sie sich vor, Sie sind der Vater von Frank. Sie haben nie über die Flucht reden wollen. Allerdings haben Sie in Ihrem Tagebuch über die Flucht an der Mauer geschrieben. Schreiben Sie diesen Tagebucheintrag." Folgenden Eintrag hat eine niederländische Deutschstudierende (Niveau: Ende B1) geschrieben (der Text wird im Original wiedergegeben): ${ }^{13}$

\section{Hallo Tagebuch.}

Heute ist etwas schreckliches passiert. Nach viele Vorbereitungen hatte ich mit Jorg ein Flucht über die Mauer versucht. Ich war wirklich gespannt und die Adrenaline hat mir in einer Trance gemacht. Jorg hatte noch 3...2...1 gesagt, wir haben so schnell wie möglich gerennt. Erst unter eine Hecke durch. Danach über der Mauer. Jorg hat mich geholfen darüber zu kommen. Aber dann passierte es wirklich laut wurde „HALT“ gerufen. Jorg hatte keine Möglichkeit zu fliehen. Sie haben ihn erschossen. Und ich ware doch an die andere Seite. Ich füll mich schuldig, so schuldig.

Wieso er? Wieso nicht ich.

Ich hoffe er ist jetzt in Himmel...

Es tut mir leit.

Karl.

Diese Aufgabensequenz kann einerseits mit den bereits zitierten Seiten aus „studio $\mathrm{d}^{\text {" }}$ eingeleitet werden, in denen am Beispiel der Bernauerstraße die Teilung Deutschland, die Entstehung und der Fall der Mauer sowie Fluchtversuche (z.B.

\footnotetext{
12 „Den Bilderrahmen eines einzelnen Panels nennt man Habitus. Er begrenzt durch eine Umrandung oder Linie die Erzählung und die Zeit des einzelnen Bildes. Seine Funktion ist ähnlich wie die eines Satzzeichen im Text.“ (Dohm 1999: 17, Hervorh. im Original).

${ }^{13}$ Die Studentin hat mit dieser Aufgabensequenz im Rahmen eines Workshops über „Geschichte mit Comics“ an der Radboud Universiteit Nijmegen im März 2013 gearbeitet.
} 
über den Tunnel 5714) thematisiert werden (vgl. Kuhn; Winzer-Kiontke; Würz 2013: 88f., 179). Die Sequenz kann außerdem mit einer weiteren Vertiefungsphase ergänzt werden, in der die Lernenden die Geschichte von Winfried Freudenberg erfahren, der bei seinem Fluchtversuch mit einem Heißluftballon als letztes Opfer der Mauer verunglückte. Mehrere Internetseiten bieten fundierte, allerdings sehr ausführliche Informationen über seine Biografie und den Vorfall an15. Für den Unterricht wäre es sinnvoll, die wichtigsten Informationen in einem gekürzten Text zur Verfügung zu stellen, um die Lernenden mit den wichtigsten Aspekten des Schicksals von Freudenberg vertraut zu machen. Das kann eine weitere produktionsorientierte Aufgabe einleiten, nämlich ein Rollenspiel, welches das Ziel verfolgt, historische Kenntnisse, die im Laufe der Stunde erarbeitet wurden, mit der Förderung der freien Sprachproduktion zu verbinden. Die Lernenden bekommen Rollenbeschreibungen von fiktiven, aber historisch plausiblen Menschen, die in Ostberlin wohnten und eine Flucht in den Westen planen und müssen Pro- und Contra-Argumente für die Flucht sammeln und zusammen eine Entscheidung treffen (das Arbeitsblatt 2 zeigt zwei Beispiele von Rollenbeschreibungen).

\subsubsection{Schmuggeln über die BRD/DDR}

\begin{tabular}{|c|c|c|}
\hline Thema & Comic & Aufgabentypen \\
\hline \multirow{2}{*}{$\begin{array}{l}\text { Schmuggeln } \\
\text { über die } \\
\text { BRD/DDR } \\
\text {-Mauer }\end{array}$} & \multirow[t]{2}{*}{$\begin{array}{l}\text { „da war mal was...“ } \\
\text { Episode von Oliver }\end{array}$} & $\begin{array}{l}\text { Aufmerksamkeitslenkende Aufgabe: } \\
\text { Nähere Betrachtung des Ereignisortes } \\
\text { (Checkpoint-Charlie) }\end{array}$ \\
\hline & & $\begin{array}{l}\text { Narrative Discourse-Aufgabe: } \\
\text { durch Vergleich mit einem historischen } \\
\text { Foto Analyse der Art, wie Farbe, Panel- } \\
\text { gestaltung, Layout, Zeichenstil zusätzli- } \\
\text { che Bedeutung für die erzählten Ereignis- } \\
\text { se transportieren }\end{array}$ \\
\hline
\end{tabular}

Dieses Beispiel stellt das gestalterische Inventar von Comics in den Mittelpunkt, was in einer Narrative-Discourse-Aufgabe analysiert wird. Das Beispiel setzt voraus, dass die Lernenden in einer kurzen Einführung in die Comicsprache bereits Grundwissen über Begrifflichkeiten und Gestaltungsmöglichkeiten erfahren und

\footnotetext{
14 Zum Fluchttunnel „Tunnel 57“ ist im April 2013 der Comic „Tunnel 57. Eine Fluchtgeschichte als Comic" (Henseler; Buddenberg 2013) erschienen. Der Comic kann in diesem Aufsatz nicht mehr berücksichtigt werden, trotzdem möchte ich darauf hinweisen. Er enthält einen umfangreichen Materialienteil mit einem Interview mit den AutorInnen über die Einarbeitung historischer Materialien sowie mit didaktisch-methodischen Hinweisen für den Geschichtsunterricht im Muttersprachenunterricht.

15 www.berliner-mauer-gedenkstaette.de/de/1989-332.html, http://www.chronik-der-mauer.de/ index.php/de/Start/Detail/id/593906/page/2 (21.6.13).
} 
verschiedene Comics nach gestalterischen Besonderheiten analysiert haben (siehe Arbeitsblatt 3). Für die weitere Arbeit wird eine Episode aus Flix’ „da war mal was... " eingesetzt, ${ }^{16}$ für die die visuelle Semantisierung, d.h. die Beladung des visuellen Raums mit zusätzlicher Bedeutung durch z.B. Farbe und grafische Gestaltung prägend ist (vgl. Cerri, i.Vorb.). Deswegen eignet sich die Episode für diese Art von Aufgaben sehr gut.

Olivers Erinnerung an die Mauer wird mit einem großen Panel (im Album so groß wie eine Doppelseite) eröffnet, die folgenden Blockkommentar enthält: „Die Mauer nimmt in meiner Erinnerung sehr viel Raum ein." Hier wird der Grenzübergang Checkpoint Charlie physisch riesengroß dargestellt und sticht im Vergleich mit den darauf folgenden kleinen Panels, die Olivers „Schmuggeln“ von Westliteratur und -medien in den Osten darstellen, sehr hervor.

Nach dem Lesen von Olivers Episode sollen die Lernenden das erste Panel beschreiben, die Aufgabe kann mündlich in Paaren gemacht werden und verfolgt das Ziel, die Aufmerksamkeit zunächst auf die physische Beschaffenheit des Ortes zu richten (deswegen handelt es sich nach Hallets Typologie um eine aufmerksamkeitslenkende Aufgabe). Da das Bild des Grenzüberganges Checkpoint Charlie zum visuellen Symbol des kollektiven Gedächtnisses geworden ist, besteht die Wahrscheinlichkeit, dass es auch im Bildrepertoire der Lernenden vorhanden ist und deswegen erkannt wird. Wenn nicht, erfolgt eine reine Ortsbeschreibung. Im folgenden Schritt lesen die Lernenden einen kurzen Text über den Checkpoint Charlie, der Hintergrundinformationen liefert (je nach Vorwissen der Lernenden kann der Text mit zusätzlichen Informationen und evtl. mit inhaltsbezogenen Fragen zum Leseverstehen erweitert werden). Nun können die Lernenden in der Narrative-Discourse-Aufgabe das Splashpanel aus Olivers Episode mit dem historischen Foto des Grenzübergangs vergleichen und besprechen, was die visuelle Darstellung (Layout, Farben, Zeichenstil etc.) über den Inhalt der Episode aussagt bzw. wie sie sich auf den Inhalt auswirkt. In Olivers Beispiel sind zwar keine comicspezifischen Zeichen wie bildliche Metapher oder Bewegungslinien, aber die Größe und Gestaltung des Splashpanels hebt die subjektive Figurenperspektive hervor und verwandelt somit den Grenzübergang in einen subjektiven Erinnerungsort (vgl. Nünning 2005: 50). Vergleicht man das Panel mit einem historischen Foto des Ortes, ${ }^{17}$ fällt zunächst die historisch treue Ortsdarstellung auf. Diese wird allerdings mit zusätzlichen grafischen Mitteln geladen (wir könnten sagen: sie wird „,fiktionalisiert", s. Dolle-Weinkauff 2000: 302): Die verblasste rosagraue Hintergrundfarbe, der starke Wind und die knallroten, in der Luft durchgewirbelten Blätter überziehen den Handlungsraum mit der Patina einer melancholischen Vergangenheitsatmosphäre, sie tauchen Olivers Erinnerungen in Schwermut und Traurigkeit

\footnotetext{
${ }^{16}$ Olivers Episode kann unter http://www.bundesstiftung-aufarbeitung.de/flix-1714.html (21.6.13) abgerufen werden.

17 Ein historisches Foto des Ortes kann man hier abrufen: http://www.welt.de/kultur/history/ article13811933/Checkpoint-Charlie-mit-neuer-Geschichtsschau.html (21.6.13).
} 
und den erinnerten Ort in Leere, Verlassenheit, Freudlosigkeit. Die NarrativeDiscourse-Aufgabe verfolgt also das Ziel, die Lernenden für die gestalterischen Besonderheiten von Comics zu sensibilisieren, die gerade bei historischen Comics selbst dann bewusst wahrgenommen werden sollten, wenn die Panels auf den ersten Blick geografische Treue aufzuweisen scheinen.

\subsubsection{Ausreise aus der DDR}

\begin{tabular}{|c|c|c|c|}
\hline Thema & Comic & Aufgabentypen & Bemerkungen \\
\hline \multirow[t]{2}{*}{$\begin{array}{l}\text { Ausreise } \\
\text { aus der } \\
\text { DDR }\end{array}$} & \multirow[t]{2}{*}{$\begin{array}{l}\text { „drü- } \\
\text { ben!“ } \\
\text { S. 69-73. }\end{array}$} & $\begin{array}{l}\text { Produktionsorientierte Aufgabe: } \\
\text { Leere Sprechblasen mit Figuren- } \\
\text { reden ausfüllen }\end{array}$ & \multirow{2}{*}{$\begin{array}{l}\text { Vertiefung } \\
\text { möglich mit } \\
\text { Auszügen aus } \\
\text { „Grenzgebiete“ } \\
\text { (32ff.) }\end{array}$} \\
\hline & & $\begin{array}{l}\text { Story-orientierte Aufgabe: } \\
\text { Diskussion über die Handlungs- } \\
\text { motive einer Figur des Comics }\end{array}$ & \\
\hline
\end{tabular}

Bei diesem Beispiel zum Thema „Ausreise aus der DDR“ werden eine produktionsorientierte Aufgabe und eine story-orientierte Aufgabe zu Simon Schwartz' Comic drüben! verbunden. Sollte die Aufgabe in eine Stationenarbeit eingebettet sein, kann man als Einstieg ins Thema zunächst mit dem sehr aussagekräftigen Titelbild des Comics arbeiten lassen, auf der die wichtigsten Figuren und der Ort zu sehen sind und woraus die historische Situation erraten werden kann (z.B. mit Fragen wie: „Was stellt die Titelseite dar? Beschreiben Sie die Figuren (Alter, Beruf, Wohnort, Gefühle); Wo befinden Sie sich, wo gehen sie hin? Worum könnte es im Comic gehen?).“

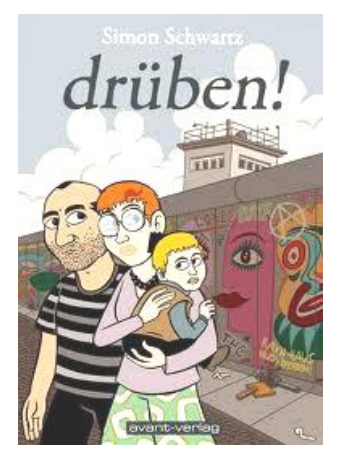

Abb. 1: Titelblatt von drüben!, Schwartz 2009

Danach könnten die Lernenden erste Informationen über den Comic erhalten (Autor, Jahr, Thema) und sie mit den eigenen Vermutungen vergleichen. Hier setzt gleich die produktionsorientierte Aufgabe an, bei der die Lernenden in einem Co- 
micauszug, in dem die Texte in den Sprechblasen gelöscht wurden (nur der Anfang und das Ende bleiben erhalten), die leeren Sprechblasen ausfüllen müssen. Der Auszug stellt einen Wendepunkt der Geschichte dar, nämlich den Zeitpunkt, als Schwartz' Vater sich entscheidet, die DDR zu verlassen. Als Lehrbeauftragter an der Hochschule Erfurt muss Schwartz' Vater eine Vorlesung zum Einmarsch der Sowjetunion in Afghanistans 1979 halten. Der Inhalt der Vorlesung wird ihm vorgesetzt, für Schwartz' Vater ist das der letzte Tropfen, der ihn zum Ausreiseantrag überzeugt. Die Sequenz ist bildlich sehr aussagekräftig, denn obwohl der Zeichenstil von Schwartz doch durch Reduktion geprägt ist, drücken die Gesichter und die Körperhaltungen der Figuren deutlich ihre Gefühlslage aus, und der Grund, warum der Vater die DDR verlassen möchte (Einschränkung der Meinungsfreiheit), kommt zum Vorschein. Als Verständnishilfen für den historischen Hintergrund erhalten die Lernenden kurze Texte über den Krieg zwischen der Sowjetunion und Afghanistan und die SED (deren Abzeichen Schwartz' Vater am Ende ablegt). Sollte mit dem Auszug nicht in einer Stationenarbeit gearbeitet werden, bei der die Texte zusammen mit dem Comicauszug verteilt und das Lesen den Lernenden überlassen wird, können natürlich auch mehr Informationen zum historischen Hintergrund in einer eigenständigen Erarbeitungsphase vermittelt werden.

Nach dem Ausfüllen der Sprechblasen vergleichen die Lernenden in Paaren oder Kleingruppen ihre Versionen, sie besprechen die Frage, was Schwartz' Vater zu seiner Entscheidung im letzten Panel geführt haben könnte (story-orientierte Aufgabe) und werden dazu aufgefordert, andere Gründe zu nennen, warum Menschen die DDR verlassen wollten, bevor sie ihre Version mit dem Originalauszug vergleichen.

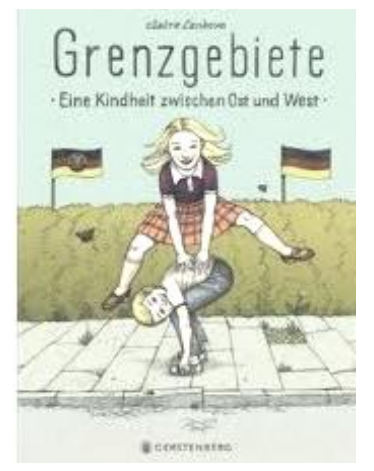

\section{Abb. 2: Titelblatt von Grenzgebiete. Eine Kindheit zwischen Ost und West, Lenkova 2009}

In der Vertiefungsphase lesen die Lernenden einen kurzen Text über die Ausreisewellen aus der DDR und die Konsequenzen, die ein Ausreiseantrag häufig mit sich brachte. Schwartz' Eltern erfahren diese Konsequenzen am eigenen Leib. Durch 
die Ergänzung ihres Schicksals mit Sachinformationen fügt sich ihre Geschichte in einen größeren historischen Zusammenhang und die Erlebnisauthentizität des Comics erhält eine faktenauthentische Tiefe.

Bei einer größeren Lerneinheit kann die Arbeit am Thema mit Auszügen aus „Grenzgebiete“ (32ff.) ergänzt werden, in denen die Autorin aus kindlicher Sicht ebenfalls vom Ausreiseantrag ihrer Familie bis zur Ankunft im Gießener Aufnahmelager berichtet. Diese Auszüge bieten sich durch den auffällig unterschiedlichen Zeichenstil für einen Vergleich der visuellen Gestaltung an, also für eine anschließende Narrative-Discourse-Aufgabe; in beiden Comics verstärkt die Gestaltung die Perspektivierung der Erzählung - „drüben!“ vermittelt mit der schwarzweiß-grauen Kolorierung der klaren, stilisierten Oberflächen und die zeichnerische Reduktion einen ernsten, nüchternen Eindruck, welcher die Sicht der Erwachsenen, aus denen die Sequenz erzählt wird, sehr gut wiederspiegelt, während die Pastelltöne und die kindlich-realistische Zeichnungen von „Grenzgebiete“ hervorragend die kindliche Perspektive verstärken. ${ }^{18}$

\subsubsection{Grenzübergang}

\begin{tabular}{|l|l|l|}
\hline Thema & \multicolumn{1}{|c|}{ Comic } & \multicolumn{1}{c|}{ Aufgabentypen } \\
\hline $\begin{array}{l}\text { Grenz- } \\
\text { über- } \\
\text { gang }\end{array}$ & „drüben!“ & \multicolumn{1}{c|}{ S. 22-29 } \\
& & $\begin{array}{l}\text { produktionsorientierte Aufgabe: } \\
\text { in einer sprachlosen Sequenz Gedanken einer Figur in } \\
\text { Gedankenblasen schreiben }\end{array}$ \\
\cline { 3 - 3 } & $\begin{array}{l}\text { Narrative-Discourse-Aufgabe: } \\
\text { Vergleich der Ortdarstellung mit einem historischem } \\
\text { Foto, Analyse der visuellen Wiedergabe der kindlichen } \\
\text { Perspektive }\end{array}$ \\
\hline
\end{tabular}

Folgende Konzeption stellt produktionsorientierte sowie Narrative-Discourse-Aufgaben in den Mittelpunkt. Gearbeitet wird wieder mit „drüben!“ von Simon Schwartz, und zwar mit der Sequenz, in der der kleine Simon die Großmutter besucht, die in Ostberlin wohnt. Das Kind wird von einer Bekannten über den Grenzübergang am Bahnhof Friedrichstraße in den Osten begleitet. Die ganze Sequenz schildert aus der kindlichen Perspektive die Erinnerungen an diesen Übergang und kommt ganz ohne Sprache aus. Simons Perspektive und Gefühle kommen allein durch die visuell starke Darstellung zum Ausdruck, die mit ständigen Einstellungs- und Perspektivwechseln arbeitet - der Wechsel von der Augenauf-

\footnotetext{
18 Weitere interessante Materialien für die Vertiefung des Themas: Unter http://www.berliner-mauergedenkstaette.de/de/zeitzeugengeschichten-489.html (21.6.13) sind verschiedene Interviews mit Zeitzeugen zu hören, die u.a. von ihrer Ausreisegeschichte erzählen. Unter http://www.hdg.de/lemo /objekte/pict/NeueHerausforderungen_karikaturHanelMauer/ index.html befindet sich eine Karikatur aus dem Jahr 1975, die die Reiseeinschränkungen in der DDR trotz des KSZE-Vertrags ironisiert.
} 
nahme (Großaufnahme von Simons Augen) zum Objekt der Wahrnehmung (Polizist im Kontrollhäuschen aus der Froschperspektive) steigert die gefühlte Bedrohlichkeit der Situation und macht die Angst des Kindes sichtbar. Durch das Fehlen von Text eignet sich die Sequenz zunächst für eine produktionsorientierte Aufgabe, in der die Lernenden die Gedanken des kleinen Simons in Gedankenblasen aufschreiben. Die Aufgabe fördert die Identifikation mit der Figur und setzt eine genaue Beobachtung von Simons Gesichtsausdruck sowie der Panelgestaltung voraus. Anschließend werden die Lernenden in einer Narrative-Discourse-Aufgabe dazu aufgefordert, die Sequenz mit einer historischen Aufnahme des Grenzübergangs Friedrichstraße zu vergleichen ${ }^{19}$ und die gestalterischen Besonderheiten der Sequenz zu nennen, insbesondere die Frage zu beantworten, mit welchen Mitteln die Perspektive des Kindes visuell wiedergegeben wird und welche Wirkung dies auf den Leser hat. Dafür bekommen sie ein Arbeitsblatt, auf dem die verschiedenen Perspektivgestaltungen (normale Perspektive, Frosch- und Vogelperspektive) und Einstellungsmöglichkeiten (von der totalen zur Detailaufnahme) mit Beispielen veranschaulicht werden. Die Aufgaben zu dieser Sequenz, genauso wie die Aufgabe unter 2 zu Olivers Geschichte, zielen also auf die Schulung der „,piktoralen" Lesekompetenz der Lernenden.

\subsubsection{Meinungsfreiheit in der DDR}

\begin{tabular}{|c|c|c|c|}
\hline Thema & Comic & Aufgabentypen & Bemerkungen \\
\hline \multirow[t]{2}{*}{$\begin{array}{l}\text { Meinungs- } \\
\text { freiheit in } \\
\text { der DDR }\end{array}$} & \multirow[t]{2}{*}{$\begin{array}{l}\text { „Grenz- } \\
\text { fall“ } \\
\text { S. } 5-8,24 \text {, } \\
35-42 .\end{array}$} & $\begin{array}{l}\text { Plot-Rekonstruktions- } \\
\text { aufgabe: } \\
\text { Erfassung der Handlung und } \\
\text { der Figurenkonstellation } \\
\text { durch anwendungsbezogene } \\
\text { W-Fragen und inhaltsbezo- } \\
\text { gene Richtig-/Falsch-Aus- } \\
\text { sagen. }\end{array}$ & \multirow[t]{2}{*}{$\begin{array}{l}\text { TN müssen bereits } \\
\text { über Grundkenntnisse } \\
\text { über DDR/BRD nach } \\
\text { dem Zweiten Welt- } \\
\text { krieg verfügen (Mau- } \\
\text { erbau, Schulsystem in } \\
\text { DDR und BRD, Pres- } \\
\text { sefreiheit und Zensur } \\
\text { der Presse in DDR) }\end{array}$} \\
\hline & & $\begin{array}{l}\text { Produktionsorientierte Auf- } \\
\text { gabe: } \\
\text { Rollenspiel mit Interview }\end{array}$ & \\
\hline
\end{tabular}

Die politische Untergrundzeitschrift „Grenzfall“ der Initiativen Frieden und Menschenrechte (IFM), einer kirchlichen Opposition in Ostberlin, gibt dem Comic den Titel. Die erste Ausgabe von „Grenzfall“ wurde im März 1986 publiziert. ${ }^{20}$ Der

\footnotetext{
${ }^{19}$ Ein solches historisches Foto ist z.B. hier zu finden: http://en.wikipedia.org/wiki/File:Bundesarchiv_Bild_183-C1031-0044-009,_Berlin,_Grenz\%C3\%BCbergang_Bahnhof_Friedrichstra\% \%C3\%9 Fe.jpg (16.6.13).

${ }^{20}$ Vgl. http://www.dradio.de/dlf/sendungen/andruck/1524183/ (21.06.2013).
} 
Schüler Peter Grimm, dessen Geschichte der Comic erzählt, gehörte zu den Hauptredakteuren der Zeitschrift; in der Zeitschrift wurden die Themen, die von der Staatssicherheit der DDR zensiert wurden, zur Veröffentlichung gebracht, z.B. Umweltbelastung, Menschenrechte, Reiseverbot usw. Im Comicauszug aus „Grenzfall“ erfahren die Lernenden zunächst von den (nicht staatskonformen) persönlichen Ansichten des Schülers Peter Grimm bezüglich Wehrdienst und Informations- und Meinungsfreiheit in der DDR und dann von dem (gescheiterten) Versuch der FDJ, den Schüler aufgrund seiner Mitarbeit in Oppositionsgruppen aus der Organisation auszuschließen. Die Arbeit mit dem Auszug verlangt also einen Grundstock an Vorwissen, deswegen sollten die Lernenden vor der Arbeit mit diesem längeren Comicauszug bereits die wichtigsten Ereignissen in der DDR/BRD nach dem Zweiten Weltkrieg kennengelernt haben, z.B.: den Mauerbau, das Schulsystem in der DDR und BRD sowie die Pressezensur in der DDR und die Jugendorganisation FDJ. Auch ist für diese Lerneinheit ein Mindestniveau von Ende B2 notwendig; die Comicauszüge werden ohne zusätzliche sprachliche Erklärungen verteilt, und die produktionsorientierte Aufgabe am Ende, nämlich das Rollenspiel, verlangt ein Sprachniveau, auf dem Diskussionen und freie mündliche Produktion problemlos vonstattengehen sollten.

Das Lesen des Auszugs wird mit einem Einstieg über Bilder zum Thema Pressefreiheit und -zensur eingeleitet, die die Lernenden beschreiben und kommentieren. ${ }^{21}$-. Danach lesen die Lernenden den Comicauszug (bis S. 39) und beantworten drei anwendungsbezogene Fragen: Welche sind die wichtigsten Figuren dieser Geschichte? Was erfährt man über diese Figuren? Welche Beziehung haben sie zueinander? Weiterhin machen sie eine einfache inhaltsbezogene Richtig- oder Falsch-Übung, die die Ansichten von Peter und den FDJ-Vorfall fokussiert:

\section{Aufgabe: Richtig oder falsch? Korrigieren Sie die falschen Aussagen.}

a. Peter will nicht am Wehrkundeunterricht teilnehmen.

b. Wenn man am Wehrkundeunterricht teilnehmen möchte, kann man Schwierigkeiten in der Schule bekommen und man kann nicht studieren.

c. Peter denkt, dass es in der DDR Informationsfreiheit gibt.

d. Viele Intellektuelle standen dem Regime der DDR kritisch gegenüber, mussten aber ihre kritische Einstellung verstecken.

e. Wichtige Prinzipien der Jugendorganisation Freie Deutsche Jugend (FDJ) waren Meinungsfreiheit und Offenheit für Andersdenkende. Diese Prinzipien wurden auch in der Realität umgesetzt.

f. Laut dem FDJ-Sekretär hat Peter die sozialistische Politik der

21 Z.B. http://germanhistorydocs.ghi-dc.org/sub_image.cfm?image_id=2358\&language=german, http://www.unesco.de/4598.html, http://www.taz.de/!42588/ (21.6.13). 


\section{DDR unterstützt.}

g. In der Abstimmung wurde die Zweidrittelmehrheit erreicht.

h. Die FDJ kann Peter nicht aus der Organisation ausschließen, weil viele Schüler hinter ihm stehen und ihn unterstützen.

i. Peters Vater teilt die Meinung seines Sohnes und verteidigt ihn.

\section{Tabelle: Beispielssätze für die R-F-Übung zu Grenzfall}

Die Übung dient zur Sicherung der wichtigsten Informationen aus der Episode. Im Folgenden bekommen die Lernenden zwei kurze Sachtexte zu folgenden Themen: Wehrdienst und ideologisierte Presse in der DDR.

\section{Beispieltext 1: Wehrpflicht in der DDR}

Bis 1962 existierte in der DDR keine allgemeine Wehrpflicht. Doch da die Freiwilligen für die Nationale Volksarmee (NVA) nicht ausreichten, verpflichtete ein neues Gesetz alle Männer zwischen 18 und 26 Jahren zum Grundwehrdienst von 18 Monaten. Einen zivilen Wehrersatzdienst gab es nicht, die einzige Alternative war, als „Bausoldat“ den Dienst ohne Waffe abzuleisten. Für junge Männer, die studieren wollten, war dies keine Alternative. Das Volksbildungsministerium hatte 1970 verlauten lassen, wer nicht bereit sei, sein Vaterland mit der Waffe zu verteidigen, sei es auch nicht wert, in der DDR zu studieren. Wer sich sogar für drei Jahre oder länger verpflichtete, wurde bei der Studienplatzvergabe bevorzugt.

Der Schauspieler Jan Josef Liefers hatte während seiner Jugend in der DDR Probleme wegen seiner Ablehnung des Wehrdienstes. „Das Abitur platzte unter anderem, weil ich nicht ,freiwillig' drei Jahre zur Armee gehen wollte“, sagte Jan Josef Liefers der „Bild“-Zeitung.

Quelle: Von der Freiwilligen-Armee zur Zwangsverpflichtung 22

Die Sachtexte werden von allen Lernenden gelesen und mündlich zusammengefasst und sollten zusätzliche Informationen für das darauffolgende Rollenspiel vermitteln. Nach dem Lesen teilt sich die Lernergruppe in 3er-Gruppen, die mit der Vorbereitung der produktionsorientierten Aufgabe, nämlich des Rollenspiels, anfangen. Im Rollenspiel werden folgende Rollen besetzt: Peter und ein Journalist sowie ein Beobachter, der das Spiel beobachtet und eine Rückmeldung gibt. Für die Vorbereitung erhalten die Lernenden unterschiedliche Rollenkarten. So bereitet der Lernende, der Peter Grimms Rolle übernimmt, Fragen vor, die die Identifikation mit Peters Rolle fördern und mit Informationen über seine Hobbys und Interessen sowie Ansichten füllen, den Vorfall in der Schule zusammenfassen und ihn

${ }^{22} \mathrm{Http}: / /$ www.mdr.de/der-turm/wehrpflicht108.html, gekürzt. 
mit Peters Gefühlen ergänzen sollen. Der Journalist soll die Infos zusammenfassen, die er über Peter Grimm und den Vorfall in der Schule bereits kennt, und überlegt, welche Fragen er zu Grimms Meinung, zu seinem Leben und zu seinen Plänen noch stellen möchte. Der Beobachter fasst die wichtigsten Informationen auf dem Comicauszug über Peter Grimm und seine Einstellungen, über den Vorfall an der Schule und den historischen Hintergrund (Meinungsfreiheit in der DDR) zusammen. Auf diese Weise zwingen alle Rollen zur erneuten, aufmerksamen Lektüre des Auszugs.

Nach der Vorbereitung der Rollen spielen die Lernenden das Interview vor. Während des Interviews hält der Beobachter Fragen und Antworten in Stichworten fest und gibt am Ende eine Rückmeldung darüber, ob die Rollen historisch treu und glaubwürdig gespielt wurden - die Glaubwürdigkeit der Rollen und nicht die schauspielerische Leistung steht im Mittelpunkt. Nach dem Rollenspiel überlegen die Lernenden kurz, wie die Geschichte weitergehen könnte, und lesen dann die letzten Seiten des Auszugs („Grenzfall“, 40-42), aus denen sie erfahren, dass Peter von der Schule ausgeschlossen wurde und kein Abitur ablegen durfte. Auch diese Aufgabensequenz verfolgt das Ziel, die Lernenden durch das Rollenspiel, welches die bewusste Verarbeitung historischer Ereignisse erfordert, zum Perspektivenwechsel anzuregen und gleichzeitig die freie mündliche Sprachproduktion zu fördern.

\subsubsection{Anne Frank und ihr Tagebuch}

\begin{tabular}{|l|l|l|}
\hline \multicolumn{1}{|c|}{ Thema } & \multicolumn{1}{|c|}{ Comic } & \multicolumn{1}{c|}{ Aufgabentypen } \\
\hline Anne Frank & „Das Leben & Thematische Aufgabe: schrittweise Erarbeitung \\
und ihr & von Anne \\
Tagebuch & $\begin{array}{l}\text { Frank. Eine } \\
\text { grafische } \\
\text { Biografie“ } \\
\text { S. 70-75. }\end{array}$ & $\begin{array}{l}\text { und Kennenlernen der Bedeutung des Tagebuchs } \\
\text { für Anne Frank und der damit verbundenen Er- } \\
\text { eignisse aus ihrem Leben }\end{array}$ \\
\cline { 3 - 3 } & $\begin{array}{l}\text { Produktionsorientierte Aufgabe: Zeitungsartikel } \\
\text { über die Veröffentlichung von Anne Franks Ta- } \\
\text { gebuch schreiben }\end{array}$ \\
\hline
\end{tabular}

Diese Aufgabensequenz fällt thematisch aus dem Rahmen der anderen Beispiele. Sie soll hier trotzdem vorgestellt werden, um zu veranschaulichen, wie die Arbeit mit einem wissenschaftlich gesicherten Comic als Alternative zum Sachbuch gestaltet und wie die Erarbeitung eines spezifischen Themas mit anwendungsbezogenen Aufgaben, die das Lesen steuern, schrittweise erfolgen kann. Die grafische Biografie von Anne Frank verfügt über wissenschaftlich gesicherte Faktenauthentizität und kann im Unterricht aus diesem Grund auch als alleiniges Material eingesetzt werden. Folgender Vorschlag verbindet eine thematische und eine produktionsorientierte Aufgabe. Der Vorschlag eignet sich gut für eine Station in Einzelarbeit 
und stellt in den Mittelpunkt die Förderung der Lese- und Schreibfertigkeit. Sollten sich die Lernenden in Hessen befinden, könnten die Aufgaben z.B. als Vorbereitung auf den Besuch der JugendBegegnungsStätte (JBS) Anne Frank in Frankfurt am Main eingesetzt werden. ${ }^{23}$

Nach einer einfachen Aktivierung des Vorwissens über Anne Frank in Form von brain storming (,Was wissen Sie schon über Anne Frank? Was wissen Sie über ihr Tagebuch? Schreiben Sie alles auf!") lesen die Lernenden einen Auszug aus dem Comic (Jacobson; Colón 2010: 70-75), in dem erzählt wird, wann und warum das Mädchen das Tagebuch bekam, wie sie es nutze, in welcher persönlichen Lage sie sich befand und wie die Familie schließlich zur Entscheidung kam, sich in dem Hinterhaus zu verstecken. Der Auszug vermittelt nicht nur historische Fakten, sondern ermöglicht auch Einblicke in Annes Adoleszenz (Schulalltag, Freundschaften, Vorlieben, erstes Schwärmen für Jungen) und schafft es also, den Menschen Anne zum Vorschein treten zu lassen. Die Lektüre des Comics wird von einer schlichten Frage begleitet: „Welche neuen Informationen haben Sie aus dem Comic erfahren? Schreiben Sie alle auf.“

Es folgt die Lektüre von kurzen Texten zum Schicksal der Familie Frank und von Originalauszügen aus Anne Franks Tagebuch, die das Thema „Tagebuch“ in einen größeren Kontext, nämlich in das Schicksal der Familie, einbetten. Die Texte und Auszüge sollten zunächst in eine sinnvolle Reihenfolge gebracht werden, daraufhin unterstreichen die Lernenden alle neuen Informationen, die sie über Anne Frank und ihr Tagebuch erfahren haben. Das Ziel dieser ersten drei thematischen Aufgaben besteht also darin, dass die Lernenden ihr Wissen über Anne Frank nach und nach erweitern und dadurch über einen Grundstock an Informationen verfügen, womit sie auf die letzte produktionsorientierte Aufgabe vorbereitet sind. Vor dieser Aufgabe schreiben sie aber zunächst einen kurzen persönlichen Kommentar zu Annes Gefühlen und ihrer Situation, was zur Versprachlichung der affektiven Involvierung mit dem Schicksal von Anne führen soll. Schließlich verfassen sie einen Zeitungsartikel über die überraschende Entdeckung und Veröffentlichung des Tagebuchs. Als Beispiel sei hier der (unkorrigierte) Zeitungsartikel einer französischen Studentin zitiert, die mit dem Comicauszug und den vorgestellten Aufgaben in einer Stationenarbeit gearbeitet hat. Die Sprachkenntnisse der Studentin befanden sich auf Anfang B1-Niveau: ${ }^{24}$

\footnotetext{
23 http://www.jbs-anne-frank.de/ (21.6.2013). Die BegegnungsStätte bietet Führungen durch die Ausstellung, die nach Rücksprache auch mit ausländischen Lernenden durchgeführt werden können. Auf der Seite der JugendBegegnungsStätte befinden sich Materialien für den Einsatz mit dem interaktiven Whiteboard, die einen Film, zahlreiche Fotos und Aufgabenideen beinhalten. Die Materialien sind nicht für den Fremdsprachenunterricht konzipiert und müssten dementsprechend angepasst werden.

${ }^{24}$ Der Text stammt aus einem Workshop, den die Verfasserin im März 2013 an der Radboud Universiteit Nijmegen (NL) mit Deutschlernenden des dritten Studienjahrs gehalten hat. Die französische Studentin hatte als Erasmusstudentin ein im Vergleich mit den anderen Studierenden viel schwächeres Sprachniveau.
} 
Die Welt 13. Juni 1947

Zwei Jahre nach dem Krieg, ist die Welt noch, um verschiedene historische Stück des Kriegs zu entdecken. Jetzt haben sie ein spezielle, neue Ausblick über der Krieg bekommen und es ist ein 13-jährige deutsche Mädchen, das uns ihr Erfahrung erzählt. Mit der Veröffentlichung ihres Tagebuchs, hat ihr Vater der Welt sein Tochter präsentiert: Anne Frank. Ganz sicher ist, dass dieser Veröffentlichung und ihr Tagebuch in den Kopf bleiben wird. Durch die Augen und Denken eines jüdischen Mädchen wir finden die Hoffnung während dunkeln Zeit und hier hat Anne eine schöne Morale gezeigt: nie die Hoffe, die Liebe und die Familie verloren und vergessen.

\section{$4 \quad$ Fazit}

Die sechs vorgestellten Beispiele verfolgten das Ziel, zu veranschaulichen, dass Geschichtscomics im DaF-Unterricht mit historischen Themen gewinnbringend eingesetzt werden können. Diesen Gewinn möchte ich wie folgt zusammenfassen:

- Zu Comics kann man vielfältige Aufgaben entwickeln, hier am Beispiel der Aufgabentypologie von Hallet (2012a) umgesetzt, die Geschichte lebendig werden lassen und personalisieren;

- Erlebnisauthentische Comics können durch die Verbindung mit Sachtexten und Informationen zum historischen Hintergrund mit Fakten untermauert und somit verwendet werden, um historische Kenntnisse zu vermitteln;

- Wissenschaftlich gesicherte Geschichtscomics verfügen grundsätzlich über Faktenauthentizität, was bei der Vermittlung historischer Kenntnisse keine Ergänzung durch Zusatzinformationen verlangt;

- Nicht zuletzt bietet die Erkundung der ästhetischen Gestaltungsmöglichkeiten von Comics spannende Aufgabenmöglichkeiten, die bei Lernenden, so die Erfahrung der Verfasserin, zu Neugier und vielen Aha-Effekten führen und genutzt werden können, um zur Auseinandersetzung mit historischen Inhalten durch das ungewöhnliche Medium anzuregen.

Die Verfasserin wünscht den lesenden Lehrpersonen viel Spaß bei der Arbeit mit historischen Comics im DaF-Unterricht und freut sich sehr über Rückmeldungen, weitere Ideen zur Arbeit mit historischen Comics, Meinungen und Erfahrungsberichte! ${ }^{25}$

25 cerri@staff.uni-marburg.de. 


\section{Literatur}

„ABCD-Thesen“, in: Deutsch als Fremdsprache 24/5 (1990), 306-308.

Arnold, Helmut (1998): „Tintin en Syldavie“. Plädoyer für die Behandlung einer bande dessinée im Französischunterricht. In: Fremdsprachenunterricht 2, 100-104.

Cerri, Chiara (2011): Comics gegen Rechtsextremismus und Rassismus im DaFUnterricht. Konzeptionelle Überlegungen. In: Palandt, Ralf (Hrsg.): Rechtsextremismus, Rassismus und Antisemitismus in Comics. Berlin: Archiv der Jugendkulturen, 337-352.

Cerri, Chiara (i.Vorb.): Erinnerungserzählungen in deutschsprachigen Geschichtscomics. In: Delhey, Yvonne; Krauss, Hannes (Hrsg.): Erzäblen und Erinnern. Tagungsband zum Workshop „Erzählen \& Erinnern“, Schloss Gnadenthal, 21.-23. März 2013.

Doff, Sabine; Wanders, Mona (2005): Stories with and without words: Comics in der Unterstufe. In: Der fremdspracbliche Unterricht Englisch 39, Heft 73, 9-17.

Dohm, Anne (1999): Historisches Lernen an Comics - untersucht an Art Spiegelmans Maus. Oldenburg: ZpB.

Dolle-Weinkauff, Bernd (2000): Geschichte zwischen Grandiosität und Gag. Historisches Erzählen in Bildgeschichte und Comic. In: GeschichtsBilder. Historische Jugendbücher aus vier Jabrbunderten. Ausstellungskatalog, Staatsbibliothek zu Berlin. Wiesbaden: Reichert, 301-316.

Gundermann, Christine (2007): Jenseits von Asterix. Comics im Geschichtsunterricht. Schwalbach: Wochenschau Verlag.

Hallet, Wolfgang (2012a): Graphic Novels: Literarisches und multiliterales Lernen mit Comic-Romanen. In: Der fremdspracbliche Unterricht Englisch 46, 2-8.

Hallet, Wolfgang (2012b): AutobioGraphic Novels: Selbsterzählungen in ComicForm analysieren und verfassen. In: Der fremdsprachliche Unterrich. Englisch 46, 34-38.

Hein, Michael (2002): Zwischen Panel und Strip. Auf der Suche nach der ausgelassenen Zeit. In: Hein, Michael; Hüners, Michael; Michaelsen, Torsten (Hrsg.): Ästhetik des Comics. Berlin: Erich Schmidt, 51-59.

Hieronimus, Marc (2009): Geschichtscomics im DaF-Unterricht. In: Nieradka, Magali Laure; Specht, Denise (Hrsg.): Fremdkörper? Aspekte der Geisteswissenschaften in der Auslandsgermanistik. und im DaF-Unterricht. Münster: Lit-Verlag, 101-114.

Hintz, Ingrid (2002): Das Lesetagebuch. Intensiv lesen, produktiv scbreiben, frei arbeiten. Bestandsausfnabme und Neubestimmung einer Methode zur Auseinandersetzung mit 
Kinder- und Jugendbüchern im Deutschunterricht. Baltmannsweiler: Schneider-Verlag Hohengehren.

Hochbruck, Sabine; Wolfgang Hochbruck (2005): Britische Alltagsgeschichte im Comic-Roman: Raymond Briggs' Ethel \& Ernest. In: Der fremdsprachliche Unterricht Englisch 39, Heft 73, 25-32.

Holocaust im Comic - Tabubruch oder Chance? Geschichtscomics für den Unterricht am Beispiel der Graphic Novel „Die Suche“ (2008). Tagungsdokumentation. HG Anne Frank-Zentrum, 17-20. http://www.annefrank.de/ projekte-angebote/materialien/geschichtscomic-die-suche (21.6.13).

Kuhn, Christina; Winzer-Kiontke, Britta; Würz, Ulrike (2013): studio d. Die Mittelstufe B2/2. Berlin: Cornelsen.

Mahne, Nicole (2007): Transmediale Eræähltheorie: eine Einführung. Göttingen: Vandenhoeck \& Ruprecht, 1-24; 44-76.

Mempel, Caterina (2010): Verstehensprobleme bei der Comic-Rezeption in der Erst- und Fremdsprache. Eine vergleichende Untersuchung mittels LautDenk-Daten. In: Lutjeharms, Madeline; Schmidt, Claudia (Hrsg.): Lesekompeten r. in Erst-, Zweit- und Fremdsprache. Tübingen: Narr, 189-205.

Mounajed, René (2008): „Geht doch rüber“ - Zeithistorisches Lernen mit Geschichtscomics. Erste Befunde einer empirischen Studie. In: Barricelli, Michele; Hornig, Julia (Hrsg.): Aufklärung, Bildung, „Histotainment“? Zeitgeschichte im Unterricht und Gesellschaft heute. Frankfurt/Main: Lang, 201-222.

Mounajed, René (2009): Geschichte in Sequenzen. Über den Einsatzvon Geschichtscomics im Geschichtsunterricht. Frankfurt/Main: Lang.

Mounajed, René (2010): Comics erz̨ählen Geschichte. Sequenzen aus Comics, Manga und Graphic novels für den Geschichtsunterricht. Bamberg: Buchner.

Munier, Gerald (2000): Geschichte im Comic. Aufkelärung durch Fik.tion? Über Möglichkeiten und Grenzen des historisierenden Autorencomic der Gegenwart. Hannover: Unser Verlag.

Nünning, Ansgar (2005): Literarische Geschichtsdarstellung: Theoretische Grundlagen, fiktionale Privilegien, Gattungstypologie und Funktionen. In: Bannasch, Bettina; Holm, Christiane (Hrsg.): Erinnern und erzählen. Der Spanische Bürgerkrieg in der deutschen und spanischen Literatur und in den Bildmedien. Tübingen: Narr, 35-58.

Schott, Peter (2010): Didaktisierung zu drüben! und Berlin - Steinerne Stadt. CD des Goethe-Instituts Nancy.

Schüwer, Martin (2005): Teaching Comics: Die unentdeckten Potenziale der grafischen Literatur. In: Der fremdsprachliche Unterricht Englisch 39, Heft 73, 2-7. 
Stenz, Michael (2006): Bandes Dessinée im Französischunterricht - pour quoi faire? In: Fremdsprachen praktisch 19, 122-127.

Vignaud, Marie-Françoise (2009): En pleine forme dans ses bulles! La Bande Dessinée en théorie er en pratique. In: Der Fremdsprachliche Unterricht Französisch 97, $2-8$.

Westhoff, Gerard (1997): Fertigkeit Lesen. Berlin u.a.: Langenscheidt (Fernstudieneinheit 17).

\section{Comics}

Buddenberg, Susanne; Henseler, Thomas (2012): Berlin - Geteilte Stadt. Zeitgeschichten. Berlin: avant-verlag.

Flix (2009): Da war mal was... Erinnerungen an hier und drüben. Hamburg: Carlsen.

Henseler, Thomas; Buddenberg, Susanne (2012): Grenzfall. Berlin: avant-verlag.

Henseler, Thomas; Buddenberg, Susanne (2013): Tunnel 57. Eine Fluchtgeschichte als Comic. Berlin: Ch. Links Verlag.

Heuvel, Eric (2007): Die Suche. In Zusammenarbeit mit dem Jüdischen Historischen Museum Amsterdam. Amsterdam: Anne Frank Haus.

Jacobson, Sid; Colón, Ernie (2010): Das Leben von Anne Frank. Eine grafische Biografie. Hamburg: Carlsen.

Lenkova, Claire (2009): Grenzgebiete. Eine Kindheit zwischen Ost und West. Hildesheim: Gerstenberg.

Lutes, Jason (2003): Berlin - steinerne Stadt. Hamburg: Carlsen.

Schwartz, Simon (2009): drüben! Berlin: avant-verlag. 


\section{Arbeitsblatt 1: Opfer der Berliner Mauer \\ (Erfassung der Handlung von Franks Episode)}

Lesen Sie jetzt die Geschichte von Frank aus dem Comic „da war mal was...".

Machen Sie sich nach dem Lesen Notizen:

\begin{tabular}{|l|l|}
\hline $\begin{array}{l}\text { Welche Figuren treten im Comic } \\
\text { auf? } \\
\text { Welche Beziehungen haben sie } \\
\text { zueinander? }\end{array}$ & \\
\hline Wer erzählt? & \\
Worüber erzählt er? \\
$\begin{array}{l}\text { Wo und wann könne das Ereignis } \\
\text { passiert sein? }\end{array}$ \\
\hline $\begin{array}{l}\text { Wie wird die Episode visuell dar- } \\
\text { gestellt } \\
\text { (Layout, Zeichenstil, Farben, } \\
\text { Sprechblasen, Bewegungslinien...)? }\end{array}$ \\
$\begin{array}{l}\text { Wie wirkt das? } \\
\text { dieser Episode }\end{array}$
\end{tabular}




\section{Arbeitsblatt 2: Rollenspiel: Flucht aus der DDR?}

Stellen Sie sich vor, dass Sie eine Gruppe guter Freunde sind. Sie leben in der DDR und überlegen, in den Westen zu fliehen. Heimlich haben Sie im Westradio von einer Flucht im Heißluftballon erfahren. Nun überlegen Sie, das Gleiche zu tun. Wahrscheinlich werden Sie aber niemals wieder in die DDR zurückkommen dürfen, weil Sie sich mit der Flucht strafbar machen würden. Nicht zuletzt ist die Flucht lebensgefährlich, da die Grenzsoldaten den Befehl haben, auf jeden Flüchtenden zu schießen.

\section{Bearbeiten Sie folgende Aufgaben Schritt für Schritt:}

1. Jeder liest die eigene Rollenbeschreibung durch.

2. Jeder schreibt für seine Rolle einen Satz, in welchem er a. Ein Argument für die Flucht äußert,

b. Ein Argument gegen die Flucht nennt.

3. Probieren Sie das Gespräch, indem Sie Ihre Argumente vorstellen und am Ende abstimmen, ob Sie flüchten wollen oder nicht.

4. Tragen Sie das Rollenspiel im Seminar vor.

\section{Zwei Beispiele von Rollenkarten:26}

Sven (40)

Sie arbeiten als Mechaniker in Ostberlin. Der Chef erwartet von Ihnen, dass Sie in die Partei eintreten, sonst würden Sie wahrscheinlich Ihre Arbeit bald verlieren. Sie wollen aber keiner Partei angehören, die den Bürgern diktiert, wie und wo sie leben müssen.

Ein Teil Ihrer Familie wohnt in Westdeutschland. Ihre Familie würde Sie unterstützen, wenn Sie in den Westen fliehen würden. Allerdings haben Sie bei einem Nachbarn erlebt, wie hart er für einen Fluchtversuch bestraft wurde. Sechs Jahre Gefängnis, nur weil er in Freiheit leben wollte.

Aufgabe: Überlegen Sie a) Svens Argument für eine Flucht.

b) Svens Argument gegen eine Flucht.

$\square$ Bei der Rollengestaltung sollte die Lehrperson darauf achten, dass die Rollen verschiedene Alter, Berufs- und Lebenssituationen widerspiegeln, um eine möglichst große Perspektivenvielfalt zu gewährleisten. 
$\operatorname{Tim}(17)$

Sie sind Auszubildender in einem Stahlwerk. Eigentlich sind Sie ganz zufrieden mit Ihrem Leben. Nur würden Sie die Ferien gerne mal in anderen Ländern als den Ostblockstaaten verbringen. Sie sind wütend, dass der Staat Ihnen das verbietet. Auch ärgern Sie sich, dass man die Radio- und Fernsehsender aus dem Westen nicht empfangen darf. Nach der Flucht in den Westen könnten Sie alle möglichen Länder der Welt bereisen. Allerdings würde die Flucht auch das Ende der Beziehung mit Ihrer Freundin bedeuten.

Aufgabe: Überlegen Sie

a) Tims Argument für eine Flucht.

b) Tims Argument gegen eine Flucht. 


\title{
Arbeitsblatt 3: Zur Ästhetik des Comics - die wichtigsten Grundbegriffe
}

\begin{abstract}
Ein einzelnes Bild eines Comics wird als Panel bezeichnet. Dabei handelt es sich um ein Einzelbild einer Sequenz. Besondere Panels sind Splash-Panels (Bsp. 1: ein Panel nimmt eine ganze Seite ein) und Split-Panels (Bsp. 2: ein Panel wird geteilt).
\end{abstract}

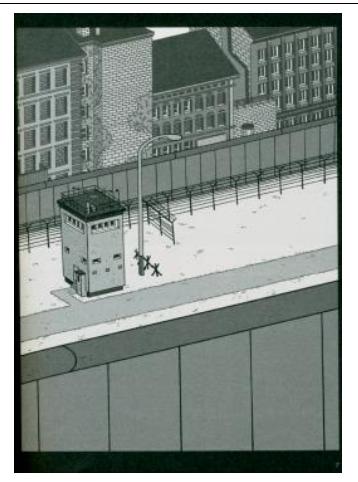

Beispiel 1 SplashPanel

(drüben! 2009)

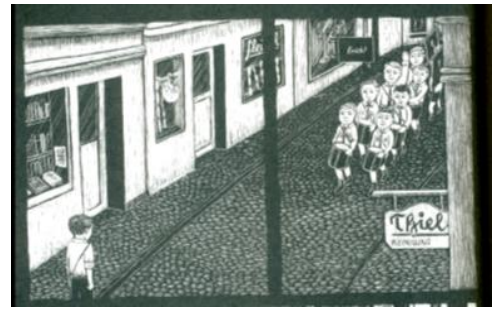

Beispiel 2 Split-Panel (Hoven 2008)

Unten: Beispiel 4 (Hage 2007: 139)

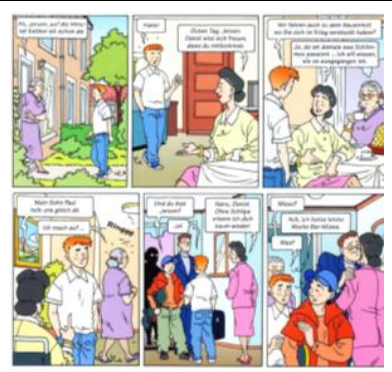

Beispiel 3 (Heuvel 2007: 5)
Farben (Bsp. 3-4): z.B. bunt oder schwarz-weiß

Layout und Panels können durch verschiedene Formen verschiedene Wirkungen erzeugen. Wie wirken das Beispiel 3 und das Beispiel 4?

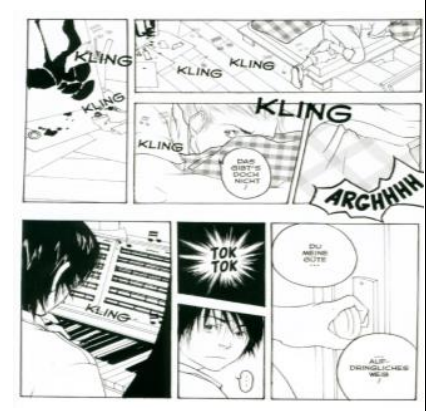

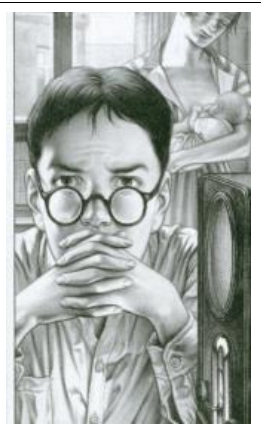

Beispiel 5: realistische Zeichnung

(Guibert 1995: 46)
Die Texte in einem Comic können in verschiedenartig aussehenden Sprechoder Gedankenblasen stehen (Bsp. 3, 4) oder als Blockkommentar (Bsp. 9) verfasst sein.

Zeichnung der Figuren: von sehr authentisch / realistisch bis künstlerisch verfremdet und stilisiert.

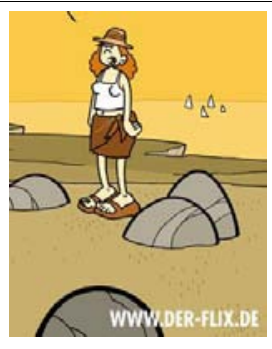

Beispiel 6: stilisierte Figurenzeichnung (www.der-flix.de, 7.7.13) 


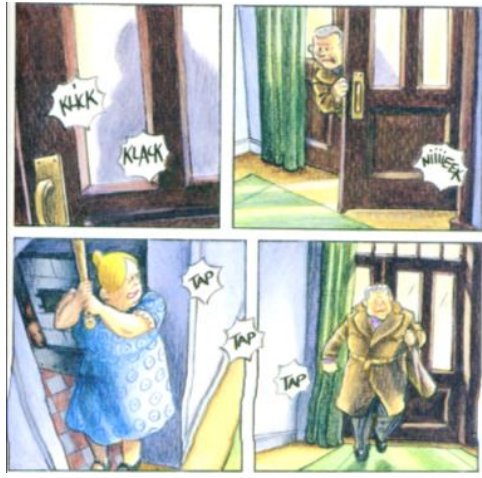

Bsp. 8: Onomatopöien (Kreitz 2004: 16)

Onomatopöien (Bsp. 8) sind lautmalende Wörter, die akustische Informationen vermitteln.

Als Lettering bezeichnet man verbalbildliche Schrift (Bsp. 10).

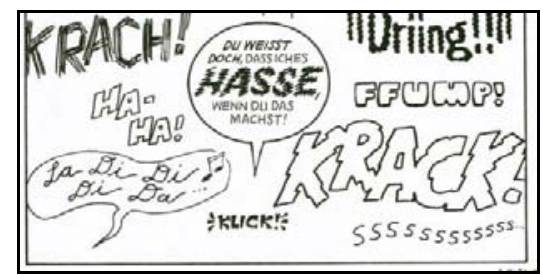

Bsp. 10: Lettering (McCloud 2001: 142)
Bewegungslinien (speed lines, Bsp. 7) sind Linien und Striche, die innerhalb eines Panels Bewegung von Gegenständen oder Figuren ausdrücken.

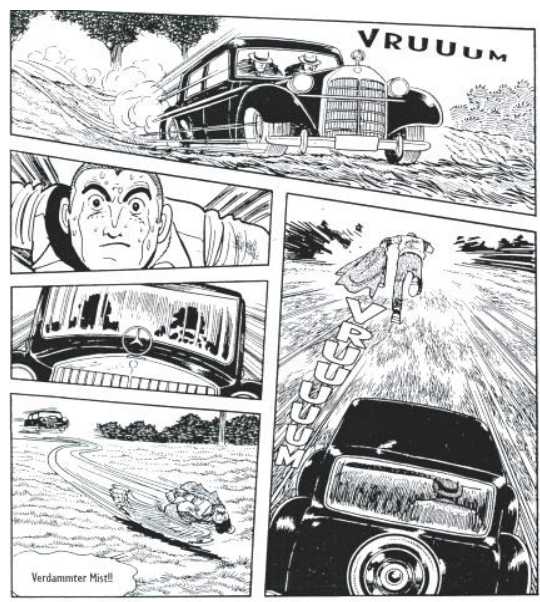

Bsp. 7 Bewegungslinien (Tezuka 1983: 47)

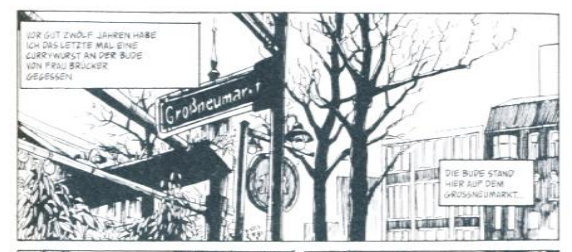

Beispiel 9: Blockkommentare (Kreitz 2005: 5)

Aufgabe: Betrachten Sie die ausgelegten Comics und analysieren Sie ihre gestalterische Besonderheiten! 


\section{Arbeitsblatt 4: Anne Franks Tagebuch}

(nach dem brain storming und dem Lesen des Comicauszuges)

1. Lesen Sie die folgenden Texte. Es sind kurze Informationen zu den Ereignissen und Auszüge aus Anne Franks Tagebuch.

Anne machte ihre Einträge* in der Zeit vom 12. Juni 1942 bis 1. August 1944 vor allem in Form von Briefen an eine gute Freundin, die sie (meistens) Kitty nannte.

$$
\text { * r Eintrag: Notiz, Vermerk }
$$

„Sehnsüchtig warten wir immer auf den Samstag, weil dann die Bücher kommen, wie kleine Kinder auf ein Geschenk. Normale Leute können nicht wissen, was Bücher für einen Eingeschlossenen bedeuten. Lesen, lernen und Radio bören sind unsere einzige Ablenkung. "

„Das Hinterbaus ist ein ideales Versteck. Obwobl es feucht und ein bißchen schief ist, wird man wohl in ganz. Amsterdam, ja vielleicht in gan. Holland, kein so bequem eingerichtetes Versteck finden."

Otto Frank tauchte mit seiner Familie am 6. Juli 1942 im Hinterhaus unter. Das war ein leer stehender Gebäudeteil hinter seiner Firma an der Prinsengracht in Amsterdam. Heute ist dort das Anne FrankMuseum.
Margot und Anne wurden beide im Oktober 1944 nach Bergen-Belsen gebracht. Beide Schwestern starben kurz nacheinander (Ende März) an Typhus. Keiner der Untergetauchten* überlebt, bis auf Annes Vater, Otto Frank.

*untertauchen: irgendwo verschwinden

Miep Gies übergab Otto Frank die Tagebuchaufzeichnungen seiner Tochter. Im Juni 1947 erschien ,Het Achterhuis' (Das Hinterhaus) mit einer Auflage von 1500 Exemplaren.

2. Setzen Sie die Texte in eine sinnvolle Reihenfolge. Unterstreichen Sie dann alle neuen Informationen, die Sie über Anne Frank und ihr Tagebuch erfahren haben!

3. Lesen Sie noch mal die Auszüge aus Anne Franks Tagebuch. Schreiben Sie einen kurzen persönlichen Kommentar zu Annes Gefühlen und ihrer Situation!

4. Juni 1947: Jahr der Veröffentlichung von Anne Franks Tagebuch! Sie sind Journalist/in einer deutschen Zeitung und schreiben einen Artikel über die überraschende Entdeckung und Veröffentlichung des Tagebuchs. Sie können die Informationen verwenden, die Sie gesammelt haben. 



\title{
Graffiti und Street Art im DaF-Unterricht
}

\author{
Miriam Bertocchi
}

\section{Einführung}

Die positive Funktion von Bildern im Fremdsprachunterricht ist unumstritten: Bilder sind nämlich seit langer Zeit unverzichtbare Mittel des Lehrens und Lernens einer fremden Sprache. In diesem Sinne können auch Kunstwerke als Medium des Sprachlernens verstanden werden und dazu beitragen, einen motivierenden, gewinnenden und effektiveren Unterricht zu gestalten (vgl. Grätz 1997: 4). Mit Kunstwerken sind aber nicht nur die berühmtesten Gemälde der großen Maler gemeint, sondern auch alternative und unkonventionelle Kunstformen, die zur populären Kultur gehören. Unter diesen Formen sind Graffitis und Street-Art-Arbeiten als Ausdruck einer urbanen Subkultur einzubeziehen.

In den folgenden Kapiteln wird ausführlich gezeigt, welche aktuelle Bedeutung die Street-Art-Produkte besitzen und wie ihr Potenzial im Unterricht gezielt genutzt werden kann.

\section{Geschichte und Bedeutung der Street-Art-Subkultur}

Graffiti und Street-Art sind eine künstlerische Ausdrucksform der Urban-Art im öffentlichen Raum. Das Wort Graffiti kommt aus dem italienischen „graffiare“, d.h. kratzen, das seinerseits aus dem griechischen „graphein“, d.h. schreiben, stammt (Schneider 2006: 10). Die Realisierung von Graffitis, die sowohl aus Buchstaben als auch aus Namen bestehen, begann Ende der 60er Jahre in Philadelphia, 
verbreitete sich in New York während der 70er Jahre und ist seit den letzten vierzig Jahren unbestreitbarer Bestandteil der urbanen Kultur in den meisten Ländern der Welt. Die Idee, direkt und spontan auf einer Wand zu schreiben, ist überhaupt nicht neu. Graffitis weisen vielfältige historische Bezüge auf. Man findet sie als Ritzzeichnungen auf Dolmen oder Einritzungen auf Höhlenwänden aus der Altsteinzeit, als Wandkritzeleien auf Häuserwänden in der Römischen Zeit, wie die Ruinen von Pompeji beweisen können, als christliche Pilgergraffitis in Sakralbauten des Mittelalters, als Polemiken und Beschimpfungen auf dafür freigegebenen Wänden in der Renaissance, als politische Graffitis an Wänden und Zäunen während der Französischen Revolution, als Durchhalteparolen im Dritten Reich (vgl. Schneider 2006: 14). Auch die Wandmalerei, die als Methode die zeitgenössische Kunst beeinflusst hat, hat eine lange Tradition und besitzt seit der Antike eine politische Dimension. Besonders deutlich ist dieser politische Wert bei den Wandbildern, die im Laufe des 20. Jahrhunderts realisiert worden sind, wie die „Murales“ von Diego Rivera in Mexiko oder die Malereien an der Berliner Mauer, die politische Protestaktionen ersetzen wollten (vgl. Lorenz 2009: 34).

Heute findet der Begriff Graffiti für legale und illegale Beschriftungen Verwendung, die mit Filzstiften oder Spraydosen auf städtische Wände gezeichnet werden. Das „Tag“, d.h. die Stilisierung des Namens, meistens des Pseudonyms oder Spitznamens des Writers, ist die einfachste Realisierung für einen Writer, da es einfarbig ist und eine lineare Entwicklung hat. Solche Tags, die oft innerhalb eines U-Bahn-Waggons oder an der Außenwand eines Zuges angebracht werden, haben Graffitis beim größten Teil der Bevölkerung in Verruf gebracht und dazu geführt, dass man mit Verachtung von Schmierereien und Vandalismus spricht. Aus dieser elementarsten Form des linearen Graffitis haben sich komplexere Kunstformen wie Throw-Ups und Pieces entwickelt. Throw-Ups sind größere Versionen von Tags, die aus einem Schriftzug mit Fill-Ins und Rahmen bestehen und mit zwei oder mehreren Farben ausgefüllt werden. Pieces, Abkürzung von Masterpieces, sind stilistisch anspruchsvollere Arbeiten, die den Namen des Sprayers mit anderen Elementen kombinieren, etwa mit Slogans oder Darstellungen von Menschengestalten. Diesen Realisierungen ist die Zentralstellung des Namens ihres Autors gemeinsam. Paradoxerweise bleibt aber der Hersteller von Graffitis anonym, weil er mit einem Decknamen seine Identität schützt. Der Writer verfolgt mit seinen Ausdrucksmitteln bestimmte Ziele: Er will seinen Existenzbeweis visuell explizieren, das Pseudonym als Selbstdarstellung bekannt machen und damit das Territorium markieren. Ruhm und Respekt von den Mitgliedern seiner Gruppe, auch Crew genannt, müssen mit dem Beweis von Geschicklichkeit erworben werden. Alle Sprayer halten sich an einen Ehrencodex und respektieren ungeschriebene Regeln. Das Anfertigen illegaler Graffitis kann als Behauptung der eigenen Existenz in der Anonymität der Großstadt und als Rebellion gegen etablierte Formen der Kunst bewertet werden. Es wird mit dieser künstlerischen Leistung keine politische Intention verfolgt. Graffitis sind eine gesetzlich verbotene Aktivität. Man riskiert dabei, ertappt zu werden - das ist der Spieleinsatz. 
Während der 90er Jahre hat sich eine Post-Graffiti-Bewegung entwickelt, die Street-Art genannt wird und eine neue Art von Kunstproduktion im öffentlichen Raum bezeichnet. Im Gegensatz zu Graffitis, in dem die Mittel sich auf Spraydosen und Marker beschränken und dessen Ziel darin besteht, den Namen des Künstlers bekannt zu machen, tritt Street-Art als facettenreiches Phänomen auf. Diese andersartige Bewegung kann nicht als völlig neu definiert werden, weil sie von vielen kunstgeschichtlichen Avantgarden beeinflusst wurde. Street-Art ist vieles zugleich: „verspielt wie Dada, politisch agitierend wie die Situationisten, werbeästhetisch-knallig wie Pop-Art oder reviermarkierend und namensfixiert wie das Graffiti Writing“ (Lorenz 2009: 50). Der größere Unterschied zu der SignaturGraffiti-Bewegung ist die Vorliebe für figurative Arbeiten, die von realistischen zu stilisierten und Comic-ähnlichen Figuren reichen. Außerdem benutzen Street-Artists unterschiedliche Techniken und Methoden, um ihre künstlerischen Ideen zu realisieren: Schablonen oder Stencils, Plakate und Aufkleber, direkten Farbauftrag auf einer kleinen Wand bis zu breiten Wandflächen wie bei den Murals.

Die Arbeit mit Schablonen ist die am meisten verbreitete Technik der StreetArt und hat ihren Ursprung in Italien: während des Faschismus benutzten Anhänger von Mussolini Schablonen, um sein Gesicht auf die Mauern der Städte zu reproduzieren. Der wichtigste und weltbekannte Künstler, der die besten Ergebnisse mit dieser Technik erhalten hat, ist der Engländer Bansky. Er strebt nach einer politischen Wirkung der Stencils und benutzt die Stencils, um gegen Konformismus, Krieg und Establishment und für den Frieden Stellung zu nehmen (vgl. Bansky 2005).

Die Intention von vielen Street-Art-Künstlern besteht hauptsächlich darin, unmittelbare Reaktionen auf gesellschaftspolitische und kulturelle Situationen zum Ausdruck zu bringen. Während Graffitis davon motiviert sind, dass Jugendliche eine Nische innerhalb ihrer Gemeinschaft und in der Stadt besetzen wollen, sind die meisten Street-Art-Hersteller eher politisch animiert.

Graffitis werden oft mit Vandalismus verbunden und bieten dem Betrachter keinen wirklichen Zugang, sie werden als kryptische Ausdrucksformen gesehen. Street-Art ist visuell und konzeptuell einfacher zu verstehen und übermittelt eine Vielzahl von aktuellen Ideen. Sie kann nämlich satirisch, politisch, figurativ, ironisch sein. Die meisten Street-Artists wenden sich an die Bevölkerung insgesamt und nicht an eine bestimmte Gruppe innerhalb der Stadt, sie wollen in einen Dia$\log$ mit den Passanten treten, sie amüsieren und gleichzeitig zum Nachdenken anregen. Street-Art tritt für Meinungs- und Redefreiheit ein und propagiert in einer indirekten Weise soziale Verantwortung.

Street-Art-Künstler setzen sich in ihren Arbeiten häufig explizit mit der Kommerzialisierung des Raumes auseinander. Die Bildsprache einer Stadt besteht in erster Linie aus Werbetafeln, Straßenschildern, Reklame, Plakaten, Geschäftsschildern, die die Bewohner als Kaufinteressenten oder als Gesetzempfänger behandeln. Street-Art-Arbeiten werden als Alternative zur Massenkultur betrachtet. Die Adressaten werden nicht als Konsumenten verstanden, sondern als intelligen- 
tes Publikum, das sich mit dem Kunstwerk auseinandersetzen kann. Deshalb sind die Künstler gezwungen, den öffentlichen Raum als Schaubühne zu wählen und geschlossene, private Orte zu vermeiden. Darüber äußert sich der berühmte französische Street-Art-Künstler Blek Le Rat: „Das Problem mit Galerien ist, dass Street-Art von 99 Prozent der urbanen Künstler als Sprungbrett für Galerien benutzt wird. Das ist ein verhängnisvoller Fehler, weil sie in Galerien von 40 Leuten gesehen werden, in Museen von 10, aber auf der Straße werden sie von 100.000 Menschen gesehen. Darin liegt die Integrität der Arbeit eines Künstlers: dass sie gesehen wird. Nicht dass sie verkauft oder in einem Museum anerkannt wird sondern dass sie von der Welt gesehen wird“" (Wacławek 2012: 70). Street-Art bleibt trotzdem eine illegale und nicht autorisierte Kunstform, und ihre Aktivisten müssen anonym oder unter Pseudonym arbeiten.

\section{Street-Art im Fremdsprachenunterricht}

Street-Art im Fremdsprachenunterricht klingt wie ein provokativer Vorschlag, denn sie steht außerhalb des traditionellen Kunstkanons und benutzt eine unkonventionelle Bildsprache. Diese Andersartigkeit kann aber eine Stärke sein. Es ist bewiesen, dass der Lernprozess nur in Gang gesetzt wird, wenn die Lernenden bereit sind, neue Inhalte und Informationen zu lernen. Diese Bereitschaft heißt Motivation und wird stimuliert, wenn neue, interessante, originelle Themen vorgestellt werden. Street-Art ist ein relativ neues und junges Phänomen und hat als Kunstbewegung schon viele Städte der Welt erobert, deshalb kann sie die Aufmerksamkeit der Schülerinnen und Schüler anziehen und ihre Neugier erwecken. Die Motivation ist aber nur der erste Schritt in einer Didaktik, die sowohl sprachliche als auch künstlerische Anforderungen zusammenführt. Im Fremdsprachenunterricht „dient das Kunstbild als Vorlage für einen Prozess, in dem die Schülerinnen und Schüler schrittweise zu einem dem Kunstbild angemessenen kunstästhetischen Verständnis geführt werden und sich dabei sprachlich und inhaltlich neue Bereiche der Zielsprache und Zielkultur erschließen. Im Laufe dieses Entschlüsselungsprozess bringen sich die Schülerinnen und Schüler immer wieder als Personen mit ihren eigenen Erfahrungen und Einstellungen ein und lernen, sich in der Fremdsprache individuell auszudrücken" (Charpentier; Cross; Dupont; Marcou 1991: 48).

Der Einsatz von Street-Art-Arbeiten im Fremdsprachenunterricht kann unterschiedliche Vorteile mit sich bringen und zudem helfen, sprachliche und ästhetische Kompetenzen zu erwerben. Street-Art-Werke eignen sich für alle Niveaustufen. Die bereits erworbene Sprachkompetenz spielt eine untergeordnete Rolle. Alle Schülerinnen und Schüler können auf ein Kunstwerk reagieren, da keine sprachliche Verständnisbarriere existiert. Da die Bilder provokativ und manchmal ironisch sind, fühlen sich die Lernenden angespornt, auf das Bild zu reagieren und ihm gegenüber Stellung zu beziehen. Die meisten Bilder der Street-Art sind von 
einer besonderen Deutungsoffenheit gekennzeichnet, sie zeigen ein visuell einfaches Bild, das mehrere Interpretationsmöglichkeiten anbietet. Diese Mehrdeutigkeit kann vom Lehrer genutzt werden, um die Interpretationsfähigkeiten der Lernenden und ihr kreatives Denken zu fördern. Manchmal weisen Bilder Leerstellen, d.h. unklare und enigmatische Elemente auf, die die Lerner mit Hilfe ihrer Phantasie ergänzen müssen. Sie können auch narrative Elemente enthalten, die als Erzählimpulse im Unterricht benutzt werden können.

Viele von der Street-Art angesprochene Themen erfüllen eine kommunikative Funktion: Sie dienen als Diskussionsanlass und bringen die Schülerinnen und Schüler dazu, eine Position einzunehmen und ihre Meinung zu äußern. In diesem Sinn ermöglichen Kunstwerke authentische Sprachhandlungen, die unter Verwendung kommunikativer Fertigkeiten zustande kommen. Kunst im Unterricht fördert die so genannte „visual literacy“, d.h. „die Fähigkeit, den kommunikativen Gehalt von Bildern zu verstehen und aktiv kommunikativ zu nutzen" (Hallet 2010: 32).

Di Street-Art-Kunst enthält außerdem einen Aktualitätsbezug, vermittelt einen kulturellen Erkenntniswert und erlaubt eine intensive Auseinandersetzung mit dem Authentischen.

Das Street-Art-Phänomen hat seit Jahren auch eine große Resonanz in der Medienlandschaft ausgelöst und kann von unterschiedlichen Gesichtspunkten und mit unterschiedlichen Materialien analysiert werden. Man kann Filme über StreetArt sehen, Zeitungsartikel, Reportagen aus Pop-Magazinen und Feuilletons lesen, Internetseiten und Soziale Netzwerke besuchen, Bücher und Ausstellungskataloge nachschlagen. Dieser rasende mediale Erfolg kann die Entdeckungslust der Lernenden erwecken und sie zwingen, das Argument zu vertiefen. Das Interesse kann sich auf den Künstler und seine Biographie oder auf die Entwicklungsgeschichte der Kunstbewegung richten. Street-Art-Künstler zeigen oft durch ihre Werke eine originelle Identität, die aber verborgen bleiben muss. Eine geheimnisvolle Person erregt immer Neugier und den Wunsch, ihre Geschichte zu entdecken. Die Arbeit mit informativen Quellen kann die Gelegenheit geben, nicht nur sprachliche Kenntnisse und Fertigkeiten zu verbessern, sondern auch landeskundliches Wissen zu erwerben.

Kunstrezeption soll außerdem dem ästhetischen Genuss dienen. Oft befriedigen die zeitgenössischen Kunstwerke unser Bedürfnis nach der spezifisch ästhetischen Qualität des Schönen nicht mehr, stattdessen informieren sie den Betrachter über aktuelle gesellschaftskritische Themen. Street-Art-Produkte erledigen diese Aufgabe, können aber auch ästhetische Werte implizieren. Kunst im Unterricht trägt dazu bei, die ästhetische Sensibilität der Lernenden zu entwickeln, und verfeinert ihre Wahrnehmungsfähigkeit. Man ist daran gewöhnt, die äußerliche Umgebung flüchtig und oberflächlich zu beobachten. Street-Artists zwingen uns, den öffentlichen Raum zu erkunden und auf seine Details zu achten.

Bei der Arbeit mit Bildern im Fremdsprachenunterricht ist nicht nur die Sprachkompetenz, sondern auch die Medienkompetenz der Lernenden gefragt. Der Begriff der Medienkompetenz kann aus mehreren Perspektiven analysiert wer- 
den. „Medienkompetenz beinhaltet Fähigkeiten, sich mit Medienwissen im Medienangebot orientieren zu können. Medien sollen kompetent und kritisch von den Gesellschaftsmitgliedern angeeignet bzw. verweigert werden, um eine gesamtgesellschaftlich verantwortliche und nachhaltige Entwicklung zu befördern" (Rosebrock; Zitzelsberger 2002: 150). Eine angemessene Medienkompetenz zu besitzen, bedeutet nicht nur, die Medien gut zu kennen und benutzen zu können, sondern auch in der Lage zu sein, sich in der Medienwelt zu orientieren und eine sachliche Analyse- und Kritikfähigkeit zu üben. In Bezug auf Kunstbilder hat diese Definition viele Konsequenzen: Der Lerner, der über Medienkompetenz verfügt, kann die Grenze zwischen Medienkonstruktion (das künstlerische Werk) und der Realität erkennen, er kann ein Bild als solches wahrnehmen und es systematisch beschreiben, er kann kulturell geprägte Elemente in einem Kunstwerk identifizieren, eine kritische Haltung einnehmen und sich darüber mit anderen auseinandersetzen, schließlich kann er Medienprodukte wie z.B. Präsentationen oder nachbearbeitete Bilder bearbeiten (vgl. Bachtsevanidis 2012: 116-119). Die Auseinandersetzung mit Street-Art-Arbeiten und ihren visuellen und konzeptuellen Aspekten aktiviert und verbessert die Medienkompetenz der Schülerinnen und Schüler.

\section{Auswahlkriterien}

Die Auswahl der Materialien im Fremdsprachenunterricht hängt von unterschiedlichen Faktoren ab: vom sprachlichen Niveau der Lernenden und ihren schon erworbenen Kompetenzen, von den Lernzielen, von ihrem Alter, ihren Interessen und ihrer Vorbildung. „Diese Unterscheidungskriterien müssen zwangsläufig Veränderungen, Ergänzungen, Bündelungen, Reduktionen oder sogar Vereinfachungen der kunstwissenschaftlichen Ansätze und Verfahren nach sich ziehen" (Badstübner-Kizik 2002: 4).

Nicht alle Angebote der Street-Art sind den Zielen des Sprachunterrichts, dem Alter der Lernenden und ihrer Bildung angemessen. Folgende Bildarten wären zu vermeiden:

- Bilder, die von der Erfahrungswelt der Schülerinnen und Schüler zu weit entfernt sind und daher nicht völlig verstanden werden können.

- Bilder, die zu einfach oder banal sind und für keine sprachliche Aufgabe taugen.

- Bilder, die keine Bedeutung haben oder keine Botschaft senden und nicht zum Nachdenken führen. Manchmal offenbaren sich Kunstwerke als Selbstzweck und bloßer Demonstration von Virtuosität. Diese Bravourstücke sind wunderschön, aber leer und ohne Substanz.

- Bilder, die politische Bezüge enthalten und die ethischen Werte der Schülerinnen und Schüler missachten können. 
- Bilder mit sexuellen Anspielungen, die gegen moralische Prinzipien verstoßen können.

- Bilder mit religiösen Figuren, die aber ein spöttisches Ziel haben und die Sensibilität der Lernenden verletzten können.

- Bilder, die andere mögliche Tabuthemen enthalten, die Wertvorstellungen und die Kultur der Schülerinnen und Schüler nicht anerkennen.

Eine solche Auswahlrichtung respektiert sowohl bildungspädagogische als auch fremdsprachendidaktische und lernwissenschaftliche Aspekte. Es ist Aufgabe des Lehrers, diese beschränkenden Kriterien in Kauf zu nehmen und die Bedürfnisse der Lernenden zu berücksichtigen. Im Internet ist es relativ einfach, Street-ArtBilder zu finden, die keine visuelle und inhaltliche Qualität haben. Deshalb soll der Lehrer in der Lage sein, die Materialien zu bewerten und ihre Benutzbarkeit im Unterricht vorherzusehen.

Grundprinzip der Didaktik ist auch die gute und ausgewogene Vorbereitung des Unterrichts. Der Lehrer soll nicht nur die didaktischen Funktionen von Bildern erkennen, sondern auch über das methodische Verfahren für die Arbeit mit Bildern informiert sein und die Planungskriterien einer auf Kunstbildern basierten Lerneinheit kennen.

\section{Unterrichtsvorschläge}

Im folgenden Kapitel werden einige Unterrichtsvorschläge skizziert, die der Lehrer umsetzen kann, um in der Praxis eine oder mehrere strukturierte Lerneinheiten aufzubauen. Die Arbeit mit Kunstbildern im Unterricht kann unterschiedliche Etappen umfassen: betrachten und beschreiben, nachdenken und beurteilen, schöpfen und gestalten, erweitern und vertiefen (vgl. Charpentier; Cros; Dupont; Marcou 1997: 9-10). Die erste Etappe entspricht der ästhetischen Wahrnehmung und der ersten Beschreibung des Kunstwerkes. Dieser Wahrnehmungsprozess kann mehrere Tätigkeiten vorsehen und verläuft parallel zur sprachlichen Beschreibung des Werkes. Der erste Bilck auf das Bild aktiviert das nötige Vorwissen, das die Rezeption steuert und beeinflusst. Die Aufnahme und Verarbeitung von Informationen, die in diesem Fall in einem Bild bestehen, aktiviert im Gehirn kognitive Schemata, die man aus den eigenen Erfahrungen und Erlebnissen gespeichert hat. Visuelles Wahrnehmen ist ein aktiver und kulturell geprägter Prozess, kein passives Rezipieren von äußerlichen Reizen. Gehören die dargestellten Elemente einem fremden Phänomen oder einer fremden Kultur an, können sie nicht über die vertrauten Schemata erschlossen werden, und das kann zu Missverständnissen und Fehlinterpretationen führen. Zusatzkenntnisse sind notwendig, die den Kontext klären und das erforderliche Grundwissen geben (vgl. Macaire; Hosch 1996: 107-108). 
Der Ausgangspunkt für eine sprachliche Reaktion auf das Bild ist die Beschreibung. Den Lernenden wird die Gelegenheit gegeben, den Bildinhalt sprachlich zu erläutern. Entsprechende Aufgabenstellungen und Leitfragen können den Rezeptionsprozess lenken und unterstützen.

Auf diese spontane Formulierung folgt eine Reflexionsphase. Durch Hypothesen und Vermutungen versuchen die Lernenden eine Bildinterpretation zu formulieren. Während dieser Phase benutzt der Lerner seine Phantasie und Kreativität, die sich in der schöpferischen Spracherarbeitung verwirklicht.

Da das Kunstwerk in einem Kontext eingebettet ist, müssen je nach Fragestellung historische, stilistische, biographische und kulturelle Informationen gegeben werden. Die Kontextualisierung erlaubt den Schülerinnen und Schülern, sich einer Gesellschaft und ihrer Kultur anzunähern und landeskundliches Wissen zu erwerben. Detaillierte Informationen über das Kunstwerk (über die Entstehungszeit, den Künstler, die Bewegung, die Verbindung mit der Tradition) sichern eine richtige Deutung und Erfassung der fremden Kultur.

Die Begegnung mit dem Bild führt letztendlich zu einer allgemeinen Beurteilung, die keine subjektive Wertung sein muss, sondern vielmehr eine kritische Evaluation des Werkes ist.

Der letzte Schritt sieht produktive und freie Aufgaben vor: Die Schülerinnen und Schüler können je nach Textsorte schriftliche oder mündliche Texte herstellen, die ihnen erlauben, die erworbenen Informationen aktiv zu verarbeiten. Kreative Arbeitsmöglichkeiten können sich auf den Inhalt des Bildes beziehen (z.B. eine Kritik schreiben, eine Diskussion veranstalten), auf die Bildrealisierung und die angewandte Technik (z.B. Collagen erstellen, Wandstellungen gestalten), auf die Kunstbewegung (eine Präsentation mit Power Point vorbereiten), sowie auf den Künstler und seine Biographie (eine Recherche machen, ein Interview erfinden).

Dieses eingeführte methodische Verfahren kann auch für die Arbeit mit StreetArt-Produkten im Unterricht angewendet werden, wie die folgenden Beispiele zeigen.

\subsection{Rezeption}

Der Einstieg in die Unterrichtssequenz erfolgt über eine Begriffserklärung. Zunächst werden die zentralen Ideen der Street-Art eingeführt, damit sie den Schülerinnen und Schülern bei der selbstständigen Arbeit zur Verfügung stehen. Man kann eine kurze Reportage über Street-Art in Berlin zeigen, in der einige berühmte Berliner Künstler auftauchen. Der Titel lautet „Urban Art - Berlin als Streetlabor Europas". ${ }^{1}$ Im Video, das nur wenige Minuten dauert, werden die Merkmale der Street-Art erläutert.

\footnotetext{
${ }^{1}$ www.youtube.com/watch?v $=08$ qLL4iqSuc
} 
Nach einer Einführung zum Thema werden die Lernenden in Gruppen geteilt. Sie bekommen die Fotos von einigen Street-Art-Werken, die der Lehrer aus Kunstbüchern fotokopiert oder aus dem Internet heruntergeladen hat. In jeder Gruppe werden Kopien von zwei oder drei Bildern verteilt. Für die im Folgenden beschriebenen Unterrichtsvorschläge wurden bewusst Bilder ausgesucht, die den Lernern ermöglichen, nicht nur ihre Kreativität und Interpretationsfähigkeitzu entfalten, sondern auch ihr landeskundliches und interkulturelles Wissen zu erweitern. Die vorgeschlagenen Themenschwerpunkte und die entsprechenden Bilder sind die folgenden:

Gruppe 1: „Ich sehe was, was du nicht siehst“. Street-Art-Arbeiten von El Bocho (Abb. 1-3)

El Bocho ist ein deutscher Illustrator und Street-Art-Künstler, der mit seinen CutOuts und Tape-Art-Arbeiten die Stadt Berlin erobert hat. Man kennt seinen echten Namen nicht, nur das Pseudonym ist bekannt und auf jeder Arbeit zu sehen. Er hat aber ein Doppelleben: Neben seinen Street-Art-Aktivitäten machte er eine blendende Karriere als Illustrator für die renommierte Frankfurter Allgemeine Zeitung. El Bocho ist trotz dieses offiziellen Auftrages einer der aktivsten und sichtbarsten Street-Art-Vertreter in der deutschen Hauptstadt. Mit seinen Werken will er das Stadtbild nicht radikal umkehren, sondern es verändern und schmücken. Mit seinen romantischen Frauengesichtern, stilisierten Manga-Figuren und ironischen Comic-Bildern möchte er die Stadt verschönern und die Passanten ergreifen. Deshalb arbeitet er nicht direkt auf den Mauern der Stadt, sondern bereitet seine Werke auf braunem Packpapier vor, das er später an leere Wände klebt. Sein Ziel ist nicht nur ästhetisch, sondern auch politisch, wie das Projekt „Ich sehe was, was du nicht siehst" beweist. Die zwei sprechenden Überwachungskameras Kalle und Bernd amüsieren die Betrachter und greifen gleichzeitig ein brisantes Thema auf: wie der Staat mit Hilfe der neuen Technologien die Bewohner ständig beobachten und kontrollieren kann. Dieses aktuelle Problem verbindet sich mit der Protestkampagne „Stasi 2.0“ (2007), die sich gegen die Sicherheitspolitik der deutschen Regierung und die Beschränkungen der Informationsfreiheit entwickelte. Das Schlagwort lässt sofort an die Überwachungspolitik der DDR durch die Staatssicherheit denken und fügt den Begriff Web 2.0 hinzu, der auf die Benutzung der digitalen Medien hinweist. El Bocho vermittelt indirekt seine Meinung und sagt uns mit Ironie, auf welcher Seite er steht. 


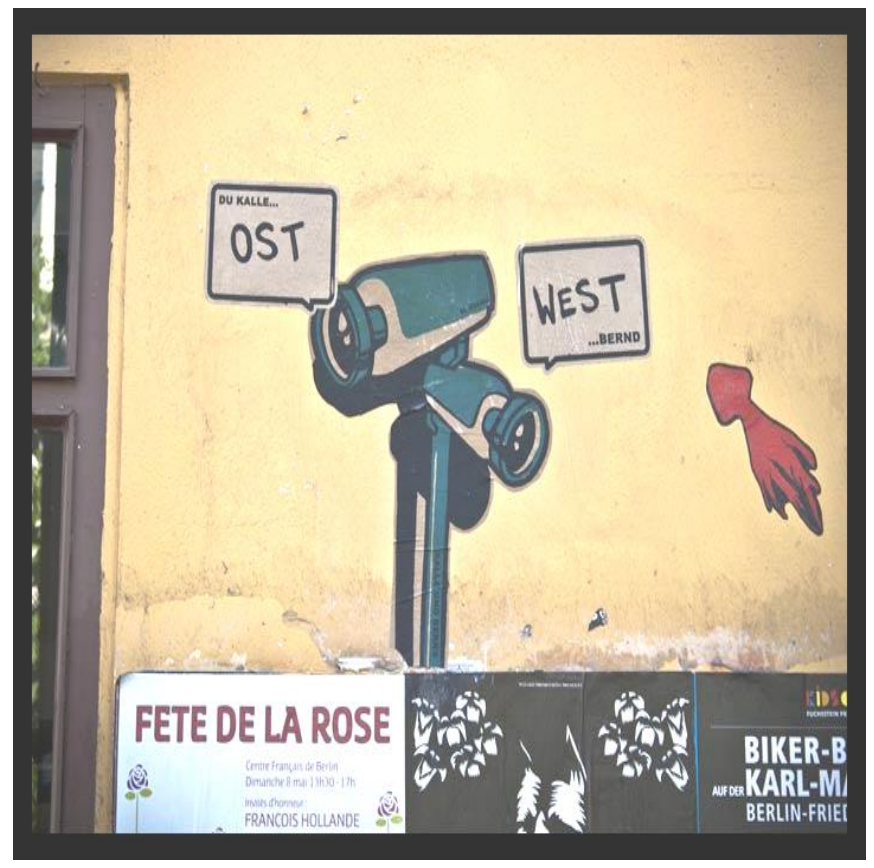

Abb. 1: E1 Bocho, Berlin

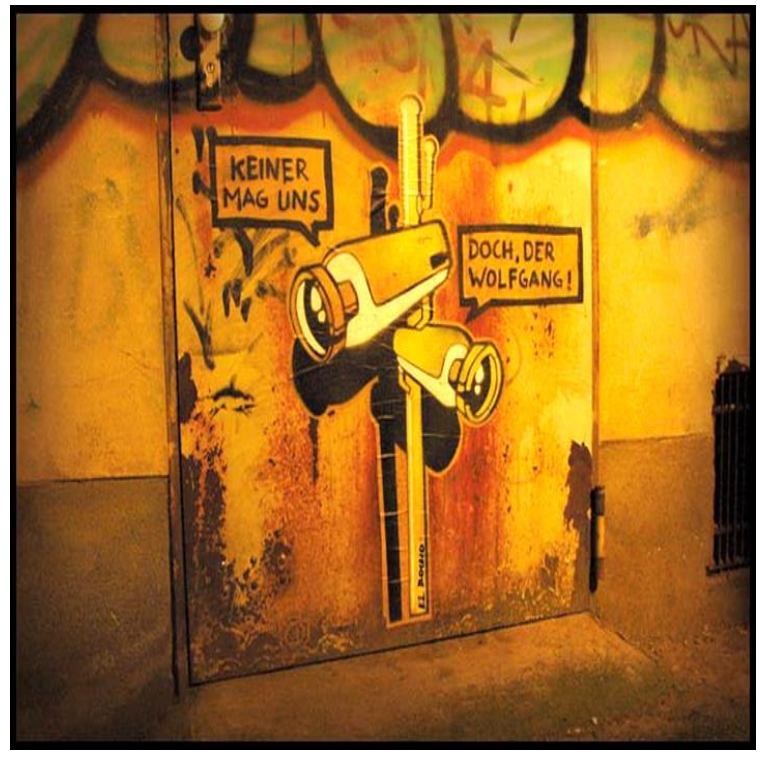

Abb. 2: El Bocho, Berlin 


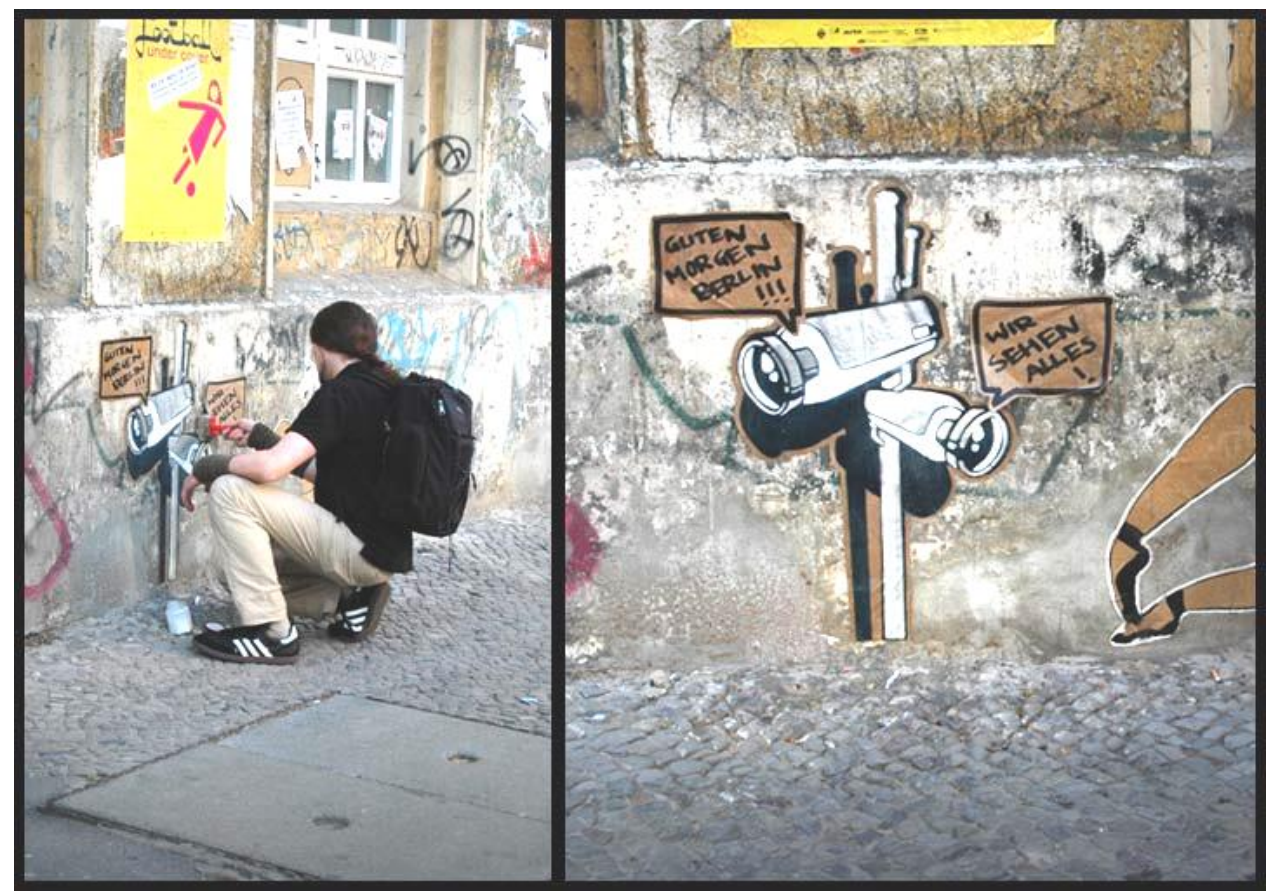

Abb. 3: E1 Bocho, Berlin

Gruppe 2: Das Projekt „Face 2 Face“ des Künstlers JR (Abb. 4-5).

JR ist ein französischer Fotograf und Street-Art-Künstler, sein Paste-Up Projekt „Face 2 Face“ hat großes Aufsehen in der Welt erregt. Zwischen 2006 und 2007 fotografierte er Menschen aus Israel und Palästina, zwei Gebiete, die durch eine 700 Kilometer lange Betonmauer voneinander getrennt und isoliert sind. JR vergrößerte diese Fotos zu riesengroßen Postern und befestigte sie überall in den Territorien - in Haifa, Tel Aviv, Hebron, Ramallah, Jerusalem und auch auf beiden Seiten der Mauer. Diese riesigen Porträts von Leuten, die die gleichen Arbeiten ausüben, aber im realen Leben theoretisch Feinde sind, wurden einander absichtlich gegenübergestellt, so dass sie von Angesicht zu Angesicht kommunizieren mussten. JR fotografierte verzerrte Gesichter und Grimassen, die einen positiven Effekt auf den Betrachter haben. Die Absicht war, die Zwiespalt zwischen den Menschen zu überwinden. Die enormen Plakate von JR wurden auch in Berlin ausgestellt, an einem für die Stadt sehr bedeutenden Ort: dem ehemaligen Grenzübergang Checkpoint Charlie. Die Trennung eines bevölkerten Gebietes durch eine Mauer ist ein Trauma, das Berlin erlebt und allmählich überwunden hat. Die Geschichte scheint sich anderswo zu wiederholen. JRs merkwürdige Ausstellung versucht, einen Beitrag zur Völkerverständigung zu leisten und das Publikum zum 
Denken anzuregen, gerade in einem Kontext, der die Last der Vergangenheit noch ertragen muss.

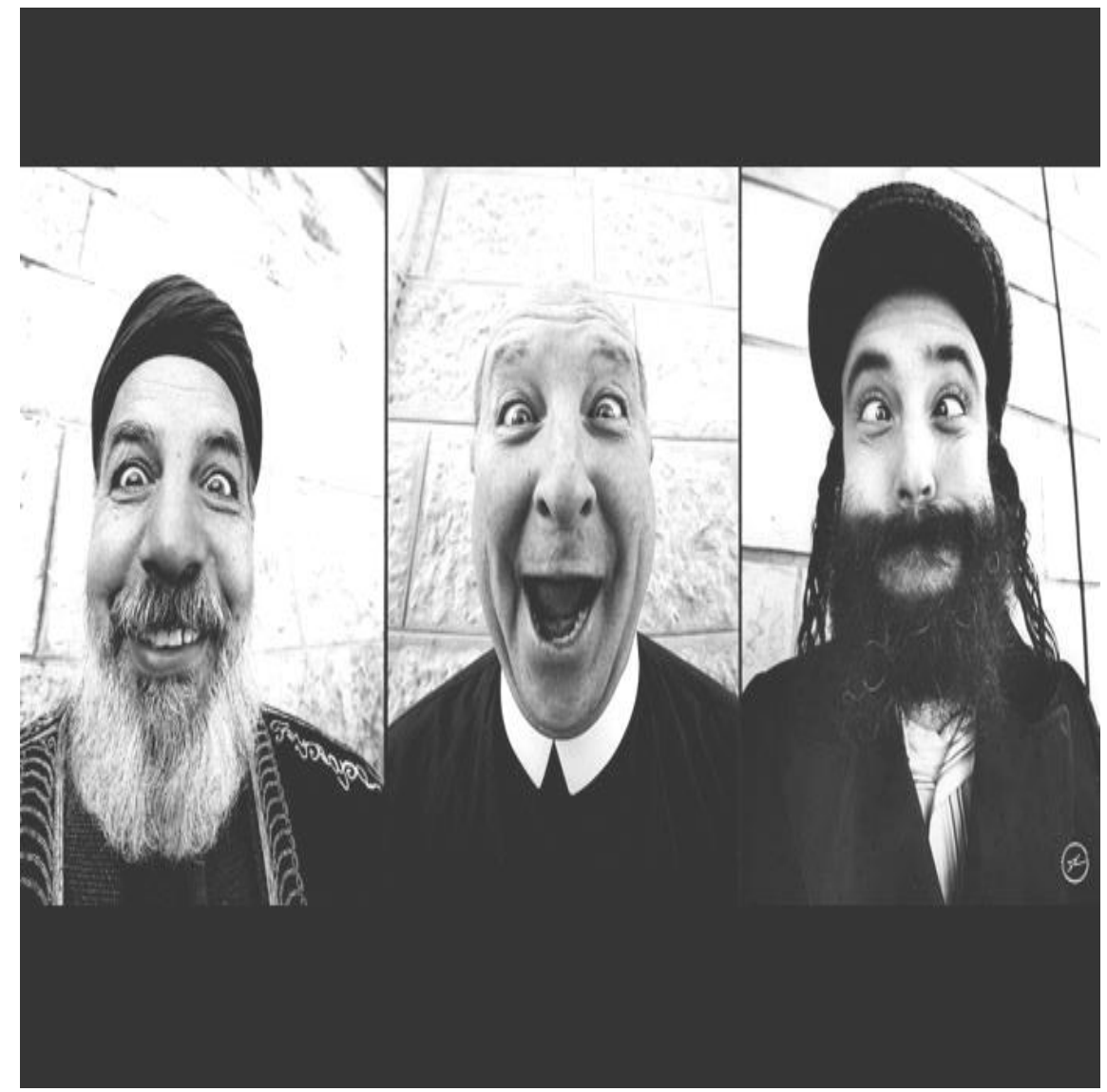

Abb. 4: JR, Berlin 


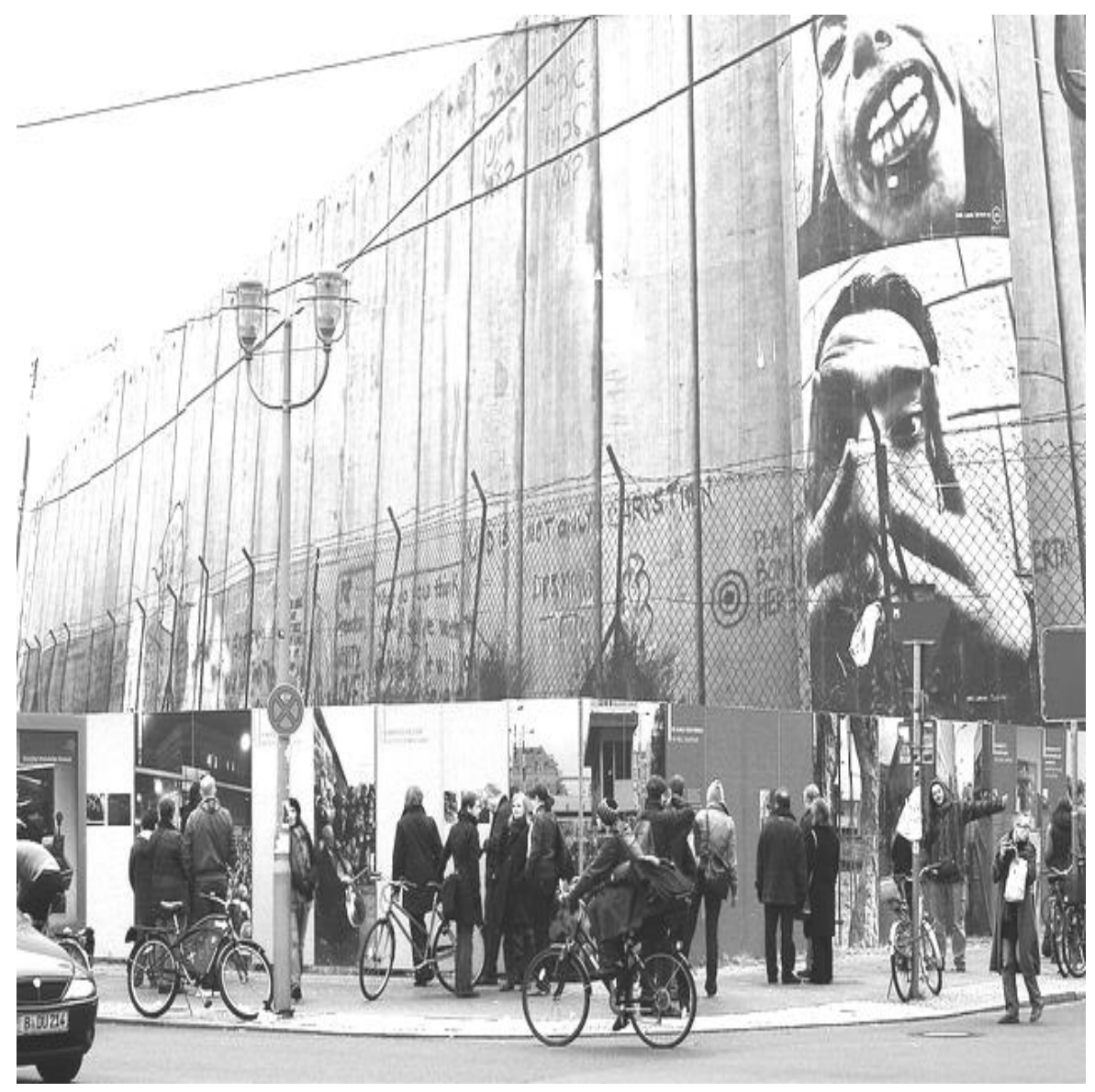

Abb. 5: JR, Berlin

Gruppe 3: Kinder in der Stadt: die Arbeiten von Alias (Abb. 6-8)

Die stärkste Präsenz im Straßenbild der letzten Zeit hat der in Hamburg und Berlin aktive Street-Art-Künstler Alias. Seine Werke bestehen hauptsächlich aus Fotomontagen und Bildverfremdungen, die auf Cut-Outs und Paste-Ups oder Stickern auf die Wände der Stadt aufgetragen werden. Der öffentliche Raum ist der perfekte Ort für seine Arbeiten, die durch die Platzierung in der passenden Umgebung ihre volle Wirkung erreichen können. Alias will den Betrachtern keine direkte politische Botschaft senden, sondern in ihnen intime Gefühle wecken. So äußert er sich in einem Interview: „Die Verbildlichung von Emotionen ist ein Schwerpunkt, wobei ich eine eher negative und resignierende Stimmung vorziehe. Was aber nicht zwingend mit Kriegen, Umweltverschmutzung oder Ausbeutung zu tun hat. Es sind die 
persönlichen Krisen, die mich interessieren, welche aber natürlich auch durch unsere gesellschaftlichen und politischen Verhältnisse beeinflusst werden" (Wittig 2012). Um diese traurige und hoffnungslose Gemütslage besser zum Ausdruck zu bringen, bevorzugt der Künstler die abgebröckelten Wände von alten Gebäuden oder dunkle abgesonderte Orte, wo er die Figuren von melancholischen und einsamen Kindern aufklebt.

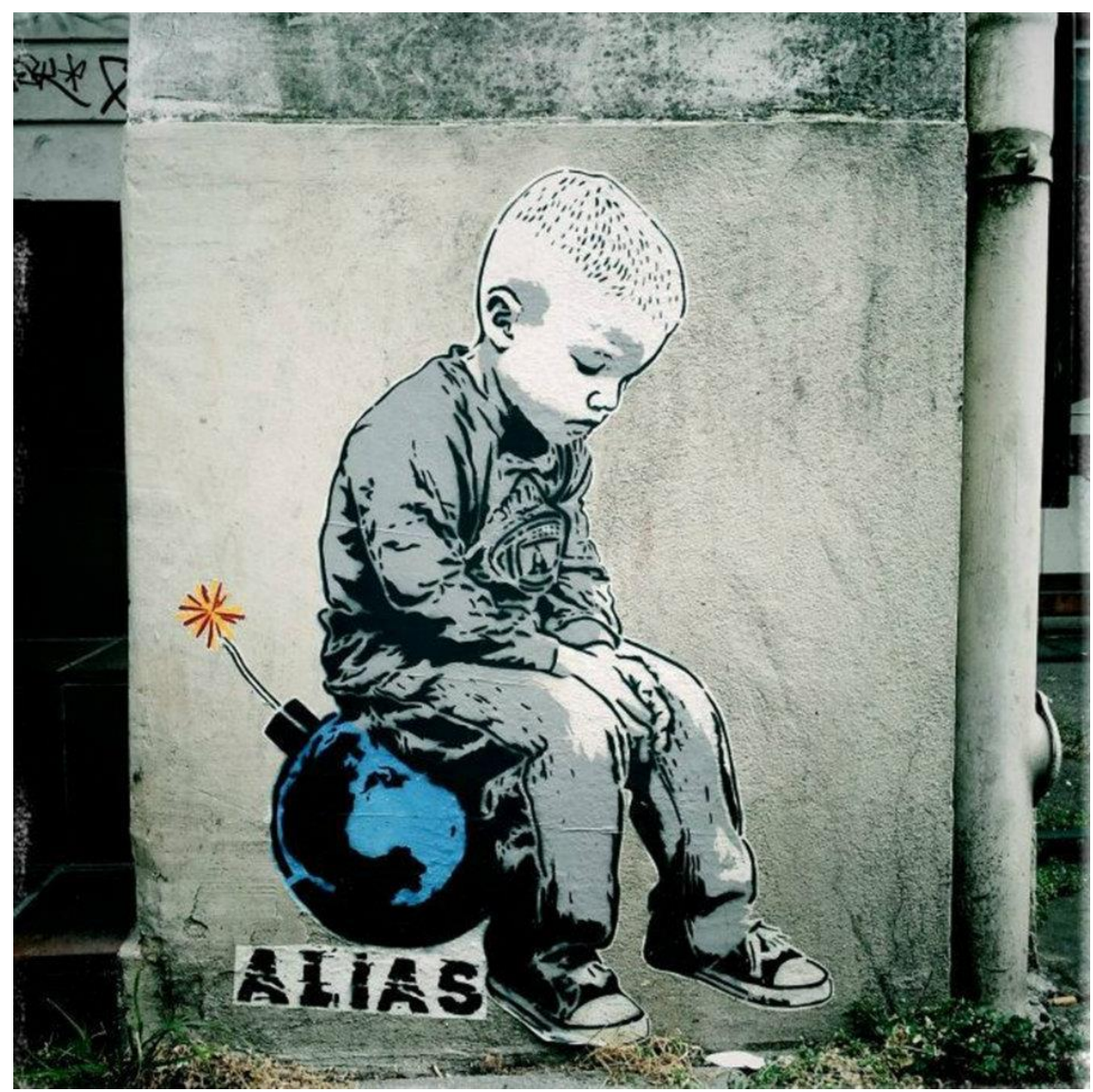

Abb. 6: Alias 


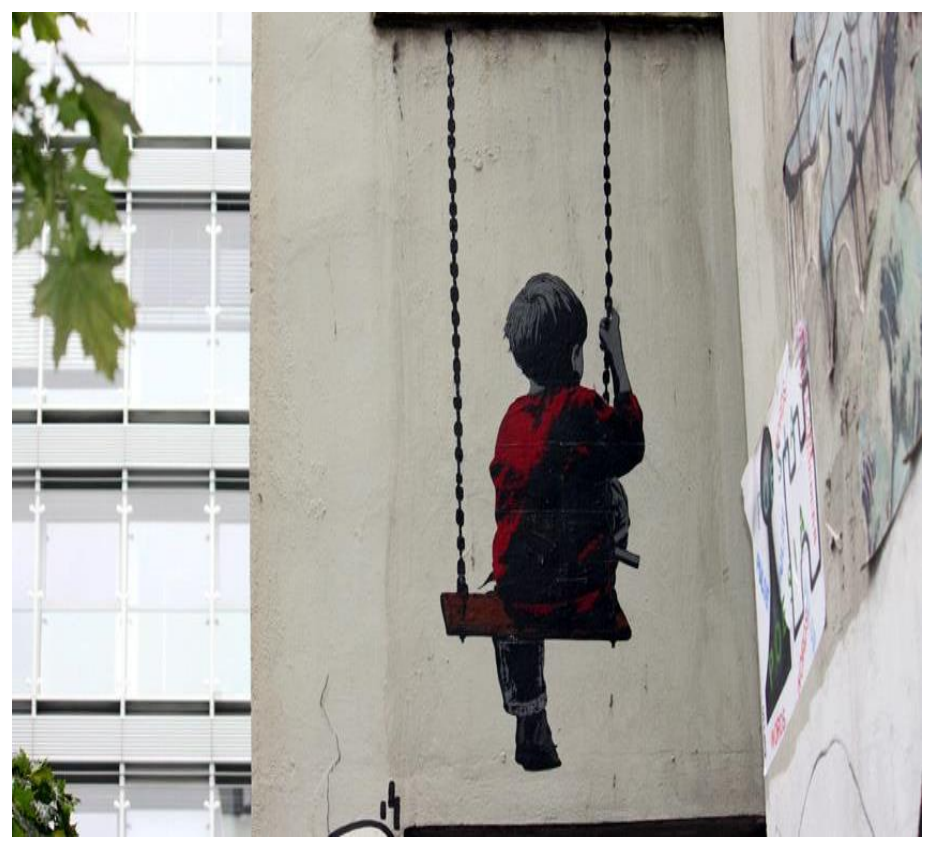

Abb. 7: Alias

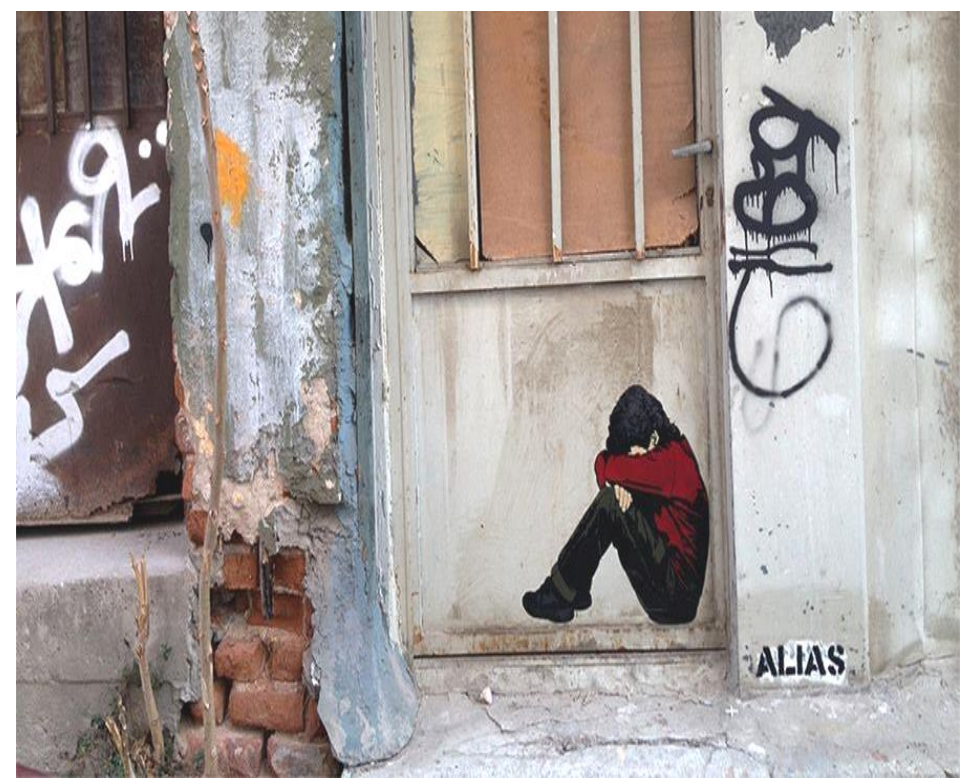

Abb. 8: Alias 
Gruppe 4: Murals von Blu in Berlin (Abb. 9-10)

Der berühmte italienische Künstler Blu hat im Rahmen einiger Street-Art-Festivals (2006-2009) den Berliner Bezirk Kreuzberg mit seinen bunten Murals geziert und optisch aufgewertet. Als Untergrund für diese Kunstwerke haben die grauen Brandwände der Stadt gedient, die noch von der Zerstörung im Zweiten Weltkrieg zeugen. Blus Murals sind echte Sehenswürdigkeiten geworden und sind ein Beispiel der Zusammenarbeit zwischen Street-Artist und der Obrigkeit, die die künstlerische Veranstaltung in Kreuzberg genehmigt hat.

Blu erzählt mit seinen riesigen Kreationen Geschichten, die durch visuell einfache Darstellung und komplexe Interpretationsmöglichkeiten bestimmt werden. Seine Arbeiten sind von Monstern, menschlichen Körpern und dem Tod bevölkert, die auf die Zuschauer eine verstörende provokante Wirkung haben. Die Werke wollen sich in den Kontext einbetten und mit den Menschen, die dort wohnen, in einen Dialog treten. Blu versucht immer, sich mit der realen Umgebung in Verbindung zu setzen. Die Realisierung der Wandgemälde wird oft auch in Videoanimationen umgesetzt, die durch die Webseite des Künstlers oder YouTube verbreitet werden. Diese Videos sind nicht nur eine Dokumentation der Arbeit auf der Straße, sondern auch authentische, mit einem neuen Medium realisierte Kunstwerke.

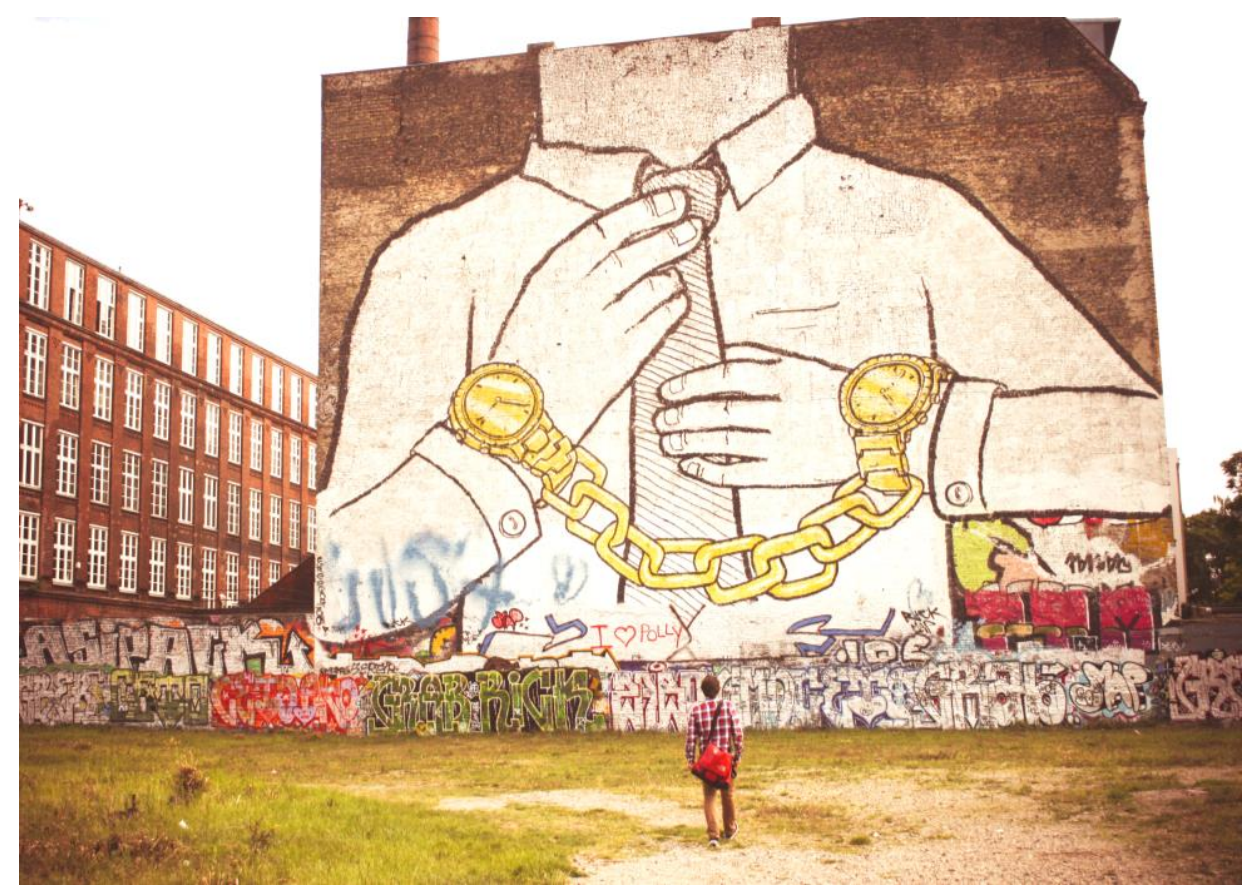

Abb. 9: Blu, Berlin 


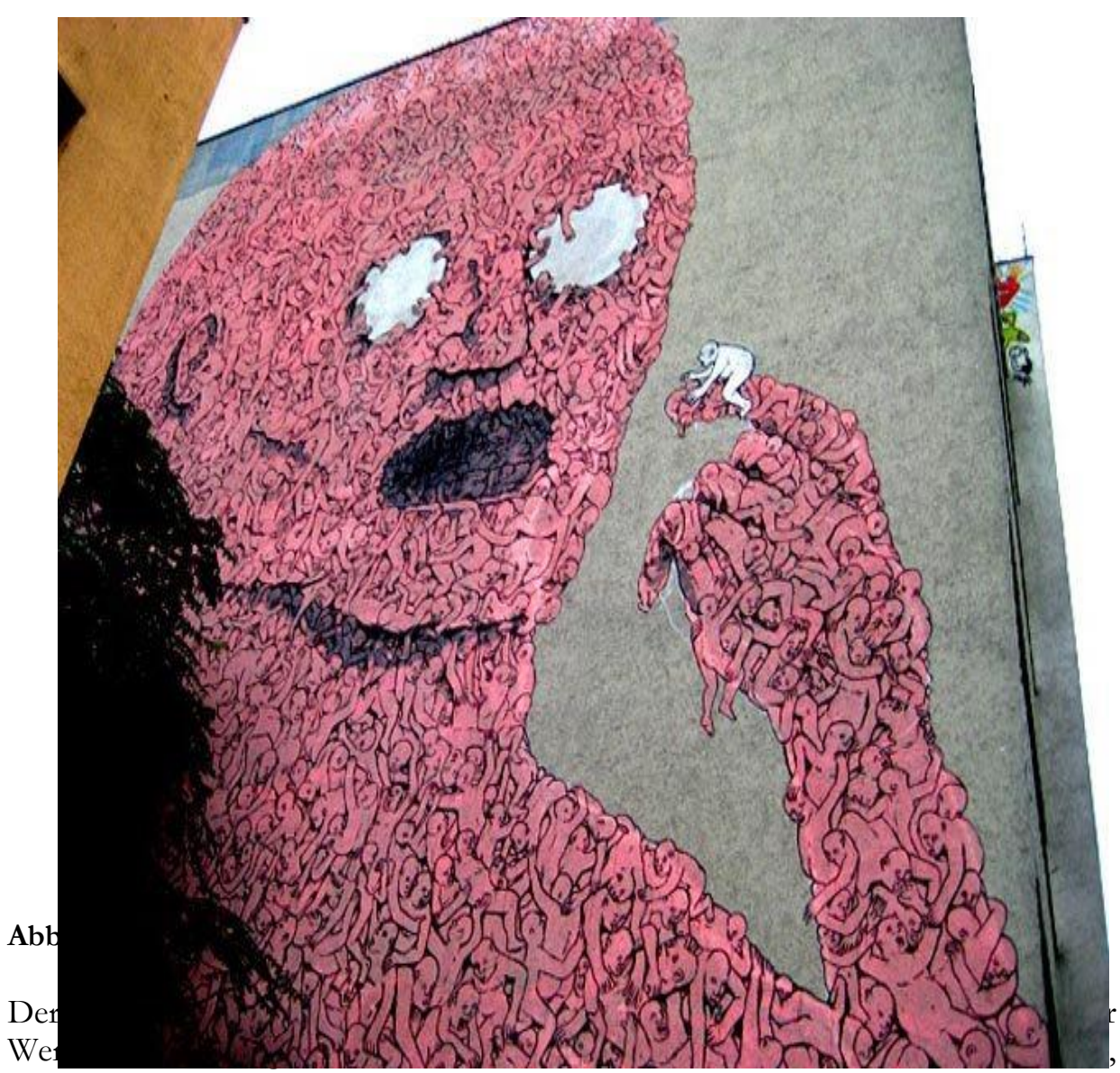

wobei dann im nächsten Schritt die persönliche Wahrnehmung mit den anderen Gruppenteilnehmern mündlich konfrontiert wird.

Die Lernenden äußern sich spontan und sagen, was ihnen einfällt. In einer zweiten Phase nennen die Schülerinnen und Schüler, was ihnen in der Darstellung aufgefallen ist, und identifizieren die einzelnen bildkonstituierenden Elemente: Figuren, Farben, Formen, Materialien und technische Mittel. Die Schüler können auch Hypothesen über die Orte aufstellen, wo sich die Kunstwerke befinden.

\subsection{Bildbedeutung und Interpretation}

Die Schülerinnen und Schüler versuchen, die Bedeutung der Bilder zu erkennen und die Absichten des Autors zu durchschauen. Der Lehrer hilft mit nützlichen Leitfragen: „Hat das Werk eine Bedeutung?“; „Was will uns der Autor mitteilen?“; „Warum hat er diese Technik benutzt?“; „Warum hat er diesen Ort für sein Werk gewählt?“. Diese Fragen können leichter beantwortet werden, wenn die Schüler 
Informationen über die ästhetischen Intentionen der Künstler erfahren können. Im Internet sind zum Beispiel Interviews und Artikel zu finden, in denen StreetArtists ihre künstlerischen Ziele erklären.

\subsection{Reflexion und Beurteilung}

Die Lernenden haben jetzt genug Material gesammelt, um ihre eigene Meinung über die Street-Art-Werke zu äußern. Es geht nicht um eine spontane Stellungnahme, sondern um eine kritische Analyse des Phänomens. „Die Semiotik unterscheidet zwischen Denotation (unmittelbare Beschreibung, unmittelbare Botschaft) und Konnotation (Hinzugedachtes, Hinzugewusstes). Die letztere führt zu Deutungen, die in die hinter dem Bild und dem Betrachter stehende(n) Gesellschaft(en) führen“" (Badstübner-Kizik 2002: 17). Die konnotative Bedeutung der Kunstwerke zwingt die Schülerinnen und Schüler, nach Informationen zu suchen, die außerhalb der Bilder zu finden sind und in der Gesellschaft liegen.

\subsection{Produktion}

In der letzten Phase der Arbeit werden einerseits die produktiven Fertigkeiten geübt, andererseits gibt man landeskundlichen und interkulturellen Aspekten Platz.

Die Lerner können eine Debatte auslösen, in der sie sich für oder gegen die StreetArt-Kunst entscheiden und ihre Position verteidigen.

Um interkulturelle Vergleiche zwischen der eigenen und der fremden Kultur anzustellen, können die Lernenden Informationen über die Street-Art im eigenen Land recherchieren und einen Aufsatz darüber schreiben. Die Tatsache, dass Künstler von verschiedenen Nationalitäten in einer einzigen Großstadt wie Berlin arbeiten, symbolisiert die internationale Wesensart dieser Kunstbewegung.

Zur urbanen Subkultur gehören Street-Art-Künstler sowie Graffiti-Sprayer. Diese zwei Phänomene sind aber sehr verschieden und folgen eigenen getrennten Regeln. Die Schülerinnen und Schüler können mit Hilfe von traditionellen und digitalen Quellen die Unterschiede zwischen den zwei Bewegungen feststellen.

Die Lernenden können auch über die Sprache der Street-Art reflektieren und den markanten Einfluss der englischen Sprache über diese Kunstbewegung erforschen.

\section{$6 \quad$ Fazit}

Zusammenfassend kann festgehalten werden, dass der Einsatz von Street-Art-Arbeiten im Fremdsprachenunterricht wesentliche Vorteile bietet: die Verbesserung der sprachlichen Kenntnisse und Fertigkeiten, den Erwerb landeskundlicher Informationen sowie die Entwicklung der Medienkompetenz. Es soll sichtbar geworden sein, dass Produkte der populären Kunst Gegenstand eines lernerzentrierten, hand- 
lungsorientierten Unterrichts sein können, weil zeitgenössische Kunstphänomene großes Interesse bei den Lernenden erregen können. Da Street-Art noch ein wenig bekanntes Kunstphänomen ist, kann der Lehrer den Neuigkeitseffekt ausnutzen, um die Motivation der Lernenden zu steigern. Danach soll er sich engagieren, um einen mitreißenden zielbewussten Unterricht zu gestalten. Der internationale Charakter der Street-Art eröffnet auch Räume für interkulturelle Vergleiche und daraus folgende Überlegungen.

\section{Literatur}

Bachtsevanidis, Vasili (2012): Was liest du aus dem Bild? Transkulturelles Bilderlesen im Daf-Unterricht. In: Zeitschrift für interkulturellen Fremdsprachenunterricht 17(2), 113-128. Http://zif.spz.tu-darmstadt.de/jg-17-2/allgemein/beitra45. htm.

Badstübner-Kizik, Camilla (2002): Kunst im fremdsprachlichen Landeskundeunterricht zwischen Kunstwissenschaft und Kunstpädagogik. Beitrag zu einer Didaktik der Landekunde. In: Zeitschrift für interkulturellen Fremdsprachenunterricht 6(3), 1-32. Http:// zif.spz.tu-darmstadt.de/jg-06-3/beitra18.htm.

Banksy (2005): Wall and Piece. London: Random House.

Charpentier, Marc von; Cros, Rotraud; Dupont, Ute; Marcou, Carmen (1991): Deutsch mit Kunst. Bilder und Texte im Fremdsprachenunterricht auf neuen Wegen. In: Fremdsprache Deutsch 5, 48-54.

Charpentier, Marc von; Cros, Rotraud; Dupont, Ute; Marcou, Carmen (1997): Entdecken - Erzählen - Schreiben. Kunstbilder als Schreib- und Bildungsanlass im Unterricht. In: Fremdsprache Deutsch 17, 9-13.

Grätz, Ronald (1997): Kunst und Musik im Deutschunterricht. In: Fremdsprache Deutsch 17, 4-8.

Hallet, Wolfgang (2010): Viewing Cultures: Kulturelles Sehen und Bildverstehen im Fremdsprachenunterricht. In: Hecke, Carola; Surkamp Carola (Hrsg.): Bilder im Fremdsprachenunterricht. Neue Ansätze, Kompetenzen und Methoden. Tübingen: Gunter Narr Verlag, 26-54.

Macaire, Dominique; Hosch, Wolfram (1996): Bilder in der Landeskunde. Berlin u.a.: Langenscheidt.

Rosebrock, Cornelia; Zitzelsberger Olga (2002): Der Begriff Medienkompetenz als Zielperspektive im Diskurs der Pädagogik und Didaktik. In: Goeben, Norbert; Hurrelmann Bettina (Hrgs.), Medienkompetenz. Voraussetzungen, Dimensionen, Funktionen. Weinheim und München: Juventa Verlag, 148-159.

Schneider, Ingrid (2006): Graffiti im Kunstunterricht. Bremen: edition-liberty. 
Wacławek, Anna (2012): Graffiti und Street Art. Berlin u.a.: Deutscher Kunstverlag.

Wittig, Michael (2012), Zwischen Protest und Humor - Deutsche Streetart in Zeiten der Krise. In: ARTE Journal, 29.Oktober 2012. Http://www.arte.tv/ de/103288.html.

\section{Internetquellen}

www.blublu.org (2.6.2014)

www.elbocho.net (2.6.2014)

www.facebook.com/ALIAS (2.6.2014)

www.jr-art.net (2.6.2014)

www.youtube.com/watch?v=08q5L4iqSuc (2.6.2014) 


\title{
Der Einsatz von Printwerbung im DaF-Unterricht. Grenzen und Möglichkeiten von Bild-Text- Relationen im Sprach- und Landeskundeunterricht
}

\author{
Michael Reichelt
}

\section{Einleitung}

Werbung ist inzwischen zu einem festen Bestandteil unserer modernen Alltagskultur geworden und spiegelt gesellschaftliche Werte und Normen wie auch personale Wünsche und Sehnsüchte wider. Die sprachliche und auch graphisch-künstlerische Darstellung, insbesondere von Printwerbung, ist dabei zumeist von hoher Kreativität geprägt, kann aber auch verallgemeinernde Denkstereotype bedienen. Dies zeigt sich neben tradierten sprachlichen Formulierungen (der Verwendung von Sprichwörtern, feststehenden Redewendungen usw.) auch in den graphischen Darstellungen (bestimmte Nationalstereotype, Frauen- und Männerklischees, bestimmte Charaktere/Typen/Persönlichkeiten vermitteln typische - oftmals wiederum national geprägte - Eigenschaften/Images des zu bewerbenden Produkts etc.). Für den DaF-Unterricht lassen sich Bilder als Bestandteil von Printwerbung sowohl für die Sprachvermittlung als auch für den Landeskundeunterricht nutzen. Bilder können beim Erwerb interkultureller Kompetenzen helfen. Sie dienen dabei als Stimuli oder Motivation für den Unterrichtsbeginn oder zu einem thematischen Einstieg, eröffnen interkulturelle Diskurse, stellen persönliche Bezüge her oder helfen dabei, den Lernstoff tiefer im Gedächtnis zu verankern. Neben klassischen Bildformen können dabei auch Firmenlogos, Symbole, Farben oder Gesten unter interkulturellen Gesichtspunkten im DaF-Unterricht thematisiert werden. Der Aufsatz themati- 
siert, wie Text-Bild-Relationen den Sprachlernern helfen, verschiedene Konnotationen aus dem syntaktisch-textuellen sowie dem visuellen Kontext zu erarbeiten, sprachliche Metaphern durch Visualisierungen einsichtig und erfahrbar zu machen, aber auch inwieweit Wort- und Bildfelder miteinander verwoben sind. AnschlieBend sollen methodisch-didaktische Vorschläge Anregungen liefern, wie Bilder als Teil der Printwerbung sinnvoll im Unterricht eingesetzt werden können.

\section{Art und Einsatz von Texten und Bildern im DaF-Unterricht}

Printwerbung unterteilt man v.a. nach der Art der Werbeobjekte in politische Werbung (Propaganda), Wirtschaftswerbung (Reklame) und religiöse und kulturelle Werbung (vgl. Meyer 2010: 59) bzw. nach handlungstheoretischer Perspektive in Produktwerbung, Imagewerbung und taktische Aktionswerbung (vgl. Janich 1999: 74). Das Verhältnis von Bild- und Textinformation kann je nach Intention und Verwendung (Kommunikationsinhalt bzw. -zusammenhang) in den jeweils verschiedenen Unterrichtsphasen (s.u.) hierbei auch sehr unterschiedlich sein. Man differenziert zwischen 1. textdominanter Werbung, 2. einem annähernd ausgeglichenem Verhältnis in der Bild- und Textrelation und 3. eher bilddominanter Werbung (vgl. ebd: 184f.).

Bei der textdominanten Art von Printwerbung dienen die Bilder entweder gar keiner näheren Veranschaulichung (d.h. der Text ist auch genauso gut ohne den Einsatz der Bildelemente verständlich); der Ergänzung des Textes; oder es trifft der Fall zu, dass „das Bild keinen direkten Bezug zur Textinformation“ hat, „sondern [...] nur Stimmungselement" (Erlach; Schurf 2011: 32) ist. Trotzdem können natürlich auch solche Werbeanzeigen für den Unterricht nutzbar gemacht werden, wie Abb. 8 zeigt.

Ein annähernd gleiches Verhältnis von Text und Bild liegt dann vor, wenn beide Elemente weitgehend dasselbe ausdrücken - der Text aber aufgrund seiner höheren Informationsdichte im Vordergrund steht; der Text die bildzentrierte Werbebotschaft ergänzt oder näher erläutert; wenn die eigentliche Werbeaussage nur durch die Kombination von Bild und Text verständlich ist.

Bei der bilddominanten Werbung vermittelt das Bild als zentrales Element die Botschaft der Werbung; hierbei erscheint der Text nur in einem untergeordneten Abhängigkeits-verhältnis zum Bild, als Erwähnung des Produkt-, Marken- bzw. Firmennamens oder als Slogan. Bilder in Werbeanzeigen lassen sich für die formale Beschreibung auf vier Untersuchungspaare reduzieren: statisch/dynamisch, wirklich/fiktional, formreal/formabstrakt und bunt/schwarz-weiß (vgl. Janich 1999: 62). Es ist also in der Planungsphase der Unterrichtseinheit sehr entscheidend, welcher Art von Bildtyp sich die im Unterricht einzusetzende Werbung bedient. Darstellende Bilder wie Fotos, Zeichnungen/Gemälde, Karikaturen, Cartoons/Comics, Wimmelbilder, Collagen, Skizzen, Piktogramme, Symbole bieten ganz andere didaktische Möglichkeiten und Einsatzfelder als beispielsweise logische Bilder wie 
Schemata/Diagramme, Grafiken/Schaubilder, Tabellen. Allein der Einsatz einer Werbung mit Foto oder Zeichnung deutet das unterschiedliche didaktische Potential an. Während Fotos als „Miniaturen der Wirklichkeit“ sehr nah an der Realität stehen und oftmals wenig Interpretationsspielraum lassen, sind Zeichnungen didaktisch flexibler und durch ihre ikonische Reduktion für den Bildbetrachter zumeist leichter zugänglich. Andererseits können sich aus dieser „Unschärfe“ natürlich auch wieder Probleme der Eineindeutigkeit ergeben, die dann im Unterricht geklärt werden müssen und folglich zu einem erhöhten Zeiteinsatz führen. Schierl führt dazu aus:

Das Bild sagt alleine nichts aus. Es muss, um eine Botschaft übermitteln zu können, in einen Kommunikationszusammenhang gestellt werden. Die Aufgabe der Klärung des jeweilig benötigten, spezifischen Kommunikationszusammenhanges kann in einer werblichen Botschaft der Text übernehmen.

Das Bild als solches ist offen. (Schierl 2001: 239f.).

In diesem Zusammenhang können Darstellungen drei verschiedene Funktionen besetzen (vgl. Janich 1999: 62f.): als Key-visual (Produktabbildung als Schlüsselbild), Catch-visual (weiteres Bildelement Blickfänger) oder Focus-Visual (Hervorhebung bestimmter Produkteigenschaften im Bildfokus). Darüber hinaus finden Bilder als Bestandteile von Printwerbung im DaF-Unterricht natürlich auch losgelöst von ihrem werblichen Zusammenhang Verwendung. Hierzu muss die Lehrperson dann die entsprechenden unterrichtsrelevanten Aufgabenstellungen verfassen.

\section{Bild-Text-Relationen}

Obwohl die linguistische Forschung, z.T. bis heute das Bild in der Textanalyse häufig ignoriert, ist dessen Wert v.a. in der Didaktik inzwischen weitestgehend anerkannt. Die Bedeutungsrelationen zwischen verbalen (Text) und visuellen Bestandteilen (Bild) sind dabei sehr komplex. Der Text bzw. die Sprache kann das Bild hierbei in Beziehung setzen und kommentieren; den Fokus auf einen bestimmten Aspekt des Bildes lenken (selektieren) oder die Art der Rezeption strukturieren und steuern. Zu den Bestandteilen einer Werbeanzeige gehören neben Bildern auf der Textebene Headline, Fließtext, Slogan, Logo und Produktname. Zwischen Bild und Text ergeben sich für das Verhältnis in Werbeanzeigen dabei eine ganze Reihe semantischer Bedeutungsverknüpfungen (vgl. Janich 1999: 186f. und Schierl 2001: 248f.). ${ }^{1}$

\footnotetext{
1 Gert Egle (2012) hat die wichtigsten Bedeutungsrelationen mit Merkmalen und Beispielen in einer Übersicht zusammengefasst, die zusammen mit den beiden bezeichneten Quellen als Grundlage für die untenstehende Übersicht diente.

http://www.teachsam.de/pro/pro_werbung/werbesprache/anzeigenwerbung/pro_werbun g_spr_anz_3_3_2_3_4.htm (18.06.2013).
} 


\begin{tabular}{|c|c|}
\hline Relation & Merkmal \\
\hline $\begin{array}{l}\text { Ähnlichkeit } \\
\text { (= visuelle Analogie) }\end{array}$ & $\begin{array}{l}\text { - die verbale Aussage wird durch ein Zeichen } \\
\text { visualisiert } \\
\text { - gewisse inhaltliche oder äußerliche Analogie } \\
\text { zwischen Bild und Text }\end{array}$ \\
\hline Beleg/Beweis & $\begin{array}{l}\text { - } \text { die verbale Aussage wird mit einem Bild belegt } \\
\text { (Glaubwürdigkeit) } \\
\text { Möglichkeiten: einfacher Bildbeleg, ein An- } \\
\text { wendungs- oder Wirkungsbeispiel, eine Ge- } \\
\text { genüberstellung (Vorher-nachher-Bild) }\end{array}$ \\
\hline $\begin{array}{l}\text { Gedankenverknüpfung } \\
\text { (= visuelle Assoziation) }\end{array}$ & $\begin{array}{l}\text { - die verbale Aussage wird durch Zeichen ver- } \\
\text { deutlicht } \\
\text { - das Zeichen wird aufgrund eines Bedeutungs-, } \\
\text { Erfahrungs- oder Wissenszusammenhanges } \\
\text { mit dem Text assoziativ verknüpft }\end{array}$ \\
\hline $\begin{array}{l}\text { Pars pro toto (= visuelle } \\
\text { Synekdoche) }\end{array}$ & $\begin{array}{l}\text { - die verbale Aussage wird durch einen Bildaus- } \\
\text { schnitt in seiner inhaltlichen Gesamtheit vi- } \\
\text { sualisiert }\end{array}$ \\
\hline Beziehungsgeflecht & $\begin{array}{l}\text { - Bild und Text stehen in einer Grund-Folge- } \\
\text { oder Ursache-Wirkungs-Beziehung zueinander }\end{array}$ \\
\hline $\begin{array}{l}\text { Wiederholung } \\
\text { (= visuelle Repetition) }\end{array}$ & $\begin{array}{l}\text { - verbales und bildliches Zeichen stellen inhalt- } \\
\text { lich oder formal den selben Sachverhalt dar } \\
\text { oder überschneiden sich (Redundanz) }\end{array}$ \\
\hline $\begin{array}{l}\text { Steigerung } \\
\text { (= visuelle Gradation) }\end{array}$ & $\begin{array}{l}\text { - die verbale Aussage wird durch visuelle Zei- } \\
\text { chen hervorgehoben, verstärkt oder überstei- } \\
\text { gert }\end{array}$ \\
\hline $\begin{array}{l}\text { Zusammenfügung } \\
\text { (visuelle Addition) }\end{array}$ & $\begin{array}{l}\text { - der Gesamtsinn ergibt sich nur aus dem Mit- } \\
\text { einander von Text und Bild, bleibt sonst un- } \\
\text { verständlich }\end{array}$ \\
\hline $\begin{array}{l}\text { Bedeutungsbestimmung } \\
\text { (visuelle Determination) }\end{array}$ & $\begin{array}{l}\text { - eine mehrdeutige, verbale Aussage wird durch } \\
\text { ein Bild näher erläutert, konkretisiert oder ge- } \\
\text { nauer festgelegt (monosemiert) }\end{array}$ \\
\hline $\begin{array}{l}\text { Verkoppelung } \\
\text { (visuelle Konnexion) }\end{array}$ & $\begin{array}{l}\text { - das Bild soll die verbale Aussage gezielt mit } \\
\text { bestimmten visuellen Zeichen in Verbindung } \\
\text { bringen }\end{array}$ \\
\hline
\end{tabular}




\begin{tabular}{|l|ll|}
\hline $\begin{array}{l}\text { Verfremdung } \\
\text { (visuelle Norm- } \\
\text { abweichung) }\end{array}$ & $\begin{array}{l}\text { das Bild ist verändert und steht mit seiner } \\
\text { neuen semantischen Bedeutung in einer uner- } \\
\text { warteten Bedeutungsrelation zum Text }\end{array}$ \\
\hline $\begin{array}{l}\text { Symbolisierung } \\
\text { (visuelle Symbolisierung) }\end{array}$ & $\begin{array}{l}\text { die Textaussage wird durch ein Zeichen (Ikon, } \\
\text { Symbol) dargestellt }\end{array}$ \\
\hline
\end{tabular}

\section{Tab. 1: Semantische Bedeutungsverknüpfungen zwischen Bildern und Texten}

Beide Zeichensysteme (sprachliches und graphisches) besitzen eine spezifische Struktur mit eigenen Regeln und Normen. Während wir für den verbalen Text die Regeln unseres Schriftsystems sehr gut kennen, stellen Bilder ein nicht so klar in Einzelheiten strukturierbares System dar. Bilder sind folglich mehrdeutiger und benötigen eine höhere bzw. gänzlich andere Lese- und Interpretationsfähigkeit. Wie Bilder in diesem Zusammenhang von unserem Gehirn verarbeitet und im Gedächtnis gespeichert werden, ist in der wissenschaftlichen Forschung bis heute umstritten, wird jedoch zumeist mit dem Ansatz der dualen Kodierung (nach $\mathrm{Pa}$ ivio: 1971; 1977) erklärt. So glaubt man, ,dass der sprachliche Kode in einen bildlichen übersetzt werden kann und umgekehrt. Bilder werden diesem Ansatz nach besonders leicht doppelt kodiert und deshalb auch besonders leicht in das Gedächtnis übernommen." (Schierl 2001: 202).

Bilder leben von ihrer Mehrdeutigkeit und Offenheit. Diese Wirkungsweise betrifft z.B. den Raum und die Zeit (Situativität) der dargestellten Motive, die soziale Stellung abgebildeter Personen oder den kommunikativen oder interkulturellen Zusammenhang des Dargestellten (vgl. Doelker 2002: 32ff.). Bilder bilden dabei immer Relationen zu anderen, schon gespeicherten Bildern oder Erlebnissen aus und besitzen daher deutliche Vorteile gegenüber Texten (vgl. Schierl 2001: 230). Sie bleiben dabei umso länger im Gedächtnis, je lebendiger und assoziationsreicher sie sind (ebd.: 201), was sich z.B. auch am Wiedererkennungswert von Farben und Symbolen für Firmenlogos bzw. bestimmter Produkte ablesen lässt. Ein Beispiel hiefür bildet Ritter-Sport-Werbung von 2011 (vgl. Abb. 1) - die meisten Deutschen können den Farben der Schokoladentafeln tatsächlich den jeweils richtigen Geschmack zuordnen. ${ }^{2}$

Die Vorteile des Bildes innerhalb der Bild-Text-Relation und im Vergleich zum Wort kann man nach Doelker (2002: 52ff.) mit vier Eigenschaften beschreiben: Vieldeutigkeit, Konkretheit, Räumlichkeit und Unmittelbarkeit der emotionalen Wirkung. Die didaktischen Vorzüge, welche sich daraus ergeben, lassen sich wie folgt zusammenfassen (vgl. Schierl 2001: 228ff, 286f.):

\footnotetext{
2 Als Beleg hierfür dient eine Befragung von Marktcheck („MARKTCHECK checkt Ritter Sport“, SWR, 20.09.2012, 21 Uhr) - http://www.swr. de/marktcheck/gesundheit-ernaehrung/ritter-sportcheck $/$ - $/$ id=2248976 $/$ nid=2248976/did=10170 462/1bargae/index.html (03.05.2013).
} 


\begin{tabular}{|c|c|}
\hline Bildvorteile & Textvorteile \\
\hline 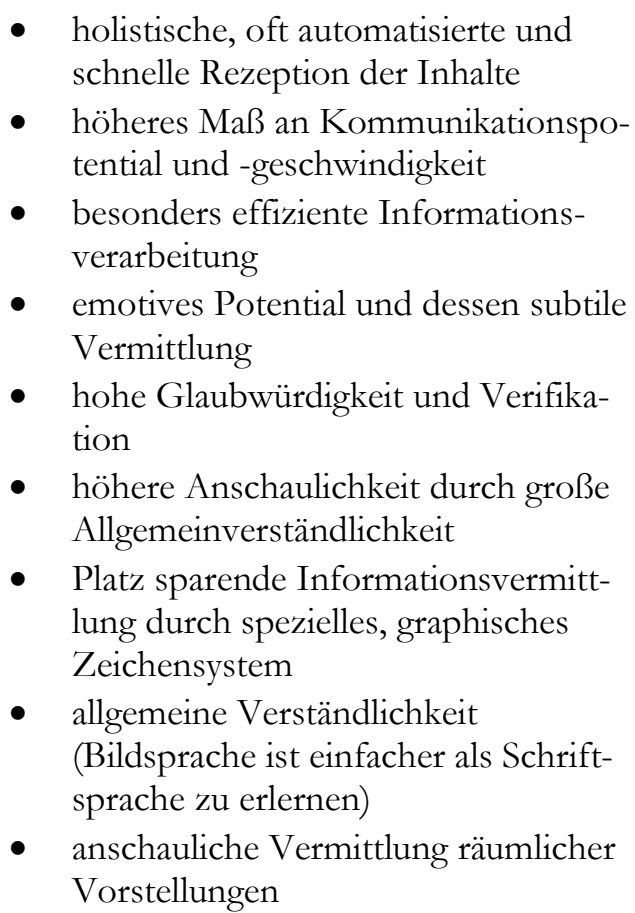 & $\begin{array}{l}\text { - } \text { größere Eindeutigkeit } \\
\text { Direktheit (z.B. durch } \\
\text { Leseransprache) } \\
\text { - } \text { kann argumentieren/ } \\
\text { - überzeugen/auffordern } \\
\text { kann Argumente wie- } \\
\text { derholen oder variieren } \\
\text { kann Schwerpunkte set- } \\
\text { zen sowie Einzelaspek- } \\
\text { te betonen und heraus- } \\
\text { stellen } \\
\text { zeitliche Vorstellungen } \\
\text { sind besser zu vermit- } \\
\text { teln }\end{array}$ \\
\hline
\end{tabular}

Tab. 2: Vorteile von Bildern und Texten innerhalb der Bild-Text-Relation

Aus den in Tabelle 2 angegebenen Vorteilen ergeben sich folglich unterschiedliche pädagogische, lernpsychologische, fremdsprachenspezifische und medientechnische Faktoren, welche für einen erhöhten Einsatz von (Werbe-)Bildern im Unterricht sprechen - und die im folgenden Kapitel thematisiert werden sollen.

\section{Didaktisches Potential - Grenzen/Möglichkeiten von Bildern im DaF-Unterricht}

Als Pestalozzi bemerkte, dass nur „ein Lernen mit Herz, Hand und Verstand“ ein nachhaltiges Lernen darstellen könne, blieben darin die „audiovisuelle Methode“ (vgl. Reinfried 2003) und weitere Bildungsreformvorhaben der frühen Siebziger Jahre, die ebenso das Bild als wesentlichen Gegenstand des Lernens postulierten, 
in diesem Leitsatz natürlich noch unberücksichtigt. ${ }^{3}$ Heutige Didaktiken verweisen darauf, dass nur ein Lernen mittels des Einsatzes aller Sinne (Handlungsorientierung, Ganzheitlichkeit, Lernorientierung) auch eine allumfassende Wissensvermittlung darstellen kann (vgl. Reichelt 2012). Schon das alte Sprichwort „Ein Bild sagt mehr als 1000 Worte" weist auf eine mögliche tiefere Verankerungsoption des Lernstoffes mittels Visualisierungen im Gedächtnis hin. Auch in der linguistischen Textanalyse hat man inzwischen weitgehend erkannt, dass für eine ganzheitliche Textbeschreibung hierfür ebenso das Verständnis der Bildinhalte benötigt wird. Die Beziehungen zwischen Bild und Text sind komplex und v.a. ästhetischer Natur. Text und Bild können dabei redundieren, sich ergänzen oder einander widersprechen.

Es geht im DaF-Unterricht natürlich darum, dass die Unterrichtsgegenstände nach didaktisch reflektierten Kriterien, z.B. dem Erwerb instrumenteller, sozialer oder kultureller Kompetenzen, ausgewählt werden müssen. Affektivität, Kognition und Handlungsorientierung/-strategien stellen dabei wesentliche Komponenten dieser Kompetenzen dar (vgl. Tenberg 1999: 65ff.). Konkretes Material in Form von Bildern als Repräsentation der außersprachlichen Umwelt können den Kompetenzzugewinn im Lernprozess steuern und erleichtern. Bilder als Elemente der Printwerbung dienen im Unterricht dabei oftmals als Stimuli zu themenbezogenen mündlichen oder schriftlichen Äußerungen eines bestimmten Themenbereichs. Sie stellen beim Bildbetrachter persönliche oder interkulturelle Bezüge her. So verweist Storch (2008: 280) darauf, dass ,interkulturell aufschlussreiche Bilder [...] direkt ein Interesse an der Lebensweise in einem fremden Land wecken und eine Auseinandersetzung mit bestimmten Aspekten der zielsprachlichen soziokulturellen Wirklichkeit anregen" können. Auch Janich meint:

Werbung ist inzwischen in unserer Gesellschaft ein Phänomen, das nicht nur als Kulisse [...] überall präsent ist und beim Medienkonsum zwangsläufig mitrezipiert wird [...] sondern auch immer mehr Kult- und Kunststatus erhält. [...] Werbung ist [...] ein Teil unserer Gesellschaft, unseres wirtschaftlichen Systems und unseres Alltags. Wer Werbung untersucht, kann viel über geltende Werte, Zeitströmungen und kulturelle Tendenzen erfahren. (Janich 1999: 7).

Printwerbung ist heute ein nicht mehr wegzudenkender Bestandteil der gedruckten Massenmedien. Sie stellt eine authentische Quelle dar und bietet dem Lehrenden wie auch den Lernenden ein unglaublich großes Repertoire an Bildmaterial an, das ihm zudem in Zeitungen und Zeitschriften, auf Postern oder auch im Internet sehr leicht zugänglich ist. Viele DaF-Lehrwerke verwenden leider nur sehr wenige au-

\footnotetext{
${ }^{3}$ Die Konzeption der „Ästhetischen Erziehung“ in den Siebziger Jahren unterschied zwischen zwei Teilzielen: „Erziehung zur Kunst“ und „Erziehung durch Kunst“. Letztere Forderung schloss die Entwicklung der Persönlichkeit des Lernenden mit Hilfe von Kunst ein, sollte Neugier, Aufgeschlossenheit, Toleranz, Empathie und Selbständigkeit üben, vgl. Badstübner-Kizik 2000: 124f.
} 
thentische Quellen, so dass sich Printwerbung als Ergänzung für den DaF-Unterricht sehr gut eignet. Da Werbung immer in einem spezifischen zeitlich-situativen, örtlichen und kulturspezifischen Kontext entsteht, kann der Fremdsprachenlerner an ihr Eigenheiten und Besonderheiten des jeweiligen Sprach- und Kulturraumes erkennen, verarbeiten und reflektieren. Werbebotschaften zielen dabei in erster Linie auf die Erzeugung von Aufmerksamkeit, das Wecken von Interessen bzw. Emotionen, den Wunsch bzw. die Aufforderung zum Kaufen des Produktes und schließlich seines Erwerbs ab, wie dies auch in den klassischen Stufen-Modellen „AIDA-Modell“, „S-R-Modell““ und „S-O-R-Modell“" (vgl. Bongard 2002: 8ff., 171ff. und Katz 2004: 8ff.) zum Ausdruck kommt. Neben der Erzeugung von Aufmerksamkeit sind die weiteren Hauptfunktionen von Bildern in der Printwerbung eine ästhetische und eine semantisch-pragmatische Funktion.

Ein weiteres Modell zur Wirksamkeit von Werbung wurde in den 1980ern mit dem Elaboration Likelihood Model (ELM) von Richard E. Petty und John T. Cacioppo entwickelt. Es untersucht die Einstellungsänderung unter sozialpsychologischen Gesichtpunkten. Das Modell schildert dabei die allgemeinen Einstellungsänderungen von Personen, die Werbung rezipieren, indem Erwartungen bzw. die Informationsverarbeitung mit zu erwartendem und bereits bestehendem themenspezifischen Wissen verknüpft wird. Trommsdorff (1993: 48) spricht in diesem Zusammenhang vom „Involvement“, der Art der Informationsaufnahme und -verarbeitung, die bewusst und zielgerichtet (also somit erwartbar) oder eher zufällig sein kann. Für den Unterricht lassen sich solche einzelnen Reaktionen relativ leicht auf ein Auffordern zum Sprechen über Werbe- bzw. Bildaussagen transformieren (vgl. Laveau; Nicolas; Sprenger 1988: 2). Dies kann dann in den verschiedenen Unterrichtsphasen unterschiedlich geschehen: 


\begin{tabular}{|c|c|}
\hline Unterrichtsphase & Anwendungsbereiche \\
\hline $\begin{array}{l}\text { Unterrichtseröffnung/ } \\
\text { Motivationsphase }\end{array}$ & - als Einstiegshilfe/„Steigbügel“ in ein Thema \\
\hline $\begin{array}{l}\text { Erarbeitungs- und } \\
\text { Übungsphase }\end{array}$ & $\begin{array}{l}\text { - als Objekt der vertieften Thematisierung und } \\
\text { Differentzierung eines Problems (z.B. zur Wort- } \\
\text { schatzerweiterung) } \\
\text { - als Beschreibungs- und Interpretationsobjekt (als } \\
\text { Realitätsersatz) } \\
\text { - als zeitgenössisches und authentisches Doku- } \\
\text { ment (Anschaulichkeit/Wissenstransfer) }\end{array}$ \\
\hline Übungsphase & $\begin{array}{l}\text { - als mnemotechnische Hilfe/Gedächtnisstütze } \\
\text { fördern sie das Erinnerungsvermögen an be- } \\
\text { stimmte Inhalte } \\
\text { - für den Wissenstransfer und die Anwendung des } \\
\text { Gelernten in einem neuen Kontext }\end{array}$ \\
\hline $\begin{array}{l}\text { Wissenssicherungs- } \\
\text { und Kontrollphase }\end{array}$ & $\begin{array}{l}\text { - als vom Lehrenden gelenkte Anwendung, z.B. } \\
\text { für grammatische Probleme }\end{array}$ \\
\hline
\end{tabular}

Tab. 3: Didaktisches Potential von Bildern - nach Unterrichtsphasen und Anwendungsbereichen

Huneke; Steinig (2000: 167) betonen dabei: „Die Entscheidung für ein Medium kann sich [...] bei geeigneter Aufgabenstellung auf die Gestaltung des ganzen Unterrichtsablaufes auswirken und die gemeinsame Arbeit weitertreiben." Dass Bilder dabei so schnell rezipiert werden, hat sich die Anzeigenwerbung durch ihren hohen Anteil an bildhaften Elementen zu eigen gemacht - dies kann aber natürlich genauso gut auch für den Unterricht genutzt werden. Behrens; Heinrich (1986: 85) verwiesen schon sehr früh darauf, dass es oft nur Sekundenbruchteile dauert, bis die wichtigsten Grundaussagen eines Bildes durch den Rezipienten erfasst werden. Die Verarbeitungsfähigkeit von Leseanteilen kann hierbei zweifelsohne nicht mithalten.

Darüber hinaus müssen bei den DaF-Lernern natürlich Vorkenntnisse im Bereich der „Visual Literacy“ (Pettersson 1994: 215), dem Verstehen der Bildbotschaft bzw. der Fähigkeit zur Interpretation von Bildern bestehen. Allgemein folgt die Bildarbeit im DaF-Unterricht dabei folgenden Grundschritten: 1. dem Betrachten des Bildes, 2. dem Aufstellen einer Hypothese, 3. der Beschreibung des Bildes und schließlich 4. seiner Interpretation.

Die sprachlich-inhaltliche Auseinandersetzung mit den Werbeanzeigen und deren ikonische Entkodierung (vgl. Biechele 2006: 33f.) kann hierbei bedeuten, sich 
beispielsweise mit Hilfe der Laswell-Formel über den bildhaften Teil der Anzeige selbst zu äußern:

\begin{tabular}{|c|c|}
\hline Fragen & Inhalte \\
\hline Wie... & $\begin{array}{l}\text {...ist die ästhetische Gestaltung der Anzeige? (ansprechend/interes- } \\
\text { sant, langweilig/ monoton usw.) }\end{array}$ \\
\hline Welche... & $\begin{array}{l}\text {...Reaktion ruft die Anzeige beim Betrachter hervor? (Trauer, Freu- } \\
\text { de, Mitleid, einen Aha-Effekt, Provokation, Zustimmung etc.) }\end{array}$ \\
\hline Welche... & $\begin{array}{l}\text {...graphischen und/oder sprachlichen Mittel, Bildarten, Kompositi- } \\
\text { onen/Anordnungen, Perspektiven, Größenverhältnisse, Farben/ } \\
\text { Schattierungen, Leserichtung werden verwendet? }\end{array}$ \\
\hline Welche... & ...Zielgruppe wird angesprochen? \\
\hline Welches... & ...Produktimage wird vermittelt? \\
\hline Wo... & $\begin{array}{l}\text {...spielt die Szene? (Gibt es historische Orte, Kulturdenkmäler } \\
\text { usw.?) }\end{array}$ \\
\hline Was... & $\begin{array}{l}\text {...wird in der Anzeige dargestellt? (Finden Personen des öffentli- } \\
\text { chen Lebens eine Verwendung? In welchem Verhältnis stehen Per- } \\
\text { sonen bzw. die dargestellten Objekte zueinander?) }\end{array}$ \\
\hline
\end{tabular}

Tab. 4: Fragen an die Bilduntersuchung, mithilfe der Laswell-Formel

Was die Printwerbung mit ihrem hohen Anteil an Bildelementen damit zu erreichen versucht, ist eine Erhöhung der Motivation bei den Lernenden, um ein Gegengewicht zu einer möglichen Überforderung beim Sprachlernen darzustellen und ausgleichend auf den Leistungsdruck der meisten Fremdsprachenlerner zu wirken. Der Einsatz von Printwerbung kann helfen, eine entspannte Lernatmosphäre zu erzeugen, denn „durch Bilder wird nicht nur der Intellekt, sondern auch die effektive Seite des Lernens angesprochen" (Scherling; Schuckall 1996: 10). Der Einsatz von Bildern aus Werbeanzeigen unterliegt dabei natürlich unterschiedlichen Kriterien, die beachtet werden müssen, um einen interessanten und qualitativ hochwertigen Unterricht zu gestalten. 


\begin{tabular}{|l|l|}
\hline \multicolumn{1}{|c|}{ Kriterium } & \multicolumn{1}{c|}{ Erklärungen } \\
\hline $\begin{array}{l}\text { Kriterium der } \\
\text { Angemessenheit }\end{array}$ & $\begin{array}{l}\text { Alter, Sozialisation, kulturelles Umfeld, } \\
\text { Sprachniveau etc. bedingen und beeinflussen } \\
\text { die Auswahl der Quellen }\end{array}$ \\
\hline Kriterium der Qualität & - $\begin{array}{l}\text { oft werden schlechte Kopien gereicht, deren } \\
\text { mangelnde Qualität auch das Lernvergnügen } \\
\text { deutlich schmälert }\end{array}$ \\
\hline Kriterium der & - $\begin{array}{l}\text { möglichst alle Teilnehmer der (zumeist inho- } \\
\text { mogenen) Lerngruppe sollen durch das aus- } \\
\text { gewählte Bild ästhetisch angesprochen und in- } \\
\text { teressiert werden; auch lustig-ironische oder } \\
\text { kritische Inhalte können vermittelt werden }\end{array}$ \\
\hline Kriterium des Inhalts & $\begin{array}{l}\text { altersgerechte Themen oder landeskundliche } \\
\text { Inhalte, die sich auch auf das eigene Land } \\
\text { transferieren lassen, wecken bei den Lernen- } \\
\text { den zumeist das größte Interesse }\end{array}$ \\
\hline Kriterium der Aktualität & $\begin{array}{l}\text { geht es um aktuelle Themen, sollte keine älte- } \\
\text { re Werbung verwendet werden - Schüler er- } \\
\text { kennen dies an Kleidung etc. sehr schnell } \\
\text { auf der anderen Seite kann ältere Werbung, } \\
\text { z.B. zur Veränderung der Frauenrolle in } \\
\text { Deutschland, als historische Quelle genutzt } \\
\text { werden }\end{array}$ \\
\hline Kriterium der & $\begin{array}{l}\text { Werbeanzeigen sind authentische Quellen, die } \\
\text { für den Unterricht nicht durch zwangsläufige } \\
\text { Veränderungen nutzbar gemacht werden sol- } \\
\text { len, sondern als originaler Unterrichtsgegen- } \\
\text { stand zu nutzen sind }\end{array}$ \\
\hline
\end{tabular}

\section{Tab. 5: Kriterien für den Bildeinsatz}

Auch für die Textelemente gibt es selbstverständlich Kriterien, wie z.B. sprachliche Angemessenheit bzw. Verständlichkeit (bestimmte Varietäten können für die DaFLerner zu unüberbrückbaren Hürden werden) oder die dem Wissensstand der Lernenden entsprechende Verwendung bekannter Lexik und grammatischer Strukturen.

In jedem Fall ist die Strukturierung der Unterrichtseinheit sowie der Lernziele unabdingbar. Der Lehrende muss sich sehr wohl darüber bewusst sein, in welcher Unterrichtsphase und mit welchem übergeordneten Lernziel er das Medium 
„Printwerbung“ im Unterricht wann, wo und wie zum Einsatz bringt. Die Anbindung einer entsprechenden Lernerfolgskontrolle ist dabei sicherlich nicht zwingend, aber sinnvoll.

\section{Beispiele für den Einsatz von Printwerbung im DaF- Unterricht}

Grundsätzlich hat jedes Unterrichtsobjekt in einem vom Lehrenden und den Lernenden bestimmten Unterrichtskontext seine Berechtigung. Genauso wie Werbung dabei nach den Wünschen der Auftraggeber bzw. durch die Werbeagenturen spezifisch gestaltet werden kann, um noch besser auf die Rezipienten bzw. Konsumenten einzuwirken, ist es natürlich im Umkehrschluss auch nur konsequent und sinnvoll, wenn für den Landeskundeunterricht gezielt nach Anzeigen mit Bildobjekten zu historischen Personen, Orten, Ereignissen, bestimmten Kulturspezifika oder Geschlechterrollen gesucht wird und diese dann im Unterricht entsprechend eingesetzt werden: „Die Auseinandersetzung mit Vorstellungen, Bildern und Stereotypen über das Zielsprachenland ist ein wichtiger Bestandteil eines interkulturell ausgerichteten Fremdsprachenunterrichts.“ (Patermann; Jürgens 2009: 73).

Bilder können dabei aus den beschriebenen unterschiedlichen Motiven für den $\mathrm{DaF}-$ Unterricht nutzbar gemacht werden. Sie besitzen in jedem Fall ein hohes Potential als Initial für unterschiedliche Sprech- und Schreibanlässe. Bei der Verwendung von Bildelementen, als Teil der Printwerbung, können verschiedenartige Arbeitstechniken eingesetzt werden:

\begin{tabular}{|l|l|}
\hline \multicolumn{1}{|c|}{ Bildtechnik } & \multicolumn{1}{|c|}{ Erklärung } \\
\hline Bildausschnitte & $\begin{array}{l}\text { sollen die Fantasie der Lerner anregen und Interesse bzw. } \\
\text { Neugier auf das wecken, was der Bildausschnitt vorenthält } \\
\text { (v.a. für die mündliche Kommunikation) }\end{array}$ \\
\hline $\begin{array}{l}\text { Arbeit mit voll- } \\
\text { ständigen Bil- } \\
\text { dern, ohne } \\
\text { Textelemente }\end{array}$ & $\begin{array}{l}\text { Lernende können Dialoge zwischen Figuren entwickeln (z.B. } \\
\text { Mittels eingezeichneter Sprechblasen), eine eigene Werbung } \\
\text { (mit Headline, Slogan usw.) kreieren }\end{array}$ \\
\hline $\begin{array}{l}\text { Arbeit mit voll- } \\
\text { ständigen Werbe- } \\
\text { anzeigen }\end{array}$ & $\begin{array}{l}\text { hierzu lassen sich am besten schriftliche Arbeiten anfertigen } \\
\text { (Kommentare, Stellungsnahmen, Kritiken usw.) }\end{array}$ \\
\hline
\end{tabular}

Tab. 6: Arbeitstechniken für den Bildeinsatz im DaF-Unterricht

Mittels farbig gestalteter Anzeigen, z.B. für die Ritter Sport-Produkte, können die deutschen Farbadjektive eingeübt werden (vgl. Hieronimus 2012: 231). Darüber 
hinaus kann man hierbei auch die Wirkung von Farben, eine lexikalische Übung zu Komposita und deren Semantik („Blauhemd“", „Grünschnabel“, „Rothaut“ etc.) oder Phraseologismen (,das Gelbe vom Ei“, „das schwarze Schaf der Familie

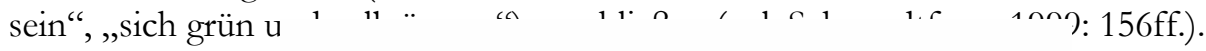

\section{Unser Beitrag gegen einseitige Ernährung.

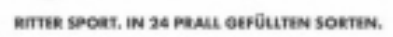

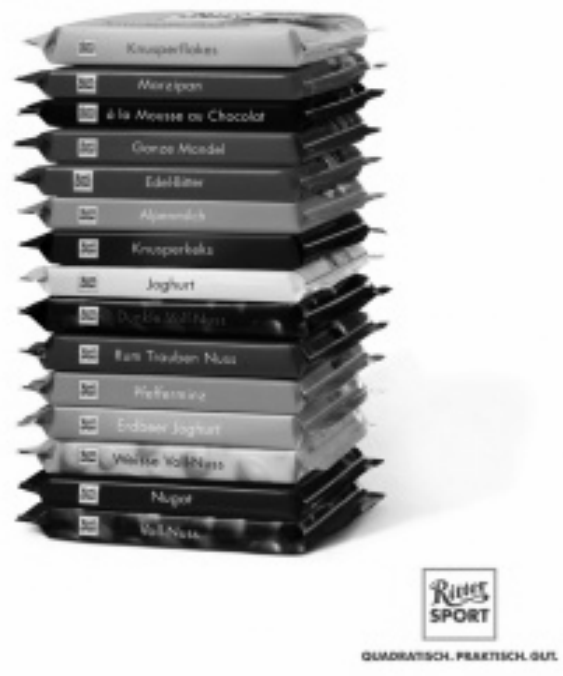

wwrevilsecyporde

\section{Abb. 1: Ritter Sport-Werbung (2011) ${ }^{4}$}

Eine weitere, schon benannte Möglichkeit, Printwerbung im Fremdsprachenunterricht einzusetzen, besteht darin, durch das Verändern oder Weglassen einzelner Bild- oder Textelemente eine inhaltliche Offenheit zu erzeugen, die bei den Lernenden Interesse wecken soll. Diese Neugierde sollte dann von den Lehrenden genutzt werden, die Studierenden zu sprachlichen Reaktionen anzuregen.

\footnotetext{
${ }^{4} \mathrm{Http} / /$ www.horizont.net/aktuell/agenturen/pages/protected/showfull.php?p=44379 (12.05.2013)
} 


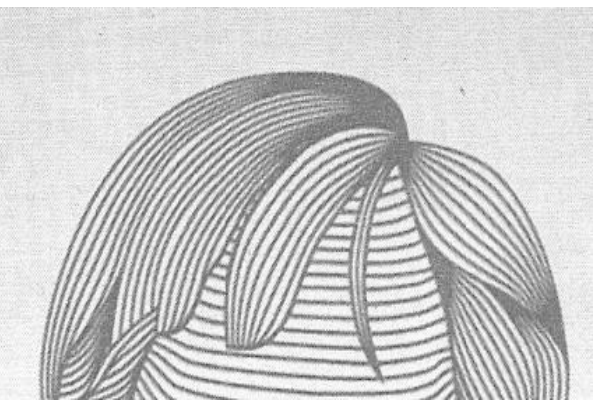

Abb. 2: Ausschnitt 1 - DigitalradioWerbung 5

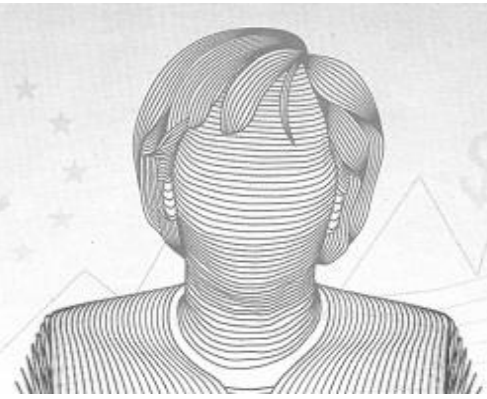

Abb. 3: Ausschnitt 2- DigitalradioWerbung

So kann z.B. als Stundeneinstieg für ein Thema „,berühmte/zeitgenössische Deutsche“ oder „Politik bzw. Bundestagswahlkampf“" ein Bildausschnitt aus der Digitalradio-Werbekampagne von 2012 (Abb. 2-4) verwendet werden. Zeigt man zunächst nur diesen sehr kleinen Ausschnitt (Abb. 2) des abstrahierten Porträts dieser computer-simulierten Zeichnung, so ist dieses Puzzleteil nur mit Mühe als Scheitel/Frisur einer Person zu erkennen. Auch in einem zweiten Schritt (Abb. 3), mit größerem Bildausschnitt, ist die Bundeskanzlerin, Angela Merkel, vermutlich noch nicht eindeutig zu identifizieren.

Nimmt man jedoch die Hände hinzu, so werden auch die meisten der Fremdsprachenlerner diese für Frau Merkel typische Geste (Abb. 4) wiedererkennen und auf sie schließen. Anhand dieses Stimulus lassen sich dann weitere Inhalte zu den jeweiligen Themen erarbeiten.

5 „Der Spiegel” 52/2012, 49. 

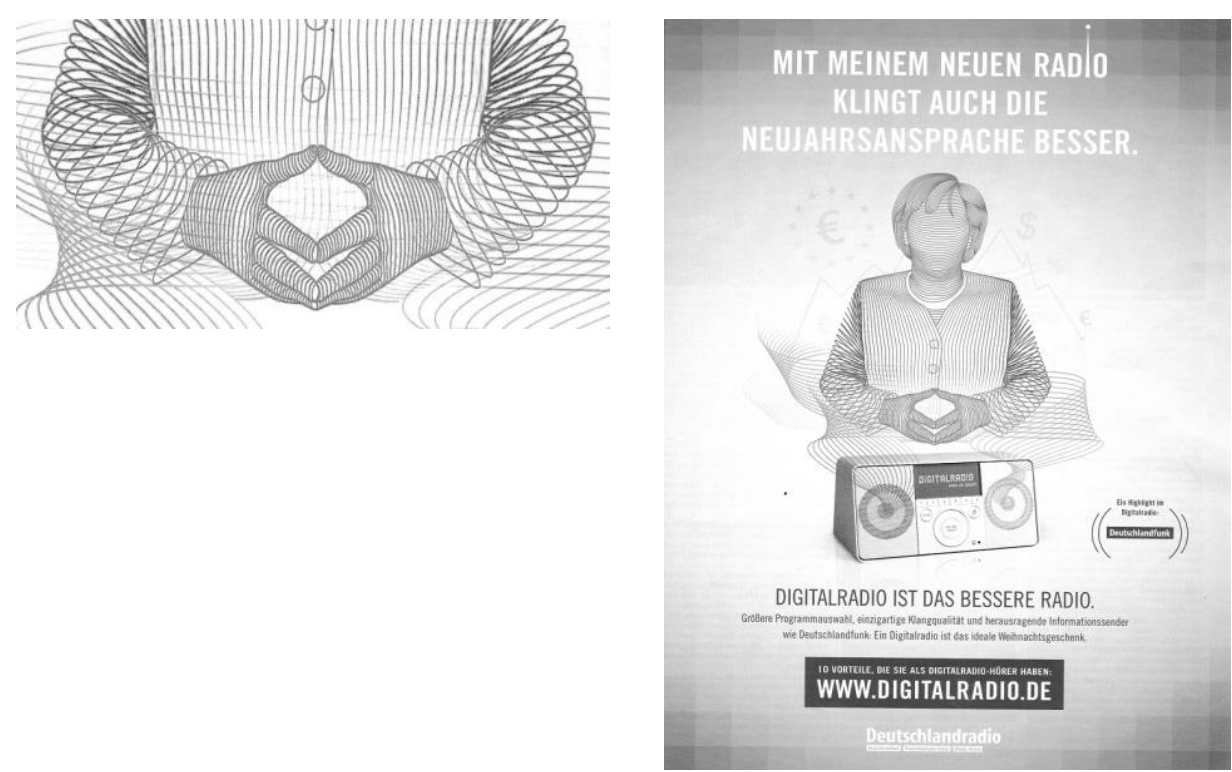

\title{
Abb. 4: Ausschnitt 3 - Digitalradio- Werbung
}

\begin{abstract}
Abb. 5: DigitalradioWerbung (2012)
\end{abstract}

Eine Verwendung der Textelemente der gesamten Werbeanzeige (Abb. 5) erscheint nur dann sinnvoll, wenn es um eine Thematisierung der Aufgaben der Kanzlerin („Neujahrsansprache“) geht oder sich eine Übung zu grammatischen Problemen (z.B. Komparation der Adjektive: „,besser/bessere“, „,einzigartig“, „herausragend“, „ideal“" und die Problematik der Steigerung von nicht steigerbaren Adjektiven/Absolutadjektiven) anschließen soll. Auch möglich ist die Verwendung der Handbewegung Angela Merkels für ein DaF-Thema „Mimik und Gestik“ bzw. „nonverbale Kommunikation“ in einer übergeordneten Stoffeinheit zu landestypischen Sitten und Bräuchen. ${ }^{6}$ Hierzu ließen sich auch weitere Werbeanzeigen finden, deren Bildelemente bestimmte Gesten darstellen.

\footnotetext{
${ }^{6}$ Ein tolles themenbezogenes und unterrichtserprobtes Unterrichtsmaterial gibt es hierzu von Eva Pfeiffer unter dem Titel „Was Hände sagen“ (Pfeiffer 2012).
} 


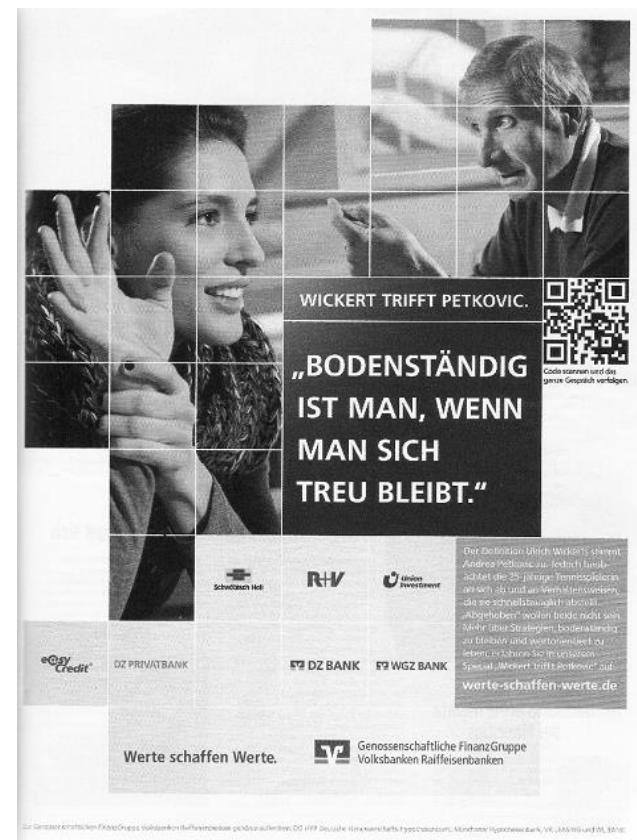

Abb. 6: Werbung der VR-Finanzgruppe (2012) ${ }^{7}$

Auch in der Werbung der Volksbanken Raiffeisenbanken Finanzgruppe (2012) kann man das Bildelement zunächst ohne eine weitere Thematisierung des Textes verwenden. Die Fotos von Ulrich Wickert und Andrea Petkovic kann man hierbei als Puzzle verwenden (was sich durch die Gitternetzlinien anbietet) - und anschließend im Unterricht über die beiden Handbewegungen, die Bedeutung und das „Verhältnis“ der beiden Personen zueinander sprechen. Schließlich kann man noch die Headline „Bodenständig ist man, wenn man sich treu bleibt.“ thematisieren, um deren Bedeutung - nun auch im Verhältnis zu den Bildern - zu erschlieBen. Als grammatisches Phänomen könnte das Indefinitpronomen „man“ problematisiert werden. Die Verfremdung der Werbeanzeigen, wie in den Beispielen Abb. 2-6, dient dabei der Erzeugung eines Spannungsbogens, der z.B. auch bewusst für die Auseinandersetzung und Thematisierung von bestimmten Denkstereotypen genutzt werden könnte. Manchmal dient diese Art des Bildeinsatzes auch nur der Verstärkung von Erwartungsbildern, denn die Werbemacher bedienen sich natürlich auch ganz bewusst der zu erwartenden Vorstellungen und Einstellungen ihres potentiellen Publikums.

So wird z.B. der in der Löwenbräu-Werbung (2009) bewusst mit bayerischen Stereotypen gearbeitet. Die Werbung lässt sich gut für einen Stundeneinstieg ver-

\footnotetext{
${ }^{7}$ „Der Spiegel” 52/2012, 67.
} 
wenden - z.B. für eine Einführungsstunde, wenn es um das Bild der Deutschen geht.

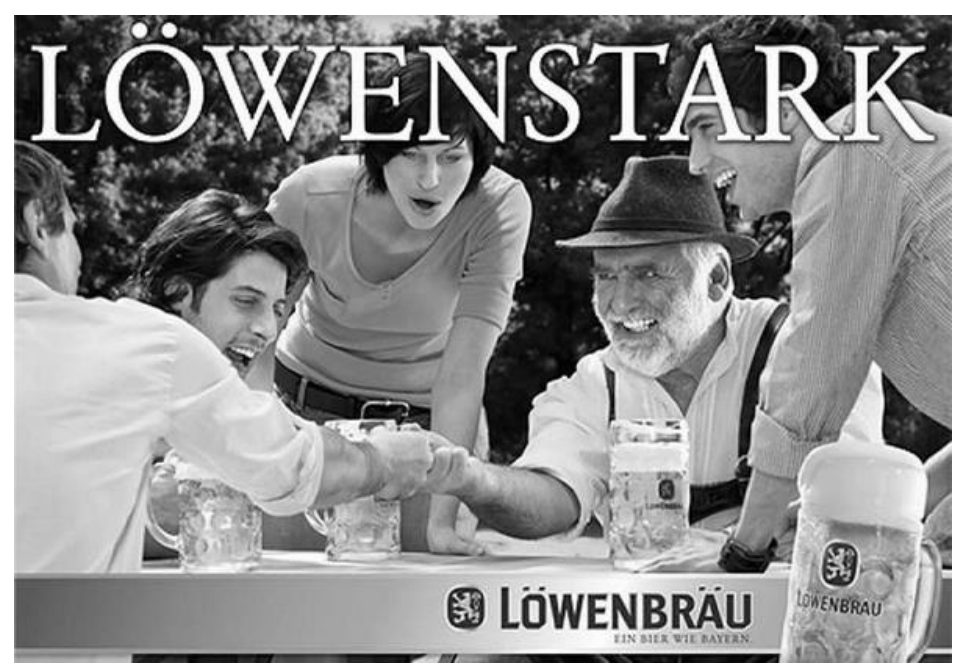

\section{Abb. 7: Löwenbräu-Werbung (2009) ${ }^{8}$}

Das Stereotyp des lederhose- und barttragenden Urbayern (= Deutschen) dient dabei dem Versuch, mittels typischen Merkmalsbündeln eine Person einer bestimmten Kategorie/ Gruppe zuzuordnen. Diese Form der ikonischen Kodierung bzw. Entkodierung hilft uns, unsere Umwelt zu clustern und damit für uns verständlicher zu machen. Die Stereotypenbildung dient folglich als eine Form der Wahrnehmungsvereinfachung (vgl. Losche 2003: 69). Anschließend an diese Überlegungen könnte eine den Text (d.h. Slogan) thematisierende Aufgabenstellung wie folgt lauten: „Finde weitere Attribute bzw. weitere zusammengesetzte Adjektive ( dies dient dann gleichzeitig als Wortschatzübung), welche deiner Meinung nach die Deutschen charakterisieren. Auch eine Diskussion über die Angemessenheit des Attributes „löwenstark“ für Deutsche ließe sich hieran anschließen bzw. über das Finden weiterer tierischer Attribute, Vergleiche, Tiermetaphern („,mucksmäuschenstill“", „Löwenmähne“) und Phraseologismen („stark wie ein Bär sein“, „wie ein Löwe brüllen") erweitern. Stellt man dagegen stärker das Bild in den eigentlichen Fokus der Betrachtung, ließe sich über eine Bildanalyse auf Traditionen in Bayern schließen (Fingerhackeln, Lederhosen und Hut als Tracht, Biertrinken), aber auch langläufig verbreitete Stereotype relativieren (es gibt durchaus fröhliche Deutsche;

\footnotetext{
8 Http://static2.kleinezeitung.at/system/galleries_520x335/upload/7/2/5/2186197/ok_ausland _726_ausdruck_311.jpg (12.05.2013).
} 
nicht alle Deutschen sind blond) oder die gleichberechtigte Rolle von Frauen und Männern in der deutschen Gesellschaft thematisieren.

Man kann jedoch auch Bilder mit ähnlichen Inhalten gegenüberstellen - z.B was die Rolle von Männern bzw. Vätern in der Gesellschaft betrifft. Während die Ing-DiBa-Werbung (2012) scheinbar die moderne Rolle des fürsorglichen Vaters betont, wird in der Astra-Werbung (2009) mittels der Headline „Alleinziehender Vater“ bewusst mit dem Klischee des „alleinerziehenden Vaters“ gespielt. Der Zusammenhang, d.h. die Redundanz, ergibt sich hier erst aus dem Zusammenspiel von Bild und Text. Dem muttersprachlichen Betrachter wird zuerst die Headline ins Auge springen, und er wird vermutlich in korrigierender Weise ,alleinerziehend" lesen. ${ }^{9}$ Dem Fremdsprachenlerner wird dieses Sprachspiel und die Ironie dahinter vermutlich nicht sofort auffallen, da er wahrscheinlich zuerst das Bild betrachtet und erst anschließend die Headline liest - und den einzelnen Mann mit Bollerwagen, der mit etwas Abstand der biertrinkenden Männergruppe folgt, auch als den Wagen ,alleinziehenden“ Mann erkennt. Hierin zeigt sich auch wieder das Problem, dass deutsche Werbeanzeigen - im übrigen genauso wie Bilder in deutschen DaF-Lehrwerken - zu verstehen und zu interpretieren häufig erst durch die Ausbildung einer eigenen „Visual Literacy“ erlernt werden müssen.

Biechele (2001: 17) betont: „Das gelingt zu häufig nicht, da Bilder verstehen können sowie Bilder als Lernmedien effektiv nutzen können als Lernleistung noch immer unterschätzt werden“. Und es ist nun einmal, wie Macaire und Hosch (1996: 19) es beschreiben: „Ein Bild spiegelt eine Welt, eine Kultur wider, und zwar des Landes, in dem das Bild entstanden ist." Bilder sind also in der interkulturellen Kommunikation, unabhängig von Muttersprache und Kultur, nur dann verständlich, wenn der Bildzusammenhang verständlich ist, wenn der Zusammenhang, in dem die Abbildung steht, klar ist. Für den DaF-Unterricht ließe sich dennoch thematisieren, zu welchem Anlass die Männer (Herrentag/Vatertag - auch als Anbindung für das Thema Feste/Sitten/Bräuche im Landeskunde-Unterricht) unterwegs sind bzw. warum ein Muttersprachler ,alleinerziehend“ lesen wird und worin, z.B. auch im Vergleich zur Ing DiBa-Werbung, die feine Ironie dieser Anzeige besteht.

Weitere Ansätze für den Unterricht wären die Thematisierung von Persönlichkeiten (Dirk Nowitzki) und ihrer Namen (,-ski“ als typische Wortbildung polnischer Familiennamen), die wortbildungstechnische Untersuchung von Firmennamen (ING DiBa = Internationale Nederlanden Groep DirektBank, als typisches Initialkurzwort; Ritter Sport $=$ Ritter als Berufsname), ${ }^{10}$ die Thematisierung von

\footnotetext{
${ }^{9}$ Hierbei handelt es sich um das Phänomen der Pareidolie bzw. Apophänie, d.h. die Tendenz des menschlichen Gehirns, vertraute Dinge (hier: bekannte Wörter in einer Zeichenkette) zu erkennen, obwohl sie in Wirklichkeit gar nicht vorhanden sind. Dadurch, dass man ein bekanntes Wort erwartet, erkennt es man es auch in einer ähnlichen Anordnung.

10 Weitere Firmennamen, die entweder sofort als Familiennamen (Müller-Drogeriekette, ReicheltSupermarktkette etc.) zu erkennen sind oder sich nach Entschlüsselung der Wortbildungsstruktur auf einen solchen Namen zurückführen lassen (Haribo, Aldi), könnten an dieser Stelle thematisiert und für eine Darstellung zu Anthroponymen in Deutschland herangezogen werden. Die Häufigkeit der
} 
Slogans (die Klimax „Quadratisch. Praktisch. Gut“ - für Ritter Sport) oder Symbolen (der „bayrische Löwe“ als Symbol für Löwenbräu; das Astra-Symbol „Herz mit Anker" als typisch stereotypes Motiv für Tätowierungen von Seemännern hier mit der Bedeutung, dass man mit Herz und Seele in St. Pauli, wo das Bier ursprünglich herstammt, verankert ist).

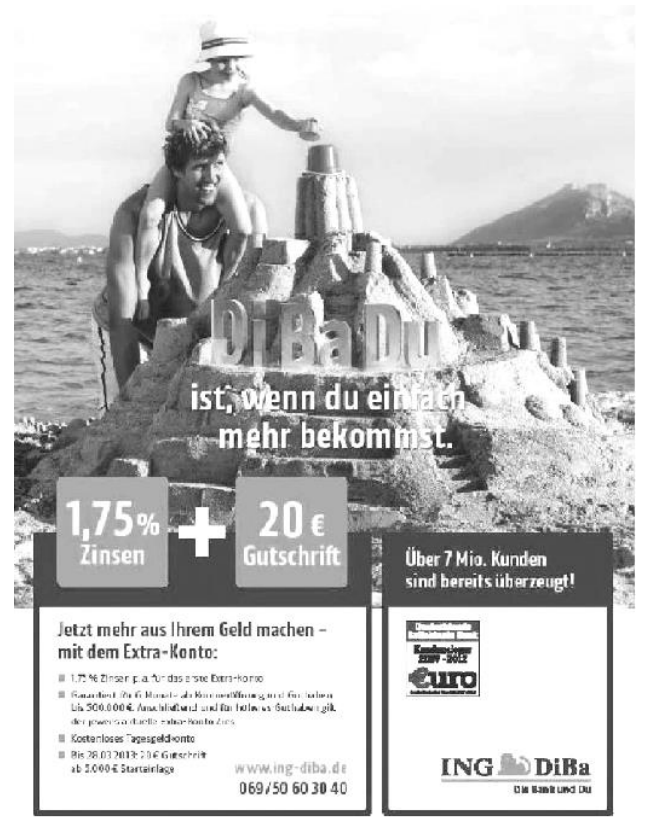

Abb. 8: Ing DiBa-Werbung (2012) ${ }^{11}$

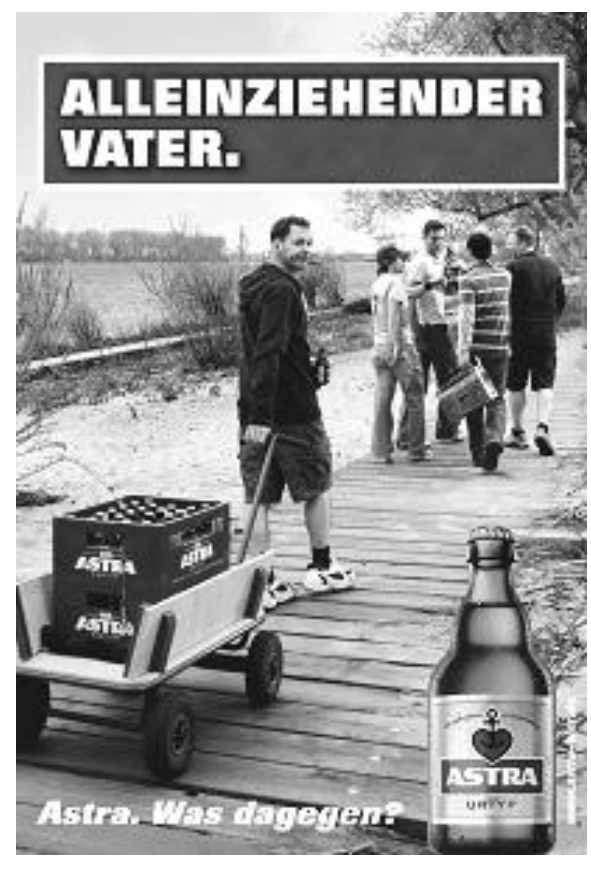

Abb. 9: Astra-Werbung (2007) ${ }^{12}$

Für die sprachliche Gestaltung der Slogans lassen sich Bereiche wie Metaphorisierungen (der Imperativ „Wecke den Tiger in dir" - Kelloggs Frosties), Personifikationen („Actimell activiert Abwehrkräfte“ - Danone, zugleich eine Alliteration), die Verwendung von Phraseologismen (Dr. Best: „Die klügere Zahnbürste gibt nach“ $=$ „Der Klügere gibt nach“) oder die Übernahme von Slogans als ,geflügelte Worte" in der Alltagssprache („Nicht immer, aber immer öfter" -Clausthaler alkoholfrei) untersuchen.

Verteilung solcher Familiennamen lässt sich dann beispielweise von den DaF-Lernenden als Gruppenarbeit mit dem Internet (z.B. mit http:// nachname.gofeminin.de) untersuchen.

11 „Der Spiegel” 52/2012, 37.

12 Http://textundblog.de/?p=1600 (15.05.2013). 
Weitere kreative Beispiele für die Arbeit mit werblichen Bildern finden sich z.B. in „Deutsch perfekt“ (04/2008: 43), bei Hieronimus (2012: 231) oder in „Schritte 6 international“" (2013: 34). Es zeigt sich also, dass im DaF-Unterricht sehr wohl ein vermehrter Gebrauch des Bildeinsatzes festzustellen ist - was zu bemängeln bleibt, ist die oftmals zu wenig an den Interessen der Lernenden bzw. der thematischen Verknüpfung orientierten Verwendung eines solchen Bildeinsatzes. Wenn der Bildeinsatz nicht nur des Einsatzes wegen seine Entsprechung im DaF-Unterricht findet, gehören Sätze wie die von Sturm (1991: 7): „Interkulturelles Bildverstehen: einer der großen ,weißen Flecken' in der Bildforschung“, sicherlich bald endgültig der Vergangenheit an.

\section{Literatur}

Badstübner-Kizik, Camilla (2001): Zu einigen Aspekten der interkulturellen Kompetenz potentieller polnischer DeutschlehrerInnen. In: Studia Germanica Gedanensia 9, 145-174.

Behrens, Gerold; Hinrichs, Alfred (1986): Werben mit Bildern. Zum Stand der Bildwahrnehmungsforschung. In: Werbeforschung \& Praxis 3, 85-88.

Biechele, Barbara (2006): Anmerkungen zum interkulturellen Bildverstehen. In: interculture journal for intercultural business 1, 17-50.

Bongard, Joachim (2002): Werbewirkungsforschung. Grundlagen - Probleme - Ansätze. Münster u.a.: Lit-Verlag.

Doelker, Christian (2002): Ein Bild ist mehr als ein Bild. Visuelle Kompetenz in der Multimedia-Gesellschaft. Stuttgart: Klett-Cotta.

Erlach, Dietrich; Schurf, Bernd et al. (Hrsg.) (2011): Kursthemen Deutsch. Sprachwandel und Sprachvarietäten: Tendenzen der deutschen Gegenwartssprache. Berlin: Cornelsen.

Hieronimus, Marc (2012): Plakate im DaF-Unterricht. In: Ders. (Hrsg.): Historische Quellen im DaF-Unterricht. Göttingen: Universitätsverlag Göttingen, 209-235.

Hilpert, Silke et al. (Hrsg.) (2013): Schritte international. Deutsch als Fremdsprache, Niveau B1/2. Band 6, Kursbuch + Arbeitsbuch. Ismaning: Hueber Verlag.

Huneke, Hans-Werner; Steinig, Wolfgang (2000): Deutsch als Fremdsprache. Eine Einfübrung. Berlin: Erich Schmidt-Verlag.

Janich, Nina (1999): Werbesprache. Ein Arbeitsbuch. Tübingen: Narr-Verlag.

Katz, Gitte (2004): Fernsehen wirkt besser: richtungsweisende Argumente für erfolgreiche Media-Strategien. Köln: IP Deutschland.

Laveau, Inge; Nicolas, Gerd; Sprenger, Margret (1988): Bild als Sprechanlaß. Werbeanzeigen. Paris/München: Goethe Institut. 
Macaire, Dominique; Hosch, Wolfgang. (1996): Bilder in der Landeskunde. Berlin/ München: Langenscheidt-Verlag.

Meyer, Urs (2010): Poetik der Werbung. Berlin: Erich Schmidt Verlag.

Patermann, Gabriele; Jürgens, Matthias (2009): Sprachliche, interkulturelle und didaktische Aspekte beim Einsatz von Werbung im DaF-Unterricht. In: Reeg, Ulrike; Ehrhardt, Claus; Kaunzner, Ulrike A. (Hrsg.): Schnittstelle Interkulturalität. Beiträge zur Didaktik Deutsch als Fremdsprache. Münster: Waxmann-Verlag, 65-91.

Pfeiffer, Eva (2012): Was Hände sagen. In: Deutsch perfek.t 5/12, 28-32.

Reichelt, Michael (2012): Ganzheitlichkeit und Handlungsorientierung als Leitprämissen im DaF-Unterricht - mit einem unterrichtspraktischen Beispiel. In: Schulgan, Elena u.a. (Hrsg.): Materialien der III. Internationalen wissenschaftsmethodischen Konferenz zur linguistischen Vorbereitung der Studenten von nichtphilologischen Universitäten. Odessa: BMB-Verlag Odessa, 124-129.

Reinfried, Marcus (2007): Visuelle Medien. In: Bausch, Karl-Richard; Christ, Herbert; Krumm, Hans-Jürgen (Hrsg.): Handbuch Fremdsprachenunterricht. Tübingen: A. Francke Verlag, 416-420.

Scherling, Theo; Schukall, Hans-Friedrich (1996): Mit Bildern lernen. Handbuch für den Fremdsprachenunterricht. Berlin/München: Langenscheidt-Verlag.

Schierl, Thomas (2001): Text und Bild in der Werbung. Bedingungen, Wirkungen und Anwendungen bei Anzeigen und Plakaten. Köln: Herbert von Halem-Verlag.

Schwerdtfeger, Inge C. (1999): Sehen und Verstehen. Arbeit mit Filmen im Unterricht Deutsch als Fremdsprache. Berlin/München: Langenscheidt-Verlag.

Storch, Günther (2001): Deutsch als Fremdsprache. Eine Didaktik. Theoretische Grundlagen und praktische Unterrichtsgestaltung. München: Fink-Verlag.

Sturm, Dietrich (1991): Das Bild im Deutschunterricht. In: Fremdsprache DeutschDas Bild im Unterricht 5, 4-11.

Tenberg, Reinhard (1999): Theorie und Praxis bei der Vermittlung ,interkultureller Kompetenzen“. In: Bredella, Lothar; Delanoy, Werner (Hrsg.): Interkultureller Fremdsprachenunterricht. Tübingen: Narr-Verlag, 65-84.

Trommsdorff, Volker (1998): Konsumentenverhalten. Stuttgart: Kohlhammer. 



\title{
Kunst und Kunstgeschichte im Deutschunterricht. Ein Unterrichtsbeispiel zu Porträts der Renaissance-Zeit
}

\author{
Dorit Kluge
}

\section{Einführung}

Ein Zusammenspiel von Kunst bzw. Kunstgeschichte und Sprachunterricht stellt heutzutage glücklicherweise keine Seltenheit mehr dar, sondern hat auf vielfältige Art und Weise Einzug in den Alltag von Kunst- und Sprachlehrern gezogen. Im Laufe meiner Unterrichtstätigkeit an der Université Blaise Pascal Clermont-Ferrand II begegneten mir die beiden Fachgebiete in unterschiedlichsten Zusammenhängen: Kunstwerke boten Anlass zu sprachlichen Äußerungen in DaF-Kursen; Kunstbilder wurden als Träger von Informationen und Ausdruck kultureller Besonderheiten im Literatur- und Landeskundeunterricht eingesetzt; einzelne Studiengänge wie der für Fremdenführer beinhalteten Fachsprachenkurse zur Kunstgeschichte, und selbst Studierende von Wirtschaftsstudiengängen forderten Themen wie Kunst- und Kulturwirtschaft im Rahmen von Deutschkursen ein. Diese Vielfalt an Kontaktmöglichkeiten der beiden Fachgebiete verdeutlicht, dass die Funktionen von Kunst und damit Bildern in Verbindung mit Sprachunterricht weit über Sprech- und Schreibanlässe und die Verdeutlichung von im Unterricht behandelten Inhalten hinausreichen. Es geht zunehmend um die Kunstwerke selbst und ihren Kontext. In dem Augenblick, wo nunmehr über das einzelne Bild hinaus Kunst, Kunstgeschichte und der Kunstbetrieb in den Fokus rücken, fühlen sich Sprachlehrer oft an die Grenzen ihrer Kompetenz gebracht (Bering et al. 2006: 56) 
und verbannen diese Themen entweder von vornherein aus dem Unterricht oder reichen sie bestenfalls an entsprechende Fachlehrer weiter.

Im Folgenden soll zunächst anhand einiger allgemeiner Betrachtungen und dann an einem konkreten Beispiel für eine Unterrichtseinheit gezeigt werden, wie eine Vernetzung von Kunstbetrachtung mit den einzelnen Komponenten des Deutschunterrichts für Germanistikstudierende im Ausland erfolgen kann, ohne dass die Lehrkraft eine umfassende Fachkompetenz in Kunstgeschichte haben muss. Klassischerweise wird der Deutschunterricht in der Auslandsgermanistik in die Teilgebiete Sprachpraxis, Linguistik, Literatur und Geschichte/Landeskunde untergliedert und umfasst damit mehr Komponenten als ein reiner DaF-Unterricht. Die Lehrkraft muss demnach eine erste Entscheidung treffen, in welchen dieser Fächer sie mit Kunst arbeiten möchte. Auf der anderen Seite muss ebenso in Bezug auf die Kunstgeschichte eine Auswahl getroffen werden. Denkbar wären einzelne Kunstgattungen (Malerei, Grafik, Fotografie, Skulptur/Plastik, Architektur, Design etc.), Genres (z.B. Historienbilder oder Stillleben innerhalb der Malerei), Epochen und Künstler. Im Normalfall würde eine Sprachlehrkraft zuerst überlegen, welches sprachliche Thema sie bearbeiten möchte, bevor sie im Anschluss daran nach einer geeigneten Umsetzung unter Einbezug der Kunstgeschichte sucht. In dem nachfolgend vorgestellten Unterrichtsbeispiel soll jedoch umgekehrt vorgegangen werden, um die vielfältigen Anwendungsmöglichkeiten eines kunsthistorischen Themas für den Deutschunterricht aufzuzeigen.

In dem Augenblick, wo man nicht die Gelegenheit hat, dreidimensionale Körper der Skulptur/Plastik, der Architektur und des Designs zusammen mit den Studierenden auf Exkursionen oder Museumsbesuchen zu erkunden, ist man gezwungen, die Vermittlung dieser Kunstgattungen mittels Bilder vorzunehmen. Künstlerische Techniken, die von vornherein zweidimensional arbeiten, d.h. Malerei, Grafik und Fotografie, sind somit etwas leichter im Unterricht einsetzbar. Obwohl die im Unterricht benutzten Abbildungen natürlich kein Original ersetzen können, muss der Betrachter in diesem Fall keine visuelle (Rück)-Übersetzungsleistung von einem zweidimensionalen Objekt hin zu einem dreidimensionalen leisten. Dies war auch einer der Gründe, die im anschließend präsentierten Unterrichtsbeispiel zur Entscheidung für die Gattung Malerei führten.

Hinsichtlich der Genres bestehen in der Malerei, insbesondere mit der Historienmalerei, den Porträts, der Genremalerei, der Landschaftsmalerei und den Stillleben zahlreiche Optionen. Jedes dieser Genres durchlief eine spezielle historische Entwicklung; Kunstepochen haben Präferenzen für einzelne Genres; und jedes Genre arbeitet mit speziellen künstlerischen Mitteln und Inhalten. Selbstverständlich gibt es auch Kunstwerke, die sich gar nicht in dieses „Schubladensystem“ einpassen lassen. Im nachfolgenden Stundenentwurf fiel die Wahl auf Porträts. Im Vergleich zu den anderen Genres sind Porträts in der Regel weniger komplex aufgebaut und ermöglichen dem Betrachter formal und inhaltlich einen leichteren Zugang. Während beispielsweise für die Betrachtung eines Historienbildes mehr kunsthistorische Vorkenntnisse und eine längere sprachliche Bildbeschreibung nö- 
tig sind, kann der Zugang zum Porträt auf kürzerem Wege eröffnet werden. Insofern eignen sich Porträts durchaus auch für kunsthistorische Laien und bringen zudem Vorteile für das Zeitmanagement im Unterricht.

Nimmt man aktuelle Lehrwerke für den DaF-Unterricht in den Blick, so fällt auf, dass es bei der Arbeit mit Kunstbildern eine ausgeprägte Präferenz für die moderne und zeitgenössische Kunst gibt. Bilder der mittelalterlichen Kunst, der Renaissance oder nachfolgender Epochen finden wesentlich seltener Eingang in Sprachlehrwerke. Am ehesten sind sie noch zum Zwecke der Illustration in landeskundlichen Lehrbüchern zu finden. Dass Kunstwerke früherer Epochen aber durchaus vielfältigere Möglichkeiten für den Deutschunterricht bieten und dass eine Sprachlehrkraft dies auch ohne zu großen Vorbereitungsaufwand bewältigen kann, soll der nachfolgende Unterrichtsentwurf zeigen, in dem die Renaissance als Epoche gewählt wurde. Der kulturelle Abstand der Studierenden zu einer weiter zurückliegenden Zeit birgt zudem den Vorteil, dass sie aufgrund des meist fehlenden Vorwissens intuitiv einen kreativen Weg zur Erschließung der Kunstwerke einschlagen.

Für die Auswahl der Künstler fiel mit Albrecht Dürer, Hans Holbein d.J. und Lucas Cranach d.Ä. die Entscheidung auf Maler aus dem deutschsprachigen Raum, wodurch ein weiterer landeskundlicher Aspekt in die Arbeit einfließen konnte. Im Fokus sollten Kunstwerke stehen, die von einheimischen Künstlern geschaffen wurden und dann ihren Weg in die Welt antraten. Neben einer solchen Innenperspektive kann natürlich auch eine Außenperspektive gewählt werden, z.B. mit Werken der italienischen Renaissance, die sich aber mit Themen des Nordens auseinandersetzen, oder auch ein komparativer Ansatz, indem beispielsweise ein Bildmotiv in seiner Umsetzung von Malern unterschiedlicher Herkunft betrachtet wird.

Schlägt man nun den Bogen zurück zum Deutschunterricht, so eröffnen sich zahlreiche Möglichkeiten zum Einsatz der soeben erläuterten künstlerischen und kunsthistorischen Punkte. In sprachpraktischen Kursen können grundsätzlich alle Fertigkeiten trainiert werden, der Schwerpunkt wird aber sicherlich beim Lesen, Sprechen und Schreiben liegen. Die Arbeit mit Bildern dient meist der Wortschatzerweiterung bzw. -anwendung, aber es lassen sich durchaus Übungen zur Grammatik und Syntax integrieren. Für den Geschichts- und Landeskundeunterricht bieten sich in Verbindung mit den oben erläuterten kunsthistorischen Themen einzelne Exkurse wie etwa zur Reformation, zum Humanismus, zu Entdeckungen (Amerika, Seeweg nach Indien) und Erfindungen (Buchdruck, naturwissenschaftliche Geräte) an. Das Genre Porträt bietet zudem die Möglichkeit, verstärkt auf Persönlichkeiten zu fokussieren, womit der Mensch im doppelten Sinne in den Mittelpunkt rückt: als Grundthema der Renaissance und als Bildsujet. Im Literaturunterricht könnten u.a. die Bibelübersetzung Luthers oder auch die Schelmenliteratur behandelt werden; und für den Linguistikbereich bietet sich eine Unterrichtseinheit zum Frühneuhochdeutschen an. Für Letzteres eignen sich als Primärquellen nicht nur literarische Texte, sondern auch Texte von Künstlern, beispiels- 
weise Auszüge aus Dürers „Vier Bücher von der menschlichen Proportion“ (1528) oder auch Briefe von Künstlern und Humanisten mit einem thematischen Bezug zur Kunst.

In Frankreich, wo der folgende Unterrichtsentwurf entstand, hat die Kunstgeschichte erst ab 2008 systematischen Einzug in die Curricula der Schulen gehalten. Daher haben die Studierenden, die momentan ihr Studium absolvieren, kaum kunsthistorisches Vorwissen. Ebenso fällt es den Studierenden erfahrungsgemäß sehr schwer, ihr Wissen aus mehreren Fächern gleichzeitig zu aktivieren und zu vernetzen. Eine weitere Schwierigkeit besteht darin, dass konzentriertes Betrachten u.a. durch die beschleunigte Medienrezeption im Internet zunehmend vernachlässigt wird. Die Lehrkraft muss demzufolge fachliches Grundlagenwissen vermitteln, Interdisziplinarität (vgl. Bering et.al. 2006: 104) herstellen und die Studierenden das Sehen lehren. ${ }^{1}$ All dies sollte letztlich aber kein Hindernis, sondern eher Motivation für die Verbindung von Kunst- und Sprachunterricht sein. Gleichberechtigte Ziele eines solchen Unterrichts sind folglich außer dem Spracherwerb und der Sprachpraxis der Wissenserwerb und die Wissensverknüpfung sowie die Fähigkeit zum verstehenden Sehen. Es geht gleichermaßen um die sprachliche, die fachliche und die visuelle Kompetenz der Studierenden. Wie bereits eingangs angedeutet ist das Kunstwerk - in diesem konkreten Fall das Bild - „Medium, Methode und Gegenstand der Betrachtung“ (vgl. Blei-Hoch 2012: 54 und Frederking; Krommer; Maiwald 2012: 10). Didaktisch bedeutet dies eine konsequente Verbindung von Medien-, Sprach- und Kunstdidaktik (vgl. Huber 2005: 4 und Frederking; Krommer; Maiwald 2012).

Für die Erstellung von Unterrichtsmaterialien lohnt sich durchaus auch ein Blick auf die Ansätze der Grundschulpädagogik. Renate Schnell und Bärbel Klein präsentieren beispielsweise Möglichkeiten, wie die visuelle Aneignung von Bildern mit Sprachhandlungen und ästhetischen Gestaltungsverfahren verbunden werden kann (Schnell; Klein 2003). Unabhängig von der Zielgruppe - seien es Grundschüler oder Studierende - bleibt die grundlegende Methodik in der Vorbereitung solcher hybriden Unterrichtseinheiten gleich: Die Lehrkraft sucht zunächst Quellen, mithin Bilder (Gemälde, Grafiken, Illustrationen etc.) und Texte (Primär- und Sekundärtexte). Anschließend werden Überlegungen zur Bildpräsentation (Cluster, Kalendertechnik, Präsentation von zwei Werken etc.) und zur Didaktisierung der Texte angestellt. Und schließlich geht es um die Frage, auf welchem Weg und in welcher zeitlichen Abfolge vom Kunstwerk zur Sprache geführt werden kann. Aus der Unmenge von Möglichkeiten zur Versprachlichung (Impressionen, Beschreibungen, Analysen, Hypothesenbildung, Titelfindung, Erzählungen zum Bild etc.) und den jeweils gewählten Methoden zur Bild- und Textpräsentation lassen sich

\footnotetext{
${ }^{1}$ Sehen lehren und lernen hat in diesem Zusammenhang eine doppelte Bedeutung. Einerseits ist das physische Hinschauen gemeint, d.h. der Betrachter muss gezwungen werden, sich längere Zeit auf das Bild zu konzentrieren, um dann mit einer gesteuerten Wahrnehmung zu beginnen. Andererseits ist das Dekodieren eines Bildes stets auch als kulturelle Leistung zu verstehen (Frederking; Krommer; Maiwald 2012: 136).
} 
schließlich beliebig viele Übungstypen ableiten, die wiederum an unterschiedliche Sprachniveaus angepasst werden können und dem Lehrenden somit größtmögliche Flexibilität in der Unterrichtsplanung geben (vgl. u.a. Macaire; Hosch 2009). Eine Auswahl von Übungen wird im nachfolgenden Unterrichtsentwurf vorgestellt und kommentiert.

Bei der Konzeption von Unterrichtseinheiten, die Kunst und Sprache miteinander verbinden, sollte eine Reihe von Grundsätzen beachtet werden: Erstens kann Bildrezeption individuell oder in der Gruppe bzw. im Plenum erfolgen. Besonders wirksam wird sie jedoch als kollektive Erfahrung, denn gemeinsam sieht man mehr (Huber 2005: 7). Ein Austausch im Plenum über die einzelnen Sichtweisen ist demnach nicht nur wünschenswert, sondern notwendig.

Zweitens sollte die Arbeit mit Texten in enger Anlehnung an die Bilder erfolgen. Häufige Querverweise zu den Kunstwerken und eine konsequente Rückkehr zum Bild am Ende der Unterrichtseinheit sind somit geboten. Letzteres bietet außerdem die Möglichkeit, im Laufe des Kurses erworbenes Wissen mit den Bildern zu verknüpfen.

Drittens sollte die Subjektivität im Umgang mit Kunstwerken gefördert und für das Sprachlernen genutzt werden, d.h. es sollten sowohl ein emotionaler Zugang zu den Bildern eröffnet ${ }^{2}$ als auch Brücken in das Hier und Jetzt ${ }^{3}$ geschlagen werden, so dass die Lernenden individuelle „Andockungsstellen“ an die Kunstwerke finden. Bildbedeutung ist nichts Eindeutiges und Objektives, sondern wird vom Betrachter im Rezeptionsprozess konstruiert (Bering et.al. 2006: 105). Die daraus resultierende Pluralität in der Kunstbetrachtung sollte in der Kommunikation über ein Kunstwerk konsequent genutzt werden. In Fortsetzung dieses Gedankens sollte der Umgang mit Bildern nicht ausschließlich rezeptionsorientiert ablaufen, sondern handlungsorientiert und kreativ ${ }^{4}$ weitergeführt werden, was wiederum die Rezeptionsfähigkeit verbessern kann. Beispielsweise könnte die eigene künstlerische Gestaltung von Porträts folgen und von sprachlichen Kommentaren begleitet werden.

Viertens ist darauf zu achten, dass keinesfalls komplexe Beschreibungen oder sogar Werkanalysen - mithin ein rein analytischer Zugang - am Anfang der Unterrichtseinheit von den Lernenden gefordert werden und dass diese auch später nie ohne Vorentlastung oder ohne sprachliche Hilfestellungen erfolgen. Die Lernen-

${ }^{2}$ Gabriele Huber führt in diesem Zusammenhang aus: „Es geht hier nicht um kunsthistorische Erkenntnisse und Erklärungsmuster, sondern um die Ermunterung, sich als Individuum mit all den eigenen Erfahrungen, Kenntnissen und Gefühlen auf einen Dialog mit einem Kunstwerk einzulassen." (Huber 2005: 2).

${ }^{3}$ Kunibert Bering et.al. sprechen hier von „Lebensweltorientierung“: „Es sollte in kunstorientierten Lernprozessen um der Nachhaltigkeit eines subjektive Relevanzerfahrungen ermöglichenden Lernens willen Wert darauf gelegt werden, Anschluss an die lebensweltlichen Gegebenheiten, die subjektiven Prädispositionen und Wahrnehmungsgefüge der Lernenden zu suchen und diese zu verarbeiten.“ (Bering et.al. 2006: 109).

${ }^{4}$ Volker Frederking, Axel Krommer und Klaus Maiwald unterscheiden diesbezüglich einen reflexivanalytischen und einen kreativ-handelnden Unterrichtsprozess. Frederking; Krommer; Maiwald 2012: 97. 
den sollten nie das Gefühl haben mit dem Bild bzw. Kunstwerk hilflos allein gelassen zu werden. Gerade am Anfang einer solchen Kurseinheit stehen sie vor einer dreifachen Klippe, denn sie haben oftmals kein kunsthistorisches Fachwissen, sie beherrschen nicht die Methoden der Bildanalyse und haben in der Fremdsprache noch nicht die dafür notwendigen sprachlichen Kompetenzen. Hinzu kommt, dass Bilder nicht wie Texte linear gelesen werden, sondern einer ,simultan-ganzheitlichen Wahrnehmung“" unterliegen (Frederking; Krommer; Maiwald 2012: 128; vgl. auch Bering et.al. 2006: 120). Betrachter müssen somit nach einer ersten ganzheitlichen Wahrnehmung das Bild Stück für Stück erkunden. Insofern sollte hier auch im Kleinen dem gefolgt werden, was Panofsky (1932 und 1955) in seinem semiotischen Ansatz für die Interpretation von Kunstwerken erarbeitet hat: Begonnen wird mit einer einfachen Beschreibung auf der vorikonografischen Ebene (z.B. „Auf dem Bild sehe ich einen Mann..."), worauf in einem zweiten Schritt eine Bedeutungszuweisung erfolgt und die ikonografische Ebene erreicht wird (z.B. „Der Dargestellte ist ein Staatsmann..."). Zum Schluss wird die ikonologische Ebene gestreift, auf der „Sinn und Zusammenhang der verschiedenen ikonografischen und formalen Elemente“ (Held; Schneider 2007: 362) erörtert werden (z.B. „Das Bild zeigt den Inbegriff eines weitsichtigen Herrschers...").

\section{Porträts der Renaissance-Zeit - ein Unterrichtsentwurf}

\subsection{Vorbemerkungen zum Kurskontext}

Der hier beschriebene Unterrichtsentwurf entstand für einen Fachsprachenkurs im dritten Studienjahr eines Germanistikstudiengangs an der Université Blaise Pascal in Clermont-Ferrand. ${ }^{5}$ Die Sprachkenntnisse der Studierenden lagen zwischen den Niveaus B2 und C1. Inhaltlich bearbeitete der Kurs Themen aus den Fachgebieten Geschichte und Kunstgeschichte, so dass die Thematisierung von Kunst per se schon gegeben und die historische und künstlerische Wissensvermittlung integraler Bestandteil des Kurses war. In der Sprachvermittlung stand die Erweiterung der allgemeinen und der Fachlexik im Vordergrund. Obwohl und gerade weil französische Studierende an derartige Kurse oft mit der Erwartung herangehen, dass es sich um Lektürekurse handele, wurde die vorliegende Unterrichtseinheit eher kommunikativ gestaltet. Sie integriert neben Leseübungen zahlreiche Sprech- bzw. Schreibübungen und bearbeitet neben dem Wortschatz auch grammatische, syn-

\footnotetext{
${ }^{5}$ Im Rahmen des bilingualen Geschichts- und Kunstunterrichts einer französischen „Europaklasse“ der gymnasialen Oberstufe erarbeitete Mme Fabre vom Lycée européen in Villers-Cotterêts 2010 einen Unterrichtsentwurf zum Thema „Humanisme et Renaissance en Allemagne“, der zwar andere Schwerpunkte als die hier vorgestellte Unterrichtseinheit setzt, ihr jedoch insgesamt thematisch nah ist und zahlreiche Übungen insbesondere für das Niveau B1 bietet. (http://www.emilangues.education.fr/ressources-pedagogiques/sequences/disciplines-non-linguistiques/humanisme-etrenaissance-en-allemagne; 05.02.2014).
} 
taktische sowie stilistische Fragestellungen. In diesem konkreten Fall erstreckte sich die Unterrichtseinheit über 8 Stunden; letztlich ist dies aber natürlich von der Anzahl der Studierenden, von ihren fachlichen Vorkenntnissen, ihrer sprachlichen Kompetenz und der Verteilung von Übungen auf den Unterricht und auf das selbstständige Arbeiten zu Hause abhängig.

\subsection{Aufgabenstellungen}

\section{A) Bildbetrachtung}

Auf den Arbeitsblättern 1 und 2 sehen Sie eine Galerie von Persönlichkeiten der Renaissance.

1. Welche dieser Persönlichkeiten wirkt sympathisch auf Sie?

2. Wenn Sie die Gelegenheit hätten, diese Person(en) zu treffen, welche Fragen würden Sie dann an diese Person(en) richten?

3. Stellen Sie zu jeder Person eine Hypothese über deren Identität (Beruf, soziale Position etc.) auf.

4. Fertigen Sie zu jedem Bild einen kurzen Steckbrief an:

- Wie viele Personen sehen Sie auf dem Bild?

- Ist eine Frau oder ein Mann dargestellt?

- Welche Kleidung tragen die Personen?

- Welche Accessoires oder Gegenstände sind zu sehen?

- Wie ist der Hintergrund gestaltet, d.h. wo könnte die Person sein?

5. Vergleichen Sie die Daten der Steckbriefe mit den Hypothesen zur Identität der Personen und passen Sie - falls nötig - die Hypothesen den neuen Ergebnissen an.

6. Lesen Sie die kurzen biografischen Angaben zu ausgewählten Persönlichkeiten der Renaissance auf dem Arbeitsblatt 3. Versuchen Sie die Namen den Bildern zuzuordnen. Eine Persönlichkeit ist auf zwei Porträts dargestellt - wer ist es?

B) Textarbeit zu Künstlerbiografien

Die Arbeitsblätter 4, 5 und 6 sind Lexikoneinträge zu den Künstlern Albrecht Dürer, Hans Holbein d.J. und Lucas Cranach d.Ä.

1. Lesen Sie die Texte und sortieren Sie für die jeweiligen Künstler die Informationen nach den Gesichtspunkten „Leben“ und „,künstlerisches / theoretisches Schaffen“. Stellen Sie nun den anderen Studierenden einen der drei Künstler in einer kurzen Präsentation vor. 
2. Die Bilder der Arbeitsblätter 1 und 2 zeigen Werke von Dürer, Holbein und Cranach. Aus den Texten zu deren Biografie lässt sich für einige Werke ableiten, wer welches Bild gemalt hat. Versuchen Sie die Maler zu den Werken zu sortieren.

3. Suchen Sie nun aus den drei Texten Wörter zum Thema Kunst und sortieren Sie diese in folgende Kategorien ein: allgemeine Begriffe, künstlerische Techniken, Wörter zum Inhalt und zum Kontext eines Werkes.

4. Finden Sie zu den in 3. gefundenen allgemeinen Begriffen Oberbegriffe und entwickeln Sie daraus kurze Definitionen, z.B. „Die Proportionslehre ist eine Theorie, die verschiedene Maße zueinander ins Verhältnis setzt und das Ergebnis dann auf Kunstwerke anwendet.."

5. Finden Sie zu jedem Nomen aus 3., das eine künstlerische Technik bezeichnet, ein passendes Verb bzw. zu jedem Verb ein passendes Nomen.

6. Ordnen Sie die in 3. gefunden Wörter zum Inhalt und zum Kontext eines Werkes nun nach den Kategorien „weltliche Kunst“ und „geistliche Kunst" und begründen Sie Ihre Wahl.

C) Textarbeit zur Renaissance und zum Humanismus

1. Lesen Sie die ersten zwei Abschnitte des Textes „Ein neues Bild der Welt“ (Arbeitsblatt 7). Welche Information finden Sie zu den Begriffen „Mittelalter“ und „Renaissance“ sowie ,Jenseits“ und „Diesseits“? Erklären Sie aus der Gegenüberstellung dieser Begriffe heraus, was das neue Zeitalter kennzeichnet.

2. Lesen Sie nun den Text „Ein neues Bild der Welt“ bis zum Schluss. Was erfahren Sie über den Humanismus? Auf welchen Wissensgebieten und in welchen menschlichen Aktivitäten gab es zur Zeit der Renaissance wichtige Neuerungen?

3. Lesen Sie den Lexikoneintrag zum Stichwort „Humanismus“ (Arbeitsblatt 8) und markieren Sie darin alle abgekürzten Wörter und Wortgruppen. Welche Wortarten und Wörter werden konsequent im gesamten Text abgekürzt? Welche anderen sprachlichen Besonderheiten weist ein Lexikonartikel gewöhnlich auf?

4. Rekonstruieren Sie nun alle abgekürzten Wörter und Wortgruppen. Lesen Sie dann den Text laut vor.

5. Suchen Sie nun in dem Lexikoneintrag vertiefende Informationen zum „Humanismus“.

6. Verfassen Sie nun selbst einen Lexikoneintrag zum Thema „Humanismus", der in einem Lexikon für Kinder erscheinen soll. Erklären Sie das Wesentliche in einfachen Sätzen und verzichten Sie so weit wie möglich auf Fachlexik. Erklären Sie statt dessen schwierige Begriffe mit einfachen Worten. 
D) Themenkomplexe zur Kunstgeschichte der Renaissance

1. Erarbeiten Sie ein Referat oder eine Gruppenarbeit zu folgenden Themen:

- Humanismus in der Kunst - der Mensch als Maß aller Dinge: die Darstellung des Menschen im Porträt, menschliche Proportionen in der Architektur und im Urbanismus

- die Renaissancekunst als bewusster Rückbezug auf die Antike bei gleichzeitiger Innovation; die Generation von neuem Wissen aus alten Quellen (Schriften, Ausgrabungen etc.) und neuen Quellen (Reisen, Beobachtungen und Forschung)

- Ausgangspunkt Italien und dann? - Die Renaissancekunst in anderen Ländern Europas (Malerei, Skulptur, Architektur: Schlösser, Rathäuser, Bürgerhäuser etc.)

- die Verbreitung von Wissen und Kunst - zur Mobilität von Künstlern (vgl. die Biografien von Holbein d.J. und Dürer) und Werken (Buchdruck, Grafik, Leinwand statt Holz für Gemälde)

2. Erarbeiten Sie ein Referat oder eine Gruppenarbeit zu folgenden Themen und erörtern Sie das jeweilige Thema anhand der Bilder auf den Arbeitsblättern 1 und 2:

- das Selbstverständnis der Künstler und ihre neue Stellung in der Gesellschaft: ein Exkurs zu den Selbstbildnissen Albrecht Dürers und Lucas Cranachs (Selbstsicht und Fremdsicht, Einbezug des Zitats im Bild, der Künstler als Genie, Universalgelehrter und Schöpfer)

- neue Prinzipien der Komposition und der Konstruktion von Perspektive: ein Exkurs zu Lucas Cranachs „Dr. Johannes Cuspinian“ und „Anna Cuspinian“ (Farb- und Luftperspektive) sowie zu Hans Holbeins „Die Gesandten“ und „Der Kaufmann Georg Gisze“ (mathematisch konstruierte Perspektive)

- Veränderungen der Farbigkeit durch die Entwicklung der Ölmalerei: ein Exkurs zu Hans Holbeins „Die Gesandten“ und „Der Kaufmann Georg Gisze“"

- die Entwicklung der Grafik: ein Exkurs zu Albrecht Dürers „Erasmus von Rotterdam“

- eine neue Darstellung des Menschen - realistisch und ausdrucksstark: ein Exkurs zu Albrecht Dürers „Die Mutter des Künstlers im Alter von 63 Jahren“ und Lucas Cranachs „Martin Luther“"

E) Porträts im Detail

1. Beschäftigen Sie sich mit dem Porträt als Genre der Malerei und erörtern Sie dabei folgende Punkte: 
- Etymologie des Wortes „Porträt" - lat. protrahere; das Wort „Bildnis“

- Abbild einer abwesenden Person oder einer Person, deren Andenken bewahrt werden soll

- Anzahl der dargestellten Personen: Porträt einer Person, Doppelporträt, Gruppenporträt

- Unterscheidung von: Herrscherporträt, Familienporträt, Selbstporträt etc.

- mögliche Ausdrucksformen: idealisiert, realitätsnah, übersteigert/karikierend

- Formen der Darstellung von Personen: Bildniskopf, Büste, Bruststück, Halbfigur, Kniestück, Ganzfigur

- Grad der Kopfdrehung: Vorderansicht, Halbprofil, Dreiviertelprofil, Profil

- die historische Entwicklung des Porträts: ägyptische Kunst, griechische Antike, römische Antike, Mittelalter, die Renaissance als Scharnier zur Moderne: Befreiung des Bildnisses aus religiösen oder architektonischen Bindungen und damit Entwicklung eines autonomen Genres

- Auftraggeber von Porträts in der Renaissance: Adel, Kirche, Bürgertum; soziale Veränderungen sind damit vor allem im Genre „Porträt“ sichtbar

2. Das Arbeitsblatt 9 zeigt Dürers Mutter als junge und als alte Frau. Erstellen Sie eine vergleichende Beschreibung der beiden Bilder.

- Beschreiben Sie zunächst die Körperhaltung (Kopf und Schultern) der Personen. Glauben Sie, dass die Personen sitzen oder stehen? Wie könnten sie die Arme und Beine halten?

- Beschreiben Sie die Kleidung der Personen.

- Schauen Sie sich nun etwas näher die Köpfe an. Beschreiben Sie zuerst detailliert den Kopf der jungen Frau und vergleichen Sie ihn dann mit dem der alten Frau. Was hat sich in der Darstellung verändert?

- Welche Rolle spielt jeweils das Kopftuch für die Komposition des Bildes und die Darstellung der Person?

- Wie wirken die beiden Personen auf Sie? Erstellen Sie Mind-Maps mit Adjektiven, die auf die zwei Frauen zutreffen, und ordnen Sie die Adjektive entsprechend der zwei Darstellungen, z.B.: „hübsch“, ,jung“, „stolz“ auf der einen Seite und „schwach“, „alt“, „,ausgemergelt“ auf der anderen Seite.

- Was ist an diesen zwei Porträts Ihrer Meinung nach typisch für die Renaissance-Zeit? Argumentieren Sie in Hinblick auf die dargestellten Personen, aber auch auf die Art ihrer Darstellung durch den Künstler. 
3. Stellen Sie sich vor, Sie wären selbst Maler und bekämen Aufträge für die folgenden Porträts. Kommentieren Sie, wie Sie die jeweilige Person darstellen würden (Körperhaltung, Kopf, Ausdruck, Attribute, Hintergrund, Farben, Bildkomposition etc.). Was würden Sie ähnlich wie die Maler der Renaissance gestalten, und worin würde sich Ihr Porträt von den Werken des 16. Jahrhunderts unterscheiden?

- Bundeskanzler(in)

- Manager(in)

- Architekt(in)

- Philosoph(in)

- Freund(in)

- Selbstporträt

\subsection{Didaktische und methodische Kommentare zum Unterrichtsentwurf}

\section{A) Bildbetrachtung}

Für diese ersten Übungen zur Bildbetrachtung eignet sich eine Bildpräsentation im Cluster. A1. und A2. sollen den Lernern zunächst einen ausschließlich subjektiven und emotionalen Zugang zu den Bildern eröffnen. Vorwissen wird an dieser Stelle bewusst ausgeblendet, so dass die Studierenden mangelndes Vorwissen nicht als mögliche Barriere für die „Bildlektüre“ empfinden.

Die Hypothesenbildung in A3. schließt ein erstes Nachdenken über die Bilder ein, ohne dass dies jedoch verbalisiert werden muss. Sprachlich realisiert wird lediglich das Endergebnis der Überlegung, wo Begriffe wie „König“, „Künstler“ etc. fallen. Die Übung dient somit nur einer ersten sprachlichen Aktivierung von Schlüsselbegriffen und soll darüber hinaus die Neugierde auf die Bilderschließung wecken.

A4. erfolgt idealerweise als Gruppenarbeit, so dass die Erschließung der einzelnen Bilder auf mehrere Gruppen verteilt wird. In dieser Übung wird versucht, die ersten Wahrnehmungen zu systematisieren, so dass der Weg zur objektiven Analyse frei wird. Die Studierenden benötigen dafür ein sehr präzises Vokabular, bei dessen Bereitstellung die Lehrkraft Hilfestellungen geben muss. In A5. erfolgt dann eine Rückkoppelung zu den in A3. getroffenen Vorüberlegungen der Studierenden, wobei die Lerner auch eigene Denk- und Arbeitsweisen reflektieren.

Die in A6. benutzten, kurzen Lesetexte vermitteln eine weitere Annäherung an die Bilder, aktivieren landeskundliches und historisches Vorwissen der Studierenden und sind nach A3. und A5. der letzte Schritt zur Identifizierung der dargestellten Persönlichkeiten. Die Lösungen der Aufgabe sind mit dem Bildnachweis zu diesem Artikel im Anhang gegeben. Es kann in der Unterrichtspraxis durchaus passieren, dass es größere Abweichungen zwischen den Eingangshypothesen der 
Studierenden und der ,,richtigen“ Bild-Text-Zuordnung gibt. Wichtig ist hier, dass unterschiedliche Ansichten zugelassen werden und die Argumentation der Studierenden zu ihren Hypothesen in den Vordergrund gerückt wird. Beispielsweise erkannte eine Studentin in Bild 5 auf dem Arbeitsblatt 1 eine Frau, und ihre Argumentation, die sich im Wesentlichen auf die Gesichtszüge der dargestellten Person bezog, war durchaus schlüssig. Auffällig war zudem, dass es für die Studierenden offenbar kein größeres Problem darstellte, wenn sie sich bei Zuordnungen täuschten, wo es sich um (für sie) unbekannte Personen handelte. Sobald ihnen aber Irrtümer bei Persönlichkeiten unterliefen, die tief im kollektiven Gedächtnis verankert sind (z.B. Luther), empfanden sie diese „Fehler“ als peinlich. Hier sollte die Lehrkraft unbedingt mit einem positiven Impuls entgegenwirken und den Unterschied zwischen subjektiver Bildrezeption durch den Betrachter, Eigenständigkeit des Kunstwerks und Bildabsicht des Künstlers thematisieren.

\section{B) Textarbeit zu Künstlerbiografien}

Die Lese- und Sprechübung B1. eignet sich für die Gruppenarbeit. Bei der Leseübung geht es zwar um selektives und detailliertes Lesen, es sollte jedoch vermieden werden, dass die Studierenden bereits hier jedes unbekannte Wort im Wörterbuch nachschlagen.

Nach der Lektüre der drei Texte (Übung B2.) lassen sich vier Bilder unmittelbar den Künstlern zuordnen: das Selbstbildnis Albrecht Dürers sowie die Gemälde „Die Gesandten“, „Erasmus von Rotterdam“ und „Der Kaufmanns Georg Gisze“ von Hans Holbein d.J. Für drei Bilder lässt sich die Zuordnung mittels der biografischen Textinformationen indirekt rekonstruieren: „Friedrich der Weise“ und „Martin Luther" von Lucas Cranach d.Ä. sowie „Thomas Morus“ von Hans Holbein d.J. Im Anschluss kann die Lehrkraft die restlichen Zuordnungen bekannt geben.

Auch die Übung B3. eignet sich für die Gruppenarbeit. Unter allgemeinen Begriffen werden Wörter wie „Kunsttheoretiker“, „Handwerkertum“ etc. verstanden, künstlerische Techniken sind z.B. „grafische Arbeiten“ oder „Holzschnitte“, und Wörter zum Inhalt und zum Kontext eines Werkes meinen beispielsweise „Landschaftsaquarelle“ oder „protestantische Kunst“.

B4., B5. und B6. bieten Ansätze zur weiteren Arbeit mit der in B3. gefundenen Lexik. Es ist darauf zu achten, dass ebenso wie in B3. stets mehrere Lösungswege möglich und damit eindeutige Resultate oft nicht zu erreichen sind. Denkbar wären an dieser Stelle auch Übungen im Mind-Map-Verfahren, ein Exkurs zur Wortbildung oder eher grammatisch orientierte Übungen zur Pluralbildung. Grundsätzlich geht es darum, dass das Fachvokabular, das in B3. gefunden wird, nicht als solches allein stehen bleibt, sondern dass Anreize zur weiteren Arbeit und damit zur Verankerung im Wortschatz der Lernenden gegeben werden. 


\section{C) Textarbeit zur Renaissance und zum Humanismus}

Der Text „Ein neues Bild der Welt“ (Arbeitsblatt 7) ist dem 2007 erschienenen Buch von Manfred Mai zur Europäischen Geschichte entnommen. Es enthält Texte zu wichtigen historischen Ereignissen und Epochen, die relativ einfache syntaktische Strukturen benutzen und sich auch durch ihren Verzicht auf ein zu komplexes wissenschaftliches Vokabular für den Einsatz im DaF-Unterricht gut eignen. Im Gegensatz dazu ist der zweite Text (Arbeitsblatt 8) aus dem Zeit-Lexikon ein typisches Beispiel für einen in jeglicher Hinsicht sehr dichten Text. Die vorgeschlagenen Übungen kreisen daher nicht ausschließlich um die beiden Texten gemeinsamen Themen Renaissance und Humanismus, sondern berücksichtigen auch die unterschiedlichen Textsorten.

C1. und C2. bieten zunächst Ansätze zum globalen und selektiven Lesen. Der Text „Ein neues Bild der Welt“ bietet durchaus Möglichkeiten für eine tiefergreifende Didaktisierung. Es wurde jedoch an dieser Stelle darauf verzichtet, da der Text hier lediglich als Sprungbrett für die nächste Stufe gedacht ist.

C3. und C4. geben den Studierenden Hilfestellungen zur systematischen Erschließung des vorliegenden Lexikoneintrages bzw. dieser Textsorte im Allgemeinen. Die Rekonstruktion der abgekürzten Wörter (vor allem offizielle Abkürzungen, Adjektive und das Stichwort des Lexikoneintrages) eignet sich hervorragend für Arbeit an der Fachlexik als auch für eine aktive Wiederholung der Adjektivdeklinationen.

C5. zielt auf selektives und detailliertes Lesen des Lexikonartikels, wobei auch hier auf eine weiterführende Didaktisierung verzichtet wurde.

C6. bietet schließlich eine Schreibübung, bei der die Textsorte „Lexikoneintrag“" und das Paraphrasieren der Fachlexik geübt werden sollen. Um den Studierenden eine Orientierungshilfe zu geben, kann auch der Text „Ein neues Bild der Welt" (Arbeitsblatt 7) noch einmal zu Rate gezogen werden.

Je nach Kontext des Kurses kann auch eine Übersetzungsübung an dieser Stelle integriert werden. Die französischen Studierenden sollten beispielsweise ausgewählte Abschnitte des Lexikoneintrages ins Französische übersetzen, was ihnen nicht nur ein noch tieferes Textverständnis brachte, sondern sie auch folgerichtig zu einer Diskussion über unterschiedliche sprachliche Strukturen (Partizipialkonstruktionen etc.) hinführte.

D) Themenkomplexe zur Kunstgeschichte der Renaissance

D1. bietet Themen für Referate, die die Studierenden einzeln oder in Gruppen erarbeiten. An die Präsentation der Ergebnisse sollte sich ein Gespräch im Plenum anschließen. Allgemeines Ziel ist, dass die Studierenden ihre Kenntnisse zur Renaissance und zum Humanismus vertiefen und mit dem Wissen aus anderen Fachbereichen verknüpfen. Vorwissen bzw. Wissen aus unterschiedlichen kulturellen Kontexten (z.B. Architektur der Renaissance im eigenen Land oder in der Heimat- 
stadt) sollen aktiviert werden. Die Bearbeitung der Referatsthemen erfordert seitens der Studierenden Materialrecherchen mittels verschiedener Medien, die systematische Erschließung von Sekundärquellen, das Redigieren eigener Beiträge sowie die Beherrschung von elementaren Präsentationstechniken.

D2. verfolgt grundsätzlich einen ähnlichen Ansatz wie D1., fordert aber von den Studierenden zusätzlich eine Anwendung des erarbeiteten Wissens auf die Bilder der Arbeitsblätter 1 und 2. Insofern geht es hier um eine Transferleistung von der Theorie hin zur Praxis. Erfahrungsgemäß fällt dies den Studierenden, vor allem in den ersten Studienjahren, oft schwer. In diesem Fall könnte ein Beispiel in Form eines Lehrervortrages mit anschließender Besprechung im Plenum erfolgen, bevor die Studierenden allein weiterarbeiten.

E) Porträts im Detail

Die in E1) vorgeschlagene Einführung zum Genre „Porträt“ kann als Lehrervortrag oder als Einzelreferat der Studierenden erfolgen, aber auch Ergebnis einer Gruppenarbeit sein. Wichtig ist die ständige Verzahnung der Informationen bzw. des Fachvokabulars mit den Bildern der Arbeitsblätter 1 und 2, d.h. wenn beispielsweise über den Grad der Kopfdrehung gesprochen wird, sollte dies unmittelbar an den Bildern nachvollzogen werden. Die Einführung zielt einerseits auf den Erwerb weiteren kunsthistorischen Grundlagenwissens und andererseits auf die Erweiterung des (Fach)wortschatzes der Studierenden.

Die Übung E2. ermöglicht den Studierenden schließlich eine detaillierte „Lektüre" und sprachliche Beschreibung von zwei ausgewählten Porträts. Sprachlich werden an dieser Stelle Begriffe zum menschlichen Körper, Adjektive zur Beschreibung von Personen, Wörter zur Analyse von Kunstwerken sowie Vokabular für Vergleiche geübt. In der letzten Teilfrage geht es um die Verknüpfung des vorher erarbeiteten Wissens über die Renaissance mit dem konkreten Bild.

Mit E3. wird schließlich der Bogen von der Renaissance zur Lebenswelt der Lerner geschlagen. Die Übung aktiviert nochmals Vokabular zur Bildbeschreibung, arbeitet jedoch verstärkt mit der Kreativität der Studierenden und regt zum Nachdenken über sich selbst, das eigene Handeln und unsere Zeit an.

\section{Literatur}

\section{Didaktik Deutsch und Mediendidaktik}

Blei-Hoch, Claudia (2012): Bilder im Deutschunterricht. In: Kliewer, Heinz-Jürgen; Pohl, Inge (Hrsg.): Lexikon Deutschdidaktik. Bd. 1. Baltmannsweiler: Schneider Verlag Hohengehren, 54-56. 
Frederking, Volker; Krommer, Axel; Maiwald, Klaus (2012): Mediendidaktik Deutsch. Eine Einfübrung. Berlin: Erich Schmidt Verlag.

Huber, Gabriele (2005): Mit Bildender Kunst Deutsch lernen? In: Zeitschrift für Interkulturellen Fremdsprachenunterricht [online] 10 (3. Http://zif.spz.tudarmstadt.de/jg-10-3/beitrag/huber1.htm (23.05.2012).

Macaire, Dominique; Hosch, Wolfram (2009): Bilder in der Landeskunde. Berlin u.a.: Langenscheidt.

\section{Weiterführende Literatur}

Blell, Gabriele; Hellwig, Karlheinz (Hrsg.) (1996): Bildende Kunst und Musik im Fremdsprachenunterricht. Frankfurt/Main u.a.: Peter Lang.

Grätz, Ronald (1997): Kunst und Musik im Deutschunterricht. In: Fremdsprache Deutsch. Zeitschrift für die Praxis des Deutschunterrichts 17.

Hecke, Carola (2012): Visuelle Kompetenz im Fremdsprachenunterricht. Die Bildwissenschaft als Schlüssel für einen kompetenzorientierten Bildeinsatz: Göttingen: Niedersächsische Staats- und Universitätsbibliothek.

Hecke, Carola; Surkamp, Carola (Hrsg.) (2010): Bilder im Fremdsprachenunterricht: Neue Ansätze, Kompetenzen und Methoden. Tübingen: Narr.

Sturm, Dietrich (1991): Das Bild im Unterricht. In: Fremdsprache Deutsch. Zeitschrift für die Praxis des Deutschunterrichts 5.

Wangerin, Wolfgang (2006): Musik und Bildende Kunst im Deutschunterricht. Baltmannsweiler: Schneider Verlag Hohengehren.

Wedewer, Rolf (1985): Zur Spracblichkeit von Bildern. Ein Beitrag zur Analogie von Sprache und Kunst. Köln: DuMont.

Wicke, Rainer-Ernst (2000): Gren₹überscbreitungen. Der Einsatz von Musik, Fotos und Kunstbildern im DaF-Unterricht in Schule und Fortbildung. München: Iudicium.

\section{Kunstwissenschaft und Didaktik Kunstgeschichte}

Bering, Kunibert et al. (2004): Kunstdidaktik. Oberhausen: Athena Verlag.

Held, Jutta; Schneider, Norbert (2007): Grundzüge der Kunstwissenschaft. Gegenstandsbereiche - Institutionen - Problemfelder. Köln u.a.: Böhlau Verlag.

Panofsky, Erwin (1932): Zum Problem der Beschreibung und Inhaltsdeutung von Werken der bildenden Kunst. In: Logos XXI, 103-119.

Panofsky, Erwin (1955): Meaning in the Visual Arts. Garden City (NY): Doubleday. 
Schnell, Renate; Klein, Bärbel (2003): Schreiben und Gestalten zu ausgewählten Kunstwerken. Donauwörth: Auer Verlag.

\section{Weiterführende Literatur}

Bering, Kunibert; Niehoff, Rolf (Hrsg.) (2005): Bilder. Eine Herausforderung für die Bildung. Oberhausen: Athena Verlag.

Eid, Klaus; Langer, Michael; Ruprecht, Hakon (2000): Grundlagen des Kunstunterrichts. Paderborn u.a.: Schöningh Verlag.

Gopon, Karl-Wolfgang (2003): Fachübergreifendes Arbeiten im Fach Kunst. In: Busse, Klaus Peter (Hrsg.): Kunstdidaktisches Handeln. Norderstedt: Books on Demand, 492-503.

Issing, Ludwig J.; Mickasch, Heidemarie; Haack, Johannes (Hrsg.) (1986): Blickbewegung und Bildverarbeitung. Kognitionspsychologische Aspekte visueller Informationsverarbeitung. Frankfurt/Main u.a.: Peter Lang.

Niehoff, Rolf (1989): Bild und Sprache. Beobachtungen, Reflexionen, Konsequenzen, Anregungen. In: Kunst+Unterricht 136, 12-20.

Niehoff, Rolf (2003): Aus kunstdidaktischer Sicht: Beobachtungen und Reflexionen zum Bildverständnis in ,,anderen“ Fächern. In: Bering, Kunibert; Bilstein, Johannes; Thurn, Hans P. (Hrsg.): Kultur-Kompetenz: Aspekte der Theorie - Probleme der Praxis. Oberhausen: Athena Verlag, 327-358.

Otto, Gunter (1983): Bildanalyse. In: Kunst+Unterricht 77, 10-12.

Peez, Georg (2008): Einführung in die Kunstpädagogik. Stuttgart: Kohlhammer.

Peez, Georg (Hrsg.) (2011): Kunstunterricht fächerverbindend und fachüberschreitend. Ansätre, Beispiele und Methoden für die Klassenstufen 5 bis 13. München: Kopaed.

Seidel, H. Joachim (1999): Worte zu Bildern - Bilder zu Worten. Interdisziplinarität als Modus Ästhetischer Bildung. In: BDK-Mitteilungen 35(1), 4-11.

Sturm, Eva (2010): Wie man anläßlich von Kunst sprechend zu Wissen kommen kann. Und was das mit Kunstvermittlung zu tun hat. In: Kunstportal des SchroedelVerlages. Http://www.schroedel.de/kunstportal/didaktik_archiv/2010-11sturm.pdf. (05.02.2014).

\section{3. Überblickswerke und Lehrwerke Kunstgeschichte}

(2004): Lexikon der Kunst. 7 Bde, Leipzig: Seemann Verlag.

(2011): Schülerduden. Kunst. Mannheim: Dudenverlag.

(Autorenkollektiv) (1992): Grundsteine Kunst 1. Stuttgart: Klett. 
(Autorenkollektiv) (1994): Grundsteine Kunst 2. Stuttgart: Klett.

(Autorenkollektiv) (1995): Grundsteine Kunst 3. Stuttgart: Klett.

Busch, Werner (Hrsg.) (1997): Landschaftsmalerei. Geschichte der klassischen Bildgattungen in Quellentexten und Kommentaren. Bd. 3. Berlin: Dietrich Reimer Verlag.

Felgentreu, Simone; Nowald, Karlheinz (2006): Duden Kunst: Lehrbuch S II. Gymnasiale Oberstufe. Berlin: Duden Paetec Schulbuchverlag.

Gaehtgens, Barbara (Hrsg.) (2002): Genremalerei. Geschicbte der klassischen Bildgattungen in Quellentexten und Kommentaren. Bd. 4. Berlin: Dietrich Reimer Verlag.

Gaehtgens, Thomas W.; Fleckner, Uwe (Hrsg.) (1996): Historienmalerei. Eine Geschichte der klassischen Bildgattungen. Bd. 1. Berlin: Dietrich Reimer Verlag.

Klant, Michael; Schulze-Weslarn, Annemarie; Walch, Josef (1988): Grundkurs Kunst 1. Themen aus: Malerei, Grafike, Fotografie. Hannover: Schroedel Schulbuchverlag.

Klant, Michael; Walch, Josef (1990): Grundkurs Kunst 2. Themen aus: Plastik, Skulptur, Objekt. Hannover: Schroedel Schulbuchverlag.

Klant, Michael; Walch, Josef (1993): Grundkurs Kunst 3. Themen aus: Architektur. Hannover: Schroedel Schulbuchverlag.

Klotz, Heinrich; Warnke, Martin (1998-2000): Gescbicbte der deutschen Kunst 6002000. 3 Bde. München: Beck.

König, Eberhard; Schön, Christiane (Hrsg.) (1996): Stilleben. Geschicbte der klassischen Bildgattungen in Quellentexten und Kommentaren. Bd. 5. Berlin: Dietrich Reimer.

Preimesberger, Rudolf (Hrsg.) (1999): Porträt. Geschichte der klassischen Bildgattungen in Quellentexten und Kommentaren. Bd. 2. Berlin: Dietrich Reimer.

Suckale, Robert (2005): DuMont-Geschichte der Kunst in Deutscbland. Von Karl dem Großen bis Heute. Köln: DuMont.

\section{Bildquellen}

\section{Arbeitsblatt 1 - Porträts der Renaissancezeit I}

1. Lucas Cranach d.Ä.: Friedrich der Weise, um 1532, Öl auf Holz, Kronach, Fränkische Galerie [Wikimedia Commons / Public Domain]

2. Albrecht Dürer: Erasmus von Rotterdam, 1520 (?), Kohlestift auf Papier, Paris, Musée du Louvre [Web Gallery of Art /Wikimedia Commons/ Public Domain]

3. Hans Holbein d.J.: Thomas Morus, 1527, Tempera auf Holz, New York City, Frick Collection [The York Project: 10.000 Meisterwerke der Malerei/ Wikimedia Commons / Public Domain] 
4. Lucas Cranach d.Ä.: Marthin Luther, 1532, Öl auf Holz, Kopenhagen, Statens Museum for Kunst [Statens Museum for Kunst / Wikimedia Commons / Public Domain]

5. Lucas Cranach d.Ä.: Dr. Johannes Cuspinian, 1502/03, Öl auf Holz, Winterthur, Sammlung Oskar Reinhart „Am Römerholz“ [The York Project: 10.000 Meisterwerke der Malerei / Wikimedia Commons / Public Domain]

6. Lucas Cranach d.Ä.: Anna Cuspinian, 1502/03, Öl auf Holz, Winterthur, Sammlung Oskar Reinhart „Am Römerholz“ [The York Project: 10.000 Meisterwerke der Malerei / Wikimedia Commons / Public Domain]

\section{Arbeitsblatt 2 - Porträts der Renaissance II}

7. Albrecht Dürer: Selbstporträt im Alter von 28 Jahren, 1500, Öl auf Holz, München, Alte Pinakothek [Cybershot800i / Wikimedia Commons / Public Domain]

8. Hans Holbein d.J.: Der Kaufmann Georg Gisze, 1532, Öl auf Holz, Berlin, Staatliche Museen zu Berlin - Preußischer Kulturbesitz [Wikimedia Commons / Public Domain]

9. Albrecht Dürer: Die Mutter des Künstlers im Alter von 63 Jahren, 1514, Kohlestift auf Papier, Berlin, Kupferstichkabinett [Wikimedia Commons / Public Domain]

10. Hans Holbein d.J.: Die Gesandten, 1533, Öl auf Holz, London, National Gallery [Google Art Project / Wikimedia Commons / Public Domain]

11. Lucas Cranach d.Ä.: Selbstporträt im Alter von 77 Jahren, 1550, Öl auf Holz, Florenz, Galleria degli Uffizi [The York Project: 10.000 Meisterwerke der Malerei / Wikimedia Commons / Public Domain]

12. Hans Holbein d.J.: Erasmus von Rotterdam, 1523, Öl auf Holz, Paris, Musée du Louvre [The York Project: 10.000 Meisterwerke der Malerei / Wikimedia Commons / Public Domain]

\section{Arbeitsblatt 9 - Porträts im Vergleich}

13. Albrecht Dürer: Die Mutter des Künstlers im Alter von 63 Jahren, 1514, Kohlestift auf Papier, Berlin, Kupferstichkabinett [Brand Philip, Lotte; Anzelewsky, Fedja: The portrait diptych of Dürer's parents. In: Netherlands Quarterly for the History of Art, Vol. 10, No. 1, 1978-79 / Wikimedia Commons / Public Domain]

14. Albrecht Dürer: Porträt der Barbara Dürer, geb. Holper, um 1490-93, Öl auf Holz, Nürnberg, Germanisches Nationalmuseum [Brand Philip, Lotte; Anzelewsky, Fedja: The portrait diptych of Dürer's parents. In: Netherlands Quarterly for the History of Art, Vol. 10, No. 1, 1978-79 / Wikimedia Commons / Public Domain] 


\section{Arbeitsmaterialien}

Arbeitsblatt 1: Porträts der Renaissance-Zeit I

Arbeitsblatt 2: Porträts der Renaissance-Zeit II

Arbeitsblatt 3: Porträts der Renaissance-Zeit III

Arbeitsblatt 4: Künstlerbiografien I - Albrecht Dürer

Arbeitsblatt 5: Künstlerbiografien II - Hans Holbein d.J.

Arbeitsblatt 6: Künstlerbiografien III - Lucas Cranach d.Ä.

Arbeitsblatt 7: Renaissance und Humanismus I

Arbeitsblatt 8: Renaissance und Humanismus II

Arbeitsblatt 9: Porträts im Vergleich 
Arbeitsblatt 1: Porträts der Renaissance-Zeit I
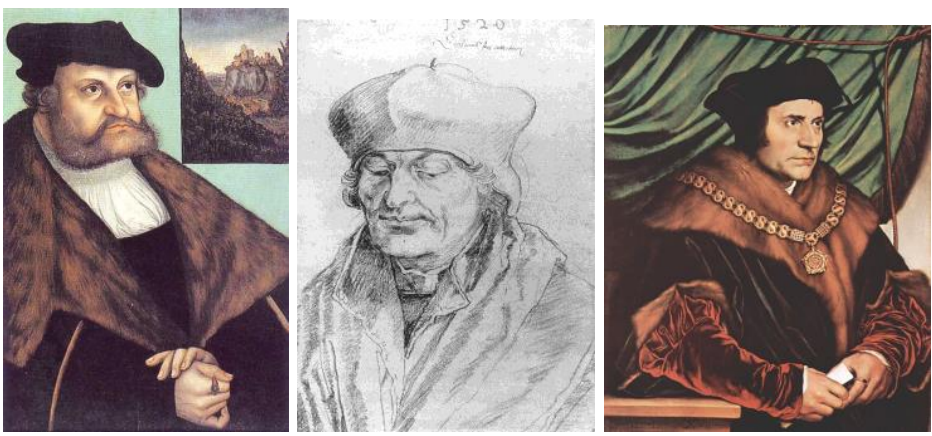

2

3
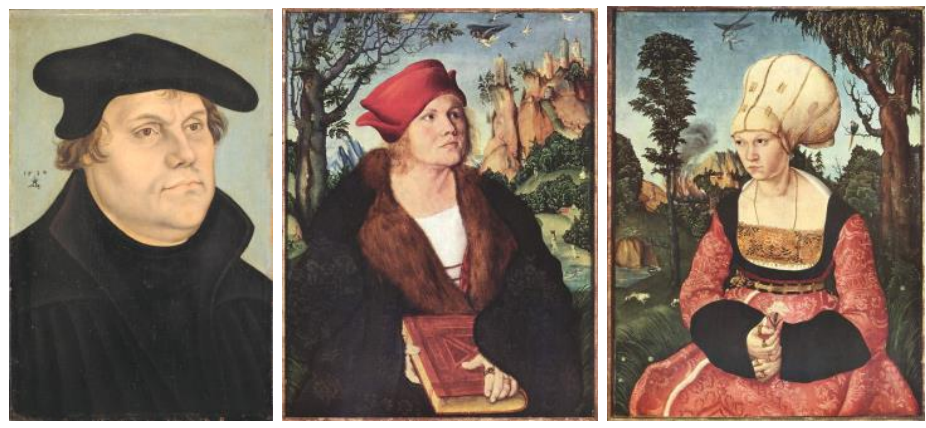

4 5 6 
Arbeitsblatt 2: Porträts der Renaissance-Zeit II
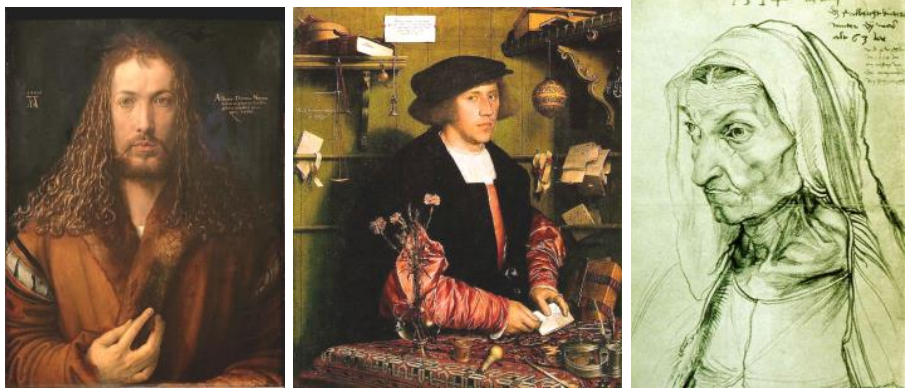

7 8 9
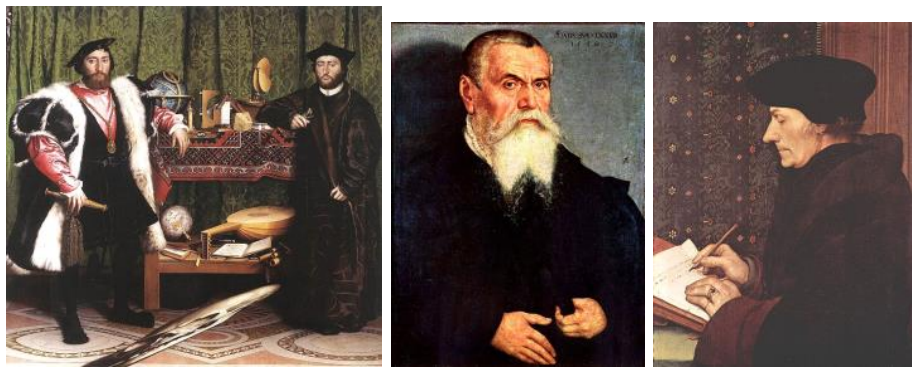

10 11 12 


\section{Arbeitsblatt 3: Porträts der Renaissance-Zeit III}

Dr. Johannes Cuspinian war Humanist, Dichter und Diplomat in habsburgischen Diensten.

Anna Cuspinian war die Frau von Johannes Cuspinian.

Erasmus von Rotterdam war ein bedeutender niederländischer Gelehrter des europäischen Humanismus. Er war Theologe, Philosoph, Philologe und Autor zahlreicher Bücher.

Barbara Holper war die Mutter Albrecht Dürers. Dessen Vater kam 1455 aus Ungarn nach Nürnberg und arbeitete dort als Goldschmied. 1467 heiratete er Barbara Holper; als drittes Kind wurde Albrecht Dürer am 21. Mai 1471 geboren.

Thomas Morus war ein englischer Staatsmann und humanistischer Autor. Er ist ein Heiliger und Märtyrer der römisch-katholischen Kirche.

Albrecht Dürer war ein deutscher Maler, Grafiker, Mathematiker und Kunsttheoretiker von europäischem Rang. Er war ein bedeutender Künstler zur Zeit des Humanismus und der Reformation.

Martin Luther war der theologische Urheber und einer der Lehrer der Reformation. Er wollte Fehlentwicklungen des Christentums und die verbreiteten Missstände in der Kirche (Ämterkauf, Ablasshandel, Machtmissbrauch) überwinden. Seine Predigten und Schriften besonders seine Bibelübersetzung - veränderten die von der römisch-katholischen Kirche dominierte Gesellschaft im ausgehenden Mittelalter und der beginnenden Neuzeit nachhaltig.

Friedrich der Weise war von 1486 bis zu seinem Tod 1525 Kurfürst von Sachsen.

Die Gesandten sind die Diplomaten Jean de Dinteville (links), im Jahr 1533 französischer Gesandter am Hof Heinrichs VIII. von England, und Georges de Selves (rechts), der bereits im Alter von siebzehn Jahren Bischof von Lavaur geworden war und ebenfalls im Jahr 1533 französischer Gesandter am Hof Heinrichs VIII. von England.

Georg Gisze war ein Kaufmann, der ab dem Jahr 1522 im Londoner Hanse-Kontor, dem sogenannten Stalhof, für die Kölner Hanseniederlassung tätig war.

Lucas Cranach d.Ä. war ein deutscher Maler und Grafiker der Renaissance.

[Quelle: nachträglich bearbeitete Texte aus wikipedia] 


\section{Arbeitsblatt 4: Künstlerbiografien I - Albrecht Dürer}

Dürer, Albrecht, Maler, Grafiker, Kunsttheoretiker, *Nürnberg 21.5.1471, †ebd. 6.4.1528; gilt als künstler. Repräsentant seiner Epoche, die ihre Wurzeln noch im spätmittelalterl. Handwerkertum hatte, aber den geistigen Neuerungen, insbes. den humanist. Strömungen der Reformation, offen gegenüber stand. Aus Italien brachte D. das Selbstverständnis des Renaissancekünstlers mit und setzte die theoret. Erkenntnisse seiner Zeit in seinem Werk um. - 1484/85 erlernte D. das Goldschmiedehandwerk in der Werkstatt seines Vaters Albrecht D. d.Ä. (*1427, †1502), war 1486 Schüler M. Wolgemuts, dann Aufenthalt am Oberrhein, 1494/95 in Oberitalien (Landschaftsaquarelle). 1498 erschienen 15 Holzschnitte zur Apokalypse, 1504 der Kupferstich „Adam und Eva“, der ein erstes Ergebnis seiner Beschäftigung mit der Proportionslehre ist. 1502-11 entstand der Holzschnittzyklus „Marienleben“, 1496-1511 die „Große Passion“, 1509-11 die „Kleine Passion“, 1507-12 die „Kleine Kupferstichpassion“. Ab 1509 Ratsherr in Nürnberg, ab 1512 für Kaiser Maximilian tätig: Zeichnungen für Holzschnitte der „Ehrenpforte“ und des „Großen Triumphwagens" sowie farbige Randfederzeichnungen zum Gebetbuch des Kaisers. Die humanistisch geprägten großen Kupferstiche „Ritter, Tod und Teufel“ (1513), „Hl. Hieronymus im Gehäus“ (1514) und „Melancolia“ (1514) zählen zu seinen bedeutendsten Leistungen. Als Maler schuf D. Andachtsbilder und Altäre, u.a. den sog. Dresdner Altar (um 1496; Dresden, Gemäldegalerie), den Paumgartner-Altar (zw. 1498 und 1504; München, Alte Pinakothek), die „Anbetung der Könige“ (1504; Florenz, Uffizien), „Rosenkranzfest“ (1506; Prag, Nationalgalerie), „Allerheiligenbild“ (1511; Wien, Kunsthistor. Museum), „Hl. Hieronymus“ (1521; Lissabon, Museu de Arte Antigua). D. hat wesentl. Anteil an der Bildnismalerei; das Persönlichkeitsbewusstsein der Renaissance drückt sich in seinen Selbstbildnissen aus (1493, Paris, Louvre; 1498, Madrid, Prado; 1500, München, Alte Pinakothek). Während bzw. nach seiner 2. Italienreise (1505-07) entstanden „Junge Venezianerin“ (1505; Wien, Kunsthistor. Museum), „Michael Wolgemut“ (1516; Nürnberg, German. Nationalmuseum), „Hieronymus Holzschuher“ und „Jakob Muffel“" (beide 1526; Berlin, Gemäldegalerie). 1526 vermachte D. seiner Vaterstadt u.a. die sog. „Vier Apostel“ (München, Alte Pinakothek). Aus seiner Spätzeit stammen freie Entwürfe, so einer Kreuzigung und eines Holzschnitts des Abendmahls (1523). - D. verfasste zahlr. Schriften, u.a. „Underweysung der Messung mit dem Zirckel und Richtschevt in Linien, Ebenen und ganzen Körpern“ (1525); „Etliche Underricht zur Befestigung der Stett, Schloß und Flecken“ (1527); „Vier Bücher von menschlicher Proportion“" (1528).

[Quelle: Die Zeit. Das Lexikon in 20 Bänden. Hamburg, Zeitverlag, 2005, Bd. 3, S. 601 f.] 


\section{Arbeitsblatt 5: Künstlerbiografien II - Hans Holbein d.J.}

Holbein, Hans d.J., Maler und Zeichner, *Augsburg 1497, begraben London 29.11.1543; gehört zu den bedeutendsten Vertretern der dt. Renaissance; lernte wie sein Bruder Ambrosius H. (*1494, †1519 oder 1520) bei seinem Vater und ging 1515 nach Basel, von wo aus er Frankreich und 1526-28 England besuchte. 1532 ließ er sich endgültig in London nieder. 1536 wurde er Hofmaler Heinrichs VIII. - In Basel entstanden außer Fresken, die zugrunde gegangen, aber durch Entwurfszeichnungen bekannt sind (Wandbilder im Baseler Rathaussaal, einige Bruchstücke erhalten), Altarbilder, graf. Arbeiten (bes. für Bücher: 58 Holzschnitte „Totentanz“; 1523-26, 1538 veröffentlicht) sowie 91 zum A.T. (vor 1531, 1538 veröffentlicht), Zeichnungen für Glasmalereien und v.a. Porträts. In London malte er Wandbilder für die dt. Kaufleute im Stalhof und für Heinrich VIII. in Whitehall, die nicht erhalten sind, und seine reifsten Bildnisse. Auch wenn er den Auftraggeber im Prunkgewand und mit reichem Beiwerk malte, blieb ihm das Wichtigste die Darstellung des Menschen. Zu seinen Meisterwerken zählen das „Doppelporträt des Basler Bürgermeisters Jacob Meyer zum Hasen und seiner Frau Dorothea“ (1516, Basel), „Die Gesandten“ (1533, London) und die in Basel befindl. Bilder „Adam und Eva“ (1517), „Bildnis des Bonifacius Amerbach“ (1519), „Der tote Christus im Grabe“ (um 1521/22). Meisterl. Darstellungen sind auch die Bildnisse des Erasmus von Rotterdam (1523, Longford Castle, Basel, Paris), die „Madonna des Basler Bürgermeisters Jacob Meyer zum Hasen“ (1526-30, Darmstadt), das Porträt seiner Frau mit den beiden älteren Kindern (1528, Basel), das „Bildnis des Kaufmanns Georg Gisze“ (1532, Berlin) sowie die Porträts von Angehörigen der engl. Königsfamilie und des Hofes [...].

[Quelle: Die Zeit. Das Lexikon in 20 Bänden. Hamburg, Zeitverlag, 2005, Bd. 6, S. 471.] 


\section{Arbeitsblatt 6: Künstlerbiografien III - Lucas Cranach d.Ä.}

Cranach, Lucas d.Ä., Maler und Zeichner, *Kronach Okt. 1472, †Weimar 16.10.1553. Seine ersten bekannten, seit etwa 1500 in Österreich entstandenen Werke, in denen sich Figurendarstellung und Landschaft zu maler. Einheit verbinden, gehören zugleich zu den frühesten Bildern der Donauschule. 1505 wurde er von Friedrich dem Weisen nach Wittenberg berufen, wo sich seine Kunst sehr bald zur linienbetonten Form seiner Spätzeit zu wandeln begann. Durch die Aufnahme des weibl. Aktes, v.a. unter mytholog. Vorwand, wurde sein Themenkreis erweitert. C. wurde durch seine Freundschaft mit Luther und Melanchthon zum Schöpfer einer prot. Kunst (u.a. Holzschnitte zur Bibel und für Reformationsschriften). Die Ausführung der Aufträge für Bildnisse, religiöse und mytholog. Bilder überließ C. immer mehr seiner Werkstatt, in der auch seine Söhne Hans C. (*um 1510, †1537) und v.a. Lucas C. d.J. $(* 1515, \uparrow 1586)$ arbeiteten.

Werke: Klage unter dem Kreuz (1503; München, Alte Pinakothek); Ruhe auf der Flucht (1504; Berlin, Gemäldegalerie); Katharinenaltar (1506; Dresden, Staatliche Kunstsammlungen); Torgauer Altar (1509; Frankfurt am Main, Städelsches Kunstinstitut); Venus und Amor (1509; Sankt Petersburg, Eremitage); Der Jungbrunnen (1544; Berlin, Gemäldegalerie); dazu Marienbilder, Bildnisse der Reformatoren und sächs. Fürsten, Holzschnitte, Kupferstiche.

[Quelle: Die Zeit. Das Lexikon in 20 Bänden. Hamburg, Zeitverlag, 2005, Bd. 3, S. 179f.] 


\section{Arbeitsblatt 7: Renaissance und Humanismus I}

Das ganze Mittelalter hindurch hatte die große Mehrheit der Menschen in Europa ein festgefügtes Weltbild. Die Zustände im Himmel und auf Erden betrachteten sie als von Gott gegeben und darum ewig und unerschütterlich. Nun aber traten Gelehrte und Künstler auf, die dieses Weltbild nicht mehr akzeptieren wollten. Sie stellten sich eine bessere und gerechtere Welt vor. Interessanterweise schauten sie beim Entwurf dieser Welt aber nicht nach vorn, sondern erst einmal weit zurück: in die Welt der Griechen und Römer, die ihnen heller als die eigene erschien. Das nun beginnende Zeitalter hat davon seinen $\mathrm{Na}$ men: „Renaissance“ - Wiedergeburt.

Die mittelalterlich-christliche Vorstellung, das Leben diene zuallererst der Vorbereitung auf das Jenseits, wollten die Gelehrten und Künstler nicht mehr gelten lassen. Sie wandten sich dem Diesseits zu und rückten den Menschen in den Mittelpunkt ihres wissenschaftlichen und künstlerischen Interesses. Der Mensch wurde nicht mehr als Teil eines Ganzen gesehen, sondern als Wesen, das seinen Zweck in sich selbst hat. Die Menschen sollten über sich und ihr Leben selbst entscheiden und ihre Fähigkeiten voll entfalten können. Als Voraussetzung dafür galt den Denkern der Renaissance eine umfassende, am antiken Vorbild orientierte Bildung. Die geistige Bewegung entstand zuerst in Florenz und Venedig, wo die europäische Kultur zu dieser Zeit am höchsten entwickelt war. Weil der Mensch im Mittelpunkt dieses Denkens stand, spricht man vom „Humanismus“.

Die Humanisten gewannen ihre neuen Erkenntnisse nicht aus der Bibel, sondern indem sie den Menschen und die Natur genau beobachteten und erforschten. So auch der Italiener Leonardo da Vinci (1452-1519), der als Inbegriff des neuen, des Renaissance-Menschen gilt. Er schuf nicht nur Kunstwerke wie die berühmte „Mona Lisa“ und „Das Abendmahl“; er war auch Bildhauer, Wissenschaftler, Architekt, Techniker und Erfinder. Man kennt von ihm sogar Pläne für Flugmaschinen. Er sezierte Leichen, weil er verstehen wollte, wie der Mensch genau gebaut ist und funktioniert, und dokumentierte, was er sah, in anatomischen Zeichnungen. Dabei war sich das Universalgenie Leonardo da Vinci seiner Verantwortung als Wissenschaftler und Erfinder so bewusst, wie man es sich von jedem Wissenschaftler wünschen möchte: „Ich weiß“, schrieb er, „wie man sich unter Wasser aufhalten und lange ohne Nahrung bleiben kann. Aber ich veröffentliche es nicht und erkläre es niemandem. Denn die Menschen sind böse und würden diese Kunst dazu verwenden, um auch auf dem Meeresgrund zu morden. Sie würden den Boden der Schiffe anbohren und sie mit allen Menschen, die darinnen sind, versenken.“

Würde man eine Aufstellung der großen Geister der Weltgeschichte versuchen, wäre die Renaissance wie kein anderes Zeitalter vertreten. Leonardos Landsmann Michelangelo, der Maler und Bildhauer, Erasmus von Rotterdam, der große Humanist und Philosoph, Nikolaus Kopernikus, der Astronom, der entdeckte, dass die Erde ein Planet ist und wie die anderen Planeten um die Sonne kreist - sie alle lebten in dieser Zeit. Dass ihre neuen Gedanken und Erkenntnisse schneller verbreitet werden konnten als jemals zuvor, hatten sie der wohl wichtigsten Erfindung der Renaissance zu verdanken: dem Buchdruck. Um 1450 war es dem Mainzer Johannes Gutenberg erstmals gelungen, Bücher mit beweglichen Buchstaben aus Metall zu drucken. Das ging schneller und war billiger, als Bücher mit der Hand zu schreiben oder mit hölzernen Druckstöcken herzustellen. Nun konnten beliebig viele Exemplare eines Buches in gleicher Qualität angefertigt werden. „Das größte Ereignis der Weltgeschichte“ nannte der französische Dichter Victor Hugo später Gutenbergs Erfindung. [Quelle: Mai, Manfred: Europäische Geschichte. München, Hanser, 2007, S. 65ff.] 


\section{Arbeitsblatt 8: Renaissance und Humanismus II}

Humanismus [nlat.] der, i.w.S. eine sich auf Humanität richtende geistige Haltung. In der europ. Geistesgeschichte ist der H. eine geistige Bewegung, die im Zeitalter der Renaissance aus der Bildung an dem neu entdeckten geistigen Gut der Antike ein neues Menschenbild und Selbstverständnis gewann und sich damit gegen die Scholastik des MA. wandte. Dieser Renaissance-H. bildete sich seit dem 14. Jh. in Italien. Zunächst griffen v.a. Bürgerliche außerhalb von Wiss. und Univ. auf lat. Schriftsteller, bes. Cicero, zurück, der v.a. von Petrarca als Muster der klass. Sprache, der hohen Rede (eloquentia), gefeiert wurde. Bei diesem Rückgriff auf die Lit. und Kultur des antiken Römertums blieb die mittelalterl. Frömmigkeit im Wesentlichen erhalten. Durch Vermittlung byzantin. Philologen nahm seit dem 15. Jh. auch die Beschäftigung mit dem grch. Schrifttum zu. Der Kreis der bekannten antiken Schriftsteller erweiterte sich bald durch systemat. Sammeln von Handschriften (Bibliotheken). Zugleich wetteiferten die Humanisten mit dem lat. Vorbild in Vers und Prosa; daraus entstand eine neulateinische Literatur. Die christl. Lehre versuchte der $H$. in einer Weise auszulegen, die den sittl. Gehalt der Evangelien mit der Ethik der nichtchristl. Antike (v.a. Platon, Stoa) versöhnen wollte. Nach Anfängen im 14. Jh. am Hof Karls IV. (Johannes von Neumarkt) und an einigen Univ. war er in Dtl. im 15. Jh. voll entwickelt (R. Agricola, K. Celtis, G. Heimburg, J. Reuchlin u.a.). Die Hochstimmung der Blütezeit des H. in Dtl. zeigen die „Epistolae obscurorum virorum“ (Dunkelmännerbriefe) mit ihrer Satire auf das Mönchslatein der Scholastik. Der H. wirkte außer auf Lit. und Philologie auch auf die naturwiss. Forschung (Regiomontanus) und v.a. auf das Schulwesen (J. Wimpfeling u.a.); bes. im 16. Jh. trug er nationale Züge (U. von Hutten). Luthers Reformation erwies sich als stark humanistisch beeinflusst. $\mathrm{Zu}$ einem eigentl. Bündnis zw. $\mathrm{H}$. und Reformation ist es jedoch nicht gekommen. Bed. Anhänger fand der H. auch in den Niederlanden (Erasmus von Rotterdam, J. Lipsius, Gerardus J. Vossius [*1577, †1649], D. Heinsius, H. Grotius u.a.), in England (T. More) und Frankreich (G. Budaeus). Dieser H. wirkte bis in das 20. Jh. fort (Neuhumanismus), löste sich aber seit dem 19. Jh. von seiner ursprüngl. Intention der individuellen Bildung und wurde im Zusammenhang eines die Welt verändernden philosoph. Systems eher zum gesellschaftl. Postulat (philosophischpolit. H.). In Anknüpfung an Hegels Dialektik von „Herr und Knecht“ sah Marx als realen H. die Aufhebung der Selbstentfremdung des Menschen durch den Kommunismus an.

[Quelle: Die Zeit. Das Lexikon in 20 Bänden. Hamburg, Zeitverlag, 2005, Bd. 6, S. 538f.] 


\section{Arbeitsblatt 9: Porträts im Vergleich}

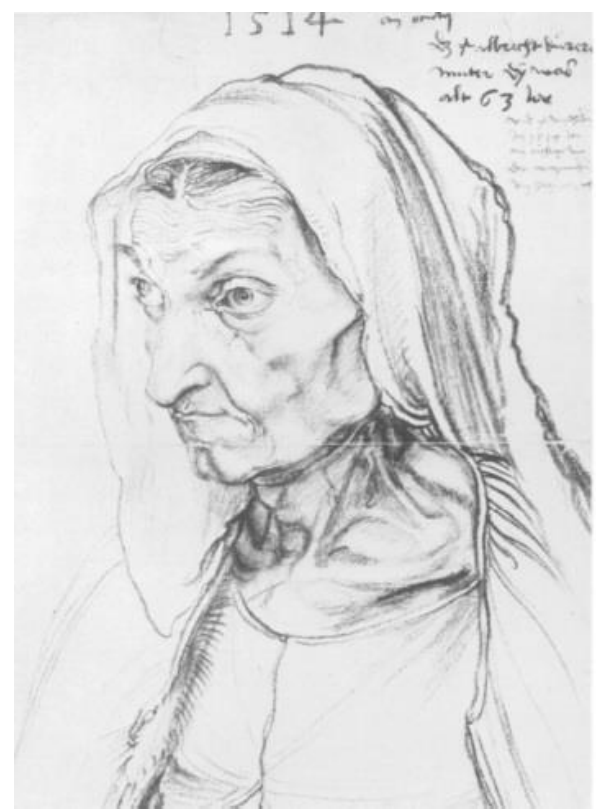

Albrecht Dürer: Die Mutter des Künstlers im Alter von 63 Jahren, 1514.

Kohlestift auf Papier. Berlin, Kupferstichkabinett.

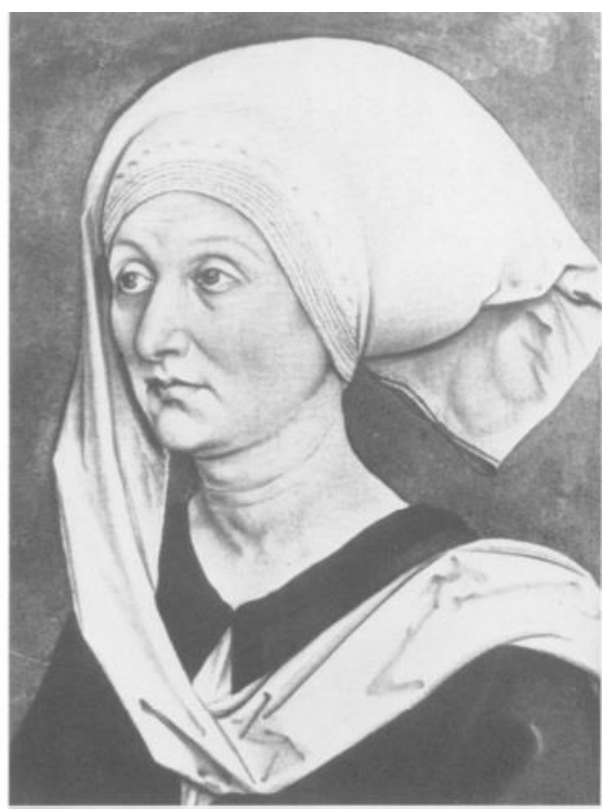

Albrecht Dürer: Porträt der Barbara Dürer, geb. Holper, um 1490-93.

Ö1 auf Holz. Nürnberg, Germanisches Nationalmuseum 


\title{
Bilderbuch einer Freundschaft? Die deutsch-französische Geschichte in Bild- und Tondokumenten des 19. und 20. Jahrhunderts
}

\author{
Franziska Flucke
}

Visuelle und audiovisuelle Dokumente bieten nicht nur zahlreiche Sprechanlässe für den modernen Fremdsprachenunterricht, sie ermöglichen auch einen motivierenden Einstieg in Themen der Landeskunde sowie eine intensive Auseinandersetzung mit der Geschichte eines Landes. In Zeiten der Kommerzialisierung von Geschichtskultur, der gesteigerten Präsenz und Vielfalt historischer Inhalte in der deutschen Medienlandschaft werden historische Inhalte immer mehr auf ikonischvisuellem Weg transportiert, rezipiert und erinnert. Aus diesem Grund ist die gezielte Förderung einer „visual literacy“ (Popp 2010: 339) auch im Fremdsprachenunterricht Deutsch zunehmend bedeutend.

Der Beitrag möchte zeigen, wie vielfältig ikonographische Dokumente im landeskundlich orientierten Fremdsprachenunterricht eingesetzt werden können. Thematisch orientiert sich die Arbeit anlässlich des 50. Jahrestages der Unterzeichnung des Elysee-Vertrages an Dokumenten zu den deutsch-französischen Beziehungen im 19. und 20. Jahrhundert, dazu gehören Gemälde, Karikaturen, Plakate, Fotos, Postkarten sowie Videodokumente, wobei der Schwerpunkt auf Fotos und Karikaturen liegt. Ziel ist dabei nicht eine „deutsch-französische Meistererzählung“ zu „propagieren“ sondern vielmehr Möglichkeiten aufzuzeigen, wie diese zusammen mit den Lernenden im Unterricht dekonstruiert werden kann. Dabei bedient sich der Aufsatz u.a. des Ansatzes der „Erinnerungsorte“ nach Pierre Nora, der sich in der Geschichtswissenschaft zunehmend etabliert, um Formen des kulturellen Ge- 
dächtnis und dessen Fortleben in der Gesellschaft auszuloten ${ }^{1}$ und der sich besonders für die Vermittlung landeskundlicher Themen im DaF-Unterricht eignet (Koreik 2012: 6).

Zunächst soll das didaktische Potential der Geschichte der deutsch-französischen Beziehungen für den Landeskundeunterricht der Auslandsgermanistik kurz beleuchtet werden. Danach werden Argumente für die Arbeit mit den unterschiedlichen Bilddokumenten erläutert, um anschließend konkrete Anregungen für den Unterricht zu geben.

\section{Deutsch-Französische Geschichte ist überall}

Schon der einfache Berlintourist begegnet beim Besuch der Monumente der Hauptstadt auf Schritt und Tritt der deutsch-französischen Geschichte: Beispielsweise wurde die Quadriga mit der geflügelten Siegesgöttin Viktoria des Brandenburger Tores, 1793 vom Bildhauer Johann Gottfried Schadow gefertigt, nach der verlorenen Schlacht bei Jena und Auerstedt 1806, während Napoleons Truppen Berlin besetzten, nach Paris abtransportiert. Welche Demütigung für die Berliner! Doch nachdem acht Jahre später die alliierten Truppen bei Waterloo über Napoleon gesiegt hatten, zog Büchner siegreich in Paris ein, wo er die Quadriga, noch in Kisten verpackt, wiederfand. Er ließ sie zurück nach Berlin bringen, damit sie dort nach Restaurierungsarbeiten ihren ursprünglichen Platz wieder einnehmen konnte. Die Berliner gaben ihr darauf den volkstümlichen Namen „Retourkutsche“, welcher nach und nach in den deutschen Sprachgebrauch überging (vgl. Pandel 2009: 103). Weitere Beispiele sind die Berliner Siegessäule und der Französische Dom, beide lassen sich ebenfalls in den deutsch-französischen Beziehungen verorten.

Im Kontext der europäischen Integration und in Zeiten der Euro-Krise schaut auch das Ausland immer wieder auf Deutschland und Frankreich. So stieß der aufmerksame Zeitungsleser in letzter Zeit auf zahlreiche Artikel zu den Beziehungen der beiden Länder. Denn im sogenannten „Deutsch-Französischen Jahr“ 2012/13 begingen Deutschland und Frankreich mit zahlreichen Veranstaltungen den 50. Jahrestag der Unterzeichnung des Elysee-Vertrags vom 22. Januar 1963 zwischen dem deutschen Bundeskanzler Konrad Adenauer und dem französischen Staatspräsidenten Charles de Gaulle. Das Thema hat somit einen großen Aktualitätsbezug, was für die Einbettung historischer Themen in den DaF-Unterricht wichtig ist (vgl. Koreik 2012: 2f.). Zudem ist es wichtig, dass Lernende der deutschen Sprache auch einen Einblick in die Beziehungsgeschichte der beiden Länder bekommen, weil der europäische Einigungsprozess ohne Deutschland und Frankreich nicht möglich gewesen wäre. Die beiden Länder haben über viele Jahrhunderte die Geschichte des europäischen Kontinents beeinflusst, und ihre Beziehungsgeschichte und das dichte Netz der Kooperationen hat in vielen Bereichen

\footnotetext{
${ }^{1}$ Zur europaweiten Übernahme des Konzepts vgl. Konczal 2011, zum Einsatz des Konzepts im DafUnterricht siehe Schmidt; Schmidt 2007.
} 
Vorbildcharakter (vgl. Seidendorf 2013: 243). Dabei ist auch die Frage nach dem Dritten in den deutsch-französischen Beziehungen interessant, z.B. im Rahmen des Weimarer Dreiecks mit Polen. Anderseits können an dem deutsch-französischen Beispiel interkulturelle Phänomene beleuchtet werden, wie sie auch in anderen zwischenstaatlichen Beziehungen auftreten, so dass damit der Anforderung einer kontrastiven Landeskundevermittlung ebenfalls Rechnung getragen und exemplarisches Arbeiten ermöglicht wird, was Wahrnehmung und Reflexion der Studierenden schult (vgl. Koreik 2012:4f).

\section{Methodische Aspekte - Argumente und Hinweise für die Arbeit mit Bildmaterial}

Bilder können Geschichte machen. Die visuellen Medien und ihre Erzeugnisse haben im letzten Jahrhundert Politik, Wirtschaft und Kultur entscheidend geprägt und die Allgegenwart von Bildern wurde zur zentralen Erfahrung der Menschen. Dies gilt umso mehr seit der flächendeckenden Nutzung des Internets und besonders sozialer Netzwerke wie Facebook. Somit sind Fotos und weitere ikonographische Dokumente Gegenstände, die die Studierenden aus dem Alltag sehr gut kennen. Den kritischen und wissenschaftlichen Umgang damit müssen sie aber noch lernen.

Bilder sind zudem Teil des kollektiven Gedächtnisses, Bilder in Verbindung mit Geschichte sind den Studierenden bereits aus den Geschichtsbüchern, der „amtlichen Version des kollektiven Bildgedächtnisses“ (Pandel 2009: 100) bekannt. Dabei sollen sie aber möglichst nicht nur als Illustration, sondern als Quelle eigener Art wahrgenommen werden. Sie können im Bereich der Ereignisgeschichte (Dokument für das Stattfinden bestimmter Ereignisse), der Sachkultur (Informationsquelle über Wohnen, Kleidung, Arbeit und Technik zu einer bestimmten Zeit), der Mentalitätsgeschichte (gesellschaftliche Wertvorstellungen, soziale Beziehungen, Wahrnehmungen und Haltungen) sowie bei der Analyse jeglicher „Propaganda“ eingesetzt werden (vgl. Sauer 2008: 193f). Für die engere Interpretation ikonographischer Dokumente hat sich das dreistufige Schemas des Kunsthistorikers Erwin Panowsky bewährt, welches je nach Situation angepasst werden sollte (vgl. Sauer 2008: 197f). ${ }^{2}$

Für die Arbeit an historischen Themen im Sprachunterricht sind Bildquellen von besonderer Bedeutung. Sie bieten zahlreiche Sprechanlässe und eignen sich aus mehreren Gründen sehr gut für Einstiege in eine Unterrichtsstunde oder sogar in eine ganze Einheit. Die Lernenden können Bilddokumente zunächst auf der reinen Beschreibungseben kommentieren. So finden sofort erste Sprachhandlungen in der Zielsprache statt, auch auf Anfängerniveau. Dafür kann die Lehrkraft bei

\footnotetext{
2 Das Schema wurde ursprünglich für Meisterwerke der Malerei der frühen Neuzeit verwendet. Eine vereinfachte, für den Daf-Unterricht geeignete Variante befindet sich am Ende des Beitrags. Zum Umgang mit Bilder im Geschichtsunterricht vgl. Buntz; Erdmann (2009).
} 
Bedarf Vokabelhilfen zur Verfügung stellen und/oder Satzanfänge wie „Ich sehe... “, „Das Bild zeigt ... " oder „Im Vordergrund/Im Hintergrund sehe ich ... “vorgeben. Dieses Vorgehen fördert zudem das genaue Hinsehen und verhindert, gleich in die Analyse und Interpretation überzugehen (Vgl. Sauer 2008: 198). Hilfreich kann auch ein Glossar mit wichtigen Begriffen zur Bildbeschreibung sein, das den Lernenden als Methodenwerkzeug zur Verfügung steht.

Zweitens können Bilddokumente Vorwissen aktivieren und die Studenten somit auf den Stundeninhalt einstimmen. Ausgehend von bekanntem Bildmaterial können neue Dokumente und somit neues Sachwissen eingeführt werden. So kann beispielsweise eine Gegenüberstellung von Herrscherbildern für die Lerngruppe sehr gewinnbringend sein. Das im europäischen Bilderkanon durchaus sehr bekannte Portrait des absolutistischen Herrschers Ludwig XIV. von Hyacinte Rigaud lässt sich mit einem Herrscherporträt Friedrichs II. von Preußen vergleichen. Daraus können die Studierenden Rückschlüsse auf das Selbstverständnis des Herrschers und seine Herrschaftsform (Absolutismus versus aufgeklärten Absolutismus) ziehen.

Die Geschichtsdidaktik kennt zahlreiche Methoden im Umgang mit Bildern, die auch den Fremdsprachenerwerb fördern können. So ist es denkbar, eine Geschichte zu einem Bild gemeinsam oder als Einzelarbeit zu schreiben oder einen Kommentar zu verfassen. Es ist auch möglich, mit Sprech- und Denkblasen zu arbeiten, die die Studierenden ergänzen müssen (siehe Abb. 1). Das fördert den kreativen Umgang mit der Sprache und ist ferner dazu geeignet, unterschiedliche Perspektiven, die in einem Bild angelegt sind, nachzuvollziehen und in der Zielsprache zu verbalisieren. 


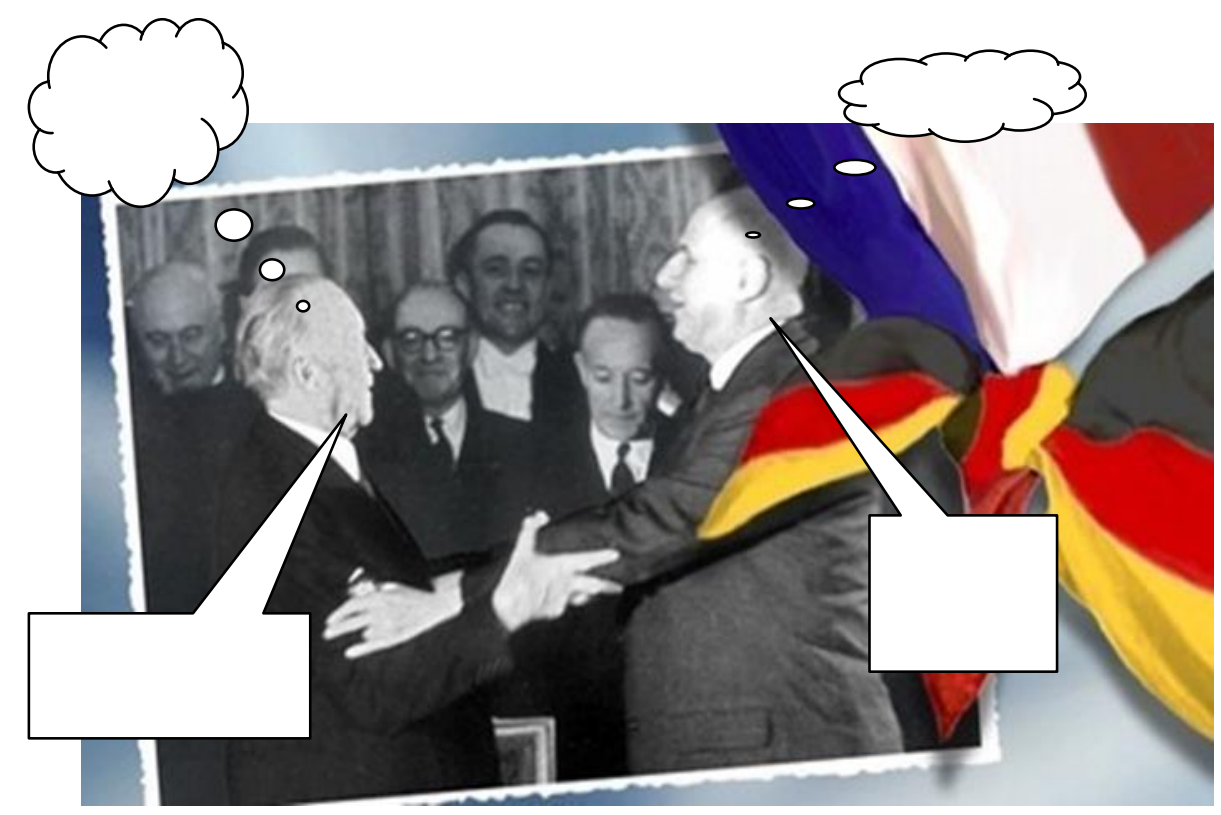

Abb. 1: Charles de Gaulle und Konrad Adenauer nach der Unterzeichnung des Elysee-Vertrag, Quelle: www.br.de vom 18. Juli 2012.

Für Studierende anderer Unterrichtstraditionen, z.B. Deutschlerner aus Frankreich, zeigt diese Variante zugleich einen neuen methodischen Umgang mit Geschichte, den sie aus ihrem Geschichtsunterricht nicht kennen. Dazu gehören auch Methoden wie das Nachstellen oder Nachspielen von Bildszenen. Dabei können Haltungen und Gefühle der Personen im Bild nachvollzogen, beschrieben und kommentiert werden (vgl. Sauer 2008: 201). Wie bereits angesprochen können auch Bildvergleiche sehr gewinnbringend sein. Darstellungen der Germania, der Marianne und andere nationale Allegorien des 19. Jahrhunderts verraten viel über die Selbstund Fremdwahrnehmung der werdenden Nationalstaaten zu dieser Zeit. Aus Perspektive der Sprachvermittlung sind bildliche Darstellungen somit ideale Stimuli für die Produktion von Sprechakten, welche über die historische und interkulturelle Komponente hinaus in mündliche oder schriftliche Textproduktionen (Zeitungsartikel, Briefe, Dialoge, Sketche usw.) münden können (Vgl. Sistig 2012: 178).

\subsection{Die Arbeit mit Fotos}

Die Fotographie ist die wichtigste Bildgattung für die Zeitgeschichte. Sie erlaubt eine große Annäherung an die Wirklichkeit und verfügt über einen hohen dokumentarischen Wert. Allerdings sind Fotos zugleich vielen Einflüssen ausgesetzt, die 
die Bildgestaltung und -reproduktion bestimmen. Fotos können retuschiert werden, wie dies bsw. in der stalinistischen Sowjetunion oft der Fall war, um die Geschichte umzuschreiben. Sie können auch so beschnitten werden, dass sich eine besonders interessante Perspektive ergibt, was oft bei Pressefotos der Fall ist. Fotos können nachgestellt sein und damit Geschichte inszenieren, die so nie stattgefunden hat. Hier sei nur an den Rotarmisten erinnert, der die sowjetische Flagge auf dem Reichstag hisst (vgl. Sauer 2008: 202f.). Fotos prägen auch unsere Erinnerung an die Vergangenheit: „Habe ich das wirklich so erlebt, oder erlebe ich das jetzt nur so, weil ich mir dieses Foto nach Jahren wieder anschaue?" (NielsenSikora 2012:72). Wir behalten beispielsweise, sei es im privaten oder im politisch öffentlichen Leben, bestimmte Ereignisse nur deshalb in Erinnerung, weil wir mehrmals das Foto betrachten und dadurch das Erinnerungsbild reproduzieren (ebd.: 2012: 74). Deshalb müssen Fotos als historische Quelle sorgfältig geprüft und interpretiert werden. Der Bilderkanon eines Landes gibt uns Auskunft, welches „Bild“ ein Land von sich selbst macht. Übertragen auf die deutsch-französischen Beziehungen heißt das, welches Bild die beiden Länder von ihrer Beziehung zueinander geben und wie sie als „Paar" wahrgenommen werden wollen.

Sauer (2008: 203) bietet ein eigenes Schema zur Analyse von Fotos an. Er geht dabei auf die Punkte Bildentstehung (Situation und Zeit, Szene oder Motiv, Fotograf, Auftraggeber, Zielpublikum ein); Bildgestaltung (Figuren, Gegenstände, Konturen, Kompositionsschema, technische Mittel wie Ausschnitt, Perspektive und Einstellung), Bildbearbeitung und -Präsentation (nachträgliche Bearbeitung, Zusammenhang der Präsentation, Bildlegende, Kommentar) ein, um abschließend den Quellenwert des Fotos bestimmen zu können.

Methodisch lassen sich Legenden schreiben, aber z.B. auch Familienbilder bezüglich ihrer historischen Aussagekraft analysieren und vergleichen. Dies ist sicherlich besonders in kulturell heterogenen Lerngruppen sehr interessant.

Für die deutsch-französischen Beziehungen bietet es sich an, die verschiedenen Fotos der Politikerpaare seit Konrad Adenauer und Charles de Gaulle vergleichend zu analysieren (siehe Arbeitsblatt 2). Daran können die Studierenden die Inszenierung von Geschichte und die Rolle symbolischer Orte in den deutsch-französischen Beziehungen nachvollziehen. Ergänzend bietet sich dazu der auf DVD oder youtube verfügbare Beitrag von Karambolage (Clairon 2004) an, weil er drei inszenierte Begegnungen bezüglich Gestik, Mimik und Aussagekraft auf amüsante Weise analysiert. ${ }^{3}$

\subsection{Die Arbeit mit Karikaturen}

Karikaturen sind sowohl im Sprach- wie im Landeskundeunterricht sehr vielseitig einsetzbar, weil sie einen sehr hohen Aufforderungscharakter haben. Hinsichtlich

\footnotetext{
3 Auch die Fotostrecke von Spiegelonline.de kann sehr interessant sein: http://www.spiegel.de/ fotostrecke/merkel-und-sarkozy-kuesschen-in-paris-fotostrecke-48728-5.html vom 11.11.2009.
} 
der formalen Darstellungsform sind apersonale Sachkarikaturen, personale Typenkarikaturen sowie die personale Individualkarikatur zu unterscheiden. Für die Beschreibung einer Karikatur sollte man in drei Schritten vorgehen: Zunächst kommt immer die Beschreibung der Karikatur. Diese sollte möglichst präzise sein. Jede Information, die für die Interpretation nützlich sein könnte, muss klar und deutlich beschrieben werden. Als nächstes folgt die Interpretation der Karikatur. In diesem Schritt werden nun die zuvor lediglich beschriebenen Dinge in der Abbildung mit einem Sinn verbunden. Es werden Zusammenhänge geknüpft und der dargestellte Sachverhalt kurz erläutert. Erst in einem dritten Schritt darf eine persönliche Wertung eingebracht werden. Dabei sollte(n) zunächst noch einmal die Kernaussage(n) der Karikatur möglichst genau definiert werden, bevor persönlich Stellung bezogen wird, indem z.B. dargelegt wird, inwieweit man der Aussage des Karikaturisten zustimmt oder nicht. Diese methodische Dreiteilung bereitet den Studenten häufig Schwierigkeiten und sollte deshalb mehrmals eingeübt werden.

Die Geschichte der deutsch-französischen Beziehungen lässt sich mit Hilfe von Karikaturen sehr anschaulich vermitteln. Eine Karikatur von Fritz Behrend aus dem Jahr 1988 thematisiert auf amüsante Weise den Wandel der deutsch-französischen Beziehungen (siehe Abb. 2) und eignet sich hervorragend als Einstieg in eine Unterrichtssequenz über Klischees und Vorurteile. In einem ersten Schritt können die Studenten die Karikatur beschreiben. Dazu ist es hilfreich, einige Vokabelhilfen vorzugeben, bzw. das nötige Vokabular zunächst gemeinsam zu erarbeiten (siehe Tabelle 1).

Auf der Karikatur sind acht Personen in zwei Reihen angeordnet. Sie tragen unterschiedliche Kleidung und halten diverse Gegenständen in der Hand.

Tabelle 1:

\begin{tabular}{|l|l|l|}
\hline \multicolumn{1}{|c|}{ Vokabel } & Erklärung / Übersetzung & $\begin{array}{c}\text { Bedeutung in der } \\
\text { Karikatur }\end{array}$ \\
\hline die Pickelhaube & & \\
\hline der Dolch & & \\
\hline die Wikingerhaube & & \\
\hline die Fackel & & \\
\hline der Tiroler Hut & & \\
\hline das Bier & & \\
\hline
\end{tabular}




\begin{tabular}{|l|l|l|}
\hline die Weißwurst & & \\
\hline der Dreispitz & $\begin{array}{l}\text { = die phrygische Mütze (ty- } \\
\text { pische Kopfbedeckung der } \\
\text { Revolutionäre und Symbol } \\
\text { der französischen Repu- } \\
\text { blikaner; in der Antike be- } \\
\text { reits Symbol für freigelas- } \\
\text { sene Sklaven) }\end{array}$ & \\
\hline die Baskenmütze & dastreitsmüre & \\
\hline der Rotwein & & \\
\hline
\end{tabular}

In einem zweiten Arbeitsschritt können die Studenten anschließend die Entwicklung beschreiben und versuchen, den einzelnen Personen bestimmte Zeitabschnitte zuzuordnen. Die Karikatur thematisiert die deutsch-französischen Beziehungen im Laufe der letzten 200 Jahre und zeigt das Feindesbild und die Klischee der jeweiligen Zeit. Die ersten beiden Personen spielen auf den Preußenstaat und das Napoleonische Frankreich an. Die sogenannte Pickelhaube war eine Kopfbedeckung preußischer Soldaten bis in den Ersten Weltkrieg und ist ein Symbol des preußischen Militarismus (Pandel 2009: 103). Der Dreispitz dagegen symbolisiert das napoleonische Frankreich. Da beide mit einem Dolch im Mund dargestellt werden, ist davon auszugehen, dass in der Zeit beide den Nachbarn als sehr kriegerisch wahrgenommen haben. Dies lässt sich zum Beispiel mit den Feldzügen Napoleons sowie den anschließenden Befreiungskriegen erklären. Die deutsche Nationalbewegung entwickelt sich in starker Abgrenzung zum westlichen Nachbarn und das Erbfeind-Denken nimmt hier einen Ursprung. ${ }^{4}$

Das zweite „Pärchen“ zeigt die wütende Germania und eine zur Revolution bereite Marianne. Es handelt sich hierbei um zwei Allegorien, die das jeweilige wütende Volk repräsentieren. Die beiden lassen sich zeitlich schwerer zuordnen, sollen aber vermutlich ebenfalls auf das 19. Jahrhundert sowie den Beginn des 20 . Jahrhundert anspielen, werden beide doch als fanatische Revolutionäre dargestellt.

\footnotetext{
4 Zur Vertiefung ist es denkbar hier, das Zitat von Ernst Moritz Arndt „Ich will den Haß gegen die Franzosen, nicht bloß für diesen Krieg, ich will ihn für immer.“ einzubauen. (Zitiert nach Tiemann (1998: 28) Ratsam ist in dem Zusammenhang aber auch auf Gegentendenzen wie sie beispielsweise von dem in Paris lebenden Heinrich Heine ausgingen, hinzuweisen.
} 
In dieser Zeit der Nationalstaatenbildung waren Allegorien wie die Germania und die Marianne häufige Motive für Künstler. ${ }^{5}$

Das dritte Pärchen zeigt die unpolitischen Durchschnittsbürger beider Länder mit traditioneller Kleidung und den Gegenständen, die dem Klischee des Anderen entsprechen (der gemütliche Bayer mit einem Glas Bier und der Franzose mit Rotwein und Baguette). Diese folkloristische Darstellung spielt auf die Zeit nach dem Zweiten Weltkrieg an. Um den Anderen identifizieren zu können, wird er mit unpolitischen Attributen beschrieben.

Das vierte Pärchen lässt nur noch anhand der Haarfarbe unterscheiden und greift weder Klischees noch Stereotype auf; es soll wahrscheinlich die Gegenwart darstellen.
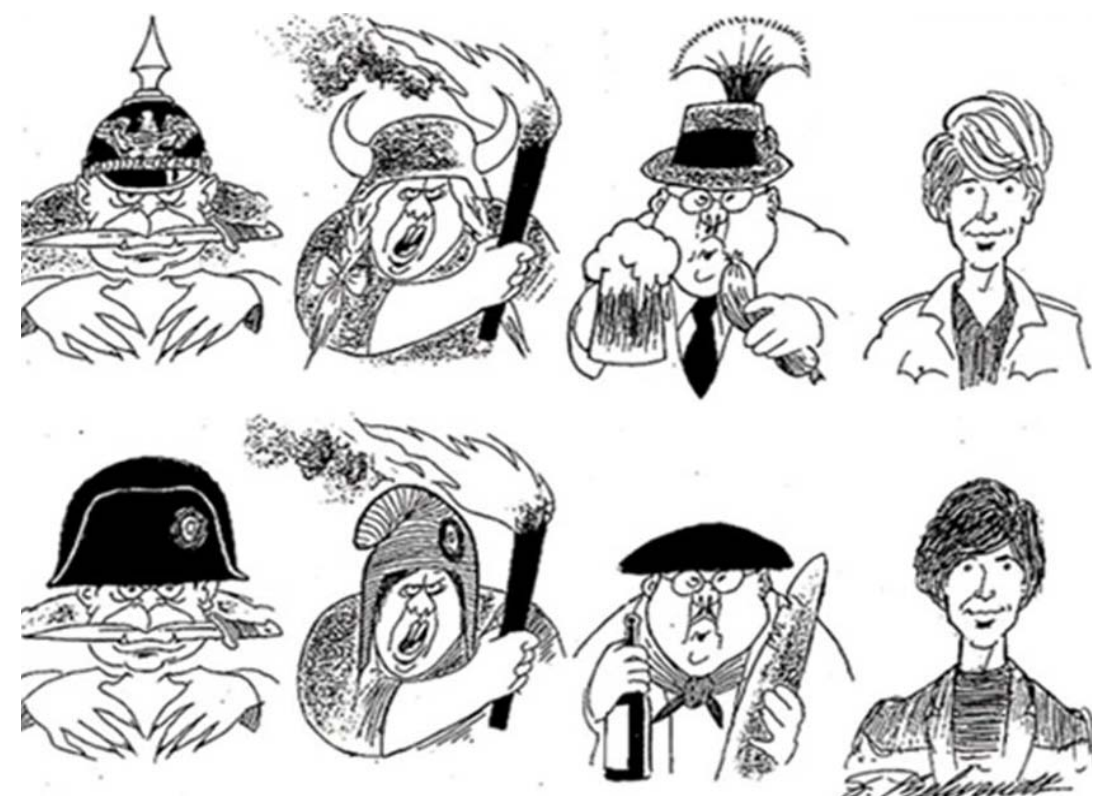

Abb. 2: Karikatur von Fritz Behrend: „Deutsch-französisches Verhältnis. Das Bild des anderen im Wandel der Zeit", 1988.

Die Karikatur suggeriert, dass die Deutschen und Franzosen eigentlich schon immer gleich waren und sich im Laufe der Geschichte zudem auch äußerlich mehr angenähert haben, so dass heute keinerlei Unterschiede mehr zu erkennen seien.

\footnotetext{
${ }^{5}$ Es sei hier nur auf Germaniadarstellungen von Christian Köhler, von Philip Veit und von Lorenz Clasen, alle zweite Hälfte des 19 Jahrhunderts entstanden, hingewiesen. Die ikonische Referenz der Germania sowie der Marianne wurde in der Zwischenkriegszeit in zahlreicheichen Varianten wiederaufgenommen, vgl. Popp 2009.
} 
Aus zwei sich kämpferisch gegenüberstehenden Völkern sind friedliche Nachbarn geworden. Letzteres sei besonders den zahlreichen zivilbürgerlichen Initiativen seit dem Ende des Zweiten Weltkriegs zu verdanken. Eine entscheidende Rolle spielten dabei auch die jeweiligen Staats- und Regierungschefs beider Länder. 1963 unterschrieben sie den Elysée-Vertrag und legten damit die Grundlage für zahlreiche Kooperationen zwischen den einstigen „Erbfeinden“ ${ }^{6}$ Diese Darstellung entspricht somit zugleich einer deutsch-französischen „Meistererzählung“, die die Wirklichkeit inszeniert, d.h. ein deutsch-französischen „Versöhnungsnarrativ“ etabliert, wobei die Geschichte der deutsch-französischen Aussöhnung zum Modell in Europa wird (Defrance 2013: 16f.).

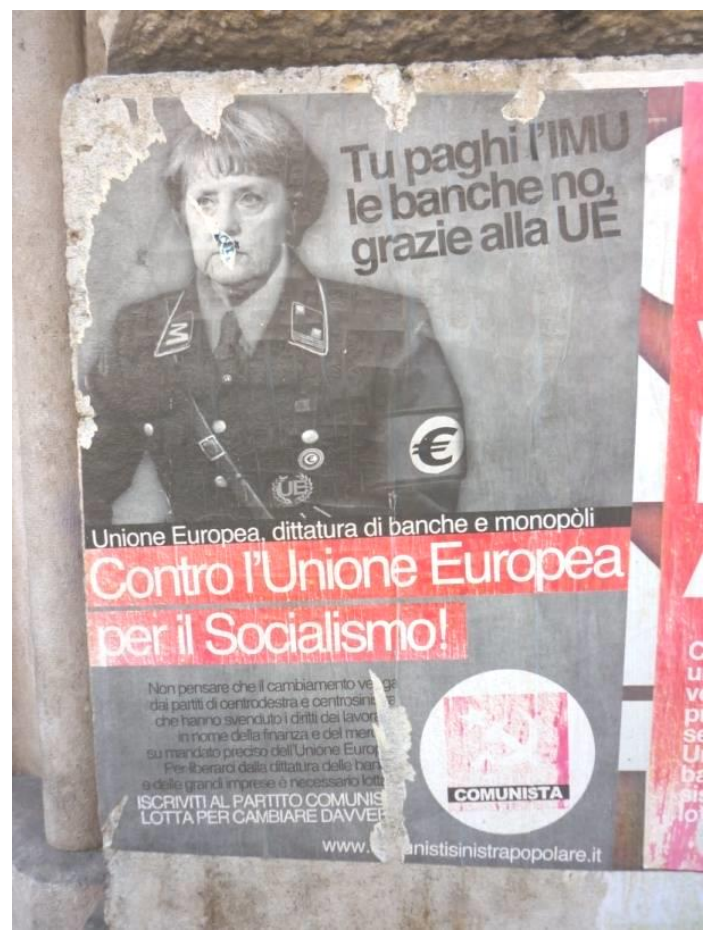

Abb. 3: Foto aufgenommen in Rom, August 2012 (Privatarchiv Franziska Flucke)

In einem dritten Arbeitsschritt ist zum Beispiel vorstellbar, dass die Studenten über weitere Klischee und Stereotypen über Deutsche, Franzosen sowie Bewohner anderer Nationalitäten berichten. Dies lässt sich mit einem konkreten Recherche-

\footnotetext{
${ }^{6}$ Der Vertrag ist als ,allmähliche Annäherung zweier Männer, zu deren Lebenszielen die deutschfranzösische Aussöhnung zählte und die sich nach dem Scheitern von multilateralen europäischen Plänen für den Bilateralismus entschieden“ (Pfeil 2013: 3) zu sehen, und seine Zielgruppe war besonders die Jugend beider Länder.
} 
auftrag zu nationale Stereotypen in der deutschen wie ausländischen Presse verbinden. Denn gerade in Zeiten der Euro-Krise haben nationale Stereotype und Vorurteile Hochkonjunktur, die zu einer Re-Nationalisierungstendenz führen und alte Ressentiments bedienen (vgl. Abb. 3).

Anhand der Karikatur von Klaus Pielert (Abb. 4) lässt sich die Entwicklung der deutsch-französischen Beziehungen von Karl dem Großen über Ludwig XIV. bis hin zu Konrad Adenauer und Helmut Kohl rekonstruieren, um so die „Meisterzählung“" zu entmythisieren.

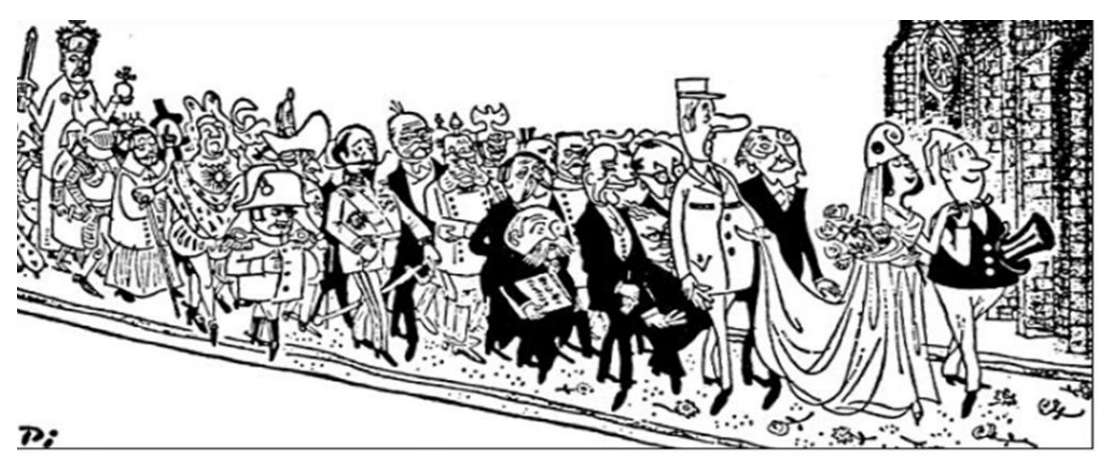

Abb. 4: Der deutsche Michel und die französische Marianne, Klaus Pielert: „Die Liebe des Jahrhunderts/ L'amour du siecle“. Kölner Stadt Anzeiger, 5. Juli 1962.

Dass die deutsch-französische „Aussöhnung“ durchaus auch sehr umstritten war, lässt sich mit Hilfe britischer Karikaturen sehr gut veranschaulichen. Denn sie zeigen die deutsch-französischen Beziehungen im Spannungsfeld des Kalten Krieges und der Europäischen Integration (vgl. Abb. 5, 6). Am 15. Juni 1963 beschloss der Bundestag bei der Ratifizierung des Elysée-Vertrags eine Präambel hinzufügen, die die atlantischen Bindungen der BRD betonte. Im deutschen Bundestag gab es eine heftige Auseinandersetzung zwischen den „Atlantikern“, die privilegierte Beziehungen zu den USA forderten, und den „Gaullisten“, deren Europa vom Atlantik bis zum Ural gehen solle. Da sich erstere mit der Präambel durchsetzten, wurde der Vertrag für de Gaulle uninteressant, denn sein Ziel der Emanzipation Europas von den USA hatte er damit nicht erreichen können (Vgl. Pfeil 2013). 


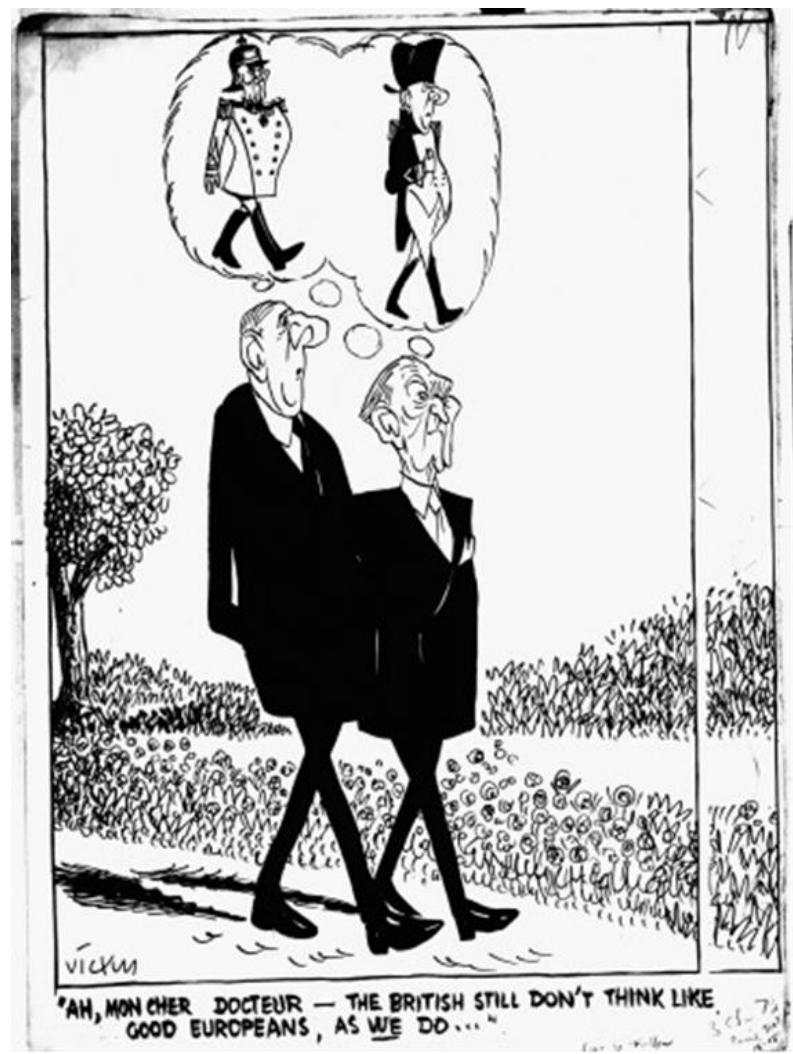

Abb: 5: “Ah, mon cher docteur - the British still don't think like good Europeans, as we do...". Evening Standard, 1. August 1961.

Zudem besuchte Präsident Kennedy Ende Juni 1963 die Bundesrepublik und hielt am 26. Juni in Berlin vor dem Schöneberg Rathaus seine berühmte Rede („Ich bin ein Berliner"). Diese Worte machten Geschichte und gehören zum Wissensbestand eines jeden Schülers in Europa. ${ }^{7}$

\footnotetext{
${ }^{7}$ Die Reise Barack Obamas im Juni 2013 nach Berlin kann als aktueller Anlass genutzt werden, das Beziehungsgeflecht des Kalten Krieges zu thematisieren. Weitere Karikaturen dazu sind auch in dem deutsch-französischen Geschichtsbuch (Le Quintrec; Geiss 2006) zu finden.
} 


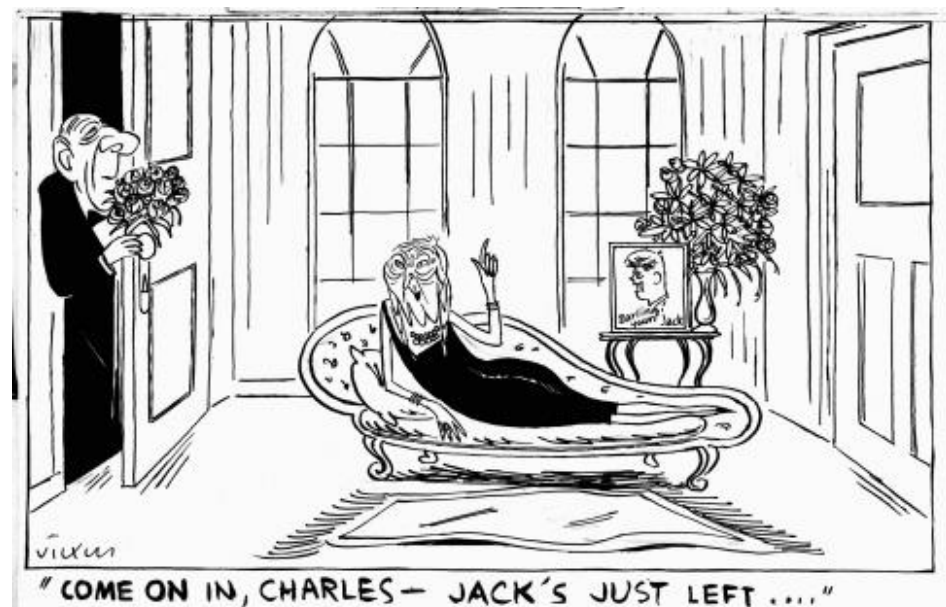

Abb. 6: Evening Standard, 1. Juli 1963.

Aber auch aktuelle Karikaturen (Abb. 7) eignen sich sehr gut, um im Unterricht über die Entwicklung und die derzeitige Situation der deutsch-französischen Beziehungen zu diskutieren. Wichtig ist dabei, dass die Schüler Typen wie die Marianne und den deutschen Michel dechiffrieren können. Denn gerade letzterer ist als etwas plumpe Selbstdarstellung des Deutschen im Ausland wenig bekannt und sollte im Unterricht thematisiert werden. ${ }^{8}$

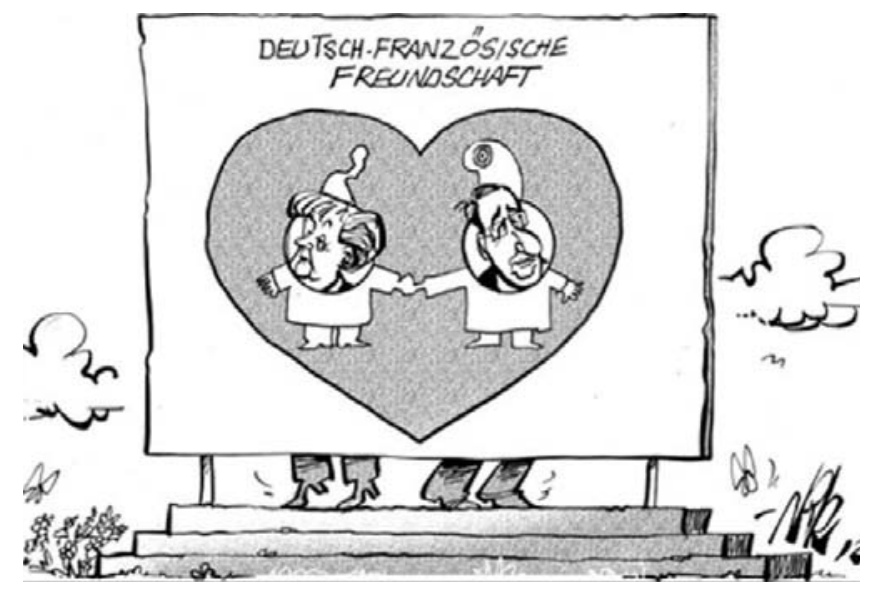

Abb. 7: Karikatur Angela Merkel und Francois Holland, Ebert: „Köpfe austauschbar/Les têtes peuvent changer“. Rheinische Post, 7. Mai 2012.

${ }^{8}$ Hilfreich kann dafür die Erklärung von Ulrich Op de Hipt (2012) sein. 
Zur vertiefenden landeskundlichen Arbeit ist es denkbar, diese Karikaturen mit schriftlichen Quellen wie Zeitungsartikel oder beispielsweise den Erinnerungen von Konrad Adenauer zu vergleichen. Zur Förderung des Hörverstehens können im Internet verfügbare Filme und Zeugenaussagen verwendet werden. ${ }^{9}$ Auch denkbar ist die Analyse der Rede Charles de Gaulles an die deutsche Jugend, die er 1962 in Ludwigsburg auf Deutsch hielt. Ein Vergleich der Reden de Gaulles und Kennedy wäre sicherlich für die Lehrenden sehr interessant, weil so zwei Perspektiven auf das Deutschland der Nachkriegszeit deutlich werden.

\subsection{Die Arbeit mit Historienbildern}

Historienbilder eignen sich besonders, um Studierenden zu vermitteln, dass Gemälde nicht einfach Abbilder sind, sondern meist mit bestimmten Deutungs- und Wirkungsabsichten gemalt wurden und somit ein „erzieherisches Ziel“ haben. Exemplarisch kann hier auf Anton von Werners „Proklamierung des Deutschen Kaiserreiches" hingewiesen werden. Dieses Gemälde gehört zu dem klassischen Bilderkanon deutscher sowie europäischer Lehrbücher (vgl. Sauer 2008: 196; Popp 2010: 343) $)^{10}$ und kann als Einstieg für den Erinnerungsort Versailles eingesetzt werden. Denn auch die Unterzeichnung des Versailler Vertrags als Revanche der Franzosen für 1871 wurde auf einem Gemälde festgehalten, das den Studierenden mit großer Wahrscheinlichkeit bereits im schulischen Geschichtsunterricht begegnet ist (Popp 2010: 343). ${ }^{11}$ Während bei Anton Werner die Säbel schwingenden Offiziere ins Auge fallen, stehen bei Orpens „Unterzeichnung des Friedensvertrags im Spiegelsaal von Versailles" leere Spiegel im Bildzentrum, die den moralischen Zusammenbruchs des europäischen Wertesystems symbolisch ins Bild setzen (Popp 2010: 346). Beide Bilder im Vergleich geben Auskunft über die Positionen Deutschlands im europäischen „Mächtekonzert" vor und nach dem Zweiten Weltkrieg.

\subsection{Der Ansatz der Erinnerungsorte}

Um die verschiedenen Facetten der deutsch-französischen Beziehungen der letzten 200 Jahre zu beleuchten, hat sich der Ansatz der Erinnerungsorte als besonders geeignet erwiesen. Er ermöglicht eine kritisch-reflektierte Herangehensweise an die

\footnotetext{
9 Auf der Seite http://www.europa-nur-mit-uns.eu/zeitzeugen.html sowie unter http:// www.arte.tv /de/ludwigsburg-merkel-und-hollande-erinnern-an-beruehmte-rede-von-de-gaulle/6961686,CmC= 6913504.html sind Zeugenaussagen zur Rede in Charles de Gaulles in Ludwigsburg im Sommer 1962 zu sehen (Zugriff Juni 2013).

${ }^{10}$ Für eine ausführliche Bildanalyse und Interpretation vgl. Buntz; Erdmann 2009: 129-132; methodische Hinweise zur Analyse des Gemäldes sowie konkrete Arbeitsaufträge befinden sich auch im deutsch-französischen Geschichtsbuch: Geiss; Henri; Le Quintrec 2008: S. $42 f$.

11 Zum Gemälde von William Orpen von 1920 gibt es eine ausführliche Bildanalyse von François Bouloc in deutscher Sprache auf der französischen Internetseite http://www.histoire-image.org/site oeuvre/analyse.php?i=907 (Zugriff Juni 2013).
} 
deutsche und die eigene Geschichte, indem sich der Studierende mit Interpretationsmustern und Geschichtsbildern auseinandersetzt und Geschichte als standortund gegenwartsgebundene (Re-)Konstruktion wahrnehmen kann. Die Arbeit mit Erinnerungsorten bietet zahlreiche Anlässe für interkulturelle Vergleiche und erlaubt es, vielfältiges Material (Fotografien, Bilder, Karikaturen, Landkarten, Lieder, Hördokumente) einzusetzen. Methodisch ergeben sich daraus zahlreiche Möglichkeiten für handlungsorientierte Aufgaben wie Projektarbeit, Internetrecherchen und Präsentationen, was die Selbstständigkeit und Eigenaktivität der Lernenden fördert (vgl. Schmidt; Schmidt 2007: 5-8). Denkbar ist eine Behandlung der Erinnerungsorte Versailles, Verdun, Reims und des Elysee-Vertrags selbst. ${ }^{12}$

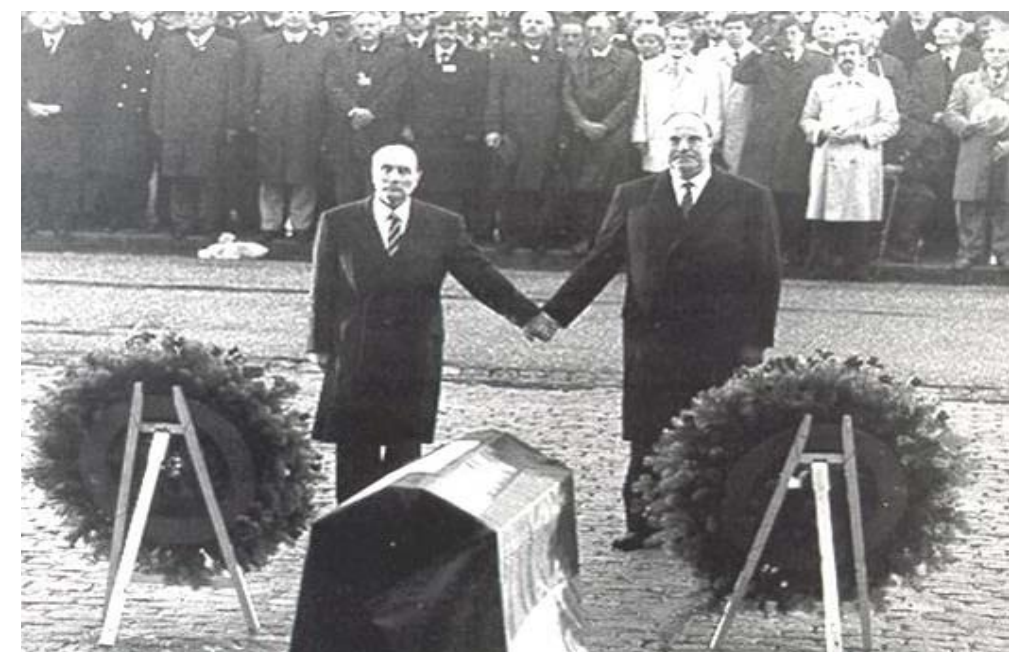

Abb. 8: Der französische Staatspräsident François Mitterrand und Bundeskanzler Helmut Kohl gedenken in Verdun gemeinsam der Toten beider Weltkriege, Verdun, 22. September 1984. Quelle: Bundesbildstelle, Bonn (C) Stiftung Haus der Geschichte der Bundesrepublik Deutschland.

Der Ort Verdun hat seit dem frühen Mittelalter eine Bedeutung für die deutschfranzösischen Beziehungen gehabt. Im Jahre 843 wurde im Vertrag von Verdun die Teilung des Karolingerreichs in drei Teile festgehalten. Aus dem Westreich ging Frankreich und aus dem Ostreich Deutschland hervor. Das Mittelreich Lotharingen spielt als Grenzregion zwischen Deutschland und Frankreich noch heute eine Vorreiterrolle bei transnationalen Kooperationen. Im Deutsch-Französischen Krieg 1870/71 wurde die Festung Verdun ein nationales Symbol für Mut, Tapferkeit und die Unsterblichkeit der französischen Nation. Im Anschluss wurde Ver-

\footnotetext{
${ }^{12}$ Hintergrundinformation sowie Unterrichtsanregungen für den deutsch-französischen Erinnerungsort Versailles bietet Clemens 2009.
} 
dun zur stärksten Verteidigungsanlage Frankreichs ausgebaut und galt als uneinnehmbar. Im Ersten Weltkrieg war der Ort Schauplatz der blutigsten Schlachten und Symbol des Stellungskrieges.

Die vergleichende Analyse der Bedeutung des Ortes Verduns für die deutsche und die französische Geschichte scheint besonders im Rahmen der Gedenkfeierlichkeiten zum hundertsten Jahrestag des Ersten Weltkrieges, die im Jahr 2014 begonnen haben, interessant und bietet einen großen Aktualitätsbezug. ${ }^{13}$ Ausgehend davon sind auch Überlegungen zur Erinnerungskultur zum Ersten Weltkrieg in den europäischen Ländern denkbar. Dabei kann das Foto von Mitterand und Kohl in Verdun 1984 als Einstieg in die Diskussion dienen und mit einer passenden Karikatur kontrastiert werden (Vgl. Abb. 8, 9). Es ist auch möglich, noch einen Schritt weiter $\mathrm{zu}$ gehen und verschiedene Karikaturen, die dieses Ereignis aufgreifen, gemeinsam oder in Gruppen analysieren zu lassen. ${ }^{14}$

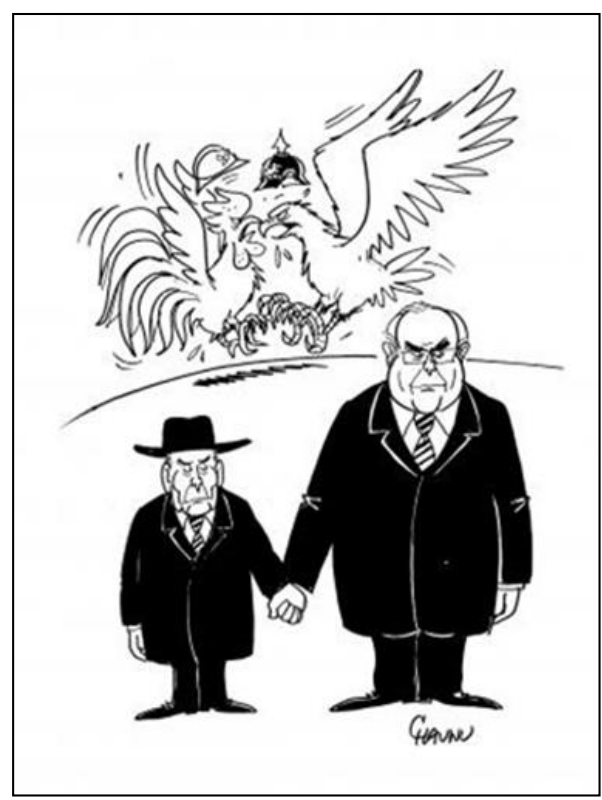

\section{Abbildung 9: Emanuel Chaunu, 1993: Francois Mitterand und Helmut Kohl in Ver- dun 1984.}

\footnotetext{
${ }^{13}$ Eine kommentierte Linkliste zur Behandlung des Themas Erster Weltkrieg bei Pallaske 2013. Die Internetseite http://www.europeana1914-1918.eu/de sammelt Materialien aus ganz Europa zu der Thematik.

${ }_{14}$ Didaktisch reizvoll kann es auch sein, das bekannte Foto mit einer eher unbekannten Perspektive, dem sogenannten „Gegenschuss“ zu vergleichen. Auf sprachlicher Ebene lassen sich auch Redewendungen rund um das Wortfeld Hand wiederholen oder einführen (z. B. sich die Hand reichen/geben, Händchen halten, von der Hand in den Mund leben,...). Eine interessante Analyse der Bildikone „Verdun-1984“ in der Karikatur bietet Délépine 2004.
} 
Mit der meisterhaften Inszenierung der gemeinsamen Erinnerung an den Ersten Weltkrieg sollen die Grenzen der Nationalgeschichte überwunden werden. Das Händereichen ist Ausdruck einer neuen Dynamik in der Versöhnungssymbolik (Defrance 2013: 219).

Zur weitergehenden Behandlung des Ersten Weltkrieges gibt es mittlerweile zahlreiches aufgearbeitetes Bildmaterial, gerade auch im Bereich der populärliterarischen Medien wie Satirepostkarten (vgl. Sistig 2012). Dabei können verschiedene Aspekte wie Fronterfahrung und Zivilleben, Propaganda, das Bild des Anderen, ${ }^{15}$ Erinnerung sowie die literarische und filmische Verarbeitung des Themas behandelt werden. Für die filmische Verarbeitung bieten sich die deutschen Filme „Im Westen Nichts Neues“ und „Merry Christmas“ an, die beispielsweise mit Ausschnitten aus französischen Filmen („Die Große Illusion - La Grande Illusion“, 1937; „Die Offizierskammer - La chambre des officiers“, 2001; „Mathilde - eine große Liebe - Un long dimanche de fiançailles“, 2004) verglichen werden können. Als Vorbereitung suchen die Studierenden sich einen Film aus. Sie analysieren dessen Plakat und recherchieren im Internet wichtige Informationen zu dem Film. Beides wird im Kurs in kurzen Präsentationen vorgestellt (siehe Arbeitsblatt 1), und anschließend können der Film „Merry Christmas"16 und „Im Westen nichts Neues" ausführlicher behandelt werden.

Ein sehr symbolischer Ort für die deutsch-französischen Beziehungen ist auch die Stadt Reims, die vom Symbol der deutschen Barbarei zum Ort der geteilten Erinnerung werden sollte. Das deutsch-französische Geschichtsbuch thematisiert Reims und Versailles als Erinnerungsorte in einem Dossier (Vgl. Le Quintrec; Geis 2006: 302). Für die Behandlung des Themas mit Studenten bietet sich der Einstieg mit einer Karikatur von Fritz Behrend aus dem Jahr 1962 an. Die Arbeit damit kann auf Grund der Vielschichtigkeit eine ganze Unterrichtsstunde einnehmen. In einem ersten Schritt müssen die Studenten die Karikatur beschreiben und die dargestellten Personen bestimmen sowie die zwei Ebenen definieren, was bereits zu einigen Schwierigkeiten führen kann. Als nächstes gilt es, die Bedeutung der Persönlichkeiten für die deutsch-französischen Beziehungen zu klären. Erst dann sollte auf das Treffen Charles de Gaulles und Konrad Adenauers in Reims im Juli 1963 im Rahmen der Frankreichreise Adenauers eingegangen werden. In einem vierten Schritt ist die historische Bedeutung der Stadt Reims in der Geschichte zu klären. Dafür ist es hilfreich, den Lernenden verschiedenes ergänzendes Text- und Bildmaterial zur Verfügung zu stellen: Denkbar ist ein Bild der Taufe Chlodwigs für die Bedeutung als Krönungsstadt der französischen Könige, eine Abbildung von Jeanne d'Arc in Reims, französische Propagandapostkarten für die Zerstörung der Stadt während des Ersten Weltkrieg und ein Hinweis auf die Unterzeichnung

\footnotetext{
${ }^{15}$ Zur Darstellung der Deutschen während des Ersten Weltkrieges auf französischen Postkarten ist der Artikel von Brouland (2012) sehr zu empfehlen. Die in dem Zusammenhang dargestellten Postkarten geben einen guten Eindruck von den Feindbildern der Franzosen während der Zeit.

${ }_{16}$ Auf der Internetseite Lehrer-online.de sind unter dem Link http://www.lehrer-online.de/merrychristmas-film.php Dossiers und Unterrichtsanregungen zu finden (Zugriff Juni 2013).
} 
der bedingungslosen Kapitulation der deutschen Wehrmacht am 8. Mai 1945. Damit können sich die Studierenden die Bedeutung der Stadt und der Kathedrale sowie den hohen symbolischen Wert der gemeinsamen Messe der einstigen Feinde erschließen. Abschließend kann der Bogen zu den Feierlichkeiten im Jahr 2012 geschlagen werden.

\section{Schluss}

Der Beitrag hat gezeigt, wie mit Hilfe unterschiedlichen Bildmaterials die „Versöhnungsnarrative" der deutsch-französischen Beziehungen im Unterricht aufgebrochen werden können. Die Lehrenden werden mit verschiedenen Aspekten der deutsch-französischen Beziehungen konfrontiert und dazu aufgefordert, sich kritisch mit der Geschichte Deutschlands und Frankreichs auseinanderzusetzen. Bildmaterial zu den deutsch-französischen Beziehungen ist in großem Ausmaß ${ }^{17}$ vorhanden und sollte nicht nur der Visualisierung dienen, sondern zunehmend selbst zum Unterrichtsgegenstand werden. So wird deutsche Geschichte ,anschaulich“, und den Lernenden bieten sich zahlreiche Sprechanlässe in der Zielsprache Deutsch, so dass inhaltliches und sprachliches Lernen kombiniert werden können.

\section{Literatur}

Buntz, Herwig; Erdmann, Elisabeth (2009): Fenster zur Vergangenheit. Bilder im Geschichtsunterricht. Band 2: Von der Frühen Neuzeit bis zur Zeitgeschichte. Bamberg: Buchner's Verlag.

Clemens, Catharina (2009): Deutsch-französische Erinnerungsorte im Landeskundeunterricht am Beispiel von Versailles. In: Nieradka, Magali Laure; Specht, Denise (Hrsg.): Fremdkörper? Aspekte der Geisteswissenschaften in der Auslandsgermanistik und im DaF-Unterricht. Berlin: LIT-Verlag, 63-78.

Delépine, Marie (2004): Verdun-1984. 20 ans après. Les avatars d'une nouvelle „icone“ de la caricature franco-allemande. In: Documents 3/2004, 23-28.

Defrance, Corine (2013): Die Meistererzählung von der deutsch-französischen „Versöhnung“. In: Aus Politik und Zeitgeschichte 1-3, 16-22.

Geiss, Peter; Henri, Daniel: Le Quintrec, Guillaume (2008): Histoire/Geschichte. Europa und die Welt vom Wiener Kongress bis 1945. Leipzig: Klett.

\footnotetext{
${ }^{17}$ Hier sei noch auf die Veröffentlichungen des Karikaturisten Plantu (2012) sowie den Ausstellungskatalog von Koch (1999) hingewiesen.
} 
Konczal, Kornelia (2011): Pierre Noras folgenreiches Konzept von „les lieux de mémoire" und seine Re-Interpretation: eine vergleichende Analyse. In: Geschichte in Wissenschaft und Unterricht 62/1-2, 17-36.

Koreik, Uwe (2012): Deutsche Geschichte im DaF-Unterricht - zur Arbeit mit historischen Quellen. In: Hieronimus, Marc (Hrsg.): Historische Quellen im DaFUnterricht. Göttingen: Universitätsverlag, 1-14.

Krumeich, Gerd (1996): Verdun: ein Ort gemeinsamer Erinnerung? In: Möller, Horst; Morizet, Jacques (Hrsg.): Franzosen und Deutsche. Orte der gemeinsamen Geschichte. München: C.H. Beck, 162-184.

Nielson-Sikora, Jürgen (2012): Fotographie als historische Quelle? In: Hieronimus, Marc (Hrsg.): Historische Quellen im Daf-Unterricht. Göttingen: Universitätsverlag, 60-89.

Pandel, Hans-Jürgen (2009): Der Mann mit der Pickelhaube. Otto von Bismarck und die preußische Haube. In: Paul, Gerhard (Hrsg.): Das Jabrbundert der Bilder Bd.1: 1900 bis 1949. Göttingen: Vandenhoeck \& Rupprecht, 100-107.

Pfeil, Ulrich (2013): Zur Bedeutung des Elysée-Vertrages. In: Aus Politik und Zeitgeschichte 1-3, 3-8.

Plantu, Jean (2012): Drôle de peuple! Komisches Volk. Dessins sur l'Allemagne. Politische Karikaturen zu Deutschland. Berlin: Schaltzeit.

Popp, Susanne (2009): Marianne und Germania. Allegorische Frauengestalten im Bilderkrieg der Kriegs- und Nachkriegszeit. In: Paul, Gerhard (Hrsg.): Das Jahrbundert der Bilder Bd.1: 1900 bis 1949. Göttingen: Vandenhoeck \& Ruprecht, 292-299.

Popp, Susanne (2010): Visualisierte Geschichte in den Lehrwerken Europas. Zwischen polysemantischen Vermittlungsstrategien und kanonischer Engführung. In: Gehler, Michael; Vietta, Silvio (Hrsg.): Europa - Europäisierung - Europäistik. Neue wissenschaftliche Ansätre, Methoden und Inhalte. Köln: Böhlau, 337-352.

Sauer, Michael (2008): Geschichte unterrichten. Eine Einführung in die Didaktik und Methodik. Seelze-Velber: Kallmeyer.

Schmidt, Katrin; Schmidt, Sabine (2007): Erinnerungsorte. Deutsche Geschichte im DaFUnterricht. Berlin: Cornelsen.

Seidendorf, Stefan (2013): Constructing european citizens? Evaluating the integrative force of teaching history. In: Kauppi, Niilo (Hrsg.): A political sociology of transnational Europe. Colchester: CCPR Press, 243-264.

Sistig, Joachim (2012): Der Erste Weltkrieg in populärliterarischen Medien. In: Hieronimus, Marc (Hrsg.): Historische Quellen im Daf-Unterricht. Göttingen: Universitätsverlag, 177-207. 
Tiemann, Dieter (1998): Das Bild im Kopf - Stereotypen früher und heute. In: Haus der Geschichte der Bundesrepublik Deutschland (Hrsg.): Vis-à-vis: Deutschland und Frankreich. Begleitbuch zur Ausstellung im Haus der Geschichte der Bundesrepublik Deutschland in Bonn. Köln: Dumont, 27-38.

\section{Internetlinks}

Bouloc, François (2013): Unterzeichnung des Versailler Vertrags http://www. histoire-image.org/site/oeuvre/analyse.php?i=907 (26.06.2013).

Brouland, Pierre (2012): Les cartes postales satiriques pendant la Première guerre mondiale: http:/ /www.caricaturesetcaricature.com/article-les-cartes-postalessatiriques-pendant-la-premiere-guerre-mondiale-96090355.html (26.06.2013).

Clairon, Elsa (2004): die Bildanalyse: drei Gesten (http://www.arte.tv/de/diebildanalyse-drei-gesten/675300,CmC=675302.html) (30.06.2013).

Guitton, Marie (2013): Der Adler und der Hahn: Eine Henne, die für Karikaturisten beider Länder goldene Eier legt. L'Aigle et le coq, une poule aux œufs d'or pour les dessinateurs: http://www.fplusd.org/kultur-und-alltagsleben/ politik-und-geschichte/der-adler-und-der-hahn-eine-henne-die-fuer-karikatu risten-beider-laender-goldene-eier-legt (30.06.2013).

Op de Hipt, Ulrich (2012): Michel: Nationalfigur und Persona non grata: http:// www.dw.de/michel-nationalfigur-und-persona-non-grata/a-16368360 (05.06.2013).

Pallaske, Christoph (2013): 100 Jahre Erster Weltkrieg. Linkliste Geschichtslernen. In: Historisch denken. Geschichte machen. Blog von Christoph Pallaske, vom 6.6.2013.: http://historischdenken.hypotheses.org/1840 (25.06.2013).

http://www.europa-nur-mit-uns.eu/zeitzeugen.html (30.06.2013).

http://www.arte.tv/de/ludwigsburg-merkel-und-hollande-erinnern-an-beruehmterede-von-de-gaulle/6961686,CmC=6913504.html (30.06.2013).

http://www.histoire-image.org/site/oeuvre/analyse.php?i=907 (30.06.2013).

http://www.lehrer-online.de/merry-christmas-film.php (30.06.2013).

http:/ /www.youtube.com/watch?v=9tVtqhEvuhg\&list=UUgAds0zjEnfh9bhAdT BP_aA\&index $=22 \mathrm{~g}(30.06 .2013)$. 


\section{Arbeitsblatt 1: Die filmische Verarbeitung des Ersten Weltkriegs}

Der Erste Weltkrieg beendete das so genannte „lange“ 19. Jahrhundert und markierte zugleich den Beginn einer neuen Zeit. Das Ausmaß des Krieges übertraf alles zuvor Erlebte. In Frankreich und Großbritannien ist die Erinnerung an den Krieg für die Familie und für die Gesellschaft sehr wichtig. Die Bedeutung des Krieges wird auch an der häufigen (auch aktuellen) filmischen Verarbeitung des Themas deutlich.

Aufgabe 1: Präsentieren Sie die Filmplakate (Titel, Farben des Plakats, Stimmung, welche Aspekte des Krieges sprechen sie an?)
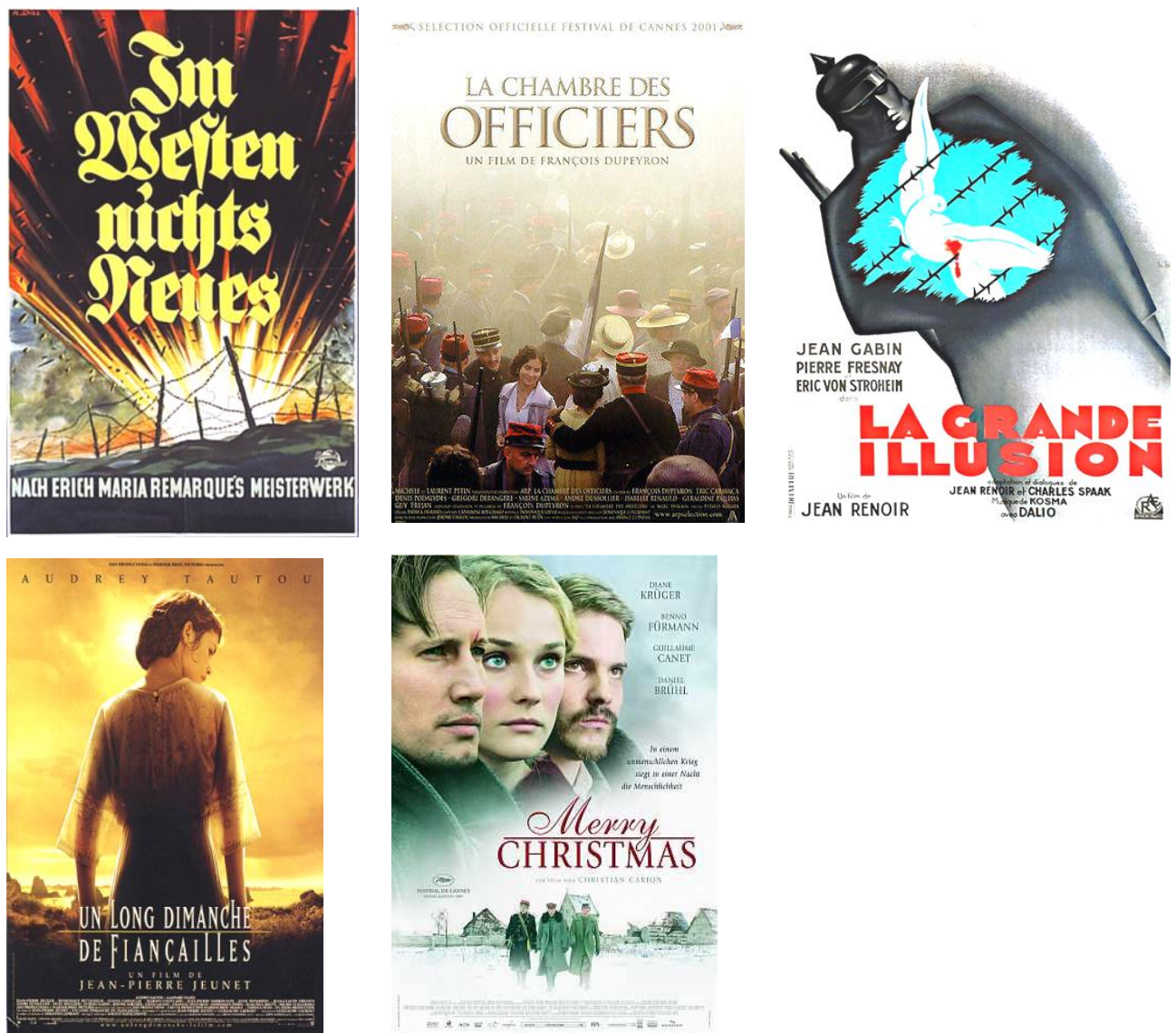
Aufgabe 2: $\quad$ Recherchieren Sie im Internet. Füllen Sie die folgende Tabelle aus.

\begin{tabular}{|l|l|l|l|l|l|}
\hline Film & $\begin{array}{l}\text { Im } \\
\text { Westen } \\
\text { Nichts } \\
\text { Neues }\end{array}$ & $\begin{array}{l}\text { La } \\
\text { chambre } \\
\text { des offi- } \\
\text { ciers }\end{array}$ & $\begin{array}{l}\text { La } \\
\text { grande } \\
\text { Illusion }\end{array}$ & $\begin{array}{l}\text { Merry } \\
\text { Christmas }\end{array}$ & $\begin{array}{l}\text { Un long } \\
\text { dimanche } \\
\text { de fian- } \\
\text { çailles }\end{array}$ \\
\hline $\begin{array}{l}\text { deutscher/franzö- } \\
\text { sischer Titel }\end{array}$ & & & & & \\
\hline Regisseur: & & & & & \\
\hline $\begin{array}{l}\text { Erstausstrahlungs- } \\
\text { datum: }\end{array}$ & & & & & \\
\hline $\begin{array}{l}\text { Hauptdarsteller: } \\
\text { risch interessant, } \\
\text { weil: }\end{array}$ & & & & & \\
\hline Inhalt: & & & & & \\
\hline & & & & & \\
\hline
\end{tabular}

Aufgabe 3: Informieren Sie sich über einen der Filme intensiver und bereiten Sie eine kurze Präsentation auf Deutsch vor. Hilfreiche deutsche Internetseiten: www.kino.de; www.cinema.de; www.kino-news.de 
Arbeitsblatt 2:

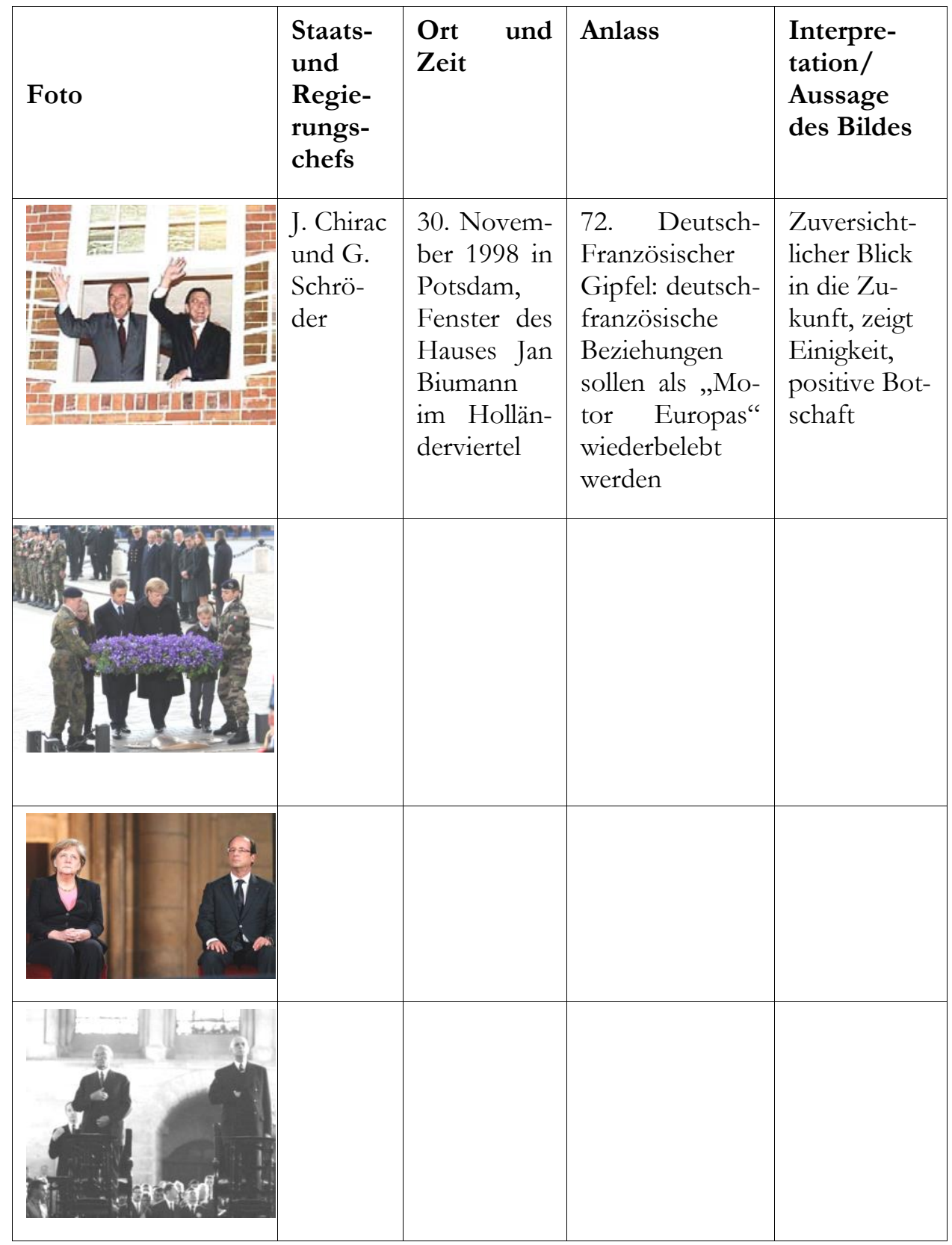




\section{Arbeitsblatt 3: $\quad$ Germania auf der Wacht am Rhein}

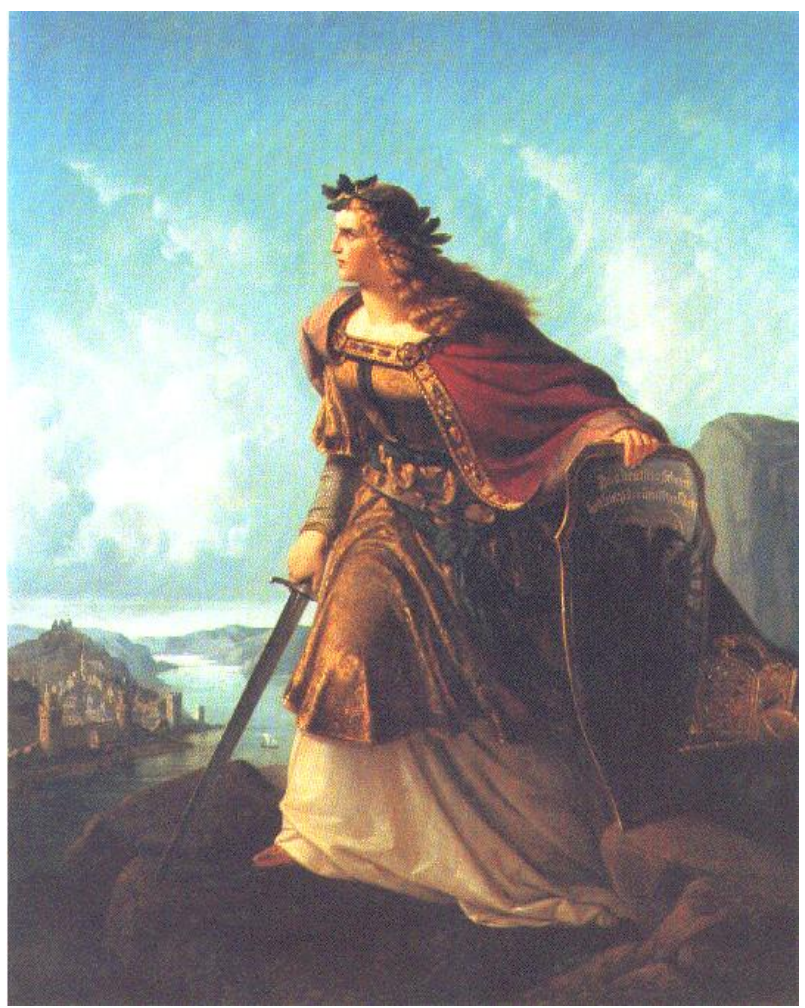

1) Betrachten Sie in aller Ruhe das Bild „Germania auf der Wacht am Rhein".

2) Lesen Sie das Gedicht „Die Wacht am Rhein“. Welche Stimmung geht davon aus? Hören Sie sich auch die Vertonung auf youtube. an. Wie wirkt diese auf Sie?

3) Informieren Sie sich über die nationalsozialistische Vergangenheit des Liedes. (http://de.wikipedia.org/wiki/Die_Wacht_am_Rhein)

4) Stellen Sie sich vor, Sie arbeiten im Kaiser-Wilhelm-Museum in Krefeld und führen eine Besuchergruppe durch das Museum. Bei diesem Bild machen Sie einen Halt, um es ausführlich zu beschreiben. Verfassen Sie Ihren Vortrag. Benutzen Sie die Methode der Bilderschließung im Anhang. 


\section{Methodische Schritte zur Bilderschließung (nach Panofsky) ${ }^{18}$}

1. Die Bildbeschreibung: Was sehe ich?

- subjektiver Eindruck

- Inhaltsangabe

- Struktur des Bildes (Aufbau, Gliederung, Figurenkonstellation, Vordergrund und Hintergrund)

- Erste Eindrücke zur Gestaltung des Bildes (Mimik und Gestik, Attribute der Figuren, Farben, Licht und Schatten der Landschaft)

2. Die Bildanalyse: Was bedeutet das Bild?

- Wer war der Künstler?

- Einordnung in den historischen Kontext:

$\circ \quad$ In welcher Zeit entstanden?

- Was waren die Quellen und Motive?

○ Gibt es ähnliche Bilder vom selben oder von anderen Künstlern?

- Warum entstand das Bild?

○ Sozialer Kontext (Auftraggeber, Adressaten, Entstehung)

○ Technischer Kontext (Herstellungsbedingungen, Erhaltung)

- Wirkungsgeschichte (Wie wirkte das Bild weiter?)

3. Die Bildbewertung: Worauf verweist das Bild?

- Erkennen des Gehalts und der „symbolischen Werte“

- Welchen Wert hat das Bild als historische Quelle?

- Wie ist das Bild als Ganzheit und Teil eines gesellschaftlichen Prozesses zu sehen?

- Wie kann das Bild auch aus heutigem historischem Wissen bewertet werden?

\footnotetext{
18 Ursprünglich für Meisterwerke der Malerei der frühen Neuzeit verwendet, muss deshalb teilweise
} adaptiert werden, vgl. Buntz; Erdmann 2009: 9. 

3. Bewegte Bilder 



\title{
Ansätze einer medienintegrativen Narratologie im Unterricht
}

\author{
Renate Bürner-Kotzam
}

\author{
Das große Kino ist nicht der Feind der \\ Literatur, sondern der Verbündete im \\ Kampf gegen Dummbeit und Gefïbl- \\ losigkeit.
}

(Georg Seeßlen)

\section{Filmisches und literarisches Erzählen}

Dass die gegenwärtig wahrnehmungsbestimmende Erzählweise das visuell basierte, häufig audiovisuelle Erzählen ist, scheint - vielfach formuliert - inzwischen eine Selbstverständlichkeit. Wie sehr Lehre und Unterricht diese mediendominierte Lebensrealität der Lerner zur Kenntnis nehmen, konstatiert Kepser schon 2004, wenn er von dem Vollzug eines grundsätzlichen Paradigmenwechsels für den Deutschunterricht ausgeht: „Eine gegenüber den Medien offene, im Kern optimistische, lustbetonte und kreative Haltung hat die ehemals eher abwehrende, pessimistische, arbeitssbetonte und streng analytische abgelöst.“ (Kepser 2004: 12).

Trotz dieser positiven Einschätzung scheint mir die zunehmende Berücksichtigung des Films bzw. der audiovisuellen Medien in Lehrplänen und das wachsende Angebot an entsprechenden Unterrichtsmaterialien dennoch weiterhin auch Ausdruck von Verunsicherung zu sein, die der Paradigmenwechsel vom Wort zum 
Bild für die textorientierte bürgerliche Bildungstradition, in der die schulischen und universitären Ausbildungsinstitutionen stehen, auslöst. Denn nicht mehr die Literatur vermittelt die dominante und kommunikativ verbindende Kulturerfahrung junger Menschen, sondern der Film. Filmgeschichten beeinflussen Lebensvorstellungen und -wünsche. Der Spielfilm ist, unabhängig von Genre und Rezeptionsmodus, „das narrative Leitmedium deutscher Abiturienten und Abiturientinnen.“ (Kepser zit. nach Abraham 2009: 25). ${ }^{1}$

Das bildlastige Erzählen des Films erschwerte schon zum Beginn der Filmgeschichte die Akzeptanz des Bürgertums. Denn das filmische Erzählen reihte sich zunächst in das tradierte Bildungskonzept, das Bildangebote primär mit einer auf Veranschaulichung angewiesenen ungebildeten Unterschicht verbindet. Die gesellschaftlich negativ markierten Aufführungsorte der ersten Filmvorführungen, nämlich Jahrmarkt und Varieté, bestätigten dies. Heidi Rösch spricht von einem Kulturkampf des frühen Kinos „zwischen Schrift und bewegtem Bild, zwischen Ordnung und Anarchie, zwischen bürgerlicher Moral und Freizügigkeit des Blicks, zwischen geordnetem logozentrischem Denken und anarchischer Macht der Bilder.“ (Rösch 2011: 27). ${ }^{2}$ Dass die Vermittlung von Medienkompetenz vor allem dem primär textorientierten Deutschunterricht zugewiesen wird, trägt möglicherweise zur Erschwerung der erforderlichen Umorientierung bei, die mehr sein sollte als die Berücksichtigung eines weiteren Themas im bestehenden Kanon. Da das Bildverstehen im Deutschunterricht ein Randthema ist, entspricht die Konzentration auf die inhaltsbezogene Auseinandersetzung mit der filmischen Erzählung dem fachlichen Profil. Sie kann auf vertraute erzählanalytische Begriffe zurückgreifen, und es fällt ihr daher leichter, das spezifisch Filmische getrennt abzuhandeln. Das Besondere des audiovisuellen Erzählens kann aber nicht ausschließlich mit Kategorien des literarischen Erzählens erschlossen werden. „Das Primat der Literatur in diesem Fach hat sich dabei als Hemmnis erwiesen, den Film als Kunstform an sich zu würdigen.“(Lorenz 2010: 13). ${ }^{3}$

Der Deutschunterricht vernachlässigt, dass Bildverstehen keine das Filmverstehen bereichernde oder vertiefende Fähigkeit ist, sondern eine unverzichtbare Voraussetzung. „Mit dem Begriff Iconic Turn ist zwangsläufig auch eine Sprachkritik verbunden, die das Sehen, das Denken in und über Bilder als erkenntnis-

\footnotetext{
${ }^{1}$ Kepser 2008 zitiert aus der online-Umfrage: Spielfilmwissen - Spielfilmdidaktik - Spielfilmnutzung. Abiturjahrgang 2006. Projektskizze und erste Ergebnisse. Universität Bremen 2006. Fachbereich 10.

2 Vilem Flusser bezeichnet „diese telematische Revolution“ des Wechsels vom Wort zum Bild als einen Gewinn, „denn mit ihr gehe die Entstehung eienr neuen, demokratischen Gesellschaft einher, die sich von der Macht der herrschaftlichen Diskurse befreien könne.“ In: Lorenz (2010: 20).

${ }^{3}$ Die Auseinandersetzung mit visuellem bzw. audiovisuellem Erzählen wird sowohl von der Narratologie gefordert, die die Herausforderung einer Neuverortung sprachlichen Erzählens aufgreift; wie z.B. Schmid 2005; Nünning 2004; Koebner; Meder 2006; Großklaus 2004; Hickethier hält „alle Ansätze einer visuellen Rhetorik oder einer filmischen Grammatik“, die sich an den linguistischen Vorbildern orientieren und diese ins Visuelle zu übersetzen versuchten und nicht vom audiovisuellen Bild selbst ausgegangen sind,“ für gescheitert, vgl. Hickethier 2007: 104.
} 
relevant für das Weltverstehen wiederentdeckt und das Nachdenken über das Bild als eigenständigen Gegenstand propagiert. Es geht dabei nicht darum, das Bild über die Sprache zu stellen, sondern um eine Neubestimmung des Verhältnisses von Sprache und Bild.“ (Müller 2013: 47). ${ }^{4}$

Einen ähnlich inhaltskonzentrierten Zugang zeigt oft auch die Auseinandersetzung mit dem Film im DaF-Unterricht. Das Interesse an landeskundlicher Information, an interkultureller Perspektive konzentriert sich - trotz nie fehlender Aufforderungen, die spezifisch filmsprachlichen Mittel mit zu beachten - auf die Geschichte, also auf Handlung, Figuren, Konflikt, so dass sich die filmsprachenspezifische Didaktik auf appellartige Mahnungen, filmspezifisches Erzählen zu beachten, reduziert. ${ }^{5}$ Dies ist um so erstaunlicher, als beinahe jeder Artikel zum Thema Film im DaF-Unterricht an die schon 1989 formulierte Einsicht Inge Schwerdtfegers erinnert, dass die visuelle Wahrnehmung eine zentrale Bedeutung für die individuelle Sprachfähigkeit und Sprechlust hat (Schwerdtfeger 1989: 24), ohne jedoch die Notwendigkeit didaktischer Hinweise zur Schulung der visuellen Wahrnehmung ernst zu nehmen.

Einem Paradigmenwechsel vom schriftsprachlichen zum audiovisuellen Erzählen wird meiner Meinung nach erst die curriculare Verankerung und methodisch-didaktische Umsetzung einer medienintegrativen Narrationsanalyse ${ }^{6}$ gerecht, die sich mit Gemeinsamkeiten und Unterschieden in medialen Erzählweisen auseinandersetzt.

Die Schwierigkeit der curricularen Verortung und entsprechenden Berücksichtigung in Unterrichtsmaterialien hängt sicher auch damit zusammen, dass diese Positionierung eine Neubewertung des kulturellen Einflusses literarischer Texte verlangt, weil es dem filmischen und anderem medialen Erzählen einen gleichberechtigten Platz neben dem tradierten literarischen Erzählen einräumt.7 Denn der Frageansatz einer solchen Narrationsanalyse, wie medial unterschiedlich erzählt wird, wie Wahrnehmung und Interpretation gesteuert werden, verpflichtet zur Gleichwertigkeit medialer Erzählweisen. Daher geht eine medienintegrative Narrationsanalyse, die einen grundlegenden Zugang zu Erzählmedien sichern möchte,

\footnotetext{
4 Wie wenig dies bisher geschehen ist, demonstriert die Publikation von Koebner; Meder (2006). Birkmeyer mahnt ebenfalls an: „Ein Desiderat in der bisherigen Filmdidaktik ist, dass die Bedeutung der Wahrnehmung des Sehens nicht hinreichend beachtet wird. Dies liegt vor allem an der theoretisch unzureichenden Verknüpfung von filmsemiotischen, narratologischen und filmästhetischen Fragestellungen im Deutschunterricht." (Birkmeyer 2010: 130).

5 So scheinen schon folgende didaktisch unzulängliche Hinweise zu reichen, um das Lehrwerk „Geni@l“ (B. Biechele, 2006) als „besonders positiv“ einzustufen: „Achte immer auch auf die Kameraperspektive.“ „Film verstehen = die Musik beachten. Die Musik ergänzt oder ,erklärt' die Situation im Film." (Chudak 2010: 91).

${ }^{6}$ Neben diesem Begriff gibt es auch noch die Verwendung von „inter-“, „trans-“, oder „plurimedialer" Narratologie, jedoch ohne klare Begriffsabgrenzung.

${ }^{7}$ Michael Staiger forderte 2010 die Anerkennung des Films als „vierte literarische Großgattung“ (Staiger 2010a: 12).
} 
von einem Textverständnis aus, „das die Gesamtheit aller Zeichensysteme“ umfasst (Lorenz 2010: 20).

\section{Medienintegrative Filmnarratologie und Unterricht}

Überlegungen zu einer medienintegrativen Narrationsanalyse berufen sich auf unterschiedliche Erzähltheorien, vor allem auf die international sehr einflussreiche strukturalistisch orientierte Erzählanalyse von Genette (1994), Schmid (2005), Branigan (1992), Bordwell (1983) und Chatman (1978). ${ }^{8}$ Markus Kuhn, der sich ebenfalls auf die beiden Medien Literatur und Film konzentriert, setzt sich in seiner primär an der Begrifflichkeit Genettes orientierten Filmnaratologie (Kuhn 2011) intensiv mit der Eignung dieser Erzähltheorien für eine Filmnarratologie auseinander, wobei er davon ausgeht, dass diese sich ,in der literaturbasierten Narratologie verankern und die spezifische Problematik der Konzepte im Medium Film berücksichtigen“" muss (ebd.: 2011: 10).

Wenn er für seine Filmnarratologie in Anspruch nimmt, sich auf ,verschiedene Modelle und Konzepte“ zu beziehen (ebd.: 14), reflektiert dies wohl auch die Schwierigkeit, dass die den Filmnarratologien zugrundeliegenden Erzähltheorien bzw. Begrifflichkeiten ursprünglich der Literatur verpflichtet sind, dennoch aber der größeren filmsprachlichen Komplexität und der „Kopräsenz der filmischen narrativen Instanzen“ (Schweinitz) gerecht werden müssen. Dies ist vermutlich auch eine der Ursachen der von Nünning schon 2002 beklagten Situation einer „schwer überschaubare(n) Konkurrenz alternativer Methoden, Begriffe und Nomenklaturen“ (Nünning 2002: 5), an der sich auch 2011 nicht viel geändert zu haben scheint , wenn Kuhn „die heterogene(n) Ansätze und terminologische Vielfalt konkurrierender Beschreibungsmodelle“ (Kuhn 2011: 9) kritisiert. Abgesehen von dieser Unübersichtlichkeit erschwert allein schon die differenzierte Begrifflichkeit den methodisch-didaktischen Anschluss an den filmnarratologischen Diskurs.

\section{Die Unterscheidung von Fiktion und Realität}

Wie Leubner und Saupe in ihren filmdidaktischen Überlegungen zu einer medienintegrativen Erzähldidaktik betonen, muss der bewusste Umgang mit „Fiktion“, die allen medialen Erzählungen in Abgrenzung von der Alltagswirklichkeit zugrunde liegt, besondere Aufmerksamkeit erhalten (vgl. Leubner; Saupe 2006: 50). Denn obwohl oder weil Realität kaum noch jenseits medialer Vermittlung existiert, wächst die Unfähigkeit, vielleicht auch Unlust, die Grenze zwischen Fiktion und

\footnotetext{
8 Michael Staiger (2010a: 25) favorisiert Chatmans Modell wegen seines medienunabhängigen Ansatzes. Chatmam hat schon 1978 den Film und den Comic in seiner Erzähltheorie berücksichtigt.
} 
Realität zu erkennen bzw. für relevant zu halten. Diese Unlust ist vermutlich mitverantwortlich für das ausgeprägte identifikatorische Lesen der Studierenden, die im Bezug der fiktionalen Geschichte auf eigene Lebenssituationen als erstes die Fiktionalität löschen. Auch historische Romane erhalten Quellenrelevanz. Aufgrund der nachvollziehbaren Sinnlichkeit ihres Erzählens scheinen sie mehr noch als historische Quellen wahren Realitätsgehalt zu verbürgen.

Noch unverzichtbarer wird die Schulung einer „Fiktions-Realitäts-Unterscheidungskompetenz" angesichts des wachsenden Einflusses hybrider Medienformate. „Hybride Formen des Dokumentarischen“ kombinieren „die dokumentarischen mit spielerisch-inszenierenden Ausdrucksformen" (Leubner; Saupe 2006: 51). Aber auch konventionelle fiktionale Motive wirken in der Verbindung mit tatsächlichen Ereignissen noch überzeugender. Der Erfolg dieser Formate ist vermutlich auch darauf zurückzuführen, dass sie der Undurchschaubarkeit und Unübersichtlichkeit einer kaum noch zu bewältigenden globalisierten Lebenswelt eine erwartungsentsprechende Annäherung von Vorstellung und Wirklichkeit entgegensetzen. Aber erst eine Fiktionskompetenz, die selbstbestimmt mit medialen Deutungsmustern umgehen kann, weil sie mit den verschiedenen Zeichensystemen vertraut ist, verhilft zu einer Medienkompetenz, die sich den Lebens- und Wirklichkeitsentwürfen medialen Erzählens nicht identifikatorisch ausliefert, sondern sie produktiv nutzen kann.

Die Überzeugungskraft der audiovisuellen Medien, die die filmisch inszenierte Realität als die tatsächliche Realität erscheinen lässt, ist vor allem auf den Abbildcharakter und die Präsenzsuggestion des filmischen Bildes zurückzuführen, so dass stärker noch als bei einem Text Wirklichkeitsbezüge mit Wirklichkeitswiedergabe verwechselt werden. Joachim Paech weist darauf hin, dass schon die in das 19. Jahrhundert zurückreichende Geschichte der technisch ermöglichten Optimierung des Sehens nicht als Augentäuschung, sondern als Wahrnehmungsermächtigung erlebt wurde. Obwohl sich auch Teleskop, Mikroskop, Röntgengerät wahrnehmungsstrukturierend zwischen Auge und Welt setzen, so dass eine illusionäre Beziehung zwischen Auge und Realität entsteht, erhebt das technisch potenzierte Sehen Wirklichkeitsanspruch (vgl. Paech 1997).

Ein methodisch-didaktischer Zugang sollte diesen Eindruck allerdings nicht als naiv diskriminieren, sondern als spezifisches Potential einer visuellen Aussage ernst nehmen. Alle Materialien des Films - viel mehr noch als die des literarischen Textes - sind der Wirklichkeit entnommen. „Die Kamera nimmt alles auf und transformiert die Materialien und setzt sie in andere Relationen und Bedeutungszusammenhänge. [...] Das Aufgenommene ist immer präsent nur anders als in der Realität. Die filmische Transformation ist demnach auch ein Modus der Anwesenheit der Realität.“ (Ellenbruch; Perivolaropoulou 2010: 46). ${ }^{9}$

\footnotetext{
9 Dass das Abbild häufig nicht nur als Bild, sondern als das Abgebildete selber verstanden wurde, dass es „für wahr und als lebendig galt" betonte der Kunsthistoriker Hamann (zit. in: Hickethier 2007: 38).
} 
Da es dem Film gelingt, sich als technisches Medium zum Verschwinden zu bringen (Balázs 2001: 204), kann der Eindruck realistischer Darstellung nicht auf das Zusammenspiel filmsprachlicher Mittel zurückgeführt werden. „Gerade das mehrdimensionale Erzählen mit seinem schnellen Wechsel der Erzählebenen, Bild, Ton, Figurenaktion und -bewegung, vermittelt den Eindruck ,die dargestellte Welt werde gerade nicht absichtsvoll von einem Erzähler erzählt, sondern die Bilder zeigen ganz ohne narrative Strategie etwas ,Reales،““ (Hickethier 2007: 10). Der Zuschauer erlebt das Geführt- und Gelenktwerden durch die filmischen Inszenierung als eigene Orientierung. Diese Macht des Filmbildes, den Anschein von Realität hervorzurufen, verleitet nicht nur dazu, sich identifikatorisch auf die Filminhalte einzulassen.

Audiovisuelle Medien bestimmen inzwischen nicht nur die Aneignung der Realität, sondern werden zum Maßstab für die Bewertung der Realität. ${ }^{10}$ Neben der Fiktionskompetenz, die fiktionale und nichtfiktionale Anteile medialen Erzählens unterscheiden kann, sollte daher ebenso die „Realitäts-Fiktions-Bezugskompetenz“ (Leubner; Saupe) als Teil einer Fiktionskompetenz fördern. Die Fähigkeit „zum Bezug von Fiktionen auf die Lebenswirklichkeit erlaubt Schülern eine Erweiterung und Differenzierung ihrer Wirklichkeitssicht." (Leubner; Saupe 2006: 51).11 Unterrichts- und Lehrangebote, die von einem kontinuierlichen Wechsel medialen Erzählens ausgehen, wie sie eine medienintegrative Narrationsanalyse nicht nur ermöglicht, sondern fordert, schulen die Kompetenz des kritischen, selbstbestimmten Umgangs mit Fiktion und Realität.

\section{Was konstituiert Erzählen medienübergreifend?}

Vor der Auseinandersetzung mit dem Spezifischen der jeweiligen Erzählweise sollten die Erzählelemente erarbeitet werden, die Erzählen medienunabhängig konstituieren, wobei man bewusst halten muss, dass die Überzeugung von einem medienunabhängigen Erzählen Gefahr läuft, Medien nur als Transmitter zu betrachten und damit den Zusammenhang von Medium und medial vermitteltem Inhalt auszublenden. Die Einsicht, dass das Spezifische des erzählerischen Um-

\footnotetext{
${ }^{10}$ Darauf wies Scheffer im Zusammenhang mit den Ereignissen vom 11.9. 2001 hin: US-Generäle drängten auf die Fortentwicklung bestimmter Computerspiele zum Training für die Soldaten: „That's the kind of realism we're trying for!'“, vgl. Scheffer 2013.

11 Diese grenzverwischende Verbindung von Fiktion und Realität bzw. der Einfluss der Fiktion auf die Wirklichkeitsvorstellung wird zwar häufig als Symptom der gegenwärtigen Kultur konstatiert, hat aber im Film eine bis in die Anfänge zurückreichende Tradition:,,Georg Meliès, der anfangs ebenfalls Aktualitäten gefilmt hatte, hatte längst damit begonnen [...] die Affaire Dreyfus, einen Vulkanausbruch oder die Krönung des englischen Königs Edward VII. in seinem Studio in Montreuil zu drehen. Auf diese Weise konnte der Film über die Krönung gleichzeitig mit der Krönung selbst gesehen werden." (Paech 1997: 26). Nachgedrehte oder sogar vor dem Ereignis gedrehte Filmaufnahmen wurden damals schon als Dokumentation ausgegeben. Paech hält diese Vermischung von Dokumentarischem und Fiktionalem für eine der Ursachen des realistischen Erzählkinos.
} 
gangs mit den Erzählelementen immer medial bestimmt ist, selbst wenn man sich in einem Gespräch auf medienübergreifende Erzählelemente einigt, sollte die Vermittlung des medialen Erzählens vor allem bestimmen. Es wäre ein großer Erfolg, wenn Lerner erkennen könnten, wie medial unterschiedlich Film und literarischer Text z.B. die Beziehungen zwischen Figuren erzählend aufbauen.

$\mathrm{Zu}$ den unverzichtbaren Elementen des Erzählens gehören Figuren, ihre Beziehungen und Interaktionen und ihre räumliche und zeitliche Verankerung, die Unterscheidung der Handlung nach dem, was passiert, also der story/histoire, und der Art und Weise der Darstellung, dem discourse/discours, die sich auf das spezifische Medium des Erzählens bezieht.12 Jeder dieser grundlegenden Aspekte sollte jedoch exemplarisch an Text- und/oder Filmbeispielen erarbeitet werden, denn abgesehen von der Anschaulichkeit zeigen Bild und Text zum einen, dass das Besondere der jeweiligen Erzählweise auf der medienspezifischen Adaption der grundlegenden Erzählelemente beruht und zum anderen, dass die Wirkung jedes filmsprachlichen Zeichens ebenso wie die jedes literarischen Erzählaspekts kontextabhängig ist.

Ein weiteres Konstituens des Erzählens ist die Perspektivität jeden Erzählens. Die fiktive Welt ist „medial immer auch an eine bestimmte Art und Weise ihrer Vermittlung gebunden." (Lorenz 2010: 63). ${ }^{13}$ Im Zusammenhang mit der anhaltend diskutierten Frage nach dem Erzähler im Film weist Stephan Rössel auf den unterschiedlichen - textimmanenten, kognitiven und rezeptionsorientierten - Zugang der drei entscheidenden filmnarratologischen Theorien von Edward Branigan, David Bordwell und Seymour Chatman hin (Brössel 2010: 56)..$^{14}$

Auch in bezug auf die umstrittene Erzählinstanz im Film ${ }^{15}$ scheint mir, dass eine didaktisch sinnvolle Entscheidung vom Alter der Lernergruppe abhängt. Für die Einübung in die Perspektivität der Wahrnehmung ist es hilfreich und vertretbar, Analogien von literarischen Erzählperspektiven und Kameraeinstellungen herzustellen, ${ }^{16}$ obwohl man im Film nicht von einem verortbaren Erzähler ausgehen kann. Die Einführung einer „mehrdimensionalen Erzählerposition“ (Hickethier), die sowohl Kamera, als auch Montage, Ton und Musik als vermittelnde Erzählfunktionen einsetzt, ist zwar dem filmischen Erzählen angemessen, aber auch abhängig von der zur Verfügung stehenden Zeit und dem Alter der Lernergruppe.

\footnotetext{
12 Andere Erzähltheorien unterscheiden zwischen plot als der Geschichte, wie sie im Film abläuft, und story als der chronologischen Handlung. Wichtiger als die Begrifflichkeit scheint mir das Einüben der Unterscheidungsfähigkeit.

13 Auch die Verbalisierung ist eine Medialisierung.

14 Auf folgende maßgebliche Erzähltheorien bezieht sich auch Brössel: Branigan 1992; Bordwell 1983; Chatman 1978. Michael Staiger (2010a: 25) favorisiert Chatmans Modell wegen seines medienunabhängigen Ansatzes. Von allen drei Erzähltheoretikern sind viele Aufsätze zur Filmnarratologie im Netz zu finden.

15 Vgl. Bach 1997. Sie setzt sich auch mit der Problematik der Übertragung der bekannten Erzähltheorien auf das filmische Erzählen auseinander.

16 Auch Spinner 2004: 200 erwähnt diesen Vorschlag.
} 


\section{Medienintegrative Filmnarratologie und Unterricht}

Hinter den folgenden Überlegungen und Unterrichtsbeispielen steht das Bewusstsein, dass es eine medienintegrative Narrationsanalyse bisher nur in Ansätzen gibt und kaum Literatur- bzw. Filmdidaktiken, die von diesen Überlegungen ausgehen. Außerdem orientieren sie sich auch an Ansprüchen, ${ }^{17}$ Bedingungen und Realiät der Lehre in einem zweisemestrigen Literaturkurs mit Studierenden aus unterschiedlichen Kulturen. Es entspricht einer mehrsemestrigen Erfahrung, dass dieser Ansatz für einen kompetenzorientierten Unterricht angesichts des begrenzten Zeitbudgets eher eine Erleichterung bedeutet, denn die Lerner eignen sich „Vorgehensweisen“ an, „die sie auch bei der Beschäftigung mit anderen Filmen und mit literarischen Texten nutzen können.“ (Spinner 2008: 46, Anm. 12) Wenn medienübergreifende Zugänge zum Interpretieren eingeübt werden, erleichtert. das im Filmunterricht Gelernte den Zugang zu literarischen Texten und umgekehrt und unterstützt einen selbstständigen und produktiven Umgang mit anderen Erzählweisen.

Unabhängig von der Erzählweise, in die zunächst oder auch vergleichend eingeführt wird, darf der analytische Zugang nicht gegen das lustvolle Freizeitsehen oder -lesen ausgespielt werden, was von der irrigen Annahme Lehrender und Lernender ausgeht, „die analytische Herangehensweise beziehe sich auf etwas anderes als auf die normale Gegenstandserfahrung - gewissermaßen auf eine Art Tiefenphänomen, das nur einer wissenschaftlichen oder wissenschaftsähnlichen Herangehensweise sich offenbart.“ (Zabka 2004: 253). ${ }^{18}$

Methodisch wird das genuine Interesse von Lernern an dem „Hergestellten“ des Erzählens dann geweckt, wenn man als Lehrender nicht auf Systematik und Vollständigkeit der Analyse besteht, sondern spontane oder angeregte Beobachtungen der Lerner aufgreift, was besonders gefallen oder missfallen hat, woran man sich besonders erinnert etc. Der Subtext dieser häufig emotional vorgetragenen Bemerkungen ist immer die Frage: „Wie kommt das?“ Diese Orientierung am Lernerinteresse stellt sicher, dass die Narrationsanalyse den sinnlichen Genuss des Filmerlebens vertiefen kann statt ihn zu blockieren.

In jedem Fall verzichtet eine medienintegrative Erzähltheorie auf eine verpflichtende Reihenfolge bei der Einführung in medial unterschiedliches Erzählen. Aufgrund meiner Erfahrung mit studentischen Lernern aus unterschiedlichen Kulturen stimme ich Kaspar Spinners Vorschlag zu, die Filmerfahrung der Lerner für die Annäherung an die Literatur zu nutzen, was Jutta Wermke schon 1997 forderte

\footnotetext{
${ }^{17}$ Mit Ansprüchen ist gemeint, dass alle Fachkurse für die Studierenden der geisteswissenschaftlichen Fächer sich an Kompetenzvermittlungen orientieren. Der Literaturkurs z.B. sollte Fähigkeiten zum analytischen und argumentativen Arbeiten vermitteln. Daher konzentriert sich die Lehre auch auf die Analyse medialen Erzählens.

${ }^{18}$ Er weist darauf hin, dass Handlungsroutinen in Unterricht und Lehre zu „einer Ablösung und Entfremdung der analytischen Operation von der Gegenstandserfahrung beitragen.“ (ebd.).
} 
(vgl. zu den einzelnen Erzählsaspekten Spinner 2004: 200). ${ }^{19}$ Die narrativen Strategien des Films können einer mediensozialisierten Generation vermutlich mehr als die eines literarischen Textes zeigen, dass mediales Erzählen Ergebnis einer spezifischen ästhetischen Verdichtung, einer komplexen, Wahrnehmung und Empfinden steuernden Konstruktion ist. Dazu trägt auch bei, dass „das Bewusstsein für die Gemachtheit, die Produziertheit von ästhetischen Produkten bei Bildern weit früher als bei Texten vorhanden ist, weswegen mit einer erhöhten Toleranz gegenüber der analytischen Betrachtung zu rechnen ist." (Zabka 2004: 255).

Im Folgenden werden vier Kursprojekte vorgestellt, die sich um Ansätze einer medienintegrativen Narratologie bemühen.

\section{Beispiele einer Filmbild- und Textanalyse}

Da die gegenwärtige curriculare Situation und der Alltag des Unterrichtens und Lehrens aufgrund der curricularen Anforderungen und auch aus Zeitgründen eine angemessene Berücksichtigung unterschiedlicher Arten medialen Erzählens selten zulässt, scheint mir der Hinweis wichtig, dass die Aufmerksamkeit für das spezifische „Gemachtsein“ literarischen oder filmischen Erzählens, seine ästhetische Eigenart, auch durch einzelne Hinweise geweckt und sukzessiv vertieft werden kann. Auch exemplarisch lässt sich zeigen, wie ästhetische Verdichtungen Wahrnehmung und Empfindung steuern. Einblicke in die Perspektivität jeder Wahrnehmung und Vorstellung und in den Zusammenhang von Inhalt und Darstellungsmöglichkeiten verlangen nicht unbedingt eine umfassende Text- und/oder Filmanalyse. Abgesehen von diesen auf den Unterrichtsalltag bezogenen pragmatischen Gründen bieten Filmbilder auf der Grundlage der Filmkenntnis die Möglichkeit, Wahrnehmungsdifferenzierung in Ruhe einzuüben.

Als Beispiel beziehe ich mich auf eine Filmaufnahme aus Stanley Kubricks letztem Film „Eyes Wide Shut“ (1999) mit Tom Cruise und Nicole Kidman. ${ }^{20}$ Sie zeigt das festlich gekleidete Ehepaar Bill und Alice Harford in seinem Badezimmer. Bill, der mit dem Rücken zu Alice steht, ist mit dem linken Ärmel seines Abendanzugs beschäftigt, während sie, auf der Toilettenschüssel sitzend, zu ihm hochschaut, weil sie seine Aufmerksamkeit für ihr Abendkleid und ihre Frisur wünscht: „Wie seh’ ich aus?“ Anstatt sie in dem vor ihm hängenden Spiegel anzuschauen,

19 Ich beziehe mich auf die Erfahrung vieler Semester der zweisemestrigen Literaturkurse am Studienkolleg München an den Freien Universitäten, dessen Curriculum die Einführung in die Filmanalyse gleichwertig neben der in die Analyse literarischen Erzählens vorsieht. Da der Film über universal nachvollziehbare filmsprachliche Zeichensystem verfügt und seine Distributionsbedingungen internationale Rezeption einschließen, können auch multikulturelle Lernergruppen auf gemeinsame Filmerfahrungen zurückgreifen.

${ }^{20}$ Der Film bezieht sich auf Arthur Schnitzlers Novelle „Traumnovelle“. Dieser Bezug wird im Nachspann als ,inspired by“ bezeichnet. 
wozu er nur leicht hochschauen müsste, bleibt er mit dem Ärmel seines Anzugs beschäftigt und antwortet ohne sie anzuschauen: „Perfekt.“ (00:00:16).

Ausgehend von der Einführung medial unterschiedlichen Erzählens für Studierende als Lernergruppen des Studienkollegs hat es sich bisher bewährt, die literarisch basierte Erzähltheorie durch ein Kompendium filmsprachlicher Begriffe zu ergänzen, das soweit wie möglich neben Erklärungen auch visuelle Veranschaulichungen enthält und jederzeit herangezogen werden kann, wenn bestimmte Wahrnehmungen kommuniziert, d.h. versprachlicht werden sollen und zunächst auch durch Beschreibungen ersetzt werden können. Im Laufe der Einführung eignen sich die Lerner die wesentlichen Begriffe ohne gesonderte Lernanstrengung und nur in Verbindung mit der entsprechenden Aussageabsicht an, weil sie einsehen, dass dies die Gesprächsverständigung erleichtert. ${ }^{21}$ Dieser praxisbasierte Vorschlag zeigt selbstverständlich auch die schon erzähltheoretisch angedeuteten Schwierigkeiten der Verbindung von filmsprachlicher Komplexität und literarisch basierter Erzähltheorie.

Wie sehr Einstellungsgrößen (ES) die eigene Wahrnehmung und damit auch Interpretation lenken, bleibt zunächst im Fluss des filmischen Erzählens unbemerkt. Die Bildaussage scheint sich aufgrund der Sichtbarkeit im ersten Verstehen zu erschöpfen. Das interpretierende Erzählen der ES macht Lernern nachvollziehbar, wie sehr Wahrnehmen differenziert werden kann. Die halbnahe ES dieser Aufnahme lenkt den Blick auf die Körpersprache der Eheleute, deren Mimik Teil des gestischen Ausdrucks ist. Sie zeigt zum einen die intime Vertrautheit der auf der Toilettenschüssel sitzenden Alice, die gleichzeitig seinen anerkennenden Blick für ihre Attraktivität wünscht. Diese Spannung einer ehelichen Beziehung von Gewöhnung und dem Wunsch nach wachgehaltener Aufmerksamkeit zeigt sich in Alices Gestik, die mit der linken Hand das Toilettenpapier hält, während sie mit der rechten Hand zur Unterstützung ihrer Frage an ihre Abendfrisur fasst. Während ihr Gesicht in einer diagonalen Blickachse zu ihrem Ehemann gewendet ist, widmet der sich ausschließlich seinem Anzugärmel, was sein auf den Ärmel gerichteter Kopf unterstützt, obwohl der vor ihm hängende Spiegel einen schnellen Blickkontakt ermöglichen würde.

Auch bei der Erschließung des Raums als Erzählelement hilft die veranschaulichende Filmaufnahme. ${ }^{22}$ Denn im Filmbild ist der Bezug von Figuren und Raum

\footnotetext{
${ }^{21}$ Jede Einführung in die Filmanalyse kann für die Zusammenstellung eines solchen Kompendiums herangezogen werden. Man kann diese Kompendien zum Teil auch von den Lernern zusammenstellen lassen, denn alle wichtigen filmsprachlichen Begriffe finden sich in Mehrfacherklärungen im Netz, wobei die unterschiedlichen Begriffserklärungen eben auch darauf hinweisen, dass dem Film keine Grammatik mit exakt definierten Begriffen zugrunde liegt.

22 Vgl. hierzu auch Spinner 2008. Die Erzähltheorie von Jurij M. Lotman fasst die Struktur einer Erzählung als globalen Raum auf, der in komplementäre Teilräume aufgeteilt ist, die mit semantischen Gegensatzpaaren verbunden werden. Aufgrund dieses erzählstrukturierenden Raummodells werden die Grenzüberschreitungen besonders interessant, vgl. Lotman 1986 und auch Martinez; Scheffel 2005. Es gibt literarische und filmische Genres, wie den Reise-, aber auch den Entwicklungsroman, das Roadmovie, wie selbstverständlich alle transkulturellen Filmgeschichten, die diesen
} 
sinnlich erlebbar und macht sofort deutlich, dass dieser private und intime Ort die einerseits vertraute, andererseits durch den Ehealltag wohl auch unaufmerksam gewordene Beziehung zwischen Bill und Alice betont. Der Bildausschnitt unterstützt die Enge des Raumes, die den Eindruck der Beziehungsambivalenz von Nähe und Distanz noch intensiviert.

Das visuelle Konzept des Films kennt ebenso wie der literarische Text geschlossene und offene Räume und ihre Wirkung. In dem gewählten Bild betont der geschlossene Raum den Kontrast von intimer Nähe und unaufmerksamer Vertraulichkeit. An dieser - wie an jeder anderen - Filmaufnahme kann ebenfalls deutlich gemacht werden, wie die Bildwahrnehmung durch die vorentschiedene Selektion eines bestimmten Ausschnitts gelenkt wird, was - vor allem bei den bewegten Bildern des Films - kaum bewusst ist. Die Cadrierung des Filmbildes bestimmt nicht nur, welcher Ausschnitt sichtbar ist, sondern ebenso, was unsichtbar bleibt, aber eingeplant mitgedacht wird, weil der Zuschauer den Raum entsprechend erweitert. Der narrative Raum ist also immer größer als der abgebildete Raum. Die im Bild eingeplante Raumkomplettierung durch den Zuschauer wird veranlasst durch das leichte Abschneiden von Personen, Gegenständen, Wänden oder Wegen.

Eine Vertiefung bleibt der Entscheidung des Lehrers bzw. dem Interesse der Lernenden überlassen. Meiner Erfahrung nach führen Lernende das Gespräch bzw. die Filmbildbetrachtung, die mit der Betonung eines Erzählelements beginnt, auch auf andere bildbestimmende Aspekte, so dass auch, wenn über diese anderen Aspekte nicht sofort grundlegend informiert wird, doch die Kontextabhängigkeit aller filmischen Zeichen deutlich wird. So zeigt diese Aufnahme, dass der enge Raum, der die intime Atmosphäre unterstützt, durch die gekippte Jalousie, die einen Blick auf die nächtlich erleuchteten Fenster gegenüber liegender Häuser erlaubt und also durchlässig ist für externe Lichtquellen, eine kontrastierende Raumtiefe erhält, die zusammen mit den bildinternen Lichtquellen den an sich kühlen Raum in einem warmen Licht zeigen, wobei das Licht- und Schattenspiel auf der Haut von Alice in ihrer exponierten Körperhaltung ihre verführerischen, vielleicht auch verführungswilligen Reize betont und damit auch die Unaufmerksamkeit ihres Ehemannes unterstreicht. Gleichzeitig weist die Kamera durch die leichte Aufsicht und die ES, die Lerner oft erwähnen, auch ohne sie begrifflich zu kennen, dem Zuschauer die Rolle eines beinahe voyeurhaften Betrachters dieser Eheszene zu. Er wird, während er den Raum ergänzt, auch in ihn hineingezogen.

Die anschauliche Erfahrung des Bezugs von Raum und Figurenkonstellation erleichtert den Lernenden den Zugang zur Bedeutung des Raums als Erzählaspekt literarischer Texte. Denn Raum und Handlung werden beim Lesen zunächst nicht getrennt, weil Räume in das Auftreten, Verhalten und Handeln von Figuren „eingeschrieben“ zu sein scheinen. Daher fällt es schwerer, sich den Raum des Textes 
gesondert anzuschauen, ihn zunächst aus dem Handlungszusammenhang herauszulösen, um zu erfassen, dass jeder Raum eine Bedeutung in den literarischen Text mitbringt und dass die Handlung der Figuren erst in Verbindung mit oder auch in Spannung zu diesem Ort ihre Bedeutung erhalten. Denn diese analytische Ortsbetrachtung verlangt nicht nur reflektierende Distanz zum Text, sondern auch zu der beim Lesen aufgebauten inneren Vorstellung.

Als Vergleichstext wähle ich den Anfang des Kurzprosatextes „Augenblicke“ von W. H. Fritz. Auch hier unterstützt der Ort eine Beziehungsaussage:

Kaum stand sie vor dem Spiegel im Badezimmer, um sich herzurichten, als ihre Mutter aus dem Zimmer nebenan zu ihr hereinkam, unter dem Vorwand, sie wolle sich nur die Hände waschen.

(Fritz in Krusche 1988: 198)

Die Studierenden konzentrieren sich zunächst ausschließlich auf die angespannte Mutter- Tochterbeziehung. Die Erinnerung an die beziehungsprofilierende Bedeutung des Raumes im Filmbild hilft zu erkennen, dass gerade der Ort in seiner besonderen Privatheit und Enge, aber auch der hier verweigerten Möglichkeit zum innerfamiliären Rückzug, die Angespanntheit dieser Beziehung deutlich macht.

Auch die studentischen Umsetzungen dieses Satzes in Filmaufnahme/n bzw. in Bilder eines Storyboards veranschaulichen diese ortsunterstützte Beziehungsqualität. Das Gespräch über die unterschiedlichen Bildumsetzungen macht den Studierenden ebenfalls deutlich, wie sehr die von ihnen gewählte Kamera, also die ES und die Perspektive, die Wahrnehmung lenkt, denn die interpretierende Blicklenkung der Einstellungsgrößen entscheidet, was wie groß zu sehen ist, ob sich die Anspannung der beiden Frauen eher in der Mimik oder in der Körperhaltung zeigt oder auch in beidem.

Auch das Erzählpotential der Montage, die den Erzählrhythmus des Films bestimmt und ihn nicht nur zeitlich, sondern auch räumlich strukturiert, so dass Staiger sie im Zentrum der Medienästhetik des Films sieht (Staiger 2010b: 103), muss zunächst aus der Selbstverständlichkeit der scheinbar leicht verständlichen Filmerzählung gelöst und entfaltet werden. Der durch das Zusammenfügen von Bildern produzierte Sinn wird so schnell und unhinterfragt der Bildaussage hinzuaddiert, dass die montagespezifische Produktion eines Sinns, der nicht in den Bildern enthalten ist, zunächst nicht wahrnehmbar scheint. Die Sensibilisierung für diese Sinnproduktion braucht Wahrnehmungsruhe und wiederholtes Einüben am Beispiel von Bildsequenzen zweier aufeinanderfolgender Filmbilder. Wenn die 1. Aufnahme aus dem Film „Le Mépris“ von Jean-Luc Godard (1963) den Schriftsteller Paul zeigt, der auf dem Flachdach der Casa Malaparte steht und nach unten schaut, und seine Frau Camille in der 2. Aufnahme mit dem Filmproduzenten Jeremy auf einer Fensterbank sitzt und aus dem Fenster nach oben auf das Dach schaut, ist jedem Lerner völlig klar, dass Camille sehen will, dass ihr Mann sie beobachtet. Bewusst gemacht werden muss, dass diese Aussage keinem der Bilder zu entnehmen ist, weil sie erst durch das Zusammenfügen der beiden Bilder 
hinzukommt. Die Einsicht in die Montage als Sinnproduzentin sollte vorausgesetzt werden, wenn der auf Montagefiguren beruhende Erzählrhythmus eines Films oder einer längeren Filmsequenz erarbeitet wird. ${ }^{23}$

\section{$7 \quad$ Filmische Adaptionen von Kurzprosa}

Mit dem unterschiedlichen Erzählen von Schriftsprache und Film haben viele Lerner dank der Filmmöglichkeit der neuen Handy-, Smartphone- und Kamerageneration und der im Netz verfügbaren Software zum Schneiden ${ }^{24}$ bereits eigene produktive Erfahrungen.

Dieses Projekt der filmischen Adaption von literarischen Texten lässt sich mühelos auf mehrere Wochen ausdehnen. Zur Ermutigung, ähnliche Versuche in den eigenen stoffbelasteten und zeitrestriktiven Unterricht zu integrieren, möchte ich hier ein eintägiges Projekt vorstellen, das im Rahmen einer Fortbildungsveranstaltung des Goethe-Instituts für Lehrende unterschiedlicher Ausbildungseinrichtungen stattfand. ${ }^{25}$ Die Vertrautheit mit den textanalytisch erforderlichen Erzählelementen ${ }^{26}$ konnte bei den teilnehmenden Lehrkräften nicht gleichermaßen vorausgesetzt werden. An kurzen Textbeispielen des Romans „Das Parfum“ von Patrick Süskind und an kurzen Filmsequenzen der filmischen Adaption von Tom Tykwer werden in Gesprächen wesentliche Elemente des schriftsprachlichen und filmischen Erzählens erarbeitet, wobei diese Gespräche nicht an der analytischen Steuerung des Dozenten orientiert sind, sondern an den Beiträgen der TeilnehmerInnen.

Aus Zeitgründen wird sowohl der narrative Beitrag von Musik und Ton als auch die Bedeutung der Montage für Sinnproduktion und Erzählrhythmus vernachlässigt. ${ }^{27}$

\footnotetext{
23 Zur Erfahrung der Aussagekraft und des Erzählrhythmus der Montage scheinen mir Filme, deren Erzählstruktur auf der Parallelmontage beruht, wie z.B. „Das Leben der Anderen“ (2006) von Henckel von Donnersmarck, sehr viel geeigneter als die sehr viel häufigeren Filmbeispiele der Kontinuitätsmontage. In diesem Film ermöglicht sie, leicht nachvollziehbar, die narrative Kontrastierung zweier Lebenswelten. Ihr kontrastives Verbinden erzählt vom Bespitzeln und Bespitzeltwerden.

${ }^{24}$ Ein begrenzt kostenlos herunterzuladendes Programm zum Schneiden, Montieren und Vertonen ist „Movie Maker“. Auch „MAGIX Video deluxe“ (Windows) kann 30 Tage kostenlos benutzt werden, siehe das Software-Verzeichnis: http://www.heise.de/software/download/videodeluxe/ 23478.

${ }^{25}$ Es handelt sich um die von Manuela Malakooti und Barbara Sabel geleitete Münchner Fortbildung „Film im Unterricht“ im Sommer 2013. Diese Gruppe hatte schon eine eintägige Einführung in das Storyboard erhalten, was produktiv genutzt werden konnte.

${ }^{26}$ Ich beziehe mich bei diesem Projekt vor allem auf Vogt 2008 und 2011. Wie auch Kuhn vorschlägt, integriere ich Begrifflichkeiten anderer Theorien, soweit die Lerner interessiert sind, ihre analytische Wahrnehmung zu differenzieren.

27 Unter „Vernachlässigung“ verstehe ich hier, dass diese Aspekte nicht Teil des Lehrangebots sind, dass aber entsprechende Fragen jederzeit beantwortet bzw. aufgegriffen werden. Obwohl die Filmanalyse gleichwertig neben der literarischen Analyse curricular im Studienkolleg verankert ist, belegen alle meine Lehr-, Seminar-, Fortbildungserfahrungen, dass der Verzicht auf narratologische Voll-
} 
In einer anschließenden arbeitsteiligen Gruppenarbeit wird wiederum anhand kurzer Textpassagen und Filmsequenzen erarbeitet, wie anders Text und Film erzählen, wobei jede Gruppe einen besonders interessanten Unterschied vorstellt. Zwei Gruppen erarbeiten anhand einer Filmbildsequenz, wie der Text visuell umgesetzt wird bzw. was aus welchem Grund nicht umgesetzt werden konnte.

Am Nachmittag erarbeiten die sechs Gruppen eine Filmerzählung eines der zwei vorgestellten Kurprosatexte, ${ }^{28}$ so dass der anschließenden gemeinsamen Reflexion der verschiedenen filmischen Erzählversuche jeweils drei vergleichbare Textbezüge zugrunde liegen. Beide Texte erzählen von Beziehungskonflikten und verweigern aufgrund der Innensicht der weiblichen Figur, d.h. des wiederholten Inneren Monologs, eine filmische Nacherzählung. Die Filmteams einigen sich zunächst auf ein Textverständnis und legen in einem Storyboard ES, Perspektive, Bildcadrierung, Kamerabewegungen und eine genaue Zeitplanung bei jedem Take fest. Schnitt und Montage war nicht verpflichtend, was die Bedeutung des Storyboards bzw. der Einzelbildaussage noch erhöht.

Bei der Vorstellung der Filme werden die Filmemacher gebeten, Änderungen der Textvorlage, aber auch Abweichungen vom Storyboard filmisch zu begründen, Schwierigkeiten beim Drehen und mögliche andere filmische Lösungen bei einem zweiten Drehen zu erläutern. Dass die Filmproduktionen beeindrucken, vor allem auch angesichts des äußerst straffen Zeitplans, bestätigen die Erfahrungen mit Filmprojekten am Studienkolleg. ${ }^{29}$ Eine Gruppe ist so fasziniert von dem spezifisch filmischen Erzählen, dass sie auf der Grundlage des literarischen Textes einen Stummfilm drehen. Selbst mögliche Zwischentitel werden durch übertriebene Mimik und Gestik ersetzt. In einer anderen Filmversion wird der Innere Monolog einer eifersüchtigen jungen Frau in ein Handygespräch umgesetzt. Das erzählerische Potential von ES und Kameraperspektive wird erstaunlich gut ausprobiert, vermutlich auch, weil sie durch den Verzicht auf Schnitt und Montage gut überlegt sind. Dennoch begleitet auch dieses an sich sehr erfolgreiche und lustbetonte Projekt ein aus meiner Sicht häufig auftauchendes Desiderat produktionsorientierten Unterrichtens, dass die spannendste Anschlusssequenz die wäre, auch an dem nicht überzeugend Gelungenen, hart gesagt, an den Schwächen dieser Minifilme, das Faszinierende beider Erzählweisen zu reflektieren.

\footnotetext{
ständigkeit und eine den Lernern gegenüber vertretbare Konzentration auf ausgewählte Erzählanteile oft Grundlage des Unterrichts ist.

${ }^{28}$ Es handelt sich um die Texte „Eifersucht“ von Tanja Zimmermann und „Happyend“ von Kurt Marti.

${ }^{29}$ In diesem Zusammenhang möchte ich auf ein weiteres Kursprojekt zur filmischen Adaption des kurzen Prosatextes „Gib's auf“ von Kafka hinweisen, das im Rahmen des Literaturkurses am Studienkolleg durchgeführt wurde, vgl. Bürner-Kotzam 2011.
} 


\section{Das Erzählen in Comic, Film und literarischem Text}

Das Projekt „Narration im Comic - Film - literarischen Text" verpflichtet sich noch entschiedener der Neugewichtung des Verhältnisses von Sprache und Bild angesichts der zunehmenden Bedeutung des Bildes in der gesellschaftlichen Wahrnehmung. Zu verstehen und kritisch reflektieren zu können, dass und wie heute in Bildern gesehen, gedacht und erinnert wird, scheint unverzichtbar für eine selbstbestimmte Orientierung in jeder Art von Öffentlichkeit.

Daher beginnt der Literaturkurs mit der Analyse der Erzählweise des Comic, um - darauf aufbauend - die Filmanalyse, und zwar die Analyse einer sogenannten „Literaturverfilmung“, anzuschließen und mit der Analyse des literarischen Textes, der dem analysierten Film zugrunde liegt, abzuschließen. Diese Reihenfolge verhindert das zwangsläufige aber unangemessene Vergleichen der „Verfilmung“ mit dem literarischen Text und unterstützt so die Eigenständigkeit der filmischen Erzählung.

Für das Comic am Anfang der Erzählanalyse spricht sowohl der relativ einfach zu verstehende Handlungsverlauf der alltagsvertrauten Geschichten, die durchschaubaren Figuren, die sich nicht verändern und ihre überschaubaren Beziehungen. Damit verbindet sich eine Wortschatzentlastung - im Vergleich zur Analyse eines Films oder literarischen Textes - die auch auf die Reduktion, Selektion und Überzeichnung der bildlichen Darstellung zurückzuführen ist.

Früher als der Film fanden Comics Beachtung in der Deutschdidaktik und im schulischen Unterricht, allerdings vor allem als Beispiel trivialer Literatur. „Schüler sollten in der Auseinandersetzung mit der Comiclektüre lernen, ihre Rolle als Konsumenten zu durchschauen." (Schüwer 2008: 15). Diese Funktion verzögert jedoch einen angemessenen Umgang mit dem Medium.

Auch unser Angebot der Comicanalyse im Rahmen des Literaturkurses stößt zunächst auf irritierte Reaktionen der Studierenden. Für sie sind Comics nicht Bestandteil ihres Kulturverständnisses. Diese Einschätzung entspricht einer allgemeinen Haltung Comics gegenüber. Sie werden zwar „als Teil der Kultur des 20. Jahrhunderts zunehmend akzeptiert", aber ihnen wird „, keineswegs ein gleichberechtigter Platz neben Literatur, bildender Kunst oder sogar Film eingeräumt.“ (Frahm 2010: 201). Die abwertende Haltung der Studierenden äußert sich zunächst in einer begrenzten Aufmerksamkeitsbereitschaft, die sie für die angeblich oberflächlichen Bildgeschichten bzw. einzelnen Bilder für angemessen bzw. ausreichend halten. Um so größer ist ihr Erstaunen angesichts des differenzierten und vielfältigen sprachlichen und visuellen Erzählens, wobei die spezifische Vielfalt dieser Erzählweise, deren Rezeption zunächst keine Verstehensanforderungen stellt, an einzelnen Panels erklärend bewusst gemacht werden muss. Erst die Beachtung des spezifischen narrativen Potentials des Comics als narrative Bildgeschichte mit einem umfassenden „Zeichenarsenal“ (Grünewald) erlaubt, auch „Qualitätsunterschiede wie etwa in der Literatur oder der Malerei“ (Baumgärtner 1973: 20) zu erkennen. 
Das besondere und auch komplexe Erzählen liegt in der comicspezifischen Verbindung von Bild, Schrift und Sprache, also der Verbindung von visuellem und sprachlichem Erzählen, die auch die verbindende Analyse von sprachlichem und visuellem Erzählen verlangt, aber auch in ihrer Besonderheit, sowohl statische Bilder als auch eine sukzessive Bildgeschichte anzubieten, wobei auch das Einzelbild aufgrund des comicspezifischen Zeichenpotentials zeitliche Abläufe abbilden kann.

Diese Eigenständigkeit des comicspezifischen Erzählens, ${ }^{30}$ seine Differenziertheit und Vielfalt und die spezifischen, sowohl visuellen als auch sprachlichen Rezeptionsanforderungen werden beachtet, also bewusst gemacht. Sie stehen aber nicht im Vordergrund dieses Projektes, das sich bei der Einführung in die Erzählanalyse des Comic, wie des Films und des literarischen Textes vor allem an einer medienintegrativen Erzähltheorie orientiert.

In diesem Kontext bietet der Comic in seiner Verbindung von sprachlichem und visuellem Erzählen die Möglichkeit, sowohl in medienübergreifende Erzählelemente einzuführen als auch in wichtige Elemente der Filmanalyse, wobei die Analyse des Einzelbildes die erzählspezifische Interaktion dieser Elemente bewusst machen kann.

Als Comicbeispiel haben wir uns vor allem auf Geschichten von „Calvin und Hobbes“ von Bill Watterson konzentriert, den auf mehrere Bände angewachsenen Comicstrip über den sechsjährigen amerikanischen Jungen Calvin, seine Eltern und vor allem seinen Stofftiger Hobbes (Watterson 2013). Das erzählerisch Reizvolle dieses Comic liegt in dem ständigen Perspektivenwechsel bzw. in dem Wechsel der Erzählhaltung, da Hobbes für die Erwachsenenwelt ein Stofftiger ist, aber in Calvins Welt, also im Zusammensein bzw. Zusammenerleben mit ihm ein echter, selbstbewusster, sprechender Tiger ist. Diese realitätsverwandelnde Perspektive bezieht sich nicht nur auf den Stofftiger, sondern auch auf andere Erlebenssituationen von Calvin, der sich z.B., um besser und schneller lernen zu können, in einem Zellumwandler in einen Elefanten transformiert, der nicht nur über ein „elefantöses“ Gedächtnis verfügt, sondern - quasi nebenbei, aber dennoch mit ärgerlichen Folgen - auch genussvoll im Schlamm badet. Zu seinem großen Erstaunen wird er jedoch von seiner Mutter nicht als Elefant, sondern als verdrecktes Kind wahrgenommen. Die Sichtweisen Calvins und seiner Umwelt wechseln ständig; in diesem Strip von der des zum Elefanten mutierten Calvin zu der seiner Mutter, die den schmutzigen Calvin wegen der verdreckten Wohnung beschimpft, und der des Jungen Calvin, wenn er sich erschrocken des „clash of realities“ be-

\footnotetext{
30 Die anhaltende Diskussion, inwieweit man von einem Erzähler bzw. von Erzählen im Comic sprechen kann, kann im Rahmen dieses Projektes nicht berücksichtigt werden. Wiederholt werden neue Erzählmodelle gefordert, die dem differenzierten visuell-sprachlichem Erzählen des Comic gerecht werden. Martin Schüwer, der sich in seiner Dissertation 2008 mit den Erzählstrukturen in der Interaktion von Sprache und Bild auseinandersetzt, fragt auf der Tagung „Comic - Intermedial und Interdisziplinär“ 2011, „ob der Comic als eine ,erzählerische Deformation“ überhaupt als narrativ zu kategorisieren" sei - ließen sich doch klassische Erzähltheorien in der Regel aufgrund ihrer Beschaffenheit nur bedingt bzw. in modifizierter Form auf den Comic anwenden (Eckstein 2011 ).
} 
wusst wird. Verbunden mit der wechselnden Perspektive des Erzählens ist häufig auch ein - an die Kameraperspektive erinnernder - Perspektivwechsel des Bildes, so wenn die Untersicht den riesigen Elefanten in dem ihn beengenden Kinderzimmer noch gigantischer erscheinen lässt. Hinzu kommen die - auch filmanalytisch relevanten - Einstellungsgrößen der Panels, hier die Großaufnahme des beinahe raumfüllenden Elefanten.

Die dem Elefanten Calvin zugewiesene große Sprechblase antwortet auf die mütterliche Frage nach seinem Herumgetrampele „wie ein Elefant" und ihrer Erinnerung an die Hausaufgaben: „Ich mache meine Hausaufgaben!“ Dieser Ausruf ist fett gedruckt, wobei das Verb „mache“ nochmals graphisch hervorgehoben wird. So wird sowohl visuell als auch sprachlich und graphisch deutlich, dass aus der Perspektive des transformierten Calvis erzählt wird, der laut und entschieden seinen Elefantenentschluss verkündet.

Dieser Wechsel der Sichtweisen ist nicht nur erzählerisch reizvoll, er erfordert auch eine besonders genaue Wahrnehmung sowohl des Einzelbildes als auch der Bildfolge. Und er macht deutlich, dass die Analyse eines Panels die erzählerische Interaktion von Sprache, Schrift und Bild beachten muss. Ebenso muss die Einzelbildanalyse auf medienübergreifende Erzählelemente wie Figuren, ihre Mimik, Gestik, Kleidung Figurenkonstellation, Erzählverhalten, Ort und zeitliche Verortung wie Jahres- oder Tageszeit, aber auch auf die Einführung in Elemente der Filmsprache zurückgreifen.

Die Wortschatzentlastung erleichtert nicht die Anforderungen an eine differenzierte Wahrnehmung, zumal nicht nur in der Ergänzung oder Entsprechung sondern auch im Widerspruch von Sprache und Bild erzählt werden kann. So wenn eine halbnahe Aufnahme den Piloten Calvin bzw. Spiff in seinem schwer getroffenen brennenden Raumschiff im gefährlichem Sturzflug zeigt, was er jedoch cool kommentiert: „Immer wenn ich gerade aus der Waschanlage komme.“

Erst einer aufmerksamen Wahrnehmung - so die Erfahrung der Studierenden - entfaltet sich das Miteinander der Aussageebenen: Die diagonale Bilddynamik verdeutlicht die Geschwindigkeit und damit auch die Absturzgefahr. Die bildliche Reduzierung Calvins auf Haare und Brille, bzw. obere Kopfhälfte drückt sowohl den Eindruck seines konzentrierten Steuerns, gleichzeitig aber auch seines Ausgeliefertseins aus. Die Einstellungsgröße unterstützt die Dramatik der Situation, ebenso wie die Untersicht, die die Absturzgefahr betont. Demgegenüber steht die Coolness Calvins, der angesichts dieser dramatischen Situation lediglich an die Verschmutzung des Raumschiffes denkt, wobei er mit seinem „immer“ auf die Normalität einer so lebensgefährlichen Situation anspielt. Der Kontrast von Bild und Sprache intensiviert die Wirkung der alle Gefahren meisternden Coolness.

Comicspezifisch ist der Einfluss von Größe und Form der einzelnen Panels, deren Kombination nicht nur den Bildaufbau einer Seite, sondern auch die Erzählstruktur mitbestimmt. Die Studierenden lernen neben dem Leseprozess der sukzessiven Geschichte nicht nur die Gestaltung des Einzelbildes sondern auch die der Bildseite als erzählerisch relevant zu beachten. So stehen neben dem die halbe 
Seite einnehmende Hochformat des Hausaufgaben ankündigenden riesigen Elefanten zwei kleine hochformatige, aber unterschiedlich breite Panels, des spielend lernenden Elefanten, der sich dann kaum durch die Tür ins Freie zwängen kann, um zu spielen. Alle drei Formate unterstützen den Eindruck des Gigantischen dieses Elefanten. In das abschließende rechteckige Panel mit einem entsetzt vom Baumast hochspringenden Hobbes angesichts des riesengroßen Elefanten vor ihm ist ein kleines rechteckiges Panel mit dem friedlich auf einem Baumast schlafenden Hobbes gesetzt. Form und Größe der letzten Panels dienen der überwältigenden Größe des Elefanten Calvin, wobei der Subtext dieser Größe die entsprechende Leichtigkeit des Lernens und Erinnerns ist.

In diesem Zusammenhang wird die ebenfalls filmrelevante Cadrierung eingeführt. Die Unterscheidung von abgebildetem und narrativem Raum gilt auch für den Comicpanel.

Dass die Bildgeschichte als sukzessive „prozessuale Geschichte“ (Grünwald) erst entsteht, weil die Leerstellen zwischen den Panels, also den statischen Einzelbildern, in der Rezeption gefüllt werden, sensibilisiert die Wahrnehmung zum einen für die Erwartungshaltung, die das Einzelbild aufbaut und die auf die Entwicklung der Situation gerichtet ist. Sie muss erkennen, was sich in zwei folgenden Bildern geändert hat und was gleich geblieben ist.

Dies bereitet die Einführung der Montage vor. Herausfordernd für die Studierenden ist - wie schon im ersten Projekt erwähnt - die Reflexion einer als selbstverständlich empfundenen Sinngebung. Die Montageaussage verdankt sich nicht den Bildern, sondern dem Zusammenfügen der Bilder, das sozusagen einen Sinn hinzufügt. Wenn dem verdutzten Piloten Spiff bzw. Calvin nach seiner Bruchlandung von einem außerdirdischen Monster mit aufgerissenem Maul ein Tablett mit einem Sandwich und Limonade gebracht wird, und im nächsten Panel die Mutter mit diesem Tablett vor dem im Sandkasten sitzenden Calvin steht, teilt erst die Montage mit, dass Calvin durch die Konfrontation mit der Mutter in die „normale“ Realität zurückgeholt wird, wobei die Sprechblasen die Kontinuität der Geschichte unterstützen. „Dabei entspricht jedes neue Bild mit einer neuen Einstellung oder einem anderen Inhalt einem Schnitt im Film, da sich der Leser jedes Mal aufs Neue über Ort und handelnde Personen orientieren muss. Im Gegensatz zum Film verfügt der Comic nicht über das Mittel der Kamerafahrt, die in einer Bildfolge nur simuliert werden kann. Bilder aus gleichem Blickwinkel entsprechen der stehenden Kamera im Film, Bilder aus marginal wechselndem Blickwinkel haben ihre Entsprechung in Kamerafahrten." (Ihme 2010: 68). Jeder Schnitt entspricht zwar einem Zeitsprung. Dieser ist allerdings unterschiedlich groß, was wiederum den Einzelbildern eine unterschiedlich große Bedeutung gibt. Dem filmischen Erzählen am nächsten kommen Bildsequenzen mit geringen Zeitsprüngen, die fortlaufendes Lesen ermöglichen. 
Diese Beschäftigung mit der Erzählweise des Comic ermöglichte, da wichtige filmanalytische Begriffe schon vertraut, d.h. geübt waren, eine intensivere anschließende Auseinandersetzung mit dem Film. ${ }^{31}$

Die alten Formen der Übermittlung nämlich bleiben durch neu auftauchende nicht unverändert und nicht neben ihnen bestehen. Der Filmsehende liest Erzählungen anders. Aber auch der Erzählungen schreibt, ist seinerseits ein Filmsehender. Die Technifizierung der literarischen Produktion ist nicht mehr rückgängig zu machen. Die Verwendung von Instrumenten bringt auch den Romanschreiber, der sie selbst nicht verwendet, dazu, das, was die Instrumente können, ebenfalls können zu wollen. (Brecht 1967: 176).

\section{Kinematografisches Erzählen}

Ein weiteres Projekt beschäftigt sich mit dem gegenseitigen Einfluss der medialen Erzählweisen. Denn ein produktiver Umgang mit beiden Erzählweisen setzt auch voraus, der gegenseitigen Beeinflussung filmischen und literarischen Erzählens nachzugehen, die noch dazu nachweisen kann, wie sehr der Erfolg des Spielfilms auf seiner Integration in die Tradition literarischen Erzählens beruht. Dieses Projekt einer integrativen Narrationsanalyse geht den Fragen nach, wie der Film auf das literarische Erzählen und wie das literarische Erzählen auf die narrative Herausforderung des Films reagiert, aber auch, was sich nur filmisch oder nur literarisch erzählen lässt. ${ }^{32}$

Vor allem in den Anfangsjahren des Spielfilms äußerten Schriftsteller ihre Faszination von den filmischen Erzähltechniken. So gesteht Tolstoi 1908 in einem Interview, wie ,sehr dieser kleine Apparat mit der Kurbel eine Revolution in unserem Leben bewirken wird - im Leben der Schriftsteller. Das ist ein direkter Angriff auf unsere alten Methoden literarischer Kunst.“ (zit. in: Paech 1997: 410).

Joachim Paech belegt die Faszination vieler expressionistischer Schriftsteller vom filmischen Erzählen, weil sie, ebenso wie die Filmemacher, interessiert waren an der erzählerischen Umsetzung von Bewegung und Beschleunigung des Sehens und Reagierens, die der neue großstädtische Lebensraum erzwingt. Einschneidend

\footnotetext{
31 Eine weitere Projektplanung wird sich auf die Comic-, Film- und literarische Erzählung eines Textes konzentrieren und zwar den Comic: Isabel Kreitz: Die Entdeckung der Currywurst. Nach einem Roman von Uwe Timm. Carlsen, den Film von Ulla Wagner: Die Entdeckung der Currywurst (2008) und die Novelle von Uwe Timm: Die Entdeckung der Currywurst (1993).

32 „Die alten Formen der Übermittlung nämlich bleiben durch neu auftauchende nicht unverändert und nicht neben ihnen bestehen. Der Filmsehende liest Erzählungen anders. Aber auch der Erzählungen schreibt, ist seinerseits ein Filmsehender. Die Technifizierung der literarischen Produktion ist nicht mehr rückgängig zu machen. Die Verwendung von Instrumenten bringt auch den Romanschreiber, der sie selbst nicht verwendet, dazu, das, was die Instrumente können, ebenfalls können zu wollen." lautet die inzwischen vielzitierte Aussage Brechts (1967: 176).
} 
veränderte Lebensbedingungen scheinen beide Erzählweisen ähnlich provoziert zu haben. Diese Provokation verfolgt Peter-André Alt z.B. im Erzählen Kafkas, einem großen Verehrer des Kinos (vgl. Alt 2009). ${ }^{33}$ Ebenso einflussreich scheint das literarische Erzählen für die Etablierung des Spielfilms seit Beginn des 20. Jahrhunderts gewesen zu sein. Um das bisher in ablehnender Distanz bleibende bürgerliche Publikum zu gewinnen, schließt der Film „deutlich an die Tradition literarischen Erzählens an, deren Paradigma der realistische Roman des 19. Jahrhunderts ist.“ (Paech 1997: 44). Das am realistischen Erzählen orientierte filmische Erzählen nutzt den immensen Geschichtenvorrat der realistisch erzählenden Romane und kann mit diesem beliebten Erzählstoff auch den bürgerlichen Wertvorstellungen entsprechen. Diese „Literarisierung“ (Paech) wird zur zukunftsweisenden Art filmischen Erzählens. Selbst scheinbar spezifisch filmische Erzählmittel wie die Parallelmontage setzt der amerikanisch Regisseur Griffith, der Erfinder des „Erzählkinos", bei der skeptischen Filmindustrie auch dadurch durch, dass er sich auf die Romane seines Lieblingsautors Dickens beruft (vgl. Petri 1975: 187). ${ }^{34}$

Griffith bindet also den Film bewusst in die literarische Tradition ein, ebenso wie der russische Regisseur Sergej Eisenstein, der sich intensiv mit der gegenseitigen Beeinflussung des literarischen und filmischen Erzählens beschäftigt hat. ${ }^{35} \mathrm{Er}$ verfolgt die Montage bis zu den realistischen Romanen von Dickens, Puschkin, Flaubert, Zola, also in eine vorfilmische Zeit, um den Zusammenhang von Gesellschaftsstruktur und Erzählweise nachzuweisen. „Bei Flaubert finden sich einige der vorzüglichsten Vorbilder einer Überkreuz-Montage [...], zum Beispiel die erneute Begegnung von Emma und Rudolf Boulanger am Jahrestag der Landwirte. Flaubert montiert die Verführungsszene zwischen den beiden im Rathaus mit der Festversammlung, die beide hören und beobachten, ,als parallele Handlungen, wobei der Blickpunkt POV, von dem Paar zur Versammlung bzw. dem Redner wechselt, wobei die Festplatzgeräusche akustisch anwesend bleiben, wenn Emma und Rudolf miteinander reden, er auch darauf reagiert, Ausdruck der Schwierigkeit den gesellschaftlichen Konventionen zu entkommen.“ Eisenstein (1974: 263).

Die narrative Beherrschung vieler Figuren, Situationen, räumlich getrennter Ereignisse scheint also zunächst im literarische Erzählen erprobt zu sein. Einige

\footnotetext{
${ }^{33}$ Dieser urbane Lebensraum ist „Einheit des wesentlich Widersprüchlichen $[\ldots]$ “, seine „Topographie beschwört eine Gleichzeitigkeit, die sich sofort in eine Vielzahl unzusammenhängender Bewegungen, das Nebeneinander oder Nacheinander auflöst. Diskontinuierlich und schockartig entstehen Eindrücke, die durch nichts anderes als durch die Gleichzeitigkeit des Ortes und die Kontingenz der Beziehung begründet sind. (Paech 1997: 125). Segeberg weist auf den Einfluss des Films auf die expressionistische Lyrik hin, vgl. Segeberg 2003: 273.

34, ,...] es war keineswegs meine Idee. Ich habe sie in den Werken von Dickens gefunden. Man kann es [das Verfahren des switching-off, RB] in allen seinen Büchern finden. Erst führt er eine Menge Figuren und Ereignisse ein, dann bricht er plötzlich ab und wechselt von einem zum anderen, und am Ende faßt er alle die scheinbar losen Enden wieder zusammen." (Griffith, zit. nach Petrie 1975: 187).

35 Eisenstein setzte sich 1930 in Paris mit James Joyce, der in Dublin Kinobesitzer war, über die „filmische Schreibweise“ auseinander, vgl. Paech 1997: 140.
} 
Jahre vor der Erfindung des Films haben Schriftsteller „,nicht nur davon geträumt, den Diskurs wie eine Kette bewegter Bilder zu konstruieren, die den Eindruck von Bewegung und Lebendigkeit geben, sondern auch mit Verfahren des Schreibens

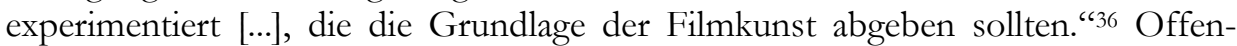
sichtlich entwickelt sich erst auf der Grundlage der Einreihung in die literarische Tradition spezifisch filmisches Erzählen und provoziert wiederum faszinierte Reaktionen der Literatur. „Für die Dichtung des 20. und 21. Jahrhunderts [ist] nicht mehr wegzudenken, dass sie direkt oder indirekt von der Existenz oder Wahrnehmung filmischen Erzählens begleitet wird.“ (Paefgen 2009: 7). Angesichts dieser intensiven Begegnung von filmischem und literarischem Erzählen erstaunt es geradezu, dass nicht diese gegenseitige narrative Faszination und „Befruchtung“ die kulturelle Tradition bestimmte, sondern eher die der wertenden Hierarchisierung, die die Minderwertigkeit des Films gegenüber der Literatur betont.

Der Zugang zum kinematografischen Erzählen eines Textes verlangt einen filmisch geschulten Blick, der, ausgehend von der notwendigen Sichtbarkeit aller Dinge, auch das literarische Erzählen anders betrachten kann, denn die im kinematographischen Erzählen literarischer Texte aufgegriffene Herausforderung des dynamisierten Sehens lässt sich mit einem filmsprachlich geschulten Blick produktiver erschließen als mit dem textorientierten Zugang. Dies setzt allerdings eine Vertrautheit der Lerner mit filmsprachlichen Begriffen wie Einstellungsgröße, Schnitt und Montage, Kamerabewegung und -perspektive voraus. Auch hier ist die Einführung und Differenzierung der filmsprachlichen Codes wiederum alters- und unterrichtsabhängig.

Wenn man literarischen Texten kinematographisches Erzählen zuspricht, geht man davon aus, dass filmspezifische Erzählstrategien sprachlich umgesetzt werden können. Untersucht wird, wie es dem literarischen Erzählen gelingt, auch als filmische Narration gelesen zu werden, d.h. wie psychologisch motiviertes Erzählen durch die Ausdrucksvielfalt des Sichtbaren ersetzt wird.

Im kinematographischen Erzählen muss das, was bisher der Innensicht vorbehalten war, externalisiert, eben sichtbar gemacht werden in körperlicher Bewegung, Gestik, und Mimik. Es geht um die Vielschichtigkeit der Textoberfläche, z.B. die Aussagekraft der Bilder und ihrer Verknüpfungen, was zum Beispiel Franz Kafka beschäftigt hat, der gesteht, er sei „verliebt in das Kino“. (Alt 2009: 7). Ihn wie auch andere Schriftsteller des Expressionismus fasziniert, wie der Film Beschleunigung und multiperspektivisches Sehen umsetzt. ${ }^{37}$

Der folgende kurze Textausschnitt soll belegen, wie sehr der filmisch geschulte Blick textanalytisches Vorgehen bereichern kann. Anschauliche Texte, die das Aussagepotential der Bilder literarisch nutzen, findet man in vielen expressionistischen

\footnotetext{
36 Guy Borrélly (1975): L`homme et son regard; zit. nach Paech 1997:121.

37 Vgl. Alt 2009. Alt führt viele kurze Textbeispiele an mit entsprechenden analytischen Hinweisen zum kinematographischen Erzählen Kafkas, die schon aufgrund der Kürze gut in Unterricht und Lehre einzusetzen sind.
} 
Texten, ${ }^{38}$ z.B. in folgendem Textausschnitt einer Taxifahrt der jungen Ich-Erzählerin Doris aus Irmgard Keuns Roman „Das kunstseidene Mädchen“, die schreiben will „wie Film“ (Keun 1979: 8):

[...] - blaue Lichter, rote Lichter, viele Millionen Lichter - Schaufenster Kleider - aber keine Modelle - andere Autos fahren manchmal schneller Bettenladen - ein grünes Bett, das kein Bett ist, sondern moderner, dreht sich ringsum immer wieder - in einem großen Glas wirbeln Federn - Leute gehen zu Fuß - das moderne Bett dreht sich - dreht sich. (Keun 1979: 127).

Die überforderte Wahrnehmung und die Geschwindigkeitsfaszination der Großstadtüberwältigung werden nicht beschrieben. Sie äußern sich in einer Aufzählung zusammenhangloser Bilder, die wie im harten Schnitt aneinandergereiht werden, deren Wahrnehmung kaum Zeit lässt, sie mit einem Attribut zu versehen.

Als zweites Textbeispiel ein Ausschnitt aus Herta Müllers Erzählung „Der Überlandbus":

[...] Ich saß im Bus zwischen leeren Feldern. Ein Mann ging quer über den Acker hin, allein. Es war ein ganzer Mensch, ein halber Irrer und ein halber Säufer. Sie hörte nicht mehr auf, die nach Schnaps riechende summende Bedrücktheit im Bus. Gerlinde, warum lässt du ihn trinken, du sitzt doch neben ihm, schrie eine Frau, die ganz vorne stand, hinter dem Schofför. Ein dickes sprachloses Kind blickte auf. Du hast keinen Verstand, Franz, sagte sie zu einem Mann mit hochroten Backenknochen, der mit einer Hand an der Stange der Gepäckablage hing und sich mit der anderen durchs Haar und ins Genick fuhr, mit einem Zeigefinger ohne Fingernagel. Schau, wie du schwitzt, dir gibt man umsonst ein reines Hemd, du bist auch dann kein Mensch.Die Chrysanthemen zitterten, in eine Zeitung gehüllt, auf der Gepäckablage. In den Kurven brachen herbe starre Blüten ab. (Müller 2010:142).

Die Mischung aus Kontaktlosigkeit und erzwungener Anteilnahme an Privatem, die der enge Transitraum des Busses herstellt, wird in eine Sequenz schnell wechselnder Schnitte, die sprachlich nicht verbundene Bilder unterschiedlicher ES bzw. ebenso unverbundene Kurzdialoge und kurzen Kamerafahrten aneinanderreihen. Auch hier würde die Aufforderung, ein Storyboard zu diesem Textausschnitt anzufertigen, auch das Spezifikum des literarischen Erzählens verdeutlichen, das filmisch anders gelöst werden müsste: Die Visualisierung der „,nach Schnaps riechen-

\footnotetext{
38 Sehr gut für eine Analyse kinematografischen Erzählens eignet sich auch der Anfang des Großstadtromans „Berlin Alexanderplatz“ von Alfred Döblin.
} 
de[n] summende[n] Bedrücktheit im Bus“ zeigt dies meistens in Detail-, Großoder Nahaufnahme von Personen und Schnapsflaschen. ${ }^{39}$

Im Anschluss an diese kurzen Projektvorstellungen möchte ich noch einmal dazu ermutigen, sich nicht durch den Anspruch umfangreicher Projekte oder Ansätze ,erschlagen“ zu lassen, sondern mit Mut zur Lücke auch einzelne Aspekte medienspezifischen Erzählens sei es am Bild oder am Text zu erarbeiten. Entscheidend ist weniger die Vollständigkeit als der Zusammenhang von Inhalt und medialer Präsentation.

\section{Literatur}

Abraham, Ulf (2009): Filme im Deutschunterricht. Seelze-Velber: Klett/Kallmeyer.

Alt, Peter-André (2009): Kafka und der Film. Über kinematographisches Eræählen. München: C.H. Beck.

Bach, Michaela (1997): Erä̈hlperspektive im Film. Eine erzähltheoretische Untersuchung mithilfe exemplarischer Filmanalysen. Essen: Item.

Balázs, Béla (2001): Der Geist des Films. Frankfurt/Main: Suhrkamp.

Birkmeyer. Jens (2010): Die (Ohn)Macht der Augen-Blicke. Narrative des Sehens in ,Das Schweigen der Lämmer“. Überlegungen zur Filmdidaktik. In: Lorenz (2010), 117-131.

Bordwell, David (1983): Narration in the fiction film. London: University of Wisconsin Press.

Branigan, Edward (1992): Narrative comprehension and film. London: Routledge.

Brecht, Bertolt (1967): Der Dreigroschenprozeß. Ein soziologisches Experiment. In: Ders.: Gesammelte Werke Bd. 18. Frankfurt/Main: Suhrkamp.

Brössel, Stephan (2010): Der komponierte Erzähler im Film. Möglichkeiten und Grenzen eines transmedialen Erzähler. Konzeptes am Beispiel von Formans „Amadeus“. In: Lorenz (2010), 53-79.

Bürner-Kotzam, Renate (2011a): Literarisches und kinematographisches Erzählen. In: Fremdsprache Deutsch 44, 41-47.

Bürner-Kotzam, Renate (2011b): Mit Filmbildern im Kopf schreibt und liest man anders. Literarisches und filmisches Erzählen und ihr gegenseitiger Einfluss.

\footnotetext{
${ }^{39}$ Genauere Erläuterungen zum kinematografisches Erzählen eines weiteren Textausschnitts aus Ingo Schulzes Erzählung „Milva, als sie noch jung war“ in den im Netz veröffentlichten Zusatzmaterialien zu Bürner-Kotzam 2011: http://www.hueber.de/sixcms/media.php/36/fremdsprachedeutsch_ heft 44_s46_ingoschulze_milva. pdf (1.7.2013).
} 
In: Ewert, Michael; Riedner, Renate; Schiedermair, Simone (Hrsg.) (2011):

Deutsch als Fremdsprache und Literaturwissenschaft. Zugriffe, Themenfelder, Perspektiven.

München: iudicium, 130-144.

Chatman, Seymour (1978): Story and discourse. Narrative structure in fiction and film.

Ithaca: Cornell University Press.

Chudak, Sebastian (2010): Arbeit mit Filmen im DaF-Unterricht als eine Möglichkeit der Förderung der interkulturellen Kompetenz auf der Fortgeschrittenenstufe. In: Chlosta, Christoph; Jung, Matthias (Hrsg.) (2010): Literatur-MedienAusbildung. 36. Jahrestagung des Fachverbandes Deutsch als Fremdsprache an der Heinrich-Heine-Universität Düsseldorf. Göttingen: Universitätsverlag, 73-97.

Eckstein, Kristin (2011): Tagungsbericht: Comic - Intermedial und Interdisqiplinär 9.-10.-12. 2011 Ruhr-Universität-Bochum.

Eisenstein, Sergej (1974): Das Mittlere von Dreien. (1934). In: Ders.: Schriften Bd. 1. München: Hanser.

Ellenbruch, Peter; Perivolaropoulou, Nia (2010): Wo beginnt die Filmerzählung? Warum die Ursprünge des Kinos eine Basis für die Filmvermittlung sein können. In: Lorenz (2010), 31-53.

Genette, Gerard (1994): Die Eræä̆hlung. Stuttgart: UTB.

Frahm, Ole (2010): Die Sprache des Comics. Hamburg: Philo Fine Arts.

Großklaus, Götz (2004): Medien-Bilder. Inszenierung der Sichtbarkeit. Frankfurt/Main: Suhrkamp.

Grünewald, Dietrich (Hrsg.) (2010): Struktur und Geschichte der Comics. Beiträge zur Comicforschung. Bochum/Essen: Ch.A. Bachmann.

Hickethier, Knut (2007): Erzählen in Bilder. Für eine Narratologie der Audiovision. In: Müller, Corinna; Scheidgen, Irina (Hrsg.): Mediale Ordnungen. Erąählen, Archivieren, Beschreiben. Marburg: Schüren, 91-107.

Ihme, Burkhard (2010): Montage im Comic. Spezifische Nutzung eines Erzählmittels. In: Grünewald (2010), 67-85.

Kepser, Matthis (2004): Medienkritik als kultureller Selbstverständigungsprozess.

In: Kepser, Matthis; Nickel-Bacon, Irmgard (2004): Medienkritik im

Deutschunterricht. Baltmansweiler: Schneider Verlag Hohengehren, 2-22.

Keun, Irmgard (1979): Das kunstseidene Mädchen. Düsseldorf: Claassen.

Koebner, Thomas; Meder, Thomas (Hrsg.) (2006): Bildtheorie und Film. München: edition text + kritik.

Krusche, Dietrich (Hrsg.) (1988): Aufschluss. Kurze deutsche Prosa im Unterricht Deutsch als Fremdsprache. Bonn: InterNationes. 
Kuhn, Markus (2011): Filmnarratologie. Ein Erzähltheoretisches Analysemodell. Berlin/ New York: de Gruyter.

Leubner, Martin; Saupe, Anja (2006): Filme, Narrationen und Schule. Filmdidaktik als Teil einer medienintegrativen Erzähldidaktik. In: Frederking, Volker (Hrsg.): Medien im Deutschunterricht 2005. Jahrbuch. Filmdidaktik und Filmästhetik. München: kopaed, 46-62.

Lorenz, Matthias N. (2010): Filmnarratologie und Literaturdidaktik. Neue Ansätze zum filmischen Erzählen für den Unterricht. In: Lorenz, Matthias N. (Hrsg.): Filme im Literaturunterricht. Von der Frühgeschichte des Kinos bis zum Symmedium Computer. Freiburg/Br.: Fillibach, 7-19.

Lotman, Jurij M. (1986): Die Struktur des künstlerischen Textes. Frankfurt/Main: Suhrkamp.

Martinez, Matias; Scheffel, Michael (2005): Einführung in die Erzähltheorie. München: C.H. Beck.

Müller, Herta (2010): Niederungen. München: Hanser.

Müller, Ines (2013): Bildgewaltig! Die Möglichkeiten der Filmästhetik zur Emotionalisierung der Zuschauer. In: IMAGE. Zeitschrift für interdisziplinäre Bildwissenschaft 17/1: 45-60. Http://www.gib.uni-tuebingen.de/own/journal/upload/ 3446bd01eed7183d0e253b2dd8f6ad1a.pdf. (20.6.2013).

Nünning, Vera; Nünning, Ansgar (Hrsg.) (2002): Erzähltheorie transgenerisch, intermedial, interdisziplinär. Trier: WVT.

Paech, Joachim (1997): Literatur und Film. Stuttgart/Weimar: Metzler.

Paefgen, Elisabeth K. (2009): Wablverwandte. Filmische und literarische Erzählungen im Dialog. Berlin: Bertz+Fischer.

Petrie, Graham (1975): Dickens, Godard and the Film Today. In: The Yale Review 64.

Rösch, Heidi et all. (2011): Interkulturelle Filmbildung in der Sekundarstufe I aller Schulformen - eine empirische Studie. Abschlussbericht zur PH-geförderten Pilotstudie. Http://www.ph-karlsruhe.de/fileadmin/user_upload/fakultaet2/deutsch/ dateien/Filmprojekt_Abschlussbericht.pdf) (10.6.2013).

Ruf, Oliver (2010): Interkulturelles filmisches Erzählen. Fatih Akins „Gegen die Wand“ und Jurij M. Lotmans Raumsemantik. In: Lorenz, Matthias N. (Hrsg.): Filme im Literaturunterricht. Von der Frühgeschichte des Kinos bis zum Symmedium Computer. Freiburg im Breisgau: Fillibach, 79-103.

Scheffer, Bernd (2013): Das Zusammenspiel von Fiktion und Realität. Der 11. September und die USA als Teil Hollywoods. (http:/ / www.medienobservationen.lmu.de/ artikel/kino/september.html) (10.5. 2013). 
Schmid, Wolf (2005): Elemente der Narratologie. Berlin/New York: de Gruyter.

Schüwer, Martin (2008): Wie Comics erzäblen. Grundrisse einer intermedialen Erzähltheorie der grafischen Literatur. Trier: Wissenschaftlicher Verlag.

Schwerdtfeger, Inge (1989): Sehen und Verstehen. Arbeit mit Filmen im Unterricht Deutsch als Fremdsprache. Berlin/München: Langenscheidt.

Segeberg, Harro (2003): Literatur im technischen Zeitalter. Von der Frühzeit der deutschen Aufkelärung bis zum Beginn des Ersten Weltkriegs. Darmstadt: WBG.

Spinner, Kaspar, H. (2004): Von der Filmerfahrung zur literarischen Textanalyse. In: Jonas, Hartmut; Josting, Petra (Hrsg.): Medien - Deutschunterricht - Ästhetik. München: kopaed, 199-207.

Spinner, Kaspar H. (2008): Raumsymbolik als didaktischer Zugang zur Filminterpretation. In: Der Deutschunterricht 60/3, 43-52.

Staiger, Michael (2010a): Literaturverfilmungen im Deutschunterricht. München: Oldenbourg.

Staiger, Michael (2010b): Montagekonzepte und filmisches Erzählen. In: Lorenz, Matthias N. (Hrsg.): Filme im Literaturunterricht. Von der Frübgeschicbte des Kinos bis zum Symmedium Computer. Freiburg/Br.: Fillibach, 103-117.

Vogt, Jochen (2008): Aspekte erzählender Prosa. Paderborn: UTB.

Vogt, Jochen (2011): Wie analysiere ich eine Erzählung. Paderborn: UTB.

Wermke, Jutta (1997): Integrierte Medienerziehung im Fachunterricht. Schwerpunkt Deutsch. München: kopaed 1997.

Zabka, Thomas (2004): Wie? - Was?: Formanalyse und Inhaltsanalyse als Bestandteile ästhetischer Bildung. In: Jonas, Harmut; Josting, Petra: MedienDeutschunterrricht-Ästhetik. München: kopaed, 251-261.

\section{DVDs}

Steinmetz, Rüdiger (2005): Filme sehen lernen. 2 DVDs. Frankfurt/Main: Zweitausendeins.

\section{Comics}

Watterson, Bill (2013): Calvin und Hobbes. Gesamtausgabe. Hamburg: Carlsen. 


\title{
Lyrikverfilmungen im DaF-Unterricht. Neue Möglichkeiten der Text- und Filmarbeit
}

\author{
Anastasia Novikova
}

Der Beitrag zielt darauf ab, das große didaktische Potenzial der Lyrikverfilmung, eines in der DaF-Didaktik noch wenig bekannten und genutzten Lerngegenstands, aufzuzeigen. Da die Lyrikverfilmung bis jetzt in der Film- und Literaturwissenschaft vernachlässigt wurde, werden zunächst die Transformationsprozesse als Zugang zur Motivation der Wort-Bild-Beziehung in der Lyrikverfilmung beleuchtet und an Beispielen veranschaulicht. Anschließend wird eine Aufgabentypologie zur Arbeit mit verfilmten Gedichten vorgestellt.

\section{Was ist Lyrikverfilmung?}

Die Lyrikverfilmung (auch Lyrikvideo, Poetry Film oder Poesiefilm genannt) ist eine Filmgattung, die so alt wie der Film selbst ist und historisch mit Namen wie Man Ray, Griffith, Cocteau u.a. verbunden ist. Einige der ersten - bis jetzt bekannten - Lyrikverfilmungen sind z.B. „Twas the Night before Christmas“ (1905) aus dem Studio von Edison nach dem Weihnachtsgedicht von Clement Clarke, „The Unchanging Sea" von Griffith aus dem Jahr 1910 nach einem Gedicht von Charles Kingsley, „Mannahatta“ (1921) von Charles Sheeler und Paul Strand nach Walt Whitman u.a. Auch wenn diese Tradition dem breiten Zuschauerkreis nicht unbedingt bewusst ist, erfreuen sich gerade in den letzten zehn Jahren Lyrikverfilmungen im europäischen Ausland und in englischsprachigen Ländern erstaunlich großer Beliebtheit (was Internetplatforms wie „Moving Poems“ eindrucksvoll be- 
legen), sie kommen mittlerweile auch in Deutschland an (das größte internationale Festival für Filme dieser Art in Europa - „Zebra Poetry Film Award“ - findet in Berlin statt) und bringen neue Möglichkeiten der Text- und Filmarbeit für den Fremdsprachenunterricht mit sich.

Einerseits gibt es sehr zahlreiche audiovisuelle Umsetzungen von Gedichten im Internet (allein vom Gedicht „Der Panther“ von Rilke auf YouTube weit über hundert!), die zum Teil als Amateurarbeiten aus eigener Initiative, zum Teil als Projektarbeiten aus dem schulischen und universitären Rahmen entstehen. Das geht mit der didaktischen Aufwertung der Medien bei der Literaturvermittlung einher, wobei die Verfilmung von Gedichten als eine neue, intensive Form der Auseinandersetzung mit Lyrik gesehen wird. Solche Arbeiten steigern zweifellos die Kreativität der Lerner, sind qualitativ jedoch unterschiedlich. Andererseits gibt es genügend „professionelle“ Lyrikverfilmungen, deren Zahl immer weiter steigt. Besonders hervorgehoben sei „Poem“ (R.: Ralf Schmerberg, D 2003), die erste deutsche abendfüllende Produktion, in der 19 Gedichte (von Goethe, Jandl, Kästner, Tucholsky u.a.) unter Mitwirkung von Schauspielern wie Jürgen Vogel, Klaus Maria Brandauer u.a. filmisch umgesetzt wurden. Hesse; Krommer; Müller (2006) haben „Poem“ für die Sekundarstufe II didaktisiert, wobei sie sechs Verfilmungen aus diesem Film für den Unterricht aufbereitet haben.

2010 erschien im Duden Verlag die DVD „Poesiefilme“, eine Sammlung von 20 verfilmten Gedichten für Oberstufe Deutsch. Diese Filme stammen aus dem Archiv des Poetry Film Festival "Zebra“ an der Literaturwerkstatt Berlin und stellen nur einen kleinen Ausschnitt seiner Bestände dar, die mittlerweile in die Tausende gehen und auch für den DaF-Unterricht genutzt werden können. Abgesehen von Eigendichtungen und Texten zeitgenössischer Autoren werden Texte der Konkreten Poesie, der Neuen Sachlichkeit und der Neuen Subjektivität von den Filmemachern gerne als Vorlage genommen. Somit gibt es auch für den DaF-Unterricht genug geeignetes Material: Verfilmungen von bekannten Texten deutschsprachiger Lyrik, die überwiegend aus dem 20. Jahrhundert stammen und die didaktischen Kriterien der chronologischen Rückläufigkeit und der literarischen Repräsentativität erfüllen.

In der Regel sind Lyrikverfilmungen zwischen 3 und 15 Minuten lang und entsprechen in dieser Hinsicht dem aktuellen Motto der Filmdidaktik des DaFUnterrichts „Viel weniger am Film ist mehr“" (Rössler 2007: 17).

Philip Brunner definiert im „Lexikon der Filmbegriffe“ des Bender-Verlags die Lyrikverfilmung folgendermaßen: „Verfilmung eines oder mehrerer Gedichte (gelegentlich auch ganzer Gedichtzyklen), typischerweise in einem kurzformatigen Experimentalfilm (wie „L'étoile de mer“ von Man Ray), der ohne weiteres auch als Animationsfilm konzipiert sein kann. Im Vordergrund steht das Bestreben, für die rein verbale Vorlage eine audiovisuelle Entsprechung zu schaffen...". ${ }^{1}$ Es gibt eine sehr bunte Vielfalt von Lyrikverfilmungen, die schwer auf einen gemeinsamen

${ }^{1}$ Brunner: Lyrikverfilmung. www.bender-verlag.de (10.06.2013). 
Nenner gebracht werden können; was sie verbindet, ist der Umstand, dass eine Lyrikverfilmung mit filmspezifischen Verfahren eine Gedichtvorlage transformiert und auf sie explizit verweist. Dabei lassen sich bei der Lyrikverfilmung „Verwandtschaftsbeziehungen“ sowohl zur Literaturverfilmung als auch zum Musikclip ausmachen; beides sind Filmgattungen, die im Fremdsprachenunterricht bereits ihre Verwendung finden.

Trotz der großen Vielfältigkeit der Lyrikverfilmungen kann eine wenn auch nur ,vorsichtige“ Typeneinteilung im Sinne einer dreifachen Differenzierung vorgenommen werden: 1. inszenierte Deklamationen, 2. Etüden sowie 3. Gedichte im Verlauf der filmischen Handlung. ${ }^{2}$ Wobei gleich anzumerken ist, dass viele Lyrikverfilmungen als Mischformen eingeschätzt werden können.

1. Die Verfilmungen des Typs inszenierte Deklamationen fokussieren den (die) Sprecher des Gedichts und die Gedichtrezitation selbst, wobei sie einen wenn oft auch minimalen - situativen Rahmen entwerfen. Sie enthalten jedoch keine Handlung („Sprache des Frühlings“, Gedicht: Hermann Hesse, R: Sarah Moll, 2007; „Was es ist“", Gedicht: Erich Fried, R: Sarah Moll, 2007).

2. Der Terminus Etüden zur Bezeichnung des zweiten Typs von Lyrikverfilmungen geht auf Klaus Göbel zurück, der damit Lyrik-Clips seiner Studenten bezeichnet, in denen mit „Farb-/Schatten-/Licht-/Klangräumen“ experimentiert wird und in denen die „Montagetechnik zum dramaturgischen Prinzip“ wird (Göbel 1997: 304). Damit werden hier handlungslose Videos bezeichnet, die vor allem auf die „Macht der Bilder“ setzen („Kleines Solo“, Gedicht: Erich Kästner, R.: Ralf Schmerberg, 2003; „Todesfuge“", Gedicht: Paul Celan, R: Herry Dim, o.J.).

3. Die Verfilmungen des Typs Gedichte im Verlauf der filmischen Handlung unterscheiden sich von den ersten zwei Typen vor allem dadurch, dass sie eine Rahmengeschichte entwerfen, und zwar unabhängig davon, ob im Gedicht selbst eine solche intendiert wird. D.h., es können auch Figuren als Handlungsträger eingeführt werden, die in der Textvorlage nicht vorkommen („Nach grauen Tagen“, Gedicht: Ingeborg Bachmann, R.: Ralf Schmerberg, 2003; „Irrlicht dieser Zeit“ nach dem Gedicht „Menschliches Elende“"von Andreas Gryphius, R.: Max Pohlenz, 2006).

\footnotetext{
2 Diese Einteilung geht von den Grundformen der Videoclips von Neumann-Braun; Schmidt 1999 aus; an Hesse et al. 2006, bei denen sich diese Systematik ebenfalls wiedererkennen lässt, wird hinsichtlich der formalen Einteilung - jedoch nicht bei der Begründung - angeknüpft. Ausführlich zur Beschreibung von Lyrikverfilmungen hinsichtlich der drei Ebenen der Wort-Bild-Beziehung (der zeitlichen, der räumlichen und der semantischen) vgl. Novikova 2013: 164-172.
} 


\section{Lernzielbereiche bei der Arbeit mit Lyrikverfilmungen}

Betrachtet man die überschaubare Forschung zu literarischen Texten im Fremdsprachenunterricht, so lässt sich feststellen, dass die Prinzipien der Literaturvermittlung im DaF-Unterricht sehr gern anhand von Gedichten erläutert werden. Seit etwa den 1980er Jahren bis heute finden sich solche Titel wie „Prinzipien der Literaturdidaktik Deutsch als Fremdsprache am Beispiel lyrischer Texte“ (Kußler 1980), „Sich die fremde Sprache nehmen - Gino Chiellinos Lyrik als kritische Aneignung der deutschen Sprache“ (Rösch 1992), „Themenorientierte fremdsprachliche Literaturdidaktik am Beispiel neuerer deutscher Liebeslyrik“" (Esselborn 2005) u.v.a. Die aktuellen Belege dafür sind die Aufsätze von Dobstadt (2009) und Dobstadt; Riedner (2011), in denen die „Literarizitätsreflexion“ als neues Paradigma im Umgang mit Literatur im DaF-Unterricht am Beispiel von lyrischen Texten dargestellt wird. Die Vorzüge eines Gedichts wie seine Kürze, die Gegliedertheit der Passagen, der pointierte Sprachgebrauch und vor allem seine „Repräsentativität" scheinen dabei auf der Hand zu liegen.

Auch in den Lehrwerken für Deutsch als Fremdsprache, in denen literarische Texte insgesamt bescheiden vertreten sind, sind die lyrischen Texte im Vergleich zu den anderen zwei Gattungen nicht in der Minderzahl, gegenüber dem Drama hat die Lyrik sogar deutlich die Oberhand (was allerdings nicht zwangsläufig bedeuten muss, dass diese Texte im Unterricht tatsächlich behandelt werden). In ihrer umfangreichen empirischen Untersuchung „Allmähliche Annäherungen“ stellt Burwitz-Melzer fest, dass Gedichte im Fremdsprachenunterricht trotz der traditionellen Auffassung, dass diese Gattung „schwierig“ sei, auch von literarisch unerfahrenen Lernern erstaunlich gern und intensiv rezipiert werden: „Die Unterrichtsstunden, die sich mit Gedichttexten beschäftigten, gehörten zu den lebhaftesten und interessantesten der Studie [...].“3 (Burwitz-Melzer 2003: 492). Somit erscheint die Idee der „Lyrikdidaktik als Literaturdidaktik“ von Gerd Katthage, die er in seinem Buch „Didaktik der Metapher“ (2004) darlegt, auch für den DaFUnterricht gar nicht abwegig.

Hat man das vor Augen, so hat auch die Lyrikverfilmung gute Chancen, zu einem fruchtbaren Lerngegenstand des DaF-Unterrichts zu werden. Die „Tradition“ der Lyrikverfilmung ist vor allem in der Art des Gebrauchs der filmischen Sprache zu sehen, die die russischen Formalisten als „poetisch“ bezeichnen. ${ }^{4}$ Zum Erlernen der filmischen Sprache sind Filme dieser Art nicht zuletzt wegen ihres „Kleinformats" sogar besonders gut geeignet: Die meisten Lyrikverfilmungen stellen sehr konzentrierte Gebilde dar, so dass die verschiedenen Codes wie Hervorhebung durch Farbe, Größe, Häufigkeit des Zeigens, Ausleuchtung, Positionierung im

\footnotetext{
${ }^{3}$ Burwitz-Melzer beschäftigt sich mit dem Englischen als Fremdsprache, aber angesichts dessen, dass empirische Untersuchungen dieser Art für den DaF-Unterricht sehr rar sind, erscheinen ihre Ergebnisse auch für diesen Bereich relevant.

${ }^{4}$ Eine Sammlung filmtheoretischer Texte der russischen Formalisten erschien zum ersten Mal 1927 in Moskau unter dem Titel „Poetika Kino“ (dt.: Beilenhof 2005).
} 
Bild, Perspektive sowie Musik oder auch das Potenzial der menschlichen Stimme u.v.a. sehr gut deutlich gemacht werden können, um ihre jeweilige Wirkung herauszuarbeiten.

Die Konfrontation mit der filmischen Versinnbildlichung eines Gedichts bietet wiederum einen authentischen Anlass, sich mit der Anschaulichkeit der Sprache (ihrer Fähigkeit, vor dem inneren Auge Bilder entstehen zu lassen) zu beschäftigen und sich ihrer bewusst zu werden. Auf diese Weise bekommt die Auseinandersetzung mit der Metapher nicht (nur) als rhetorischem Mittel, sondern vor allem als Konzeptualisierungsstrategie im Sinne der kognitiven Metapherntheorie bei der Arbeit mit Lyrikverfilmung eine besondere Rolle. Diese von Lakoff; Johnson in den 1980er begründete Theorie hat in den Fremdsprachenunterricht im Bereich der Wortschatzarbeit (Kispál 2011; Novikova 2012; Koch 2013; Weininger 2013) bereits Eingang gefunden, sie kann aber auch intensiv und fruchtbar im Bereich der Text- und Filmarbeit genutzt werden.

Die Lyrikverfilmung ist sowohl für die Fremdsprachenlerner als auch für die Lehrenden ein sehr interessanter und dankbarer Lerngegenstand, weil er auf authentische Weise Kreativität und Phantasie und somit die Kommunikation in der Fremdsprache fördert und vielfältige produktions- und handlungsorientierte Aufgabenstellungen (s. Aufgabentypologie) erlaubt, und zwar in allen Phasen der Filmarbeit. Denn die Arbeit mit Lyrikverfilmungen ermöglicht gerade dank der spezifischen Ästhetik dieses Mediums, das den Gedichttext als Ganzes erhält und durch die filmische „Versinnbildlichung“ das poetische Wort synästhetisch erleben lässt, eine sehr breite Zielsetzung. Sie geht vom Üben der Fertigkeiten des Spracherwerbs bei gegenseitiger Bedingtheit von Rezeption und Produktion über die Erweiterung der „media literacy“ der Lerner bis zur Einordnung der Lyrikverfilmung in den didaktischen Kontext des poetischen Verstehens, das im Rahmen des DaFUnterrichts eng mit der Ausbildung der interkulturellen Kompetenz verbunden ist. Das Letztere vor allem, weil die Lyrikverfilmung nur im Sinne einer interpretierenden „subjektiven Äquivalenz“ zur Vorlage und nur als eine von vielen Konzeptualisierungsmöglichkeiten verstanden werden kann. Eine Lyrikverfilmung stellt den literarischen Text immer in Frage bzw. denkt ihn weiter und verlangt dasselbe auch von ihrem Rezipienten sowohl in Bezug auf das Gedicht als auch ihr selbst gegenüber, was nicht immer einfach ist. Auf diese Weise fordert und fördert sie auch die Ambiguitätstoleranz.

Bei der Arbeit mit Lyrikverfilmungen können sowohl die Reflexion der eigenen Wahrnehmungsmuster (Selektivität der Wahrnehmung und Subjektivität der Interpretation) als auch das Erkennen der Bedeutung der eigenen Voreinstellungen für die Text- und Filmdeutung angestrebt werden. ${ }^{5}$ Auf diese Ziele kann im Prozess des Nacherzählens (Was habe ich gelesen/gesehen?) wie auch im Prozess des Deutens (Was sagt das Gedicht/der Film für mich aus?) hingearbeitet werden.

\footnotetext{
${ }^{5}$ Vgl. die Übung zur Filmwahrnehmung http://www.nibis.de/nli1/chaplin/portal\%20neu/medien_ und_schule/lernen_mit_medien/filmanalyse/uebung_wahrnehmung.pdf (10.06.2013).
} 
In der Bewusstwerdung unterschiedlicher Wahrnehmungsmechanismen, die dadurch bedingt sind, dass Personen aus anderen Kulturen zu demselben Objekt verschiedene „Assoziationsketten und Gedanken“ haben können, sieht die Interkulturalitätsforschung den „Schlüssel zum interkulturellen Verständnis“ (Vogler-Lipp 2010: 271).

In dieser Hinsicht macht die individuelle, subjektive Prägung von Lyrikverfilmungen gerade ihren Wert aus: Sie helfen, die Vielfalt und darüber hinaus die Relativität des Begriffs „Kultur“ zu begreifen. Nichtsdestoweniger beinhalten Lyrikverfilmungen wie „Todesfuge“ (Gedicht: Paul Celan, R.: Herry Dim, o.J.) oder „Nach grauen Tagen“ (Gedicht: Ingeborg Bachmann, R.: Ralf Schmerberg, 2003) obwohl es nicht als Selbstzweck zu betrachten ist - auch historisches und soziologisches Material. Die Themenbreite ist dabei enorm; um nur diese zwei sehr unterschiedlichen Beispiele aufzugreifen: das Thema der Judenvernichtung in der Verfilmung „Todesfuge“ und das Leben einer sozialschwachen kinderreichen Familie im heutigen Deutschland in der Verfilmung „Nach grauen Tagen“.

Mit der kulturwissenschaftlichen Öffnung des Fremdsprachenunterrichts werden Literaturverfilmungen als ein Zugang zu fremdkulturellen Wirklichkeiten gesehen. Das trifft jedoch auf die Arbeit mit Filmen jeglicher Art zu. Das Besondere beim unterrichtlichen Einsatz von Literaturverfilmungen ist aber, wie Carola Surkamp (2004; 2009) hervorhebt, die Möglichkeit oder sogar die Notwendigkeit der Auseinandersetzung mit den intermedialen Transformationsprozessen zwischen Buch und Film. Dieser Zugang verabschiedet sich von der Vorstellung einer werktreuen und „richtigen“ filmischen Realisierung und bietet im Unterricht die Chance einerseits, den Film und das literarische Werk als sich gegenseitig erhellende Phänomene zu sehen und andererseits, die Konstruiertheit von Medien (und zwar nicht nur des Films, sondern auch des literarischen Texts) zu thematisieren.

\section{Transformationsprozesse in der Lyrikverfilmung aus didaktisch-methodischer Sicht}

Die Betrachtung von intermedialen Transformationsprozessen in der Lyrikverfilmung ist keine rein theoretische Frage, sondern besitzt vor allem didaktische Relevanz. Am wichtigsten ist zunächst das Verständnis dafür, dass der Film eine eigenständige mediale Kunstform ist, dass eine Lyrikverfilmung keine „Bebilderung“ des Gedichts bedeutet und dass die eigenen „Bilder im Kopf“ (images), die beim Lesen des Gedichts entstehen, mit den filmischen Bildern (pictures) sehr wahrscheinlich nicht übereinstimmen werden. Die Herstellung bzw. Aufdeckung der Wort-BildBeziehung in der Lyrikverfilmung und ihrer nicht immer offenkundigen Motivation bietet im Unterricht, so zeigt auch die eigene Erfahrung, einen authentischen Sprechanlass, aus dem sich weiterführende, lebhafte Diskussionen entwickeln können. 
Das Problem der Segmentierung der Transformationseinheiten ist sowohl für das Gedicht als auch für den Film nicht von der Hand zu weisen. „Die ,Einstellung“ im Film ist [...] mehr einer Äußerung als einem Wort ähnlich [Hervorhebung C.M.]“, meint Christian Metz (1980: 194). Im Falle der Lyrikverfilmung, die einen lyrischen Text als Vorlage hat, ist darüber hinaus davon auszugehen, dass die transformierten Einheiten nicht unbedingt mit den kleinsten lexikalischen Einheiten, also einzelnen Wörtern, identisch sind, sondern Äußerungen sein können, wie im Falle der Metapher, die immer im Sinne einer metaphorischen Aussage zu verstehen ist. Wie Manfred Bierwisch zutreffend anmerkt: „Die Lautfolge eines Satzes wie ,im Winde klirren die Fahnen', mit dem Hölderlins ,Hälfte des Lebens“ endet, gibt keine Abfolge von Wind, Klirren und Fahnen wieder, sondern die simultanen Momente einer einzigen Situation mit Wind und klirrenden Fahnen (was auch immer das ist).“ (Bierwisch 2009: 15).

Obwohl die Verwendung der Begriffe „filmisches Zeichen“ und „filmische Sprache“, wie Keppler anmerkt, nur „,in metaphorischer Bedeutung sinnvoll ist“ (Keppler 2006: 70f.), haben sich diese Termini fest etabliert und werden hier ebenfalls benutzt, wenn auch mit diesem Vorbehalt.

Die semiotische Terminologie ist im DaF-Unterricht ihrer fachlichen Komplexität wegen eher mühsam zu vermitteln; in der Unterrichtssituation können daher die einfachen Begriffe „Wort“ für die sprachliche Sinneinheit und „filmisches Bild“ (immer als audiovisuelles Bild zu verstehen) für die filmische Sinneinheit verwendet werden.

Die für die Literaturverfilmung zentrale Kategorie der Transformation muss für die Lyrikverfilmung präzisiert werden und ist als eine doppelte Transformation zu beschreiben. ${ }^{6}$ Die Transformation in der Lyrikverfilmung unterscheidet sich von der in der Literaturverfilmung vor allem dadurch, dass das System der literarischen Vorlage auf der ersten Transformationsstufe mit demselben (verbalen) Code vollständig in das Medium Film umgesetzt wird (wie auch im Musikclip), was zunächst die der Transformation eigenen Prozesse der Kürzung, Adaption, Umstellung und Ergänzung ausschließt. Zusätzlich werden einige ausgewählte Elemente der Inhaltsebene und/oder der Ausdrucksebene (deren Anzahl sehr gering ausfallen kann, z.B. nur einige wenige sprachliche Bilder) mit mehreren anderen Codes (visuell, akustisch, synästhetisch) in das filmische Zeichensystem transformiert, wobei nun die genannten Transformationsprozesse stattfinden. Dies wird als zweite Transformationsstufe bezeichnet. Dabei ist anzumerken, dass diese Differenzierung rein methodische Gründe hat.

Während die erste Transformationsstufe, bei der es sich vor allem um die Transformation der Vermittlungsinstanz(en) handelt, sich relativ einfach beschreiben lässt, ist die zweite Transformationsstufe ungleich komplexer. Auf dieser Stufe kann zunächst zwischen illustrierender und (um)deutender Transformation unterschieden werden.

${ }^{6} \mathrm{Zu}$ den Transformationsproessen in der Lyrikverfilmung s. ausführlich Novikova 2013: 87-173. 
Von einer illustrierenden Transformation wird hier dann gesprochen, wenn das verbale Zeichen und das filmische Zeichen redundant sind, d.h., sie weisen auf dasselbe Objekt hin und die Beziehung Zeichen/Objekt beruht beim filmischen Zeichen auf Ähnlichkeit (im Sinne von icon bei Peirce). Z.B. wird das Objekt „Sonne“ im Text durch das verbale Zeichen „Sonne“ und in der Verfilmung durch das Zeichen „filmisches Bild Sonne“" vertreten (s.u. Bsp. 1 in Tab. 2).

Eine (um)deutende Transformation findet statt, wenn das verbale Zeichen und das filmische Zeichen zwar auf dasselbe Objekt verweisen, aber die Beziehung filmisches Zeichen/Objekt nicht auf Ähnlichkeit, sondern auf Indizien und Konvention basiert, die unterschiedlich stark sein können (im Sinne von index und symbol bei Peirce zusammengefasst). ${ }^{7}$ So kann auf das Objekt „Sonne“ durch unendlich viele filmische Zeichen wie „filmisches Bild schöne Frau“, „filmisches Bild Glühbirne" oder auch durch musikalische Hinweise bzw. eine vom Filmemacher dem Objekt „Sonne“ zugeordnete beliebige Figur hingewiesen werden, deren „Zeichencharakter" erst aus dem Kontext erschlossen werden kann. Solche filmischen Transformationen haben einen stark konnotativen Charakter und stellen für den DaF-Unterricht deswegen eine besondere Herausforderung dar.

In der Lyrikverfilmung ist nicht die illustrierende, sondern die (um) deutende Transformation die grundlegende Transformationsart. Genau deswegen kommt es bei den Rezipienten oft zu Reaktionen wie: „Die Bilder passen doch nicht zum Gedicht, oder?"

Bei der (um)deutenden Transformation kann dann in Anlehnung an die Binaritätsannahme von Roman Jakobson (vgl. Jakobson 1996: 168 ff.) - dass nicht nur in der Sprache, sondern auch in anderen Zeichensystemen ein Gegenstand einerseits mittels metaphorischer (auf Analogiebildung - Ähnlichkeit und Kontrast - basierender) und andererseits mittels metonymischer (auf Kontiguitätsassoziationen basierender) Operationen in einen anderen Gegenstand überführt werden kann zwischen metonymischer und metaphorischer Transformation unterschieden werden.

Dabei ist für die Interpretation und Didaktisierung von Lyrikverfilmungen vor allem Folgendes relevant:

\footnotetext{
${ }^{7}$ Der Zeichenbegriff von Peirce wird in der Medienwissenschaft sehr breit rezipiert, deswegen wird im eigenen Ansatz darauf Bezug genommen. Zur Differenzierung icon/index/symbol s. Peirce: Collected Papers 2, Abschnitte 247-249.
} 


\section{Metonymische Transformation}

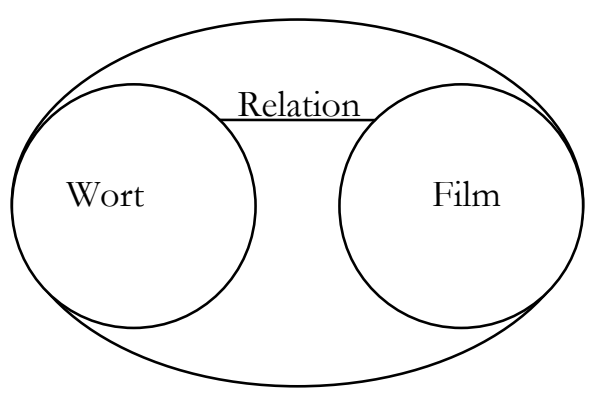

auf der Basis der Kontiguität

\section{Metaphorische Transformation}

Gemeinsame Merkmale

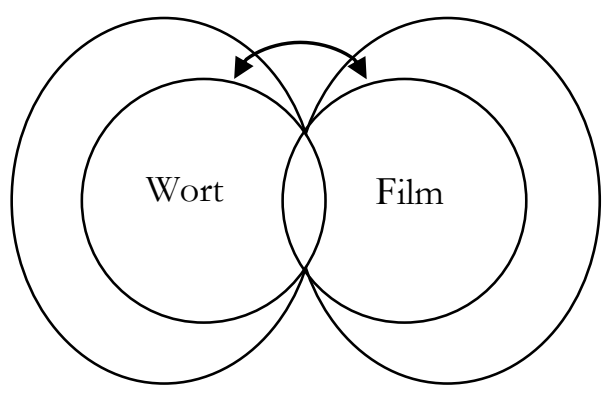

auf der Basis der Analogie

Abb. 1: Schemata der metonymischen und metaphorischen Transformation

Bei der metonymischen Transformation gehören das Wort und das filmische Bild ein und demselben thematischen Bereich an. Die Auseinandersetzung mit dieser Art der Transformation beinhaltet vor allem die Aufdeckung der Relation, der konkreten Verbindung zwischen dem Wort und dem filmischen Bild auf der Basis der Kontiguität, d.h. ihres operativen, temporalen, räumlichen etc. Zusammenhangs.

In den Darstellungen zum Phänomen der Metonymie werden mehrere metonymische Relationen unterschieden (vgl. z.B. Plett 2000; Lausberg 2008; Dölling 2009). In der Lyrikverfilmung lassen sich in Bezug auf das Verhältnis Wort/filmisches Bild potenziell alle diese Relationen beobachten (vgl. Novikova 2013: 137139). Fasst man sie zusammen, erscheinen die folgenden vier verallgemeinerten Schemata für die Filmarbeit besonders relevant: Objekt für Sachverhalt, Objekt für Person, ein Teil für das Ganze und Person für Sachverhalt. Anzumerken ist, dass alle diese Relationen auch umgekehrt funktionieren und dass es sich bei ihnen allen um Objekte und Personen mit einem symbolischen Wert handeln kann. „Symbolische Metonymien sind entscheidende Bindeglieder zwischen der Alltagserfahrung und den kohärenten metaphorischen Systemen, durch die Religionen und Kulturen gekennzeichnet sind.“ (Lakoff; Johnson 2008: 51, s.u. Bsp. 2 in Tab. 2).

Bei der metaphorischen Transformation gehören das Wort und das filmische Bild zumindest formal - unterschiedlichen thematischen Bereichen an, d.h., der Zusammenhang zwischen ihnen ist nicht sofort ersichtlich. Hier geht es also darum, die partiellen strukturellen Gemeinsamkeiten zwischen dem Wort und dem filmischen Bild zu entdecken. Im Unterricht kann in diesem Fall mit der Technik der Bisoziation gearbeitet werden. Bisoziation ${ }^{8}$ bezeichnet den kreativen Vorgang der Herstellung von Kohärenzen zwischen Begriffen aus unterschiedlichen Bezugsrahmen, zwischen denen normalerweise keine Verbindung besteht (s.u. Bsp. 3 in Tab. 2).

${ }^{8}$ Der Begriff wurde 1964 von Arthur Koestler in „The Act of Creation“ eingeführt, deutscher Titel: „Der göttliche Funke“. 
Hervorgehoben sei, dass es im Unterrichtskontext nicht darum gehen muss, im Sinne einer Abgrenzung zu bestimmen, ob es sich in einem konkreten Fall um eine metaphorische oder metonymische Transformation handelt. Die genuine Verwandtschaft zwischen Metonymie und Metapher wird hier vorausgesetzt. Wichtig ist vor allem die Herstellung einer Verbindung zwischen dem Wort und dem filmischen Bild, und zwar immer unter der Prämisse der partiellen Veränderung der Wortbedeutung durch das filmische Bild und umgekehrt.

Es kann davon ausgegangen werden, dass alle für die Lyrikverfilmung spezifischen Elemente des Systems „Gedicht" - sprachliche Bilder, thematischer und situativer Rahmen, Figuren, Gefühle und Einstellungen sowie die (vermutliche) Aussage des Gedichts im Film metaphorisch oder metonymisch transformiert werden können. Sie alle können aber auch in der Verfilmung ganz fehlen. Gefühle und Einstellungen, der thematische Rahmen sowie die (vermutliche) Aussage des Gedichts können wegen ihrer Abstraktheit sogar prinzipiell nicht illustrativ transformiert werden. Die einzige Möglichkeit ihrer Realisierung im Film ist die analoge (Metapher) bzw. die auf Indizien basierte (Metonymie) Darstellung.

\begin{tabular}{|l|c|c|c|c|}
\hline $\begin{array}{l}\text { Elemente des } \\
\text { Systems „Gedicht“ }\end{array}$ & $\begin{array}{l}\text { Null- } \\
\text { Realisierung }\end{array}$ & illustrativ & metaphorisch & $\begin{array}{l}\text { metony- } \\
\text { misch }\end{array}$ \\
\hline situativer Rahmen & + & + & + & + \\
\hline $\begin{array}{l}\text { thematischer Rah- } \\
\text { men }\end{array}$ & + & - & + & + \\
\hline $\begin{array}{l}\text { Figuren } \\
\text { sprachliche Bilder }\end{array}$ & + & + & + & + \\
\hline $\begin{array}{l}\text { Gefühle und } \\
\text { Einstellungen }\end{array}$ & + & - & + & + \\
\hline Aussage & + & + & + & + \\
\hline
\end{tabular}

Tab. 1: Arten der Transformation einzelner Elemente des Systems „Gedicht“ in der Lyrikverfilmung 
Die illustrierende Transformation ist eher selten und kommt bei einzelnen sprachlichen Bildern, dem situativen Rahmen und bei Figuren vor.

Die folgenden drei Beispiele für die Transformationsarten aus verschiedenen Lyrikverfilmungen sollen die obigen Überlegungen verdeutlichen; die transformierten Elemente sind in den Zitaten in der linken Spalte jeweils kursiv hervorgehoben.

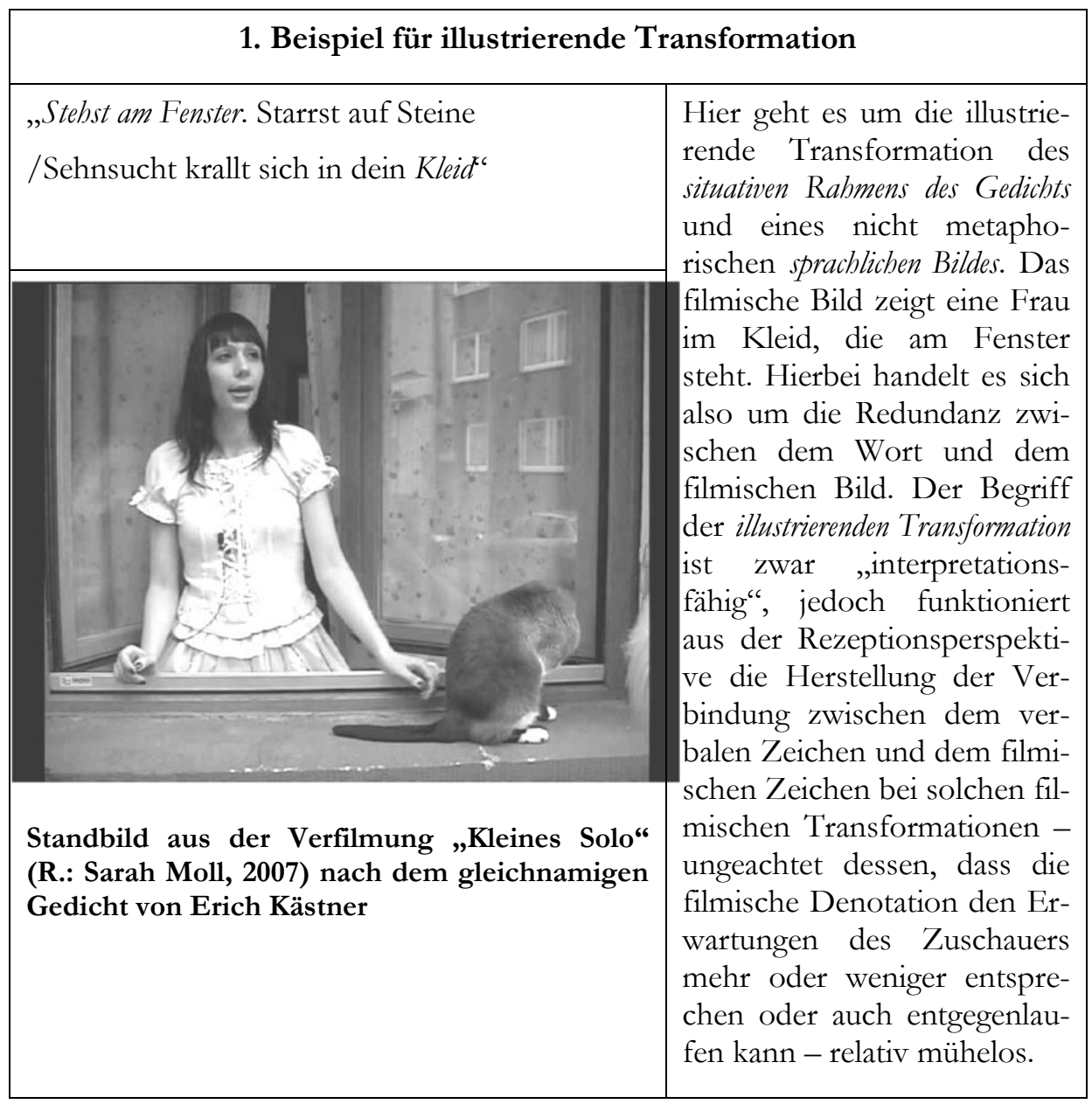




\begin{tabular}{|c|c|}
\hline \multicolumn{2}{|c|}{ 2. Beispiel für umdeutende metonymische Transformation } \\
\hline $\begin{array}{l}\text { Figur der angesprochenen Geliebten: „Du weißt } \\
\text { es.“" }\end{array}$ & $\begin{array}{l}\text { Die Figur der ange- } \\
\text { sprochenen Geliebten, an die } \\
\text { die (negative) Liebeserklärung }\end{array}$ \\
\hline & $\begin{array}{l}\text { erichtet ist, und die im Text } \\
\text { lur als „du“ angedeutet ist, } \\
\text { vird durch das Bild eines } \\
\text { 3rautkleids im Film meto- } \\
\text { ymisch transformiert (Rela- } \\
\text { ion Objekt für Person). Da- } \\
\text { lurch, dass mehrere Braut- } \\
\text { leider im Bild zu sehen sind, } \\
\text { ann außerdem von der Rela- } \\
\text { ion das Ganze für einen Teil (in } \\
\text { liesem Fall das Kollektive für } \\
\text { las Individuum) gesprochen } \\
\text { verden, wobei eine Art Ste- } \\
\text { eotyp suggeriert wird. }\end{array}$ \\
\hline $\begin{array}{l}\text { Standbild aus der Verfilmung „Ich kann dir die } \\
\text { Welt nicht zu Füßen legen“ (R.: Ralf Schmer- } \\
\text { berg, D. 2003) nach dem gleichnamigen Gedicht } \\
\text { von Heiner Müller. }\end{array}$ & \\
\hline
\end{tabular}

Die entwickelte Methodik zum Einsatz der Lyrikverfilmung im DaF-Unterricht geht nun gemäß dem wahrnehmungspsychologischen Ansatz davon aus, dass das (intensive) Sehen einer Lyrikverfilmung auf die Herstellung einer Analogie bzw. eines Zusammenhangs zwischen dem Wort und dem filmischen Bild und darüber hinaus auf die Generierung der Bedeutung dieser Verbindung gerichtet ist. Somit wird die prozessorientierte, „lesende“ Auseinandersetzung mit diesem Medium als der dem ästhetischen Wert der Lyrikverfilmung angemessene und unter den Bedingungen der Fremdsprache einzig sinnvolle Rezeptionsweg betrachtet. Dabei gilt es aber, in der Unterrichtssituation die Lyrikverfilmungen nicht auf die Bezüge zu ibren Vorlagen zu redurieren, sondern in einem breiteren Kontext zu sehen, was das Thematisieren von durch die Verfilmung evozierten sog. „kulturellen Assoziationen“ zu einem unentbehrlichen methodischen Schritt macht. 


\begin{tabular}{|l|l|}
\hline \multicolumn{2}{|c|}{ 3. Beispiel für umdeutende metaphorische Transformation } \\
\hline ,Seltsam, im Nebel qu wandern! \\
Einsam ist jeder Busch und Stein, \\
Kein Baum sieht den andern, \\
Jeder ist allein."
\end{tabular}

Tab. 2: Beispiele für Transformationsarten

\section{Aufgabentypologie}

In der folgenden Aufgabentypologie werden drei Phasen der Auseinandersetzung mit dem Film berücksichtigt, die in der Filmdidaktik des DaF-Unterrichts allgemein üblich sind: I. Vor dem Sehen, II. Während des Sehens und III. Nach dem Sehen (vgl. z.B. Brandi 1998; Sass 2007).

Das Lesen des Gedichts spielt im DaF-Unterricht bei der Arbeit mit einer Lyrikverfilmung eine sehr große Rolle, da der im Film vorgetragene lyrische Text für die Lerner nur vom Hören her sehr schwer zu verstehen ist. Deshalb sollte das Lesen des Gedichts in der Regel dem Sehen der Lyrikverfilmung vorangestellt werden bzw. mit ihm möglichst parallel erfolgen. Eine enge Verbindung von Text und Film ist hier bei der Aufgabenstellung von besonderer Bedeutung. Entsprechend 
der Wichtigkeit des Leseprozesses bei der Filmarbeit werden die Aufgaben zu den Phasen I und II in zwei Gruppen unterteilt: Vor dem Lesen bzw. während des Lesens und Nach dem Lesen.

Es wird erläutert, welche Aspekte der Lyrikverfilmung bei der jeweiligen Aufgabe im Vordergrund stehen können, und es werden Vorschläge dazu gemacht, welche Aufgaben für welchen Lyrikverfilmungstyp (s. Abschnitt 1) am besten geeignet sind, ebenfalls werden dabei die drei Ebenen der Wort-Beziehung in der Lyrikverfilmung berücksichtigt.

Wort und filmisches Bild stehen in der Lyrikverfilmung in einer dreifachen Relation zueinander: einer semantischen, einer „räumlichen“ und einer zeitlichen.9

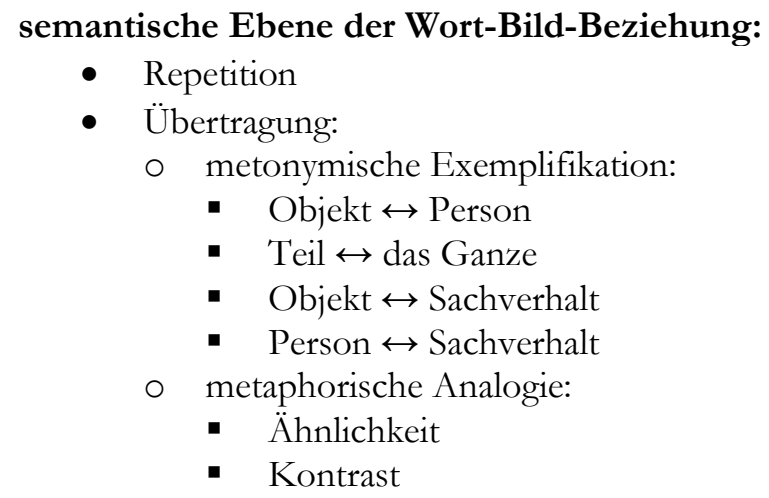

- Repetition

- Übertragung:

- metonymische Exemplifikation:

- Objekt $\leftrightarrow$ Person

- Teil $\leftrightarrow$ das Ganze

- Objekt $\leftrightarrow$ Sachverhalt

- Person $\leftrightarrow$ Sachverhalt

- metaphorische Analogie:

- Ähnlichkeit

- Kontrast

„räumliche“ Ebene der Wort-Bild-Beziehung

(„Positionierung“ des Texts im Film):

- akustisch (Gedichtrezitation):

$\circ$ off screen

$\circ$ on screen

- visuell (eingeblendeter Text):

○ im Verlauf des Films

- im Abspann

Sonderfall: logische Verknüpfung (Verweis auf die Vorlage im Vor- oder Abspann)

\footnotetext{
${ }^{9}$ Die Anregung zu dieser Systematik kommt aus der Arbeit „Theorie des Films“ von Siegfried Kracauer (1993: 147-183), in der er anhand von drei Begriffspaaren - Parallelismus/Kontrapunkt, aktueller Ton/kommentierender Ton (vergleichbar mit der jetzt gängigen Unterscheidung zwischen on- und offTon), Synchronismus/Asynchronismus - die Möglichkeiten der filmischen Synchronisierung (Bild-TonMontage) beschreibt.
} 


\section{zeitliche Ebene der Wort-Bild-Beziehung}

(Verhältnis der Wort- und Bildkette):

- synchron

- asynchron

Sonderfall: formale Synchronität (Übereinstimmungen wie Wort = Einstellung; Vers = Einstellung; Strophe $=$ Einstellung oder Sequenz u.ä.)

\section{Tab. 3: Drei Ebenen der Wort-Bild-Beziehung}

Die semantische Relationsebene Wort - filmisches Bild ist für die Analyse der Lyrikverfilmung die interessanteste und komplizierteste. Als Resultat der illustrierenden Transformation stehen Wort und filmisches Bild in der Relation der Repetition zueinander (redundante verbale und filmische Zeichen), als Resultat der (um)deutenden Transformation in der der Übertragung. Außer der Wort-Bild-Semantik spielt auch eine Rolle, ob eine Tonquelle auf dem Bildschirm zu sehen ist und ob die verbale und die visuelle Botschaft in unmittelbarer Nähe zueinander stehen. Solche Faktoren erleichtern das Verständnis und sollten im Fremdsprachenunterricht bedacht werden.

\begin{tabular}{|l|l|}
\hline Aufgabe und Analyseaspekt(e) & Verfilmungstyp \\
\hline I. Vor dem Sehen \\
\hline 1.1. Vor dem Lesen bzw. während des Lesens \\
\hline $\begin{array}{l}\text { Vermutungen äußern zu Standbildern bzw. zu einem } \\
\text { Sequenzauftakt: Den Lernern werden ein Standbild } \\
\text { (bzw. einige wenige Standbilder) oder eine Film- }\end{array}$ & $\begin{array}{l}\text { Verlauf der filmischen } \\
\text { Hequallung }\end{array}$ \\
$\begin{array}{l}\text { überlegen ohne Gedichttext präsentiert. Die Lerner } \\
\text { gehen könnte. Je nach angestrebtem Analyseaspekt }\end{array}$ & \\
werden die Standbilder und Sequenzen sorgfältig \\
ausgesucht: Mit dieser vorbereitenden Aktivität kann \\
z.B. bereits auf die Aufdeckung von Transforma- \\
tionsprozessen bei der filmischen Umsetzung des \\
thematischen Rahmens des Gedichts, einzelner \\
sprachlicher Bilder etc. hingearbeitet werden.
\end{tabular}




\begin{abstract}
z.B. um die (vermutliche) Aussage des Gedichts, zentrale sprachliche Bilder, im Gedicht evozierte Gefühle und Emotionen handeln. Die Lerner können explizit aufgefordert werden, sich auch Bilder, Geräusche, Musik etc. zum vorgegebenen Begriff vorzustellen. Auf diese Weise werden die Lerner auf die sog. „Transformationsereignisse“ (unerwartete filmische Umsetzungen) vorbereitet.
\end{abstract}

Erwartungen zum Titel äußern und begründen: Die Lerner werden mit einem Titel konfrontiert und erklären, was sie von einem Gedicht mit einem solchen Titel und von einem Film mit dem gleichen Titel erwarten. Dabei kann bereits auf die Medienspezifik bei der Umsetzung von bestimmten Themen und Inhalten eingegangen werden.

Film-Gedicht-Puzzle 1: Die Lerner sollen (in Gruppenarbeit) Passagen, einzelne Ausdrücke oder auch nur Schlagwörter aus dem Gedicht einzelnen Standbildern aus der Verfilmung zuordnen und ihre Wahl begründen. Auf diese Weise kann die filmische Transformation von einzelnen sprachlichen Bildern aus dem Gedicht thematisiert werden. Die Lerner können auf diese Weise auf das „Transformationsereignis" vorbereitet werden und ihre Fähigkeit zur Perspektivenübernahme wird gefördert. Im Fall der metaphorischen Transformation kann die Fragestellung lauten: „Was haben das Wort und das filmische Bild gemeinsam? Finden Sie Ähnlichkeiten (oder auch Kontraste)!"“ und im Fall der metonymischen Transformation: „In welchem Zusammenhang stehen das Wort und das filmische Bild? Entwickeln Sie eine Art ,Rahmen‘, um diesen Zusammenhang herzustellen!“،

\subsection{Nach dem Lesen}

Konkretisierung des Sprechers des Gedichts, z.B. anhand von Steckbriefen mit Fragen, über die die Lerner Vermutungen äußern sollen. Mögliche Fragen: „Wie alt ist die Person? Ist das ein Mann oder eine Frau? Aus welcher Zeit ist diese Person? Wie
Verfilmungen, in denen Wort und Bild auf semantischer Ebene im Verhältnis der Übertragung zueinander stehen

alle Verfilmungstypen

Etüden, Gedichte im Verlauf der filmischen Handlung

inszenierte Deklamationen
und ggf. Gedichte im Ver-
lauf der filmischen Hand-
lung, falls in ihnen ein
on-screen-Sprecher




\begin{abstract}
fühlt sich diese Person? Wie sieht die Person aus? Wie ist sie gekleidet? Womit beschäftigt sich diese Person gern? Wie ist ihre Beziehung $\mathrm{zu}$ anderen Menschen?" Selbstverständlich kann die Aufgabenstellung sich auf eine oder einige wenige Fragen beschränken, die dann aber ausführlich und am besten schriftlich beantwortet werden soll(en). Auf diese Weise wird auch der erste Schritt zum Thematisieren von Vermittlungsinstanzen im Gedicht und im Film gemacht.
\end{abstract}

Entwerfen eines situativen Rahmens: Die Lerner überlegen sich, aus welcher Situation das Gedicht „erwächst“. Sie sollen das Gedicht mit einer konkreten Situation verbinden, der Phantasie sind dabei keine Grenzen gesetzt. Mögliche Fragen: „Was ist passiert (bzw. was passiert gerade) und kann Auslöser für die im Gedicht dargestellten Gefühle sein?" Auch konkrete Fragen zur Atmosphärengestaltung sind hilfreich: „Wie sehen die Räumlichkeiten aus? Welche Gegenstände sind zu sehen? Wie ist das Wetter? Welche Jahres-/Tageszeit stellen Sie sich vor? Sind auch Figuren zu sehen? Wenn ja, welche?" Das ist bereits eine anspruchsvolle Aufgabe, die eine Phase der Textarbeit voraussetzt. Die Lerner sollen einerseits sich dessen bewusst werden, dass ihre Assoziationen individuell sind und sich von den Assoziationen der anderen Gruppenteilnehmer unterscheiden können, andererseits sollen sie ihre Antworten am Text festmachen können und verstehen, dass das eine das andere nicht ausschließt.

So setzen sich die Lerner mit dem thematischen Rahmen des Gedichts und seiner möglichen Transformation im Film aktiv auseinander.

Assoziationen sammeln $\mathrm{zu}$ einzelnen Bildern aus dem Gedicht: ähnlich wie Assoziationen sammeln zu einem Begriff (s.o.), jedoch handelt es sich hier um sprachliche Bilder, die bereits in einem Kontext vorkommen und dadurch eine bestimmte Prägung erfahren. Dies soll auch thematisiert werden. Dabei soll es sich um Bilder handeln, die für das Text- vorkommt

inszenierte Deklamationen, Gedichte im Verlauf der filmischen Handlung 


\begin{tabular}{|c|c|}
\hline $\begin{array}{l}\text { verständnis am wichtigsten sind und in der Lyrikver- } \\
\text { filmung (um)deutend transformiert werden. Wichtig } \\
\text { ist bei dieser Aufgabe, sicherzustellen, dass die Ler- } \\
\text { ner genügend literarisches, filmisches, landeskund- } \\
\text { liches etc., also im weiten Sinne kulturelles Vorwissen } \\
\text { besitzen, um die Assoziationen der Filmemacher } \\
\text { nachvollziehen zu können. }\end{array}$ & \\
\hline $\begin{array}{l}\text { Assoziationen sammeln zur (möglichen) Aussage des } \\
\text { Gedichts: Dieser Schritt erfolgt erst nach einer aus- } \\
\text { führlichen Beschäftigung mit dem Text und ist sehr } \\
\text { arbeitsintensiv: Die Lerner sollen ihre Assoziationen } \\
\text { sammeln und versuchen, abstrakte Begriffe in kon- } \\
\text { krete Bilder zu transformieren. Als Arbeitsform ist } \\
\text { Gruppenarbeit gut geeignet. Dabei sollte klar werden, } \\
\text { dass es verschiedene Weisen gibt, einen Sachverhalt } \\
\text { auszudrücken. }\end{array}$ & alle Verfilmungstypen \\
\hline $\begin{array}{l}\text { Identifizieren von Bildern, die in der Verfilmung } \\
\text { vorkommen „,sollten“: Die Lerner suchen in Einzel- } \\
\text { oder Gruppenarbeit sprachliche Bilder, die in der } \\
\text { Lyrikverfilmung ihrer Meinung nach vorkommen } \\
\text { „sollten“. Vorher muss thematisiert werden, dass die } \\
\text { Lyrikverfilmung keine „Bebilderung“ des Gedichts } \\
\text { ist, die möglichst viele Bilder aus dem Gedicht fil- } \\
\text { misch aufgreifen will, und dass in ihr nur wenige } \\
\text { sprachliche Bilder oft (um)deutend transformiert } \\
\text { werden. Die Lerner sollen selbst Ideen entwickeln, } \\
\text { wie das umgesetzt werden könnte: sowohl auf der } \\
\text { visuellen Ebene als auch mithilfe von Musik oder } \\
\text { verschiedener Geräusche etc. Nach der Filmpräsen- } \\
\text { tation werden ihre Erwartungen nochmals rekapitu- } \\
\text { liert. Es muss jedoch bedacht werden, dass die Er- } \\
\text { wartungen der Lerner enttäuscht werden können. } \\
\text { Deswegen ist es wichtig, die mit der zweiten Trans- } \\
\text { formationsstufe in der Lyrikverfilmung verbundenen } \\
\text { Reduktions- und Auswahlprozesse sowie die Syno- } \\
\text { nymie als Darstellungsprinzip zu thematisieren. }\end{array}$ & alle Verfilmungstypen \\
\hline $\begin{array}{l}\text { Film-Gedicht-Puzzle 2: Die Lerner beziehen in } \\
\text { Gruppenarbeit Standbilder aus der Lyrikverfilmung } \\
\text { auf Gedichtstellen und begründen ihre Wahl. Auf }\end{array}$ & $\begin{array}{l}\text { Etüden, Gedichte im Ver- } \\
\text { lauf der filmischen Handlung }\end{array}$ \\
\hline
\end{tabular}




\begin{tabular}{|c|c|}
\hline $\begin{array}{l}\text { diese Weise können die Transformation von einzel- } \\
\text { nen Elementen des Systems „Gedicht“, ihre Art und } \\
\text { Wirkung thematisiert sowie ggf. auch Vermutungen } \\
\text { über die Struktur der Lyrikverfilmung geäußert wer- } \\
\text { den. }\end{array}$ & \\
\hline $\begin{array}{l}\text { Übungen zur gestischen Sprache 1: Die Lerner tragen } \\
\text { das Gedicht in einer bestimmten Haltung vor, dann } \\
\text { geben die anderen Gruppenteilnehmer Rückmeldung } \\
\text { darüber, wie sie den Vortrag empfunden haben, an- } \\
\text { schließend erklären die Vortragenden, welche Situa- } \\
\text { tion und Gefühlslage sie sich vorgestellt hatten. Da- } \\
\text { bei kann die Selbst- und Fremdwahrnehmung reflek- } \\
\text { tiert werden. Nach dem Zeigen des Films werden die } \\
\text { Ergebnisse noch einmal rekapituliert und es werden } \\
\text { die Wirkungen des auf verschiedene Weisen vorge- } \\
\text { tragenen Texts besprochen, dabei sollen die bedeu- } \\
\text { tungsstiftenden Faktoren wie Gestik, Mimik, Stimm- } \\
\text { lage etc. thematisiert werden. }\end{array}$ & $\begin{array}{l}\text { inszenierte Deklamationen } \\
\text { und ggf. Gedichte im Ver- } \\
\text { lauf der filmischen Hand- } \\
\text { lung, falls in ihnen ein } \\
\text { on-screen-Sprecher } \\
\text { vorkommt }\end{array}$ \\
\hline $\begin{array}{l}\text { Aufdeckung des unsichtbaren Sprechers: Die Lerner } \\
\text { bekommen den Ton aus der Verfilmung vorgespielt, } \\
\text { die Gedichtrezitation wird reflektiert und die Lerner } \\
\text { spekulieren über das Aussehen des Sprechers, wobei } \\
\text { sie ihre Vermutungen begründen. So wird die } \\
\text { „Stimme als Medium“ thematisiert. }\end{array}$ & $\begin{array}{l}\text { inszenierte Deklamationen } \\
\text { und ggf. Gedichte im Ver- } \\
\text { lauf der filmischen Hand- } \\
\text { lung, falls in ihnen ein } \\
\text { on-screen-Sprecher } \\
\text { vorkommt }\end{array}$ \\
\hline $\begin{array}{l}\text { Schreiben eines Drehbuchs zum Gedicht: vgl. dazu } \\
\text { auch die Aufgabe Eigene Lyrikverfilmung aus der Phase } \\
\text { Nach dem Sehen. Diese Aufgabe führt zu einer intensi- } \\
\text { ven Auseinandersetzung mit dem Gedicht, was aller- } \\
\text { dings auch die Gefahr mit sich bringen kann, dass die } \\
\text { Lerner von der gezeigten Verfilmung „enttäuscht“ } \\
\text { werden, da diese ihrer eigenen Sichtweise nicht ent- } \\
\text { spricht. Auch hier ist es deshalb wichtig, synonyme } \\
\text { Transformationsmöglichkeiten zu thematisieren. }\end{array}$ & $\begin{array}{l}\text { Etüden, Gedichte im Ver- } \\
\text { lauf der filmischen Handlung }\end{array}$ \\
\hline
\end{tabular}




\section{Während des Sehens}

2.1. Vor dem Lesen bzw. während des Lesens

Rekonstruktion einer entfernten Sequenz: Der Moment des Gedichtvortrags wird herausgeschnitten und die Lerner werden gefragt, was an dieser Stelle passieren könnte (vor dem Lesen des Gedichts).

bedingt geeignet, vor allem für Gedichte im Verlauf der filmischen Handlung, in denen das Gedicht „punktuell““ (als Ganzes an einer Stelle) vorgetragen wird

Antizipierende Methode: Bei diesem Verfahren wird die Lyrikverfilmung vor dem Lesen des Gedichts eingesetzt: Sie wird nur bis zu einem relevanten Punkt gezeigt und vorerst abgebrochen. Der mögliche weitere Geschehensverlauf wird von den Lernern im Plenum oder in Gruppenarbeit skizziert und anschließend mit dem Verlauf in der Verfilmung verglichen.

Isolierung des visuellen Kanals: Eine Lyrikverfilmung oder eine ausgewählte Sequenz wird (evtl. mehrfach) obne Ton gezeigt und es wird über die Wirkung der filmischen Bilder (Mehrdeutigkeit der Bilder) diskutiert. Danach stellen die Lerner ihre Vermutungen an, um was es sich in der Gedichtvorlage handeln könnte, reden darüber, welche Assoziationen die gezeigten Bilder in ihnen hervorrufen. Anschließend wird das Gedicht gelesen und die Wirkung der Verfilmung mit Ton betrachtet: Nachgedacht wird jetzt über die Bedeutung des Tons. Auf diese Weise werden die Lerner für die Komplementarität der Zeichensysteme im Film, seine „zusammengesetzte“ Semantik, sensibilisiert.

\subsection{Nach dem Lesen}

Fokussierte Inhaltsanalyse: Dieses Verfahren beinhaltet eine Filmrezeption, bei der - etwa mit Hilfe eines Beobachtungsbogens - die Aufmerksamkeit der Lerner auf ausgewählte Aspekte gelenkt wird: Transformation der Vermittlungsinstanz(en) und einzelner sprachlicher Bilder etc. (in Einzel- oder Gruppenar-
Gedichte im Verlauf der filmischen Handlung

Etüden, Gedichte im Verlauf der filmischen Handlung

alle Verfilmungstypen,
insbesondere geeignet
für zeitlich asynchrone
Verfilmungen, in denen
Wort und Bild auf se-
mantischer Ebene im




\begin{tabular}{|l|l|}
\hline beit mit unterschiedlichen Beobachtungsaufgaben). & Verhältnis der Übertra- \\
Dabei soll die Notwendigkeit des strategischen Vor- & gung zueinander stehen \\
gehens beim Filmsehen thematisiert werden. An- & \\
schließend werden die Ergebnisse im Plenum zu- & \\
sammengetragen und in Bezug zur Gedichtvorlage & \\
gesetzt. Auf diese Art werden die Lerner auch auf die & \\
filmischen Codes und ihre Wirkung aufmerksam & \\
gemacht. & \\
\hline $\begin{array}{l}\text { Einfrieren von Standbildern: Bei diesem Verfahren } \\
\text { werden wichtige Einstellungen im Rahmen einer } \\
\text { genauer analysierten Sequenz angehalten und ge- } \\
\text { meinsam als Einzelbilder eingehend betrachtet. Auf } \\
\text { diese Weise wird der Blick der Lerner für die filmi- } \\
\text { schen Gestaltungsmittel geschärft und sie können } \\
\text { ihre eigenen assoziativen Bilder (s. Aufgaben aus der } \\
\text { Phase Vor dem Sehen des Films) mit denen der Filme- } \\
\text { macher vergleichen. }\end{array}$ & \\
\hline $\begin{array}{l}\text { Einem Teil der Gruppe die Verfilmung zeigen: Die } \\
\text { Verfilmung wird einem Teil der Gruppe (Variante: } \\
\text { ohne Ton) gezeigt, diese Teilnehmer sollen nach dem } \\
\text { Sehen für die zweite Gruppenhälfte den Film nach- } \\
\text { erzählen, ohne den Gedichttext einzubringen. Die } \\
\text { zweite Hälfte der Gruppe liest das Gedicht und fasst } \\
\text { seinen Inhalt und seine (mögliche) Aussage für die } \\
\text { erste Gruppenhälfte zusammen. Handlung }\end{array}$ & \\
\hline
\end{tabular}




\section{Nach dem Sehen}

Beifügen von Untertiteln: Untertitel erleichtern das Filmverständnis um ca. 30\% (vgl. Sass 2007: 9). In den Lyrikverfilmungen wird das Gedicht im ,authentischen" Tempo nur einmal vorgetragen, was das Hörverstehen für fremdsprachige Lerner schwierig macht. Das Hinzufügen von Untertiteln durch die Lerner selbst, falls die technischen Möglichkeiten es erlauben, ist zudem ein wichtiger Schritt in der Auseinandersetzung mit dem filmischen Bild, wobei die Transformationsprozesse aufgedeckt werden und die Struktur der Lyrikverfilmung bei der Arbeit mit Untertiteln deutlich wird.

Sequenzplan (Sequenzliste): Die Lerner erstellen einen Sequenzplan der Lyrikverfilmung, analysieren mit dessen Hilfe ihren Aufbau und vergleichen ihn mit der Struktur des Gedichts. Der Sequenzplan kann je nach Erkenntnisinteresse unterschiedlich komplex sein; eine einfache Form wäre die folgende (auf die Kommentarleiste kann auch verzichtet werden):

\begin{tabular}{|l|c|l|c|}
\hline $\begin{array}{l}\text { Nr. der } \\
\text { Sequenz }\end{array}$ & Zeit & $\begin{array}{l}\text { Inhalt }+ \\
\text { Standbild }\end{array}$ & Kommentar \\
\hline
\end{tabular}

Als nächster Schritt kann eine Art „Synopse“ erstellt werden, wobei die Lerner den Verfilmungssequenzen Verse aus dem Gedicht zuordnen. Dadurch wird das Verfilmungskonzept deutlich und eine gute Basis für die Analyse geschaffen.

\begin{tabular}{|c|c|c|c|c|}
\hline $\begin{array}{l}\text { Nr. der } \\
\text { Sequenz }\end{array}$ & Zeit & $\begin{array}{l}\text { Inhalt }+ \\
\text { Standbild }\end{array}$ & Gedichttext & \\
\hline \multicolumn{4}{|c|}{$\begin{array}{l}\text { Verfilmungsprotokoll (sound and shooting } \\
\text { transcript): Das ausführliche Protokollieren von } \\
\text { Filmsequenzen ist ein wichtiger Schritt in der Filma- } \\
\text { nalyse. Die Transkription eines ganzen Films ist für } \\
\text { den Unterricht normalerweise zu aufwendig, eine } \\
\text { Lyrikverfilmung kann jedoch wegen ihrer Kürze auch }\end{array}$} & $\begin{array}{l}\text { alle Verfilmungstypen, } \\
\text { insbesondere asynchro- } \\
\text { ne Etüden und Gedichte im } \\
\text { Verlauf der filmischen } \\
\text { Handlung, in denen Wort } \\
\text { und filmisches Bild im }\end{array}$ \\
\hline
\end{tabular}

alle Verfilmungstypen, insbesondere asynchrone Etüden und Gedichte im Verlauf der filmischen Handlung, in denen Wort und filmisches Bild im Verhältnis der Übertragung zueinander stehen

alle Verfilmungstypen, insbesondere asynchrone Etüden und Gedicbte im Verlauf der filmischen Handlung, in denen Wort und filmisches Bild im Verhältnis der Übertragung zueinander stehen; aber auch formal synchrone Lyrikverfilmungen, weil dadurch diese Art der Synchronität oft erst deutlich gemacht werden kann 


\begin{abstract}
als Ganzes in dieser Weise protokolliert werden. Dieses Verfahren ist sehr hilfreich, denn dadurch werden die Lerner zum genauen Anschauen der Verfilmung gebracht: Bei der Erarbeitung ihrer Struktur werden sie auf die visuellen und auditiven Codes aufmerksam, die die Bedeutung des Films und seine Wirkung auf den Zuschauer konstituieren, und können deren Korrespondenz mit den poetischen Mitteln im Gedicht klarer nachvollziehen. So wird das Vergleichen der Lyrikverfilmung mit der literarischen Vorlage erleichtert und anschaulich gemacht. Das Erstellen von Verfilmungsprotokollen trägt zur Erweiterung der media literacy der Lerner bei, denn auf diese Weise werden sie für die Mikrostruktur eines Films sensibilisiert: Sie verstehen sein Bedeutungsund Wirkungspotential als Folge der eingesetzten filmischen Codes.
\end{abstract}

Verhältnis der Übertragung zueinander stehen; aber auch formal synchrone Lyrikverfilmungen, weil dadurch diese Art der Synchronität oft erst deutlich gemacht werden kann.

Verfilmungsprotokoll

\begin{tabular}{|c|c|c|c|c|c|c|}
\hline & \multicolumn{4}{|c|}{ Bild } & \multicolumn{2}{|c|}{ Ton } \\
\hline \multirow{2}{*}{$\begin{array}{l}\text { Se- } \\
\text { quenz- } \\
\text { Nr./ } \\
\text { Zeit }\end{array}$} & \multirow{2}{*}{$\begin{array}{l}\text { äußere } \\
\text { Handlung/ } \\
\text { situativer } \\
\text { Rahmen + } \\
\text { Standbild }\end{array}$} & \multirow{2}{*}{$\begin{array}{l}\text { Beleuch- } \\
\text { tung } \\
\text { Farbgebung }\end{array}$} & \multicolumn{2}{|c|}{ Kamera } & \multirow{2}{*}{$\begin{array}{l}\text { Geräu- } \\
\text { sche } \\
\text { /Musik/ } \\
\text { externe } \\
\text { Dialoge }\end{array}$} & \multirow{2}{*}{$\begin{array}{l}\text { Ge- } \\
\text { dicht- } \\
\text { text }\end{array}$} \\
\hline & & & $\begin{array}{l}\text { Einstel- } \\
\text { lungs- } \\
\text { größe }\end{array}$ & $\begin{array}{l}\text { Pers- } \\
\text { pektive }\end{array}$ & & \\
\hline
\end{tabular}

Eigene alternative Fassung: Die Lerner entwerfen ihre eigene Lyrikverfilmung: Veränderung des Ortes, des Sprechers, Einbettung des Gedichts in eine Handlung etc. (vgl. dazu auch die vorhergehende Aufgabe und die Aufgabe Eigene Lyrikverfilmung).

Bild-Ton-Montage: Falls die technische Ausrüstung es erlaubt, können die Lerner ausgewählte Sequenzen oder die ganze Lyrikverfilmung mit neuem Ton (Geräusche, Musik, andere Sprechweise) versehen, ihre Wahl in Bezug auf das Gedicht begründen und die Wirkung des neuen Tons mit der des Originaltons in der Lyrikverfilmung vergleichen. Dabei werden sie für die Funktion des Tons sensibilisiert und auf die alle Verfilmungstypen

Etüden, Gedichte im Verlauf der filmischen Handlung 


\begin{tabular}{|c|c|}
\hline $\begin{array}{l}\text { Steuerung der Wahrnehmung von Bildern durch den } \\
\text { Ton aufmerksam gemacht. }\end{array}$ & \\
\hline $\begin{array}{l}\text { Vergleich von mehreren Verfilmungen desselben } \\
\text { Gedichts: Dabei werden die Verfilmungen wieder- } \\
\text { holt angesehen (ggf. mit „Einfrieren“ wichtiger Bil- } \\
\text { der). Es kann mit Transkripten oder mit einem Be- } \\
\text { obachtungsbogen gearbeitet werden, in dem festge- } \\
\text { legt wird, auf welche Aspekte die Lerner achten sol- } \\
\text { len. Durch den Vergleich erkennen die Lerner Unter- } \\
\text { schiede und Gemeinsamkeiten in den filmischen } \\
\text { Interpretationen in Bezug auf die Vorlage, versuchen, } \\
\text { die innere Logik der Bilder zu erkennen und zu ver- } \\
\text { stehen, worauf die Unterschiede bei den Verfilmun- } \\
\text { gen zurückzuführen sind (welche Aspekte jeweils } \\
\text { betont, welche filmischen Codes verwendet werden } \\
\text { etc.). }\end{array}$ & alle Verfilmungstypen \\
\hline $\begin{array}{l}\text { Eine Rezension oder Filmkritik zur Verfilmung } \\
\text { schreiben, in einem Brief den Film nacherzählen und } \\
\text { bewerten etc.: Solche Aufgaben sollen nicht nur die } \\
\text { Fertigkeit Schreiben an sich schulen, sondern auch } \\
\text { die literarische Kompetenz und media literacy der Ler- } \\
\text { ner erweitern, denn für die argumentierende Stel- } \\
\text { lungnahme zur Lyrikverfilmung sind Kenntnisse aus } \\
\text { diesen Bereichen unabdingbar. Diese Aufgaben set- } \\
\text { zen also eine intensive Phase der Text- und Filmar- } \\
\text { beit voraus. }\end{array}$ & alle Verfilmungstypen \\
\hline $\begin{array}{l}\text { Podiumsdiskussion: Lyrikverfilmungen bieten wegen } \\
\text { der in ihnen enthaltenen Ambivalenzen und Mehr- } \\
\text { deutigkeiten einen authentischen Äußerungsanlass, } \\
\text { der nicht nur für das Unterrichtsgespräch, sondern } \\
\text { auch für das zusammenhängende Sprechen im ,for- } \\
\text { malen“ Rahmen einer Podiumsdiskussion genutzt } \\
\text { werden kann. Genauso wie bei dem vorhergehenden } \\
\text { Aufgabentyp erfordert dies eine Vorbereitungsphase, } \\
\text { damit die Lerner den von ihnen übernommenen } \\
\text { Rollen (z.B. Filmkritiker, Regisseur, Literaturexperte, } \\
\text { Moderator, aktiver Zuschauer, der sich in die Diskus- } \\
\text { sion anbringt, etc.) gerecht werden können. }\end{array}$ & alle Verfilmungstypen \\
\hline Übungen zur gestischen Sprache 2: Ähnlich wie & inszenierte Deklan \\
\hline
\end{tabular}




\begin{abstract}
der Phase Vor dem Sehen, nur wird als erstes die Gedichtrezitation aus der Lyrikverfilmung und ihre Wirkung auf die Textrezeption besprochen. Danach tragen die Lerner das Gedicht in einer bestimmten Haltung vor, die anderen Gruppenteilnehmer geben ihre Rückmeldung darüber, wie sie den Vortrag empfunden haben, anschließend erklären die Vortragenden, welche Situation und Gefühlslage sie sich vorgestellt hatten. Dabei können die Selbst- und Fremdwahrnehmung reflektiert sowie Faktoren wie Gestik, Mimik, Stimmlage etc. thematisiert werden, die auch im Prozess der Alltagskommunikation bedeutungsstiftend sind.
\end{abstract}

Eigene Lyrikverfilmung: Dieses Verfahren der produktiven Textüberschreitung macht die Auseinandersetzung mit dem lyrischen Text für die Lerner besonders intensiv. Es ist auch ein sehr guter Weg, die erworbenen Kenntnisse über die Filmsprache zu vertiefen. Als Sozialform ist Gruppenarbeit nahe liegend. Folgende Vorgehensweise ist möglich: es kann mit dem intensiven Lesen des Gedichts und dem Erstellen einer Bilderreihenfolge sowie dem Aussuchen der passenden musikalischen Untermalung begonnen werden; anhand dieser Ergebnisse wird ein Drehplan erarbeitet (nach Göbel 1997: 308).

\begin{tabular}{|l|l|l|l|l|l|}
\hline Zeit (Sek.) & $\begin{array}{l}\text { Bildinhalt/ } \\
\text { Handlung }\end{array}$ & $\begin{array}{l}\text { Kamera- } \\
\text { einstellung }\end{array}$ & Beleuchtung & Musik & Text \\
\hline
\end{tabular}

Alternative Möglichkeit (nach Hesse et al. 2006: 109):

\begin{tabular}{|l|l|l|l|l|}
\hline Szene & $\begin{array}{l}\text { Skizze/ } \\
\text { Zeichnung } \\
\text { der Szene }\end{array}$ & $\begin{array}{l}\text { Beschreibung } \\
\text { der dargestellten } \\
\text { Situation }\end{array}$ & $\begin{array}{l}\text { Hinweise zu den filmi- } \\
\text { schen Mitteln (Einstel- } \\
\text { lungsgröße, Kamerabewe- } \\
\text { gung, Ton, Licht etc.) }\end{array}$ & Notizen \\
\hline
\end{tabular}

Erst danach kann zum eigentlichen Filmen übergegangen werden. Dieses Verfahren ist zeitaufwendig und arbeitsintensiv, setzt auch eine entsprechend leistungsfähige und motivierte Zielgruppe voraus. Es könnte sich z.B. als Semesterbzw. Kursprojekt eignen. Die Verfilmungen werden anschließend im Plenum präsentiert und diskutiert. 


\section{Literatur}

Beilenhoff, Wolfgang (Hrsg.) (2005): Poetika Kino. Frankfurt/Main: Suhrkamp.

Bierwisch, Manfred (2009): Sprache - Musik - Bild. Zeichentypen und ihre Konsequenzen. In: Zeitschrift für Literaturwissenschaft und Linguistik 155, 8-34.

Brandi, Marie-Luise (1998): Video im Deutschunterricht. Berlin: Langenscheidt.

Brunner, Philipp: Lyrikverfilmung. In: Wulff, Hans J. (Hrsg.): Lexikon der Filmbegriffe: Bender www. bender-verlag.de (10.06.2013)

Burwitz-Melzer, Eva (2003): Allmähliche Annäherungen: Fiktionale Texte im interkulturellen Fremdsprachunterricht der Sekundarstufe 1. Tübingen: Gunter Narr.

Dobstadt, Michael (2009): „Literarizität“ als Basiskategorie für die Arbeit mit Literatur in DaF-Kontexten. Zugleich ein Vorschlag zur Neuprofilierung des Arbeitsbereichs Literatur im Fach Deutsch als Fremdsprache. In: Deutsch als Fremdsprache 46, 21-30.

Dobstadt, Michael; Riedner, Renate (2011): Fremdsprache Literatur - Neue Konzepte zur Arbeit mit Literatur im Fremdsprachenunterricht. In: Fremdsprache Deutsch 44, 5-15.

Dölling, Johannes (2009): Seminarreader Bedeutungsvariationen. Http://www.unileipzig.de/ doelling/veranstaltungen/bedeutvariat1 (09.06.2013).

Esselborn, Karl (2005): Themenorientierte fremdsprachliche Literaturdidaktik am Beispiel neuerer deutscher Liebeslyrik. In: Informationen Deutsch als Fremdsprache 6, 583-596.

Göbel, Klaus (1997): Lyrik und Video. In: Deutschunterricht 6, 301-310.

Hesse, Matthias; Krommer, Axel; Müller, Julia (2006): Poem. Ein Film von Ralf Schmerberg. Unterrichtsmodell. Braunschweig u.a.: Schöningh.

Jakobson, Roman (1996): Der Doppelcharakter der Sprache und die Polarität zwischen Metaphorik und Metonymik. In: Haverkamp, Anselm (Hrsg.): Theorie der Metapher. Darmstadt: Wissenschaftliche Buchgesellschaft,163-174.

Katthage, Gerd (2004): Didaktik der Metapher. Baltmannsweiler: Schneider Verlag Hohengehren.

Keppler, Angela (2006): Die Einheit von Bild und Ton. Zu einigen Grundlagen der Filmanalyse. In: Mai, Manfred; Winter, Reiner: Das Kino der Gesellschaft - die Gesellschaft des Kinos. Köln: Herbert von Halem Verlag, 60-78.

Kispál, Tamás (2011): Die kognitiv-metaphorische Motiviertheit beim Erlernen von Idiomen am Beispiel eines Aufgabenblattes. In: Linguistik online 47. 3/11, 119-130. Http://www.linguistik-online.de/47_11/kispal.pdf. 
Koch, Corinna (2013): Metaphern im Fremdsprachenunterricht: Englisch, Franæösisch, Spanisch. Frankfurt/Main: Peter Lang.

Koestler, Arthur (1966): Der göttliche Funke. Der schöpferische Akt in Kunst und Wissenschaft. Bern/München/Wien: Scherz Verlag.

Kracauer, Siegfried (1993): Theorie des Films: die Errettung der äußeren Wirklichkeit. Frankfurt/Main: Suhrkamp.

Kußler, Rainer (1980): Prinzipien der Literaturdidaktik Deutsch als Fremdsprache am Beispiel lyrischer Texte. In: Zielsprache Deutsch 2, 16-22.

Lakoff, George; Johnson, Mark (2008): Leben in Metaphern. Heidelberg: Carl-AuerSysteme.

Lausberg, Heinrich (2008): Handbuch der literarischen Rhetorik. Eine Grundlegung der Literaturwissenschaft. Stuttgart: Franz Steiner Verlag.

Metz, Christian (1980): Probleme der Denotation im Spielfilm. In: Bruneck, Manfred (Hrsg.): Film und Fernsehen. Materialien zur Theorie, Soziologie und Analyse der audio-visuellen Massenmedien. Bamberg: C. C. Buchners Verlag, 189-215.

Neumann-Braun, Klaus; Schmidt, Axel (1999): McMusic. In: Neumann-Braun, Klaus (Hrsg.): Viva MTV! Popmusik im Fernsehen. Frankfurt/Main: Suhrkamp, 7-42.

Novikova, Anastasia (2012): Metaphern beim Sprachenlernen. In: Junge, Mathias (Hrsg.): Metaphern und Gesellschaft. Die Bedeutung der Orientierung durch Metaphern. Wiesbaden: VS Verlag für Sozialwissenschaften, 87-103.

Novikova, Anastasia (2013): Lyrikverfilmungen im Deutsch-als-Fremdsprache-Unterricht. Theoretische Grundlagen und didaktische Praxis. Hamburg: Verlag Dr. Kovač.

Peirce, Charles S. (1958): Collected Papers, Bde. I und II, Cambridge (MA): Harvard University Press.

Plett, Heinrich (2000): Systematische Rhetorik. München: Wilhelm Fink Verlag.

Poesiefilme (2010). Deutsch Oberstufe. DVD: Duden.

Rösch, Heidi (1992): Sich die fremde Sprache nehmen - Gino Chiellinos Lyrik als kritische Aneignung der deutschen Sprache. In: Berliner Beiträge zu Deutsch als Fremdsprache 5, 75-84.

Rössler, Lydia (2007): Viel weniger am Film ist Mehr! In: Fremdsprache Deutsch 36, 17-20.

Sass, Anne (2007): Filme im Unterricht - Sehen(d) lernen. In: Fremdsprache Deutsch $36,5-13$. 
Surkamp, Carola (2004): Spielfilme im fremdsprachlichen Literaturunterricht: Beitrag zu einer kulturwissenschaftlichen Filmdidaktik. In: Bredella, Lothar u.a. (Hrsg.): Literaturdidaktik im Dialog. Tübingen: Gunter Narr Verlag, 239-265.

Surkamp, Carola (2009): Literaturverfilmungen im Unterricht: Die Perspektive der Fremdsprachendidaktik. In: Leitzke-Ungerer, Eva (Hrsg.): Film im Fremdsprachenunterricht. Literarische Stoffe, interkulturelle Ziele, mediale Wirkung. Stuttgart: ibidem Verlag, 61-80.

Übung zur Filmwahrnehmung. Http://www.nibis.de/nli1/chaplin/portal\% 20neu/medien_und_schule/lernen_mit_medien/filmanalyse/uebung_wahrne hmung.pdf (10.06.2013).

Vogler-Lipp, Stefanie (2010): Übung: Was siehst du? In: Hiller, Gundula; VoglerLipp, Stefanie (Hrsg.): Schlïsselqualifikation Interkulturelle Kompetenz an Hochschulen: Grundlagen, Konzepte, Methoden. Wiesbaden: VS Verlag für Sozialwissenschaften, 267-276.

Weininger, Anna (2013): Grundlagen, Funktionen und kognitive Potentiale alltagssprachlicher Metaphern im Fremdsprachenunterricht. In: Zeitscbrift für Interkulturellen Fremdsprachenunterricht Didaktik und Methodik im Bereich Deutsch als Fremdsprache 1, 21-34. 


\title{
Dokumentarfilme und Künstlerportraits! Gerhard Richter, Pina Bausch und Sasha Waltz im DaF-Unterricht
}

\author{
Luise Holke
}

In den letzten Jahren erhielt der Dokumentarfilm im Kino mit internationalen Filmen wie „Buena Vista Social Club“ von Wim Wenders, „Exit through the gift shop“ von und über Banksy, „Shine a Light“ von Martin Scorsese, „Etre et avoir“ von Nicolas Philibert oder auch durch die Filme von Michael Moore eine immer größere Präsenz und Publikumsresonanz. In der Unterrichtspraxis führt diese Gattung bis jetzt jedoch noch zu Unrecht ein Schattendasein. Dabei ist der Sinn für das Dokumentarische heute untrennbar mit unserer Alltagspraxis verbunden: Fotos, Videos, Überwachungskameras sind etwas Selbstverständliches. Filme von Fatih Akin wie „Müll im Garten Eden“ und der als bester Dokumentarfilm 2013 prämierte Film über das Bienensterben „More than honey“ von Markus Imhoof gehen explizit auf die Aktualität ihrer Themen und die Verbindung zur heutigen Gesellschaft ein. Das Potential des Dokumentarischen besteht also vor allem im Sichtbarmachen und Fokussieren von aktuell relevanten Gesellschaftsthemen. Es ist im besten Fall gut recherchierte und gefilmte Aktualität, ein klares Statement, das zu Reaktionen auffordert in Form von Diskussionen, vertiefender Recherche oder Kritik. Schon mit dieser kleinen Filmauswahl wird das mögliche thematische Spektrum angedeutet. An dieser Stelle wird der Fokus auf drei Künstlerdokumentationen gerichtet: „Gerhard Richter Painting“ von Corinna Belz, „Pina“ von Wim Wenders und „Dialoge 09“ von Sasha Waltz. Beispielhaft sollen Denk- und Hand- 
lungsanstöße für eine intensivere Integration von Dokumentarfilmen in die Unterrichtspraxis gegeben werden.

\section{Dokumentarfilme: Ein Blick und Einblicke}

Will man das Wesen des Dokumentarischen verstehen, ist es vielleicht eine Hilfe, an das berühmte Pfeifen-Bild von René Magritte zu denken. Der Vermerk „Ceci n'est pas une pipe“ unter der gemalten Pfeife spielt mit der gleichen Diskrepanz zwischen Realität und Darstellung wie sie auch für das Dokumentarische so typisch ist. Im Dokumentarfilm wird durch Fotografie und Montage, wie es Alexander Kluge sagt, ein „Tatsachenzusammenhang““ hergestellt (vgl. Heller 2011: 154). Der Film macht sichtbar, kann Zusammenhänge bewusst machen, ist aber in jedem Fall selektiv und subjektiv. Der Regisseur bietet einen individuellen Blick auf sein Thema, ermöglicht Einblicke und eröffnet oft eine unmittelbare Nähe. Doch ist der Dokumentarfilm bei aller Nähe zur Authentizität und Wahrheit ein filmisches Produkt von Regisseur und Kameramann. Von „Realitäten“ bewusst im Plural zu sprechen, erscheint mir sinnvoll, denn nonfiktionale Filme zeigen Teile einer realen Welt. Sprachlich ist der Begriff Dokumentarfilm äußerst interessant und ambivalent, da er leicht mit Wahrheit und Authentizität in Verbindung gebracht werden kann. Die Abgrenzung zum Spieffilm kann nicht immer eindeutig gezogen werden, sodass Thorolf Lipp den Begriff des „nonfiktionalen Films“ empfiehlt, der sich sprachlich klar vom fiktionalen Film abgrenzt (Lipp 2012: 16).

Die Anfänge des Films allgemein sind untrennbar mit dem Dokumentarischen verbunden. „Vues“ (Ansichten) nannten die Brüder Lumières 1895 ihre ersten Aufnahmen wie z.B. den Klassiker „La sortie de l'usine”. Walther Ruttmann schuf 1927 mit „Berlin. Die Sinfonie einer Großstadt“ ein einmaliges Portrait der Stadt. Leni Riefenstahls Film „Olympia“ von 1938 ist ein Paradebeispiel für ideologisch gefärbte Inszenierung der Bilder sowie der manipulativen Kraft der Einstellungen und Montage. Claude Lanzmanns „Shoa“ gilt als Meilenstein der Erinnerungskultur. Dies sind nur einige Filmbeispiele, die für die Gattung Dokumentarfilm von größter Relevanz sind.

Spannend sind aber auch Spielfilme, die dokumentarische Elemente integrieren oder mit der Gattung und den Grenzen von Realität und Fiktion spielen wie z.B. „Hannah Arendt" von Margarethe von Trotta, „Kriegerin“ von David Wnendt, „Drei“" von Tom Tykwer, Filme von Ulrich Seidl wie „Import Export" oder auch „Sturm“ von Hans-Christian Schmid. Nicht zu vergessen sind natürlich auch die Klassiker der Nouvelle Vague, des Neo-Realismus, des Neuen deutschen Films sowie der Berliner Schule, bei denen meist Städte die authentische Kulisse des Films bilden und die Themen und Handlungen sehr realitätsnah sind.

John Grierson hat bereits in den 20er Jahren den Dokumentarfilm als „creative treatment of actuality" bezeichnet (vgl. Heller 2011: 152) und damit die Nähe zum Zeitgeschehen, zum Alltag und der Gesellschaft deutlich gemacht. Auch heute gibt 
es ein natürliches Bedürfnis, private und öffentliche Ereignisse zu dokumentieren, als Erinnerung festzuhalten, sichtbar zu machen und mit anderen zu teilen. Dokumentarische Prinzipien z.B. in Form von Live-Streams sind somit untrennbar mit dem 21. Jahrhundert verbunden. Lipp unterstreicht die Notwendigkeit von ,gut recherchierten, gründlich reflektierten, komplexen nonfiktionalen Filmen als schöpferische“ Behandlung des Aktuellen" (Lipp 2012: 130) im Kontext der vermehrten Audiovisionen der heutigen Gesellschaft.

Aktuelle Dokumentarfilme werden auf folgenden Festivals gezeigt: DOK Leipzig, Dokvillle Ludwigsburg, Max Ophüls Festival und während der Berlinale. Wichtige Preise sind darüber hinaus der Deutscher Filmpreis sowie der jährlich vergebene Dokumentarfilmpreis des Goethe Instituts.

\subsection{Exkurs: Filmische Künstlerportraits}

Innerhalb der Dokumentarfilme stellen Künstlerportraits ein besonderes Genre dar, welches in den letzten Jahren mit Filmen wie „Ai Weiwei Never sorry“, „The artist is present" oder den bereits genannten Banksy-Film immer präsenter wurde. In Montréal gibt es zu Ehren des Genres eine jährliches Festival artifa (Festival international du film sur l'art). Im deutschsprachigen Raum sind es Filme wie „Rythm is it“ von Thomas Grube, „Tanzträume“ von Anne Linsel, „Die Spielwütigen“ von Andreas Veiel oder „Baselitz“ von Evelyn Schels, die interessante Projekte und Künstlerpersönlichkeiten thematisieren. Es sind filmische Portraits. Den Begriff „Künstlerfilm“ vermeide ich bewusst, da unter diesem Begriff sowohl primär Filme von Künstlern, als auch fiktionale und non-fiktionale Filme über Künstler vereint werden (Felix 2011: 389ff.).

Das Besondere von Künstlerportraits ist die Nähe zum Künstler, die durch die Kamera und ggf. Interviews geschaffen wird. Begegnet man in Ausstellungen meist nur dem fertigen Kunstwerk, eröffnet die direkte Begegnung mit dem Künstler meist noch ein besseres Verständnis seiner Arbeiten. Besonders interessant sind diese Filme vor allem dann, wenn sie dem Betrachter viel Autonomie in der Wahrnehmung der Filmbilder einräumen. Dies ist besonders dann der Fall, wenn auf verbale Kommentare und ggf. auch auf Musik verzichtet wird, wie es in den Filmen „Gerhard Richter Painting“, „Pina“ und „Dialoge 09“ oft der Fall ist, und die Filmbilder ihre ganze visuelle Präsenz entfalten können. Eine unschätzbare Fundgrube für Künstlerportraits ist das Institut für Kunstdokumentationen und Szenografie. Dort werden regelmäßig DVDs publiziert und Filme ins Online-Filmarchiv gestellt. ${ }^{1}$

${ }^{1}$ Vgl. http://www.iks-medienarchiv.de/de/archiv.php. 


\section{Dokumentarfilme im DaF-Unterricht}

Warum werden Dokumentarfilme in der Praxis und Didaktik bis jetzt so wenig beachtet? Die Antwort darauf muss sicher jeder zunächst für sich selbst finden. Ein Hauptgrund könnte das Vorurteil der Langeweile und Monotonie im Vergleich zum unterhaltsamen Spielfilm sein. Für Peter Krieg ist der Dokumentarfilm „das einzige Schlafmittel, das man mit den Augen einnehmen kann“" (vgl. Niney 2012: 17). Demgegenüber stellt Niney den Reiz des Dokumentarischen als das Sichtbarmachen des Einzigartigen dar: „Uns vor Augen zu führen, was wir den anderen verdanken, das ist vielleicht die schönste Tugend des dokumentarischen Films [...] $]^{\text {“ }}$ (Niney 2012:14). Zwischen beiden Polen liegt ein unschätzbarer Fundus an Themen, Sichtweisen, Erfahrungspotentialen und vor allem Einblicken in Lebenswelten, die nur durch den fertigen Film einem größeren Publikum zugänglich gemacht werden können. Auffallend ist die Benutzung eines undifferenzierten Filmbegriffs in der Didaktik und Praxis. „Film“ wird weitestgehend automatisch mit „Spielfilm“ gleichgesetzt (vgl:: Abraham 2012; Ganguly 2011). Ausnahmen stellen die Publikation zu Filmperspektiven von Kamp und Braun dar, die in einem Kapitel auch auf nonfiktionale Filme eingehen (Kamp; Braun 2011) sowie ein Aufsatz in der Englischdidaktik (Grimm 2009). Der Dokumentarfilm führt grundsätzlich jedoch ein Nischendasein, insbesondere in der DaF-Didaktik. Dabei bietet gerade ein kontrastives Bewusstsein und eine Nutzung beider Gattungen ein enormes Erfahrungspotential auf sprachlicher, filmästhetischer und inhaltlicher Ebene.

Annäherungen an Dokumentarfilme können sprachlich auf die Unterschiede zwischen beiden Gattungen eingehen, indem Begriffspaare gebildet werden: real/wahr - fiktiv; Fakten/Tatsachen - Erzählung; authentische Personen - Schauspieler etc. Ganz automatisch wird es bei diesen Gegenüberstellungen zur Feststellung kommen, dass es oft Überschneidungen gibt und eine klare Trennung nur eingeschränkt möglich ist.

Filmästhetisch können die Gestaltungselemente des Films bewusst gemacht werden, um für den Dokumentarfilm deutlich zu machen, dass es sich um eine selektive Darstellung der Wirklichkeit handelt und somit ähnlich gestalterische Überlegungen zu einer Erzählung und Haltung führen wie beim Spielfilm. Insbesondere die Wahl des Ausschnitts, der Einstellung und der späteren Montage haben entscheidenden Einfluss auf die Aussagekraft und Rezeption. Formt man Daumen und Zeigefinger beider Hände zu einem Rechteck, einem kleinen Guckkasten wie das Kameraauge, kann man auf ganz einfache Weise die Erfahrung des selektiven Blicks erleben, indem man, bei wechselndem Abstand der Arme zum Auge, durch dieses Rechteck schaut.

Inhaltlich bietet der Dokumentarfilm ein unerschöpfliches Themenspektrum (vgl. die Filmempfehlungen am Ende des Artikels) und Einbettungskontexte und eröffnet somit einen wahren Schatz an Diskussions-, Kultur-, Gesellschafts- und Aktualitätsthemen, den es aktiv zu nutzen gilt. 


\subsection{Künstlerportraits im DaF-Unterricht}

Ebenso wie Dokumentarfilme eine größere Präsenz im Unterricht erhalten sollten, ist auch die verstärkte Integration von Kunst- und Kulturthemen wünschenswert. Diese Forderung begründet sich einerseits durch die positiven Unterrichtserfahrungen, bei denen die Studenten sich mit den Inhalten identifizieren konnten und die Sprache eine dienende Funktion hatte, vor allem aber auf die Konzepte des CLIL (Content and Language Integrated Learning) (vgl. Haataja 2010: 1047ff.). Zudem bieten Kunstthemen eine ideale Plattform zur Sensibilisierung der interkulturellen Kompetenz; da Kunstwerke und Künstler meist ungewohnte Positionen präsentieren, kann an deren Wahrnehmung ideal die eigene Ambiguitätstolerenz geschult werden. Zudem wird die visuelle Kompetenz in filmischen Künstlerportraits doppelt geschult, da es einerseits die repräsentierten Werke innerhalb des Films gibt, andererseits die medialen Filmbilder. Insgesamt sollte in die Richtung CLIL unter bewusster Einbeziehung der Künste im DaF-Bereich in Zukunft verstärkt gedacht und gehandelt werden (vgl. Badstübner-Kizik 2010).

Gerade auch für Theaterstücke stellen Dokumentationen eine wichtige Möglichkeit dar, die Inszenierung eines Regisseurs und die Schauspieler zu sehen, wie z.B. „Woyzeck“ von Thomas Ostermeier. Interessant ist auch die verstärkte Tendenz der Theater, wie beim Film Trailer ihrer aktuellen Stücke online zu stellen. Durch diese kurzen Einblicke bekommt man bereits eine Vorstellung über die Art der Inszenierung. Eine ähnliche Entwicklung ist bei Ausstellungen zu beobachten. Immer häufiger werden Kuratoren- und Künstlerinterviews mit Einblicken in die Ausstellung produziert, um so zu informieren und den Besuch anzuregen.

\section{Einblicke: Gemeinsamkeiten der drei gewählten Dokumentarfilme}

Besonders charakteristisch ist die Intensität der gefilmten Bilder, die meist ganz pur für sich stehen ohne eine zusätzliche Leitung des Blicks und der Wahrnehmung durch erklärende Kommentare. Visuell anspruchsvoll, direkt und ungefiltert fordern alle drei Filme zum intensiven Sehen auf und können sowohl als Ausgangspunkt für eine vertiefende Auseinandersetzung als auch als ergänzende Information bei einem breiten Vorwissen voller Sinn sein. Alle drei Filme eröffnen eine außergewöhnliche Nähe zu den Künstlern, die an keiner Stelle unterbrochen wird. Ganz direkt bekommt der Zuschauer eine sehr komplexe und authentische Vorstellung der Persönlichkeiten und taucht ein in ihre besonderen Gedanken- und Schaffenswelten. Alle drei Filme stehen für eine Momentaufnahme in einer bestimmten Phase und haben nicht den Anspruch ein vollständiges Portrait zu liefern. 
3.1 Gerhard Richter über die Schulter geschaut! Einblicke in das aktuelle Schaffen und Denken

Im Vorfeld der drei großen Retrospektiven, 2011 in London, 2012 in Berlin und Paris, zum 80. Geburtstag gedreht, ermöglicht der Film von Corinna Belz ganz private Einblicke ins Atelier und das Entstehen neuer abstrakter Bilder. Ganz nah kommt der Zuschauer dem Menschen Gerhard Richter, seiner Art des Arbeitens, Denkens, Sprechens. Neben den Atelierszenen gibt es zahlreiche Einblicke in Ausstellungsvorbereitungen sowie Ausschnitte aus Dokumentationen der frühen 60er/70er Jahre. Charakteristische Merkmale des Films sind die pointierte Gestaltung des Tons und die Atelierszenen bei der Entstehung der neuen abstrak-

Gerhard Richter: 1932 in Dresden geboren, Studium der Malerei in Dresden, Ausreise in den Westen im März 1961, zweites Malerei-Studium in Düsseldorf. Unscharfe, figurative Bilder nach Fotos sowie abstrakte Bilder und Installationen. Internationale Anerkennung. Lebt und arbeitet in Köln.

ten Bilder. Das Klecksen der Farbe, das Schaben der Rakel wird zu einem intensiven Klangerlebnis, das prozesshafte Ringen um ein neues Bild wird sicht- und hörbar. Rhythmisiert wird der Film durch kurze Interviewpassagen und Kommentare zu Bildern und Fotos, bei denen Richters Ernst im Umgang mit den Bildern deutlich wird. Ausgezeichnet wurde der Film zu Recht als bester deutscher Dokumentarfilm mit dem deutschen Filmpreis 2012. 2

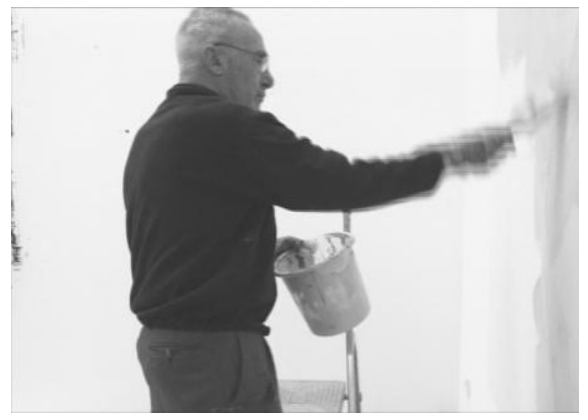

Abb. 1 (12:40)

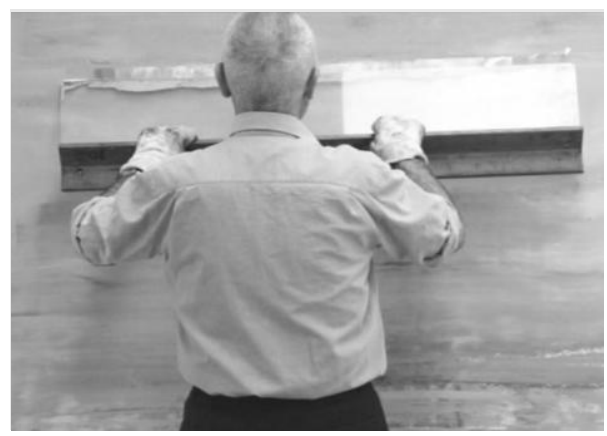

Abb. 2 (51:05)

Es bieten sich folgende Schwerpunkte zur Analyse des Films an: Atelierszenen bei der Entstehung abstrakter Bilder (vgl. Abb. 1 und 2; (Kap. 2: 12:00-14:28)) und zum Malen unter Beobachtung (44:00-46:47, 48:30-51:30), Historische Atelieraufnahmen in schwarz/weiß von 1966 (08:54-10:00) sowie die Rolle der Regisseurin

\footnotetext{
${ }^{2}$ Zum Film existiert eine Homepage: http://www.gerhard-richter-painting.de/zum_film.php. Exzellente Homepage zu Leben und Werk: http://www.gerhard-richter.com.
} 
im Film und der Einsatz der filmischen Mittel. Insbesondere die Kommentare zum Malen unter Beobachtung sind in Verbindung mit der Gattung Dokumentarfilm sehr interessant. Richter beschreibt die Veränderung des Verhaltens durch die Präsenz der Kamera. Diese Frage lässt sich wunderbar diskutieren und mit eigenen Erfahrungen ergänzen.

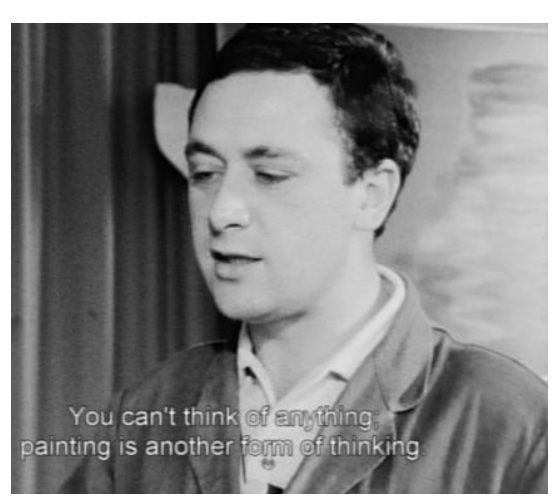

Abb. 3 (9:44)

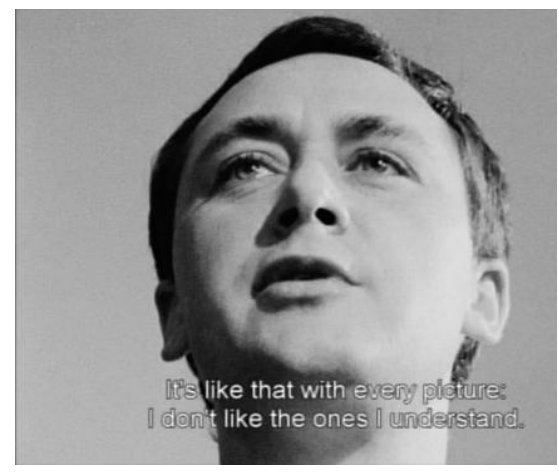

Abb. 4 (9:58)

Interessant sind auch Richters künstlerische Selbstaussagen insbesondere zum Verhältnis von Sprache und Malen: „Malen ist eine andere Form des Denkens.“ (Abb. 3; 9:44) oder zum Verhältnis zu Bildern: „Ich finde die Bilder schlecht, die ich begreifen kann.“ (Abb. 4; 9:58) Diese Aussagen können wunderbare Diskussionen über das eigene Verhältnis zu Bildern auslösen, aber auch die Frage, was ein gutes, interessantes Bild ist. Ergänzend kann noch folgendes Zitat produktiv genutzt werden: „Ein Bild kann uns helfen, etwas zu denken, was über dieses sinnlose Dasein hinausgeht.“ (vgl. Borchardt-Hume 2012: 163)

Über den Film hinaus lohnt sich die Beschäftigung mit Richters Biografie, seinem Weggang aus der DDR kurz vor dem Mauerbau in den Westen und seiner Doppelausbildung in Dresden und Düsseldorf. Die Vielfalt seiner berühmten unscharfen Bilder auf Grundlage von Fotos, sein Kerzenbild, der RAF-Zyklus oder auch das September-Bild zu den Terrorangriffen 2001 sind alle auf der oben genannten exzellenten Homepage anzusehen und laden zum intensiveren Kennenlernen ein. Gerade die Verbindung aus individueller Biografie, deutscher Geschichte und die Vielfalt der Bildthemen machen aus der Person Gerhard Richter ein äuBerst dankbares, vielfach einsetzbares und überaus lebendiges Thema.

\subsection{Pina. Ein Film für Pina Bausch von Wim Wenders}

„Erst durch Pinas Tanztheater habe ich auf Bewegungen, Gesten, Haltungen, Gebärden, Körpersprache achten gelernt. [...] Welcher Schatz unseren Körpern innewohnt, sich ohne Worte mitzuteilen, und wie viel Geschichten erzählt werden 
können, ohne dass ein Satz gesagt wird.“ Mit diesen Worten kommentiert Wim Wenders den Zauber und das große künstlerische Erlebnispotential beim Anblick des Tanztheaters der Pina Bausch. ${ }^{3}$ Der Film ist ein einzigartiges Beispiel einer filmischen Hommage, hier an die Erfinderin des Tanztheaters. Gleichzeitig macht er auf schönste Art die Fähigkeit des Dokumentarfilms deutlich, Menschen in Bildern lebendig zu halten, die Erinnerung an die Person und ihr Werk sichtbar zu machen: Dokumentarfilm als ein Denkmal.

Wichtig ist es noch, auf die aufwändigen Dreharbeiten des Films in 3D hinzuweisen. Die dritte Dimension war bis jetzt immer fiktionalen Filmen vorbehalten und hat durch Wim Wenders Initiative Einzug in den Dokumentarfilm erhalten, was bei den Tanzszenen zu dem einzigartigen Erlebnis führt, sich mit den Tänzern gemeinsam auf der Bühne zu fühlen. Der Film funktioniert aber auch dank seiner dynamischen Musik, der Farbigkeit der Bilder und dem lebendigen Zusammenschnitt der Interviews und Szenenausschnitte in 2D hervorragend. Ausgezeichnet wurde er als bester Dokumentarfilm 2011 mit dem Deutschen Filmpreis und dem Deutschen Dokumentarfilmpreis, darüber hinaus gab es eine Oscar-Nominierung.

Bereits der Trailer bündelt die Stärken des Films sowie das Wesen des Tanztheaters auf pointierte Weise: Sprache, Tanz und Musik werden intensiv verwoben und bieten einen impulsartigen Einblick in verschiedenste Choreografien und Orte. Fast alle Szenen sind dabei im Außenraum aufgenommen, sodass der Tanz ungewohnt mit Stadtraum, Architektur und Landschaft kontrastiert. Wuppertal und das Ruhrgebiet sind die sichtbare Bühne des

Pina Bausch (1940-2009): Choreografin. Studium an der Folkwang Schule in Essen. Erfinderin des Tanztheaters in Wuppertal. Bekannte Stücke: Café Müller, Sacre du Printemps, Kontakthof, Vollmond. http://www.pina-bausch.de Lebens. Diese Entkontextualisierung der Tänze außerhalb des klassischen Bühnenraums schafft neue Wahrnehmungen und Sichtweisen auf die Bewegungen und die Umgebung. Dieses Vorgehen stellt somit eine ganz produktive Erweiterung des Erfahrungshorizonts dar.

Besonders interessant ist die Auseinandersetzung mit dem Stück Kontakthof. Bereits der Titel löst unzählige Vermutungen über diesen besonderen Ort aus, den es heute eher nur noch virtuell gibt. Das Stück hat über die Jahre nichts an seiner tiefen Wahrheit, detaillierten Beobachtung und präzisen Darstellung verloren,

\footnotetext{
${ }^{3}$ Vgl. Homepage des Films: http://www.pina-film.de.
} 
sondern strotzt von Aktualität, wenn es um das Thema der zwischenmenschlichen Beziehungen geht. Das berühmte Zitat von Pina Bausch „Mich interessiert nicht, wie die Menschen sich bewegen, sondern was sie bewegt." (vgl. Bentivoglio 2007: 2) wird in diesem Klassiker sicht- und fühlbar. Die Verbindung von Gesten, Tanz, Musik, dem Spiel im Raum und mit den Partnern ist mit all den komischen, tragischen und vor allem energetischen Momenten ein Höhepunkt des Tanztheaters.

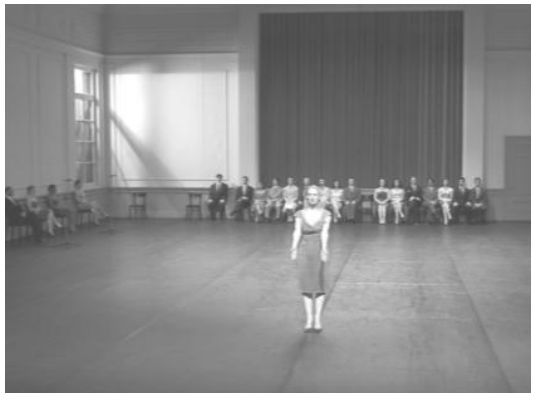

Abb. 5 (44:06): Einzelpräsentation einer Frau

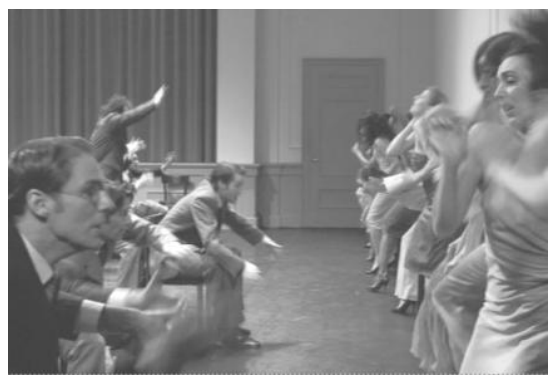

Abb. 7 (49:12): Annäherung der Männer und Frauen

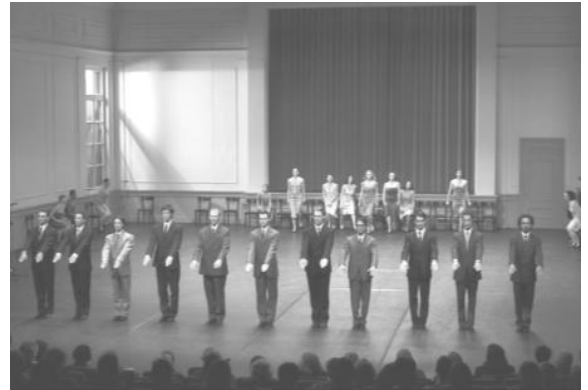

Abb. 6 (47:48): Gruppenpräsentation der Männer

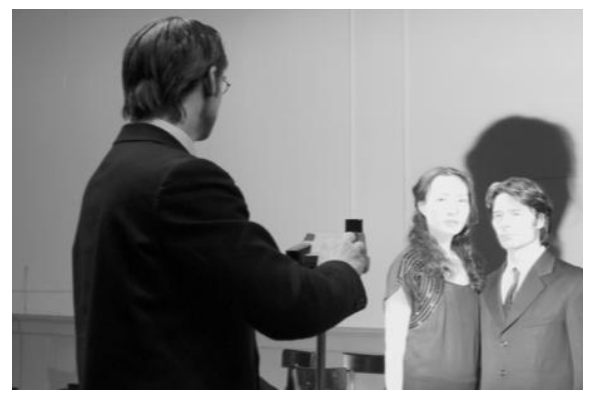

Abb. 8 (55:00): Polaroid mit inszenierter Überblendung im Film

Die Auswahl der 4 Szenenbilder (Abb. 5-8) zeigt unterschiedliche Momente der individuellen Präsentation, Annäherung und Emotionen. In Abb. 8 wird zudem das Spiel mit der Polaroid-Kamera sichtbar, im Film wird der Moment des Auslösens als Freeze mit starker Überblendung festgehalten - ein wunderbares Beispiel für den Umgang mit dokumentarischer Fotografie im Stück. Auch sprachlich ist die Inszenierung äußerst interessant, da intensiv Liebeslieder aus den 20er Jahren zu hören sind wie z.B. „Einmal ist kein Mal“, „Du bist nicht die Erste“. In Zeiten der virtuellen Partnersuche und Identitätskonstruktion ist es ein hochaktuelles und wunderbar zeitloses Stück, welches die zwischenmenschlichen Beziehungen mit aller Komik, tiefstem Ernst, Poesie und Melancholie sicht- und fühlbar macht. 


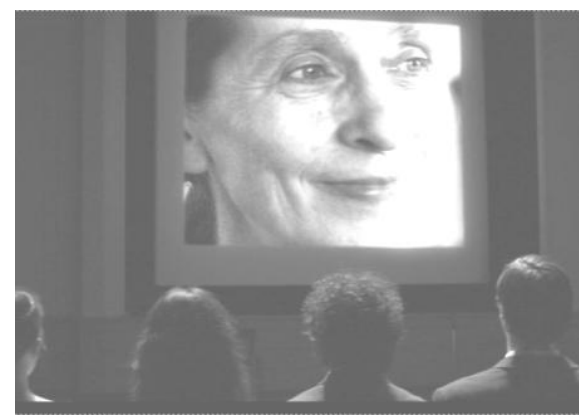

Abb. 9 (1:00:45): Portrait Pina Bausch

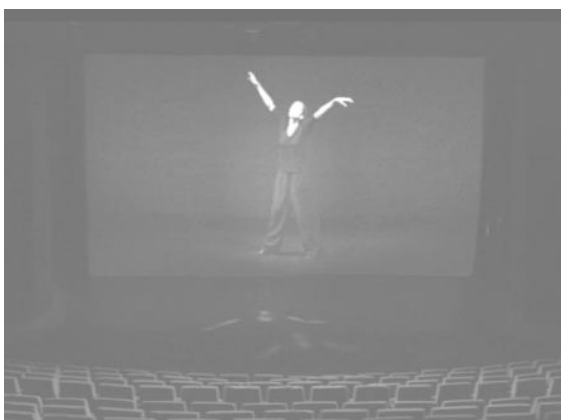

Abb. 10 (1:35:01): Inszenierung der Distanz: Pina Bausch entschwebt

Filmästhetisch ist eine Analyse der dargestellten Hommage und Trauer interessant. Auffallend ist einerseits die meist distanzierte Darstellung von Filmdokumenten und Interviewszenen, bei denen Pina Bausch sichtbar ist wie z.B. in Abb. 9 und 10. Andererseits deutet das tiefe Schwarz auf die Trauer hin. Am Ende des Films sieht man eine atemberaubend sinnlich tanzende Pina Bausch, die wie im „Himmel über Berlin“ zu entschweben scheint und sich ein letztes Mal verneigt. Der gesamte Film ist eine Huldigung dieser einzigartigen Persönlichkeit, eine Liebeserklärung an den Tanz.

\subsection{Sasha Waltz im Neuen Museum Berlin: Dialoge zwischen Architektur, Körper und Raum}

Der Wiederaufbau des im 2. Weltkrieg zerstörten Neuen Museums auf der Museumsinsel durch David Chipperfield ist ein Paradebeispiel für die gelungene Verbindung von alter und neuer Architektur sowie den Umgang mit Geschichte und Erinnerung. Bis in die 1990er Jahre war das Museum eine Kriegsruine im Zentrum von Berlin; anstatt die Gebäudereste abzureißen; integrierte man die noch vorhandenen Teile in den Neubau, sodass die Narben der Geschichte wie Einschusslöcher noch heute sichtbar sind (Abb. 14). 2009 wurde es durch Sasha Waltz tänzerisch eingeweiht. Der Film dokumentiert diese Aufführung mit Publikum. ${ }^{4}$

\footnotetext{
${ }^{4}$ www.sashawaltz.de.
} 


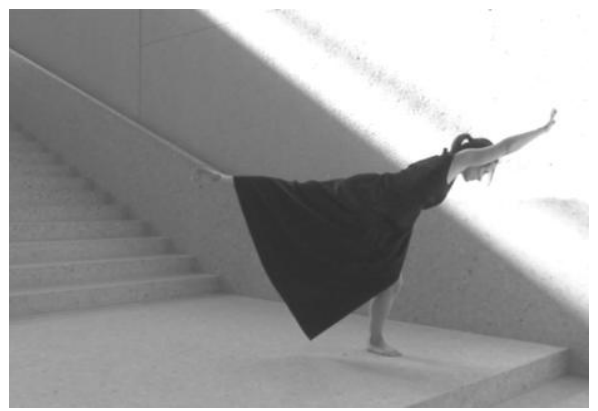

Abb. 11 (03:54)

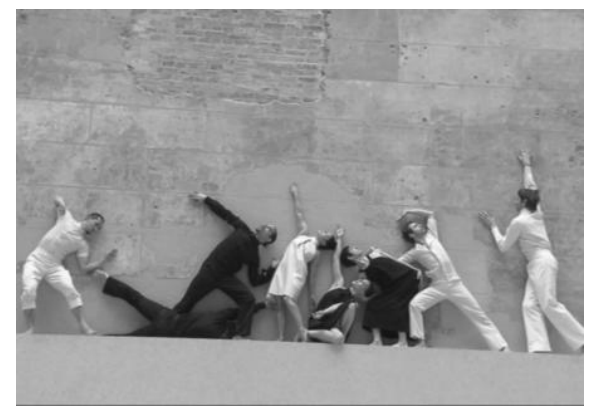

Abb. 12 (05:55)

Nimmt man Pina Bausch als die Gründerin des Tanztheaters wahr, kann man Sasha Waltz in der 2. Generation der Tanztheaterchoreografen verorten. Beide Persönlichkeiten lassen sich somit sehr gut miteinander in Beziehung setzen und thematisieren. Was kann nun das Projekt und der Film „Dialoge 09“ dem Betrachter eröffnen? Vor allem das Bewusstsein für eine kreative Annäherung an Räume, Körper und Architektur durch ein dialogisches Pendeln. Die Wahrnehmung von Körper und Raum wird gesteigert, ästhetisiert, poetisiert, beide Elemente sind gleichwertige Gegenspieler. Dieser interdisziplinäre Ansatz wurde erstmalig 1999 im Jüdischen Museum in Berlin ausprobiert und seitdem zahlreich fortgesetzt. Über die Wichtigkeit des Raums für ihre Arbeit sagt Sasha Waltz: „Ich denke an den Raum, noch bevor ich an Bewegung denke. Der Raum muss für mich die Essenz des Stückes in sich tragen. Er ist Ausgangspunkt, der Träger der Atmosphäre. [...] Räume erzählen immer etwas, und ob sie alt oder neu sind, ist dabei eigentlich egal. Räume bündeln Kräfte, je nachdem wie die Proportionen ausgerichtet sind.“ (Schlangenwirth 2012: 13).

Bereits in den ersten 8 Minuten des Films bekommt man komplexe Einblicke in die Vielfalt der Körper-Raum-Dialoge, die Ästhetik der Inszenierung sowie die Architektur des Museums (Anfang-8:00). Da der Film bis auf

Sasha Waltz: Choreografin und Tänzerin, geboren in 1963 in Karlsruhe, Ausbildung in Amsterdam und New York, seit Anfang der 1990er Jahre in Berlin: Künstlerhaus Bethanien, Sophiensäle, Schaubühne, Radialsystem V. Bekannte Stücke: „Allee der Kosmonauten“, „Körper-Triologie", zahlreiche interdisziplinäre Projekte: Opern (Gesang und Tanz: „Dido \& Aeneas“), Dialoge (Architektur und Tanz: Jüdisches Museum), preisgekrönter Siegerentwurf des Freiheits- und Einheitsdenkmals in Berlin (Realisierung in den kommenden Jahren). einen kurzen Einleitungstext vollständig auf Kommentare verzichtet, stehen die Filmbilder ganz für sich, und der Betrachter kann vollständig in die Körper-RaumSzenarien eintauchen. Als Fokus zum Sehen bieten sich folgende Schwerpunkte an: architektonische Kontraste zwischen alt und neu (vgl. Abb. 13 u. 14), Dialoge zwischen Körper und Raum in der Inszenierung, Überlegungen zum Mehrwert der 
künstlerischen Raumerforschung, Benennung und Kommentierung der unterschiedlichen Atmosphären durch das Zusammenspiel von Körper, Raum, Musik.

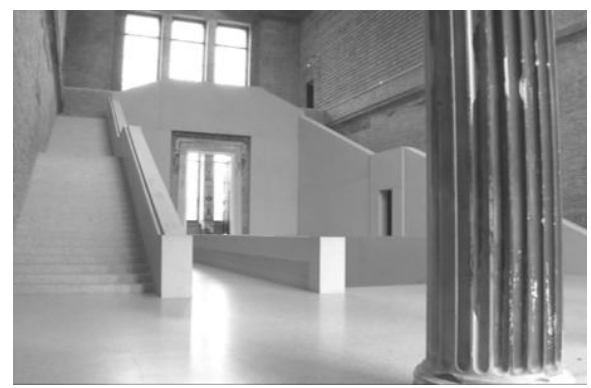

Abb. 13 (00:33): Alt trifft neu - 19. und 21. Jahrhundert

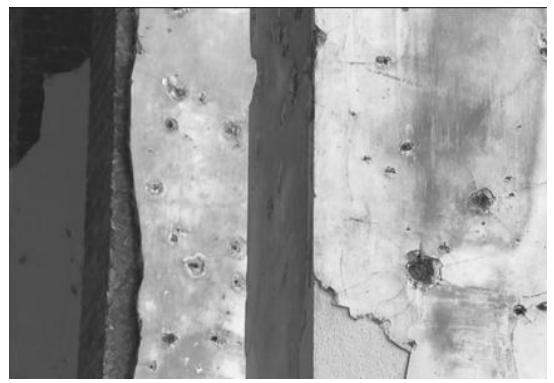

Abb. 14 (01:32): Einschüsse in einer Wand nach Sanierung

Der Film bietet zahlreiche Anknüpfungspunkte und bietet somit ein reiches Netz an Bezügen. Vertiefend kann z.B. die Museumsinsel mit den aktuellen Neuerungsplänen thematisiert werden. Ein weiterer Dokumentarfilm von Brigitte Kramer, „Im Garten der Lüste“, beleuchtet die Entwicklung des Lebens und Werks von Sasha Waltz und gibt zahlreiche Beispiele aus den Stücken. Will man sich intensiver mit dem Neuen Museum beschäftigen, sind die Fotos von Candida Höfer zu empfehlen. Sie hat die ganz leeren Museumsräume in klaren Bildern festgehalten. Ein sehr dankbares Thema ist auch die Planung des Freiheits- und Einheitsdenkmals, welches in Verbindung mit dem Humboldt-Forum in den nächsten Jahren entsteht. Der Denkmalentwurf „Bürger in Bewegung“"von Sasha Waltz wurde ausgewählt und wird realisiert.

\section{$4 \quad$ Fazit und Ausblick}

Wenn Sie Lust bekommen haben, ein paar der Filmempfehlungen zu sehen, zunächst für sich selbst zu entdecken, um eine eigene Begeisterung zu entwickeln und dann sinnvoll in die Unterrichtspraxis zu integrieren, ist mein Wunsch, dem Dokumentarfilm zu mehr Präsenz zu verhelfen, erfüllt. Erst durch die bewusste Integration von Dokumentarfilmen in die Praxis kann von einer umfassenden Filmbildung und visuellen Kompetenz gesprochen werden. Die Relevanz dieser Gattung ergibt sich nicht nur im Kontrast zum Spielfilm, sondern auch durch die allägliche Praxis dokumentarischer Handlungen in der Gesellschaft. Die Schulung des Blicks und die Sensibilisierung der Wahrnehmung ist somit von entscheidender Bedeutung, um als autonomer und kritischer Betrachter filmische Bilder zu analysieren und zu kommentieren. Bildwahrnehmung und sprachliche Verarbeitung sind somit untrennbar. „Sehen ist Wahrnehmen“ wie es Wim Wenders sagt (Wenders 1992: 60). Und Wahrnehmen ist ein aktiver Prozess. 
Künstlerdokumentationen bieten zudem das Potential, in kreative Welten Einblick zu bekommen, dem Befremdlichen mit Offenheit, Unvoreingenommenheit und Neugier zu begegnen und dadurch entschieden die interkulturelle Kompetenz zu trainieren. Darüber hinaus bieten Künstlerdokumentationen die Möglichkeit, die Lebendigkeit der schöpferischen Tätigkeit sichtbar zu machen und zu den Künstlern direkte Zugänge zu bekommen. Für die Praxis und Forschung sind die vertiefende Auseinandersetzung mit CLIL-Themen und die stärkere Berücksichtigung künstlerischer Inhalte im Sprachunterricht aus diesem Grund besonders wünschenswert.

\section{Literatur}

Abraham, Ulf (2012): Filme im Deutschunterricht. Seelze: Kallmeyer.

Badstübner-Kizik, Camilla (2010): Kunst und Musik im deutsch als Fremd- und Zweitsprache-Unterricht. In: Krumm, Hans-Jürgen; Fandrych, Christian et al. (Hrsg.) (2010): Deutsch als Fremd- und Zweitsprache. Ein internationales Handbuch. Berlin: de Gruyter, 1596-1601.

Bentivoglio, Leonetta (2007): Pina Bausch oder Die Kunst über Nelken zu tanzฺen. Frankfurt/Main: Suhrkamp.

Borchardt-Hume, Achim (2012): „Dreh Dich nicht um“: Richters Bilder aus den späten 1980er Jahren. In: Godfrey, Mark; Sirota, Nicholas (Hrsg.): Gerhard Richter Panorama. Ausstellungskatalog. München: Prestel, 163-175.

Felix, Jürgen (2011): Künstlerfilm. In: Koebener, Thomas (Hrsg.): Reclams Sachlexikon des Films. Stuttgart: Reclam, 389-391.

Ganguly, Martin (2011): Filmanalyse Themenheft. Stuttgart: Klett.

Grimm, Nancy (2009): „The Corporation“. Zum reflektiert-kritischen Einsatz von Dokumentarfilmen im Englischunterricht. In: Leitzke-Ungerer, Eva (Hrsg.): Film im Fremdsprachenunterricht. Literarische Stoffe, interkulturelle Ziele, mediale Wirkung. Stuttgart: Ibidem-Verlag, 342-358.

Haataja, Kim (2010): Fach- und sprachintegrierter Unterricht. In: Krumm, HansJürgen; Fandrych, Christian et al. (Hrsg.) (2010): Deutsch als Fremd- und Zweitsprache. Ein internationales Handbuch. Berlin: de Gruyter, 1047-1052.

Heller, Heinz-B. (2011): Dokumentarfilm. In: Koebener, Thomas (Hrsg.): Reclams Sachlexikon des Films. Stuttgart: Reclam, 150-155.

Kamp, Werner; Braun, Michael (2011): Filmperspektiven. Filmanalyse für Schule und Studium. Haan-Gruiten: Europa-Lehrmittel.

Lipp, Thorolf (2012): Spielarten des Dokumentarischen. Marburg: Schüren. 
Niney, François (2012): Die Wirklichkeit des Dokumentarfilms. Marburg: Schüren

Schlangenwirth, Michaela (2012): Nahaufnahme Sasha Walt: Berlin: Alexander Verlag.

Wenders, Wim (1992): The Act of Seeing. Texte und Gespräche. Frankfurt/Main: Verlag der Autoren.

\section{Internetquellen}

http://www.iks-medienarchiv.de/de/archiv.php

http://www.gerhard-richter.com

http://www.gerhard-richter-painting.de/zum_film.php

http://www.pina-bausch.de

http://www.pina-film.de

http://www.sashawaltz.de

\section{Filme und Filmempfehlungen}

Althen, Michael (2009): Auge in Auge. Eine deutsche Filmgeschichte. Goethe Institut.

Ballhaus, Michael (2010): In Berlin. Farbfilm-Verleih.

Bausch, Pina; Weyrich, Pit (2010/1978): Café Müller/Sacre du Printemps. Goethe Institut.

Beat, Cynthia (2009): The invisible frame. Filmgalerie 451.

Belz, Carola (2011): Gerhard Richter Painting. Soda Pictures Ltd. Piffl. DVD.

Bergmann, Ruij (2007): Neo Rauch - Ein deutscher Maler. Zweitausendeins Edition.

Blümer, Bettina (2009): Prinzessinnenbad. Goethe Institut.

Dahrendorf, Sibylle (2012): Knistern der Zeit. Christoph Schlingensief und sein Operndorf in Burkina Faso. Filmgalerie 451.

Fiennes, Sophie (2010): Over your cities grass will grow. A film of the work of Anselm Kiefer. Artificial Eye.

Goertz, Ralph (2011): Candida Höfer. Institut für Kunstdokumentationen und Szenografie.

Grube, Thomas (2005): Rhythm is it. You can change your life in a dance class. Goethe Instiut. 
Kapfer, Marianne (2011): Die Fotografen Bernd und Hilla Becher. Goethe Institut.

Kramer, Brigitte (2008): Garten der Lüste. Die Choreographin Sasha Waltr. Nachtaktivfilm.

Linsel, Anne (2009): Tanzträume - Jugendliche tanz̨en „Kontakthof"von Pina Bausch. 89Minuten

Rohde-Dahl, Gerburg (2010): Ein weites Feld. Das Holocaust Mahnmal in Berlin. Absolut Medien.

Rossacher, Hannes (2004): Woyz̨eck. Georg Büchner. Insæenierung von Thomas Ostermeier. Arte.

Schadt, Thomas (2009): Berlin: Sinfonie der Großstadt. Arthaus.

Schmidt-Garre, Jan (2011): Andreas Gursky. Arthaus.

Siegert, Hubertus (2012): Berlin Babylon. Piffl Medien.

Stutterheim, Kerstin (2009): Bauhaus. Modell und Mythos. Arte.

Veiel, Andreas (2007): Die Spielwütigen. Goethe Institut.

Wagenhofer, Erwin (2009): We feed the world - Essen global. Universum Film.

Waltz, Sasha (2009): Dialoge 09. ZDF/arte. DVD.

Waltz, Sasha (2011): Körper/ S / noBody. Körper Trilogie. Arthaus.

Wenders, Wim (2011): Pina. Tanzt, tanzt sonst sind wir verloren. Ein Film für Pina Bausch. Neue Road Movies. DVD. 



\title{
Aktuelle Kurzfilme im DaF-Unterricht: „Feierlich reist" und „Fraktur“"
}

\author{
Benjamin Schmäling
}

Während der Kurzfilm für die Verwendung im Unterricht lange Zeit nur wenig Beachtung fand (vgl. Abraham 2013: 4), gab es in den letzten Jahren einige Versuche, ihn etwas stärker ins Zentrum des didaktischen Interesses zu rücken (vgl. z.B. Welke 2007; Rössler 2009; Abraham 2013) - in Anbetracht seines unterrichtspraktischen Potenzials sowie der momentan erstaunlich hohen Zahl an deutschen Kurzfilmproduktionen ${ }^{1}$ eine erfreuliche Entwicklung. Vor diesem Hintergrund versteht sich der vorliegende Artikel als ein Beitrag zur stärkeren Etablierung dieses Formats im Sprachunterricht sowie als Versuch, zwei für Unterrichtszwecke bislang weniger beachtete aktuelle Produktionen in den Fokus zu rücken. Nach einer kurzen Einführung in das Wesen des Kurzfilms, die Kurzfilmanthologie „Deutschland 09“ und die Verwendung von Kurzfilmen im DaF-Unterricht, sollen die beiden „Deutschland 09 “-Beiträge „Feierlich reist“ von Tom Tykwer und „Fraktur" von Hans Steinbichler unter inhaltlichen und didaktischen Gesichtspunkten analysiert werden, um so einige Anregungen für ihre Verwendung im Unterricht zu geben.

${ }^{1}$ Die Zahl der deutschen Kurzfilmproduktionen belief sich 2012 auf rund 2.500 (vgl. AG Kurzfilm 2013: 8), gegenüber etwa 800 im Jahr 1995 (vgl. AG Kurzfilm 2006: 7). 


\section{Kurzfilme: Kürze und Innovation}

Ebenso einfach wie stichhaltig lässt sich der Kurzfilm definieren als „[e]in Film, dessen Länge relativ kurz ist, d.h. jeder Film, der drei Filmrollen bzw. eine Dauer von 30 Minuten nicht übersteigt" (Behrendt 2011: 396). Da in den Anfangsjahren des Kinos zunächst alle Filme technisch bedingt Kurzfilme waren, hat sich der Begriff erst nach 1915 mit dem Aufkommen der ersten Langfilme etabliert. Er beschränkt sich nicht auf bestimmte Gattungen, sondern umfasst Spielfilme aller Genres ebenso wie etwa Dokumentar- und Animationsfilme (vgl. Wulff 2012). Seine „äußere Kürze“ (Heinrich 1997), die sich auf die reduzierte Erzählzeit bezieht, wirkt sich zwangsläufig auf die narrative und filmästhetische Gestaltung des Films und damit auf seine ,innere Kürze“ aus, welche sich etwa in einer Reduktion der Handlung, des Figureninventars oder der Schauplätze, in einer narrativen und gestalterischen Verdichtung sowie in einem abrupten Anfang und offenen Schluss manifestiert. Das Thema des Films sowie der Eindruck, den dieser aufgrund seiner metaphorischen, suggestiven Gestaltung beim Zuschauer hinterlässt, sind somit oft wichtiger als die Handlung selbst. Anders als Langfilme, die sich in den meisten Fällen einem bestimmten Genre zuordnen lassen, fließen in Kurzfilmen nicht selten Elemente aus verschiedenen Genres zusammen, was ihnen einen gewissen Hybridcharakter verleiht (vgl. Rössler 2009: 309ff.). Darüber hinaus bieten sie dank ihrer Kürze und des damit verbundenen geringen finanziellen Aufwandes bei der Produktion vor allem jungen Regisseuren ein großes $\mathrm{Ma} ß$ an Gestaltungsfreiheit, und stellen damit eine wichtige Grundlage für filmästhetische und inhaltliche Innovationen dar, die erst danach auch in Langfilmen zur Anwendung kommen (vgl. AG-Kurzfilm 2006: 5).

Während Kurzfilme im Fernsehen eher ein Schattendasein fristen (vgl. AGKurzfilm 2006: 59), bieten zahlreiche landesweite und internationale Festivals den Filmemachern die Möglichkeit, ihre Produktionen einem breiteren Publikum bekannt zu machen, und sich mit Kollegen, Verleihern und Produzenten auszutauschen. Allein in Deutschland gibt es derzeit etwa 90 Kurzfilmfestivals, zu deren bedeutendsten die Internationalen Kurzfilmtage Oberhausen, das Internationale KurzFilmFestival Hamburg, das Filmfest Dresden sowie das Interfilm Berlin gehören (vgl. AG-Kurzfilm 2006: 65). International ist beispielsweise das Kurzfilmfestival in Clermont-Ferrand von herausgehobener Bedeutung, bei dem Deutschland im Jahr 2013 mit 417 Einreichungen vertreten war, und damit Platz vier hinter Frankreich, den USA und England belegte (vgl. Festival International du Court Métrage 2013).

\section{Dreizehn kurze Filme zur Lage der Nation}

Für den Unterricht bietet sich aufgrund ihrer inhaltlichen und ästhetischen Vielfalt sowie der zahlreichen Beiträge von namhaften deutschsprachigen Regisseuren unter anderem die Kurzfilmsammlung „Deutschland 09. 13 kurze Filme zur Lage 
der Nation“ an. Sie ist im Jahr 2009 auf Initiative von Tom Tykwer und dem NDR hin entstanden und mittlerweile auch über den Filmdienst des Goethe-Instituts verfügbar. In Anlehnung an den Omnibusfilm „Deutschland im Herbst“ von 1978, in dem sich elf Regisseure des Neuen Deutschen Films mit jeweils einem Kurzfilmbeitrag zur Lage der Bundesrepublik im Herbst 1977 äußerten, war der Ausgangspunkt die Frage, wie sich die politische und gesellschaftliche Situation Deutschlands im Jahr 2009 darstellt, und wie sie sich filmisch festhalten lässt. Anders als bei „Deutschland im Herbst“ verzichtete man jedoch auf eine gemeinsame Botschaft oder Ästhetik, sondern gewährte den beteiligten Regisseuren ein Maximum an inhaltlicher und gestalterischer Freiheit, um ein möglichst breites Kaleidoskop individueller Sichtweisen zu schaffen (vgl. Making of Deutschland 09). Als einziges die Filme in der Rückschau verbindendes Moment könnte man festhalten, „[d]ass Deutschland ein bisschen als Patient gesehen wird“ (Tykwer, Making of Deutschland 09), dessen Symptome und Genesungsmöglichkeiten von den Regisseuren auf vielfältige Art und Weise ausgelotet werden. So beleuchten etwa Hans Weingartner und Fatih Akin in ihren Beiträgen jeweils exemplarisch die Beugung rechtsstaatlicher Prinzipien vor dem Hintergrund des internationalen Terrorismus. Sylke Enders widmet sich den sozialen Disparitäten und dem Thema Vorurteile, während Angela Schanelec mit Bezug auf einen Text von Wolf Dieter Brinkmann die Ästhetik der alltäglichen Wiederholung thematisiert. ${ }^{2}$

\section{3 „In der Kürze...“ - Kurzfilme im DaF-Unterricht}

Ohne das angedeutete Sprichwort zu Ende führen zu wollen, muss konstatiert werden, dass gerade in der Kürze das große didaktische Potenzial dieser Filme liegt. Anders als Langfilme, deren Verwendung im Unterricht aus Zeitgründen oftmals nur in Ausschnitten möglich ist, können Kurzfilme dank ihrer ,,äußeren Kürze" komplett und sogar mehrmals gesichtet werden, und so ihre Wirkung auf den Rezipienten voll entfalten. Ihre „innere Kürze“ wiederum fördert die aktive gedankliche Mitarbeit und Imaginationskraft der Lerner und bietet aufgrund der rekurrenten Leerstellen im Handlungsverlauf zahlreiche Möglichkeiten zur kreativen Weiterarbeit nach der Sichtung (vgl. Rössler 2009: 313f.). Ganz im Sinne der Rezeptionsästhetik regen ihre Mehrdeutigkeit und Vielschichtigkeit die produktive Rezeption und die Motivation zu einer vertiefenden Auseinandersetzung mit dem Medium auf sprachlicher, inhaltlicher und filmästhetischer Ebene an (vgl. Welke 2007: 22). Hierzu leistet auch ihre innovative Gestaltung jenseits konventioneller Sehgewohnheiten einen wichtigen Beitrag, ohne jedoch den weniger geübten $\mathrm{Zu}$ schauer mit einer zu großen Zahl an filmischen Mitteln zu überfordern (vgl. Rössler 2009: 313). Im Hinblick auf ihre Bedeutungsoffenheit und das damit verbundene didaktische Potenzial sollte bei der Verwendung von Kurzfilmen im Unterricht

\footnotetext{
2 Detaillierte Informationen zu allen Beiträgen und den beteiligten Regisseuren finden sich auf der Webseite des Films: www.deutschland09-derfilm.de.
} 
ganz besonders darauf geachtet werden, das Deutungsspektrum nicht im Vorfeld einzuschränken oder die Interpretation des Films in eine bestimmte Richtung zu lenken, sondern ein Höchstmaß an Offenheit walten zu lassen (Abraham 2013: 7).

Welche konkreten Formen eine Verwendung von Kurzfilmen im DaF-Unterricht annehmen kann, soll im Folgenden anhand der Deutschland 09-Beiträge von Tom Tykwer und Hans Steinbichler exemplarisch gezeigt werden, die sich beide erfahrungsgemäß besonders gut für den DaF-Unterricht eignen. Die Vorschläge stützen sich auf mehrere Unterrichtseinheiten, die in den letzten beiden Jahren im Rahmen verschiedener Sprachkurse mit Studierenden unterschiedlicher Disziplinen an der Universität Lille 3 erprobt wurden.

\section{Tom Tykwer: „Feierlich reist“}

\subsection{Handlung und Darstellung}

Als Manager eines internationalen Modeunternehmens reist der Protagonist Jürgen Feierlich (Benno Fürmann) innerhalb kürzester Zeit in verschiedene Metropolen der Welt. Der Ablauf seines Arbeitstages, den der Film mit zunehmendem Erzähltempo schlaglichtartig dokumentiert, ist immer gleich: Flug, Ankunft am Flughafen, Fahrt ins Hotel, Meeting, Kaffee bei Starbucks, Übernachtung im Hotel ganz unabhängig davon, ob er sich in Paris, Kairo oder Hongkong befindet. Auch die Umwelt, in der er sich bewegt, ist weitgehend homogen, von den sehr reduzierten und schematisierten Dialogen bis hin zu den omnipräsenten globalen Marken. In dieser Gleichförmigkeit folgt auch der Protagonist den immer

Tom Tykwer (geb. 1965 in Wuppertal) gilt spätestens seit „Lola rennt“ (1998) als einer der wichtigsten deutschen Regisseure. Neben deutschen (z.B. „Die tödliche Maria“ (1993), „Winterschläfer“ (1997), „Drei““ (2010)) auch internationale Produktionen (z.B. „Das Parfum“ (2006); „The International“" (2009), „Cloud Atlas“ (2012)) und Tätigkeit als Produzent (www.filmportal.de). gleichen, ritualisierten Handlungsschemata, vom Zuziehen der Vorhänge im Hotelzimmer bis hin zur Bestellung des Kaffees. Gleichzeitig erlebt er mit jedem neuen Ortswechsel eine partielle Verschlechterung seines Zustandes: Er wird zusehends müder, unaufmerksamer, unausgeglichener, und scheint sich die Frage nach Sinn und Inhalt seines Lebens zu stellen. Ob die Rückkehr nach Hause in der letzten Sequenz dieser Entwicklung Einhalt gebieten kann, bleibt offen.

Diese inhaltlichen Aspekte finden in der filmischen Gestaltung auf vielfache Weise ihren Niederschlag. So wird durch Nah- und Großaufnahmen immer wieder die Relevanz moderner Kommunikationsmittel und technischer Geräte (Smartphone, Laptop, Ticketlesegerät) für den Menschen und damit die Automatisierung 
seines Alltags besonders hervorgehoben (1). ${ }^{3}$ Auf die gleiche Weise werden internationale Marken (z.B. San Pellegrino, Starbucks) als Symbole eines globalen Kapitalismus inszeniert (2), die in Kombination mit den das Straßenbild dominierenden Marken- und Firmenlogos die ,ästhetische, erfahrungsraumhafte Gleichschaltung der Welt" (Tykwer, Interview) illustrieren. Der Protagonist hingegen wird oft in der Totalen und Halbtotalen gezeigt, die ihn in anonymen, sterilen und standardisierten Büro- und Stadträumen einsam und verloren erscheinen lassen (3).

Die Verschlechterung seines Gemütszustandes und in Verbindung damit auch der Wunsch, der Gleichförmigkeit seines Alltags und seiner Umgebung zu entkommen, äußern sich filmtechnisch in einer Erhöhung der Schnittfrequenz und einer Verkürzung der Sequenzdauer mit jeder Reise. Die damit verbundene Beschleunigung alltäglicher Abläufe gipfelt schließlich symbolisch zu Beginn der letzten Reise in der Überlagerung der Stimmen sowie in der Großaufnahme, die den in den Tomatensaft fließenden Kaffee zeigt (5). Durch den bisweilen stattfindenden Wechsel zwischen der Perspektive des Protagonisten (interne Fokalisierung) und seinem von außen beobachteten Gesichtsausdruck wird die Veränderung seiner inneren Befindlichkeit für den Zuschauer wahrnehmbar gemacht (4).

Bei alldem versteht sich der Film jedoch nicht als eine allgemeine Globalisierungskritik, sondern vielmehr als eine exemplarische Darstellung der individuellinternalisierten Globalisierungserfahrung, bei der sich die kulturellen Unterschiede in der Wahrnehmung des Individuums nivellieren: ,[U]nser Hauptdarsteller könnte in Kairo oder Hongkong jederzeit einfach um die Ecke gehen und eine völlig neue Erfahrung machen. Aber er hat schon längst Ängste, von denen er nicht weiß, dass sie ihn dominieren: nämlich vor einer Situation zu stehen, die er nicht kennt und in der ihn vielleicht tatsächlich eine gewisse Handlungsunfähigkeit überkommt" (Tykwer, Interview).

\subsection{Verwendung im Unterricht}

\section{Zielgruppe und Lernzielbestimmung}

Der im Folgenden skizzierte Unterrichtsentwurf ist auf ca. vier Zeitstunden angelegt und richtet sich an Lerner aller Altersstufen, deren Niveau sich zwischen A2 und B1 des Gemeinsamen Europäischen Referenzrahmens bewegt. Bei entsprechender Modifikation der Aufgabenstellung bzw. des Erwartungshorizontes ist es jedoch durchaus möglich, den Film bereits ab dem Niveau A1 einzusetzen, da er fast gänzlich ohne Dialoge auskommt bzw. die wenigen Dialoge, die stattfinden, ebenso fragmentarisch wie selbsterklärend sind. Daher liegen die Lernziele der Unterrichtsskizze auch hauptsächlich im Bereich der beiden produktiven Kompetenzen. Darüber hinaus bietet „Feierlich reist“ die Möglichkeit, auf nicht allzu ho-

\footnotetext{
${ }^{3}$ Die Ziffern in Klammern beziehen sich auf die Screenshots des im Anhang 1 abgedruckten Arbeitsblatts.
} 
hem sprachlichem und technischem Niveau einige filmische Gestaltungsmittel kennenzulernen, und bei entsprechender Ausstattung in einer eigenen kleinen Produktion umzusetzen. Ferner geben die individuellen und ggf. auch kulturspezifischen Globalisierungserfahrungen der Teilnehmer Anlass zum interkulturellen Lernen.

\section{Ablauf des Unterrichtsentwurfs}

Auch wenn der Film dank seines leichten sprachlichen wie inhaltlichen Zugangs ohne weiteres selbst als Einstieg in eine Unterrichtsstunde gezeigt werden kann, sollen hier im Interesse der Teilnehmeraktivierung zunächst Mutmaßungen zum Inhalt geäußert werden. Als Impulsgeber fungieren dabei einige an die Wand projizierte Screenshots (Abb. 1), die vier für Feierlichs Arbeitsalltag typische Situationen zeigen, und im weiteren Verlauf der Unterrichtseinheit wieder aufgegriffen werden können. ${ }^{4}$

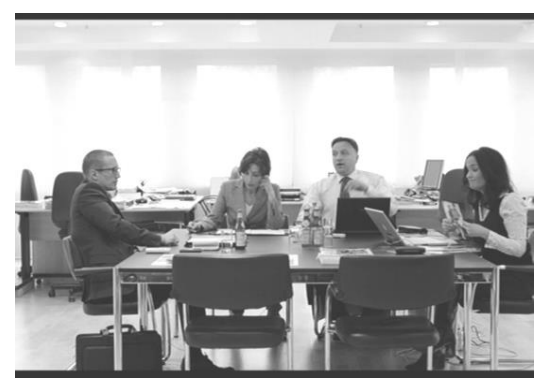

(1:36:19)

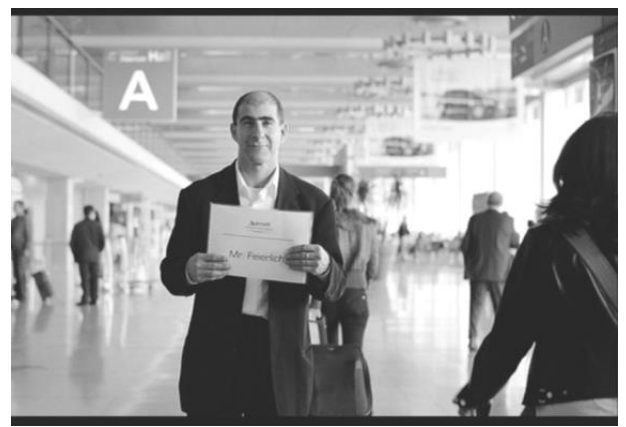

(1:37:00)

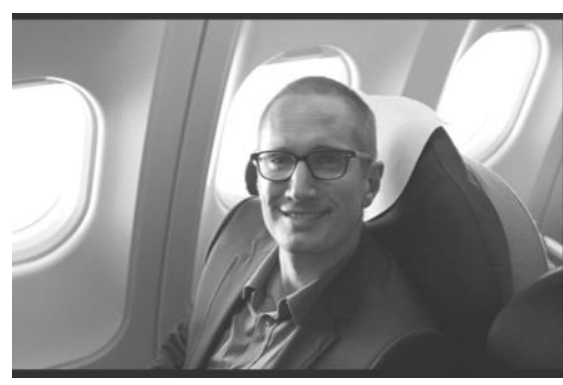

$(1: 36: 52)$

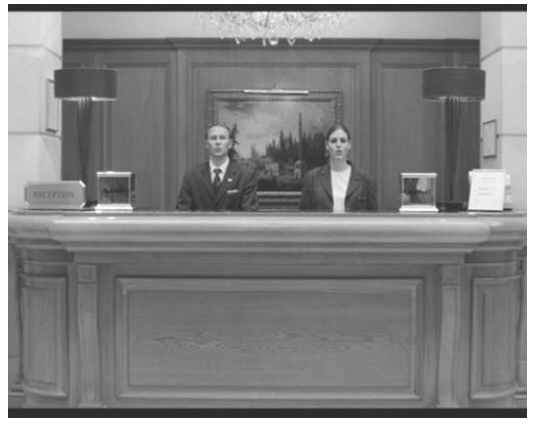

$(1: 37: 12)$

Abb. 1: Vier Screenshots aus „Feierlich reist“

\footnotetext{
${ }^{4}$ Die Möglichkeit, Screenshots zu erstellen, bieten mittlerweile zahlreiche DVD-Leseprogramme. Die hier und weiter unten abgebildeten wurden mit dem kostenlos herunterladbaren VLC Mediaplayer erstellt und stammen allesamt von der DVD „Deutschland 09. 13 kurze Filme zur Lage der Nation“.
} 
Im Anschluss daran kann der Film in voller Länge und ohne Unterbrechung gesichtet werden. Um eine allzu passive Rezeptionshaltung zu vermeiden, ist es alternativ auch denkbar, ihn nach der ersten Geschäftsreise nach Paris (1:38:34) kurz anzuhalten und die Teilnehmer über den Fortgang der Handlung mutmaßen zu lassen. Der Überraschungseffekt stellt sich meist dann ein, wenn sie feststellen, dass es im Grunde genommen keine weitere Handlung gibt, sondern dass jede Reise identisch abläuft.

Nach der Sichtung sollten in einem ersten Schritt die zentralen Themen Globalisierung, Uniformisierung der Welt und Beschleunigung des (Arbeits-)Alltags, bei gleichzeitiger zunehmender Verlorenheit und Vereinsamung des Subjekts, in einem Unterrichtsgespräch herausgearbeitet werden. So bietet der Film auf der Inhaltsebene schon nach der ersten Sichtung zahlreiche Redeanlässe, in denen die Kursteilnehmer ihre Meinung und ihre persönlichen Erfahrungen mit diesen Themen diskutieren oder schriftlich festhalten können. Mögliche Leitfragen für ein Partneroder Gruppengespräch können lauten:

- Was sind die zentralen Themen des Films?

- Was bleibt immer gleich, was verändert sich mit jeder Reise?

- Was erfahren Sie über den Protagonisten Jürgen Feierlich? Wie erlebt er die Globalisierung?

- Wie erleben Sie selbst die Globalisierung, und wie wirkt sie sich auf Ihren Alltag aus (Studium, Familie, Konsumverhalten etc.)?

Nachdem auf diese Weise zentrale inhaltliche Aspekte zur Sprache gekommen sind, kann man sich in einem zweiten Schritt dem typischen Tagesablauf Jürgen Feierlichs widmen. Auf sprachlicher Ebene bietet das die Möglichkeit, einige alltagspraktische Kommunikationssituationen zu trainieren, indem man die Teilnehmer bittet, in Partner- oder Gruppenarbeit die im Film lediglich angedeuteten Dialoge im Flugzeug, am Flughafen, im Hotel oder im Café mit Inhalt zu füllen, und anschließend die selbst entworfenen Dialoge szenisch darzustellen. Hierbei können wiederum die oben abgebildeten Screenshots als Impulsgeber fungieren. Um daneben auch die schriftliche Produktion zu berücksichtigen, erstellen die Teilnehmer anschließend ein kurzes Porträt des Protagonisten oder einen Tagebucheintrag aus seiner Perspektive.

Während bislang der Schwerpunkt auf Sprache und Inhalt lag, bietet es sich an, im weiteren Verlauf die filmästhetischen Charakteristika etwas genauer zu analysieren, und im Interesse einer analytischen Sensibilisierung der Lerner auch einige Begrifflichkeiten einzuführen (vgl. 4.1 und Anhang 1). Zu diesem Zweck sollte der Film ein zweites Mal mit einem entsprechenden Beobachtungsauftrag gesichtet werden, bevor anhand des im Anhang abgedruckten Arbeitsblattes einige ausgewählte Phänomene etwas eingehender besprochen werden können. Diese Analyse der Darstellung wiederum kann in Verbindung mit den sprachlichen und inhaltlichen Aktivitäten die Grundlage für das Verfassen einer Filmkritik darstellen. 
Wenn es die technische Ausstattung und die Zeit erlauben, ist es für einen handlungs- und produktionsorientierten Unterricht und im Hinblick auf die Lernermotivation sinnvoll, die Kursteilnehmer selbst einen kleinen Film oder eine Filmszene produzieren zu lassen, angefangen mit einem Brainstorming zu Figuren und Inhalt über das Verfassen eines Drehbuchs und eines Storyboards bis hin zum Dreh des eigenen Kurzfilms.

Eine Frage, die regelmäßig zu fruchtbaren Diskussionen führt, ist die Interpretation des Endes von „Feierlich reist“. Kehrt er zu seiner Frau zurück, und wird damit die Partnerschaft oder das Familienleben zu einem positiv gesetzten Gegenpol zu einer immer hektischer und uniformer werdenden Welt? Oder ist die letzte Sequenz lediglich ein Traum des Protagonisten, der eine Flucht aus dem als negativ gesetzten beruflichen Alltag als Utopie entlarvt? Fragen und Anlässe zur produktiv-kreativen Weiterarbeit ausgehend von solchen und ähnlichen Fragen rund um den Film gibt es zur Genüge.

\section{Hans Steinbichler: „Fraktur“}

\subsection{Vorbemerkung: Chancen und Risiken bei der Verwendung im Unterricht}

Während man „Feierlich reist“ - mit entsprechend angepasster Aufgabenstellung - auf jeder Niveaustufe und in nahezu allen Lernkontexten verwenden kann, ist bei Hans Steinbichlers Satire „Fraktur“ in dieser Hinsicht etwas Vorsicht geboten. Dies ist zum einen der Tatsache geschuldet, dass sein Protagonist mit einer deutlichen dialektalen Einfärbung spricht, sowie der Befürchtung, dass das ebenso überraschende wie brutale Ende des Films auf manche Lerner etwas schockierend wirken kann. Dass sich der Film in gewissen Lernergruppen und Kontexten erfahrungsgemäß dennoch sehr gut für eine Verwendung im

Hans Steinbichler (geb. 1966 in Solothurn), der auch regelmäßig fürs Fernsehen dreht (z.B. „Polizeiruf 110“), hat sich insbesondere durch die Kinoproduktionen „Hierankl“ (2003) und „Winterreise“ (2006) einen Namen gemacht.

(www.filmportal.de)

Unterricht eignet, liegt an dem erheblichen Diskussionspotenzial, das er auf inhaltlicher Ebene bietet, sowie an den zahlreichen historisch-kulturellen Anspielungen, die eine gute Grundlage für Reflexionen über allgemeine und deutschlandspezifische Klischees liefern. 


\subsection{Inhalt und zentrale Themen}

Nach seiner Rückkehr von einer Reise muss der Protagonist Riesch Beintl ${ }^{5}$ (Josef Bierbichler), Logistikunternehmer aus Berchtesgaden-Obersalzberg, zu seiner groBen Empörung feststellen, dass die Frankfurter Allgemeine Zeitung ihr Layout geändert hat - ein Foto auf der Titelseite, Wegfall der Linien zwischen den Spalten und Austausch der Schrifttype „Fette Gotisch“ über den Kommentaren gegen eine Times-Schrift. ${ }^{6}$ Da er die Herausgeber der Zeitung telefonisch nicht erreicht, beschließt Beintl kurzerhand, persönlich nach Frankfurt zu fahren, um sich über diese „Schande“ zu beschweren. Vor Ort lässt er die zahllosen, von seinen Mitarbeitern antransportierten Exemplare der FAZ anzünden, bevor er die gesamte Chefredaktion während einer Sitzung niederschießt.

Neben zentralen Themen wie Zorn, Selbstüberhebung und Rache sind insbesondere die im Film verhandelten Deutschlandbilder von großem Interesse für eine Auseinandersetzung im Unterricht. So lassen sich zwei gegenläufige Tendenzen feststellen, die einerseits an Riesch Beintl, andererseits an der modernisierten FAZ exemplifiziert werden. Während sich der konservative Beintl um die Rettung des deutschen Kulturguts ${ }^{7}$ bemüht, steht (in der Logik des Films: ausgerechnet) die FAZ für ein modernes und fortschrittliches Deutschland, das mit der Zeit bzw. mit dem Zeitgeist geht. Strukturell manifestiert sich dieser Gegensatz in den zwei semiotisch oppositionell gesetzten topographischen Räumen „Stadt“ und „Land“: Während Frankfurt als Sitz der FAZ und Finanzmetropole mit seinen Wolkenkratzern ein modernes und international offenes Deutschland repräsentiert, wird der Herkunftsraum des Protagonisten schon im Establishing Shot (1:00:23), der das Topos des „deutschen Waldes“ aktualisiert, als ein Hort des „Konservativen“, „Mystischen“, „Tiefgründigen“, „Romantischen“ semantisiert, in dem auch Emotionen wie Wut und Rachegelüste, sowie Brutalität und Wahnsinn gedeihen, die Beintl verkörpert. Ihren ultimativen Ausdruck finden sie auf sprachlichtechnischer Ebene schließlich in dem als Zwischentitel mit Voice Over eingeblendeten Sonett Nr. 62 von Shakespeare in einer freien Übersetzung des Regisseurs (1:11:39). ${ }^{8}$ Diese topologische Opposition wird durch Beintls Anweisung, die Fahrer könnten wieder ,zurück in die Heimat“ (1:09:39) fahren, noch einmal besonders hervorgehoben. Dass in dieser Aussage als Heimat nicht Deutschland, sondern der bayerische Herkunftsraum des Protagonisten gesetzt wird, verweist zudem auf ein in Deutschland stärker regional ausgeprägtes Identifikationsmoment.

\footnotetext{
${ }^{5}$ Der Name Riesch Beintl kann als Anagramm des Nachnamens des Regisseurs gelesen werden.

${ }^{6}$ Diese Layoutänderung der FAZ, durchgeführt am 4. Oktober 2007, wurde (wie auch im Film erwähnt) von der großen Mehrheit ihrer Leser begrüßt (vgl. FAZ.net vom 4.10.2007).

7 „Der Verzicht auf die Frakturschrift „Fette Gotisch“ über den Kommentaren ist der brutalstmögliche Angriff auf deutsche Kultur! Meine Damen und Herren, wer die Fraktur nicht lesen kann, der kann das deutsche Wesen nicht lesen“, so Beintl in seiner Tirade am Ende des Films (1:10:47 bis 1:11:13).

8 „So anmutig wie mein Gesicht ist kein anderes, so wahr ist keine Gestalt. Es gibt kein Wahres, das so gilt. Und für mich selbst bestimm ich meinen Wert. Wie ich in allem Wert ganz alle anderen überrage."
} 
Darüber hinaus wird Beintl durch Anspielungen auf die nationalsozialistische Vergangenheit Deutschlands in die Nähe Adolf Hitlers gerückt, der am Obersalzberg eine Residenz hatte (wie Beintl sein Anwesen), der auf besondere Weise mit der deutschen Autobahn in Verbindung gebracht wird (wie Beintl, vgl. 1:08:19), und der 1933 die Verbrennung von Büchern veranlasst hat, ebenso wie Beintl die Zeitungen hat anzünden lassen (vgl. 1:09:35).

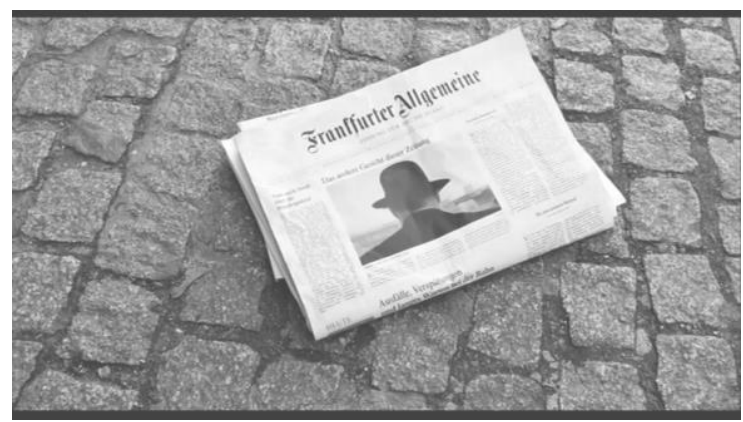

\section{Abb. 2: Schlussbild aus „Fraktur“ (1:12:30)}

Dabei ging es dem Regisseur insbesondere darum, „einen ,deutschen Zug“, den es immer noch gibt, auf eine extreme Art zu beschreiben“ (Steinbichler, Interview), und auf ebenso amüsante wie schockierende Weise zu zeigen, worin Konservatismus, Ressentiments und Selbstgerechtigkeit im schlimmsten Falle gipfeln können. „[D]ie Leute sollen lachen, aber das Lachen darf ihnen auch im Hals stecken bleiben bei diesem Film“ (Steinbichler, Interview), um eine gewisse Anfälligkeit der deutschen Gesellschaft für „urdeutsche Tugenden“ (Steinbichler) vor Augen geführt zu bekommen. Das Schlussbild (vgl. Abb. 2) hingegen legt nahe, dass das von Beintl angerichtete Blutbad wirkungslos war und dass das moderne Deutschland letztlich obsiegt.

\subsection{Verwendung im Unterricht}

Anders als „Feierlich reist“ erfordert „Fraktur“ eine sprachliche und ggf. auch inhaltliche Vorentlastung, so beispielsweise die Klärung einiger dialektaler Eigenheiten oder zentraler, in den Dialogen vorkommender Lexeme. ${ }^{9}$ Auf inhaltlicher Ebene kann der Einstieg in die Arbeit mit dem Film beispielsweise durch Assoziationen zum Titel oder zu den im Anhang abgebildeten Screenshots erfolgen, woraufhin die Kursteilnehmer einige, im Idealfall durch Anschauungsmaterial unterstützte, Informationen zur Layoutänderung der FAZ erhalten.

\footnotetext{
${ }^{9}$ Eine Transkription der Dialoge kann auf Wunsch vom Autor zur Verfügung gestellt werden.
} 
Die daran anschließende Sichtung kann, je nach Niveau der Kursteilnehmer, am Stück erfolgen oder in Etappen, um die einzelnen Sequenzen besser nachvollziehen zu können und (eventuell mithilfe des Transkripts) das Verständnis der Dialoge zu sichern. Alternativ hierzu kann der Film zunächst auch gänzlich ohne Ton gezeigt werden, so dass die Teilnehmer die Gelegenheit haben, zu ausgewählten Szenen selbst die Tonspur zu erarbeiten und diese bei einer zweiten stummen Sichtung zu ,synchronisieren“.

Während sich bei einem hohen Sprachniveau der Teilnehmer bei einer weiteren Sichtung eine Aufgabe zum Hörverstehen anbietet, liegt der Schwerpunkt auch bei diesem Film im Bereich der produktiven Kompetenzen. So ist es beispielsweise denkbar, zur Verstehenssicherung zunächst den Handlungsverlauf mit Hilfe der Screenshots (Anhang 2) mündlich nachzuvollziehen. Anschließend kann in Gruppen eine alternative Reaktion Beintls erarbeitet werden, etwa in Form eines Gesprächs mit seiner Haushälterin, mit dem Chefredakteur oder mit einem Familienmitglied. Auch die Redaktionssitzung könnte von der Lernergruppe neu inszeniert werden. So könnten die Teilnehmer in die Rolle der anwesenden Redakteure schlüpfen und versuchen, mit Beintl zu diskutieren, statt nur (wie im Film) auf ihre Exekution zu warten. Das szenische Nachstellen einer Gerichtsverhandlung, in der Beintl für seine Bluttat bestraft wird, ist eine weitere Möglichkeit, die Drastik von Inhalt und Darstellung zu entschärfen. Eine Gruppendiskussion über die im Film verhandelten Deutschlandbilder und das Deutschlandbild der Teilnehmer kann darüber hinaus zur Reflexion über Selbst- und Fremdbilder sowie deren mediale Inszenierung anregen und so zum interkulturellen Lernen beitragen. Für eine abschließende, sprachlich und inhaltlich vertiefende Auseinandersetzung mit dem Film bieten sich zahlreiche schriftlich-produktive Aufgaben an, wie das Verfassen einer Filmkritik, eines Leserbriefs aus der Perspektive des Protagonisten oder einer Fortsetzung des Drehbuchs.

\section{$6 \quad$ Fazit}

Während das Medium Film in der sprachdidaktischen Forschung kein Novum mehr darstellt, ist es in der Unterrichtspraxis nach wie vor oftmals unterrepräsentiert (vgl. Leitzke-Ungerer 2009: 11). Dabei bieten, wie gezeigt wurde, gerade Kurzfilme aufgrund ihrer zahlreichen Einsatzmöglichkeiten zur Schulung der sprachlichen Fertigkeiten und der Medienkompetenz in Kombination mit ihrer zeiteffizienten Nutzung hierfür einen idealen Einstieg - für Lerner wie für Unterrichtende. Es wäre daher schön, wenn diese exemplarischen Anregungen einen kleinen Beitrag dazu leisten können, das Medium Film im Allgemeinen und den Kurzfilm im Besonderen noch stärker als einen integralen, eigenwertigen Bestandteil des Unterrichts zu etablieren. Ausgangsmaterial ist mit Blick auf die aktuelle Zahl deutscher Kurzfilmproduktionen jedenfalls ausreichend vorhanden. 


\section{Literatur}

Abraham, Ulf (2013): Kurzspielfilme im Deutschunterricht. In: Praxis Deutsch 237, 4-14.

Behrendt, Esther Maxine (2011): Kurzfilm. In: Koebner, Thomas (Hrsg.), Reclams Sachlexikon des Films. Stuttgart: Reclam, 396-398.

Heinrich, Katrin (1997): Der Kurafilm. Geschichte, Gattungen, Narrativik. Alfeld: Coppi.

Leitzke-Ungerer, Eva (2009): Film im Fremdsprachenunterricht: Herausforderungen, Chancen, Ziele. In: Dies. (Hrsg.): Film im Fremdsprachenunterricht. Literarische Stoffe, interkulturelle Ziele, mediale Wirkung. Stuttgart: Ibidem, 11-32.

Rössler, Andrea (2009): Überraschende Begegnungen der kurzen Art: Zum Einsatz von Kurzspielfilmen im Fremdsprachenunterricht. In: Leitzke-Ungerer, Eva (Hrsg.): Film im Fremdsprachenunterricht. Literarische Stoffe, interkulturelle Ziele, mediale Wirkung. Stuttgart: Ibidem, 309-326.

Welke, Tina (2007): Ein Plädoyer für die Arbeit mit Kurzfilmen im Unterricht. In: Fremdsprache Deutsch 36, 21-25.

\section{Internetquellen}

AG Kurzfilm (Hrsg.) (2006): Kurzfilm in Deutschland. Studie zur Situation des kurzen Films, 2006. Http://www.ag-kurzfilm.de/shared/doc/upload/page/212/ page_en_212_a2. pdf (7.05.13).

AG Kurzfilm (Hrsg.) (2013): German Short Films 2013. Http://ag-kurzfilm.de/ shared/doc/upload/page/993/page_de_993.pdf (7.05.13).

Einladend, frisch, übersichtlich. Das neue Kleid der FAZ. Http:/ /www.faz.net/ aktuell/feuilleton/medien/das-neue-kleid-der-f-a-z-einladend-frisch-ueber sichtlich-1494037.html. FAZ.net vom 4.10.2007 (7.05.13).

Festival International du Court Métrage (2013): Statistique des inscriptions 2013. Http://www.clermont-filmfest.com/01_festival/commun/ stats13.pdf (15.06.13).

Hans Steinbichler (Informationen zur Person). Http://www.filmportal.de/ person/hanssteinbichler_1d7c7988429e443e8dbc9ade51caa15b. (24.06.2013).

Interview mit Hans Steinbichler. Http://deutschland09-der-film.de/hanssteinbichler-fraktur\#interviewStart (27.05.2013).

Interview mit Tom Tykwer. Http:/ / deutschland09-der-film.de/tom-tykwerfeierlich-reist\#interviewStart (27.05.2013). 
Making of Deutschland 09. Ein Gespräch mit Tom Tykwer, Dirk Wilutzky und Verena Rahmig. Http://deutschland09-der-film.de/13-kurzfilme. (27.05.2013).

Tom Tykwer (Informationen zur Person). Http://www. ilmportal.de/person/tomtykwer_d239370ec2454b4597f70f293478d485. (24.06.2013).

Wulff, Hans Jürgen (2012): Kurzfilm. Http:// filmlexikon.uni-kiel.de/index.php? action=lexikon\&tag= $\operatorname{det} \& i d=242(27.05 .2013)$.

\section{Filme}

Deutschland 09.13 kurze Filme zur Lage der Nation (2009). DVD, 152 Min., Deutschland: Piffl Medien.

Deutschland im Herbst (1978). DVD, 119 Min., Deutschland: Kinowelt. 


\section{Anhang 1: Arbeitsblatt zu „Feierlich reist“ (Tom Tykwer 2009)}

Im Folgenden sehen Sie einige Beispiele für filmästhetische Mittel aus dem Kurzfilm Feierlich reist. Beschreiben Sie stichpunktartig den Inhalt der Screenshots sowie deren Funktion.

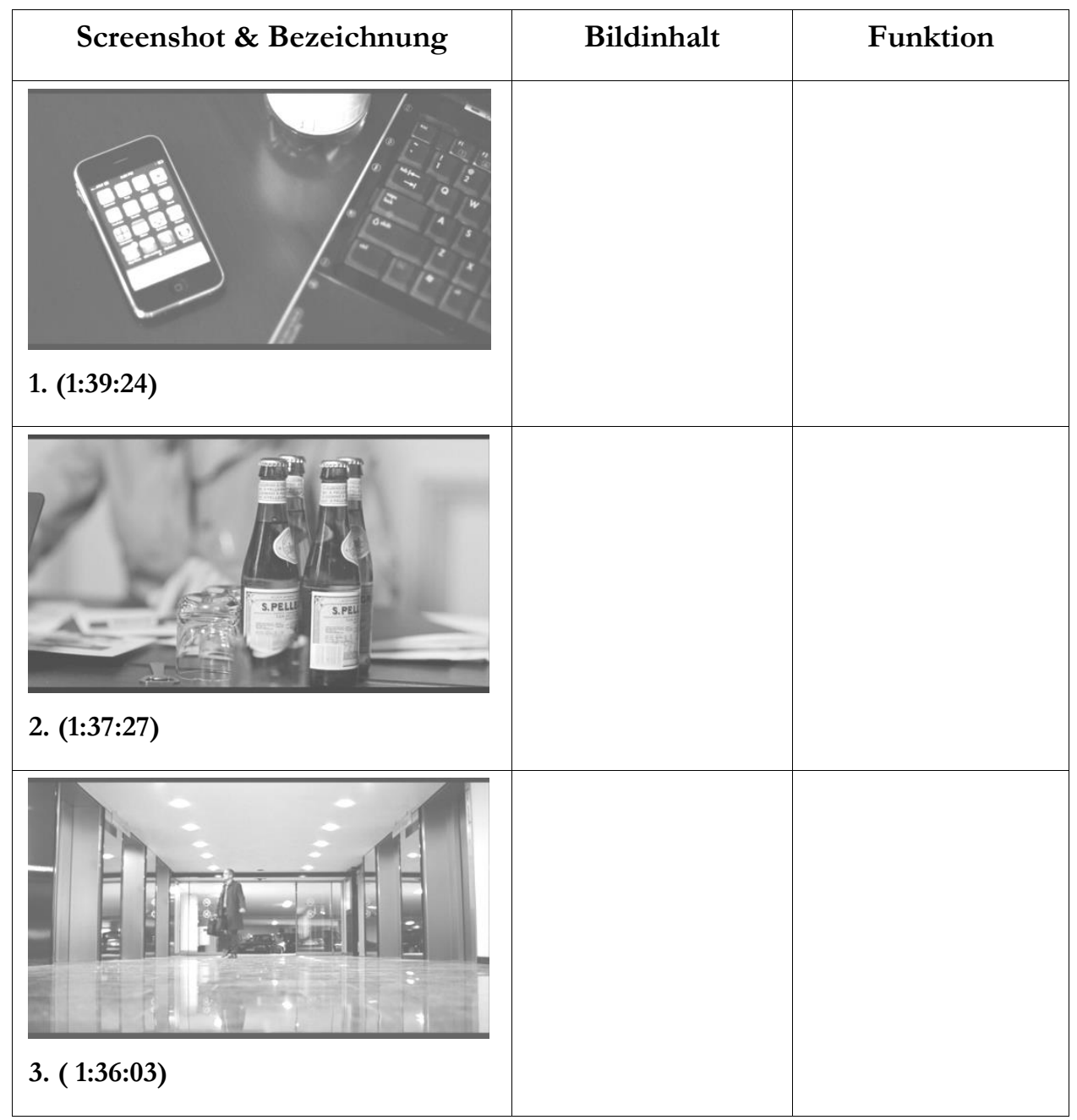




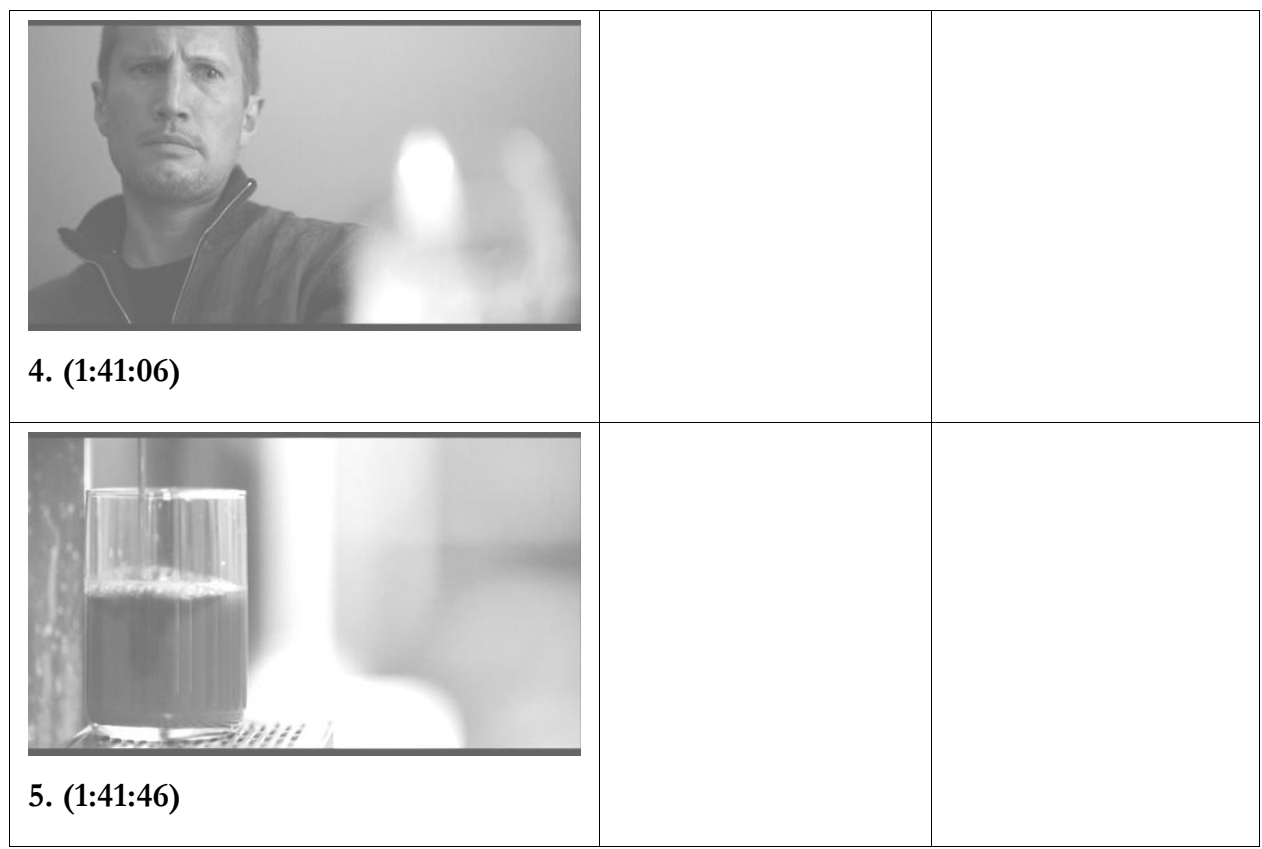

Anhang 2: Arbeitsblatt zu „Fraktur“ (Hans Steinbichler 2009)

Fassen Sie mit Hilfe der folgenden Screenshots die Handlung des Films „Fraktur,, zusammen.

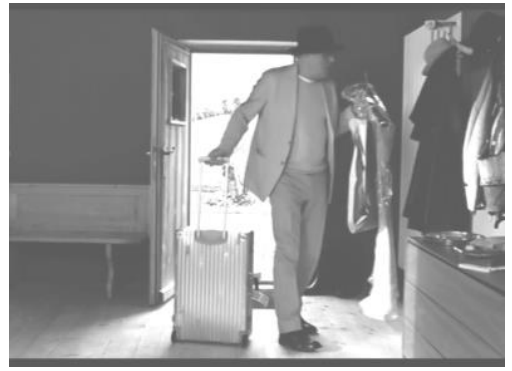

(1:00:39)

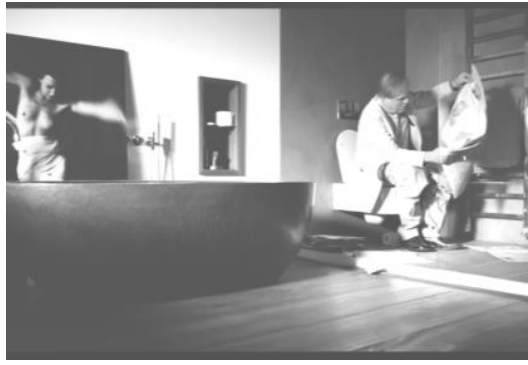

$(1: 01: 22)$ 


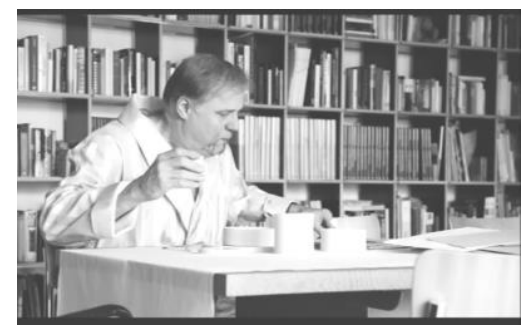

(1:02:08)

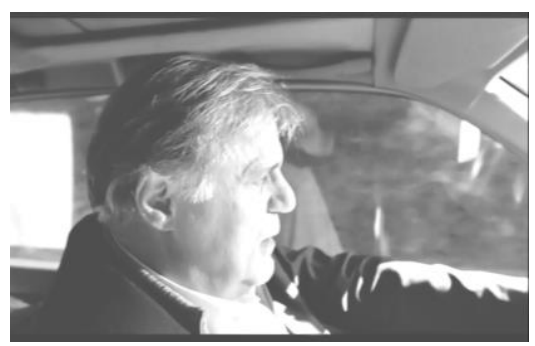

(1:06:50)

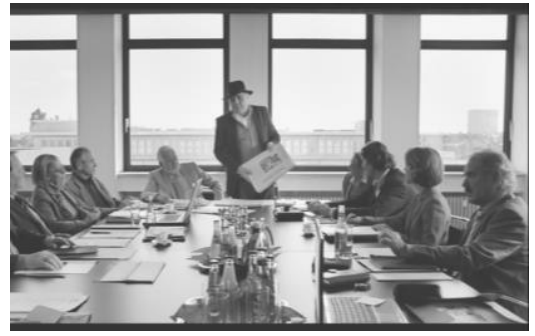

(1:10:15)

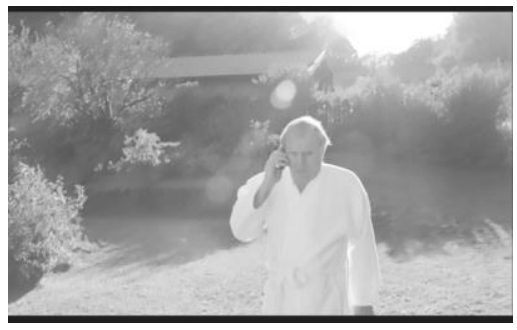

(1:03:31)

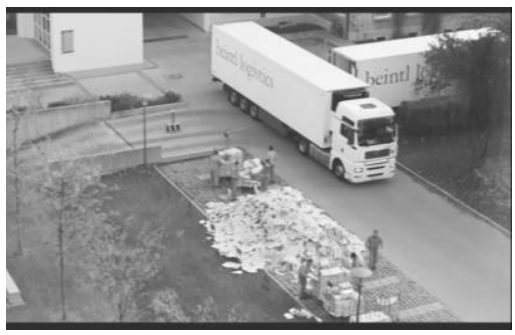

(1:09:07)

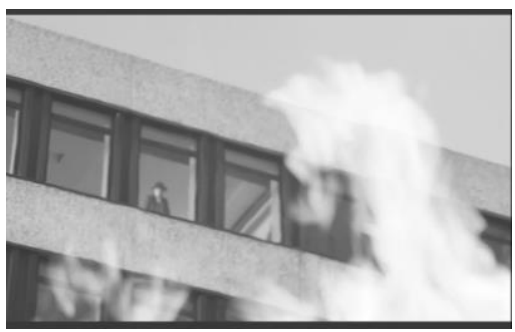

(1:12:12) 


\title{
Fernseh-Werbespots im handlungsorientierten Fremdsprachenunterricht
}

\author{
Anna Svet
}

\section{Einführung}

Seit das Potenzial des Films und später auch des Fernsehens als Medium für den Unterricht allgemein erkannt wurde, werden diese mit Enthusiasmus im Fremdsprachenunterricht eingesetzt. Die Zuschauer begeben sich beim Fernsehen meist in eine passive Konsumentenrolle (vgl. Raabe 2003: 424). Die Filme, Kurzfilme sowie Werbespots im Fremdsprachenunterricht werden anders wahrgenommen als die Filme, die im privaten Bereich gesehen werden: Da es zum Zwecke der Aneignung der Fremdsprache geschieht, wird mit den Filmen aktiv umgegangen.

Der heutige Fremdsprachenunterricht befasst sich zunehmend mit aktuellen gesellschaftlichen Entwicklungen und hat dabei zum Ziel, die Vielzahl von verschiedenen Themen zu behandeln, die mit dieser Gesellschaft und mit dem von ihr bewohnten Land eng verbunden sind. Der effektivste Weg, eine andere Gesellschaft zu erkunden und gleichzeitig die notwendigen Kompetenzen zum selbständigen Handeln in dieser Gesellschaft zu stärken, führt über die neuen Medien wie z.B. Video, Film, Fernsehen. Diese Medien sind in der heutigen Gesellschaft omnipräsent. Werbung ist ein ständiger Begleiter, so alltäglich, dass sie nicht immer oder kaum noch bewusst wahrgenommen wird. Sie ist stets präsent und prägt unser Leben, wie auch unser Konsumverhalten, weitaus mehr als uns manchmal bewusst ist. 
Der vorliegende Artikel beschäftigt sich mit dem Einsatz von Fernseh-Werbespots im Unterricht Deutsch als Fremdsprache ${ }^{1}$ und geht der Frage nach, welche Möglichkeiten und welches Potenzial dieses Medium im handlungsorientierten Fremdsprachenunterricht aufweist. Angesichts des übermäßigen Medienangebots und der unterschiedlichen Vorteile, die Videos im Allgemeinen und Werbespots im Besonderen als Lerngegenstand eröffnen, ist dieses Thema gerade heute von großer Bedeutung. Dies wird vor allem durch die mittlerweile langjährigen Diskussionen in Fachkreisen, die speziell um den Einsatz von authentischem Videomaterial im Fremdsprachenunterricht geführt werden, deutlich.

\section{Werbung}

Interesse an Werbung besteht in vielen Wissenschaftsdiziplinen. Ein wesentlicher Teil der Untersuchungen findet sich im wirtschaftswissenschaftlichen Kontext. Marketing hat Werbung früh als Marktkommunikation erkannt und erforscht. Dabei zeigt sich besonders ausgeprägt die Verbindung von Werbung und Psychologie - nämlich die Konsumenten- und Werbepsychologie - die das Erleben und Verhalten der Werbeadressaten thematisiert. Die Wissenschaften, die sich partiell mit Werbung beschäftigen, sind Soziologie, Linguistik und Semiotik, aber auch Publizistik- und Kommunikationswissenschaft (vgl. Siegert; Brecheis 2005: 17ff.).

Aus der wirtschaftlichen Perspektive ist Werbung „eine absichtliche und zwangsfreie Form der Kommunikation, mit der gezielt versucht wird, Einstellungen von Personen zu beeinflussen“ (Kloss 2007: 6). Die werbewirtschaftliche Definition besagt, dass Werbung

ein geplanter Kommunikationsprozess ist und gezielt Wissen, Meinungen, Einstellungen und/oder Verhalten über und zu Produkten, Dienstleistungen, Unternehmen, Marken oder Ideen beeinflussen. Sie bedient sich spezieller Werbemittel und wird über Werbeträger wie z.B. Massenmedien und andere Kanäle verbreitet (Siegert; Brecheis 2005: 26).

Selbst wenn jede Disziplin ihre eigene Definition von Werbung hat, so stimmen meist zwei Elemente überein. Zum einem ist Werbung ein Kommunikationsmittel und zum anderen geht es um eine Form der Beeinflussung, ,die zum Ziel hat, das Verhalten des Empfängers der Nachricht zu verändern“ (Weis 1994: 18).

Dies wirft die Frage auf, wie die Werbung von Konsumenten wahrgenommen wird und wie sich diese auf das Verhalten der Beworbenen auswirkt. Kloss (1998: 33) bezeichnet Wahrnehmung der Werbung als einen Prozess der Aufnahme, Selektion, Weiterleitung und Verarbeitung von Reizen aus der Umwelt durch einen

\footnotetext{
${ }^{1}$ Der Schwerpunkt der vorliegenden Arbeit ist DaF-Unterricht und der Einsatz von Fernseh-Werbespots im handlungsorientierten DaF-Unterricht. Jedoch kann vieles sowohl auf den Deutsch-alsZweitsprache Unterricht (DaZ-Unterricht) als auch auf den Unterricht in anderen Fremdsprachen übertragen werden.
} 
oder mehrere Sinnesorgane (Sehen, Hören, Tasten, Riechen, Schmecken). Eines der Charakteristiken der Wahrnehmung ist Selektivität. Selektive Wahrnehmung erfolgt immer bei aktivierten Bedürfnissen. Dementsprechend beruht die Wahrnehmung der Werbung auf einem Zusammenspiel von objektiven Umweltreizen und subjektiver Erfahrungswelt des Empfängers (vgl. Kloss 1998: 59). Die Wahrnehmung der Reize geschieht dabei in einem bestimmten Umfeld und dieses Umfeld beeinflusst auch die Interpretation des Signals. In der Werbung wird vor allem auf bewusst wahrgenommene Reize abgehoben, weil es zweifelhaft erscheint, ob die unbewusst wahrgenommenen Reize spezifische Verhaltensaktionen auslösen könnten. In der Gestaltung der Werbemittel achtet man dementsprechend darauf, dass die Wahrnehmung selektiv erfolgt. Dabei sollten die Reize Anwendung finden, zu welchen der Betrachter einen persönlichen Bezug hat (vgl. Kloss 2007: 59f.).

Zur Erklärung der Werbewirkung wurden verschiedene Modelle$^{2}$ konstruiert. Eines der bekanntesten Modelle ist die amerikanische AIDA-Formel, die folgende Wirkungsabsichten verfolgt: Attention - Interest - Desire - Action. Werbung soll dabei Aufmerksamkeit erregen, um das Interesse zu wecken, welches zu realen Wünschen führt, die wiederum eine Kaufhandlung auslösen (vgl. Janich 2001: 22). Dabei deutet Janich (2001) darauf hin, dass die Werbewirkung durch unterschiedliche Werbestrategien erzielt werden kann. Die Werbung zielt letztendlich darauf ab, die Konsumenten dazu zu bewegen, die beworbenen Produkte zu kaufen. Kroeber-Riel, W./Esch, F.R. (2004: 39) entwickeln hierzu ein Modell ${ }^{3}$, welches das komplexe System von Werbezielen und -wirkungen auf eine einfache Struktur mit drei grundlegenden Beeinflussungszielen reduziert: Aktualisierung, Emotion und Information. Das vierte Ziel ist die Kombination von Emotion und Information. Werbung will bekannt machen, informieren, Aufmerksamkeit schaffen, Neugier wecken, Sympathie vermitteln, Aktualität erzeugen und emotionalisieren (vgl. Kloss 2007: 51). Laut Janich (2006) vermittelt die Werbung nur die Informationen über die verkaufenden Produkte, welche die Hersteller für verkaufsfördernd halten, und liefert dabei keine objektiven Informationen. Ihre Ziele erreicht Werbung durch verschiedene Werbemittel. Diese haben ihrerseits unterschiedliche Möglichkeiten der Darstellung und Gestaltung von Werbebotschaften und arbeiten mit verschiedenen Kommunikationsinstrumenten (Wort, Bild, Ton, Symbol). Schmidt (2004: 131) unterscheidet wiederum folgende wichtige Werbemittel: Plakat-, Fernseh-, Radio-, Print-, Außen- und Internetwerbung. ${ }^{4}$ Aufgrund der Tatsache, dass sich dieser Artikel mit dem Einsatz von Fernseh-Werbespots im Fremdsprachen-

\footnotetext{
2 Darunter auch Stimulus-Response-(S-R)-Modell, Stimulus-Organismus-Response-(S-O-R)-Modell, vgl. Rosenstiel; Kirsch 1996: 49.

${ }^{3}$ Näher dazu in Kroeber-Riel; Esch 2004: 39.

4 Schmidt 2004: 147-160 zählt zu den Werbemitteln auch noch Direkt-Marketing. Diese Art der Werbung umfasst: Haushaltswerbung, Werbegeschenke, Werbebriefe, Business-to-Consumer-Werbung, Door-in-the-Face-Prinzip, Foot-in-the-door-Technik u.a.
} 
unterricht beschäftigt, besteht im Folgenden die Notwendigkeit; die Fernsehwerbung von der Printwerbung abzugrenzen und die Unterschiede zu verdeutlichen. ${ }^{5}$

\subsection{Bausteine der Werbespots}

Bei der Übertragung der Botschaften mittels Fernsehen geht es um die klassische Form der Massenkommunikation. Im Vergleich zu den anderen Massenmedien bietet das Fernsehen die Möglichkeit, realitätsnahe Situationen zu simulieren. Durch das belebte Bild kann dem Betrachter das Gefühl vermittelt werden, Augenzeuge des Geschehens zu sein. Für die Fernsehwerbung ergibt sich ein nahezu unbegrenzter Gestaltungspielraum, da sich auch phantastische, märchenhafte Erlebniswelten abbilden lassen. Zur Umsetzung der Werbeinhalte dient eine Vielzahl von Gestaltungselementen, wobei neben der verbalen Botschaft in der Fernsehwerbung stets auch nonverbale Signale vertreten sind (vgl. Beckmeier 1989: 52f.).

Ein Werbespot ist „ein visuell-akustisches Mittel der Werbung, das den Verbraucher durch die bewegten Bilder und die Sprache in gleicher Weise ansprechen soll. Es handelt sich um einen Kurzfilm [...], der speziell für Fernsehen produziert wird“ (Weis 1994: 86). Die Bausteine eines Fernseh-Werbespoty unterscheiden sich von den Elementen der Printwerbung. Das Bild, der Text/die Sprache, die Musik und die Farbe wirken in den Werbespots unmittelbar auf die Konsumenten ein. Das Zusammenspiel der einzelnen Elemente ist für die Gesamtwirkung des Produktes entscheidend. Jedes dieser Elemente wird gezielt eingesetzt, um Emotionen und Assoziationen auszulösen.

Die Bilder, die in der Werbung genutzt werden, erfüllen folgende Aufgaben: auffallen, informieren und emotionale Erlebnisse transportieren (vgl. Kroeber-Riel 1996: 12). Bilder vermitteln Informationen wirksamer als Sprache, und sie vereinfachen abstrakte Informationen. Dabei sind Bilder besser als Sprache geeignet, Emotionen zu vermitteln und eine fiktive Wirklichkeit zu erzeugen (vgl. ebd.).

Die Bild-Text-Kombination präsentiert das Produkt auf verschiedenen Ebenen. Der Text unterstützt und lenkt dabei die Bildinterpretation. Die größtmögliche Wirkung erzielen Werbespots, wenn sich Bild und Text gegenseitig ergänzen, d.h. wenn die Textaussage durch Bilder und Bildaussage durch Text vertieft werden (vgl. Ochmann 2003: 6). Das dritte Element der Werbespots ist Musik, die entspannt, unterhält, ablenkt etc. Dabei handelt es sich um eine im Unterbewusstsein stattfindende Beeinflussung. Die Werbung nutzt dies, um mit Hilfe der Musik Stimmungen und Emotionen zu schaffen (vgl. Leo 1999: 17). Ein weiterer Bestandteil eines Werbespots ist die Farbkomposition. Farben haben eine vielschichtige Wirkung auf die Psyche des Betrachters. Sie können Wohlbefinden und Sehnsüchte, aber auch Aggressionen auslösen. Schon durch geringe Farbnuancierungen gelingt es, den Eindruck von Dingen und Räumen zu verändern (vgl. Ochmann 2003: 7).

${ }^{5}$ Zur Printwerbung im DaF-Unterricht vgl. den Beitrag von Michael Reichelt im vorliegenden Band. 
Vier Bausteine eines Werbespots (Bild, Sprache, Musik und Farbe) bilden eine komplexe Einheit aller hieran beteiligten Teilbereiche, welche sich nachträglich nicht mehr in einzelne Bestandteile zerlegen lassen. Jedes der Elemente spielt eine große Rolle, damit die Werbung bzw. der Werbespot die Konsumenten zum Kauf der Produkte anregt und letztlich zur Befriedigung ihrer Bedürfnisse beiträgt. Diese vier Elemente werden durch weitere Teilgebiete - paraverbale, nonverbale und extraverbale Elemente ${ }^{6}$ - ergänzt. Diese erfüllen entscheidende Kommunikationsund Gestaltungsfunktionen in der Werbung. Damit können vorteilhafte Effekte erzielt werden. Die Fernsehwerbung entfaltet dann ihre positive Wirkung, hinterlässt einen glaubhaften Eindruck und entspricht dem Geschmack der Konsumenten (vgl. Beckmeier 1989: 53). Da die Werbung bzw. Werbespots als Kommunikationsprozess zwischen dem Konsumenten und Werbeagenturen gesehen wird, ist es auch wichtig diese Elemente bei der Analyse der Werbespots hervorzuheben.

Die Vielschichtigkeit eines Werbespots und die damit verbundenen Rezeptions- und Interpretationsbedingungen werfen die Frage auf, auf welche Art und Weise Werbespots im Fremdsprachenunterricht am effektivsten Verwendung finden können.

\subsection{Eignung der Werbespots für den Fremdsprachenunterricht}

Wie eingangs bereits festgestellt ist Werbung aus unserem Alltag nicht mehr wegzudenken, da man täglich bewusst oder unbewusst mit Werbung für Produkte und Dienstleistungen konfrontiert wird, die unser Leben bereichern und/oder verbessern sollen (vgl. Lühken 2007: 374). Werbespots haben die Vorteile des Filmeinsatzes im Fremdsprachenunterricht nicht nur übernommen, sondern auch ausgebaut. Die vielfältigen Eigenschaften und Potenziale von Filmen sowie von Werbespots lassen ihren Einsatz zielführend erscheinen.

Biechele (2006: 310) sieht dabei die Möglichkeit der Entwicklung von HörSeh-Verstehen im modernen Fremdsprachenunterricht. Die in den Werbespots dargestellten kommunikativen Situationen fördern wichtige zielsprachige Fertigkeiten der Lernenden, insbesondere das visuell unterstützte Hörverstehen. Durch Bild-Ton-Kombination werden die kommunikativen Ereignisse im Zusammenhang gezeigt. Für die Eignung des Einsatzes der Werbespots zur Förderung von Hör-Seh-Verstehen spricht ihre Kürze (vgl. Ochmann 2003: 6). Sie dauern zwischen 30 und 60 Sekunden und sind so vielschichtig, dass sie auch beim mehrmaligen Vorführen nicht langweilig werden. Dies stellt einen Vorteil für den Fremdsprachenunterricht dar, da die Werbespots als Alternative zu den Filmen im Unterricht verwendet werden können, wenn es aus zeitlichen Gründen heraus nicht möglich ist, den ganzen Film zu zeigen. Dabei haben die Werbekomponenten

\footnotetext{
${ }^{6}$ Paraverbale Elemente - Artikulation, Lautstärke, Sprechtempo, Sprachmelodie, Prechpausen etc.; Nonverbale Elemente - Körpersprache mit Mimik, Gestik, Augenkontakt, auch Zeichen und Symbole, Kleider etc.; Extraverbale Elemente - soziale Variablen, wie Alter, Rolle, Beruf, Geschlecht, Status, Zeit und Raum, vgl. Beckmeier 1989.
} 
einen motivierenden Effekt für die Lehrenden, da es sich um einen didaktischen Input handelt, der mehrere Sinne und Wahrnehmungsfunktionen und somit auch verschiedene Lerntypen anspricht (vgl. Vences 2002: 68). Durch das Zusammenspiel von Bild, Text und Ton wird das Verstehen erleichtert und die visuelle Wahrnehmung kann dabei geschult werden. Die nonverbalen, paraverbalen und extraverbalen Elemente unterstützen das gesamte Verständnis. Durch lerner- und inhaltsorientierte Auswahl der Werbespots werden die Lerner zum Sprachlernen aktiviert und motiviert. Dadurch kann das Hör-Seh-Verstehen bereits im Anfängerunterricht durch den Einsatz von Fernseh-Werbespots gefördert werden. Dafür sind primär Werbespots ohne Werbetext geeignet, die nur die bildliche und akustische Ebene ansprechen.

„Als authentischer Text der Zielkultur gewährt Werbung Einblick in die alltagskulturellen gesellschaftlichen Zusammenhänge“, postuliert Schumann (2008: 48). Die Werbung enthält authentische Informationen über das Zielsprachenland und bietet gute Möglichkeiten, sich im Ausland die Kultur des Landes zu vergegenwärtigen (vgl. Li 2007: 180). Werbespots ermöglichen, andere Sprachverfahren als die der Standardsprache kennen zu lernen, z.B. Wortschöpfung, Wortwahl, Wortreim etc. Dabei kann der spielerische Umgang mit der Sprache erprobt werden (vgl. Schumann 2008: 48). Die Wortneuschöpfungen erregen die Aufmerksamkeit der Lernenden, die dadurch neue Erkenntnisse über die Wortbildung erlangen. Die Lehrenden müssen dabei aufpassen, dass die Werbespots das Sprechverhalten der Lernenden nicht prägen (vgl. Vences 2002: 68). Die Werbesprache kann auch verwirrend wirken und zu Missverständnissen führen, aber die Beschäftigung mit ihr ermöglicht den Lernenden, Erfahrungen mit der deutschen Sprache und ihren Variationen zu machen. Gestik, Mimik und Körpersprache werden dadurch als wesentlicher Teil der Fremdsprache deutlich (vgl. Li 2007: 181). Werbespots, wie Filme, ermöglichen ein mit Emotionen verknüpftes Lernen (vgl. Sass 2007: 7), da sie von Menschen und Geschichten erzählen und Situationen für authentische Sprechanlässe anbieten. Dem Ziel der fremdsprachlichen Kommunikationsfähigkeit wird erst dann Rechnung getragen, wenn Werbespots sowie Filme und Videos aktiv rezipiert werden und die Lernenden Gelegenheit erhalten, produktiv zu handeln (Blell; Lütge 2004: 405).

„Kein Fremdsprachenunterricht kann heute darauf verzichten, auf die Befähigung zu interkultureller Kommunikation hinzuwirken" (Doyé 1994: 44). Der Fremdsprachenunterricht als solches hat die Auseinandersetzung mit anderen Kulturen zum Gegenstand und besitzt daher die günstigsten Voraussetzungen dafür, die erstrebte Kommunikationsfähigkeit zu vermitteln. Durch interkulturelles Lernen findet die Entwicklung der interkulturellen Kommunikation statt. Während der Rezeption deutscher Werbung durch die fremdsprachigen Lernenden kann die interkulturelle Kommunikation bereits gefördert werden. Die interkulturellen Komponenten der Werbespots erweitern das Blickfeld der Lernenden (vgl. Dohrn 2009: 117). 
Werbung ist [...] dazu geeignet, interkulturelles Lernen zu befördern. Ihre Botschaft enthält in knappster sprachlicher Form kulturelle Wertsetzungen und bedient sich nationaler Images, um ihr Produkt kulturell zu verankern (Schumann 2008: 48).

Die Werbespots dienen zum Sprechanlass und vermitteln dabei einen Einblick in die kulturellen und gesellschaftlichen Gegebenheiten des Zielsprachenlandes. Patermann; Jürgens (2009: 66) behaupten, dass Werbung „ein Ausdruck verschiedener Einstellungen, Wertmaßstäbe, Ängste und Sehnsüchte [ist], die in einer Gesellschaft oder bei einzelnen gesellschaftlichen Gruppen vorhanden sind“. Im Fremdsprachenunterricht bildet die Werbung den Rahmen für die Auseinandersetzung mit aktuellen landeskundlichen Themen und regt zum Nachdenken sowie zur Diskussion über dargestellte soziale und kulturelle Wahrnehmungsmuster an (vgl. Patermann; Jürgens 2009: 67). Darüber hinaus können Werbebilder und Werbesprache kulturelle Merkmale und Konventionen in verschiedenen Ausdrucksformen einzelner Kulturen wiedergeben (vgl. Lühken 2007: 375). Somit erscheinen besonders die Werbespots mit ihren alltäglichen Stereotypen als ideale Möglichkeit, kulturelle Besonderheiten zu analysieren und zu verstehen (vgl. ebd.).

Die Wahrnehmung der Werbespots geschieht unter begrenzter kognitiver Kontrolle. So werden Sprache und Dialoge, Handlung und Schauplätze bewusst wahrgenommen, während Musik und Geräusche sowie die Aspekte der Bildkomposition, Kameraeinstellung und -perspektive, Farben, Formen - also nonverbale und extraverbale Elemente der Werbespots - unbewusst aufgenommen werden. Letztere sind jedoch oft kulturspezifisch. Biechele (2006: 317) plädiert dafür, dass das Ziel des Einsatzes von Filmen, Videos und nicht zuletzt von Werbespots darin bestehen sollte, die meist unbewusst ablaufenden Prozesse der Wahrnehmung und Wirkung bewusst zu machen und auch auf unterschiedliche Sehgewohnheiten der Lernenden einzugehen.

Da die Werbung den Alltag durchdringt und ohne Frage heute allgegenwärtiger, raffinierter, ausgefeilter und mächtiger geworden ist, besteht die Gefahr, ihre Manipulationseigenschaft bei ihrem Einsatz im Klassenraum einzuholen (vgl. Fenske; Rühle 2003: 5). Jedoch soll die Verwendung der tagesaktuellen Werbung nicht als Gefahr, sondern als besondere Chance zur Anreicherung des Unterrichtsstoffs gesehen werden. Werbung bzw. Werbespots im Fremdsprachenunterricht gelten als Gegenstand der kritischen Analyse und damit auch als Teil der Medienerziehung.

Das Medium Werbespot, sowie Filme, weisen viele Potenziale für den Unterricht auf, wobei auch nicht außer Acht gelassen werden sollte, dass es viele Faktoren gibt, die die Integration von Werbespots im Fremdsprachenunterricht erschweren. $\mathrm{Zu}$ diesen erschwerenden Faktoren gehört z.B. die Beschaffung von Werbespots für den Unterricht. Einige Lehrende haben keinen hinreichenden Zugang zu den entsprechenden Quellen (z.B. Internet oder deutsches Fernsehen) und in den meisten Fällen keine ausreichende Technik, die Werbespots aufzunehmen und im 
Unterricht zu präsentieren. Darüber hinaus können Urheberrechte und seine Fragen den Einsatz von Werbespots hindern.

Zusätzlich zu diesen Faktoren können beim Einsatz von Werbespots unterschiedliche Probleme bei Lernenden auftreten, die das Verstehen für das Ganze erschweren. Primär sind hier die kommunikativen Werbekomponenten zu nennen verbale, paraverbale, nonverbale und extraverbale Elemente der Werbespots. Da die Werbung bzw. Werbespots fest in der Gesellschaftskultur verankert sind, determinieren sich diese Probleme mit der Zielgruppe der Fremdsprachenlernenden.

Die Werbung baut auf Klischees und Stereotypen auf, sodass sich die Deutschlernenden durch die deutschen Werbespots weniger angesprochen fühlen. Häufig haben die Lernenden andere Vorstellung von Statussymbolen und fassen die deutsche Werbung anders auf als die deutschen Muttersprachler. Dies könnte auch zu falschen Interpretationen führen. Autos und Designerparfüms können in anderen Kulturkreisen zweifellos Statussymbole sein, in Deutschland dagegen sind diese zwar ein Zeichen für guten Geschmack, aber längst keine Statussymbole mehr (vgl. Ising 2007: 147f.). Die deutschen Werbespots mit Prominenten, TV-Moderatoren und Schauspielern können für die Deutschlernenden keine Aussage bzw. keine Botschaft übertragen, da sie sich mit den Vorbildern der deutschen Kultur nicht identifizieren können. Prominente verlieren dadurch an Bedeutung und werden zu einfachen Konsumenten, wodurch auch die Werbung falsch interpretiert werden kann.

Aufgewachsen mit anderen Werten als die Deutschen gehen die Deutschlernenden auch mit entsprechenden Erwartungen an die deutsche Werbung heran. In Deutschland konzentriert sich die Werbung auf Geschichten aus dem Alltagsleben, in denen sich die Konsumenten leicht wiederfinden können.

Dies deutet darauf hin, dass das Verständnis der Werbespots durch paraverbale, nonverbale und besonders extraverbale Elemente erschwert wird, wenn man nicht über generelles Weltwissen verfügt. Dieses Weltwissen, aber auch narratives Wissen können durch den Einsatz von Fernseh-Werbespots im Fremdsprachenunterricht vermittelt werden. Diese Faktoren sollten die Lehrenden bei der Auswahl der Fernseh-Werbespots für den Unterricht berücksichtigen. Die kulturelle Vielfalt führt oft dazu, dass manche sprachliche oder bildliche Mittel außerhalb des Erfahrungs- und Entstehungszusammenhangs der Lernenden gar nicht oder falsch verstanden werden. Das begründet sich dadurch, dass das kulturelle Wissen zwischen dem Adressaten und dem Rezipienten fehlt. Dieses Problem wird auch in der Werbung offensichtlich: oft weiß man nicht, worum und warum das Produkt so beworben wird, da die Rezipienten zu bestimmten Zusammenhängen und Symbolen andere Konnotationen als die Einheimischen haben (vgl. Li 2007: 186). Diese Verständnisprobleme von Lernenden im Umgang mit Werbespots sollen dabei nicht als Hindernis angesehen und unterdrückt werden, sondern als bestätigende Motivation zu weiterer Auseinandersetzung mit kulturellen Inhalten und vertieftem Verständnis der fremden und eigenen Kultur. 
Themenwahl, Aufbau, Bild- und Sprachanteile sind Teile der Werbung, die analysiert werden und sprachlich interessant für die Lernenden sein können. Mit den von Werbespots zur Verfügung gestellten thematischen Impulsen wird ein lernerorientierter, aufregender, methodisch abwechslungsreicher und handlungsorientierter DaF-Unterricht ermöglicht.

\section{Handlungsorientierter Fremdsprachenunterricht mit Fernseh-Werbespots}

Der Begriff der „Handlungsorientierung“ kommt aus der kommunikativen Wende. Mit der Formulierung von kommunikativer Kompetenz als oberstem Ziel des Fremdsprachenunterrichts wurde der Fokus auf kommunikative Intentionen, Situationen, authentische Sprechanlässe und Lernmaterialien sowie pragmatisches, angemessenes Sprachhandeln gelegt (vgl. Barkowski; Krumm 2010: 112f.). Dabei geht es nach der methodenbezogenen Definition von "Handlungsorientierung“ um einen ganzheitlich ausgerichteten Unterricht, in dem die Lernenden selbständig und mit „Kopf, Herz und Hand“ zuvor vereinbarte Handlungsprodukte herstellen oder Aktivitäten selbständig planen und durchführen (vgl. ebd.: 113). Es darf aber nicht übersehen werden, dass es sich bei handlungsorientiertem Unterricht nicht um eine ständige Unterrichtsform handelt, die den gewöhnlichen Unterricht ablöst, sondern „dass er nur eine der vielen Möglichkeiten ist, Unterricht zu gestalten“ (Jung 2001: 81). Unterricht in dieser Gestaltungsform ist dabei durch seinen nicht vorgefertigten, nicht vorhersehbaren Ablauf offen, spannend, aber auch risikoreich. Oft können die Lernenden nicht allein arbeiten oder sind daran nicht interessiert, da ein hoher persönlicher Einsatz gefordert wird. Der handlungsorientierte Unterricht verlangt von allen Mitarbeit und führt zu einer größeren Identifikation mit dem Stoff bzw. Produkt. Im Rahmen solchen Unterrichts werden die Lern- und Arbeitstechniken vermittelt, die dann auf andere Aufgaben übertragen und angewendet werden können (vgl. ebd.: 80f.).

Das Ziel des handlungsorientierten Unterrichts ist, die Lernenden mit umfassender Handlungskompetenz auszustatten (vgl. Gudjons 1987: 10) und diese zur Selbständigkeit anzuleiten (vgl. Jung 2001: 81). Dabei besteht die Handlungskompetenz aus Selbst- und Sachkompetenz (Ausdauer, Genauigkeit, Selbststeuerung etc.), Sozialkompetenz (Kommunikations-, Kooperations- und Integrationsfähigkeit, Verantwortung, Kritikfähigkeit etc.), Methodenkompetenz (Lern- und Arbeitstechniken etc.) sowie Fachkompetenz (vgl. Gudjons 1987: 5ff.). Handlungsorientierter Unterricht ist der Versuch, Handlung als Lernmedium zu integrieren, wobei die Lehrenden die Handlungssituationen schaffen, ,in denen handelnd gelernt und lernend gehandelt wird" (Ballin; Brater 1996: 33); sie bereiten alle geeigneten Sach-, Sinn- und Problemzusammenhänge und das Grundmaterial zusammen mit den Lernenden vor. 
Trotz vieler Vorteile des handlungsorientierten Unterrichts gibt es Gründe, die die Einbettung von Fremdsprachen in einen solchen Unterricht erschweren können. Einerseits stellt die geringe Stundenzahl ein Problem dar, andererseits kommt das heterogene fremdsprachliche Vorwissen der Lernenden erschwerend dazu (vgl. Linthout 2004: 35). Zusätzlich kann die geringe mündliche Sprachkompetenz in der Zielsprache als problematisch angesehen werden, was oft dazu führt, dass die Muttersprache bei der Gruppenarbeit verwendet wird (vgl. ebd.). „Zufälligkeit und Unsystematik des Lernens" erkennen Ballin und Brater (1996: 42) in diesem Kontext als potenzielles Problem. Trotz dieser Hindernisse appelliert Linthout (2004) an die Lehrenden, dass der handlungsorientierte Unterricht, wo möglich, praktiziert werden soll, denn „die strukturelle Integration der Fremdsprachen in den handlungsorientierten Unterricht unterstreicht die natürliche Einheit von Fremdsprache und Fach“. Dies impliziert nicht, dass der traditionelle Unterricht abgelöst wird. Seine Formen werden für bestimmte Ziele weiterhin ihre Berechtigung behalten. Dabei kann festgestellt werden:

Es ist nicht damit getan, dass die Schüler durch die Klasse wuseln und am Stundenende glücklich und erschöpft sind. Es muss auch etwas Vernünftiges dabei herauskommen (Jank; Meyer 2008: 355).

Durch die Beschäftigung mit der Werbung bzw. mit den Werbespots im Fremdsprachenunterricht werden Sprachwissen und kulturelles Wissen erworben, die Fachkompetenz wird gefördert. Die in der Werbung gegebenen landeskundlichen Informationen können der Werbung nicht direkt entnommen werden, weil Werbung selten fertige landeskundliche Informationen in sich trägt und nicht immer die reale Welt widerspiegelt. Damit die Lernenden das relevante landeskundliche Wissen erwerben können, bedarf es einer Auseinandersetzung mit entsprechend relevanten Themen (vgl. Li 2007: 191ff.). Da es von den Wissenschaftlern (u.a. Hackl et al. 1998; Meijer 1998; Zeuner 1997) mehrheitlich empfohlen wird, Landeskunde nicht als ein separates Fach zu unterrichten, sondern in den Fremdsprachenunterricht zu integrieren, stellt der Einsatz von Werbung bzw. Werbespots einen zielorientierten Ansatz dar, landeskundliche Themen auf interdisziplinärer Ebene zu behandeln.7

Neben der Vermittlung von Fachwissen geht es auch um die Sensibilisierung und die Entwicklung von Fähigkeiten im Umgang mit fremden Kulturen (vgl. Dohrn 2009: 115). Die interdisziplinäre Herangehensweise gibt den Lernenden die Möglichkeit, die fremde Kultur als ein komplexes System zu erfassen und sich damit aus verschiedenen Perspektiven auseinander zu setzen (vgl. Li 2007: 193). Die durch den Einsatz von Werbespots veränderte Lernmethode versetzt die Lernenden in Lage, Informationen aus den Werbespots nicht nur aufzunehmen, sondern interpretieren zu können, da die Sachverhalte nicht zusammenhängen und oft

\footnotetext{
${ }^{7}$ In der Werbung treffen viele Wirkungsebenen zusammen: wirtschaftliche, politische, religiöse, soziale, humanitäre, künstlerische, wissenschaftliche und persönliche (vgl. Li 2007: 193).
} 
mit der realen Welt nicht übereinstimmen (z.B. die Darstellung der Frauen bzw. alter Menschen in den Werbespots). ${ }^{8}$ Die Lernenden müssen im Unterricht lernen, die Rückschlüsse aus der Werbung nicht unmittelbar auf das reale Leben zu beziehen.

Dabei entwickeln sie eine Kompetenz, andere Medien gezielt einzusetzen, um das durch Werbung gewonnene Bild zu relativieren und sich die gegebene fremdkulturelle Realität bewusst zu machen. Das Bedürfnis nach Erkundung entsprechender Themen soll im Fremdsprachenunterricht ausgelöst werden. Die Lernenden werden dabei zum inhaltlichen Recherchieren der behandelten Themen motiviert. Es findet ein autonomer Wissenserwerb statt. Neben diesem autonomen Wissenserwerb müssen die Lernenden eine reflektierende Wahrnehmung entwickeln, die ihnen die Differenz zwischen der Realwelt und der abgebildeten Welt der Werbung bewusst macht. Dabei gehen sie kritisch mit den in den Werbespots dargestellten Stereotypen und Klischees um (vgl. Li 2007: 193ff.). Dohrn (2009: 115) nennt die Reflexionsfähigkeit eine „Fähigkeit, die eigene und die fremde Kultur zu untersuchen, ihre jeweiligen Normen und Wertevorstellungen, Referenzsysteme und Verhaltensmuster zu vergleichen und in ihrer angenommenen Absolutheit zu hinterfragen“. Der autonome Wissenserwerb und die Reflexionsfähigkeit gehören zu der Methodenkompetenz, die im handlungsorientierten Unterricht mit den Werbespots ebenfalls entwickelt werden kann.

Da die Werbung immer mit Stereotypen arbeitet und diese auch bewusst einsetzt, werden mit der Vermittlung von Sozial- und Selbstkompetenz die Fähigkeiten wie Offenheit, Toleranz, Empathie, Fähigkeit der Identitätsaushandlung, kritischen Auseinandersetzung mit Stereotypen geschult (vgl. Dohrn 2009: 115).

Damit setzt die Arbeit mit Fernseh-Werbespots einen handlungsorientierten Fremdsprachenunterricht voraus und ermöglicht zahlreiche Handlungssituationen. Neben den zahlreichen erwähnten Vorteilen, die in Bezug auf den Einsatz von Fernseh-Werbespots erwähnt wurden, bringen diese den Lernenden die jeweiligen kulturellen Situationen näher, mit denen sie sich auseinandersetzen sollen.

\section{Kriterien zur Auswahl der Fernseh-Werbespots im Fremdsprachenunterricht}

Am Anfang aller didaktischen Überlegungen steht neben den Rahmenbedingungen für den Fremdsprachenunterricht mit Fernseh-Werbespots immer die Auswahl des Materials. Dohrn (2009: 116) weist darauf hin, dass die Motivation der Lernenden und die Lernfortschritte davon abhängen, ob die Werbespots für die Lernergruppe

\footnotetext{
8 Die neueren Analysen zeigen, das in der deutschen Realität die Frauen neuere, emanzipiertere Rollen übernommen haben, als in der Werbung gezeigt wird. Die Darstellung der älteren Menschen in der Werbung bedeutet nicht, dass Älterwerden in der deutschen Gesellschaft mit positiven Konnotationen verbunden ist. Das verfolgt nur das Ziel, diese Bevölkerungsgruppe positiv auf das Konsumieren einzustimmen, vgl. Li 2007: $193 \mathrm{f}$.
} 
sowie für die Zielsetzung des Unterrichts und seiner Schwerpunkte geeignet sind und wie die Inhalte methodisch vermittelt werden.

Das im hier vorliegenden Artikel vorgestellte Kriterienraster soll eine Entscheidungshilfe für die Lehrenden bei der Auswahl der Werbespots für den handlungsorientierten DaF-Unterricht zur Förderung von Hör-Seh-Verstehen anbieten. Dabei müssen die Rahmenbedingungen und Lernziele des Unterrichts berücksichtigt werden. Einige Kriterien wurden dabei aus dem Raster von Li (2007: 232ff.) ${ }^{9}$ übernommen, da diese entscheidend bei der Auswahl sowohl der Printwerbung als auch der Werbespots sind. Die Kriterien werden unter dem allgemeindidaktischen Aspekt, dem Informationsaspekt und dem interkulturellen Aspekt aufgestellt und eingeordnet.

\subsection{Allgemeindidaktischer Aspekt}

\section{Bezug zu Lernenden}

- Spricht der Werbespot die Interessen und das Alter der Lernenden an?

- Schließt er an die Erfahrungswelt der Lernenden an?

- Erlaubt er den Lernenden eine persönliche Anteilnahme (Identifikationsmöglichkeit; Ärger; Freude)?

- Ist das Thema den Lernenden zumutbar (Meinungsfreiheit, Sex)?

\section{Förderung von Hör-Seh-Verstehen}

- Lässt der Werbespot Raum für Vermutungen und Fragen?

- Unterstützt das Bild/der Ton das komplexe Verstehen des Werbespots?

- Schafft der Werbespot die Vorentlastung über Bilder bzw. Bildsequenz (Darsteller, Raum, Zeit, Nonverbales, Farben etc.) oder über Ton (Verbales, Paraverbales, Geräusche, Musik, Stille)? Befindet sich der Sprecher im Bild oder außerhalb (Off vs. On)? Sind die Geräusche authentisch und anschaulich?

- Inwieweit unterstützen nichtsprachliche Merkmale (Alter, Kleidung, Geschlecht, Beruf etc.) und Verhaltensweisen (Gesichtsausdruck, Blick, Gesten, Körperhaltung etc.) der Kommunizierenden im Werbespot den HörSeh-Verstehensprozess der Lernenden?

- Ist der Werbespot geeignet, über die erzeugte Wirklichkeit Hypothesen zu bilden?

\footnotetext{
${ }^{9} \mathrm{Li}$ (2007) fokussiert sich bei der Entwicklung eines handlungsleitenden Kriterienrasters zum Einsatz der Werbung in den integrativen DaF-Landeskundeunterricht auf die Plakat- und Anzeigewerbung. Dieses Kriterienraster wird als Basis genommen und mit den Kriterien vervollständigt, die in Bezug auf den Einsatz von Werbespots im DaF-Unterricht relevant sind.
} 
- Wie sieht das Zusammenspiel von Bild, Text und Ton aus? Machen Bild, Text und Ton eine Gesamtaussage? Kann man Bild, Text und Ton zum werbenden Produkt eindeutig zuordnen?

- Kann man über bestimmte Arbeitstechniken, wie z.B. Weglassen einzelner Elemente des Werbespots, eine Offenheit erzeugen, die die Lernenden neugierig macht?

- Gibt der Werbespot die Möglichkeit zur Vermittlung und Anwendung von Verstehensstilen (global, detailliert, selektiv etc.)?

- Orientiert der Werbespot auf die Vermittlung und Anwendung von HörSeh-Strategien?

- Gibt der Werbespot Gelegenheit, die Übungen während des Sehens einzusetzen, ohne dass die Lernenden kognitiv überlastet werden?

- Ermöglicht der Werbespot, die Einstellung von Lernenden zu ihm herauszubilden?

- Stellt die Arbeit mit dem Werbespot die Verwendung verschiedener Sozialformen dar?

- Schafft der Werbespot den Anlass zum Sprechen, Denken und Handeln?

- Bekommen die Lernenden die Gelegenheit zu antizipieren, zu inferieren, zu elaborieren, zu generalisieren und zu analysieren?

- Können sich die Lernenden über den Werbespot selbst äußern (den Eindruck, die Wirkung)?

3. Förderung der Handlungsorientierung

- Regt der Werbespot zur Stellungnahme oder Kritik an?

- Kann die Handlungssituation beim Lernen aufgestellt und die Lernumgebung ausgeweitet werden? Kann dabei die Methodenkompetenz vermittelt werden?

- Gibt der Werbespot Anregungen zu schriftlichen und mündlichen Präsentationsformen (Poster; Produktpräsentationen etc.)?

- Ist das durch den Werbespot vermittelte Wissen für das Handeln außerhalb des Unterrichts (im Alltag der Zielkultur) relevant?

- Wird die selbständige Arbeit der Lernenden im Unterricht mit dem Werbespot gefördert?

- Schafft der Werbespot Anlässe für Rollenspiele, Fallstudien etc.?

4. Entwicklung der Medienkompetenz

- Können die Lernenden den Hintergrundgedanken der Werbung verstehen? 
- Erlaubt der Werbespot, seine Inhalte den eigenen Zielen und Bedürfnissen der Lernenden entsprechend zu nutzen?

- Schafft der Werbespot die Möglichkeit, Situationen zu erkennen, einzuschätzen, zu analysieren, zu beurteilen und auf diese zu reagieren?

- Ermöglicht der Werbespot, die Strategien im Alltag umzusetzen, die Entscheidungen zu treffen und die Folgen von diesen abzuschätzen?

- Lernen die Lernenden dabei, mit den Medien kritisch umzugehen?

\section{Sprachliches Wissen}

- Kennen die Lernenden das notwendige Vokabular, das sie brauchen, um mit dem Werbespot zu arbeiten?

- Muss neuer Wortschatz vorgegeben werden?

- Wird die Möglichkeit für den Einsatz von Wortschatz- bzw. Grammatikübungen geschaffen?

- Entspricht der Werbetext bzw. der Werbeslogan dem sprachlichen Niveau der Lernenden?

- Bietet der Werbespot die Möglichkeiten an, den Wortschatz auszubauen?

- Bezieht sich der Werbespot auf gegenwärtige und zukünftige Sprachbedürfnisse der Lernenden?

- Ist der Werbespot für Binnendifferenzierung geeignet?

6. Aktualität

- Von wann stammt der Werbespot? Ist die angesprochene Thematik aktuell?

- Ist der Werbespot historisch? Aus welchem Jahr stammt er?

- Kann man den Werbespot zum Vergleich mit anderen Werbespots heranziehen?

- Kann man daraus Rückschlüsse zu einer historischen Entwicklung ziehen (z.B. Werbespots aus den 60en Jahren)?

7. Technische Qualität

- Ist die Qualität gut? Kann man alles im Bild, in dem eingeblendeten Text erkennen? Sind der Ton und das Bild aufeinander abgestimmt, wenn der Werbespot vom Internet heruntergeladen wurde?

- Ist der Werbespot technisch zu verbessern, wenn das Original nicht gut genug ist? 


\subsection{Informationsaspekt}

\section{Vorwissen}

- Ist das beworbene Produkt den Lernenden bekannt oder fremd?

- Erfordert der Werbespot ein Vorwissen? Werden die Lernenden überfordert oder unterfordert?

- Benötigen die Lernenden Zusatzinformationen, um überhaupt mit dem Werbespot zu arbeiten? Welche sind das?

\section{Informationspotenzial}

- Hat der Werbespot eine (landeskundliche) Aussage? Präsentiert er direkt (landeskundliche) Information oder soll diese Information interpretiert werden?

- Lässt sich von dem Werbespot auf bestimmte (landeskundliche) Informationen rückschließen?

- Ist der Werbespot als Aufhänger für weitere (landeskundliche) Themen geeignet?

- Werden die Lernenden dadurch motiviert, sich über (landeskundliche) Themen durch andere Medien zu informieren?

3. Themenbezogenheit

- Zielt der Werbespot auf ein Grundthema bzw. ein relevantes (landeskundliches) Thema ab?

- Bezieht er sich auf ein Tabuthema bzw. spricht er Sachverhalte an, die den Lernenden tabu sind?

- Bezieht er sich auf Themen über andere deutschsprachige Länder oder über den Umgang mit anderen Kulturen in Deutschland?

- Sind die Themen kritisch, problemorientiert oder gesellschaftsintern kontrovers?

- Hat das Thema im Werbespot einen Bezug zur Alltagserfahrung der Lernenden?

\subsection{Interkultureller Aspekt}

1. Das interkulturelle Spannungspotenzial

- Hat der Werbespot kulturspezifische Elemente, wie z.B. Symbole, Zeichen und nonverbales Verhalten? Welche sind das? Sollen diese im Klassen- 
raum erklärt werden oder lässt sich die Bedeutung aus dem Kontext erschließen?

- Ermöglicht der Werbespot den Lernenden die Einsicht in das sprachlichkommunikative Normverhalten der Zielkultur?

- Kann der Werbespot Interesse an der Kultur und den Lebensweisen eines fremden Landes wecken? Ist er dazu geeignet, sich mit bestimmten Aspekten dieser Kultur auseinander zu setzen?

- Wie wirken die in dem Werbespot zum Ausdruck gebrachten Werte auf die Lernenden?

\section{Anregung zum Vergleich}

- Werden im Werbespot kulturelle Vergleiche bzw. Differenzen aufgegriffen und bearbeitet?

- Löst der Werbespot das Bedürfnis aus, zwischen der Zielkultur und der eigenen Kultur zu vergleichen?

- Bietet er die Möglichkeit, ihn auf die eigene Kultur zu beziehen und die eigene Kultur zu reflektieren?

\section{Stereotypenkritik}

- Gibt der Werbespot eine Hilfestellung, um sich über die eigene Vorstellung von „den Deutschen“ bewusst zu werden?

- Bietet er eine Möglichkeit, das Fremdbild kennenzulernen?

- Wird bei der Betrachtung des Werbespots Perspektivenwechsel gefordert?

Wenn der Werbespot gesellschaftliche Probleme widerspiegelt und sogar interdisziplinär eingeführt werden kann, „kommt es gerade in diesem Bereich des DaFUnterrichts darauf an, die fremde Kultur als komplexes System erfassbar zu machen“ (Dohrn 2009: 116). Dabei ist die Auseinandersetzung mit dem Unterrichtsgegenstand aus verschiedenen Perspektiven notwendig. Variable und vielseitige Aufgaben- und Übungstypen, abwechslungsreicher Umgang mit Sozialformen, Behandlung von generativen Themen, Vernetzung von Themenkomplexen erleichtern den Einstieg und eine Anbindung an die Lebenswelten und -erfahrungen der Lernenden. Denk- und Handlungsanstöße können zu kooperativen Lösungen anregen, was wiederum zu interessanten und relevanten Gesprächsthemen führt und in authentischer Weise die Kommunikationsfähigkeit und sprachliche Kompetenz fördern kann (vgl. Dohrn 2009: 116f.).

Bei der Auswahl der Werbespots für den Fremdsprachenunterricht ist es unabdingbar zu überprüfen, ob die im Werbespot thematisierten Inhalte der Zielgruppe, ihren Interessen und der Zielsetzung des Unterrichts angemessen sind. Dabei 
sind dem vorgestellten Kriterienraster die relevanten Kriterien zu entnehmen und bei Bedarf das Raster zu erweitern.

\section{5 „Werbespotspezifische“ Übungen}

Im Vorfeld der Übungsgestaltung im Kontext von Werbespots im Fremdsprachenunterricht müssen die Lehrenden grundlegende Überlegungen über den Einsatz von Filmen allgemein und Werbespots insbesondere reflektieren. Das gesamtmethodische Design sollte dem Ziel untergeordnet sein, so genau wie möglich wahrzunehmen, so tief wie möglich zu verstehen und gleichzeitig Freude an Werbespots zu haben.

Da es bei den Werbespots um eine Art fiktionalen Film bzw. Kurzfilm handelt, kann man die Übungstypologien, die für den Einsatz von Spielfilmen und Kurzfilmen entwickelt wurden, verwenden. In der einschlägigen Literatur werden Übungen zum Hör-Seh-Verstehen vorgeschlagen, welche in drei Phasen durchzuführen sind: vor dem Sehen, während des Sehens und nach dem Sehen (vgl. Schwerdtfeger 2003; Sass 2007; Biechele 2008; Lonergan 1987; Brandi 1996). Neben der Förderung von Hör-Seh-Verstehen ist es bei der Arbeit mit Filmen bzw. Werbespots notwendig, die ästhetischen Lernziele innerhalb einer didaktischen Filmanalyse zu verfolgen. Aufgaben, die den ästhetischen Lernzielen untergeordnet sind, sollen die Wahrnehmung vertiefen und filmstilistische Funktionen erfüllen, die zur tieferen Reflexion und Interpretation des Gesehenen anregen und die Medienkompetenz fördern (vgl. Schwerdtfeger 1989; Biechele 2008: 119f.). Solche Übungen sollten den Lernenden Gelegenheit geben, die Elemente herauszufinden, die für die Wahrnehmung gesprochener Sprache und nonverbaler Zeichen relevant sind. Dabei können die Lernenden die Rolle der Gestik und Mimik für die gesprochene Sprache erschließen und die Kulturspezifik erkennen. Die Lernenden werden für die Signale in sozialen Begegnungen sensibilisiert, was ihnen eine Hilfestellung für die Bewältigung der Alltagssituationen gibt.

In den Übungen zu den filmspezifischen Aspekten (Bildsprache, Kameraeinstellung, Perspektive etc.) geht es um den Aufbau von Fachvokabular, „um das Sehverstehen der Lernenden zu fördern, die Prozesse, die zur Bedeutungszuweisung bei der Wahrnehmung führen, durchsichtig zu machen" (Schwerdtfeger 1989: 77). Da die Werbegestalter dieselben Techniken wie z.B. die Filmproduzenten verwenden (vgl. Kloss 2007), lassen sich die Gestaltungsmittel des Films, auf Grund ihres Abstraktionsgrades und der Notwendigkeit der individuellen Beschäftigung, ausschließlich mit Aufgaben mit freisetzender Struktur selektieren. Aktivitäten dieser Art sind solche zur Beurteilung des Filmvorspanns, Hypothesenbildungen, Charakterisierungen von Protagonist/-innen, Analyse zur Kameraführung, Musik, Szenen etc. (vgl. Biechele 2008: 120).

Arnsdorf (1991: 24f.) schlägt in Bezug auf die Arbeit mit Fernseh-Werbespots im DaF-Unterricht eine Übungstypologie vor. Die Übungs- und Aufgabenkonzep- 
tion im vorliegenden Artikel sollen im Weiteren auch innerhalb der drei Phasen vor, während und nach dem Sehen von Werbespots betrachtet und näher dargestellt werden. Dies dient dazu, die theoretischen Klassifizierungen auch in einen praktischen Kontext zu stellen und gleichzeitig aufzeigen zu können, wie vielfältig die Aktivitäten innerhalb der drei Phasen sind. Diese Typologie wird selektiv mit den Vorschlägen von Brandi (1996), Biechele (2008) und Schwerdtfeger (1989) ergänzt, welche nicht nur für die Arbeit mit Filmen sondern auch mit Werbespots geeignet sind. Die angeführten Beispiele stellen allerdings nur eine Auswahl der breiten Palette methodischer Möglichkeiten dar.

\subsection{Vor dem Sehen}

Diese Phase bereitet auf die sprachliche und inhaltliche Information vor und hat zum Zweck, das Interesse der Lernenden aufzubauen und das Verständnis zu erleichtern. Das Vorwissen der Lernenden muss dabei berücksichtigt und den Lernenden muss gleichzeitig bewusst gemacht werden, dass der Umgang mit Werbespots im Unterricht permanent mit Aktivität und Kreativität verbunden ist. Hier empfehlen sich folgende Vorgehensweisen:

- Vorwissen abrufen durch:

- Assoziogramm

- Zuordnung von Nomen und Verben als Eigenschaften eines Produktes

- Fragen zum Namen des Produktes stellen, wenn der Name allgemein aus anderen Bereichen bekannt ist (z.B. Geschichte, Geografie): Was verbinden Sie mit dem Namen...? Wer war sie/er? Für welches Produkt könnte man mit dem Namen... werben?

- Wenn im Werbespot ein landeskundliches Thema angesprochen wird, könnte man nach den Meinungen der Lernenden über den Sachverhalt in Deutschland fragen: z.B. Hochzeit, Geburtstag, Urlaub, Freizeit in Deutschland etc.

- Vor- und Nachteile eines Sachverhaltes zusammentragen

- Zeitungswerbung besprechen und Vermutungen äußern, wie der Werbespot zu dem jeweiligen Produkt aussehen könnte

- Werbetext lesen und Vermutungen äußern

- das Produkt, für das geworben wird, in die Klasse mitbringen und dazu einen Werbetext entwerfen lassen

- Begriffe zu dem im Werbespot dargestellten Thema sammeln und klären

- Lückentext als sprachanalytische Übung; dabei können bestimmte grammatikalische Strukturen oder Phänomene im Vordergrund stehen 


\subsection{Während des Sehens}

Beim ersten Sehen des Werbespots sollte das Hör-Seh-Verstehen im Vordergrund stehen. Beobachtungsblätter, auf denen nur Stichwörter eingetragen werden sollten, bieten sich während des Sehens an und sollen während des zweiten Sehens auch ausgefüllt werden (vgl. Brandi 1996: 41). Die Arbeitstechnik des NotizenMachens soll nicht unterschätzt werden, da die Lernenden meist auch nicht wissen, worauf sie dabei genau achten sollen. Wichtig ist es deswegen, am Anfang mehrere Anhaltspunkte auf Beobachtungsblättern, in Form von Ankreuzen von Informationen oder das Eintragen von Stichwörtern in ein Raster zu geben. Nach dem mehrmaligen Sehen des betreffenden Spots können freiere Lernaktivitäten erfolgen. Was die Anzahl der Wiederholungen angeht, richtet sich der Lehrende nach den Bedürfnissen der Lernenden (vgl. Lonergan 1987).

In dieser Phase sollen die Lernenden die wesentlichen Informationen aus dem Werbespot durch Beobachtungsaufgaben herausfiltern, die das genaue Wahrnehmen auf optischer und akustischer Ebene erfordern und trainieren. Diese Übungen dürfen nicht zu umfangreich sein, damit sich die Lernenden nicht überfordert fühlen. Durch derartige Übungen kann die Aufmerksamkeit der Lernenden auf bestimmte Inhalte gezielt gelenkt werden (vgl. Lonergan 1987; Brandi 1996). Es gibt drei Möglichkeiten der Präsentation eines Werbespots: Tonspur ohne Bild, Spot ohne Ton, Spot mit Bild und Ton.

- Tonspur ohne Bild

- Geschichte zur Musik erfahren

- das Arrangement der Szene vorhersagen

O die Personen, die man hört, beschreiben

○ Notizen machen (z.B. Vorzüge aufschreiben)

○ das Produkt, für das geworben wird, erraten

○ Assoziationen zu Situationen/Personen aufschreiben

- Spot ohne Ton

○ Hypothesen bilden/Fragen stellen

○ Handlung erzählen

- Personen/Szenen beschreiben

○ Zusammenhänge herstellen (gehören die Personen zusammen?)

- einen Text zu den Bildern entwerfen

- das Produkt erraten

- Vorteile/Vorzüge des Produktes erfinden

- Unterschiede zwischen Video und Textvorlage herausfinden

- ein Videoprotokoll anfertigen

- Spot mit Bild und Ton

- Spot an einer wichtigen Stelle stoppen

- raten, für welches Produkt geworben wird

- die nächsten Bilder vorhersagen 
- $\quad$ eine Geschichte erfinden (wie geht es weiter?)

- Notizen machen, Vokabeln festhalten

- Argumente sammeln, die für das Produkt sprechen

- Szene(n) beschreiben

- Sprache/Musik mit den Bildern vergleichen

○ Handlung erzählen

- Werbespot mit den Vermutungen aus der Vorphase vergleichen

Darüber hinaus macht Brandi (1996: 47-51) darauf aufmerksam, dass in der zweiten Phase die Übungen zu filmischen Aspekten gemacht werden müssen. Diese sollen durch Beobachtungen bewusst gemacht und explizit thematisiert werden, um den kritischen Umgang mit dem Medium zu fördern und somit auch die Medienkompetenz zu schulen. Vor allem Fragen zu Bildsprache, Kameraführung und Musik bieten sich hierbei an.

\subsection{Nach dem Sehen}

Die Phase nach dem Sehen soll dazu dienen, das Gesehene und das Gehörte zu verarbeiten, zu vertiefen und zu ergänzen (vgl. Brandi 1996: 15). Folglich sind hier handlungsorientierte Übungen angebracht.

- den Spot analysieren (Zielgruppe bestimmen, Intentionen der Werbung herausarbeiten, Aufbau des Spots untersuchen)

- Stellung zu Situation und Sachverhalten im Spot nehmen

- den Spot mit anderen Spots vergleichen

- $\quad$ über die Werbung im eigenen Land berichten

- Szenen nachspielen

- einen neuen Werbespot zu einem Phantasieprodukt schreiben bzw. drehen

- den Spot mit der Zeitungswerbung vergleichen

- andere Texte heranziehen

- neue Situationen finden

- $\quad$ eine Geschichte schreiben

- $\quad$ einen Dialog schreiben

- Rollenspiele

Nach dem Sehen eignen sich Diskussionen, Podiums- und Rundgespräche zur Entwicklung der Sprachkompetenz. Als Hilfestellung für eine spontane Äußerung der Lernenden dienen die Redemittellisten, welche von den Lehrenden im Voraus vorbereitet werden müssen (vgl. Sass 2007: 11).

Die aufgestellten Übungsvorschläge können erweitert werden, indem die Lehrenden konkrete Ideen aus anderen Quellen holen. Eine umfangreiche Materialienauswahl bieten die von Ochmann (2003) zusammengestellten 26 Werbespots mit 
didaktischen Anleitungen für den Unterricht. Wenn Werbung zum Thema des Unterrichts wird, bieten die von Fenske und Rühle (2003) zusammengestellten Kopiervorlagen zum Thema Werbung reichlich Ideen zur Durchführung von Projekten im Deutschunterricht. Diese Kopiervorlagen, die sich hauptsächlich an Printwerbung orientieren, aber als Grundlage für die weitere Arbeit mit FernsehWerbespots geeignet sind, können helfen, einzelne Aspekte der Werbung im Unterricht zu beleuchten. Dabei müssen die Unterrichtsziele und das Vorwissen der Lernenden beachtet werden.

\subsection{Beispiel für die Arbeit mit Werbespots im DaF-Unterricht}

Im Folgenden wird anhand eines Werbespots des Unternehmens „Volkswagen“ beleuchtet, wie sich das theoretische Konzept des Einsatzes von Fernseh-Werbespots im handlungsorientierten Fremdsprachenunterricht in der Unterrichtspraxis realisieren und begründen lässt. Der Unterrichtsvorschlag wurde im Rahmen einer Sommerschule im Jahr 2011 erprobt und ausgewertet.

Es wird empfohlen, diesen Werbespot auf dem Niveau B1 des Gemeinsamen Europäischen Referenzrahmens (GER) im Deutschunterricht mit Jugendlichen in der Altersgruppe von 19 bis 23 Jahren einzusetzen. Entsprechend dem GER sollten die Lernenden auf diesem Sprachniveau die meisten sprachlichen Situationen bewältigen, sich zusammenhängend über vertraute Themen und persönliche Interessensgebiete äußern, über Ereignisse und Erfahrungen berichten, zu persönlichen Ansichten Begründungen und Erklärungen geben können (vgl. GoetheInstitut 2011). Auf dieser Basis wird auch die Auswahl des Werbespots begründet.

Die Auswahl des Werbespots erfolgte nach den im vorliegenden Artikel zusammengestellten Auswahlkriterien. Der Volkswagen-Werbespot „Das Auto“ aus dem Jahr 2008 zeigt viele kleine Kurzsequenzen aus der geschichtlichen Entwicklung des VW-Konzerns: VW-Käfer und sein Beitrag zur Mobilität für jede Familie in den frühen 50er Jahren, Hippie-Welle in den 1960er Jahren und die damit assoziierten Weltreisen mit dem VW-Kleinbus, die neue Generation von Familien in den 1990ern mit ihrem kleinen Golf, moderne VW-Autos mit hoher Sicherheit für die ganze Familie, für junge Leute und für jeden Anlass, neue Technologien und Innovationen, welche das Unternehmen Volkswagen in den letzten Jahrzehnten erreicht hat.

Der Werbespot ist für die anvisierte Zielgruppe gut geeignet, indem er z.B. ihre Interessen anspricht. Dabei lässt er Raum für Vermutungen bzw. Fragen und schafft eine Offenheit der Hypothesenbildung durch Weglassen von einzelnen Elementen (z.B. Ton). Da der Werbespot nicht nur eine Geschichte erzählt, sondern aus kleinen Bildsequenzen besteht, bietet er die Möglichkeit, die filmischen Darstellungsmittel den Lernenden zu vermitteln, indem sie das beworbene Produkt in verschiedenen Zusammenhängen analysieren und vergleichen können. Durch seine Bilder in Verbindung mit den nichtsprachlichen Merkmalen schafft der Werbespot Vorentlastung und unterstützt den Hör-Seh-Verstehensprozess der Lernenden. So 
kann er die Handlungsorientierung im Unterricht fördern, indem er Anregungen zu schriftlichen bzw. mündlichen Präsentationsformen im Klassenraum gibt und Anlässe für Rollenspiele schafft. Die Lernumgebung kann dabei ausgeweitet werden, wenn die Lernenden z.B. Informationen über bestimmte Zeitabschnitte in der Entwicklung des Volkswagen-Konzerns im Internet recherchieren können. Hierbei wird auch die Methodenkompetenz gefördert. Der Werbespot regt auch an, über die Erscheinung „Werbung“" nachzudenken, Vor- und Nachteile zu finden und sich damit kritisch auseinanderzusetzen.

Der Werbetext entspricht dem Niveau B1 nach GER und bedarf deswegen keiner sprachlichen Vorentlastung. ${ }^{10}$ Darüber hinaus kann der Wortschatz rund um das Thema „Auto“ ausgebaut werden. Die Bandbreite des Informationspotenzials des Werbespots reicht von der landeskundlichen Information über Automobile Deutschlands bis zur Wirtschaft- und Industrieentwicklung in Deutschland und kann zur Behandlung weiterer Themen wie z.B. Umweltschutz in Deutschland oder neue Technologien und Mobilität animieren. Der Bekanntheitsgrad des beworbenen Produktes erfordert dabei kein spezielles Vorwissen, sodass die Lernenden sich nicht überfordert fühlen. Bei der Arbeit mit diesem Werbespot im Unterricht kann das Bedürfnis ausgelöst werden, die Lebensweisen zwischen der deutschen und der eigenen Kultur zu vergleichen. Hier gibt der Werbefilm den Lernenden Hilfestellung, sich eine Vorstellung über die Lebenseinstellung der Deutschen und die Rolle des Autos zu machen und ermöglicht den interkulturellen Vergleich der deutschen Autowerbung und der Autowerbung des jeweiligen Herkunftslandes des Lernenden.

Im Rahmen der Arbeit mit dem vorgestellten Werbespot können neben den Hauptzielen Förderung von Hör-Seh-Verstehen und Handlungsorientierung weitere Ziele verfolgt werden:

- Über deutsche Autos und ihre Geschichte sprechen

- Landeskundliche Zusammenhänge erkennen und darüber diskutieren

- Die landeskundlichen Zusammenhänge mit dem Vorwissen verknüpfen und sichern

- Wichtige Merkmale und Komponenten eines Werbespots kennenlernen

- Die Werbung analysieren können

- Sich mit der Werbung kritisch auseinandersetzen

- Selbständige Arbeit und Aneignen der Informationen fördern

- Eigenen Werbespot drehen bzw. Werbetext schreiben

\footnotetext{
10 „Erst wenn ein Auto eine Ära geprägt hat. Wenn es zu einer Lebenseinstellung wurde. Und einer ganzen Generation ihren Namen gab. Erst wenn ein Auto nicht nur groß ist, sondern großartig. Wenn es den ganzen Familien ein Zuhause ist, und jeden an seinen Innovationen teilhaben lässt. Wenn es sich mit keinem Rekord zufrieden gibt und Technologien schafft, die neuen Wege ermöglichen. Erst wenn das Auto heute schon an morgen denkt, dann ist es das Auto.“
} 
Um die Teilnehmer auf den Unterricht einzustimmen und sie in das Thema „Werbung" einzuführen, können im ersten Teil des Unterrichts folgende Aktivitäten durchgeführt werden: Brainstorming zum Thema „Werbung“, Sammeln der Vorund Nachteile von Werbung, Diskussion über Werbung in den jeweiligen Ländern etc. Die Teilnehmer können einander dabei zum Thema Werbung interviewen (z.B. „Schaust du dir die Werbung im Fernsehen oder im Kino an?“ „Wovon fühlst du dich in der Werbung angesprochen?" „Spielt die Werbung bei deinem Einkauf eine Rolle?“ „Hältst du die Werbung für notwendig?““ etc.). In den Diskussionsrunden können die Teilnehmer ihr Vorwissen zum Thema abrufen und sich gleichzeitig kritisch mit dem Gegenstand auseinandersetzen. Hierbei bieten sich unterschiedliche Sozialformen wie Partner- oder Kleingruppenarbeit an. Als Diskussionsgrundlage können die Behauptungen über Werbung (s. Anhang) genommen werden. Die Ergebnisse der Diskussion können an der Tafel festgehalten werden.

Im weiteren Verlauf wird explizit auf die Arbeit mit dem erwähnten Werbespot eingegangen. Zur besseren Veranschaulichung werden hierbei die weiteren Unterrichtsaktivitäten detailliert beschrieben.

- Lehrende/r (L.) stellt die Fragen, welche deutsche Automarken die Teilnehmer (TN) kennen und ob sie über die Geschichte dieser Marken Kenntnisse haben. L. steuert die Diskussion und fragt gezielt über Volkswagen und seine Geschichte. Dabei weist L. auf das weitere Recherchieren zum Thema im Internet und anderen Medien hin, regt somit das autonome Lernen an.

- Vor dem Sehen des Werbespots gibt L. gezielte Hinweise, worauf die TN ihre Aufmerksamkeit beim Sehen lenken sollen. Dabei ist es wichtig, dass die TN nach dem ersten Sehen einen allgemeinen Eindruck bekommen und nach dem zweiten Sehen die Personen, ihre Mimik und Gestik, andere nichtsprachliche Merkmale, die Zusammenhänge zwischen Bildern erkennen und darüber sprechen. L. spielt den Werbespot ohne Ton zweimal ab und die TN machen Notizen auf dem Arbeitsblatt mit den gesteuerten Fragen. Die TN äußern ihre Eindrücke über den Werbespot, besprechen, worum es inhaltlich geht und was die nichtsprachlichen Merkmale, Mimik und Gestik der agierenden Personen über das Produkt aussagen. L. verteilt ein Arbeitsblatt mit den durcheinander zusammengestellten Standbildern aus dem Werbespot. Die TN arbeiten in Kleingruppen und bringen die Bilder in die richtige Reihenfolge. Zur Überprüfung spielt L. den Werbespot noch einmal ab. Danach erfinden die TN in Kleingruppen möglichst zu jedem Bild eine Überschrift bzw. einen Slogan.

- Im weiteren Verlauf vervollständigen die TN die zergliederten Sätze aus dem Werbetext (s. Anhang). L. weist darauf hin, dass es Konditionalsätze sind und erinnert die TN an die Wortfolge. Nachdem die TN die Sätze 
vorgelesen haben, spielt L. den Werbespot einmal mit Ton ab. Die TN vergleichen diesen mit den am Anfang gestellten Hypothesen.

- L. spielt den Werbespot noch einmal ab, die TN achten auf die Autoteile, die im Werbespot gezeigt werden und markieren diese auf dem Arbeitsblatt mit dem abgebildeten Auto. ${ }^{11}$ Als Erweiterung und Zusammenfassung dieser Übung können die TN einen kurzen Aufsatz zum Thema „Mein Traumauto" schreiben, eventuell als Hausaufgabe.

- Anschließend lenkt L. die Aufmerksamkeit der TN auf die Produktion eines eigenen Werbespots, stellt relevante Fragen, die schon im Laufe des Unterricht angesprochen wurden: Was ist an einem Werbespot wichtig? Was macht einen Werbespot aus? etc. L. sammelt die Ideen und notiert diese an der Tafel. L. schlägt vor, sich vorzustellen, dass sich die TN um eine Arbeitsstelle in der Marketingabteilung beim Volkswagen-Konzern in Wolfsburg bewerben. Für die Bewerbung ist es wichtig, ein eigenes Werbekonzept für Volkswagen zu entwerfen. Als Grundlage sollen die TN die Bilder nehmen, die ihnen der Konzern zur Verfügung stellt. Um das Drehen des Werbespots im Klassenraum zu ermöglichen, wurden im Voraus die Standbilder aus den verschiedenen VW-Werbespots erzeugt, bunt ausgedruckt und auf Karteikarten (z.B. DIN A6) geklebt. Die TN bilden zwei Gruppen, sollen die Bilder in die gewünschte Reihenfolge bringen und dazu einen Werbetext entwerfen. Für Hintergrundmusik können die TN die Melodien von ihren Handys nutzen. Die restliche Zeit des Unterrichts verbringen die TN mit der Gestaltung eigener Werbespots. Am Ende des Unterrichts sollen zwei Werbespots für Volkswagen entstanden sein. Die Präsentation der Werbespots erfolgt in der Form, dass die Gruppenmitglieder die Bilder in der Hand halten und diese mit Text und Musik präsentieren. Die Präsentation wird von L. mit einer Videokamera aufgenommen. Die aufgenommenen Präsentationen können im nächsten Unterricht im Klassenraum gezeigt werden, was zur Reflexion und Wiederholung des Stoffes führt.

Das vorgestellte Unterrichtsbeispiel zeigt eine der Einsatzmöglichkeiten von Werbespots zur Förderung von Hör-Seh-Verstehen im handlungsorientierten DaFUnterricht. In diesem Zusammenhang lässt sich noch einmal erwähnen, dass die Werbespots Authentizität in den Klassenraum bringen, die Lernenden für ein autonomes Lernen animieren, dass sie Alltagssituationen darstellen und die Lernenden in diesen handeln lassen. Nicht zuletzt wird das Hör-Seh-Verstehen durch verschiedene Präsentationsmöglichkeiten des Werbespots im Unterricht gefördert. Die Lernenden bleiben dabei Mittelpunkt des Unterrichts und bekommen eine Möglichkeit, zielorientiert zu handeln und wichtige Kompetenzen wie Sprach-, Sozial- und Methodenkompetenz zu entwickeln. Reflektierend auf den vorgenom-

${ }^{11}$ Hierbei wird ein Bildwörterbuch empfohlen, womit die Arbeitsblätter erstellt werden können. 
menen Unterrichtsversuch lässt sich feststellen, dass gerade die Komplexität die Attraktion des Unterrichts mit Fernseh-Werbespots ausmacht und mit einer engagierten Lernergruppe durchaus Erfolge erzielt werden können.

\section{Zusammenfassung und Ausblick}

Zusammenfassend lässt sich sagen, dass die Arbeit mit Fernseh-Werbespots im Fremdsprachenunterricht sehr vielschichtig ist. Diese Tatsache begründet der vorliegende Artikel, der zum Ziel hatte, Werbung als Unterrichtsgegenstand aus verschiedenen Perspektiven zu beleuchten. Es konnte festgestellt werden, dass sich die grundlegenden Prinzipien bei der Arbeit mit Filmen auf die Anwendung von Fernseh-Werbespots im Fremdsprachenunterricht übertragen lassen. Dabei sollte die Werbeanalyse beim Einsatz von Werbespots im DaF-Unterricht bedeutender Bestandteil sein.

Heutzutage gewinnen Werbespots als Träger der landeskundlichen Information in der modernen Didaktik und Methodik zunehmend Aufmerksamkeit. Werbespots sind - wie Filme - Ausdruck kultureller Identität und bieten vor allem für Fremdsprachenunterricht reichhaltige Möglichkeiten, landeskundliche Inhalte unmittelbar zu erarbeiten und den interkulturellen Blick zu erweitern. In den Werbespots werden die Menschen in verschiedenen, auch kommunikativen, Situationen dargestellt, die einen direkten und zeitökonomischen Zugang zum kulturellen Fundus ermöglichen. Dadurch können die Lernenden für zahlreiche Aspekte des Zielsprachenlandes sensibilisiert werden. Sie sehen und erleben Ausschnitte der Wirklichkeit und verschiedene Daseinsformen der Zielkultur.

Diese Erkenntnisse sind für den Fremdsprachenunterricht nützlich, da den Lernenden hierdurch Kulturspezifika vermittelt werden. Um die Werbung richtig verstehen zu können, müssen die in der Werbung dargestellten Konventionen und Werte richtig interpretiert werden. Die Lernenden bekommen durch Bewusstmachen der Werbewirkung einen tieferen Einblick in die Zielkultur und nehmen die Unterschiede der fremden und der eigenen Kultur genauer wahr.

Durch die beschriebenen Einsatzmöglichkeiten der Werbespots wird die Handlungsorientierung im Unterricht gefördert. Der Einsatz von Fernseh-Werbespots versetzt die Lernenden in die Lage, die gezeigten Informationen nicht nur aufzunehmen, sondern diese zu interpretieren, da die dargestellten Gegebenheiten oft mit der Realität nicht übereinstimmen. Diese „Surrealität“ lehrt die Lernenden, kritisch mit dem Medium Werbung umgehen und animiert sie, sich zusätzliche Informationen aus anderen Quellen zu beschaffen.

Der Einsatz von Fernseh-Werbespots im Fremdsprachenunterricht hat das Potenzial, die Lernenden für das Sprachenlernen zu begeistern und sie zum Handeln und autonomen Wissensaneignen zu animieren. Dies fördert implizit die Fertigkeit des Hör-Seh-Verstehens der Lernenden. Aus diesem Grund sollten die FernsehWerbespots regelmäßig eingebaut werden und somit auch zur Ausgewogenheit des 
Fremdsprachenunterrichts beitragen. Abschließend sei geraten, die vorgeschlagenen Herangehensweisen für den Einsatz von Werbespots lediglich als Ausgangsbasis zu betrachten, da diese im Kontext der aktuellen methodisch-didaktischen sowie auch Werbeentwicklungen regelmäßig neu adaptiert werden müssen.

\section{Literatur}

Arnsdorf, Dieter (1991): Die Krönung der schönsten Stunden: 30 Werbespots als Sprechanlaß. Begleitheft zum Video mit Unterrichtsvorschlägen. Ismaning: Verlag für Deutsch.

Ballin, Dieter; Brater, Michael (1996): Handlungsorientiert lernen mit Multimedia. Nürnberg: BW Bildung und Wissen.

Barkowski, Hans; Krumm, Hans-Jürgen (Hrsg) (2010): Fachlexikon Deutsch als Fremd- und Zweitsprache. Tübingen: Francke.

Biechele, Barbara (2006): Film/Video/DVD in Deutsch als Fremdsprache - Bestandsaufnahme und Perspektiven. In: Barkowski, Hans; Wolff, Armin (Hrsg.): Umbrüche. Materialien Deutsch als Fremdsprache 76. Regensburg: FaDaF, 309-328.

Biechele, Barbara (2008): Sehen und Hören bringen Verstehen: Filmverstehen im Konzept der Fertigkeiten eines modernen Fremdsprachenunterrichts. In: Kadzadej, Brikena; Kristo, Ema; de Matteis, Mario; Röhling, Jürgen (Hrsg.): Methodik. und Didaktik. für den Deutschunterricht (DaF). Oberhausen: ATHENA-Verlag, 105-123.

Blell, Gabriele; Lütge, Christine (2004): Sehen, Hören, Verstehen und Handeln. In: PRAXIS Fremdsprachenunterricht. Zeitschrift für das Lebren und Lernen fremder Sprachen 6, 402-405.

Brandi, Marie-Luise (1996): Video im Deutscbunterricht. Eine Übungstypologie zur Arbeit mit funktionalen und dokumentarischen Filmsequenzen. München: Langenscheidt.

Dohrn, Antje (2009): Interkulturelle Werbung im DaF-Unterricht. In: Fan, Jieping; Li, Yuan (Hrsg.): Deutsch als Fremdsprache aus internationaler Perspektive. Neue Trends und Tendenzen. München: Iudicium, 109-120.

Fenske, Ute; Rühle, Christian (2003): Rund um Werbung Kopiervorlagen für den Deutschunterricht. Berlin: Cornelsen.

Gudjons, Herbert (1987): Handlungsorientierung als methodisches Prinzip im Unterricht. In: Westermanns pädagogische Beiträge 5, 6-13.

Hackl, Wolfgang; Langner, Michael; Simson-Pelanda, Hans (1998): Landeskundliches Lernen. In: Fremdsprache Deutsch. Zeitschrift für die Praxis des Deutschunterrichts $18,5-12$. 
Ising, Svetlana (2007): Deutsche und russische Fernseh-Werbeslogans im Vergleich. Eine linguistische und interkulturelle Analyse. Duisburg: Universitätsverlag Rhein-Ruhr.

Janich, Nina (2001): Werbesprache. Ein Arbeitsbuch. Tübingen: Narr.

Janich, Nina (2010): Werbesprache. Ein Arbeitsbuch. Tübingen: Narr.

Jank, Werner; Meyer, Hilbert (2008): Didaktische Modelle. Berlin: Cornelsen.

Jung, Lothar (2001): 99 Stichwörter zum Unterricht-Deutsch als Fremdsprache. Ismaning: Hueber.

Kloss, Ingomar (1998): Werbung. Lehr-, Studien- und Nachschlagewerk. München: Oldenburg.

Kloss, Ingomar (2007): Werbung: Handbuch für Studium und Praxis. München: Vahlen.

Kroeber-Riel, Werner (1996): Bildkommunikation. The New Science of Imagination. München: Vahlen.

Kroeber-Riel, Werner; Esch, Franz-Rudolf (2004): Strategie und Technik der Werbung. Verbaltenswissenschaftliche Ansätze. Stuttgart: Kohlhammer.

Leo, Hildegund (1999): Musik im Fernsehwerbespot. Frankfurt/Main: Lang.

Li, Yuan (2007): Intregative Landeskunde. Ein didaktisches Konzept für Deutsch als Fremdsprache in China am Beispiel des Einsatzes von Werbung. München: Iudicium.

Linthout, Gisela (2004): Handlungsorientierter Fremdsprachenunterricht. Ein Trainingsprogramm zur Kompetenzentwicklung für den Beruf. Amsterdam: Rodopi.

Lonergan, Jack (1987): Video im Fremdsprachenunterricht. München: Hueber.

Lühken, Annette (2007): Werbung als Mittler kultureller Spezifika im Französischunterricht. In: frañösisch beute 4, 373-386.

Meijer, Dick (1998): Landeskundliche Inhalte - Qual der Wahl. In: Fremdsprache Deutsch. Zeitschrift für die Praxis des Deutschunterrichts 18, 18-25.

Ochmann, Nana (2003): Kauf Mich! Werbespots aus dem Fernsehen und Kino im Unterricbt. München: Goethe-Institut.

Patermann, Gabriele; Jürgens, Matthias (2009): Sprachliche, interkulturelle und didaktische Aspekte beim Einsatz von Werbung im DaF-Unterricht. In: Reeg, Ulrike; Gallo, Pasquale (Hrsg.): Schnittstelle Interkulturalität. Beiträge zur Didaktik Deutsch als Fremdsprache. Münster: Waxmann, 65-89.

Raabe, Horst (2003). Audiovisuelle Medien. In: Bausch, Karl-Richard; Christ, Herbert; Krumm, Hans-Jürgen (Hrsg.): Handbuch Fremdsprachenunterricht. Tübingen: Francke, 423-426. 
Rosenstiel, Lutz von; Kirsch, Alexander (1996): Psychologie der Werbung. Rosenheim: Komar-Verlag.

Sass, Anne (2007): Filme im Unterricht - Sehen(d) lernen. In: Fremdsprache Deutsch 36, 5-13.

Schmidt, Siegfried J. (2004): Handbuch Werbung. Münster: LitVerlag.

Schumann, Adelheid (2008): Interkulturelles Lernen mit Werbung. In: PRAXIS Fremdsprachenunterricht. Zeitschrift für das Lebren und Lernen fremder Sprachen 2, 48-53.

Siegert, Gabriele; Brecheis, Dieter (2005): Werbung in der Medien- und Informationsgesellschaft. Eine kommunikationswissenschaftliche Einführung. Studienbücher zur Kommunikations- und Medienwissenschaft. Wiesbaden: Verlag für Sozialwissenschaften.

Schwerdtfeger, Inge Christine (1989): Sehen und Verstehen. Arbeit mit Filmen im Unterricht Deutsch als Fremdsprache. München: Langenscheidt.

Schwerdtfeger, Inge Christine (2003): Übungen zum Hör-Sehverstehen. In:

Bausch, Karl-Richard; Christ, Herbert; Krumm, Hans-Jürgen (Hrsg.): Handbuch Fremdsprachenunterricht. Tübingen: Francke, 299-302.

Vences, Ursula (2002): Guck mal! - Fernseh-Werbespots im Spanischunterricht. In: Hispanorama 95, 65-71.

Weis, Gabi (1994): Werbung im Französischunterricht. Mediensperifische und didaktische Reflexionen. Bochum: Brockmeyer.

\section{Internetquellen}

Goethe-Institut (2011). Gemeinsamer europä̈scher Referenzrabmen für Sprachen: Lernen, lehren, beurteilen. Http://www.goethe.de/Z/50/commeuro/i1.htm (16.05.2013).

Interview von Janich, N. (2006): Da weiß man, was man hat? - Die Sprache der Werbung. Http://www.kulturinstitut.org/fileadmin/user_upload/SPRACH STELLE/Nachlese/Interview_Nina_Janich.pdf (24.03.2013).

Zeuner, U. (1997). Landeskunde und interkulturelles Lernen. Eine Einfübrung. Http://wwwpub.zih.tu-dresden.de/ uzeuner/studierplatz_landeskunde/ zeuner_reader_landeskunde.pdf (27.04.2013). 


\section{Arbeitsblatt 1}

Versuchen Sie die drei Behauptungen durch Begründungen und Beispiele zu untermauern.

1. Durch Werbung behalten viele Menschen ihren Job, weil...

2. Werbung schafft Wettbewerb, weil...

3. Ohne Werbung würden viele Jobs auf wackeligen Beinen stehen, da...

Welche der drei Behauptungen überzeugt Sie nun am meisten?

Bilden Sie zwei Gruppen. Finden Sie Vorteile und Nachteile der Werbung und diskutieren Sie darüber. ${ }^{12}$

\section{Arbeitsblatt 2}

Ergänzen Sie die Sätze:

Wenn ein Auto eine Ära geprägt hat, ...

Wenn das Auto zu einer Lebenseinstellung wurde, ...

Wenn ein Auto den ganzen Familien ein Zuhause ist, ...

Wenn ein Auto Technologien schafft, ...

Wenn ein Auto jeden an seinen Innovationen teilhaben lässt, ...

12 Quelle: Fenske, Rühle 2003: 6. 



\title{
Der Einsatz der Videokamera im Sprechtraining DaF. Ein Werkstattbericht
}

\author{
Monika Wolf
}

\section{Einleitung}

In einem Artikel in dem Konferenzband über „Grundlagen einer sprachwissenschaftlichen Quellenkunde“ äußert sich Johannes Schwitalla dazu, wie die technische Errungenschaft, gesprochene Sprache akustisch und visuell festzuhalten zu können, die Linguistik nachhaltig verändert hat:

Eröffnet hat sich mit der Möglichkeit der Untersuchung fixierter gesprochener Sprache nicht nur ein ganzer Kosmos neuer Forschungsgegenstände, sondern das Bild, das Linguisten von Sprache und Kommunikation hatten, hat sich grundsätzlich gewandelt. (Schwitalla 2013: 136).

Während vor der Erfindung des Tonbands und der Videokamera Sprache allgemein mit Schrift gleichgesetzt wurde bzw. zumindest von den Sprachpflegern die Schriftsprache als einzige gültige Norm betrachtet wurde, stellte sich nun die Komplexität der gesprochenen Sprache heraus:

Komplexität und die Auflösung eines zentralen Ordnungsprinzips sind auch die Folgen der neueren Studien zur menschlichen Kommunikation. Der Blick hat sich geweitet von den traditionellen Gegenständen der Phonetik, der Lexik und der Syntax zu den Formen der sprachlichen und prosodischen Kontextualisierung und zu nonverbalen Signalisierungen. (Ebd.: 142). 
Im Fremdsprachenunterricht kommt es bisweilen selbst im Sprechtraining heute noch vor, dass der Schwerpunkt auf Wortschatz und Grammatik und die Bereitstellung von Redemitteln gelegt und die Aussprache nur dann berücksichtigt wird, wenn zusätzliche Zeit zur Verfügung steht. Dabei werden wichtige Bereiche der mündlichen Kommunikation unter den Tisch gekehrt, deren sich die Linguistik früher nicht bewusst war. Die ganze Komplexität der gesprochenen Sprache mit ihren teilweise unbewusst eingesetzten Komponenten wurde erst durch ihre Dokumentation durch die Videokamera bekannt und ist so in das Zentrum des Interesses gerückt:

Man hat festgestellt, dass das kommunikative Geschehen derart komplex ist, dass die Beteiligten es gar nicht in seinem ganzen Umfang bewusst registrieren können; sie müssen sich auf das für sie Wesentliche konzentrieren. Gleichzeitig entschwindet die eine, steuernde Instanz. Gerade bei den unauffälligen Momenten der Gesprächsorganisation, beim Herstellen und Auflösen einer Interaktion, bei den Verschiebungen und Gewichtungen der Beteiligungsrollen, bei den Signalisierungen von Nähe und Distanz, von Sympathie und Antipathie, Zustimmung und Ablehnung - und noch bei vielem Anderem mehr - verlassen wir uns auf die Mechanismen der sprachlichen, prosodischen und nonverbalen Regelungen, die einfach eingespielt sind, die wir zum großen Teil nicht bewusst und gewollt einsetzen und die meist auch gelingen, weil sie in unzähligen Malen hervorgebracht, im Gehirn abgespeichert und interaktiv bestätigt wurden. (Ebd.).

Dank dieser technischen Neuerungen wissen wir also wesentlich mehr darüber, wie Sprache bzw. Kommunikation funktioniert und können bzw. sollen diese Kenntnis auch im Sprachunterricht verwenden. Die Kosten für die entsprechenden technischen Hilfsmittel sind mittlerweise stark gesunken und befinden sich nun allgemein in einem erschwinglichen Rahmen. Schon mit einfachen Mitteln lassen sich im Sprachunterricht erstaunliche Dinge verwirklichen.

\section{Das Beispiel Frankreich}

In meiner Tätigkeit als freiberufliche Lehrkraft und DAAD-Lektorin an der Universität Toulouse II - Le Mirail setze ich seit etlichen Jahren die Videokamera im Bereich Sprechtraining ein, wobei es sich vorwiegend um junge Deutschlerner französischer Muttersprache handelt. Die Gruppen von Schülern, angehendenden Germanisten und Studierenden, die Deutsch als Wahlpflichtfach belegen, sind generell sehr heterogen in Bezug auf Lernniveau und Motivation. Dazu kommt, dass einige Deutschlerner im Vergleich zu Lernenden anderer Muttersprachen enorme Hemmungen haben, sich in der Zielsprache zu äußern, obwohl auch an französischen Schulen laut des „Plan de renovation de l'enseignement des langues“ von 
2005 der Schwerpunkt des Unterrichts auf dem mündlichen Ausdruck liegt. ${ }^{1}$ Allerdings wird seit einigen Monaten in der französische Presse die Tatsache diskutiert, dass französische Schüler im internationalen Vergleich eine extrem hohe Angst vor Fehlern bzw. vor Versagen haben und darauf mit einer Vermeidungsstrategie reagieren, indem sie bestimmte Aufgaben erst gar nicht bearbeiten. ${ }^{2}$ Im Fremdsprachenunterricht äußert sich dies darin, dass sich die Lernenden auffallend wenig aktiv am Unterricht beteiligen und sogar große Scheu davor haben, auch nur einen kurzen Satz mündlich zu formulieren.

Ein weiteres Problem ist das Sprachniveau, mit denen Schulabgänger an die Universität kommen. Laut des „Plan de rénovation de l'enseignement des langues“ von 2005 des französischen Bildungsministeriums erreichen Schüler am Ende der 9. Jahrgangsstufe das Niveau A2 und mit dem Abitur das Niveau B2. Ob es sich dabei um die erste, zweite oder eventuell dritte Fremdsprache handelt, wird allerdings nicht erwähnt. ${ }^{3}$ In der Realität gibt es selbst in der Germanistik nicht wenige Studienanfänger, die nicht einmal das Niveau A2 vorweisen können. Allerdings gibt es unter anderem aufgrund des Status von Toulouse als Airbus-Standort mit einer relativ großen deutschsprachigen Bevölkerung einige „falsche“ oder „echte“ Muttersprachler, die sich für ein Studium entscheiden, in dem Deutsch zumindest ein Wahlpflichtfach darstellt.

2012 erlangten 76,7 \% eines Jahrganges die Hochschulreife. ${ }^{4}$ Die guten Schüler erhalten die Zulassung für die Vorbereitungsklassen auf die Aufnahmeprüfung zu einer der staatlichen Eliteschulen. Wer sich an der Universität einschreibt, hat dies also nicht geschafft. Ich stehe als Lehrkraft also häufig vor Gruppen sehr junger Lernender, die sich nicht als Teil der intellektuellen Elite sehen, sondern sich eher als aussortiert empfinden, die zum Teil nicht in der Lage sind, sich flüssig auf Deutsch auszudrücken und im Unterricht mit muttersprachlichen Studienkollegen konfrontiert sind.

Von diesem Hintergrund ausgehend werde ich im Folgenden berichten, wie ein einstündiges Videotraining pro Woche den Studierenden helfen kann, sich innerhalb eines Jahres zu selbstbewussten Deutschsprechern zu entwickeln. Die technischen Voraussetzungen für ein Videotraining sind eine einfache Videokamera oder Fotokamera mit Eignung für Videos, wie sie ab ca. 200 Euro gehandelt werden. Bei größeren Kursgruppen wird ein Beamer oder zumindest ein Fernseher zur Wiedergabe benötigt. Bei Kleingruppen bis zu zehn Personen kann ein

\footnotetext{
${ }^{1} \mathrm{Http}: / /$ eduscol.education.fr/cid45756/plan-de-renovation-de-l-enseignement-des-langues.html. 26.7. 2013.

2 „Les élèves français du primaire et secondaire ont peur de mal faire“. In: Le Monde 28.01.2013. Http:/ / educationdechiffree.blog.lemonde.fr/2013/01/08/les-eleves-francais-du-primaire-et-secon daire-ont-peur-de-mal-faire. 26.07.2013.

${ }^{3}$ Http://eduscol.education.fr/cid45678/cadre-europeen-commun-de-reference-cecrl.html. 29.07. 2013 .

${ }^{4}$ Http://infogr.am/Les-chiffres-cls-du-bac-2013. 26.07.2013.
} 
Laptop mit größerem Bildschirm (ab ca. 17 Zoll) im Notfall ausreichend sein. Ein einfaches Stativ, erhältlich ab 20 Euro, wäre sinnvoll, wenn dies das Budget zulässt.

Von Anfang an sollten die Kursteilnehmer mit Aufnahmen von ihren Darbietungen konfrontiert werden. Sie müssen allerdings behutsam auf diese Arbeitsweise vorbereitet werden, denn den meisten ist es sehr unangenehm, gefilmt zu werden. Es muss vorher unbedingt geklärt werden, dass jeder Bildrechte hat und diese Aufnahmen außerhalb des Unterrichts nicht an Dritte gezeigt werden, es sei denn es liegt eine Genehmigung des Betroffenen vor, die allerdings jeder ohne Konsequenzen verweigern darf. Es muss ihnen also erläutert werden, dass die Aufnahmen ausschließlich didaktischen Zwecken dienen und als solche einen großen Wert haben. Sollten sie tatsächlich z.B. für Vorführungen oder für die Webseite des Instituts o. ̈̈. verwendet werden, darf dies nur geschehen, wenn die entsprechende Genehmigung schriftlich vorliegt.

\section{Erste Übungen}

Als erste Übung ist eine kurze Selbstpräsentation geeignet. ${ }^{5}$ Es reicht z.B., dass jeder Namen und Herkunft erwähnt und erzählt, warum er/sie Deutsch lernt. Jeder tritt vor die Kamera, stellt sich in zwei bis drei Sätzen vor. Unmittelbar danach wird der Auftritt gemeinsam angesehen, bevor die nächste Person ihre Darbietung macht. Ich frage die betroffene Person zuerst, was ihr an der eigenen Vorstellung gefallen hat, um die Lernenden gleich daran zu gewöhnen, den eigenen Vortrag zu analysieren. Erfahrungsgemäß folgt die Antwort, dass er ihm/ihr überhaupt nicht gefallen habe. Dann richte ich dieselbe Frage an die ganze Gruppe. Auch die Kursteilnehmer wissen oft nicht, was sie antworten sollen. Es ist wichtig, dass die Lehrkraft an dieser Stelle mindestens einen positiven Punkt nennt, um die Studierenden zu ermutigen, z.B. die kräftige Stimme, der gute Blickkontakt zum Publikum oder die gute Körperhaltung. Beim ersten Kandidaten kann zumindest dessen Spontanität hervorgehoben werden. Die konstruktive (Selbst-)Kritik folgt, wobei gelernt werden muss, diese sachlich zu formulieren. Vor allem muss unbedingt vermieden werden, dass Kritik in einen verbalen Angriff ausartet, denn das wäre kontraproduktiv. Hier kann die Frage „Was würden Sie verändern?“ hilfreich sein, wobei stets darauf geachtet werden muss, dass die Kritik auf das Wesentliche fokussiert wird. Es dürfen also nicht zu viele Punkte auf einmal genannt werden. Zu Beginn geht es vor allem um die Lautstärke und den Blickkontakt zum Publikum, dann folgen mit weiteren Übungen allmählich die aufrechte Körperhaltung und die Gestik. Entsprechende Anregungen für die Lehrkraft sind im Internet zu finden. ${ }^{6}$

Die einzelnen Fertigkeiten wie z.B. das laute Sprechen sollten zwischen den gefilmten Aufgaben gesondert geübt werden. Fällt es vielen bereits in der Mutter-

\footnotetext{
5 Viele weitere Anregungen zu Übungen finden sich bei Niehoff 2005, der grundsätzlich allgemeiner ist als der vorliegende; gleichzeitig treffen sich beide Artikel in manchen Punkten.

${ }^{6} \mathrm{Vgl}$. die umfangreiche Linkliste im Anhang.
} 
sprache schwer, die Stimme vor Publikum zu heben, so gibt es in der Fremdsprache erst recht Hemmungen. Dagegen helfen Spiele, in denen immer wieder etwas laut gerufen werden muss, wozu es auch nützlich sein kann, den Kursraum zu verlassen und im Freien zu arbeiten. Eine gute Übung ist es, den Sprecher in einem großen Abstand zum Publikum stehen zu lassen oder das Publikum in verschiedene Richtungen zu verteilen. Er muss sich nun in einer für alle verständlichen Lautstärke ausdrücken und dabei Geräusche, die beispielsweise von Wind, einem vorbeifahrenden Auto oder einem Flugzeug verursacht werden, berücksichtigen. Dann sollte jeder auch mit der Akustik im Kursraum arbeiten und lernen, mit diesen Bedingungen zurechtzukommen. Bei der nächsten Darbietung vor der Videokamera muss es nicht explizit um die Lautstärke der Stimme gehen, sie sollte aber in der direkt anschließenden Analyse schwerpunktmäßig angesprochen werden. Es ist insofern sinnvoll, dass die Analyse unmittelbar folgt, weil die Kursteilnehmer somit von den Fehlern der anderen lernen und dann versuchen, sie zu vermeiden, wenn sie selbst an der Reihe sind bzw. die Stärken der anderen imitieren.

Damit die Studierenden nicht demotiviert werden, muss, immer wieder Positives hervorgehoben werden, und es sollte auch betont werden, dass die ersten Kandidaten generell zu mehr Fehlern neigen, was keine Schande, sondern für die gesamte Gruppe lehrreich ist. Sollte jemand allzu große Hemmungen davor haben, vor Publikum zu treten, so kann es ihm/ihr helfen, den Kursraum für ein paar Sekunden zu verlassen. Die Darbietung beginnt in diesem Fall mit dem Eintritt des Sprechers in den Saal. Mit dem Überschreiten der Türschwelle schlüpft er symbolisch in eine andere Rolle und überwindet so auch seine Hemmschwelle.

Nach diesem Muster laufen generell alle Übungen im Laufe des Jahres. Die Aufgaben sollten in ihrer Art natürlich variieren, und den Lernenden sollte zuvor das dabei erstrebte Ziel erklärt werden. Eine der Übungen, die ich gerne zu Beginn einsetze, ist das Lesen vor Publikum, wobei auch die Intonation eine große Rolle spielt. Während des ersten Semesters ist es eine Prüfungsaufgabe der Studierenden, Nachrichten zu simulieren. Sie müssen dabei zu zweit oder zu dritt agieren, um sich an Gruppenarbeit zu gewöhnen, worauf in Frankreich eher wenig Wert gelegt wird. Sie lernen, einem Partner das Wort zu überlassen und Übergänge zwischen den einzelnen Darbietungen zu schaffen. Die Texte sollen sie selbst verfassen und dürfen ihrer Phantasie freien Lauf lassen. Es geht nicht um die Ernsthaftigkeit des Inhaltes, sondern um die oben erwähnten Kriterien wie Stimm-Modulation, Mimik und Körperausdruck.

Auch die Prüfungen werden gefilmt. Die Kandidaten nehmen ihre Aufgaben ernster, wenn sie wissen, dass sie mit der Videokamera festgehalten werden. Außerdem können anschließend die einzelnen Kriterien wie Intonation/Akzentuierung, Aussprache/Artikulation, Flüssigkeit, Grammatik/Vokabular und Körperausdruck/Mimik/Stimm-Modulation präziser analysiert und beurteilt werden, denn die einzelnen Filme können beliebig oft angehalten und wiederholt werden. 
Ein sehr angenehmer und wichtiger Aspekt ist die Motivationssteigerung. Da die Studierenden Text und Inhalt frei erfinden dürfen und Humor ausdrücklich willkommen ist, werden Hemmungen abgebaut, und es entstehen die ausgefallensten Szenen. Es kommt auch vor, dass sich die Kandidaten auf ihre Prüfung geradezu freuen und stolz auf ihre Ideen und Darbietungen sind. Die Schwierigkeit des Vorlesens wird mitunter aber auch unterschätzt. Deswegen ist es wichtig, dass jeder schon vor der Prüfung mindestens einmal gefilmt wurde und sich selbst sehen konnte.

Um weiter an der Intonation zu arbeiten, eignen sich Rollenspiele, in denen emphatisch gesprochen wird. Akzentuierung und Satzmelodie sollen dabei übertrieben werden, um sie zu verinnerlichen. Es ist hilfreich, Bespiele vorzuführen und sich von diesen Szenen zum Nachspielen inspirieren zu lassen. Möglichkeiten wären Loriots Sketch „Zwei Herren im Bad“ oder einfach Ausschnitte aus Seifenopern. Gerade durch das szenische Spielen entsteht eine Dynamik im Kursraum, bei der die Studierenden lernen, auch nonverbal aufeinander einzugehen, ihre Intuition kommunikativ einzusetzen und auf die Gruppe zu reagieren, was auch für das Hörverstehen förderlich ist. Es kommt immer wieder vor, dass Kursteilnehmer große Hemmungen haben, in die Rolle einer anderen Person zu schlüpfen. Hier kann anfangs das Arbeiten mit Masken hilfreich sein, welche die Studierenden als Hausaufgabe aus bunten Kartons selbst herstellen. Mit einem verdeckten Gesicht fällt es einigen leichter, sich vor einem Publikum auf eine Bank zu stellen und so ihren Körper zu exponieren, während sie sich als typischen Charakter einer Seifenoper vorstellen, wie z.B. das blonde Gift, der ölige Herzensbrecher aus Argentinien, die bösartige, alkoholkranke Hausmeisterin etc.

Als Prüfung wird schließlich in Kleingruppen eine etwa fünfminütige Seifenopernszene gedreht. Der Text ist wiederum von den Studierenden selbst verfasst worden, er soll aber auswendig rezitiert werden. Auch darauf müssen die Kursteilnehmer vorher ausdrücklich vorbereitet werden, denn nicht wenige gehen davon aus, dass wie in der ersten Prüfung in allen weiteren abgelesen werden darf. Immer wieder habe ich während dieser Art der Übung große Überraschungen erlebt. Manche können in der Rolle einer anderen Person zum ersten Mal aus sich herausgehen und behalten den Rollennamen weiterhin als Spitznamen, zumindest im Unterricht. Auch Unterbewusstes kann zutage treten. So sprach eine Studentin während eines Rollenspiels plötzlich mit schwäbischem Akzent, ohne dies selbst zu bemerken. Auf Nachfragen erfuhr ich, dass sie in Freiburg geboren wurde, Deutschland aber als Zweijährige verlassen hatte und Deutsch später als Fremdsprache lernte. Allerdings fiel sie danach wieder in den französischen Akzent zurück. Es blieb bei einem einmaligen Erlebnis dieser Art.

Bei der Auswahl der Übungen sollte im Laufe des Kurses sowohl das monologische als auch das dialogische Sprechen berücksichtigt werden. Es wird gerne vergessen, dass auch die Eröffnung und das Beenden von Vorträgen und Gesprächen sowie die Mechanismen des Sprecherwechsels gesondert einstudiert werden müssen. In Dialogen mit mehr als zwei Teilnehmern zeigt sich ein weiterer Vorteil 
der videographischen Aufnahme, denn hier verlieren Zuhörer bei einer reinen Tonaufnahme schnell den Überblick, wie Schwitalla (2013: 139) betont: „Das Tonband stößt da an seine Grenzen, wo die aufgenommene Gruppe zu groß ist und eine zunächst zentrierte einzige Interaktion sich in mehrere Interaktionskonstellationen spaltet.“

Des Weiteren sollte im Kurs besprochen werden, wie man mit falsch produzierten Äußerungen umgehen und diese eventuell noch im Vortrag „reparieren“ kann. Etliche Sprecher verziehen das Gesicht, wenn sie einen Fehler bemerken, verlieren die Fassung und kommen ins Stocken oder Stottern. Dies zu vermeiden, kann ebenfalls gelernt werden, wodurch ein Vortrag viel flüssiger und der Sprecher wesentlich kompetenter wirkt. Auch Muttersprachler bedienen sich nonverbaler Mittel, wenn ihnen z.B. ein Wort nicht einfällt, in dem sie etwa mit den Händen den gemeinten Begriff ikonisch abbilden (vgl. Schwitalla 2013: 141).

\section{Weiterführende Übungen}

Im zweiten Semester geht es mir vor allem darum, das Sprechen der Kursteilnehmer zu professionalisieren, indem sie Powerpoint-gestützte Präsentationen üben. Im Internet finden sich Youtube-Tutorials über die Arbeit mit Powerpoint oder Open Office Presentations in vielen verschiedenen Sprachen. Ich habe ein Video in französischer Sprache ausgewählt, dessen Link ich in den MoodleKursraum gesetzt habe, damit sich diejenigen, die sich mit keinem der beiden Programme auskennen, außerhalb des Unterrichts damit vertraut machen können. Gute und schlechte Beispiele für einzelne Präsentationsfolien und den Aufbau des Vortrags werden während des Kurses gezeigt. Auch unerfahrene Teilnehmer finden sich sehr schnell mit der Technik zurecht. Wichtig ist, dass diese nun immer wieder geübt und auch wiederholt gefilmt wird, denn das Gelernte wird mit der Einführung von neuen Themen gern vergessen.

Generell sind die Kursteilnehmer nun selbst in der Lage, ihre Darbietungen zu analysieren und kritisieren und den Lernfortschritt festzustellen. Interessanterweise kann aber jeder Aspekt auf verschiedene Menschen unterschiedlich wirken. So entstehen öfters angeregte Diskussionen darüber, ob eine Geste eines Sprechers nun störend ist oder nicht. Die Kursteilnehmer nehmen sich selbst auf dem Bildschirm häufig negativer wahr als ihre Kollegen. Als Übung kann der Kurs auch in einzelne Gruppen eingeteilt werden, von denen sich jede beim Analysieren der Präsentationen auf eine bestimmte Kategorie wie Aussprache/Intonation oder Körperausdruck konzentriert.

Zwischen den einzelnen Videoübungen setze ich nun gerne Phonetikübungen ein. Durch das wiederholte Ansehen der eigenen Vorträge werden Kursteilnehmer allmählich für eine korrektere Aussprache sensibilisiert. Grundsätzlich müssen sie wieder in Gruppen arbeiten, damit zwischen Monologen und Dialogen gewechselt und die Koordination der Beteiligten mit ihren Teammitgliedern während der 
Darbietung geübt wird. Außerdem entsteht durch die Zusammenarbeit oft eine erstaunliche Kreativität, und die Studierenden lernen voneinander. Vor allem den „Schwächeren“ wird bewusst, dass auch sie Stärken haben, von denen das Team profitieren kann.

Beim ersten Versuch stelle ich den Teilnehmern das Thema der Präsentation völlig frei. Es geht beim Analysieren also nicht um das $W$ as, sondern um das Wie. Ein sehr häufiger Fehler ist der fehlende Abschluss. Erst wenn die Lernenden ihren Vortrag selbst ansehen, wird ihnen oft bewusst, wie abrupt ihr Ende ist. Lehrreich sind kleine Wettbewerbe um das pfiffigste Ende eines Vortrags.

Der richtige Einsatz der Gestik bzw. das Vermeiden überflüssiger oder gar störender Gestik, die in keiner Beziehung zum Inhalt des Gesagten steht, wird beim formellen Vortrag besonders wichtig. Natürlich wird ein professionelles Training aus zeitlichen Gründen oft nicht möglich sein und sprengt auch den Rahmen des Sprachunterrichts, aber auch hier kann zumindest ein Bewusstmachen sogenannter motorischer „Ticks" Abhilfe schaffen. Hilfreich ist beim Abspielen der Aufnahmen die Funktion der Beschleunigung, wenn sich eine störende Geste häufig wiederholt. Der betroffenen Person wird dies so eindrücklicher nahegelegt. Genauso kann aber auch der Film verlangsamt oder zurück- und vorgespult werden, um bestimmte Phänomene aufzuweisen bzw. zu finden, die für das Training relevant sind.

Ein Aspekt, der beim Sprechen vor Publikum eine große Rolle spielt, ist die Aktion im Raum. Die Beteiligten müssen lernen, sich während ihrer Darbietungen frei im Raum zu bewegen und sich stimmlich an seine Akustik anzupassen. Ein Vorteil dieser gefilmten Präsentationen ist, dass auch die Manipulation von Gegenständen wie des Laserpointers oder der Präsentationsmaus während des Sprechens geübt wird (vgl. Mondada 2007). Das gleiche gilt für die Interaktion mit dem Publikum. Die Lernenden achten allmählich darauf, wie die Zuschauer im Raum verteilt sind und arbeiten auch mit deren Reaktionen.

Durch das wiederholte intensive „Beobachtetwerden“ durch die Kamera gewöhnen sich die Lernenden also an das Agieren vor Publikum. Es ist freilich nicht möglich, fremde Zuschauer in den Kursraum zu bringen, aber eine solche Situation kann am ehesten simuliert werden, wenn die Beteiligten üben, als fokussiertes Objekt zu handeln, bis sie diese Fokussierung nicht mehr als störend auffassen. So ist das Videotraining beispielsweise sehr ergiebig, wenn das Verhalten während Vorstellungssprächen in der Zielsprache geübt werden soll. Wie bereits erwähnt, empfinden viele zunächst ein starkes Unbehagen, wenn sie gefilmt werden, denn „das Filmen dringt auch stärker ins Bewusstsein der Aufgenommenen ein als das Tonband“ (Schwitalla 2013: 140).

Schmitt; Fiehler; Reitemeier (2007) beschreiben in einem Artikel über audiovisuelle Datenkonstitution, wie verschiedene Schüler auf die Anwesenheit der Videokamera regieren: Sie „,blenden sich aus“, in dem sie sich hinter ihrer Hand oder einem Heft verstecken, wenden sich ab, nehmen eine aufrechtere Haltung ein, schneiden Grimassen, winken in die Kamera oder ignorieren sie. Die unterschied- 
lichen Verhaltensweisen hängen von der Relevanz ab, welche die Aufnahmesituation für die einzelnen Beteiligten darstellt (ebd.: 386).

Des Weiteren kommen während einer formellen Rede Sprecher häufiger ins Stocken, stottern oder verwenden zu oft Füllwörter. Laut Schwitalla (2013: 138) wirken in einem Gespräch solche Elemente nicht unbedingt störend, aber durch die Aufnahme wird das gesamte Geschehen archiviert, dadurch objektiviert, indem es allen auf gleiche Weise zugänglich wird und kann wiederholt angeschaut und auch mit verschiedenen Schwerpunkten stets aufs Neue analysiert werden: Das Tonband ist kein mechanisiertes Hören. Beim Sprechen und Hören im dialogischen Kontext konzentriert sich unser psychischer Apparat darauf, was gesagt wird. Alles andere wird ausgeblendet. Das Tonband registriert alle Laute und Geräusche und vermittelt dadurch dem Hörer verwirrende Hörwahrnehmungen. Dies wurde schon früh als störend empfunden; wie ein Sprecher ,sich räuspert und wie er spuckt, all jene individuellen Entgleisungen, die die Schallplatte festhält" (Gerhardt 1947: 138) passten nicht ins Bild gesprochener Sprache.

Bei einem formellen Monolog wie dem Powerpoint-gestützten Vortrag fallen oft wiederholte Geräusche wie Räuspern und Füllwörter deutlich stärker auf und wirken störend. Praktischerweise misst die Videokamera auch die Zeit der Aufnahme. So kann gezählt werden, wie oft innerhalb einer Minute ein Sprecher einen Verlegenheitslaut von sich gibt. Ergebnisse wie alle acht Sekunden ein ,ähm“ sind nicht selten. Das Bewusstmachen ist der erste Schritt zur Reduzierung bzw. Vermeidung, allerdings ist dies ein sehr langer Prozess.

Es ist überhaupt eine gute Übung, innerhalb einer vorgegebenen Zeit zu sprechen. Es fällt sehr vielen Leuten schwer, sich an ein Zeitfenster zu halten, da dies nur selten geübt wird. Studenten höheren Niveaus lasse ich als Prüfung einen Kurzvortrag von zwei Minuten über ein Thema ihrer Wahl halten. Zehn Notizen sind erlaubt, allerdings keine vollständigen Sätze. Punktabzüge gibt es für eine Zeitüber- oder -unterschreitung ab 30 Sekunden sowie für ein abruptes Ende des Vortrages. Ein gelungener Abschluss wird also vorausgesetzt. Natürlich gelten wieder die oben genannten Kriterien für die Bewertung. Diese Art von Rede kann vorher mit kürzeren und längeren Zeitvorgaben geübt werden.

Wie bereits erwähnt, habe ich eine relativ hohe Anzahl von Muttersprachlern in meinen Lehrveranstaltungen. Die meisten von ihnen haben ihren Schulabschluss in Frankreich absolviert. Es ist auch schon vorgekommen, dass deutschsprachige Erasmus-Studenten deutsches Sprechtraining als Wahlpflichtfach nehmen, in der Regel in der Absicht, ohne Anstrengung ECTS-Punkte zu erlangen. Allgemein gibt es keine Probleme, sie in die mündlichen Sprachkurse zu integrieren, denn auch sie profitieren sehr von der Arbeit mit der Videokamera, auch wenn sie akzentfrei und fließend Deutsch sprechen. Besonders die Übungen zum formellen Sprechen sind hilfreich für sie, was ihnen vor allem dann bewusst wird, wenn sie die erste Aufzeichnung ihrer Darbietungen sehen. Sie merken selbst, dass es nicht ausreichend ist, Muttersprachler zu sein, um einen guten Vortrag zu halten, sondern dass es auch für sie einer sorgfältigen Vorbereitung bedarf. Ein ungeübter Sprecher ist 
kaum in der Lage, spontan eine professionelle Präsentation zu machen, denn wie Schwitalla (2013: 137) bemerkt, ist es

[...] nicht so, dass ein Sprecher für das, was er sagen will, in seinem Gehirn die Wörter sammelt, sie in eine syntaktische und morphologische Form bringt und sie dann mittels phonetischer Übersetzungen ausspricht. Wir sprechen in einem ständigen Prozess des Entwerfens und des nachträglichen Reformulierens.

So kann selbst für diese Zielgruppe der DaF-Unterricht lehrreich sein, und die anderen Kursteilnehmer lernen wiederum von ihnen. Freilich ist es sinnvoll, dass deutsche Muttlersprachler keinen reinen Anfängerkurs im Sprechtraining belegen.

Eine weitere Übung mit ebenfalls kameraerfahrenen Kursteilnehmern ist die Gästeführung. Sollten die Lehrveranstaltungen zu weit von einem Stadtzentrum entfernt sein, ist eine Campusführung möglich. Die Studierenden sollten sich gemeinsam eine Route ausdenken, bei der jeder eine Etappe übernimmt und erläutert. Dabei kann als Einleitung ein Überblick der Geschichte der Universität gegeben oder die Struktur der entsprechenden Hochschule erläutert werden. Ich überlasse es den Studierenden immer selbst, ob sie sich an Fakten halten oder den Vortrag frei erfinden möchten. Auch hier geht es nicht um den Inhalt, sondern um die Art und Qualität der Darbietung. Hinzu kommt, dass es gerade bei einer Führung immer wieder zu „Störungen“ durch Nebengeräusche oder durch das Eingreifen Unbeteiligter kommt.

Als Ortslektorin an der Universität Avignon habe ich Führungen durch das historische Stadtzentrum abhalten lassen. Immer wieder stellten sich Passanten zur Gruppe, hörten zu und gaben sogar Kommentare ab, was auf unerfahrene Redner sehr irritierend wirken kann. Diese Art der Simulation kommt einer realen Sprechsituation also sehr nahe. In diesem Kontext wird oft vor allem in Bezug auf Körperausdruck das vergessen, was im Kursraum mühsam einstudiert wurde. Durch die Kamera wird den Beteiligten dies bewusst gemacht. Ein typischer Fehler ist es, sich vom Publikum wegzudrehen und sich dem Gegenstand der Führung zuzuwenden. Dies zu vermeiden wurde bereits mit dem Powerpoint-Vortrag geübt. Es bleibz aber sinnvoll, wenn solche Aspekte in den verschiedensten Situationen geübt werden und die Lernenden sich das Ergebnis immer wieder ansehen, bis sich eine gewisse Routine einstellt.

Unbedingt sollte die Lehrkraft bei der Gästeführung beachten, dass diese aufgrund von Bildrechten nur außerhalb von Gebäuden auf öffentlichem Gelände stattfinden und gefilmt werden darf. Selbst auf dem Campus ist es möglich, dass vorher eine Filmgenehmigung eingeholt werden muss. Ansonsten kann es zu unangenehmen Begegnungen mit dem Wachpersonal oder dem Hausmeister kommen. Ebenso muss an manchen Universitäten eine Genehmigung vorliegen, um gefilmte Sequenzen in den Moodle-Kursraum oder die Internetseite des Instituts zu setzen. 
Letztere kann sehr kreativ mit den Produkten der Arbeit mit der Videokamera gestaltet werden. Ein sehr lohnendes, wenn auch zeitaufwendiges Projekt ist es, die Studierenden selbst einen Film drehen zu lassen. Es kann sich um einen kurzen Spielfilm handeln, aber auch der Werbe- oder Dokumentarfilm kommen in Frage. So mussten z.B. die Germanistikstudenten im dritten Semester für das Deutschstudium in Toulouse werben und im zweiten Semester den studentischen Austausch mit der Universität Bonn dokumentieren. Die Kursteilnehmer schlüpfen so in die Rolle des Kursleiters, indem sie nicht mehr nur vor der Kamera stehen, sondern selbst Regie führen. In Teamarbeit treffen sie Entscheidungen darüber, was gedreht wird, und wählen aus dem gefilmten Material die Sequenzen aus, die zum fertigen Film geschnitten werden. Sollte ein zweisprachiger Film entstehen, notieren sie die Äußerungen und übersetzen sie in die deutsche bzw. französische Sprache für die Untertitelung.

Im Internet gibt es kostenlose Software zur Videobearbeitung und entsprechende Tutorials dazu. ${ }^{7}$ An Universitäten ist es oft möglich, technische Unterstützung durch das Medienzentrum zu erhalten, wo eventuell sogar die gesamte Montage übernommen wird. Häufig gibt es auch versierte Kursteilnehmer, die gerne ihr Knowhow zur Verfügung stellen. Ansonsten müssen sich die Lehrkraft und die Lernenden die entsprechenden Kenntnisse aneignen, wovon sie jedoch dauerhaft profitieren. Professionelle Filme sind nicht vorauszusetzen. Auch amateurhafte Produkte können sehenswert sein, und generell sind die Beteiligten auf das Resultat sehr stolz, wodurch sich ihre Motivation für zukünftige Projekte und allgemein für das Deutschlernen enorm steigert.

\section{Ausblick}

Die erhöhte Motivation ist meines Erachtens auch eines der wichtigsten Argumente für den Einsatz mit der Videokamera im DaF-Unterricht. Sicherlich erfordert dieser zumindest zu Beginn einen großen Arbeitsaufwand. Ebenso wird eine nicht unerhebliche Unterrichtszeit in Anspruch genommen, bis sich sowohl bei der Lehrkraft als auch bei den Lernenden eine gewisse Routine eingestellt hat. Dabei sind ebenso, zumindest am Anfang bzw. bei niedrigem Sprachniveau, relativ viele Erläuterungen in der Muttersprache der Kursteilnehmer nötig, was sich aber mit der Zeit gibt. Letztendlich ist auch davon auszugehen, dass ein Transfer von der Übung vor der Kamera zur Realität nicht gleich von Anfang an stattfindet, sondern dass es hierfür einer gewissen Geduld bedarf.

Der Aufwand lohnt sich allerdings in vielerlei Hinsicht. Die Studierenden erwerben durch die Analyse der Filmsequenzen die Fähigkeit zur Selbstkorrektur, indem sie lernen, die eigenen Fehler, aber auch die Lernfortschritte zu erkennen. Dadurch werden Hemmungen abgebaut, und die „Fremdsprachenverwendungs-

${ }^{7}$ Hier sei erneut an die Linkliste verwiesen. 
angst" (Schoormann; Schlak 2012: 176) schwindet. Routine im Sprechen vor Publikum entsteht, Erkenntnisse und Kompetenzen im Bereich Stimm-Modulation, Körperausdruck, Prosodie und Aussprache und ihre soziokulturelle Bedingtheit werden gewonnen. Das Selbstvertrauen verstärkt sich, was mit einer Motivationssteigerung einher geht. Teamarbeit und autonomes Lernen werden trainiert, wobei die Kreativität der einzelnen gefördert wird. Die Lernenden gewöhnen sich an Projektarbeit mit Einhaltung vorgegebener Termine.

Nicht zuletzt ist das videographische Festhalten von Prüfungsaufgaben von großem Vorteil bei der Beurteilung der Performanz durch die Lehrkraft, denn das Aufgenommene oder bestimmte Ausschnitte davon können beliebig oft wiedergegeben werden, wodurch eine objektivere Bewertung möglich ist, als wenn eine Darbietung nur einmal angesehen bzw. -gehört wird. Das mehrfache Ansehen des Aufgenommenen ist sogar notwendig, da das Geschehen bei der mündlichen Rede derart komplex ist, dass es mit einem Mal von einer einzelnen Person nicht umfassend aufgenommen werden kann (vgl. Schwitalla, 2013: 140). Werden die einzelnen Filmsequenzen den Lernenden z.B. durch Moodle zugänglich gemacht, haben diese ebenfalls Gelegenheit, sie wiederholt anzusehen, zu analysieren und die Entwicklung des Lernfortschritts mitzuverfolgen.

Die Vorteile überwiegen also eindeutig. Daher sollte sich niemand von technischen Schwierigkeiten abschrecken lassen, sondern mit einfachen Übungen beginnen, die hin und wieder den Unterricht ergänzen. Auch die Lehrkraft muss zunächst eine gewisse Routine entwickeln und sollte daher nicht mit allzu ehrgeizigen Projekten beginnen. Ebenso darf am Anfang nicht zu viel von den Kursteilnehmern erwartet werden, wenn sie mit diesem Ansatz vorher nie konfrontiert waren. Wenn aber für eine gute Lernatmosphäre im Unterricht gesorgt wird, ermutigen sich die Lernenden gegenseitig und lassen sich von der Arbeit und den Ideen der anderen inspirieren. Sie merken, dass sie sich für die Darbietungen vorbereiten können und müssen, und es wird so manchem klar, dass es auch in einem nichtmuttersprachlichen Umfeld wie in Frankreich möglich ist, die Sprechfertigkeit im Deutschen zu verbessern. Und so kommt es doch gelegentlich vor, dass kleine Wunder geschehen und vermeintlich Stumme zu sprechen beginnen.

\section{Literatur}

Mondada, Lorenza (2007): Interaktionsraum und Koordinierung. In: Schmitt, Reinhold (Hrsg.): Koordination. Analysen multimodaler Interaktion. Tübingen: Gunter Narr, 55-93.

Niehoff, Marion (2005): Handlungsorientiertes Video im Fremdsprachenunterricht. In: Ludwigsburger Beiträge ₹ur Medienpädagogik: Online-Magazin des Interdis₹iplinären Zentrums für Medienpädagogik. und Medienforschung an der PH Ludwigsburg 7. Ludwigsburg: IZMM. Http://www.ph-ludwigsburg.de/fileadmin/subsites/ 1b-mpxx-t-01/user_files/Online-Magazin/Ausgabe7/Niehoff7.pdf. 
Schmitt, Reinhold; Reinhard Fiehler; Ulrich Reitemeier (2007): Audiovisuelle Datenkonstitution und Koordinationsprozesse. In: Reinhold Schmitt (Hrsg.): Koordination. Analysen multimodaler Interaktion. Tübingen: Gunter Narr, 377-410.

Schoormann, Matthias; Torsten Schlak (2012): Sollte korrektives Feedback „maßgeschneidert" werden? Zur Berücksichtigung kontextueller und individueller Faktoren bei der mündlichen Fehlerkorrektur im Zweit-/Fremdsprachenunterricht. In: Zeitschrift für Interkulturellen Fremdsprachenunterricht 17, 2,172-190. Http://zif.spz.tu-darmstadt.de/jg-17-2/beitrag/ Schoor-mann_Schlak.pdf.

Schwitalla, Johannes (2013). Tonband und Videokamera als Erkenntnisinstrumente zur Untersuchung mündlicher Kommunikation. In: Kratochvílová, Iva; Wolf, Norbert Richard (Hrsg.): Grundlagen einer sprachwissenschaftlichen Quellenkunde. Tübingen: Gunter Narr, 135-144.

Streeck, Jürgen (2007): Geste und verstreichende Zeit. Innehalten und Bedeutungswandel der „bietenden Hand“. In: Hausendorf, Heiko (Hrsg.): Gespräch als Prozess. Linguistische Aspekte der Zeitlichkeit verbaler Interaktion. Tübingen: Gunter Narr, 157-177.

\section{Weiterführende Literatur}

Aguado, Karin; Karen Schramm; Helmut Vollmer J. (Hrsg.) (2010): Fremdsprachliches Handeln beobachten, messen, evaluieren. Neue methodische Ansätze der Kompetenzforschung und der Videographie. Frankfurt/Main: Peter Lang.

Heidtmann, Daniela; Marie-Joan Föh (2007): „Verbale Abstinenz als Form interaktiver Beteiligung." In: Reinhold Schmitt (Hrsg.): Koordination. Analysen multimodaler Interaktion. Tübingen: Gunter Narr, 263-292.

Schoormann, Matthias; Torsten Schlak (2011): ,Zur Komplexität mündlicher Fehlerkorrekturen." Beiträge zur Fremdsprachenvermittlung 51, 77-105. Http:/ /www. vep-landau.de/bzf/2011_51/bzf\%2051-2011\%20(pdf)/_06_\%20Schoormann $\% 20$ Schlak\%20_77-105_.pdf.

\section{Mündliche Kommunikation}

Http:/ /www.communicationorale.com. (30.6.2013)

\section{Sprechen vor der Kamera}

Http:/ / theaterdaf.wikispaces.com/4.+Spiel!Film+-+Die+Kamera+1\%C3\%A4uft. (30.6.2013)

Http:/ /www.mediamanual.at/mediamanual/workshop/video/kamera/index.php. (30.6.2013) 
Http://www.dummies.com/how-to/content/finetuning-your-acting-performanceon-film.html. (30.6.2013)

Http://www.movie-college.de/filmschule/schauspiel/stimmbildung.htm. (30.6.2013)

Http://www.movie-college.de/filmschule/schauspiel/stimme2.htm. (30.6.2013)

Http://www.movie-college.de/filmschule/schauspiel/stimme-vokale.htm. $(30.6 .2013)$

Http://www.movie-college.de/filmschule/schauspiel/textarbeit.htm. (30.6.2013)

Http://www.youtube.com/watch?v=Q117WgOAeMI. (30.6.2013)

Http://www.youtube.com/watch?v=3T_cXOVQGrk. (30.6.2013)

\section{Körpersprache}

Http://www.movie-college.de/filmschule/schauspiel/koerpersprache.htm. (30.6.2013)

Http://dasgehirn.info/handeln/mimik-gestik-koerpersprache. (30.6.2013)

Http://www.sueddeutsche.de/thema/Körpersprache. (30.6.2013)

Http://www.focus.de/finanzen/karriere/management/koerpersprache/koerpersp rache/koerpersprache_aid_5470.html. (30.6.2013)

Http://wwws.phil.uni-passau.de/histhw/TutKrypto/tutorien/koerpersprache. htm. (30.6.2013)

Http://www.samy-molcho.de/bdk1.htm. (30.6.2013)

Http://www.welt.de/themen/koerpersprache. (30.6.2013)

Http://www.frank-wittke.de/nonverbal-und-koerpersprache. (30.6.2013)

Http://www.br.de/grips/faecher/grips-deutsch/04-koerpersprache-friseur100. html. (30.6.2013)

Http://www.br.de/fernsehen/br-alpha/sendungen/grundkurs-deutsch/ grundkurs-deutsch-lehrgang-deutsch100.html. (30.6.2013)

Http://nonverbalekommunikation.org. (30.6.2013)

Http://www.nonverbale-kommunikation.info/definition.php. (30.6.2013)

Http://arbeitsblaetter.stangl-taller.at/KOMMUNIKATION/KommNonverbale. shtml. (30.6.2013)

Http://www.magic-point.net/fingerzeig/grundlagen-deutsch/kommunikation/ koerperspr/koerperspr.html. (30.6.2013) 
Http:/ /www.planet-wissen.de/kultur_medien/kommunikation/koerpersprache/ index.jsp. (30.6.2013)

\section{Filmtechnik}

Http:/ / www.achsensprung.net/?page=article\&action=show\&id=13\&afm_redirect $=1$. $(30.6 .2013)$

Http://www.teachsam.de/deutsch/film/film_einstellung_2.htm. (30.6.2013)

Http:/ / www.uni-duesseldorf.de/ jucquois/texte.php?seminar=40\&aid=185. (30.6.2013)

Http://wavepictures.bplaced.net/media/tutorials/kameraperspektiven_und_einstellungen.pdf. (30.6.2013)

\section{Erstellung eines Drehbuchs oder Storyboards}

Http://www.e-teaching.org/didaktik/konzeption/inhalte/drehbuch. (30.6.2013)

Http://www.e-teaching.org/didaktik/konzeption/inhalte/storyboard. (30.6.2013)

Http://www.mediamanual.at/mediamanual/workshop/video/animation/animat_ 06.php. (30.6.2013)

Http://www.teachsam.de/deutsch/film/film_storyboard.htm. (30.6.2013)

Http://www.movie-college.de/filmschule/filmgestaltung/storyboard.htm. (30.6.2013)

\section{Digitale Videoverarbeitung mit Windows Movie Maker}

Http://lehrerfortbildung-bw.de/werkstatt/video/wmmtut. (30.6.2013)

Http:/ / windows.microsoft.com/de-de/windows-vista/getting-started-withwindows-movie-maker. (30.6.2013)

Http:/ /www.chip.de/artikel/Workshop-Microsoft-Windows-Movie-Maker2.0_12813301.html. (30.6.2013)

Http:/ /www.pcwelt.de/ratgeber/Videoschnitt-Movie-Maker-Videos-schneidenSchritt-fuer-Schritt-4063787.html. (30.6.2013) 



\section{Neue Medien}





\title{
Multimodale Kompetenz und multimodale Kommunikation im DaF-Unterricht
}

\author{
Christina Margrit Siever
}

\section{Förderung multimodaler Kompetenz im DaF-Unterricht}

Kommunikation findet im 21. Jahrhundert häufig in den digitalen Medien statt, und Kommunikation in den digitalen Medien wiederum ist heutzutage multimodaler denn je. Unter Multimodalität wird die Kombination von mehreren Sinnesmodalitäten (visuell, auditiv, olfaktorisch, gustatorisch, taktil) oder Kodalitäten (Sprache, Bild, Ton) verstanden, wobei bei mehreren Sinnesmodalitäten und Kodalitäten von Multimodalität im engeren Sinne, bei einer Kodalität und mehreren Modalitäten oder einer Modalität und mehreren Kodalitäten von Multimodalität im weiteren Sinne gesprochen wird (vgl. Siever im Druck). Im vorliegenden Beitrag liegt der Fokus auf der visuellen Sinnesmodalität, und zwar auf den Zeichenkodalitäten Sprache und statisches Bild.

Im Jahr 2013 wurden täglich rund 550 Millionen Bilder ins Social Web hochgeladen, was jährlich knapp 200 Milliarden Bildern entspricht, mittlerweile dürften es sogar mehr sein. Zudem muss konstatiert werden, dass wohl lediglich etwa $15 \%$ der weltweit gemachten Fotos ins Social Web gelangen (vgl. Siever im Druck). Geräte zur Erstellung digitaler Fotos sind weit verbreitet, nicht zuletzt auch aufgrund der Verbreitung von Smartphones, die allesamt über Kameras verfügen. Auch die Verbreitung von (Breitband-)Internetanschlüssen sowie Internet-Flatrates für Mobilgeräte tragen dazu bei, dass heute Kommunikation mit Bildern alltäglich geworden ist, sei es im Social Web oder auf Smartphone-Apps wie beispielsweise WhatsApp oder Snapchat. Bilder nehmen also gegenwärtig in der Kommunikation einen 
großen Stellenwert ein, weshalb es im (Fremd-)Sprachenunterricht neben der Sprachkompetenz auch die multimodale Kompetenz zu fördern gilt (vgl. Müller 2012; Stöckl 2011). Stöckl (2011: 45) versteht unter multimodaler Kompetenz kognitive und textpraktische Tätigkeiten, die sowohl für die Produktion als auch für die Rezeption von multimodalen Kommunikaten benötigt werden, um „die Integration der verschiedenen Zeichenressourcen zu einem syntaktischen, semantischen und funktionalen Ganzen“ zu ermöglichen.

Zur multimodalen Kompetenz zählen die Fähigkeiten

1. Sorten bzw. Typen von Bildern kategorisierend zu erkennen

2. dem Bild eine im Verwendungskontext relevante Bedeutung zuzuweisen

3. den Sprachtext im Abgleich mit der visuellen Botschaft zu verstehen

4. semantisierte Sprache und kontextualisiertes Bild zu integrieren und

5. die Bildlichkeit der Sprache und der Textfläche bzw. des Schriftkörpers in den Prozess des Gesamtverstehens einzubeziehen (ebd.).

Betrachtet man diese einzelnen Fähigkeiten, so wird klar, dass multimodale Kompetenz neben der Sprachkompetenz auch Bildkompetenz voraussetzt. Die multimodale Kompetenz wiederum kann als ein Teilbereich der kommunikativen Kompetenz angesehen werden. Den Ausdruck „kommunikative Kompetenz“ hat Dieter Baacke in Anlehnung an Jürgen Habermas in den 1970er-Jahren geprägt, „um die Fähigkeit des Menschen zu bezeichnen, sich im Alltag zu orientieren und diesen durch kommunikatives Handeln zu bewältigen. Dabei sind sowohl Fähigkeiten zur personalen Kommunikation als auch zur Medienkommunikation gemeint" (Süss 2013: 209).

Geht man davon aus, dass es das Ziel des (Fremd-)Sprachenunterrichts ist, die kommunikative Kompetenz zu fördern, so muss folglich nicht nur die Sprachkompetenz, sondern auch die multimodale Kompetenz gefördert werden. Wie eine solche Förderung aussehen kann, wird im vorliegenden Beitrag aufgezeigt. Der Fokus liegt dabei auf statischen Bildern und multimodalen Kommunikaten im (Social) Web. Im folgenden Abschnitt wird ein kurzer Überblick über die multimodale Kommunikation im Social Web gegeben, im Anschluss daran wird in Abschnitt 3 erläutert, wo im Social Web Bilder gefunden werden können und was es dabei in rechtlicher Hinsicht zu beachten gilt. Bevor im letzten Abschnitt konkrete Vorschläge für den Unterricht gemacht werden, werden im Abschnitt 4 Vor- und Nachteile des Einsatzes des Social Webs im DaF-Unterricht diskutiert. 


\section{Multimodale Kommunikate und multimodale Kommunikation im Social Web}

Die Multimodalität ist ein wesentliches Merkmal der Kommunikation im sogenannten Social Web. Mit Social Web (auch bekannt unter Web 2.0) wird derjenige Teil des WWWs bezeichnet, der sich durch die Partizipation der Nutzenden auszeichnet.

Das Social Web umfasst

1. Communitys wie Social-Networking-Communitys (z.B. Facebook) oder Social-Sharing-Communitys (z.B. YouTube, Flickr)

2. den darin entstehende User Generated Content (= nutzergenerierte Inhalte) sowie

3. die sich bildenden sozialen Netzwerke zwischen den Nutzenden.

Dass Bilder - und hier insbesondere Fotos - eine tragende Rolle im Social Web spielen, zeigt ein kurzer Blick auf die Zahlen: Bei Facebook waren im Januar 2013 bereits über 240 Milliarden Fotos hochgeladen, monatlich kommen durchschnittlich rund 10 Milliarden Bilder hinzu. Die weltweit größte Foto-Community stellt Flickr mit über 8 Milliarden Fotos dar.

Im Hinblick auf die Förderung multimodale Kompetenz im DaF-Unterricht gilt es folgende Unterschiede zwischen den zwei Arten von Communitys hervorzuheben: Die User verfolgen unterschiedliche Ziele, bei den Social-Sharing-Communitys steht der User Generated Content, im Falle von Foto-Communitys also Fotos, im Mittelpunkt, wohingegen in Social-Networking-Communitys die Kommunikation mit Familie, Freunden und Bekannten im Vordergrund steht, die nicht nur verbal, sondern auch über Bilder stattfindet. Vielen DaF-Lernenden wird die (multimodale) Kommunikation in Social-Networking-Communitys vertraut sein. Gemeinsam ist beiden Arten von Communitys, dass die dort veröffentlichten Bilder stets mit Texten versehen werden können, so beispielsweise mit Albumtiteln, Bildtiteln, Bildunterschriften, Tags (Schlagworten) und Kommentaren unterhalb oder innerhalb der Bilder. Gerade die sogenannten Notizfunktion, mittels der Kommentare innerhalb von Bildern angebracht werden können, ist - wie noch zu zeigen sein wird - für den DaF-Unterricht von besonderem Interesse.

In Abb. 1 ist ein Beispiel einer Seite aus der Foto-Community Flickr zu sehen. Das vom Nutzer erstellte multimodale Kommunikat besteht aus der Fotografie, dem Bildtitel „Stadtbahn Bochum Rathaus Süd“, der Bildbeschreibung „Eine richtig beeindruckende Haltestelle, finde ich...“ sowie den Tags „stadtbahn / bochum / rathaus / süd / 29.01.2006“". 


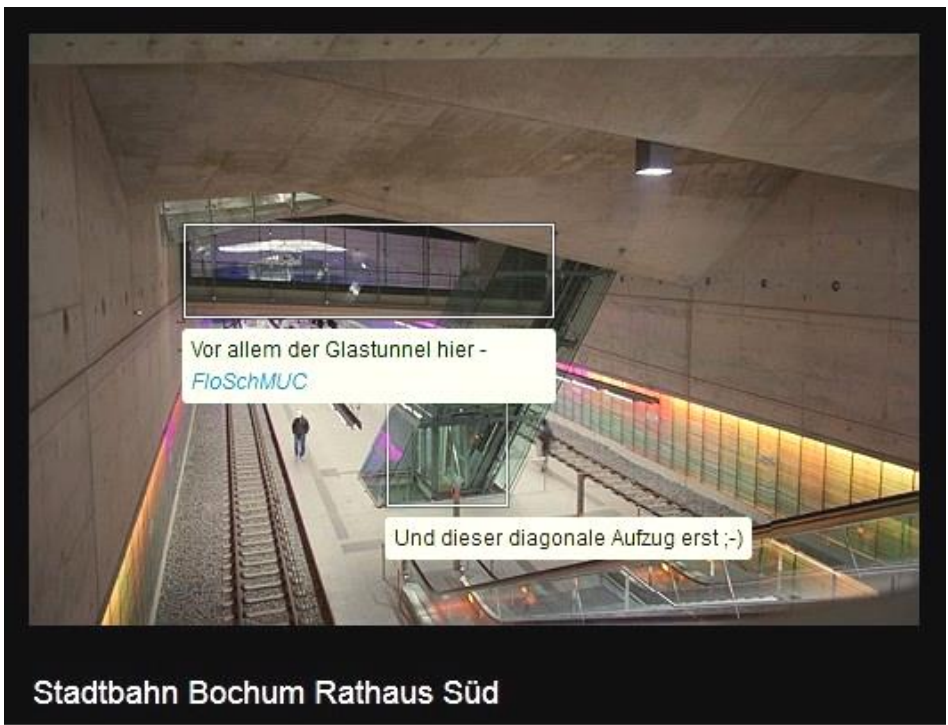

Eine richtig beeindruckende Haltestelle, finde ich...

Lammbader, Dirk65 und mihaly_foki haben dieses Foto zu ihren Favoriten hinzugefügt.

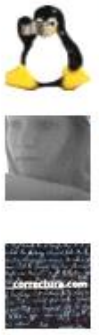

\section{computix}

finde ich auch, vor allem das farbige Licht sieht interessant aus

debbie noire

moderne architektur geht mir aufn piss!

Tags (Tag hinzufügen)
stadtbahn bochum rathaus süd
29.01 .2006

\section{Abb. 1: Beispiel für Bild, Bildtitel, Bildbeschreibung, Kommentare und Notizen auf Flickr $^{1}$}

Auf die elliptisch formulierte Aussage „[Das ist] Eine richtig beeindruckende Haltestelle des Fotografen" finden sich sowohl Reaktionen unterhalb als auch innerhalb des Bildes. Der Nutzer „computix“ reagiert zustimmend und dies ebenfalls

\footnotetext{
1 Das Bild stammt von Matthew Dolibog: https://www.flickr.com/photos/mattathyah/92936486. Aus Platzgründen ist hier kein Original-Screenshot zu sehen, sondern eine Zusammenstellung der wichtigsten Elemente. Im aktuellen Layout von Flickr befinden sich das Bild, der Bildtitel und die Kommentare nicht direkt untereinander, die Tags sind weiter rechts auf der Seite angeordnet.
} 
elliptisch: „[Das] finde ich auch“ und präzisiert, was ihn konkret beeindruckt, nämlich das farbige Licht. Die Nutzerin ,debbie noire“ hingegen ist von der Haltestelle nicht beeindruckt, vielmehr missfällt ihr die moderne Architektur, was sie mit der umgangssprachlich-derben Formulierung „,geht mir aufn piss“ klar zum Ausdruck bringt. Der Nutzer „FloSchMUC“ reagiert in seiner Notiz wiederum zustimmend und ebenfalls elliptisch: „[Mich beeindruckt] Vor allem der Glastunnel hier.“ Der Urheber des Fotos reagiert darauf mit „Und dieser diagonale Aufzug erst ;-)“.

Analysiert man die sprachliche Form der Kommentare unterhalb oder innerhalb der Bilder, so wird zweierlei deutlich. Zum einen zeigt sich, dass in der schriftbasierten Interaktion „Sprache nun auch in technisch übertragener Form elliptisch werden [kann], wie sie es in nichttechnisierter Kommunikation (im mündlichen Alltag) auf andere Weise immer schon war“ (Schmitz 2004: 84). „Ellipse“ ist auf das griechische Substantiv „élleipsis“ zurückzuführen, das soviel wie „Mangel“ bedeutet (vgl. Duden 2007b). Dieser Mangel ist jedoch lediglich in Bezug auf die syntaktische Ebene der Sprache zu verstehen: „Denn in der Regel [...] werden syntaktisch elliptische Äußerungen im Alltag als (pragmatisch) hinreichend vollständig empfunden“" (Schmitz 2001: 428). Dies ist eine Thematik, die auf jeden Fall mit fortgeschrittenen DaF-Lernenden besprochen und diskutiert werden sollte, wenn mit authentischen Flickr-Fotoseiten gearbeitet wird. Zum andern wird anhand der Kommentare innerhalb der Bilder deutlich, dass die Notizfelder mit den Notiztexten die Möglichkeit der Deixis, also des Zeigens, bieten: „In Zweifelsfällen und in Fällen, in denen es auf Details ankommt, hilft unter Anwesenden das Zeigen, dient es doch genau dazu, sinnliche Wahrnehmung(en) kommunikativ verläßlich [sic!] zu etablieren, also, wenn man so will, Wahrnehmung unmittelbar in die Kommunikation einzubinden" (Hausendorf 2006: 89f.). So wird in Abb. zweimal Objektdeixis realisiert, einmal mit dem Demonstrativpronomen (,dieser diagonale Aufzug“) und einmal mit dem definiten Artikel („der Glastunnel“). Darüber hinaus ist Lokaldeixis im Lokaladverb „hier“ zu finden, mit welchem auf den gewählten Ausschnitt des Bildes verwiesen wird.

\section{Nutzung von Bildern aus dem Web}

Das Social Web sowie Bilder aus dem Social Web können sowohl Unterrichtsgegenstand als auch Quelle für Unterrichtsmaterial sein. Bevor in den folgenden Abschnitten auf den Unterrichtsgegenstand eingegangen wird, soll in diesem Abschnitt aufgezeigt werden, wo im Social Web Bilder gefunden werden können und welche rechtlichen Aspekte es dabei zu beachten gilt.

Bilder unterstehen meistens dem Urheberrecht. Für den Unterrichtsgebrauch innerhalb einer einzigen Klasse dürfen zwar urheberrechtlich geschützte Bilder verwendet werden. Ein mit Bildern versehenes Arbeitsblatt darf jedoch nicht an andere Lehrpersonen weitergegeben werden. Aus diesem Grund ist es sinnvoll, Bilder zu verwenden, die über sogenannte Creative-Commons lizenziert sind. 
Während bei urheberrechtlich geschützten Bildern alle Rechte vorbehalten sind, sind bei den Creative Commons nur manche Rechte vorbehalten, wobei es sechs verschiedene Standardlizenzen gibt. Die Namensnennung (BY) der Urheberschaft muss immer erfolgen, darüber hinaus gibt es drei weitere Optionen, die vom Lizenzierenden gewählt werden können: 1. NC: kommerzielle Nutzung ist ausgeschlossen, 2. ND: das Werk darf nicht verändert werden sowie 3. SA: Weitergabe unter gleichen Lizenzbedingungen.

Creative-Commons-Bilder können beispielsweise über die Metasuchmaschine „Creative Common Search“" gefunden werden, durchsucht werden die Datenbanken von Flickr, Fotopedia, Google Images, Open Clip Art Library und Pixabay. Weitere Quellen für Bilder sind „Freeimages“, „Wikimedia Commons“ und „Pixelio".3 Bei der Suche gilt es zu beachten, dass die Metadaten zu den Bildern zumeist von den Urhebern selbst erstellt werden, und dies in verschiedenen Sprachen. Bei der Bildersuche lohnt es sich deshalb oft, Suchbegriffe in verschiedenen Sprachen zu verwenden. Ein weiteres Problem beim Retrieval von Bildern stellt die sogenannte „basic level variation“ (Golder, Huberman 2005: 2) dar: Auf Bildern abgebildete Gegenstände können auf einem Kontinuum der Präzision (sehr allgemein - sehr spezifisch) benannt werden, so beispielsweise mit den Schlagworten „Säugetier - Rüsseltier - Elefant“. Da man bei der Suche nicht weiß, auf welcher Ebene der Urheber das Bild verschlagwortet hat, ist es unter Umständen notwendig, Abfragen auf diesen verschiedenen Ebenen durchzuführen. Schließlich ist es auch möglich, Bilder nach Farben zu suchen. ${ }^{4}$ Im DaF-Unterricht könnte dies von Nutzen sein, wenn man die Farbadjektive behandeln möchte (z.B. „Was ist auf diesem Bild zu sehen? - „Ein rotes Auto, eine weiße Wolke und ein grüner Baum“; „Ich sehe was, was du nicht siehst und das ist (Farbadjektiv)“ - Mitspieler versucht zu erraten, was gemeint sein könnte).

Nicht zuletzt sei auch erwähnt, dass DaF-Lernende oftmals über eine eigene Digitalkamera oder ein Mobiltelefon mit integrierter Kamera verfügen. Werden im DaF-Unterricht Bilder benötigt, können diese auch selbst erstellt und allenfalls auch ins Social Web hochgeladen werden für Unterrichtsprojekte.

\section{Einsatz des Social Webs im DaF-Unterricht: Pro und Kontra}

Zweifelsfrei stellt das Social Web eine tolle Fundgrube für Bilder dar, die im DaFUnterricht genutzt werden können. Das Social Web bietet darüber hinaus jedoch auch zahlreiche Möglichkeiten zur Kommunikation, sei dies innerhalb eines DaFKurses oder auch mit deutschen Muttersprachlern, die Social-Web-Communitys nutzen. Im Folgenden sollen die Vor- und Nachteile in Bezug auf den Einsatz des Social Webs im DaF-Unterricht erörtert werden.

\footnotetext{
2 http://search.creativecommons.org/?lang=de.

${ }^{3}$ http://www.freeimages.com; http://commons.wikimedia.org; http://www.pixelio.de.

${ }^{4}$ http://labs.tineye.com/multicolr.
} 
Zunächst einmal muss natürlich die notwendige Infrastruktur vorhanden sein, sprich: Nicht jede Schule verfügt über Klassensätze mit Laptops und/oder Computerräume. Zudem muss die Lehrperson entsprechende Kenntnisse und Fähigkeiten mitbringen, um Social-Web-Projekte durchführen zu können, d.h. eine entsprechende Einarbeitungs- und Vorbereitungszeit muss eingeplant werden. Ein Vorteil von Social-Web-Projekten ist aber sicherlich, dass keine besondere Software benötigt wird, ein Computer mit Internetanschluss reicht aus. Dies ist auch deshalb von Vorteil, weil die DaF-Lernenden ebenfalls zuhause weiterüben oder Hausaufgaben erledigen können.

Während für einige Teilnehmende der Umgang mit dem Computer eine Herausforderung darstellen könnte, kann es für andere Teilnehmende motivierend wirken, die digitalen Medien für das Lernen einzusetzen. Der innovative und allenfalls auch spielerische Charakter von Social-Web-Projekten kann sowohl zum Lernen anspornen als auch als wohltuende Abwechslung zum restlichen Unterricht betrachtet werden.

Wie am Beispiel in Abb. 1 gezeigt handelt es sich bei der Kommunikation im Social Web oftmals um schriftbasierte dialogische Kommunikation. Für DaF-Lernende hat dies den Vorteil, dass sie mit anderen Nutzern dialogisch kommunizieren können, ähnlich wie in mündlichen Dialogen, doch können sie sich mehr Zeit nehmen, um zu überlegen, wie sie etwas formulieren wollen, sie können in Ruhe ein Wörterbuch aufrufen und unbekanntes Vokabular nachschlagen. In diesem Zusammenhang ist es folglich auch sinnvoll, zunächst Wissen und Fertigkeiten im Bereich der Benutzung digitaler Wörterbücher zu vermitteln und aufzuzeigen, welche Ressourcen es überhaupt gibt (vgl. Müller, Siever 2011: 44-46). Zu nennen sind hier insbesondere „Beolingus" für Englisch, Spanisch und Portugiesisch sowie LEO für Englisch, Französisch, Spanisch, Italienisch, Chinesisch, Russisch, Portugiesisch und Polnisch. Besonders hervorgehoben sei im Zusammenhang mit der multimodalen Kompetenz das Bildwörterbuch von Pons, das auch für Social-WebProjekte sicherlich sehr nützlich ist. ${ }^{5}$

${ }^{5}$ http://dict.tu-chemnitz.de; http://www.leo.org; http://bildwoerterbuch.com. 


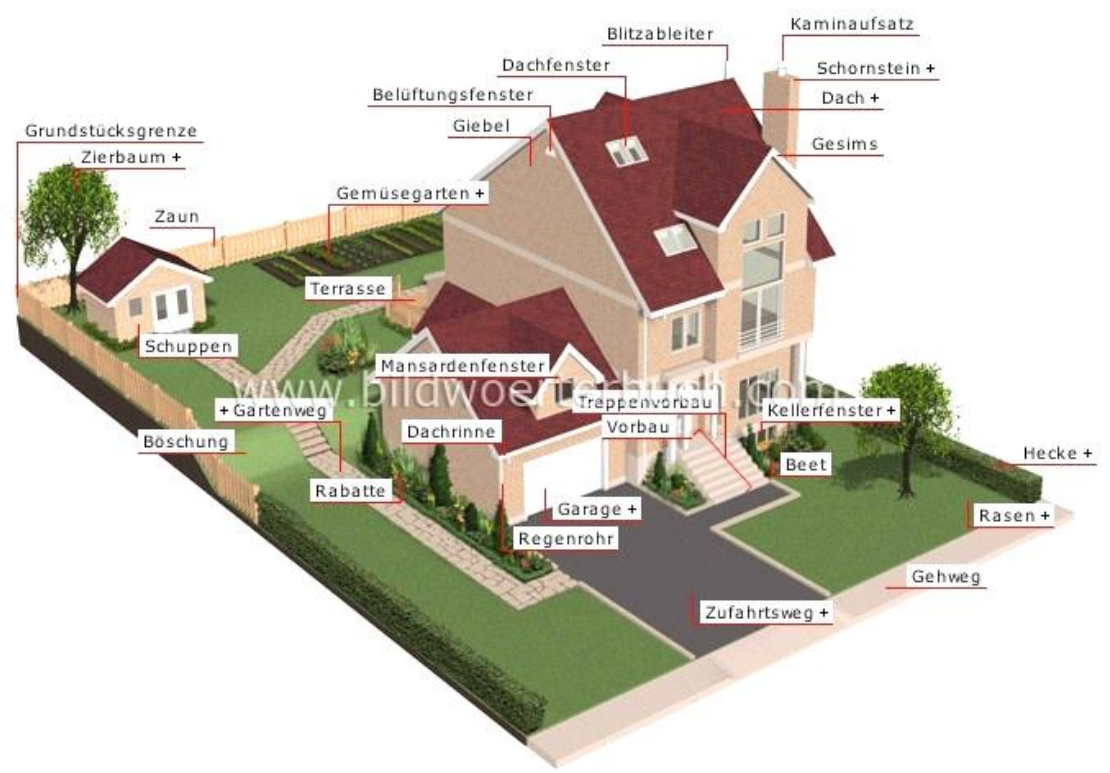

Abb. 2: Bildwörterbuch von Pons: Außenansicht eines Hauses

Am Beispiel in Abb. 1 haben wir gesehen, dass es in der Foto-Community „Flickr“ die Möglichkeit gibt, Notizen innerhalb des Bildes anzubringen, die beispielsweise auch für Beschriftungen wie in Bildwörterbüchern (vgl. Abb. 2) genutzt werden können, sprich: DaF-Lernende können selbst Bildwörterbücher erstellen. In diesem Zusammenhang sei auf eine Eigenheit der Notizen hingewiesen, die gleichzeitig einen Vor- und Nachteil darstellt: Für die Flickr-Notizen wird die Technik der sogenannten Hoverboxen genutzt. Dies bedeutet, dass wenn man mit der Maus über das mit einer Notiz versehene Bild fährt (sogenannte Mouseover-Position), eine transparente Pop-up-Box gemeinsam mit einem schwebenden Text erscheint. Falls auf einem Bild mehrere Notizen angebracht sind, werden bei Mouseover-Position zuerst einmal alle Hoverboxen angezeigt. Will man die Notiztexte lesen, so muss man den Mauszeiger direkt über das entsprechende Notizfeld halten, d.h. es sind niemals alle Notiztexte eines Bildes gleichzeitig sichtbar. Wenn DaF-Lernende also ein Bildwörterbuch wie in Abb. 2 erstellen wollen, ist eine Anzeige aller Notizen gleichzeitig nicht möglich. Der Vorteil jedoch ist, dass dadurch das Vokabular bestens eingeübt werden kann: Die DaF-Lernenden können sich die einzelnen Hoverboxen ansehen und überlegen, wie die einzelnen markierten Objekte auf Deutsch heißen, und dann mittels Mouseover-Position überprüfen, ob ihre Antwort korrekt war.

Notizen können aber selbstverständlich für viele weitere Formen der Kommunikation verwendet werden. Denkbar sind Diskussionen über die Bilder, die ver- 
gleichbar sind mit mündlichen Gesprächen über Bilder, wie dies beispielsweise bei einem gemeinsamen Besuch einer Kunstausstellung oder beim gemeinschaftlichen Ansehen von Urlaubsfotos üblich ist. Während in der mündlichen Kommunikation mittels Zeigegesten auf einzelne Ausschnitte von Bildern verwiesen werden kann und diese sodann auch kommentiert werden können, kann dies bei Flickr schriftbasiert mittels Notizen erfolgen. Solche schriftbasierten Dialoge können auch als Vorbereitung auf mündliche (Anschluss-)Kommunikation genutzt werden.

Kommunikation im Social Web kann jedoch nicht nur innerhalb eines DaFKurses stattfinden, sondern auch mit Nutzenden der Community, die deutscher Muttersprache sind. Auch dies bringt wiederum verschiedene Vor- und Nachteile mit sich, die im Folgenden erörtert werden sollen. Zunächst einmal stellt sich die Frage, welches Deutsch im DaF-Unterricht erlernt werden soll, was an dieser Stelle nur in aller Kürze diskutiert werden kann (vgl. dazu ausführlich Durrell 2012). Gutes Deutsch muss nicht unbedingt korrektes Deutsch bedeuten, sondern vielmehr angemessenes Deutsch (vgl. ebd.: 91). Die Standardsprache verfügt zwar über Prestige, sie stellt jedoch das Register der formellen Sprache und v.a. der Schriftsprache dar, die nicht in jeder Situation angemessen ist. Dies bedeutet, dass neben der Beherrschung der Standardsprache auch die weiterer Varietäten notwendig ist, die teilweise vom kodifizierten Standard abweichen (vgl. ebd.: 85). Insbesondere vor dem Hintergrund, dass die durchschnittlichen DaF-Lernenden hauptsächlich Kompetenzen in der (gesprochenen) Alltagssprache benötigen (vgl. (ebd.: 89-90), kann die Position, dass einzig die Standardsprache unterrichtet werden soll, nicht länger vertreten werden. Doch das Unterrichten der informellen Alltagssprache bringt auch Probleme mit sich, und zwar ist sie zum einen im Gegensatz zur Standardsprache nicht ausführlich in Nachschlagewerken beschrieben, zum andern wird sie in den meisten DaF-Lehrwerken kaum berücksichtigt (vgl. ebd.: 89; 99). Das Social Web bietet hier die Möglichkeit, dass die DaF-Lernenden mit authentischen Texten konfrontiert werden können, die hauptsächlich einem informellen geschriebenen Register entsprechen.

Wenn die DaF-Lernenden mit deutschen Muttersprachlern kommunizieren (besonders geeignet ist dafür z.B. die Flickr-Gruppe ,Wir sprechen Deutsch“), ${ }^{6}$ kann es - je nach Kompetenzniveau - zunächst einfach ein Erfolgserlebnis sein, dass Kommunikation mit Muttersprachlern möglich ist. Wie bereits angesprochen, kann es bei der Verständigung in der informellen Alltagssprache jedoch zu Verständnisproblemen kommen, die die DaF-Lernenden unter Umständen nicht mittels Nachschlagewerken lösen können, weshalb einerseits die Lehrperson diesbezüglich Hilfestellung leisten muss, andererseits können die DaF-Lernenden auch ermuntert werden, dass sie nachfragen, wenn sie bestimmte Wörter oder Formulierungen nicht verstehen. So ist beispielsweise in einem Kommentar zum Foto in

${ }^{6}$ Https://www.flickr.com/groups/92751773@N00. 
Abb. 1 zu lesen „aufn piss“. Hier haben die DaF-Lernenden Glück, denn im Rechtschreibduden (2013) ist beides zu finden:

1. „aufn, auf'n (umgangssprachlich für auf den, auf einen)“

2. „Piss, der; -es (so viel wie Pisse)“ sowie „Pis|se, die; - (derb für Harn)“

Doch da es sich um eine Redewendung handelt, dürfte der Ausdruck als Ganzes dennoch den DaF-Lernenden Schwierigkeiten bereiten. Hier muss die Lehrperson erläutern, dass die Wendung in Analogie zu ,jemandem auf den Docht (auch: ,Senkel“ oder ,Zeiger“, derb auch: ,Sack') gehen“ gebildet wurde: „Die umgangssprachliche Redewendung bedeutet, jemandem lästig werden, ihm auf die Nerven gehen“" (Duden 2007a).

Oftmals sind Texte im Social Web auch fehlerhaft, seien es Schreib- oder Tippfehler. Dies sollte ebenfalls thematisiert werden im Unterricht: Die Lernenden sind es sich gewohnt, dass sie unbekannte Wörter im Wörterbuch nachschlagen können, doch in solchen Fällen sind sie unter Umständen nicht erfolgreich. Auch hier gibt es wiederum zwei Möglichkeiten; einerseits kann die Lehrperson helfend zur Seite stehen, andererseits ist jedoch auch Hilfe zur Selbsthilfe gefragt. Die Lernenden müssen in solchen Fällen Detektivarbeit leisten, so kann ihnen beispielsweise der Tipp mit auf den Weg gegeben werden, dass man solche Wörter googeln kann. Gibt man bei der Suchmaschine Google den Suchterm „Rythmus“ ein, wird zurückgefragt „Meinten Sie: ,Rhythmus??". Fehler im Social Web, so könnte man argumentieren, führen allenfalls dazu, dass sich DaF-Lernende falsche Schreibungen einprägen. Gleichzeitig dürfte es für DaF-Lernende auch befreiend sein zu sehen, dass auch Muttersprachler Fehler machen. Die authentische Kommunikation mit deutschen Muttersprachlern kann nicht zuletzt der Sensibilisierung für die Existenz verschiedener Register einer Sprache und deren Angemessenheit in verschiedenen Kontexten (verschiedene Kommunikationsformen/Textsorten/Adressatenkreise etc.) dienen.

\section{Einsatzmöglichkeiten im DaF-Unterricht}

Bilder aus dem Social Web können einerseits offline verwendet werden, andererseits auch online. Im Folgenden soll auf die Online-Verwendung fokussiert werden, für den Offline-Bereich hat Badstübner-Kizik (2007) einen umfangreichen Katalog zusammengestellt, der auch teilweise als inspirierende Basis für die folgenden Unterrichtsvorschläge im Online-Bereich verwendet wurde.

Die Foto-Community „Flickr“ eignet sich meines Erachtens besonders für den Einsatz im DaF-Unterricht, und dies aus verschiedenen Gründen. Zunächst einmal sei erwähnt, dass die oben vorgestellte Notiz-Funktion ein besonderes Merkmal von Flickr (sowie der Community „Ipernity“) ist. Notizen können gerade im DaFUnterricht vielfältig eingesetzt werden. Dann gibt es auf Flickr Bilder unter der Creative-Common-Lizenz, die für Projekte verwendet werden können; zudem ist 
es möglich, eigene Gruppen (offen oder geschlossen) für Projekte zu gründen, Bilder nur für bestimmte Nutzergruppen zugänglich zu machen sowie Alben mit eigenen Fotos und Galerien mit Fotos anderer zu erstellen. Schließlich sollte die Tagging-Funktion genutzt werden, sofern mit fremden Bildern gearbeitet wird. Sogenannte Identifizierungs-Tags können benutzt werden, damit in einem Projekt alle Teilnehmenden die relevanten Ressourcen markieren und auffinden können. Es handelt sich dabei oftmals um Buchstabenfolgen, die in keiner Sprache eine Bedeutung tragen, damit das verwendete Tag auch tatsächlich ein eindeutiges Identifizierungs-Tag bleibt.

Flickr gibt es zudem in zehn verschiedenen Sprachversionen (Deutsch, Englisch, Französisch, Italienisch, Portugiesisch, Spanisch, Koreanisch, Indonesisch, Chinesisch, Vietnamesisch), d.h. es besteht die Möglichkeit, dass die DaF-Lernenden allenfalls die Plattform zunächst in ihrer Muttersprache verwenden, was das Einarbeiten, sprich: die Navigation erleichtert. Da es sich um eine internationale Plattform handelt, sind viele Community-Mitglieder auch offen, sich auf andere Sprachen einzulassen, ihre Texte nach Möglichkeit bei Nachfragen zu übersetzen oder zu erläutern. Schließlich ist Flickr mit über 8 Milliarden Fotos die weltweit größte Foto-Community und bietet dadurch eine enorme Fülle an Material.

Im Folgenden sind nun einige konkrete Ideen für Einsatzmöglichkeiten im DaF-Unterricht aufgelistet, sortiert nach einzelnen Bereichen des Fremdsprachenunterrichts.

\section{Wortschatz / Wortfelder und Wortfamilien / Semantik}

1. Mithilfe der Notizfunktion können Bildwörterbücher erstellt werden, der Wortschatz kann mithilfe der Mouseover-Position (aufdecken der Lösung) trainiert werden.

2. Thematische Wortschätze zu einem Thema/Bild erstellen, und zwar sowohl Wortfelder als auch Wortfamilien, entweder mithilfe der Tagging- oder über die Kommentarfunktion.

3. Wortschatzübungen rund um Foto-Communitys und digitale Medien (z.B. Kommentar hinzufügen, Kommentar posten, hochladen/uploaden, herunterladen/ downloaden, per Drag-and-Drop ablegen, nach rechts scrollen, Dialogfeld schließen, Foto bearbeiten, löschen, Foto hinzufügen, Gruppe erstellen, Gruppe verlassen, Titelfoto ändern, registrieren/neuen Account erstellen, anmelden/ einloggen, abmelden/ausloggen etc.). Bei der Arbeit im Social Web kann die Worliste stets erweitert werden, wenn unbekannte Wörter auftauchen. 
4. Bild-Wort-Memory erstellen (z.B. auf http://www.mein-memo.net/): Auf Flickr werden Fotos nach Themenbereichen heruntergeladen, ein weiteres Bild mit dem entsprechenden Wort wird erstellt; Memory kann ausgedruckt und im Unterricht oder zuhause verwendet werden

5. Der Reihe nach sollen in einer Gruppe oder im Plenum Gegenstände oder Eigenschaften von Gegenständen genannt werden, die im Bild zu sehen sind, und zwar alphabetisch (z.B. „Ampel“, „Bus“, „Cabrio“, „Dackel“, „Erstklässler“, „Frau“ etc.)

6. Icon Poet: 5 Bilder/Icons werden ausgewählt, die allesamt in einer Geschichte vorkommen sollen. Die Bilder können entweder selbst erstellt sein und in einem Album abgelegt, oder es kann auf Flickr eine Galerie/Sammlung erstellt werden mit fremden Bildern. Zunächst sollen einzeln oder in Gruppen zu den verschiedenen Bildern passende Wörter gesammelt werden (Kommentar- oder Tagging-Funktion nutzen). Dabei sollen sowohl Wortfamilien (Wörter mit demselben Wortstamm) als auch Wortfelder (Synonyme, Quasi-Synonyme, etc.), Homonyme, Metaphern oder andere Stilmittel verwendet werden. Wahlweise können die Geschichten frei erfunden werden oder nach bestimmten Vorgaben, z.B. bestimmte Textsorten. Im Buch „Icon Poet“ (Matscher 2011) finden sich zahlreiche Szenarien, die verwendet werden können, beispielsweise Ausreden, Werbeslogans, Heiratsanträge, Alibi bei Mord etc. In Abb. 3 ist ein kurzes Icon-Poet-Beispiel zu finden, die Geschichten können selbstverständlich auch länger ausfallen (verschiedene Vorgaben sind möglich, z.B. ein Satz pro Bild, ein Absatz pro Bild etc.). Im Text sollen die verwendeten Bilder jeweils unterstrichen werden.
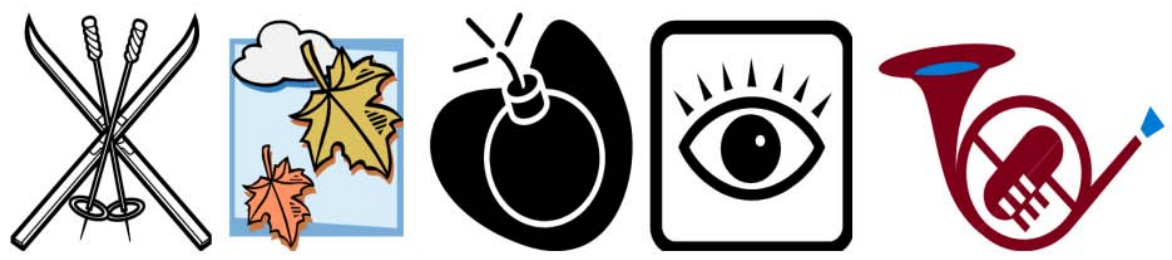

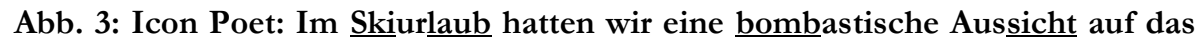
Matterhorn.

7. (In-)Kongruenz Wort-Bild: Lehrperson oder andere Lernende vergeben passende sowie unpassende Tags zu einem Bild; Lernende sollen überprüfen, welche Tags zum konkreten Bild passen und welche nicht (inkl. Begründung)

8. Wort-Bild-Zuordnung: Lehrperson oder andere Lernende vergeben Tags zu einem Bild. Andere Lernende ordnen die einzelnen Tags mittels Notizen mit demselben Text dem entsprechenden Bildausschnitt zu

9. Lehrperson oder andere Lernende verfassen eine Bildbeschreibung mit Lü- 
cken. Die Wörter, die in die Lücken gehören, werden als Tags angegeben und sollen von den Lernenden an der richtigen Stelle eingesetzt werden (Varianten: Tags entweder flektiert oder unflektiert angeben)

10. Bildbeschreibung verfassen: Verwendet werden müssen im Text alle Tags, die ein Bild enthält. Verwendet werden können beliebige Flickr-Fotos oder Fotos mit Tags, die andere Lernende oder die Lehrperson vergeben haben.

11. Die heutige Kommunikation, insbesondere auch auf Smartphones, enthält immer mehr Bildelemente, z.B. im Nachrichtendienst WhatsApp. Aber auch für die Betriebssysteme Windows und Apple sind inzwischen Schriftarten für die sogenannten Emojis (Segoe UI Emoji bzw. Apple Color Emoji) verfügbar.

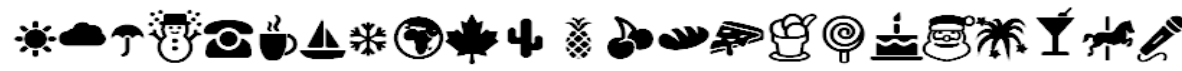

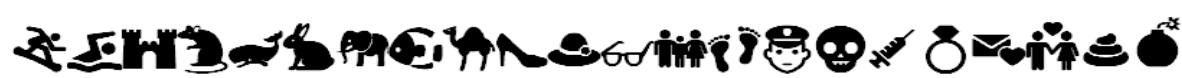

Abb. 4: Emojis in der Schriftart Segoe UI Emoji

Die Lernenden sollen Texte erstellen, bei denen Wörter oder Wortbestandteile durch Emojis ersetzt werden (vgl. Abb. 5)

\section{Lieber Tim, wir wollten ja eigentlich heute Abend im Kino den neuen James-Bond- anschauen, da es jetzt aber doch nicht $\log ^{\circ}$ und die so schön scheint, wollte ich fragen, ob wir nicht stattdessen in den [D- garten wollen? Wir könnten mit dem hinfahren, könnte dich so um Uhr abholen, was meinste? Lg Uwe}

08:20

Abb. 5: WhatsApp-Beispiel

Andere Lernende können im Anschluss daran die Texte vorlesen und die Bilder in Worte „übersetzen“. 


\section{Phraseologie}

1. Die Lernenden suchen zu bekannten deutschen Sprichwörtern oder Redewendungen Bilder, die diese illustrieren. In einer Galerie können die gefundenen Bilder abgelegt werden. Davor sollen im Plenum die Bedeutungen der einzelnen Sprichwörter erläutert werden und die Sprichwörter/Redewendungen werden als Tag hinzugefügt.

2. Die Lehrperson teilt den Lernenden (einzeln oder in Paaren/Gruppen) eine Liste mit bekannten deutschen Sprichwörtern aus (siehe z.B. Baur; Chlosta 1996: 22). Die Lernenden suchen auf Flickr nach diesen Sprichwörtern, speichern dann das Bild und das Sprichwort separat ab. Die Lernenden der anderen Paare/ Gruppen sollen im Anschluss daran die Bilder den Sprichwörtern zuordnen (entweder werden die Bilder/Texte ausgedruckt oder es wird wiederum ein Memory daraus gemacht, siehe oben). Im Anschluss daran sollen die Bedeutungen der einzelnen Sprichwörter diskutiert werden, da zu erwarten ist, dass jeweils eine wörtliche und eine phraseologische Bedeutung vorliegt (vgl. Burger 2008, Rentel 2011).

3. Modifikationen von Sprichwörtern/Redewendungen: Indem nur nach einem Teil eines Sprichwortes gesucht wird, und zwar mit Anführungszeichen, können Modifikationen entdeckt werden (z.B. „Wo ein Wulle ist, ist auch ein Weg“ oder „Radkappe fällt nicht weit vom Stamm“).7 Im Anschluss daran sollen selbst Bilder mit Modifikationen von Sprichwörtern kombiniert werden.

\footnotetext{
7 https://www.flickr.com/photos/95993007@N02/13984196965; https://www.flickr.com/photos/ bartholmy/217239554.
} 


\section{Grammatik}

1. Wie beim Wortschatz beschrieben sollen Memory-Kärtchen erstellt werden, auf einem jeweils das Bild, auf dem anderen das dazugehörige Wort inkl. Genus, Pluralform, Konjugation der Verben etc. Nachdem das Memory mehrmals gespielt wurde und die Lernenden sich vielleicht schon einiges merken konnten, können die Kärtchen aneinandergeklebt und für das selbstständige Lernen genutzt werden.

2. Die Lehrperson oder Lernende legen den anderen Lernenden Bildtitel vor, die anderen Lernenden sollen mutmaßen, was auf dem Bild zu sehen ist. Dabei sollen vorgegebene Strukturen verwendet werden, z.B. Konjunktivkonstruktionen, „entweder - oder“, „einerseits - andererseits“ etc. Im Anschluss daran folgt die Auflösung, was auf dem Bild tatsächlich zu sehen ist. Umgekehrt kann auch aufgrund des Bildinhaltes gemutmaßt werden, was der Bildinhalt sein könnte.

3. Anhand vorgegebener Strukturen (z.B. Lagepräpositionen) beschreiben Lernende in Paaren oder Gruppen sich gegenseitig Bilder, die anderen versuchen jeweils aufgrund der Beschreibung eine Skizze anzufertigen (Vergleich der Skizzen mit dem Original im Anschluss daran).

\section{Sprachreflexion}

1. Im Unterricht soll anhand von Beispielen reflektiert werden, inwiefern sich die deutsche Sprache im Internet und hier spezifisch in einzelnen Kommunikations(platt-)formen wie Flickr vom Sprachgebrauch des Standards unterscheidet (z.B. Schreibfehler, Tippfehler, Smileys, Abkürzungen, konzeptionelle Mündlichkeit). Ziel ist, über unterschiedliche Register nachzudenken und ein Bewusstsein für situationsadäquate Kommunikation zu schaffen (vgl. Chardaloupa et al. 2013: o. S.).

2. Lernende sollen sprachliche Fehler auf allen Ebenen (Graphie, Grammatik) auf Flickr-Fotoseiten aufdecken (in den Bildtiteln, Bildbeschreibungen, Kommentaren). Die Lernenden sollten die Textbeispiele herauskopieren, die Lehrperson stellt die fehlerhaften Texte zusammen und erstellt daraus ein Arbeitsblatt (Papier oder digital), die Lernenden korrigieren im Anschluss daran alle gefundenen Fehler. 


\section{(Dialogische) Kommunikation}

1. In der Kunstkommunikation müssen fünf zentrale kommunikative Aufgaben gelöst werden, und zwar Bezugnehmen (über deiktische Ausdrücke oder Notizen auf Flickr), Beschreiben (was ist zu sehen?), Deuten (Mutmaßungen zum Bild), Erläutern (Verwendung von Hintergrundwissen) und Bewerten (wie gefällt mir das Bild?) (vgl. Hausendorf 2011: 524). Die Kommentarfunktion kann beispielsweise genutzt werden, um die einzelnen kommunikativen Aufgaben zu lösen.

2. Bilder bewerten: Mehrere Bilder sollen mittels Komparation miteinander verglichen werden (z.B. „schön - schöner - am schönsten“ oder „,bunt - bunter - am buntesten“ etc.; ,das interessanteste Bild ist - am interessantesten ist...").

3. Flickr verfügt auch über einen internen Nachrichtendienst. Wenn Projekte mit Partnerschulen oder Partnerklassen ( $\mathrm{zu}$ finden auf dem Portal www.etwinning.net) durchgeführt werden, ist Kommunikation mit den einzelnen Lernenden - neben der Kommunikation in Gruppen, auf Fotoseiten etc. über diesen Nachrichtendienst möglich.

4. Lernende stellen zu einzelnen Bildern im Kommentarfeld Fragen, z.B. „Wie viele XY sind auf dem Bild zu sehen?“; „Ist auf dem Bild a) eine Ente, b) eine Gans oder c) eine Schwalbe zu sehen?"; „Sind auf dem Bild 3 verschiedene Obstsorten abgebildet?" etc. Die anderen Lernenden beantworten jeweils die davor gestellten Fragen und stellen im selben Kommentar eine neue Frage, die dann wiederum jemand anderes beantworten kann usw.

5. Innerhalb von Bildern sollen Dialoge erstellt werden, einerseits können die Notizen als Sprechblasen verwendet werden, andererseits können mit dem „Bubblr" Bilder gesucht und mit Sprechblasen versehen werden. Solche Projekte können bei Bubblr auch abgespeichert werden.

6. Ebenfalls mit Bubblr können verschiedene Bilder zu einem Thema herausgesucht und beschriftet werden, beispielsweise Hobbys der Lernenden, ${ }^{9}$ mögliche Gedanken von Zootieren etc.

7. Zu zweit „Ich sehe was, was du nicht siehst“ spielen, die erratenen Gegenstände werden im Anschluss mit Notizen beschriftet.

8. Die Lernenden sollen sich Titel zu Bildern ausdenken, im Anschluss daran werden diese mit den Originaltiteln verglichen und Unterschiede/Gemeinsamkeiten diskutiert.

\footnotetext{
8 http://www.pimpampum.net/bubblr.

${ }^{9}$ Vgl. http:/ / www.pimpampum.net/bubblr/?id=44182.
} 
9. Die Lernenden suchen sich Bilder, die sie interessieren, und versuchen über Fragen oder Kommentare mit den Fotografinnen und Fotografen ins „Gespräch" zu kommen.

10. Die Lernenden erstellen eine grobe Skizze ihrer Geschichte, machen dann passende Fotos, die sie in ein Flickr-Album hochladen und ergänzen Texte, z.B. Sprechblasen mittels der Notiz-Funktion, die Geschichte in der Bildbeschreibung. Alternativ können auch online sogenannte „Minibooks“ (www.minibooks.ch) erstellt werden, die abgespeichert und ausgedruckt werden können. Um gemeinsam an Bildergeschichten zu schreiben, eignet sich „Google Docs“", da hier alle Lernenden Änderungen vornehmen können. ${ }^{10}$

11. Landeskunde: Fotos über die Stadt/Region, in der sich die Lernenden befinden, werden auf Flickr gesucht oder selbst geschossen. Es können Sammlungen oder Collagen zu verschiedenen Aspekten erstellt werden, z.B. Lieblingsorte in der Stadt, Ausflugtipps, Historisches zur Stadt etc.

12. Die Lernenden können Bilder/Sehenswürdigkeiten aus ihrem Herkunftsland zusammenstellen und den anderen Lernenden präsentieren.

\section{Fazit}

Das Social Web bietet eine große Fülle an Bildern, die für den Unterricht genutzt werden können. Ziel der in Abschnitt 5 dargestellten Unterrichtsvorschläge ist es, nicht nur die Sprachkompetenz im DaF-Unterricht, sondern generell die kommunikative Kompetenz, d.h. auch die Bildkompetenz und die multimodale Kompetenz, zu fördern. Bilder sollen, das sollte deutlich geworden sein, nicht nur Mittel zum Zweck, sondern auch Lerninhalt darstellen (vgl. Badstübner-Kizik 2007: 11).

Das Internet und insbesondere das Social Web lassen sich sehr gut für Kommunikationszwecke einsetzen, vor allem auch mit Muttersprachlern. Dadurch lässt sich auch die interkulturelle Kompetenz bestens fördern. Das Social Web eignet sich zudem, um die informelle Alltagssprache zu erlernen, denn es gilt: „Nicht in allen kommunikativen Praktiken und Situationen sind standardnahes Sprechen und Schreiben angemessen. Häufig ist man sozial deutlich erfolgreicher, wenn man andere Varietäten, Register und Stile beherrscht" (Schneider 2013: 34).

Nicht zuletzt soll erwähnt werden, dass für solche Unterrichtsvorhaben auf der Seite der Lehrenden mediendidaktische Kompetenzen und somit auch Kompetenzen im Umgang mit digitalen Medien vorhanden sein müssen, zudem bedarf es des Engagements sowie Mut, Neues auszuprobieren (vgl. Würffel 2010: 1240). Außer in Weiterbildungskursen können sich Lehrende auch autodidaktisch Kompetenzen

10 https://docs.google.com, vgl. auch Reuen 2005. 
aneignen. Um zu verstehen, wie Kommunikation im Social Web abläuft, kann zunächst sogenanntes „Lurking“ - d.h. stilles Mitlesen und Beobachten - betrieben werden. Nach dem Learning by Lurking folgt das Learning by Doing (vgl. Wampfler 2013: 18) sowie das Nachdenken darüber, wie bestimmte Kommunikations(platt-)formen sinnvoll für den DaF-Unterricht eingesetzt werden können. Wenn der vorliegende Beitrag den einen oder anderen dazu bewegt hat, das Social Web und vor allem Foto-Communitys im Unterricht zu nutzen, so hat er sein Ziel erreicht.

\section{Literatur}

Badstübner-Kizik, Camilla (2007): Bild-und Musikkunst im Fremdsprachenunterricht. Zwischenbilanz und Handreichungen für die Praxis. Frankfurt/Main: Peter Lang.

Baur, Ruprecht; Chlosta, Christoph (1996): Welche Übung macht den Meister? Von der Sprichwortforschung zur Sprichwortdidaktik. In: Fremdsprache Deutsch $15,17-24$.

Burger, Harald (2008): Das idiomatische „Bild“ und seine Modifikationen durch materielle Bilder. Theoretische und empirische Aspekte. In: Mellado Blanco, Carmen (Hrsg.): Beiträge zur Phraseologie aus textueller Sicht. Hamburg: Kovac, 89-113.

Chardaloupa, Johanna; Perperidis, Georgios; Buchberger, Gerlinde; Heckmann, Verena; Lachner, Elke; Frey, Jennifer (2013): Fremdsprachen im Schulunterricht. Mit Technologien Sprachen lernen und lehren. In: Ebner, Martin; Schön, Sandra (Hrsg.): Lehrbuch für Lernen und Lebren mit Technologien. Norderstedt: Books on Demand.

Duden (2007a): Das große Buch der Zitate und Redewendungen. Über 15000 klassische und moderne Zitate und feste Wendungen [CD-ROM]. 2., überarb. u. aktual. Mannheim: Duden Verlag.

Duden (2007b): Das Herkunftswörterbuch [CD-ROM]. 4., neu bearb. Aufl. Mannheim: Duden Verlag (= Der Duden in 12 Bänden, 7).

Duden (2013): Die deutsche Rechtschreibung. Das umfassende Standardwerk auf der Grundlage der aktuellen amtlichen Regeln [CD-ROM]. 26. Aufl. Berlin: Duden Verlag.

Durrell, Martin (2012): Zur Relativierung von hochsprachlichen Normen in der deutschen Sprache der Gegenwart. Der Blick von außen. In: Günthner, Susanne; Imo, Wolfgang; Meer, Dorothee; Schneider, Jan Georg (Hrsg.): Kommunikation und Öffentlichkeit. Sprachwissenschaftliche Potenziale zwischen Empirie und Norm. Berlin: de Gruyter, 85-101. 
Golder, Scott A.; Huberman, Bernardo A. (2005): The Structure of Collaborative Tagging Systems, 1-8. Http:/ / arxiv.org/ftp/cs/papers/0508/ 0508082.pdf (28.05.2014).

Hausendorf, Heiko (2006): Gibt es eine Sprache der Kunstkommunikation? Linguistische Zugangsweisen zu einer interdisziplinären Thematik. In: Mattenklott, Gert; Vöhler, Martin (Hrsg.): Sprachen ästhetischer Erfahrung. Berlin: Akademie Verlag, 65-98.

Hausendorf, Heiko (2011): Kunstkommunikation. In: Habscheid, Stephan (Hrsg.): Textsorten, Handlungsmuster, Oberflächen. Linguistische Typologien der Kommunikation. Berlin: de Gruyter, 509-535.

Matscher, Hans-Rudolf (2011): Icon Poet. Alle Geschichten dieser Welt. Ein grosser Wurf der Gebrüder Frei. Mainz: Hermann Schmidt Verlag.

Müller, Christina Margrit (2012): Multimodalität und multimodale Kompetenz. Text-Bild-Kommunikate im Social Web. In: Der Deutschunterricht 6, 22-33.

Müller, Christina Margrit; Siever, Torsten (2011): Neue Medien und Wortschatzarbeit. In: Informationen zur Deutschdidaktik. Zeitschrift für den Deutschunterricht in Wissenschaft und Schule 1, 42-53.

Rentel, Nadine (2011): Die Didaktisierung von Phraseologismen im DaF-Unterricht anhand multimodaler Texte. In: Linguistik online 47(3), S. 55-66. Http://www.linguistik-online.de/47_11/rentel.pdf (28.05.2014).

Reuen, Sascha (2005): Fotoromane im Deutschunterricht. In: Der Deutschunterricht 4, 77-84.

Schmitz, Ulrich (2001): http://www.ellipsen.de. In: Lehr, Andrea; Kammerer, Matthias; Konerding, Klaus-Peter; Storrer, Angelika; Thimm, Caja; Wolski, Werner (Hrsg.): Sprache im Alltag. Beiträge zu neuen Perspektiven in der Linguistik. Herbert Ernst Wiegand zum 65. Geburtstag gewidmet. Berlin: de Gruyter, 423-438.

Schmitz, Ulrich (2004): Sprache in modernen Medien. Einführung in Tatsachen und Theorien, Themen und Thesen. Berlin: Erich Schmidt Verlag.

Schneider, Jan Georg (2013): Sprachliche „Fehler“ aus sprachwissenschaftlicher Sicht. In: Sprachreport 29 (1-2), 30-37. Online verfügbar unter http://pub.idsmannheim.de/laufend/sprachreport/pdf/sr13-1a.pdf (28.05.14).

Siever, Christina Margrit (im Druck): Multimodale Kommunikation im Social Web. Forschungsansätze und Analysen zu Text-Bild-Relationen. Frankfurt/Main: Peter Lang.

Stöckl, Hartmut (2011): Sprache-Bild-Texte lesen. Bausteine zur Methodik einer Grundkompetenz. In: Diekmannshenke, Hajo; Klemm, Michael; Stöckl, Hartmut (Hrsg.): Bildlinguistik. Theorien - Methoden - Fallbeispiele. Berlin: Erich Schmidt Verlag, 45-70. 
Süss, Daniel (2013): Medienkompetenz. In: Bentele, Günter; Brosius, Hans-Bernd; Jarren, Otfried (Hrsg.): Lexikon Kommunikations- und Medienwissenschaft. Wiesbaden: Springer Verlag, 209-210.

Wampfler, Philipp (2013): Facebook, Blogs und Wikis in der Scbule. Ein Social-MediaLeiffaden. Göttingen: Vandenhoeck \& Ruprecht.

Würffel, Nicola (2010): Deutsch als Fremd- und Deutsch als Zweitsprache-Lernen in elektronischen Umgebungen. In: Krumm, Hans-Jürgen et al. (Hrsg.): Deutsch als Fremd- und Zweitsprache. Ein internationales Handbuch. Berlin: de Gruyter, 12271243 . 


\title{
„Queer Media“: (Audio-)Visuelle Medien und Gender-Vielfalt im DaF-Unterricht
}

\author{
Danielle Verena Kollig und Japhet Johnstone
}

\section{Einleitung}

Die Haltungen der deutschsprachigen Gegenwartsgesellschaft zu Themen, die im Rahmen der anglo-amerikanischen Gender und Queer Studies mit den Begriffen von „sexual and gender diversity“ beschrieben werden, sind oftmals widersprüchlich. Im Grunde eines der liberaleren und gesamtgesellschaftlich toleranteren Länder, wenn es um die Akzeptanz nicht-heterosexueller Lebensentwürfe geht, treten doch immer wieder auf sozialer Ebene Gegebenheiten zutage, die ahnen lassen, dass nicht-heterosexuelle Menschen letztlich noch immer „die Anderen“ sind. Die Anderen: Das sind die, die man vielleicht aus den Medien kennt, aus der Zeitung oder dem Fernsehen, aber nicht diejenigen, die man „,normalerweise“ im Alltag zu Gesicht bekommt. Und auf deren Befinden man demnach keine besondere Rücksicht nehmen muss. So zeigt sich Deutschland durchaus sehr tolerant, wenn es um die Akzeptanz homosexueller Personen des öffentlichen Interesses geht. Beispielsweise berichtet die ZEIT in ihrer Online Ausgabe vom 23. September 2007: „In den neuen Bundesländern sehen 87 Prozent kein Hindernis, dass ein Homosexueller Kanzler wird, in der alten Bundesrepublik 77 Prozent. Bei den Frauen können sich 83 Prozent einen homosexuellen Kanzler oder eine homosexuelle Kanzlerin vorstellen, 15 Prozent hätten damit Probleme“. ${ }^{1}$

${ }^{1}$ http://www.zeit.de/news/artikel/2007/09/23/2385480.xml. 
In Alltagssituationen von scheinbar kleinerem Umfang, die aber einen engeren Kontakt zwischen den Mitgliedern einer Gesellschaft voraussetzen, kommt allerdings weniger Verständnis auf: Hier wird, zumindest in den Medien, vielmehr das Verständnis einer irgendwie bestehenden Norm proklamiert, die selbstredend „heterosexuell“" geprägt ist und die Existenz ausschließlich zweier Geschlechter voraussetzt, die sich wechselseitig komplementieren und keine Zwischenstufen zulassen. Manche dieser Meinungen sind harmlos und gar ironisierend formuliert, wie etwa das Plädoyer des ZEIT-Kolumnisten Harald Martenstein für die Beibehaltung der getrenntgeschlechtlichen öffentlichen Toiletten, die auch von Transsexuellen gemäß ihres jeweiligen Aussehens ,korrekt" genutzt werden sollten. ${ }^{2}$ Andere hingegen haben gewaltsamere Auswirkungen, sei es, dass homosexuelle SchülerInnen und StudentInnen Gewalt und soziale Ausgrenzungen zu befürchten haben, oder sei es, dass, wie im Falle der transsexuellen Alex aus Berlin, zeitweise die Einweisung in die Psychiatrie drohte, da man ihr die Selbstzuschreibung als Mädchen nicht oder nur unter Vorbehalt abnehmen wollte. ${ }^{3}$

Als SprachwissenschaftlerInnen sind wir immer auch kulturwissenschaftlich orientiert. Daher gehen uns die Diskurse an, die hinter gesellschaftlichen Debatten und Ereignissen wie die oben genannten stehen. Soziokulturelle Ausdrücke von Identitäten (zu denen Aspekte von Gender und Sexualität gehören, ohne sich in ihnen zu erschöpfen) sind deshalb wichtige Themen im Fremdsprachenunterricht, weil es gerade im Sprachunterricht nicht nur darum geht, grammatische Strukturen zu erlernen, sondern zu zeigen, wie Sprache Kultur transportiert und darüber hinaus selbst ein Teil dieser Kultur ist. Um jene kulturellen Mechanismen zu verstehen, ist der didaktische Umgang mit visuellen Medien hilfreich, ja geradezu geboten, da diese zum Alltagsgebrauch gehören und Diskurse mitgestalten.

Wenn wir über den pädagogischen und didaktischen Verdienst (audio-)visueller Medien (in elektronischer und nicht-elektronischer Form) im DaF-Unterricht nachdenken, muss über kurz oder lang auch über die Aufklärungsarbeit bezüglich sexueller Identität und Orientierung gesprochen werden. In diesem Artikel schlagen wir didaktische und pädagogische Maßnahmen vor, mit Hilfe derer StudentInnen an High Schools und Colleges im DaF-Unterricht einen offenen Umgang mit der Vielfalt von Lebensentwürfen erlernen und praktizieren, der die Einbeziehung nicht-heterosexueller Lebensdesigns und Partnerschaften explizit macht. Die in diesem Artikel vorgenommene Beschränkung auf die höheren Bildungsstufen High School und College ist der Natur der hier besprochenen Medien geschuldet. Schließlich wenden wir in einem zweiten Schritt die Maximen dieser theoretischen

\footnotetext{
2 http://www.zeit.de/news/artikel/2007/09/23/2385480.xml.

${ }^{3}$ Siehe Oestreich 2012: „Das Kind, das sich sein Leben lang als Mädchen fühlt und wie ein Mädchen lebt, darf nun in die Berliner Charité zwangseingewiesen werden. Das Jugendamt konnte diese Entscheidung treffen, weil die getrennt lebenden Eltern unterschiedliche Auffassungen über die medizinische Behandlung des Kindes hatten und die Gesundheitsfürsorge deshalb ans Jugendamt abgetreten hatten". Zwar ist Alex letztlich nie eingewiesen worden, allein die Debatte aber zeugt von einem nicht gerade unverkrampften Umgang mit dem Thema Transsexualität.
} 
und praktisch-didaktischen Forderungen auf deutschsprachige Medien an und untersuchen diese in Bezug auf ihr Potential zur lehrhaften Überschreitung konventionell gezogener Grenzen sexueller Orientierungen und Gender-Identitäten. Ziel dieses Artikels ist es, die German Studies sowie Auslandsgermanistiken mit den im anglo-amerikanischen Raum verwurzelten Gender und Queer Studies zu vernetzen und StudentInnen der deutschen Sprache, Literaturen und Kulturen mit den soziokulturellen Entwicklungen eben dieser zu studierenden Kulturen bekannt zu machen. Nicht zuletzt geht es uns damit auch um eine weiterreichende Modernisierung der Auslandsgermanistiken und German Studies.

\section{Beitrag der Visuellen Medien im DaF-Unterricht}

Nach Finney (2006) ist das Studium audio-visueller Medien wie Film, Fernsehen oder Performancekunst ein Bestandteil der Kulturwissenschaft; sie können bereits auf eine längere Tradition verweisen ${ }^{4}$ und erfordern mehrdimensionale, d.h. nichtlineare Lese- und Interpretationsverfahren. ${ }^{5}$ Daher wollen wir didaktische Wege aufzeigen, wie neue Lehren zur simultanen Erschließung audio-visueller Medien den DaF-StudentInnen vermittelt werden. Anschließend schlagen wir vor, wie die neu erworbenen Interpretationskompetenzen auf die Beschäftigung mit alternativen Geschlechtern und Sexualitäten angewandt werden können. Dabei greifen wir beispielhaft zurück auf Film und Fernsehen, sowie auf visuelle Medien wie dem „Missy-Magazine“, dessen Beiträge sich besonders auf nicht-heteronormative Lebensentwürfe, Selbstdefinitionen und Orientierungen beziehen.

Wir suchen den Dialog zwischen den Disziplinen der Fremdsprachenpädagogik und den Queer Studies, welche ursprünglich aus dem US-amerikanischen akademischen Umfeld stammen und in den letzten Jahrzehnten auch in der deutschsprachigen Hochschule zunehmend bekannter und auch populärer werden. ${ }^{6}$ Die Leitfragen in diesem Artikel lauten wie folgt: Wie können audio-visuelle Medien den DaF-Unterricht dahingehend bereichern, dass sie über deutsche Sprachen, Literaturen und Kulturen informieren und darüber hinaus einer multikulturellen und vielseitigen Schüler- und Studentenschaft Rechnung tragen, diese anerkennen und im Unterricht ansprechen? Wie kann die Disziplin der Queer Studies, verstanden als eine mit den Gender Studies verwandte Forschungsrichtung, zu einer aufgeklär-

\footnotetext{
4 Siehe Finney 2006: 1: , ,...] while the pressure of the visual is enormous and omnipresent during the postmodern era, the entire twentieth century can be characterized as the visual age - the era in which the image becomes paramount.“

${ }^{5}$ Siehe Alter 2006: 17: ,We all have a basic knowledge of how to read written texts. But we generally accept that literary scholars have spent a considerable amount of time studying the operation of texts and are better equipped than most to analyze textual complexities. It follows that the same should hold true for the scholar of visual images, such as the art historian or critic."

6 Siehe beispielsweise in den USA das Erscheinen des „Routledge Queer Studies Reader“ (Hall; Jagose 2013) sowie die für 2014 geplante CLAGS Konferenz, oder in Deutschland das Erscheinen des Sammelbandes Queer Studies in Deutscbland (Kraß 2009), die Gründung von GeStiK in Köln (2012) oder die Verleihung des Adorno Preises an Judith Butler in Frankfurt am Main am 11.09. 2012.
} 
ten und modernen Pädagogik und Didaktik beitragen und damit einer Unterrichtspraxis entgegenwirken, die als heteronormativ charakterisiert werden kann? Wie kann unsere Arbeit also dazu beitragen, dass sich nicht-heterosexuelle SchülerInnen und StudentInnen in Klassen- und Seminarräumen genauso akzeptiert und integriert fühlen wie heterosexuelle?

Es ist hierbei nicht unsere Intention, einen Sprachunterricht künstlich zu „sexualisieren“. Nach Foucault (1983) allerdings ist die diskursive Reverenz und Gestaltung von Sexualität auch ein rhetorisches und administratives Konstrukt, das in weitaus mehr Bereichen des Lebens wirksam ist als lediglich in der individuellen Intimsphäre. ${ }^{7}$

Das bedeutet auch, dass Geschlecht und Sexualität, so wie wir sie in unseren respektiven kulturellen Lebensräumen erfahren und verstehen, keinesfalls natürliche Gegebenheiten sind. Vielmehr, so lernen wir von Judith Butler, sind Vorstellungen von Geschlecht oder Gender sowie von Sexualität durch sprachlich codierte Kultur vermittelt und erlernt. Das gilt auch für Vorstellungen von Heterosexualität und den in westlichen Kulturkreisen weit verbreiteten Zwei-GeschlechterModellen: „The constructed character of sexuality has been invoked to counter that claim that sexuality has a natural and normative shape and movement, that is, one which approximates the normative phantasm of a compulsory heterosexuality" (Butler 1993: 93). Indem Queer Studies und ihre Didaktik sowie Pädagogik tradierte und implizit gelehrte und gelernte Konventionen des Normalen kritisch hinterfragen, um Alternativen herauszuarbeiten, müssen sie auch ihre eigenen methodologischen Dispositionen hinterfragen. Queere Lesarten sind solche, die sich einer unilinearen Methodik widersetzen. Damit sind visuelle und audio-visuelle Medien ein bevorzugtes Medium in den Queer Studies. In diesem Sinne kann man auch wichtige Themenbereiche aus den Printmedien, Film und Fernsehen, welche sich mit etablierten Diskursfeldern wie Familie, Freundschaft und nationalen Stereotypen beschäftigen, mit einer queer Perspektive mitdenken: ,[...] visual texts are inherently dynamic, often involving the audial and the tactile as well as the optical sense, and substantial meaning is lost if the focus is exclusively on the visual component" (Alter 2006: 18). Indem Lernende im DaF-Unterricht ,gegen den Strich“ lesen lernen, lernen sie, wie sehr auch so genannte „normale“, d. h. konventionelle Lebensbereiche wie die traditionelle Kernfamilie oder die Männerfreundschaft im Sportverein die jeweiligen Produkte sozialer kommunikativer Verhandlungsprozesse sind und sich daher von vermeintlich ,nicht-normativen“ Lebensentwürfen allenfalls graduell unterscheiden.

Eine queere Perspektive ist eine Betrachtungsart, die das Normale in Frage stellt. In der zeitgenössischen Wissenschaftslandschaft ist die Bedeutung von queer sehr umstritten. Für viele QueertheoretikerInnen ist queer immer unmittelbar mit

\footnotetext{
7 Siehe Foucault 1983: 38: „Im Zentrum des ökonomischen und politischen Problems der Bevölkerung steht der Sex: man muß die Geburtenrate und das Heiratsalter analysieren, die Geschlechtsreife und die Häufigkeit der Geschlechtsbeziehungen, die Mittel, fruchtbar oder unfruchtbar zu machen, die Wirkung von Ehelosigkeit und Verboten...".
} 
Fragen von Geschlecht und Sexualität verbunden, wobei andere queer als allgemeinen Begriff für das Nicht- oder Anti-Normale in anderen Zusammenhängen verstehen, die nicht offensichtlich unmittelbar mit Geschlecht und Sexualität verbunden sind. Beispielsweise schreibt die Sozialwissenschaftlerin und Queer StudiesTheoretikerin Nina Degele: „To queer hat damit zu tun, etwas oder jemanden aus dem Gleichgewicht zu bringen, aus seiner selbstverständlichen Ordnung zu bringen. Queer soll verstören, anstatt theoretische, methodische oder disziplinäre Sicherheiten zu schaffen." (Degele 2008: 11). Dieses vermeintliche Gleichgewicht existiert aber vornehmlich in Bereichen, die mit Geschlecht und/oder Sexualität zu tun haben, beispielsweise im Design von sozialen Bereichen wie Familie, Freundschaft, Ehe, Liebe und dem Berufsleben. Daher wollen wir auch in dem hier vorliegenden Zusammenhang auf Fragen von Geschlechteridentität und Sexualität zielen, obwohl ein breiteres Verständnis von queer dadurch nicht ausgeschlossen bleiben soll.

Unser Verständnis von queer bezieht sich auf eine „Anti-Bias“-Voraussetzung, die sich einen toleranten, verständnisvollen Umgang mit Menschen unterschiedlichster Hintergründe (race, class, gender z.B.) als Ziel setzt. ${ }^{8}$ Aber eine queere Perspektive impliziert für uns auch etwas, was vielleicht auf den ersten Blick paradox erscheint: Eine queere Perspektive stellt auch die Bedingungen der Kommunikation selbst in Frage. Sie fragt beispielsweise, wie bestimmte Individuen „überlesen“, „unlesbar" werden, oder wie andererseits andere Individuen „lesbar" gemacht werden und somit an Kommunikation teilnehmen können.

\section{Definitionsversuch einer „queeren Pädagogik“}

Was heißt „queere Pädagogik“? Unter ,queerer Pädagogik“ verstehen wir eine Betrachtung des Unterrichtssettings in dreierlei Hinsicht: 1. Von der Definition der Rolle der Lehrerin beziehungsweise des Lehrers, 2. die Schaffung einer (anti-bias) Atmosphäre für LSBT/I-Lernende, und 3. vom Inhalt des Unterrichts. Diese drei Punkte wurden in einer Graduierten-Arbeitsgruppe zur „Queer Pedagogy“ an der University of Washington entwickelt und dienen als Rahmen für eine strukturelle Überlegung zu einer möglichen queeren Didaktik und zu queeren Lehrmethoden, oder um die Erweiterung von Kursmaterial um Gender und queere Themen ins Auge zu fassen. ${ }^{9}$

Eine Voraussetzung der queeren Pädagogik ist, dass heteronormative und sexistische Merkmale auf verschiedenen Ebenen im Klassenzimmer auftauchen kön-

\footnotetext{
8 Für mehr zum Anti-Bias Ansatz, siehe http://www.anti-bias-netz.org/wp-content/uploads/2013/ 03/S_60_12_42-45_Anti_Bias.pdf und/oder Winkelmann; Trisch 2007.

${ }^{9}$ Die Arbeitsgruppe QPP wurde 2009 von Doktoranden an der University of Washington, Seattle gegründet, um Fragen zur Performativität, Öffentlichkeit, und Pädagogik mit einem queeren Fokus zu betrachten. Am Ende hat die Gruppe sich auf Unterrichtspraxis konzentiert und einen Workshop zur „Queer Pedagogy“ entwickelt. Der Workshop fand im Frühling 2012 in Seattle statt und war auch nach diesem 3 Rechtlinien strukturiert. Der Workshop hieß „Performances of Queer Pedagogy”.
} 
nen, und zwar unabhängig vom Fach. ${ }^{10}$ Bei manchen Fächern sind diese Merkmale deutlicher zu sehen bzw. werden auch direkt thematisiert. Bei anderen Fächern ist nicht so klar, wie und wann Heteronormativität und/oder Sexismus eine Rolle spielen. Diese Voraussetzung beim Sprachunterricht ist besonders wichtig, da es beim Sprachunterricht um zwischenmenschliche Kommunikation, persönlichen Umgang mit Sprache und Ausdruck sowie kulturellen Austausch und Verständnis geht. Das heißt, dass die Fragen, wie man mit Sprache (Fremd- oder Muttersprache) umgehen kann, um diskriminierende Mechanismen zu vermeiden, von großer Wichtigkeit sind.

Eine queere Pädagogik ist aber nicht nur mit sozialer und politischer Aufklärung verbunden (eine andere Grundannahme der queeren Pädagogik wäre auch die Verschränkung von „privat“ und „öffentlich“ - private und public), sondern zielt auch auf eine innovative Lehrsituation, die das Prozesshafte beim Unterricht betont und sich nicht nur auf fertige Lernkompentenzen bezieht. In einem „queer-friendly“ Klassenzimmer geht es, anders gesagt, eher um die Fragen als um die Antworten.

Wenn man versucht, sich einen Überblick über queere pädagogische Ansätze in der Forschungsliteratur zu verschaffen, merkt man sehr schnell, dass es ein deutliches Desiderat gibt, und zwar in einem Gebiet, das sowieso wenig erforscht ist, nämlich zum Zusammendenken von Gender, Medien und Sprachunterricht. Viele Artikel, die sich mit dem Thema Gender und Sprachunterricht beschäftigen, unterstützen essentialistische Trennungen von Geschlechtern und argumentieren z.B. für einen Unterricht, der dem Lernprofil von Mädchen/Frauen besser entspricht (vgl. z.B. Kublitz-Kramer; Neuland 1996). Nur wenige Artikel setzen sich mit der kritischen Geschlechterforschung (Feminist, Queer, Gender, Gay and Lesbian Studies) auseinander. Eine positive Ausnahme findet man in Aneta Pavlenkos Artikel von 2004 über „Gender and Sexuality in Foreign and Second Language Education“ (Pavlenko 2004). Pavlenko hebt deutlich den großen Vorteil des Sprachunterrichts hinsichtlich Fragen der Geschlechterzugehörigkeit und des Sexismus hervor: „Language classrooms introduce students to ,imaginary worlds“ of

\footnotetext{
${ }^{10}$ So beobachtete der Autor und Anwalt David Campos noch 2005 für US-amerikanische Schulen: [...] learning communities are hostile toward gay and lesbian youth. Human Rights Watch (2001), the American Association of University Women (2001), the Gay, Lesbian and Straight Education Network (GLSEN), and a host of other organizations have consistently reported that gay and lesbian youth are victimized more often than heterosexual youth, and teachers often dismiss, trivialize, or ignore the plight of these youth" (Campos 2005: 9). Und auch für das gegenwärtige schulische Umfeld in Deutschland beobachtet die Journalistin Akiko Lachenmann der Stuttgarter Zeitung: „Fast zwei Drittel aller Schüler lehnen bundesweiten Umfragen zufolge Homosexualität ab, finden sie "nicht gut‘ oder ,überhaupt nicht gut'. Auf Pausenhöfen sind Ausdrücke wie, voll schwul' oder ,Schwuchtel' weit verbreitete Schimpfwörter" (Lachenmann 2012). Solche konkreteren Beobachtungen sind nicht auf den deutschsprachigen Raum beschränkt. Michael Bochenek stellte in einer im Rahmen der Human Rights Watch entstandenen Untersuchung fest, dass Diskriminierung und Gewalt mit homophobem Hintergrund auch dann aufkommen kann, wenn der oder die Betroffene einem gängigen Klischeebild eines oder einer Homosexuellen entspricht: „It quickly became obvious from our research that the abuse of lesbian, gay, bisexual, and transgender youth is predicated on the belief that girls and boys must strictly adhere to rigid rules of conduct, dress, and appearances based on their sex" (Campos 2005: 49).
} 
other languages where gender and sexuality may be constructed and performed differently than in their own culture" (Pavlenko 2004: 55). Pavlenkos Kontext ist hauptsächlich „ESL“ Unterricht, was aber sehr gut auf ein DaF-Modell in Deutschland passt, und insofern ist ihr Artikel auch sehr praxisorientiert. Zum Beispiel schlägt sie vor, dass Lehrende Aufgaben in den Unterricht miteinbeziehen sollten, die ein Vokubular einführen, das die Studierenden brauchen könnten, wenn sie mit sexueller Belästigung (sexual harassment) konfrontiert werden. Vielleicht ist die wichtigste Frage, die man von Pavlenkos Überlegungen weiteruntersuchen könnte, ob es Medien gibt, die man in den Unterricht einbringen kann, die dieses kritisches Denken besonders fördern, bzw. wie man audio-visuelle Medien einsetzen kann, um dieses kritische Denken zu fördern.

Ein anti-sexistischer Umgang mit Sprache ist anti-normativ, nicht nur in Bezug auf eine rigide Aufteilung der Gesellschaft in „männlich“ und „weiblich“. Ein derartiger Umgang mit Sprache, wie er von Pavlenko gefordert wird und der sich an den methodologischen Forderungen Brownes und Nashs orientiert, ${ }^{11}$ hinterfragt auch die Konstruktion einer binären Hierarchie zwischen LehrerIn und SchülerIn bzw. StudentIn und destabilisiert diese Positionen. Der Klassen- und Seminarraum, der als „Safe Space“ entstehen soll, kommt auch dadurch zustande, dass die sprachlichen Voraussetzungen des Unterrichtsrahmens selbst untersucht werden. Gerade auch zu diesem Aspekt eignen sich (audio-)visuelle Medien, da sie dem sprachlichen Ausdruck ein visuelles Umfeld geben, ihn daher diskursiv einbetten. Darüber hinaus tragen (audio-)visuelle Medien zur Herausarbeitung einer kulturellen Lesekompetenz bei.

\section{Wie verhält sich der Begriff der ,visuellen Lesekompetenz“ zu demjenigen der „kulturellen Lesekompetenz“?}

Ein Ziel des Fremdsprachenunterrichts ist es, die Lesekompetenz von SchülerInnen und StudentInnen zu entwickeln, damit sie Texte aus der Zielsprache verstehen können. Bei audio-visuellen Medien kann man aber auch noch andere Lesekompetenzen erarbeiten, die nicht nur auf grammatischen Strukturen und einem bestimmten Lexikon basieren. „Visuelle Lesekompetenzen“ könnte man solche Kompetenzen nennen, die man braucht um - nicht nur! - Bilder, Filme oder Abbildung zu lesen. Diese Art von „visuellem Lesen“ hat viel mit kulturellen nichtliteralen lebensweltlichen Zeichensystemen zu tun, die ja auch eine gewisse Grammatik und Vokabeln haben. Bei der visuellen Lesekomptenz geht es darum, wie die Lehrperson die Studierenden auf jene visuellen Codes aufmerksam macht, damit diese ein Grundverständnis für die Bedeutung visueller Zeichensysteme entwickeln. Ein einfaches Beispiel aus dem ersten Jahr DaF wäre eine interaktive Auf-

\footnotetext{
${ }^{11}$ Siehe Browne; Nash 2010: 7: „Queer scholarship [...] is anti-normative and seeks to subvert, challenge and critique a host of taken for granted ,stabilities' in our social lives [...] yet queer rarely recognizes its own location and how it travels".
} 
gabe wie „Nach dem Weg fragen“, wo man Straßenschilder präsentiert, damit die Studierenden eine visuelle Lesekompentenz für die Straßenverkehrsordnung bekommen. Ein anderer Aspekt visueller Lesekompetenz wird gefördert, wenn man mit den Studierenden beispielsweise einen Ikea-Katalog als visuelles Medium thematisiert (siehe Werner 2013: 19).

Man könnte das Ziel setzen, die Studierenden sollten ein Bestellformular ausfüllen oder mit Collagen ein Zimmer einrichten, in dem das Mobiliar mit den entsprechenden männlichen bzw. weiblichen Vornamen genannt wird. In einem zweiten Schritt können die Studierenden argumentieren, warum sie sich für das entsprechende Mobiliar entschieden haben, und ob dessen geschlechtliche Konnotation etwas mit ihrer Entscheidung zu tun hatte. Diesen Aspekt visueller Lesekompetenz könnte man zusätzlich als „kulturelle Lesekompetenz“ verstehen, da die Beschäftigung mit den geschlechtlichen Pronomina insbesondere der deutschen Sprache einen guten Einblick gewährt in die Kontiguität geschlechtlicher Zuordnungen, was letztlich nichts anders ist als ein Vorgang kultureller Kodifizierung. „Lesen“ hat eine besondere Bedeutung im Kontext der kulturellen Lesekompetenzen sowie der Queer Theorie. Der Begriff „reading“ hat eine neue Konnotation vor allem durch Butlers Kommentare zum Film „Paris is Burning“, der von feministischen und queeren KritikerInnen oft besprochen worden ist. Judith Butlers Aufsatz „Gender is Burning“ setzt sich mit verschiedenen Lesarten des Filmes auseinander und unterstreicht die Relevanz des Begriffs „reading“ für die Performanz von Geschlechterrollen. ${ }^{12}$ Im Film ist „reading“ eine Praxis der Beleidigung, die darauf hinausläuft, einen Fehler in der Inszenierung der Geschlechterrolle einer anderen Trans*person zu finden, und diesen Fehler dann als hinterlistige Bemerkung zu äußern. Butler betont, dass dieses „Lesen“ mit „Texte lesen“ gemeinsam hat, dass es in beiden Fällen darum geht, ein kulturelles Produkt zu rezepieren, und dieses Produkt, sei es die verkörperte Inszenierung vom Geschlecht oder ein Gedicht von Annette Dröste-Hülshoff, auf seine Stimmigkeit und Bedeutung zu prüfen. Um überhaupt lesen zu können, muss man Erfahrung in der Sprache haben, sei diese Sprache eine Körpersprache, eine Zeichensprache oder sonst ein semiotisches System. Wir möchten daher eine Definition von kultureller Lesekompetenz vorschlagen, die das Lesen im Sinne von „Paris is Burning“" versteht: als einen Vorgang der Interpretation, der nicht nur die jeweilige sprachliche Äußerung untersucht, sondern deren gesamten, plastischen, realsozialen Zusammenhang. In eben jenem Zusammenhang existiert Geschlecht nicht einfach, sondern wird beständig neu verhandelt. Geschlecht ist damit das sprachliche und auch visuell erzeugte, immer nur vorläufige Produkt einer „embodiment of norms,

\footnotetext{
12 In „Paris is Burning“ wird diese Performanz der Geschlechter, aber auch von sozialer Klasse und Ethnizität, besonders explizit herausgestellt durch die von Regisseurin Jennie Livingston dargestellten „Drag- Bälle“: „The balls are contests in which the contestants compete under a variety of categories. The categories include a variety of social norms, many of which are established in white culture as signs of class, like that of the ,executive and the Ivy League student; some of which are marked as feminine, ranging from high drag to butch queen; and some of them, like that of the ,bangie', are taken from straight black masculine culture." (Butler 1993: 127f.).
} 
a reiteration of norms, an impersonation of a racial and class norm, a norm which is at once a figure, a figure of a body, which is no particular body, but a morphological ideal that remains the standard which regulates the performance, but which no performance fully approximates." (Butler 1993: 128). Wir möchten einen kritischen Blick bei den Studierenden erzeugen, der nicht so sehr nach Authentizität sucht, sondern nach Zusammenhängen und kulturellen Voraussetzungen, die nötig sind, Botschaften und Bedeutung auch von Geschlecht und Sexualität zu rezipieren und zu empfangen.

Der US-amerikanische Queer-Studies-Theoretiker David Halperin beschreibt in seinem 2012 erschienen Buch „How to Be Gay“, wie Kulturen der Homosexualität genauso wie solche der Heterosexualität (Romantik, Partnerschaftsbeziehungen sowie Institutionen wie Heirat und Elternschaft, die jeweils einen Mann und eine Frau einbeziehen) durch soziale Lernprozesse erworben werden müssen. Dementsprechend geht es Halperin darum, eine Methodologie des Queering nicht nur auf Repräsentationsformen von LSBT/I-Kulturen anzuwenden, sondern vielmehr alle Lebensentwürfe und damit auch solche, die im Alltag wenig bis gar nicht hinterfragt werden, auf ihren konstruktiven und auf ihren kontingenten Charakter hin zu analysieren. ${ }^{13}$ Dennoch, so Halperin, gibt es kulturelle Zirkel und Medien, die eine queere, nicht-normative Klientel anvisieren: „As a cultural practice, male homosexuality involves a characteristic way of receiving, reinterpreting, and reusing mainstream culture, of decoding and recoding the heterosexual or heteronormative meanings already encoded in that culture, so that they come to function as vehicles of gay or queer meaning." (Halperin 2012: 12). Was Halperin hier beispielsweise für kulturelle Ausdrucksformen von männlicher Homosexualität angibt, zeigt sich in Filmen, Musik, Theater sowie politischen Programmen, die es zu verstehen und $\mathrm{zu}$ erlernen gilt, will man nicht-heterosexuelle Kulturen „lesen“ lernen. ${ }^{14}$

Dieses Lernen darüber, was es in einer Gesellschaft bedeutet, entweder ein Mann oder eine Frau zu sein, mit den Prädikaten „männlich“ oder „,weiblich“ versehen zu werden (handelt es sich nun um Menschen oder um Dinge), was es bedeutet, Partnerschaftsbeziehungen entweder mit einem Mann oder einer Frau einzugehen, und welche sozialen Institutionen auf Geschlechteridentitäten und sexueller Orientierung basieren, das ist das, was wir als kulturelle Lesekompetenz bezeichnen wollen. Der Begriff, auf die Arbeitsgebiete der Queer Studies bezogen, fragt also weniger danach, was eine Frau oder ein Mann, was Homo-, Bi- oder Heterosexualität sind; vielmehr erkundigt sich kulturelle Lesekompetenz danach, was es bedeutet, in einer bestimmten Gesellschaft als Mann oder als Frau wahrge-

\footnotetext{
13 Siehe Halperin 2012: 37: „My plan is to examine the figural and formal dimensions of some of the mainstream cultural objects that gay male culture appropriates and endows with queer value. I will seek meaning in style and I will look for queer content in form itself."

${ }^{14}$ Siehe Halperin 2012: 15: „If we could figure that out, we would also be in a better position to understand the larger relations between sexuality and culture, between kinds of desire and conventions of feeling."
} 
nommen und anerkannt zu werden, und was es darauf aufbauend bedeutet, Liebesbeziehungen einzugehen, Familien zu gründen, Freundschaften zu schließen und dergleichen mehr.

Für Lehrmaterialien, die im DaF-Bereich einsetzbar sind, ergeben sich damit auch neue Aufgaben in der optischen und inhaltlichen Gestaltung, auf die im weiteren Verlauf näher eingegangen werden soll.

Für queere Jugendliche und junge Erwachsene ist der Aspekt der Wahrnehmung besonders pikant, eben auch deswegen, weil Visualität eine Präsenz impliziert, die im Zeitalter interaktiver, sozialer Online-Netzwerke oft gleichzusetzen ist mit Bekanntheit und Beliebtheit. SchülerInnen und Studierenden, die u.a. als geschlechtliche bzw. sexuelle Minderheit angesehen werden, erfahren Diskriminierung nicht nur durch offen vorgebrachte Anfeindungen, sondern auch durch eine weitgehende Isolation. Dadurch werden die Betroffenen nicht nur ausgegrenzt, sie werden zudem auch ,,unsichtbar“ oder, wie weiter oben angegeben, ,unlesbar“. 15 Der österreichische Fernsehsender 3Sat bezeichnet den Schulaltag für schwul-lesbische Jugendliche sinngemäß als „Schulhölle“: Am Beispiel einer lesbischen Schülerin unter dem Pseudonym Franky wird demonstriert: „Sie war an einer Schule in Potsdam, ist lesbisch und wurde in der achten Klasse von einer Freundin geoutet. $\mathrm{Ab}$ diesem Tag wurde sie fast täglich gemieden, gemobbt und beleidigt. In der elften Klasse hat Franky die Schule abgebrochen" (3Sat Web Präsenz). ${ }^{16}$

Aber nicht nur MitschülerInnen können zu Feinden schwul-lesbischer Jugendlicher auf dem Schulgelände werden. Auch die eventuelle Passivität des Lehrpersonals kann sich problematisch auf deren Wohlbefinden auswirken: „Zu der sozialen Isolation kommt oftmals ein Leistungsabfall. Wie im Fall von Marcus. Zwar hat er sich erst nach seiner Schulzeit geoutet, gemobbt wurde er jedoch schon in der Grundschule, weil er zu sanft, zu lieb und zu ruhig war. Er war schon immer die Schwuchtel [...]. Auch Marcus hat die Schule früher verlassen als geplant. Er hätte sich Unterstützung durch seine Lehrer erhofft. Doch die gab es nicht" (Scobel 2013). Das Zitat stammt aus einem Artikel, welcher unter dem unten angegebenen Link zur 3-Sat-Website zu finden ist und eine Abbildung enthält, die sich hervorragend im Rahmen des DaF-Unterrichtes einsetzen lässt. Jenes Bild kann man in drei visuelle Ebenen unterteilen. Den Hintergrund bildet das leicht verschwommene Foto einer davonfahrenden Untergrundbahn, davor projiziert sind zwei junge Frauen, welche zum einen aus unterschiedlichen Kulturen stammen und sich zum Anderen küssen. Sie sind eindeutig als ein Paar erkennbar. Ein gelb-rot gehaltener Schriftzug sagt auf Türkisch, Arabisch und Deutsch „Liebe verdient Respekt“. Darunter, in den Vordergrund der Ebenen gesetzt, jedoch deutlich kleiner als das Bild der beiden Frauen, befinden sich die InitiatorInnen der „Berliner Kampagne gegen Homophobie" abgelichtet, ihrerseits ebenfalls Menschen verschiedener kultureller

\footnotetext{
15 http://www.stuttgarter-zeitung.de/inhalt.toleranz-in-der-schule-warum-homosexualitaet-immernoch-ein-tabuthema-ist.8d12f467-50cc-4de5-92b5-4a9cbe3d7c2c.html.

16 http://www.3sat.de/page/?source=/scobel/158221/index.html.
} 
Ursprünge. Nicht nur auf einer geschlechtlich-sexuellen Ebene können SchülerInnen und StudentInnen Aspekte des Queerings hier diskutieren. Gleichsam lassen sich anhand dieser Abbildung Stereotypen auf der Schnittstelle zwischen Ethnizität und Sexualität diskutieren. Beispielsweise kann folgenden Fragen nachgegangen werden: Welches Bild von einem Mann bzw. einer Frau kommen mir in den Sinn, wenn ich die Worte „schwul“ oder „lesbisch“ höre? Sehen diese Menschen auf eine gewisse Art und Weise aus, d.h. tragen sie etwa für mich charakteristische oder gar stereotype Kleidung? Gibt es Kulturen, in denen ich gleichgeschlechtliche Paare eher zu treffen vermute als in anderen? Woher habe ich diese Eindrücke erhalten? Im Anschluss an Diskussionen dieser Art leiten Links weiter zu einer Bildergalerie über Stereotypen hinsichtlich des Aussehens und der sozialen Präsenz nicht-heterosexueller Menschen in Deutschland, Österreich und der Schweiz, ${ }^{17}$ sowie zu Video-Interviews schwul-lesbischer Menschen, die in vermeintlich heterosexuell konnotierten Bereichen arbeiten.

Beispielsweise berichtet die ehemalige Fußballerin Tanja Walther-Ahrens von ihren Erfahrungen als lesbische Sportlerin in einer vermeintlich heterosexuellen Männerdomäne. ${ }^{18}$ Nach der Vorführung von Teilen des Interviews sowie der Bildergalerie bezüglich geschlechtlich-sexueller Stereotypen können SchülerInnen und StudentInnen, möglichst in Gruppenarbeit, diskutieren: Welche Formen der Kleidung erkenne ich als männlich, welche als weiblich, vor dem Hintergrund, dass diese Kleidung in Deutschland, Österreich oder der Schweiz getragen wird (ein Rock ist z.B. in Schottland nicht unbedingt ein Zeichen von Weiblichkeit!)? Welche Sportarten identifiziere ich im Rahmen deutschsprachiger Kultur als typisch männlich, welche als typisch weiblich? Indem sich SchülerInnen und StudentInnen derart selbstkritisch mit (audio-)visuellen Medien im DaF-Unterricht befassen, mit Medien, die auch dem deutschsprachigen Kulturraum entstammen, schärfen sie ihre Aufmerksamkeit für nicht-normative Identitäten und Lebensdesigns, die bei ansonsten unreflektiert übernommenen kulturellen Stereotypen „unlesbar“ bleiben und damit in Isolation verharren könnten.

Gefahren einer sozialen Isolation sind vor allem an Schulen eklatant, da speziell die „high school“-Phase für Jugendliche in einem Alter eintritt, in dem sie erste wichtige Erfahrungen in der Aufnahme zwischenmenschlicher Beziehungen machen ${ }^{19}$ und die im Falle von LSBT/I-Jugendlichen noch verkompliziert werden. ${ }^{20}$ Aus dem Blickwinkel queerer Pädagogik und Didaktik für den DaF-Unter-

\footnotetext{
17 http://www.3sat.de/page/?source=/scobel/karussell/158222/index.htm, 27.06.2013.

18 Interview vom Donnserstag, 2. November 2011, unter http://www.3sat.de/mediathek/ index. php?display $=1 \&$ mode $=$ play\&obj $=27803$.

${ }^{19}$ Siehe Savin-Williams (2004: 113): „Developmentally, dating is a means by which romantic relationships are practiced, pursued, and established. It serves a number of important functions, such as entertainment, recreation, and socialization, that assist participants in developing appropriate means of interacting."“

${ }^{20}$ Siehe Savin-Williams (2004: 119): ,,The vast majority of lesbian, bisexual, and gay youths are closeted, not out to themselves, let alone to others. A second barrier, reviewed earlier in this chapter, is the consequences of same-sex dating, such as verbal and physical harassment from peers. A third impe-
} 
richt haben visuelle (bzw. audio-viselle) Medien nun die Aufgabe, queere Identitäten im Rahmen des deutschsprachigen Kulturraumes sowie im Austausch mit jenem „,in die Mitte“ zu rücken. Letzteres bedeutet aber nicht, sich auf eine Minderheit als Minderheit zu konzentrieren. Vielmehr bedeutet es, sie in eine kulturelle Gesamtschau zu integrieren und ihre Konstruiertheit dazustellen, die sich aber in (fast) nichts von der Konstruiertheit eines sogenannten „normalen“ Lebensstils unterscheidet.

Um diese Visibilität muss es uns gehen. Darüber hinaus soll die neue Sichtbarkeit queerer Lebensentwürfe nicht nur um ihrer selbst Willen in den Lehrplänen für den DaF-Unterricht zu finden sein, denn damit alleine wäre nichts gewonnen. Das Hauptaugenmerk muss darauf liegen, inwiefern queere Identitäten und Orientierungen zu einem tieferen Verständnis von Kultur beitragen, die durch die deutsche Sprache augedrückt und vermittelt wird. Mit anderen Worten: Queere Designs werden dann erst besondes interessant für den DaF-Unterricht, wenn man versteht, wie sie zur kulturellen Lesekomptenz oder „Cultural Literacy“ beiträgt. Was man genauer darunter versteht, soll anhand der folgenden Beispiele verdeutlicht werden.

\section{Beispiel 1: Gleichgeschlechtliche Liebe im Kontext der Daily Soap}

Die Vorabendserie „Verbotene Liebe“ wird bereits seit dem 2. Januar 1995 im öffentlich-rechtlichen Programm der ARD ausgestrahlt.. ${ }^{21}$ Sie ist eine sogenannte Daily Soap und wird von der Potsdamer Produktionsgesellschaft GrundyUFA hergestellt und vertrieben. Wie der Titel der Serie vermuten lässt, geht es in einem Großteil der Handlungsstränge um Liebesbeziehungen, Affären und erotisch-romantische Abenteuer, die für gewöhnlich Anlass zu öffentlicher Besorgnis oder gar Aufregung sind. Dabei konzentriert sich die Serie allerdings hauptsächlich auf Segmente der so genannten „high society“, nicht aber so sehr auf die Liebesbeziehungen und -probleme der breiteren Bevölkerung.

Gleichzeitig entwickelte die Serie als eine der ersten ihres Genres so genannte Nebenhandlungsstränge, die sich mit Liebesbeziehungen und romantischen Affären beschäftigen, welche auch Thema einer „queer soap" wie etwa "The L Word" oder „Queer as Folk“ sein könnten. Dabei werden dann auch schon mal Versuche eines sozialen Queerings unternommen. Ein besonders prominentes Beispiel hier-

\footnotetext{
diment is the lack of public recognition or ,celebration' of those who are romantically involved with a member of the same gender. Thus, same-sex dating remains hidden and mysterious, something that is either ridiculed, condemned, or ignored.“

${ }^{21}$ Eine Auflistung aktueller Folgen findet sich auf der Homepage der ARD unter http:// www.ard mediathek.de/sendung/verbotene-liebe?documentId=439104.
} 
für ist die Beziehung zwischen der reichen Gutstochter und Designerin Rebecca von Lahnstein und der bürgerlichen Barkeeperin Miriam Pesch. ${ }^{22}$

$\mathrm{Zu}$ Beginn ihrer Bekanntschaft identifizieren sich beide Frauen als heterosexuell und klagen sich gegenseitig ihr Pech bei den Männern. So erweisen sich Rebeccas Männerbekanntschaften häufig als verheiratet, und Miriam ist Dauersingle. Mit ihrer gemeinsamen Jagd auf Männer performen sie Rollen, die traditionell weiblich-heterosexuell konnotiert sind, nämlich die des "Girl-Talks“ unter Freundinnen, wie er medial besonders durch „Sex and the City" bekannt geworden ist. Als die beiden Freundinnen beschließen, nach einer Reihe missglückter Flirtversuche einen entspannenden Nachmittag in einem Kölner Wellnessclub zu verbringen, werden sie wiederholt von drei jungen Männern gestört. Um deren permanente Anbahnungsversuche endgültig von sich zu weisen, küsst Miriam Rebecca auf den Mund, um den Eindruck zu erwecken, sie und Rebecca seien lesbisch und ein Paar. Diese Aktion aber hinterlässt einen bleibenden Eindruck bei den Frauen. Sie versuchen, zunächst noch getrennt voneinander, sich über ihre neu aufgetretenen Gefühle klar zu werden. Wenn sie sich treffen, wechseln sich Situationen voller Spannung und Streit ab mit jenen, die schließlich überwiegen: Auf Miriams Geburtstagsfeier im Café küssen sich die Frauen erneut und verbringen eine romantische Nacht miteinander. Doch schließlich geht Rebacca in Miriams Augen zu weit, als sie auf einem Galaempfang ihrer Familie Miriam als feste Freundin und Partnerin präsentiert. Miriam überzeugt Rebecca schließlich, dass ihre Verbindung keine wirkliche Beziehung ist, sondern vielmehr der Ausdruck einer Frauenfreundschaft, die aufgrund der vorher erlebten Enttäuschungen von Männern eine erotische Komponente angenomen hat. Die beiden Frauen beschließen, zur vorherigen platonischen Ebene ihrer Freundschaft zurückzukehren.

Die Episoden, die sich mit Miriams und Rebeccas Beziehung zueinander befassen, scheinen zunächst diverse heteronormative Vorurteile zu bedienen. So ist es ein gängiges Stereotyp, dass Frauen, die keinen Erfolg bei Männern haben beziehungsweise von Männern enttäuscht worden sind, sich aus Frustration anderen Frauen zuwenden. Außerdem klingt das Fehlurteil an, dass Frauen nur an den „richtigen“ Mann geraten müssen, um - freiwillig! - zur Heterosexualität zurückzufinden. Aber ganz so einfach macht es uns „Verbotene Liebe“ nicht, wenn wir uns die mediale Repräsentation von Rebeccas und Miriams Beziehung genauer ansehen. Die Beziehung der beiden Freundinnen vollzieht diverse Aspekte eines Queering nicht nur in Bezug auf sexuelle Orientierung. Folgende Bereiche sind dabei von Interesse:

\footnotetext{
22 Die Story mit Miriam und Rebecca als Liebespaar wurde von der ARD und Grundymedia bis zum 6. Januar 2011 ausgestrahlt. Der Charakter der Rebecca wurde damals noch von der Schauspielerin Jasmin Lord, der Charakter der Miriam von Romina Becks gespielt. Beide Schauspielerinnen haben die Serie mittlerweile verlassen, die Figur der Rebecca besteht aber weiterhin (gespielt von Tatjana Kästel) und hat auch eine neue Beziehung zu einer Frau. Referenzen zur Beziehung sowie lizensierte Fotos findet man unter http://www.t-online.de/unterhaltung/tv/id_43467220/sid_40814446/ si_0/heisse-kuesse-bei-verbotene-liebe-.html.
} 
1. Das soziale Umfeld. Hier findet zuallererst ein soziales Queering statt. Rebecca ist aus einer wohlhabenden adligen Familie, ganz im Gegensatz zu Miriam. Das real bestehende ökonomische Gefälle in ihrer Beziehung wird aber durch die Performanz der Freundschaft wiederholt untergraben, und zwar durch Miriams Darstellung von traditionell „maskulinem“ Rollenverhalten. Miriam ist die treibende Kraft hinter der gemeinsamen Freizeitgestaltung und übernimmt die Initiative, wenn es um die Annäherung zwischen ihr und ihrer Freundin geht. Das hat zur Folge, dass Miriam auch dann sicherer, souveräner und bestimmender auftritt, wenn sie sich zusammen mit Rebecca in ,,adliger“ Umgebung befindet.

2. Trotzdem widerspricht die Beziehung zwischen Miriam und Rebecca der dichotomen Aufteilung zwischen Maskulinität und Femininität, welche es auch in gleichgeschlechtlichen Beziehungen geben kann. Hier kommt die visuelle Ebene der anzusehenden Folgen explizit zur Geltung: Miriam und Rebacca stellen eine fast schon „klassische“ Femininität durch Kleidung und Makeup dar, die sich hier aber einem heterosexuellen und heteronormativen Kontext entgegenstellt. Wir müssen uns daran erinnern, dass Queering auch normativen Strömungen in gleichgeschlechtlichen Lebensentwürfen entgegenwirkt.

3. Fluidität von Definitionen in Bezug auf Begriffe, die auf die Wortfelder „Familie“, „Freundschaft“, „Liebe“ verweisen. Nicht nur die Beziehung zwischen Miriam und Rebecca entzieht sich einer festen und dauerhaften Definition. Die beiden Freundinnen sind abwechselnd Freundinnen und Liebhaberinnen, außerdem befinden sie sich in familiären Verbindungen, die als Patchwork zu verstehen sind. Rebeccas familiärer Kontext ist derart weitläufig, dass die Grenzen zwischen Verwandtschaft durch Geburt, Heirat und Adoption verschwimmen. Miriam definiert ihren engsten Freundeskreis kurzerhand zur Familie um und hinterfragt damit besonders konsequent die traditionelle Definition derselben. Und damit werden auch traditionelle Geschlechterrollen hinterfragt. Zur beständigen situativen Neudefinition wird angeregt.

4. Eine ähnliche Fluidität wird von der Serie „Verbotene Liebe“ auch dann vorausgesetzt, wenn es um die Definition von Sexualität/sexueller Orientierung geht. Weder Homo- noch Heterosexualität sind Definitionen, die sich dauerhaft auf Rebecca und Miriam anwenden lassen. Auch wenn die romantische Beziehung der beiden Frauen letztlich nicht bestehen bleibt, so bedeutet das dennoch keine Rückkehr zu einer heteronormativen Ordnung. In späteren Episoden der Serie wird sich Rebecca erneut verlieben in eine Figur mit dem Namen Marlene.

Der Zuschauer/die Zuschauerin wird also zu einer beständigen Reflexion bezüglich der Begriffe von Männlichkeit/Weiblichkeit, Hetero- und Homosexualität angehalten, damit auch zu Reflexion bezüglich der Hinfälligkeit eines streng binären 
Geschlechtermodells. Von der Serie „Verbotene Liebe“ sind bislang nur die ersten 100 Folgen auf DVD erschienen. Die ARD stellt allerdings eine Zeitlang die aktuellen Folgen der Serie auf ihre Website, wo im geschlossenen Rahmen des Unterrichts einzelne Szenen betrachtet und diskutiert werden können, etwa nach den Kriterien, die oben für das Verhältnis und die visuelle Darstellung der Figuren Rebecca und Miriam erläutert worden sind. Diese können dann beispielsweise auf die sich fortsetzende Beziehung zwischen Rebecca und ihrer neuen Freundin Marlene angewandt werden. Die oben genannten Aspekte des Queerings können von den Studierenden auf ihr fortlaufendes Vorhandensein überprüft werden, insbesondere auch im Hinblick auf ihre Lesbarkeit in einem scheinbar heterosexuellen Rahmen, der ja oft als die gesellschaftliche Norm angesehen wird.

\section{Beispiel 2: „Missy Magazine“ - Neue Frauenbilder und queere Lesarten im Klassenzimmer}

Wenn man mit visuellen Medien neue Lesekompentenzen fürSchülerInnen und StudentInnen bereitstellen möchte, die auch interkulturelle Kompetenzen fördern, kann man sehr gut mit Zeitschriften arbeiten. Zeitschriften beinhalten eine Vielfalt von visuellen Informationen und kulturellen Kontexten, die man erst erschließen kann, wenn man die passenden Lesekompetenzen hat. Das „Missy Magazine“ bietet eine Möglichkeit, mit SchülerInnen über Gendervielfalt und -themen im deutschsprachigen Raum zu reden. Darüber hinaus bietet das „Feministische Magazin für junge Frauen“ eine Gelegenheit, über Geschlechteridentität nachzudenken und darüber, wie wir Geschlecht mit bestimmten kulturellen Erwartungen wahrnehmen und lesen.

„Missy Magazine“ erscheint seit 2008 in Deutschland und wurde als Pendant zu anderen Popkultur-Zeitschriften (wie „Spex“ oder „Neon“) konzipiert, um ein Forum für feministische Frauen zu bieten. Weiterhin arbeitet die Zeitschrift sehr stark mit visuellen Medien. Von der Gestaltung (Layout) bis hin zu den Fotos, Abbildungen und auch Comics findet man eine Mischung von visuellen Texten im selben Heft. Neben der Print-Ausgabe gibt es auch „Missy Online“. Die Webseite bietet in Sachen visueller Medieneine Menge: Videoclips, Fotoreihen und Links zu Produktkatalogen oder Veranstaltungen. Die Formate von Print- und Online„Missy“ unterscheiden sich formal nicht sehr von anderen Zeitschriften. Das, was „Missy" als innovatives Lehrmaterial auszeichnet, ist an ihren Inhalt gebunden.

„Missy Magazine“ besteht aus Artikeln mit einem deutlich feministischen Fokus. Die Debatte darüber, welche Form von Feminismus in der Zeitschrift vertreten wird, soll nicht stillschweigend übergangen werden, ${ }^{23}$ aber die Zeitschrift tendiert in Richtung eines pluralistischen feministischen Ansatzes, so dass man vielleicht eher von „Feminismen“ anstatt von „dem Feminismus“ reden müsste. In-

${ }^{23}$ Siehe den Artikel von Gesche Gerdes (2012). 
wiefern diese Problematik Teil des DaF-Unterrichts sein kann, bleibt offen. Unser Schwerpunkt im Rahmen dieses Artikels ist aber ein anderer: Wie kann „Missy“ als Grundlage für eine DaF-Einheit dienen, die StudentInnen und SchülerInnen queere visuelle Lesekompetenzen vermitteln kann?

„Missy“ eignet sich aufgrund der vielen kleinen Artikel für text-basierte Lesekompetenzen im DaF-Unterricht. Die meisten sind nicht länger als eine Seite, so dass man sehr gut kleine Leseübungen zum Leseverständnis oder als Diskussionsgrundlage oder Grundlage für Partnerübungen entwickeln kann. Zum Beispiel in der Rubrik „Mode“ in Ausgabe 2 (2013): Dort findet man eine Reihe von Fotos, die verkleidete Schuhe abbilden, dazu gibt es einen Kurztext „Tipps für Vintage Shoe Lovers“ (Abbildung ebd.: 85). Mit Texten und Bildern könnte man eine Aktivität entwickeln, in der die StudentInnen zunächst Beschreibungen von den Bildern anhören und die jeweilige Beschreibung dem passenden Bild zuordnen müssen (receptive phase). Dann könnten die StudentInnen selber ein Bild eines/r PartnerIn beschreiben (1. productive phase). Anschließend könnten die StudentInnen selber eine kleine Schuhskulptur erstellen und erklären, woher die verschiedenen Teile kommen (2. productive phase). Am Ende würde ein Gespräch über Schuhe und interkulturelle Unterschiede anschließen - z.B. über die verschiedenen GröBensysteme, Gender-Vorurteile zu Schuhen und „Missy“s Rubrik „Mode“ im Vergleich mit anderen Frauenmagazinen.

Neben „Mode“ gibt es bei „Missy“ außerdem die Rubrik „Mach es selbst“. Diese Rubrik bietet die Möglichkeit, mit Abbildungen zu arbeiten und auch Fragen über Gender-Stereotypen zu besprechen. Zum Beispiel kann man in der aktuellen Ausgabe lesen, wie man einen ,veganen Flogger" macht. Wenn ein solches Bastelprojekt eventuell den Rahmen einer Unterrichtsstunde sprengen sollte, kann man mit dem einseitigen Artikel eine Aktivität entwickeln, die neben einer „Kochennach-Rezept-Aktivität ganz andere kulturelle Kenntnisse vermitteln kann.

In der aktuellen Ausgabe von „Missy“ gibt es desweiteren einen Artikel, der auf eine sehr spannende Weise visuelle und kulturelle Lesekompetenzen mit Fragen von Geschlechteridentität kombiniert. Jill Peters Fotos und das Interview zu ihrem Fotoprojekt „Sworn Virgins of Albania“ zeigt eine Reihe von sieben Bildern von „Burrnesha“ aus Albanien, d.h. Frauen, die auf eine traditionelle weibliche Existenz verzichten und eine andere maskulinere Weiblichkeit annehmen (um mit Halberstams Begriffen zu reden/spielen). Dieser Artikel eignet sich besonders für eine queere Perspektive zum Thema der visuellen Lesekompetenz, weil die Bilder uns einladen, das Geschlecht von den Figuren zu „lesen“. Auf den ersten Blick sieht man, dass es um einen anderen Umgang mit Weiblichkeit und Männlichkeit geht. Ohne begleitenden Text (das Interview kommt erst am Ende des Artikels) versuchen wir, die Figuren einzuordnen: Ist das eine Frau in Männerkleidung? Oder ein älterer Mann ohne Bart? Auch wenn es in der ersten Interviewfrage heißt, dass es „Frauen in Albanien, die auf Ehe und Liebe verzichten und in ihren Familien die Rolle von Männer einnehmen“ sind (Peters 2013: 36), ist man ohne queere Lese- und Kulturkompetenzen noch verblüfft. 
Mit diesen Bildern und dem Artikel könnte man sehr früh im DaF-Unterricht, z.B. beim Erwerb von Vokabeln für Kleidungsstücke, diese Bilder einsetzen, um nicht nur über Kleidung zu reden, sondern auch darüber, wie wir Geschlecht durch ÄuBerlichkeiten lesen. Von der Redewendung „Kleider machen Leute“ zum Poplied „Wann ist ein Mann ein Mann?" kann man die Themen Geschlecht, Kleidung und Identität hier auffächern und elaborieren. Man könnte als erstes die Bilder zeigen und „geschlechtsneutrale“ Fragen stellen: „Trägt diese Person ein Hemd?“; „Trägt diese Person eine Brille?"; „Wie alt ist diese Person?" In einem zweiten Schritt würden die StudentInnen die Figuren einem/r PartnerIn beschreiben. Wenn sie dann die Figuren geschlechtlich zuordnen, könnte man als Schlussdiskussion genau diese Zuordnung thematisieren und nach den Kriterien fragen, nach denen sie die Figuren als männlich oder weiblich eingeordnet haben.

Natürlich ist das Risko bei so einer Aktivität, die Epistemologie der Geschlechter wieder zu unterstützen, indem man die StudentInnen einlädt, über das Geschlecht zu rätseln, bzw. das Rätsel dann am Ende zu lösen. Insofern sollte man das Interview ebenfalls mit einbeziehen, in dem es deutlich darum geht, ein verbreitetes Genderverständnis zu entwickeln, das nicht immer nur danach strebt, Personen in Mann oder Frau einzuordnen.

Natürlich kann man nicht davon ausgehen, dass die visuellen Medien, mit der „Missy Magazine“ arbeitet, allein dafür sorgen können, eine queere Unterrichtspraxis aus dem Nichts hervorzuzaubern. Vieles hängt davon ab, wie LehrerInnen eine Atmosphäre von Offenheit und Toleranz (wenn auch dieses Wort seine eigenen Probleme mit sich bringt) schaffen, und von der Gruppe von SchülerInnen und StudentInnen - inwieweit sie sich darauf einlassen. Nichtsdestotrotz hat man in „Missy“ eine Quelle für visuelle Medien, die „normale“ und „normative“ Lesarten in Frage stellen. Insofern bietet sich an, mit „Missy“ zu arbeiten, wenn man die interkulturellen Kompetenzen durch visuelle Medien erweitern will.

\section{Schluss}

Wir wollen mit diesem Artikel sowohl Lehrer als auch SchülerInnen und StudentInnen anregen, darüber nachzudenken, wie scheinbar selbstverständlich wir Menschen und Dinge geschlechtlich belegen. Wenn unsere Muttersprache die Kategorie Genus kennt, denken wir uns für gewöhnlich nichts dabei, dass wir, wie das im Deutschen oder im Französischen der Fall ist, scheinbar willkürlich Gegenstände und Sachverhalte mit maskulinen oder femininen Artikeln versehen. Im Bereich der Bezeichnung von Menschen aber haben wir begonnen, genauer hinzuhören. Denn die Verwendung von Artikeln vor der Bezeichnung von Geschlechtern, aber auch Berufen und Positionen verrät bei genauerem Hinsehen einiges darüber, welche Vorstellungen von Männlichkeit und Weiblichkeit in einer Sprachgemeinschaft vorhanden sind und Geltung beanspruchen. Worüber wir uns aber auch, und das gerade beim Erlernen einer Fremdsprache, im Klaren sein müssen, ist, dass diese 
Vorstellungen womöglich nicht alle Lebensentwürfe berücksichtigen, die sich potentiell im Diskursfeld „Geschlecht“ bewegen. Und dieses Diskursfeld, so hat unser Artikel gezeigt, ist extrem vielfältig und weitreichend.

Visuelle Medien können helfen, solche nicht oder nur marginal erfassten Lebensentwürfe ins Blickfeld zu rücken und ihnen eine sprachliche und gesellschaftliche Validität zu ermöglichen. Darüber hinaus stellen sie unser Selbstverständnis in Frage, mit dem wir uns durch unsere eigenen sozialen Lebenswelten bewegen. Letztlich, so zeigen unsere beispielhaften Verweise, ist unser gesamtes Leben, egal in welcher Kultur, sprachlich konventionalisiert.

\section{Literatur}

3Sat Mediathek (2011): Interview mit Tanja Walther-Ahrens. In: 3sat.de. Http:// www.3sat.de $/$ mediathek $/$ index.php?display $=1 \&$ mode $=$ play\&obj=27803).

Alter, Nora M (2006): Questions of Methodology in Visual Studies. In: Finney, Gail (Hrsg.): Visual Culture in Twentieth-Century Germany: Text as Spectacle. Bloomington: Indiana UP, 15-22.

Bochenek, Michael (2001): Hatred in the Hallways. Violence and Discrimination Against Lesbian, Gay, Bisexual, and Transgender Students in U.S. Schools. New York: Human Rights Watch.

Browne, Kath; Nash, Catherine (Hrsg.) (2010): Queer Methods and Methodologies. Intersecting Queer Theories and Social Science Research. Farnham: Ashgate.

Butler, Judith (1993): Bodies that Matter. On the Discursive Limits of Sex. New York, London: Routledge.

Campos, David (2005): Understanding Gay and Lesbian Youth. Lessons for Straight School Teachers, Counselors, and Administrators. Lanham: Rowman \& Littlefield Education.

Degele, Nina (2008): Gender/Queer Studies. München: Fink.

Foucault, Michel (1983): Sexualität und Wabrheit, Bd. 1. Der Wille zum Wissen. Frankfurt/Main: Suhrkamp.

Gail Finney (Hrsg.) (2006): Visual Culture in Twentieth-Century Germany. Text as Spectacle. Bloomington: Indiana UP.

Gerdes, Gesche (2012): Der Postfeminismus-Vorwurf. Beobachtungen zum feministischen Selbstkonzept junger Theaterkünstlerinnen und Journalistinnen am Beispiel des „Missy Magazine“. In: Gender. Zeitschrift für Geschlecht, Kultur, Gesellschaft 1, 9-23. 
Hahn, Jetti; Kübler, Annette; Kontzi; Nele (2012): Mit dem Anti-Bias-Ansatz die „Rolle vorwärts“ wagen! Oder: Warum es so wichtig ist, bei sich selbst anzufangen. In: Lernende Scbule 60, 42-45.

Hall, Donald E.; Jagose, Annamarie (Hrsg.) (2013): The Routledge Queer Studies Reader. New York: Routledge.

Halperin, David (2012): How to be Gay. Cambridge: Belknap.

Kraß, Andreas (Hrsg.) (2012): Queer Studies in Deutscbland. Interdisziplinäre Beiträge zur kritischen Heteronormativitätsforschung. Berlin: trafo Wissenschaftsverlag.

Kublitz-Kramer, Maria; Neuland, Eva (Hrsg.) (1996): Differenzen - Diesseits und jenseits von Geschlechterfixierungen. In: Deutschunterricht: Beiträge zu seiner Praxis und wissenschaftlichen Grundlegung 48.1, 1-110.

Lachenmann, Akiko (2012): Toleranz in der Schule. Warum Homosexualität noch immer ein Tabuthema ist. In: Stuttgarter-zeitung.de Http://www.stuttgarterzeitung.de/inhalt.toleranz-in-der-schule-warum-homosexualitaet-immer-nochein-tabuthema-ist.8d12f467-50cc-4de5-92b5-4a9cbe3d7c2c.html (05.12.2012).

Martenstein, Harald (2013): Über öffentliche Toiletten für Männer, Frauen und Andere. In: Zeit Online Zeitgeschehen (http://pdf.zeit.de/2013/12/MartensteinOeffentliche-Toiletten.pdf).

Oestreich, Heide (2012): Streit um Elfjährige Transsexuelle. Alex soll in die Psychiatrie. In: taz.de Http://www.taz.de/!90229 (23.03.2012).

Pavlenko, Aneta. (2004): Gender and Sexuality in Foreign and Second Language Education: Critical and Feminist Approaches. In: Norton, Bonny; Toohey, Kelleen (Hrsg.): Critical Pedagogies and Language Learning. Cambridge: Cambridge UP, 53-71.

Peters, Jill (2013): Sworn Virgins of Albania. In Missy Magazine 2, 31-37.

Savin-Williams, Ritch C. (2004): Dating and Romantic Relationships Among Gay, Lesbian and Bisexual Youths. In: Kimmel, Michael S.; Plante, Rebecca F. (Hrsg.): Sexualities. Identities, Behaviors, and Society. New York/Oxford: Oxford University Press, 113-122.

Scobel (2011): Die Schulhölle. Diskriminierung von Homosexuellen Jugendlichen. In: 3sat.de November 2011. Http://www.3sat.de/page/?source=/scobel/ $158221 /$ index.html.

Scobel (2013): Unmännlich oder Uncharmant. Gängige Klischees in unseren Köpfen. In: 3sat.de. Http://www.3sat.de/page/?source=/scobel/karussell/ 158222/index.htm.

Werner, Ella Carina (2013): Fredrik und Fredrika: Im schwedischen Möbelhaus sind die Verhältnisse klar geregelt: Bürostühle männlich, Gardinen weiblich. In 
Missy Magazine 2, 19. Https:// missy-magazine.de/2013/05/07/fredrik-undfredrika.

Winkelmann, Anne; Trisch, Oliver (2007): Vorurteile, Macht und Diskriminierung - die Bildungsarbeit der Anti-Bias-Werkstatt. In: Sir Peter Ustinov Institut (Hrsg.): Kind und Vorurteil. Erforschung von Ursachen und Strategien. Wien: Europahaus Aurich/Anti-Bias-Werkstatt, 107-124.

Zeit Online (2007): Umfrage: Für 79 Prozent Homosexualität kein Hindernis für Kanzlerwahl. Http://www.zeit.de/news/artikel/2007/09/23/2385480.xml. 


\title{
Deutsch lernen mit DaF-Apps
}

\author{
Christian Müller und Ralph Olsen
}

\section{Einleitung}

In unserer Gesellschaft vollzieht sich seit geraumer Zeit ein Wandel von der traditionellen Printkultur hin zu einer multimedialen: Texte werden vermehrt digital gelesen, Verlage öffnen sich dem Markt der E-Books, Schulbuchverlage stellen Überlegungen an, wie das Schulbuch der Zukunft multimedial gestaltet sein könnte, Hochschulen verknüpfen Veröffentlichungen und Veranstaltungen immer stärker mit digitalen Medien und neue, weiterentwickelte Medienformate lösen die vorherigen in immer kürzeren Abständen ab, wie dies aktuell bei den sogenannten Apps (Applikationen) zu beobachten ist.

Im Zuge eines symmedialen DaF-Unterrichts ${ }^{1}$ ist eine Weiterentwicklung der Inhalte und Lernmöglichkeiten der bisher verwendeten Bücher mit Audio-CDs und CD-ROMs von besonderem Interesse. Neben den bis heute häufig verwendeten bebilderten Schulbüchern und Arbeitsheften in Papierform etablieren sich Apps zusehends als attraktive Lernform - auch außerhalb des Unterrichts. Aus den technischen Anwendungsmöglichkeiten und digital erstellten DaF-Lernmaterialien der CD-ROMs haben sich mittlerweile ( $\mathrm{DaF}-)$ (Lern-)Apps herausgebildet, die für

\footnotetext{
${ }^{1}$ In diesem Beitrag fokussieren wir ausschließlich den gesteuerten - also unterrichtlich begleiteten Spracherwerb. Dies wird durch die Wendung „Deutsch als Fremdsprache“ (DaF) angezeigt. Eine klare Abgrenzung zu „Deutsch als Zweitsprache“ (DaZ) ist schwierig, da auch dort unterrichtliche Steuerungen stattfinden können. Somit können unsere Ausführungen in diesem Sinne auch für den DaZ-Bereich gelten.
} 
den DaF-Unterricht wertvoll sein können und aus diesen Gründen didaktisch zu beleuchten sind.

Audiovisuelle Medien fördern das Hörverstehen, bieten von Muttersprachlern gesprochene Texte, die als Modelle dienen (vgl. Storch 2001: 273 ff.) und bahnen nicht zuletzt das Textverstehen an. Bönnighausen verweist beispielsweise auf das Imaginationspotenzial von Texten, das durch die Überschneidungen von Ton, Bild und Schrift entstehen könne (vgl. Bönnighausen 2006: 198). Dies ist beispielsweise der Fall bei DaF-Lernkrimis (z.B. Borbein; Lohéac-Wieders 2010). Das Verstehens- und Lernpotenzial - dies wird künftig empirisch untersucht werden müssen - könnte durch die neuen, interaktiven Elemente des Berührens (touch-Funktion), der Bewegung des Hybridmediums (Smartphone oder Tablet-PC) und neuere bildtechnische Möglichkeiten (Dimensionalität, HD) erhöht werden. Zuletzt haben sich Abraham; Kepser 2000 mit „living books“ und Bertschi-Kaufmann; Tresch 2003 mit ,interactive books“ als bereits den heutigen Apps nahe kommenden CDROM-Vorläufern beschäftigt.

Als hybride Form weisen DaF-Apps weiterentwickelte und neue interaktive, multimediale Elemente auf. Mit Smartphones oder Tablet-PCs verschiedener Anbieter können Apps auf Onlineplattformen (z.B. „App Store“) in Sekundenschnelle erworben werden. Auf Grund des oftmals höheren Anschaffungspreises eines Buchs mit oder ohne Audio-CD oder einer CD-ROM im Gegensatz zur gleichnamigen App ist eine Tendenz zur Kaufentscheidung für die App nicht verwunderlich. Visuell aufbereitet werden die Apps ähnlich wie die Bilderbücher in Papierform. Sie weisen kindgerechte und in bestimmten Größen entworfene Schriften, Formen und Zeichnungen auf. Was gedruckte Bücher, Audio-CDs oder CD-ROMs nicht oder nur eingeschränkt leisten können, sind die zahlreichen Animationen und die Interaktivität. Mehr Freude am Lernen könnten darüber hinaus der Einsatz von Musik und die verschiedenen Spielformen bieten.

Einige Apps haben Lobfunktionen, die bei richtigen Antworten oder Lösungen erteilt werden. Belohnungen werden in Form von Spielmöglichkeiten, aufwändigen bunten und auditiven (Gratulations-)Animationen oder Musik erteilt. Hybridmedien und die auf diesen genutzten DaF-Apps können überall hin mitgenommen werden und bieten Schülerinnen und Schülern einen weiteren Zugang zum DaF-Lernen.

Im Fokus dieses Beitrags stehen eine Bestandsaufnahme und deskriptive Darstellung der in App Stores verfügbaren (DaF-)(Lern-)Apps (im Folgenden als DaFApps abgekürzt) und deren Einsatzmöglichkeiten im DaF-Unterricht. Betrachtet werden nicht nur die spezifischen Apps hierfür, sondern auch Apps, die sprachliches Lernen für DaF-Lerner jeder Niveaustufe ermöglichen können. Es wird beleuchtet, welche Möglichkeiten die Apps mit all ihren Funktionen beim Lernen bieten und wie Apps den DaF-Unterricht medienintegrativ und kreativ beeinflussen können. 


\section{Bestandsaufnahme und deskriptive Darstellung}

Gibt man in einem App Store (z.B. von Apple) den Suchbegriff „DaF“ ein, erhält man 36 Suchergebnisse. 27 Einträge weisen keine nähere Verbindung zu „Deutsch als Fremdsprache“ auf, acht Apps sind verschiedene Ausgaben der „Lernkrimis $\mathrm{DaF}$ “ des Cornelsen-Verlags und ein Suchergebnis bezieht sich auf die „DeutschBox“ des Hueber-Verlags. Sucht man mit den Begriffen „Deutsch als Fremdsprache“, erhält man lediglich fünf Suchergebnisse, von denen vier DaF-Inhalte aufweisen: zwei Wörterbücher für Deutsch als Fremdsprache von Langenscheidt und PONS sowie zwei Deutschtrainings-Apps „Die Schneider-Methode“. Eine ergiebige Auswahl an Apps erhält man mit den weiten Suchbegriffen „Deutsch lernen“; allerdings sind diese Apps nicht alle dem Bereich DaF zuzuordnen. Die meisten der 373 Suchergebnisse (Stand: 31.07.2013) weisen keine engeren Bezüge für das Erlernen der deutschen Sprache auf. Aus diesen Gründen werden in der folgenden Kategorisierung nur Apps berücksichtigt, die sich als nützlich für das DaF-Lernen erweisen können. Die ausschließlich für den DaF-Unterricht entwickelten Apps werden genauer im dritten Kapitel behandelt.

\subsection{Kindersprachspiel-Apps für frühe DaF-Lerner}

DaF-Lernen kann schon im Vorschul- oder Grundschulalter beginnen und erfordert ein spielerisches und multimediales Angebot, da intensives Lernen noch ohne Lernen von Vokabeln stattfindet. ${ }^{2}$

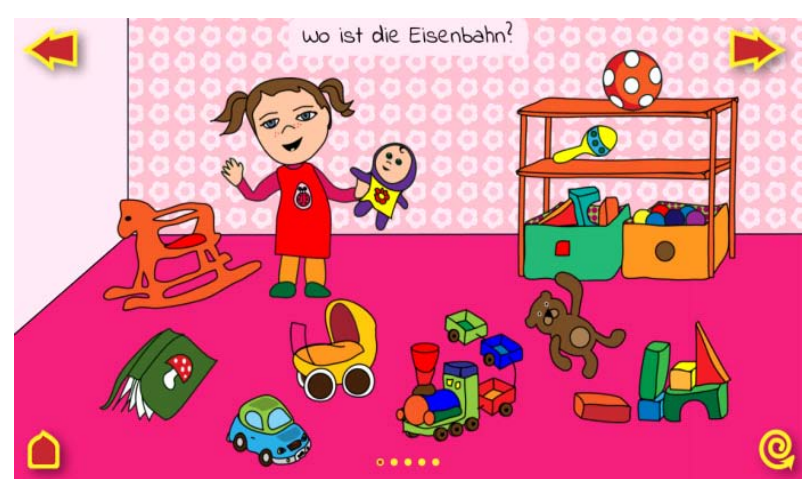

Abb. 1: KinderApp (2011)

Eine Möglichkeit, dem frühen DaF-Lernen zu begegnen, bieten KindersprachspielApps, die teilweise - laut den Autoren, Entwicklern und Produktionsfirmen schon für Kinder im Elementarbereich konzipiert wurden.

2 (vgl. http://www.goethe.de/ges/spa/dos/daf/unt/de4568347.htm und http://www.goethe.de/ $\mathrm{lhr} / \mathrm{mat} / \mathrm{ffl} /$ deindex.htm). 
Anwenderinnen und Anwender agieren auf Niveaustufen, auf denen sie die Namen einfacher und lebensnaher Wörter lernen - wie Objekte ihrer häuslichen Umgebung (siehe Abb. 1). Es wird auf Objekte getippt und eine Sprecherin oder ein Sprecher nennt das zugehörige Wort. Bei einer höheren Spielstufe wird nach dem Start der App nach den zuvor gehörten Objekten gefragt, bei Nicht-Antippen noch einmal dazu aufgefordert, bevor um das Berühren des nächsten Objekts gebeten wird. Bei einer zu lange auf sich warten lassenden Nicht-Berührung des Bildschirms oder einem falschem Antippen wackelt das richtige Objekt; diese Funktion kommt einer Binnendifferenzierung und Lösungsaufforderung gleich, die den Lernern einen Fortschritt im Spiel ermöglicht. Auf Grund der Frage, der Nachfrage und der Berührung des Objekts durch die touch-Funktion hören die Lerner das jeweilige Wort dreimal (z.B. bei Erdelyi 2011 oder ähnlich bei Elevision 2013).

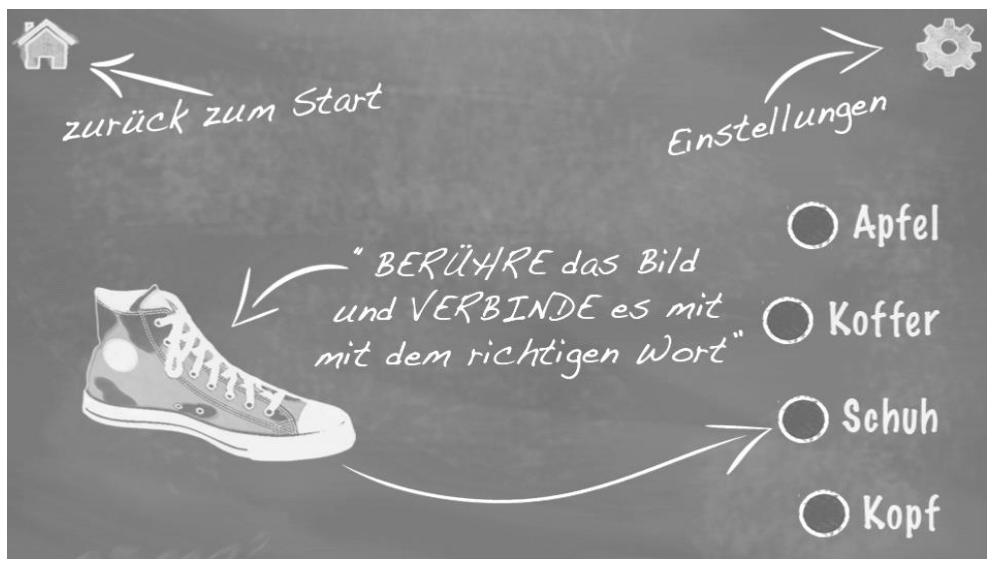

Abb. 2: Zuordnungsspiel

Dominiert bei einigen Apps das Bestimmen durch Antippen, so gibt es auch Apps, bei denen durch Zuordnen gelernt werden soll (z.B. bei Schoellmann 2012), wie Abb. 2 zeigt. Die Lerner verbinden mit dem Finger das angezeigte Bild mit dem richtigen Wort. Ein Sprecher liest das Wort vor, der Anwender bekommt einen Punkt und die nächste Aufgabe folgt. Ludische Elemente wie Puzzle, Rätsel und Quizformen zur Erarbeitung oder Wiederholung von Gelerntem lassen sich in den meisten dieser Apps finden.

\subsection{Wörterbuch-Apps}

Wörterbuch-Apps werden von Langenscheidt und PONS angeboten. Die Langenscheidtschen sind vollständig offline nutzbar in den Sprachen Englisch, Französisch und Spanisch. Darüber hinaus gibt es Schulwörterbücher in denselben Sprachen und Latein. Sie haben die gleiche Anzahl an Einträgen samt Sprichwörtern, 
Wendungen und Übersetzungen wie die gedruckten Wörterbücher. Entscheidend für den DaF-Unterricht: Die von Muttersprachlern vertonten Wörter können in beide Übersetzungsrichtungen anzeigt werden. Durch das Tippen und die automatische Vervollständigungsoption werden sie schneller gefunden. Wird ein Begriff häufiger gesucht, hilft der Suchverlauf beim Auffinden. Zudem profitieren Lerner von den Listen ähnlicher Wörter bei falscher Schreibweise. Bei den Schulwörterbüchern gibt es die Option einer Handschriftenerkennung, die technisch allerdings noch nicht ausgereift ist: Ein gesuchtes Wort wird mit dem Finger in ein Schreibfeld geschrieben, die Erkennungssoftware findet das Wort im Falle des Vorhandenseins in der Wörterbuch-App und ruft es auf.

\subsection{Deutschtraining-Apps}

Neben den Apps „Die Schneider-Methode“ und den „Lernkrimis DaF“, die unten bei den „Einsatzmöglichkeiten“ ausführlich besprochen werden, ist die Deutschlern-App „Deutsch lernen (Hello-Hello)“ ein umfassender Sprachkurs mit 30 Lektionen, die nacheinander erworben werden können und in Zusammenarbeit mit dem „American Council on the Teaching of Foreign Languages (ACTFL)“ erstellt wurden.

Der Schwerpunkt des Lernens liegt auf der Kommunikation in Alltagssituationen, die simuliert werden durch drei gezeichnete Figuren, die die Lerner durch die Lektionen begleiten. Man hört in animierten Kurzvideos das Gespräch (siehe Abb. 3 unten) und wiederholt es Teil für Teil anschließend mündlich mit einer Audio-Aufnahme-Funktion oder schriftlich. Es können Vokabelkarten angelegt und Notizen zu den einzelnen Lektionen angefertigt werden.

Die App „Deutsch für Anfänger“ vom Anbieter „linguaTV“ ist ein Videosprachkurs, in dem die Geschichte zweier Personen (gespielt von muttersprachlichen Schauspielern) erzählt wird, die in typischen Gesprächssituationen miteinander kommunizieren. Hilfe leisten die Untertitel in der Lernsprache Deutsch, ein interaktiver Vokabel- und Aussprachetrainer, Übungen und Tests. 


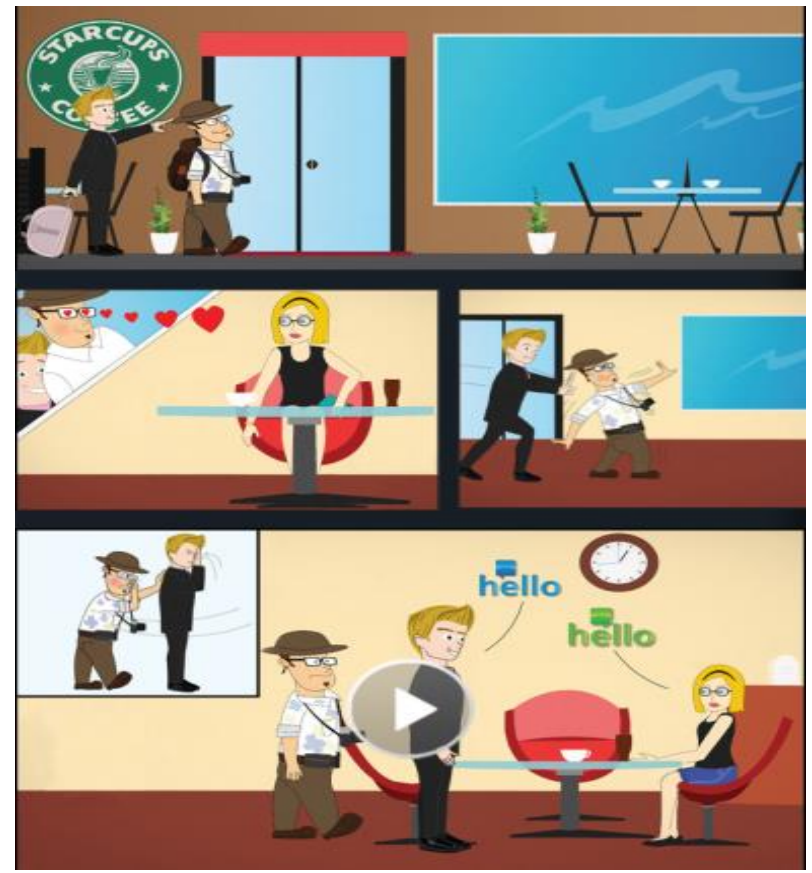

Abb. 3: Deutsch lernen (2013)

\section{Einsatzmöglichkeiten ausgewählter DaF-Apps}

Die meisten der im zweiten Kapitel beschriebenen Apps sind im DaF-Unterricht in einigen Unterrichtsphasen denkbar. Die Konzeptionen unterscheiden sich in den Lernniveaus, Schul- und Altersstufen erheblich, sodass die Lehrkraft die Apps für einen didaktisch sinnvollen Einsatz mit Bedacht auswählen muss. Im Folgenden werden einige Einsatzmöglichkeiten aufgezeigt.

\subsection{Nachschlagen und Lernen mit DaF-Wörterbüchern}

Als DaF-Nachschlagewerke sind im Besonderen die Apps „Großwörterbuch Deutsch als Fremdsprache Langenscheidt" und „Wörterbuch Deutsch als Fremdsprache Premium von PONS“ zu beachten. Das Wörterbuch-App von Langenscheidt unterscheidet sich in folgenden Aspekten von den bereits oben genannten Wörterbüchern: Es enthält zehntausende Beispielsätze und Wortzusammensetzungen für die aktive Wortschatzerweiterung aus allen Stilebenen der deutschen Allgemeinsprache und verständliche Definitionen. Hyperlinks ermöglichen den Wechsel zwischen Artikeln und Sprachrichtungen. Des Weiteren lassen sich ausführliche 
Grammatikangaben und über zweitausend Hinweise zum richtigen Sprachgebrauch finden. Die App eignet sich nicht nur zum Nachschlagen, sondern bietet DaF-Lernern auch die Option, Vokabellisten für ein Quiz anzulegen und so ein individualisiertes Wortschatztraining absolvieren zu können. Ein dauerhafter Einsatz über ganze Schuljahre ist möglich, indem in die App sukzessive die schwierigen, wichtigen oder auch gelernten Wörter individuell eingetragen und geübt werden. So bieten sich im alltäglichen Unterricht immer wieder Phasen des eigenständigen Übens mit den noch zu lernenden oder zu wiederholenden Vokabeln an.

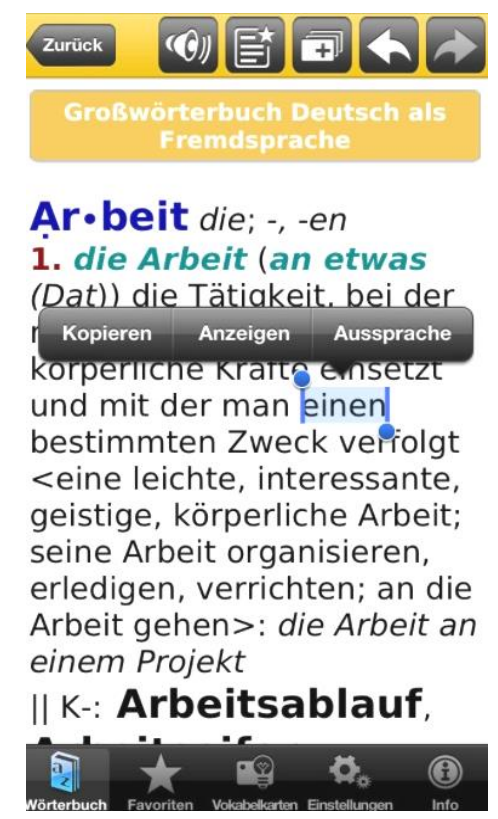

\section{Abb. 4: Wortmarkierung Langenscheidt (2013)}

Unterrichtsphasen des individuellen Sprachtrainings werden durch die Verwendung von Kopfhörern möglich, die bei jedem Smartphone zur Grundausstattung gehören. Die Schülerin oder der Schüler hört sich sein zu lernendes Wort ungestört und fokussiert an und spricht es nach. Wird ein Wort berührt, bei dessen Aussprache sich der DaF-Lerner nicht sicher ist, wird es von der Software farbig unterlegt. Dieses Wort kann nun kopiert werden, um es beispielsweise bei den Vokabelkarten zu hinterlegen. Des Weiteren kann sich die Anwenderin oder der Anwender das Wort im Wörterbuch anzeigen oder vom Sprecher aussprechen lassen (siehe Abb. 4).

Die Rechtschreibung unbekannter Wörter herauszufinden, wird für die Schülerinnen und Schüler durch die sogenannte „Wildcard“-Funktion vereinfacht. Herrscht Unsicherheit bei einem Wort, können Buchstaben mit Fragezeichen oder 
Sternchen im Suchfeld eingetragen werden (siehe Abb. 5). Die ältere WörterbuchApp von PONS (2011) ist im Vergleich zur App von Langenscheidt weniger aufwändig strukturiert und hat nicht so viele Funktionen. Das Erstellen von Wortlisten in der Offline-Nutzung ist ebenso möglich. Es gibt auch eine Wildcard-Suchfunktion und diverse Hyperlinks.

\begin{tabular}{|c|c|}
\hline I Langenscheidt & (ㄴ) \\
\hline $\mathrm{gl} \mathrm{c}^{*} \quad \times \quad$ a|? $\mathrm{lc}$ & \\
\hline atQ & 辰 \\
\hline Glace & \\
\hline Glaceehandschuh & \\
\hline Glacéhandschuh & \\
\hline glich & \\
\hline Glocke & \\
\hline Glockenblume & \\
\hline glockenförmig & \\
\hline Glockengeläut & \\
\hline Wôtrerbuch Favoriten Vokabalkaten Enstellungen & (i) \\
\hline
\end{tabular}

\section{Abb. 5: Wildcard-Funktion Langenscheidt (2013)}

Das Nachschlagewerk „Lingolia Deutsche Grammatik“ ist zugleich eine App mit einer umfassenden Übungssammlung und eignet sich für Schülerinnen und Schüler bis Klasse 10. Es beinhaltet Grammatikregeln, die mit bebilderten Beispielen versehen sind. Wortarten, Zeitformen und Satzbau sind im Detail erklärt und können zumeist umfassend geübt werden. Beispielsweise müssen Wörter oder Sätze ergänzt werden. Die Antworten können überprüft und die Lösungen angezeigt werden. Auf diese Weise lassen sich Inhalte im Unterricht zunächst zusammen oder selbständig erarbeiten und können anschließend im eigenen Lerntempo vertieft werden.

\subsection{Das Genus von Nomen üben}

Für Unterrichtsstunden mit dem Schwerpunkt auf dem Erlernen des Genus von Nomen können die Apps „Die Schneider-Methode - DerDieDas“ in zwei unterschiedlichen Versionen angewandt werden. Sie zeigen nach Themen (Sportarten, 
Tiere, Essen und Trinken, Transport, Berufe, Umwelt) geordnete, einfach aufgebaute Folien mit einem Nomen, zu dem das richtige Genus angetippt werden muss. Ein Sprecher liest das Wort zu Beginn vor, der bestimmte Artikel wird zugeordnet. Ist die Antwort richtig, erscheint ein Foto eines sich freuenden Menschen, dessen Daumen nach oben zeigen. Es ertönt Applaus. Ist die Antwort falsch, wird ein Mensch mit nicht erfreuter Mimik und nach unten zeigendem Daumen eingeblendet. Es ertönt ein Paukenschlag. Anschließend soll der bestimmte Artikel der Pluralform des Nomens - sofern eine existiert - bestimmt werden. Ausgangssprachen sind Englisch und Spanisch.

Bevor die App im Unterricht zum selbständigen Lernen eingesetzt wird, sollte die Lehrkraft in die Thematik einführen. Die App eignet sich auch für Phasen der Wiederholung der Nomen im Singular, nach denen Unterrichtsabschnitte für die Vertiefung der Pluralformen folgen können.

\subsection{Vokabellernen}

Mit Hilfe der App „Deutsch-Box“ des Hueber Verlags (ab 12 Jahren) werden die Niveaustufen A1, A2 und B1 in einem virtuellen Vokabelkarteikasten (siehe Abb. 6) mit Audio-Option erlernt und gefestigt. Die ausgewählten Vokabeln können in drei Modulen einzeln erworben und gelernt werden, bauen aufeinander auf und beziehen sich inhaltlich auf Alltagssituationen.

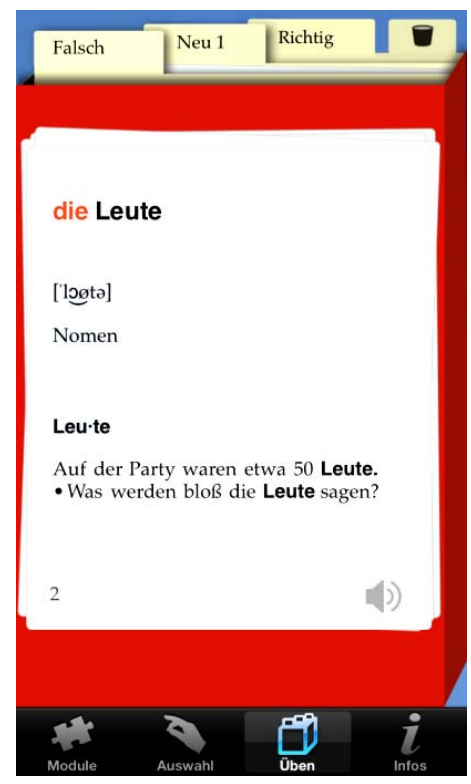

Abb. 6: Deutsch-Box Hueber (2013) 
Das Einsteiger-Modul A1 für Lerner ohne Vorkenntnisse beinhaltet alle Wörter des „Europäischen Referenzrahmens“ und ist mit Bild und Ton unterlegt. Die Module A2 und B1 sind für Lerner mit wenigen Vorkenntnissen geeignet. Der Einsatz im Unterricht kann auf Basis der Wortarten (Nomen, Adjektive, Verben) oder Themen (Angaben zur Person, Arbeit und Beruf, Essen und Trinken, Freizeit, Kommunikation) vollzogen werden.

Die App „Deutsch Vokabeltrainer“ vom Goethe Institut weist ähnliche Funktionen auf und ist auch nach Niveaustufen und Themenbereichen geordnet; nach einer Anmeldung auf der Homepage des Goethe-Instituts ist es vollständig nutzbar.

\subsection{DaF-Spiel- und Krimigeschichten}

Das Goethe-Institut hat zwei Apps („Lernabenteuer Deutsch. Das Geheimnis der Himmelsscheibe“ und „Lernabenteuer Deutsch. Ein rätselhafter Auftrag HD“) entwickelt, bei dem der Wortschatz aus den Niveaustufen A1, A2 und B1 in Dialogen und Lückentexten geübt wird.

\section{KAPITEL 2}
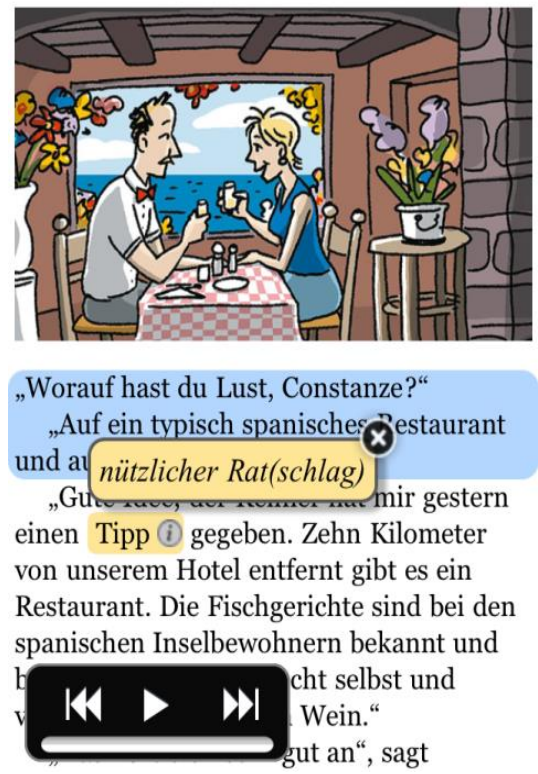

\section{Abb. 7: Hyperlink Lernkrimi Cornelsen (2010)}

Die Spielgeschichte über die Suche nach einer Himmelsscheibe ist eine spannende Abenteuergeschichte, in der die Lernerin beziehungsweise der Lerner mitbestim- 
men kann, wie typische Situationen bei einem Aufenthalt in Deutschland gestaltet und gelöst werden sollen. Die vertonte Spielzeit dauert über zwei Zeitstunden und kann daher in einer mehrstündigen Unterrichtseinheit zum Lese- und Hörverstehen gemeinsam über Hybridmedium und Beamer gehört und gelesen werden. Verschiedene Entscheidungssituationen in der Geschichte können der Lerngruppe als Sprech- und Diskussionsanlässe dienen.

In der Spielgeschichte „Ein rätselhafter Auftrag“ erlebt die Lernerin oder der Lerner bei einem Deutschlandaufenthalt eine Detektivgeschichte, die es zu lösen gilt. Zur Erreichung dieses Ziels muss sich die Figur der Geschichte in einem deutschen Unternehmen bewerben und Berufsvokabular erlernen. DaF-Lernerinnen und -lerner ab dem Niveau B1 bekommen in verschiedenen Themenbereichen Informationen und Übungen zur Verfügung gestellt.

Bei den Apps der DaF-Lernkrimi-Reihe von Cornelsen hilft die DaF-Lernerin oder der DaF-Lerner (Niveau A2-B1) einem Detektiv beim Lösen des Falls. Das Lesen des vergrößer- und verkleinerbaren Texts wird erleichtert, indem er durch eine Markierung des jeweiligen Abschnitts angezeigt wird. In der App befinden sich Hyperlinks für die Erklärungen der wichtigsten Vokabeln und landeskundliche Informationen (siehe Abb. 7). Der persönliche Lernstand wird durch Wissensüberprüfungen in interaktiven Übungen deutlich (siehe Abb. 8).

\section{ÜBUNG 1}

\section{Welches Wort gehört nicht dazu?}

01. $\begin{aligned} & \text { Anmeldung, Ausstellung, } \\ & \text { Frühstücksbuffet, Hotel, } \\ & \text { Übernachtung, Zimmerservice }\end{aligned}$
02. $\begin{aligned} & \text { Besichtigungsprogramm, } \\ & \text { Museum, Stadtplan, } \\ & \text { Stadtrundfahrt, Souvenir, } \\ & \text { Tagestour, Telefon }\end{aligned}$
03. joggen, laufen, reiten,
sonnen, tauchen, schwimmen
abb. 8: Übung Ler
Natur, Strand, Sonne, Markt,
Meer, Sand, Wasser

Der Vorteil bei de lose Wiederholun: 
können sofort oder später noch einmal bearbeitet werden, bis der gewünschte Lernerfolg eintritt - dies wäre nur schwerlich möglich beim handschriftlichen Lösen von Aufgaben in Printmedien. Lernerfolge und Lösungen werden in den Apps sofort auf dem Bildschirm angezeigt; es ist folglich nicht mehr nötig, zu den Lösungsseiten zu blättern, wie dies bei einem Buch zu tun wäre.

\section{Schlussbetrachtung und Ausblick}

Der praktische Nutzen von Apps liegt in der Mobilität der Smartphones und Tablets, die überall und schnell verwendet werden können - auch außerhalb des Unterrichts oder Klassenraums. Es ist kein Buch, keine Audio-CD oder CD-ROM mehr nötig, die den Transport eines schwereren und größeren Notebooks nach sich zieht. Das mitunter länger dauernde Hochfahren des Notebooks und das Einlegen und Laden der CD-ROM wird durch Berührung des App-Icons ersetzt und spart somit Zeit.

Mobiles Lernen ist nach einer zügigen Einarbeitung wesentlich einfacher, muss jedoch kein vollständiger Ersatz für die traditionellen Lehr- und Lernmedien sein, sondern kann sie sinnvoll ergänzen.

Die vorgestellten Apps weisen zahlreiche Vorteile auf, jedoch müssen diese auch von einer kritischen Warte her betrachtet werden. Es bedarf zukünftig dringend empirischer Untersuchungen, die belegen oder widerlegen, dass die Hybridmedien mit all ihren Bedienungs- und Lernmöglichkeiten einen Erfolg für das Erlernen von Deutsch als Fremdsprache (nicht) gewährleisten. Im Fokus empirischer Studien müssen folglich der Lernerfolg und die Abgrenzungsmerkmale der App-Funktionen zu den traditionellen Medien stehen:

- Gibt es einen Unterschied in der touch-Funktion im Vergleich zum Klicken mit einer PC-Maus oder dem Blättern in einem Buch?

- Inwieweit motiviert die neue visuelle Gestaltung der Apps?

- Können App-Animationen das Lernen unterstützen oder lenken sie ab?

- Welche Auswirkungen haben die ludischen Elemente für den Lernerfolg?

- Lassen sich mit oder ohne Musik bessere Lernergebnisse erzielen?

- Fühlen sich Anwender beim Lernen durch Lobfunktionen und Belohnungen bestärkt?

- Ermöglichen die Suchfunktionen ein besseres und schnelleres Lernen?

- Wie verändern videogestützte Apps das Lernen?

- Wie verändert sich das Vokabellernen durch die digitale Speicher- und Abrufmöglichkeit?

- Welche Auswirkungen hat das Lesen der Texte mit ihren Hilfefunktionen auf das Textverstehen?

- Welche Effekte hat das selbständige Lernen mit Apps? 
Empirische Untersuchungen zu diesen und weiteren Fragestellungen können belegen, ob und wie Apps das Lernen verändern. Wenn sich bei einigen Aspekten Lernerfolge erzielen lassen, werden im Anschluss Überlegungen folgen müssen, wie ein DaF-App aufgebaut und gestaltet sein muss und welche Funktionen einen Lernerfolg wirksam unterstützen.

Solange nicht erwiesen ist, dass Apps sich letztlich doch negativ auf das Lernen der deutschen Sprache auswirken, muss und sollte weiterhin davon ausgegangen werden, dass sie den DaF-Unterricht zeitgemäß und sinnvoll unterstützen.

\section{Literatur}

Abraham, Ulf; Kepser, Matthis (2000): Living books zwischen Computermedien und Buchliteratur: medientheoretische und fachdidaktische Überlegungen. In: Der Deutschunterricht 1. Seelze: Friedrich, 45-53.

Bertschi-Kaufmann, Andrea; Tresch, Christine (2003): „Cool, heute gingen wir wieder an den Computer!“ - Interactive Books und ihre Effekte auf das Geschichtenverstehen und das Schreiben. In: Hurrelmann, Bettina; Becker, Susanne: Kindermedien nutzen. Medienkompetenz als Herausforderung für Erziehung und Unterricht. Weinheim: Juventa, 74-86.

Bönnighausen, Marion (2006): An den Schnittstellen der Künste. Vorschläge für einen intermedialen Deutschunterricht. In: Frederking, Volker (Hrsg.): Filmdidaktik - Filmästhetik. Jabrbuch Medien im Deutschunterricht 2005. Band 4. München: kopaed, 191-203.

Borbein, Volker; Lohéac-Wieders, Marie-Claire (2010): Lextra-Deutsch als Fremdsprache. DaF-Lernkrimis. Ein Fall für Patrick. Reich. Jeder ist käuflich. A2 - B1. Berlin: Cornelsen.

Storch, Günther (2001): Deutsch als Fremdsprache - eine Didaktik. Theoretische Grundlagen und praktische Unterrichtsgestaltung. München: Fink.

\section{Apps}

Adnet und Partner S.L. (2012): Die Schneider-Methode - DerDieDas (I) und (II).

Cornelsen Verlag GmbH (2010): Lernkrimi DaF-Reihe.

Elevision GmbH (2013): LinguPinguin.

Erdelyi, Kornelia (2011): KinderApp - Kinder lernen sprechen in den Sprachen Deutsch, Englisch, Ungarisch.

Goethe-Institut (2012): Deutsch Vokabeltrainer. 
Goethe-Institut (2013): Lernabenteuer Deutsch. Das Geheimnis der Himmelsscheibe.

Goethe-Institut (2013): Lernabenteuer Deutsch. Ein rätselhafter Auftrag HD.

Hello-Hello LLC (2013): Deutsch lernen (Hello-Hello).

Hueber Verlag (2012): Deutsch-Box.

Langenscheidt KG (2013): Großwörterbuch Deutsch als Fremdsprache Langenscheidt für Handys und Smartphones.

Lingua TV (2012): Deutsch für Anfänger.

Mobile Systems (2011): Wörterbuch Deutsch als Fremdsprache Premium von PONS.

Pahlow, Heike (2013): Lingolia Deutsche Grammatik.

Schoellmann, Ron (2012): Lesespiel.

\section{Internetquellen}

http://www.goethe.de/ges/spa/dos/daf/unt/de4568347.htm (21.07.2013)

http://www.goethe.de/lhr/mat/ffl/deindex.htm (21.07.2013) 


\section{Autoren}

\section{Dr. Miriam Bertocchi}

via Indipendenza $2 / \mathrm{c}$

I-25030 Castelcovati (BS)

miriam.bertocchi@unimi.it

\section{Dr. Renate Bürner-Kotzam}

Kaiserstraße 38

80801 München

rbuerner@t-online.de

\section{Dr. Chiara Cerri}

Philipps-Universität Marburg

Fachbereich 09: Institut für Germanistische Sprachwissenschaft

Abteilung Deutsch als Fremdsprache

Wilhelm-Röpke-Straße 6A

35032 Marburg

cerri@staff.uni-marburg.de

\section{Franziska Flucke}

Université Paris-Ouest Nanterre La Défense

UFR Langues et Cultures Étrangères

Département d'Allemand

200, Avenue de la République

F-92001 Nanterre Cedex

fflucke@u-paris10.fr

\section{Dr. Marc Hieronimus}

Dansweilerweg 1

50933 Köln

hieronimus.m@t-online.de

\section{Luise Holke}

63, rue Henri Kolb

F-59000 Lille 
Japhet Johnstone

Zentrum für Literatur- und Kulturforschung

Schützenstraße 18

10117 Berlin

Prof. Dr. Dorit Kluge

HWTK Berlin

Friedrichstraße 189

10117 Berlin

\section{Danielle Verena Kollig}

Frankenallee 96

60326 Frankfurt/Main

\section{Christian Müller}

PH Karlsruhe

Institut für Deutsche Sprache und Literatur

Bismarckstraße 10

76133 Karlsruhe

Dr. Anastasia Novikova

Friedrichsfelderstraße 51

68535 Edingen-Neckarshausen

novikova@uni-heidelberg.de

\section{Prof. Dr. Ralph Olsen}

PH Ludwigsburg

Institut für Sprachen

Abteilung Deutsch

Reuterallee 46

71634 Ludwigsburg

\section{Ralf Palandt}

Barthstraße 5

80339 München japhetj@u.washington.edu

dorit.kluge@hwtk.de

verena.kollig@t-online.de

christian.mueller@ph-karlsruhe.de olsen@ph-ludwigsburg.de

ralf.palandt@gmx.net 
Dr. Markus Raith

Institut für Romanistik /

Institut für deutsche Sprache und Literatur

Pädagogische Hochschule Freiburg

Kunzenweg 21

79117 Freiburg

\section{Dr. Michael Reichelt}

Nationale Metschnikow-Universität Odessa

Fakultät für Romanistik und Germanistik

Lehrstuhl für Deutsche Philologie

Franzuskij Bulvar 224/26

65058 Odessa (Ukraine)

\section{Benjamin Schmäling}

17, rue du Cambodge

F-75020 Paris

\section{Dr. Tobias Schöttler}

Fakultät III, Institut für Philosophie

Ruhr-Universität Bochum

Universitätsstraße 150

44801 Bochum

\section{Christina Margrit Siever}

Friesenstraße 51

30926 Seelze

\section{Dorothea Spaniel-Weise}

Institut für Auslandsgermanistik/

Deutsch als Fremd- und Zweitsprache

Friedrich-Schiller-Universität Jena

07743 Jena raith@ph-weingarten.de

bschmaeling@gmx.net

tobias.schoettler@rub.de

c.siever@mediensprache.net

dorothea.spaniel-weise@uni-jena.de 


\section{Anna Svet}

Institut für Auslandsgermanistik/

Deutsch als Fremd- und Zweitsprache

Friedrich-Schiller-Universität Jena

07743 Jena

anna.svet@uni-jena.de

\section{Monika Wolf}

11, rue Charles Bacqué

F-32600 L'Isle-Jourdain

Monika_Wolf@t-online.de 
Visuelle Medien sind allgegenwärtig. Die Verbesserung der Druck- und Aufnahmetechniken im 20. und die längst nicht abgeschlossene digitale Revolution seit der Wende zum 21 . Jahrhundert haben eine in der Menschheitsgeschichte bislang einzigartige Verbildlichung der Umwelt nach sich gezogen. Die Geisteswissenschaften reagieren darauf mit der für angemessene Reflexion und Institutionalisierung wohl notwendigen Verzögerung. Die Entwicklung der Bildmedien und das „Geschäft" der bildgestützten Sprachvermittlung aber gehen indessen weiter.

Die Beiträge des vorliegenden Bandes sollen helfen, die Lücke zwischen Bildentwicklung und reflektierter Bildverwendung zu schließen. Teil eins bietet Ansätze zur Didaktik des Visuellen, Evaluationskriterien für Verbundmedien und Grundlagenwissen zur Bildwissenschaft und dem „Stiefkind“ Comic. Teil zwei widmet sich den starren Bildern Street Art, Printwerbung, Porträt, historischer Fotografie und Comic im Unterricht Deutsch als Fremdsprache. Im dritten Teil zum weiten Spektrum der bewegten Bilder geht es um Dokumentar- und Kurzfilme, Werbespots, Lyrikverfilmungen und den Videoeinsatz im Sprechtraining. Der abschließende vierte Teil behandelt soziale Netzwerke, Deutschlern-Apps und „queere“ Medien im DaF-Unterricht.

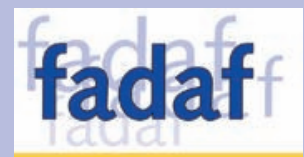

fadaf.de

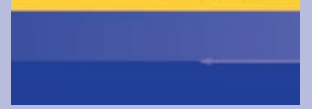

ISBN: 978-3-86395-174-0

ISSN: 1866-8283

\section{Universitätsdrucke Göttingen}

